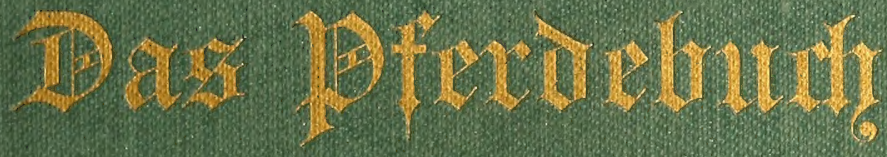

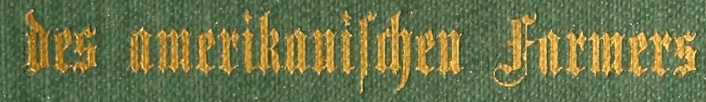

gin 015

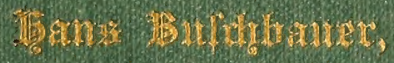

(3). 15. 5. 


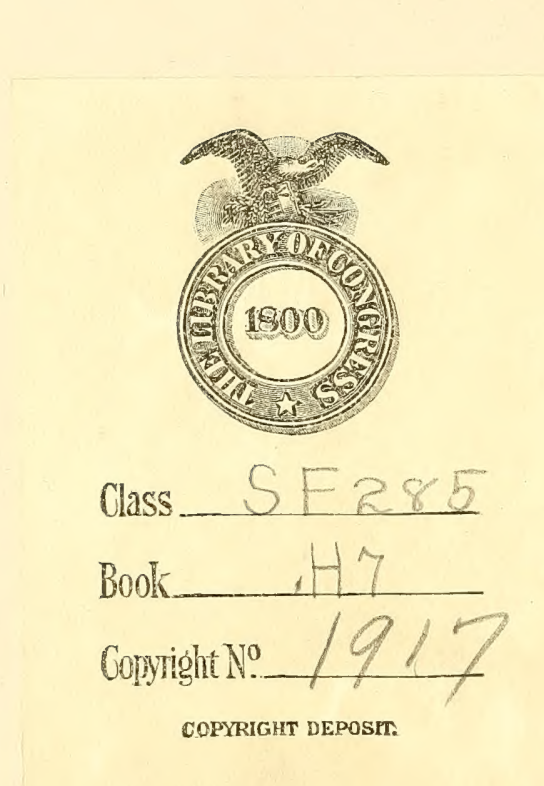


. 



\title{
Dax Pferdefuntry
}

\section{Det \\ amexikanifinen $\mathfrak{T a x m e x}$}

\author{
von
}

F⿱宀

五. WD. 看.

\section{Teubrarbeifete tu gabe}

mif 3 \#axbenfafeln, 46 Iexfabbiloungen unt simem Jithang über lunfugenden bex pferde.

Mithauker, Wifr.,

Derlag Der Germania publthing (to. 


\section{$S_{2} 85$ \\ . H7}

Copyright, 1917

by

GERMANIA PUBLISHING CO.,

Milwaukee, Wis.

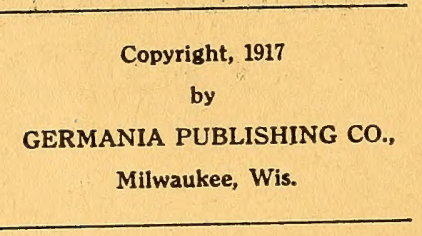

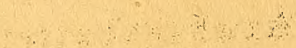

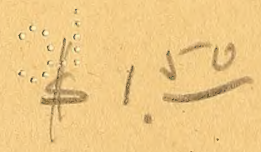

DEC 291917

(C) $\mathrm{II} A 481200$ 


\section{Bormaxt.}

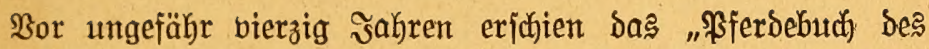
amerifanifachen Farmers" in erjter $\mathfrak{A}$ uflage, und e? wurbe damit ben Farmern ein wertbolles $\mathfrak{B}_{\mathfrak{u}}$ in in die Sand gegeben. Damals - und fehr oft aud heute nod) - wohnt der Farmer in einer abgelegenten

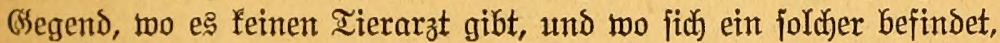

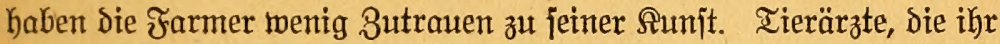
Fach) gründlid) veritehen, find jelbjt in den bidftbefiedelten (segenden felten. So find sie Farmer häufig gezmuntgen, ihre franfen Iiere irgendeinem Pfujffer in Befandlung zu geben. Die Şeilerfolge find dementjprechend. Das "\$Ferdebuth" wollte und hat Gjer Arbhilfe

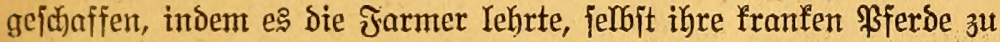
bebandeln.

Seit dem eriten Ericheinen des Burhes hat sie Tierheilfumbe, wie alle andern ich) bermeife mur auf bie Entoeclung der Bafterien und deren Iätigfeit. Manche Sirantheit, Deren Entitehung man nidft fannte umb folglid, nidjt ridjtig Gehandeln fonnte, ijt heute ifrem ganzen befannt und find bamit ber Şeilfunde neue SMege vorgezeichnet wor= den. Die Chemie hat unz eine ganze Reihe neuer Şeilmittel in ben

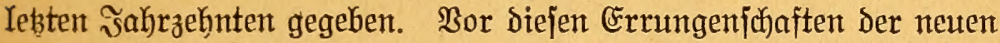
Iierarzneifunde fonnten niele Rapitel des alten \$fferdebuches nidft mehr hejtehen; fie find wertlos geworden.

Eine neue $\mathfrak{S}$ uflage bes $B$ udfes war notwendig gemorden; follten

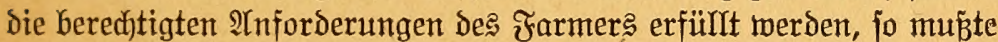
eine böllige Hmarbeitung des alten Buthes jtattfinden. Diejer $\mathfrak{A} r b e i t$

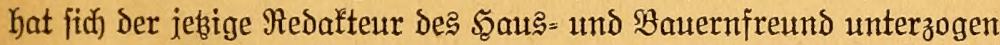
und Dabei feine praftifit)en Erffahrungen auf Der Farm 孔 verwerten

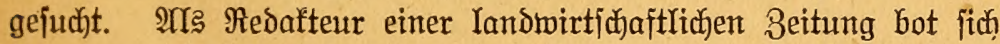
ihm ferner täglid) (Selegenheit, mehr Senntnifife in ber Tierheilfunde

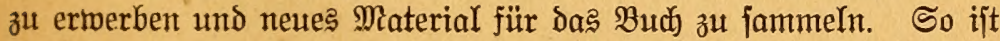




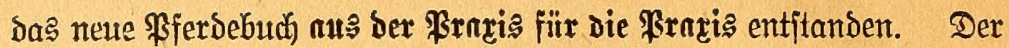

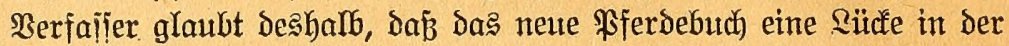

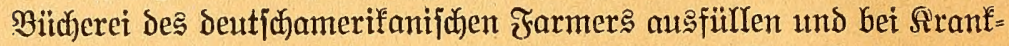

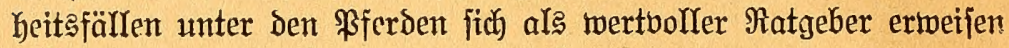
woiro.

$\mathfrak{A n}$ guten $\mathfrak{B u ̈ h}$ jern diejer $\mathfrak{A}$ rt ijt fein Mangel; wir haben vor=

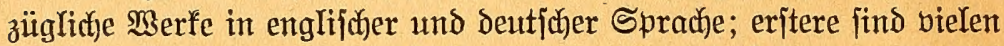
Farmern, weldhe bie englijuche Sprache nidht Eeberrichen, unveritänd: Iidf). Die Tierarzmeibüctber aus Deutf(c)land aber, jo wertvoll fie an fich find, haben für unjere Farmer boch mur einen geringen $\mathfrak{B}$ ert, meil Die Benennungen der Sranfheiten, der $\mathfrak{A}$ rzneien und die Serwichts= und Má̧̧angaben nidjt verjtanden werden. Das bejte Rezept aus einem Iterarzneibutbe von brüben fann der Farmer in den meiften Ipothefen nicht vertwerten. So war ein Buch in beuticher Spracke, in meldtem hiejigen $\mathfrak{B e r h a ̈ l t n i f f e n ~ v o l l a u f ~ \Re e c h n u n g ~ g e t r a g e n ~ u n d ~ D a s ~}$ Bejte der Iiterarzneifunde bon hüben und orüben vereinigt ijt, eine

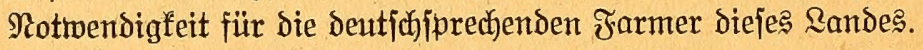

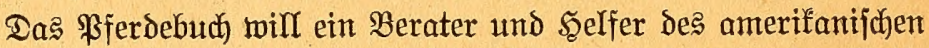

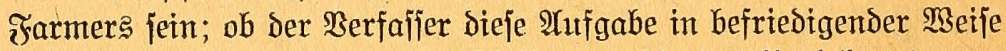
gelöjt hat, müifien biejenigen enticheiden, welche das Buch benuken.

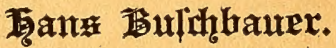




\section{$\mathfrak{I} \mathfrak{n} \mathfrak{h} \mathfrak{a} \mathfrak{l t}$.}

Seite

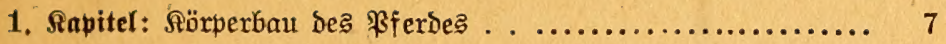

2. Sapitel: Erfennen Der Tierfranffheiten im alfgemeinen ....... 49

3. Rapiter: $\mathfrak{B o m}$ Eingeben Der $\mathfrak{A r}_{\mathfrak{z} z \text { meien }} . \ldots \ldots \ldots \ldots \ldots \ldots \ldots$. 2

4. Rapitel: Bom Biehen dę Şaarjeir $\ldots \ldots \ldots \ldots \ldots \ldots \ldots \ldots, 54$

5. Sapiter: Bom Deffnen einer $\mathfrak{B l u t}=$ oder Gitergefdr)wulit ....... 55

6. Rapitel: $\mathfrak{B o n}$ bem $\mathfrak{B r e n n e n . . . . . . . . . . . . . . . . . . . . . . . ~} 57$

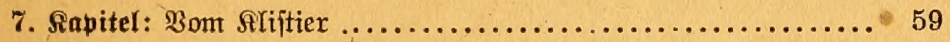

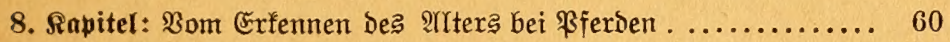

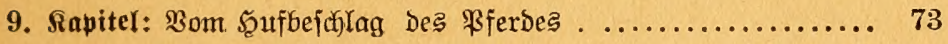

10. Rapiter: Bon Den Šufen........................ 77

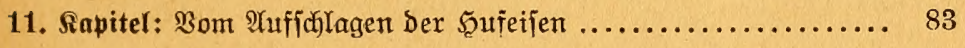

12. Sapitel: Sranffyeiten ber $\mathfrak{B e x b a u u n g ̧ o r g a n e ~ . . . . . . . . . . . . . ~} 85$

13. Rapiter: Rranfheiten Der Reber und Şarnorgane.......... 107

14. Sapiter: Sranfheiten Der $\mathscr{U}$ tmungsorgane . ............ 119

15. Rapitel: Sranfheiten ber Beugungsorgane . . . . . . . . . 131

16. Sapitel: Sranffeiten Des Si erbenfyitem . . ............. 144

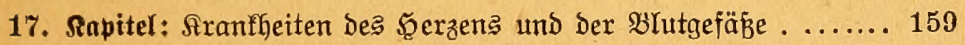

18. Sapiter: Aranfleiten bes S1tges. . .................... 161

19. Sapitel: Rahmheit, ihre Ulrjachen und Behanolung ......... 167

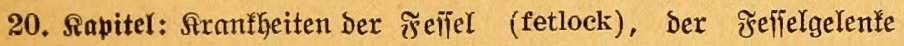

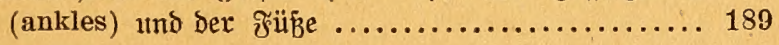

21. Sapiter: Sautfranfleiten ........................ 198

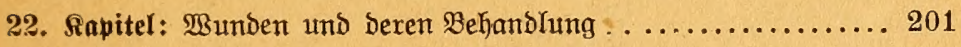

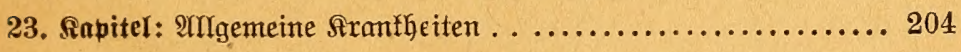

Inthang: Unarten ber $\mathfrak{P f e r d e}$.......................... 212 



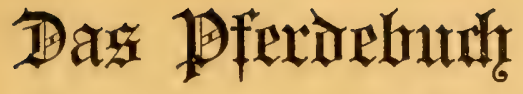

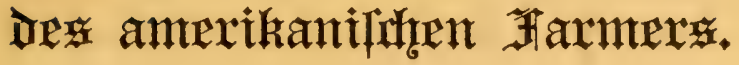

\section{Taprifel.}

\section{Der Sürperbaut bez \$Ferbez.}

IIm Sie Rranfheiten Dę \$ferdes ertennen und ridjtig behandeln 孔 föntn, it cs notwendig, Den Rörperbau des Tieres zu fennen. Wir müijen wijjen, wenn eine Stelle des Rörpers verlest ijt, weldje Inodjen, Mußfeln, Sehnen fich Dort befinden; zur Beurteilung ber

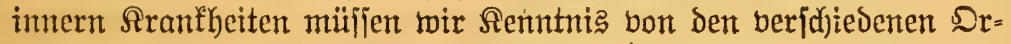
ganen und Deren Lage haben. Demgemä́ Yernen wir Juerit Das

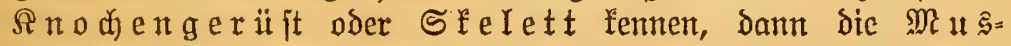

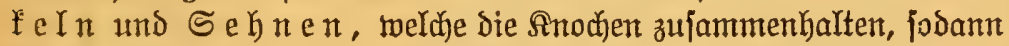

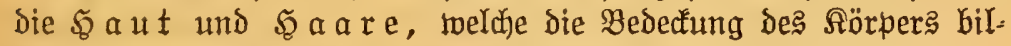
ben; Darauf folgt bie innere Finriditung: $\mathfrak{L} \mathfrak{n} \mathfrak{g} \in \mathfrak{n}, \mathfrak{S}$ e.r $z$, Eingetoeide, Şarngefäbe und Foren, Julebt da: Drüjent= und $\mathfrak{x}$ ervenjtitem.

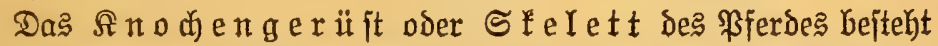

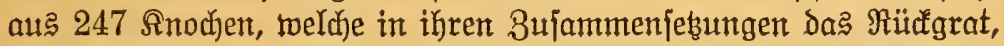
Den Bruftforb, Dą Becfen, Den Sdjweif. und die borderen und hinterent

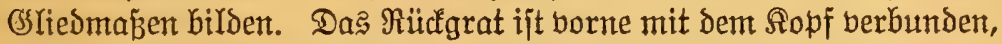
Yebterer bejteht aus Gsejtats= und Sajäbelfnodjen und enthält die Bähne. Mit bem Sopfe berbunsen, Durch weiche Teile hinter ber Bunge, Yiegt Das Bungenbein.

1. Soirnjđääbel (brain pan or scull).

2. Unterfiefer (lower jaw).

3. इalsminbel (cervical vertebrae).

4. 4. Rüffentwirbel (dorsal vertebrae).

5. 5. Rendentrirbel (lumbar vertebrae).

6. 6. Areuzbein (sacrum or sacred bone).

7. 7. Sdyweifruirbel (tail bones).

8. 8. Brujtbein (breast bone or sternum).

9. 9. Die twabren Rippen (true ribs). 


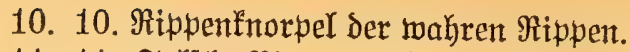

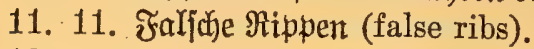

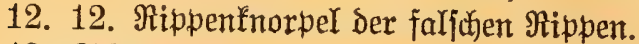

13. Schulterblatt (shoulder blade).

14. Irrmbein (humerus).

15. Norarmbein (radius or arm).

16. Frrenbogenbein (elbow).

17. Soadenbein (os pisiforme).

18-23. Antefnochen (carpal bones).

24. Shienbein (shank bone).

25. 26. Briffelbeine (splint bones).

27. 28. GT(eid)beine (sesamoid bones).

29. Feljelbein (upper pastern).

30. Aronbein (lower pastern).

31. Sufbein (coffin bone).

32. Strahlbein (shuttle bone).

33-36. Bedfenbeine (pelvis bones).

37. ऽberifhenfelbein (femur or thigh bone).

38. Sró̧ę IUnteridenfelbein (flute or pipe bone).

39. J゙erjenbein (os calcis).

40. Rolnbein (astragalus).

41-44. Sprunggelentafnod)en (tarsal bones).

45. Schienbein (large metatarsal bones).

46. 47. Sriffelbeine (small metatarsal bones).

A. Bactzähne (molars).

B. H. Šadenzähne (canine teeth).

C. I. Sdfneidezähne (incisors).

E. IYtrą oder $\mathfrak{T}$ räger (atlas).

G. $\mathfrak{A}$ ugenhöhle (orbit).

M. Schnabel= oder Şabidjtalnorpel (carniform cartilage).

N. Schtwertfnorpel (ensiform cartilage).

O. Bitbenfortjak (coracoid process).

P. Srfulterblattgräte (spine).

Q. Schulterblattfnorpel (cartilage).

R. Sberer Umbreber (trochanter major).

S. Ramm bes Dberidenfelbeins (subtrochanterian crest).

T. Rollfortjas (trochlea).

U. Gselenffopf (external condyle).

V. Iniejcheibe (patella),

W. Sprunggelent (hock joint). 


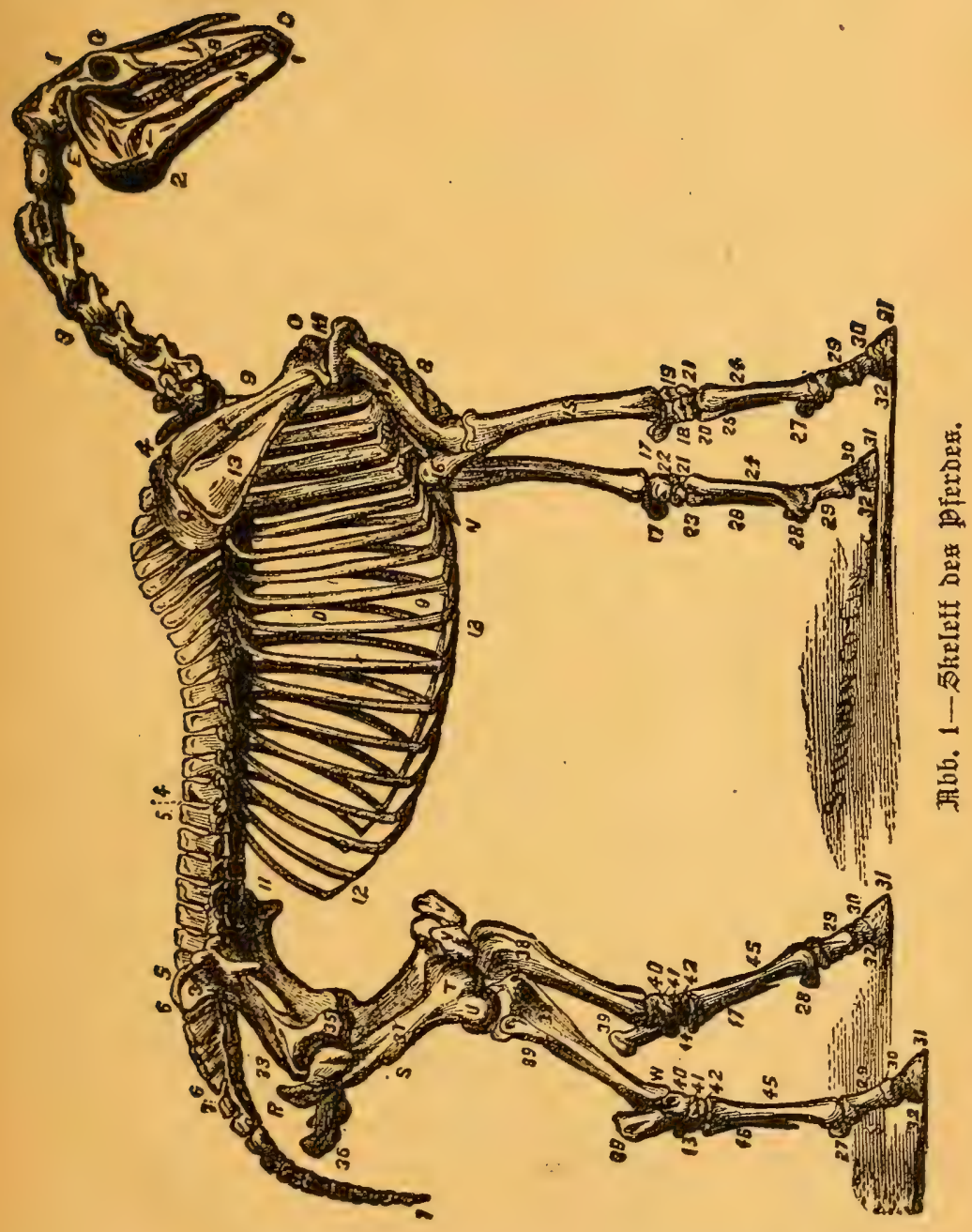


Der $\Re$ ü $\mathfrak{d} \mathrm{g}$ rat (spine) oder bie Mirbeljäule befteht auঙ 7

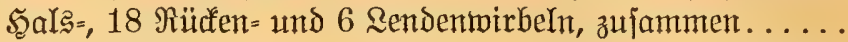

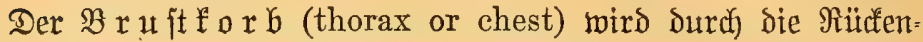

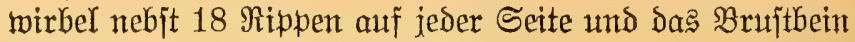
in ber Mitte gebildet, zulammen............ 37

Das $\mathfrak{B}$ e if e $\mathbb{n}$ (pelvis) hat zmei $\mathfrak{B}$ edtenbeine und Das Sreuzbein,

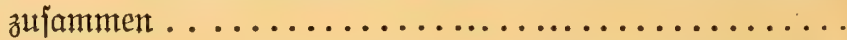

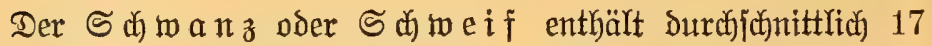

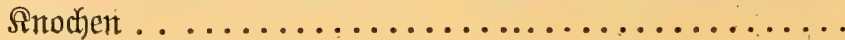

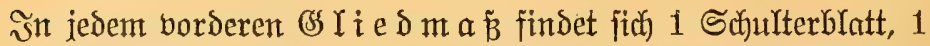
2Irmbein, 1 Borarmbein, 1 Erlenbogenbein, 8 Aniebeine, 1 Sdjenbein, 2 Sriffelbeine, 1 Felf̈lbein, 1 Anronbein, 1

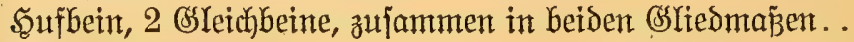

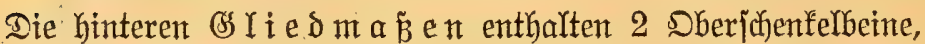
2 Intejujeiben, 2 großje Unterjubenfelbeine, 2 fleine Unter= fuenfelbeine, 12 Sprunggelenţbeine, 2 Shienbeine, 4

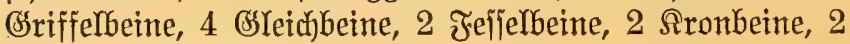
Fुufbeine, 2 Strahlbeine, zuโammen..............

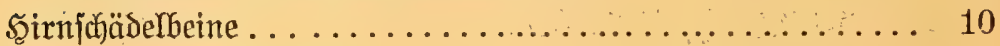

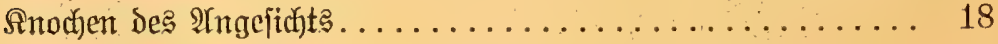

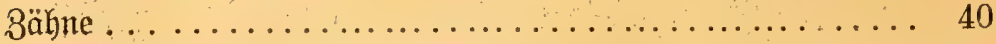

(Sebörtnöheldyen, 4 in jedem $\mathfrak{D h r e . . . . . . . . . . . . . ~} 8$

Bungenbein, aus 5 Ieilen bejtehend............ 5

ธumma ........................247

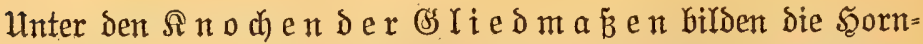

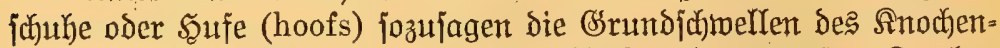
gerïites und fichliejen das Şufbein (coffln-bone), den eriten Anochen ber đsliedmaken vollfommen ein. Sberhalb derjelben befindet fich bas Sronbein (lower pastern-bone), das vorn auf dem Şufbein ruht, hinten aber mit einer (s)rube berjehen ijt, in Der wir einen Hleinen

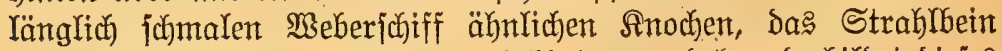
(shuttle-bone), finden. Sich nach hinten autsobmend, bildet biejes

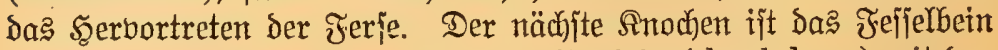
(upper pastern-bone), tworauf Das Sifjenbein (shank-bone) mit Den (SYeid)beinen (sessamoid bones) ruht. Die (SI eichbeine ftehen in $\mathfrak{B e r}=$ bindung mit bem Fefjelgelenf (ankle-joint) und ragen etwą über bie

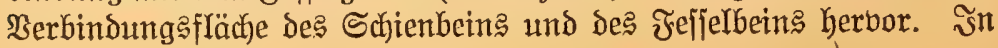


Dem Ŝniegelent find adjt Sinodjen. Şinter Dem Sinie und gerabe unterbalb crifredfen fid) 3u beiden Seiten bes vorberen S(fjienbein?,

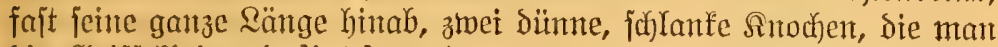
bie Griffelbeine (splint-bones) nennt. Dherhalb Des Sintegelenfe?

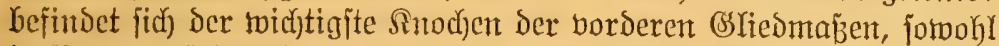

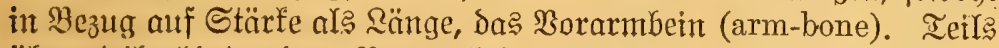
ïber, teils hinter bem \$orarmbein und mit ifm unbemeglide berGumben, finten wir das Enfenbogenbein (ulna or elbow). Dberhalb Des Erfenbogenbeints und mit demfelben durch ein bolffommenes MedjfelgeYenf berbunden, zeigt fich Der lebte finochen Der vorderen

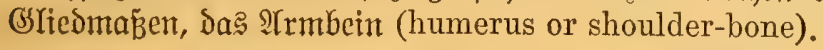

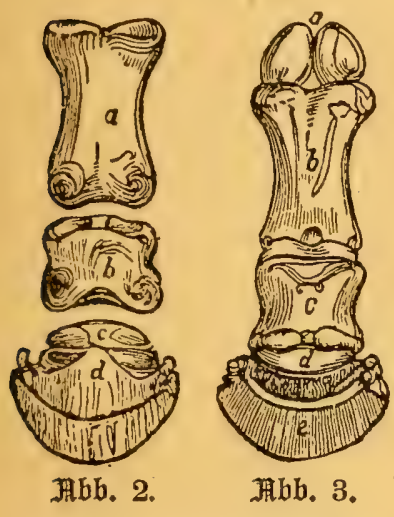

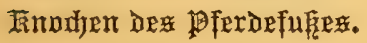

ITb. 2.

a) Trefielbein (upper pastern).

b) Sironbein (lower pastern).

c) Strahbein (shuttle or navicular bone).

d) Şufbein (coffln-bone).

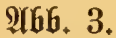

a) (STetchbeine (sessamoid bones).

b) Fefjelbein (upper pastern).

c) Sronbeit (lower pastern).

d) Strahlbein (shuttle or navicular bone).

e) Şufbein mit dem Şormiduh (coffln-bone).

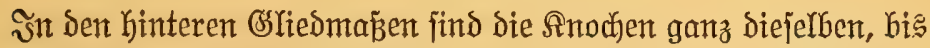

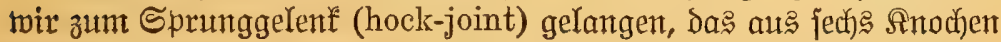
beiteht. Die Şerborragung am Sprunggelent mird dutrd Das Far= jenbein (heel-bone) gebildet. Heber Dem Sprunggelenfe befindet fid

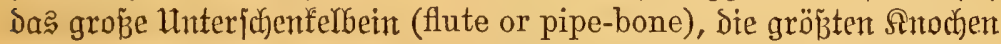

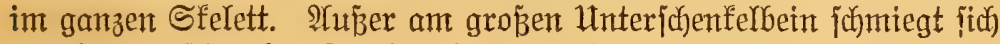
cin langer jajmaler Snochen fejt an, Das fYeine Interichenfelbein (fibula). Das Iniegelent (stifle-joint) wird gebildet oben Durch Da’ Dberichentelbein (femur or thigh-bone), und unten Durd) Dą grö̌e

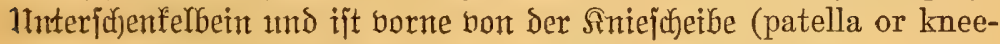

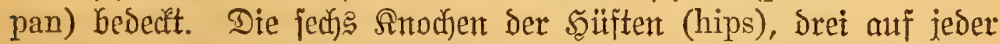

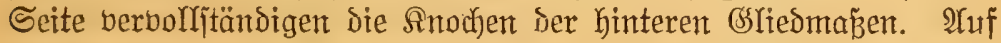

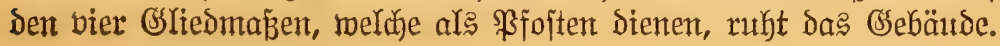


Mir mögen mun bie $\Re$ opflnody en anfübren. Bon biejent fint die wichtigiten die Rieferbeine (jaw-bones), bas grop̉e und Fleine

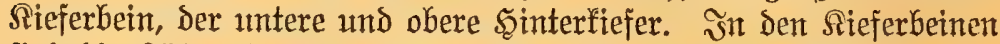
find bie Bähne befejtigt, 24 Badłzähne (molars), 6 anf jeber Seite oben und unten; 12 Schneidezäbne (incisors) oder vordere 3ähne, 6 oben und 6 unten; und 4 Şafenzähne (canine), einer auf jeder Seite, fowohl oben als unten. (Sieke: Bühne Des \$f̣erdes.)

Sie Sijäbelfnodien (skull bones) beiteken auts breiten gebogenen

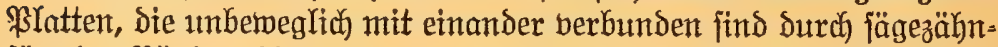

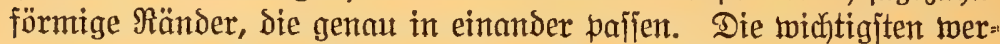
Den nach ifrer $2 a g e$ Dberhauptbein (occipital), ఇajenbein (nasal bone) und Stimbein (frontal bone) genannt. IUnterbalb des Stirn:

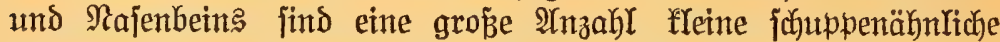
Snochen, wobon einige nidjt mit anderen Inodjen berbunden, bie meijten aber mit ben Schädelfnochen vereinigt find. Dieje find

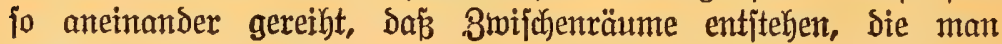
Şöhlen nennt.

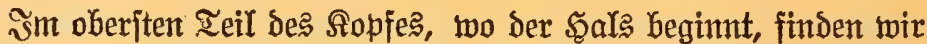
das Sberbauptbein (occipital bone), mit weldjem der erjte Sals= wirbel oder Iräger Durch ein eigentünliches Band verbunden ijt.

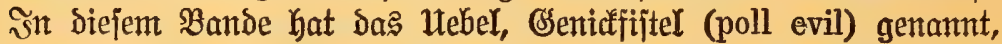
jeinen Sik.

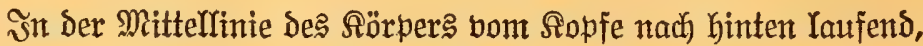

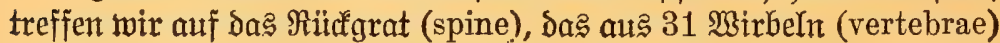
bejteht, die miteinander mitteljt Bänder bereinigt jind. Die jieben, bie fich am Sals befinden, nennt man die Salswirbel (cervical

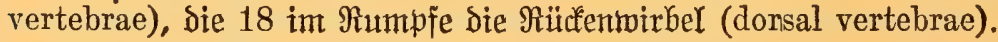
Die lebteren befiben bedeutende nach oben gefehrte Servorragungen,

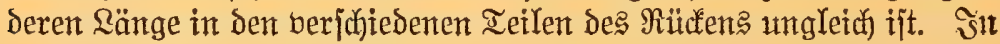
ber ๔(f)ultergegend beträgt fie niemals weniger als drei Boll und in mandfen ßferden fommt fie auf $4-5$ 3oll. Gegen die Mitte des Mï̈dfens wird jie geringer, etra 11/2-2 3oll. Die nächjten 6 Wirbel, weldye ihren Sib in Der Rendengegend haben und beahalb Renden= wirbel (lumbar vertebrae) heipen, berbolljtändigen das eigentlicfe Rüctgrat oder die Mirbelfäule. Die Mirbelfäule wird jedoch fortge=

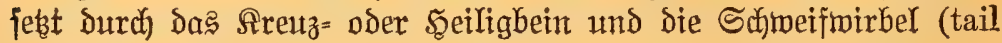
bones), Deren Bahl nidyt immer siejelbe bet allen \$sferden ift, Durafjchnittlidu aber 17 beträgt. Die midbtigiten Şüftfnochen (hip bones)

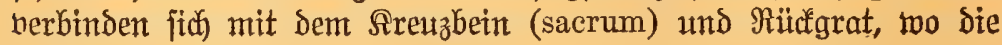
Rendentwirbel auffören. 


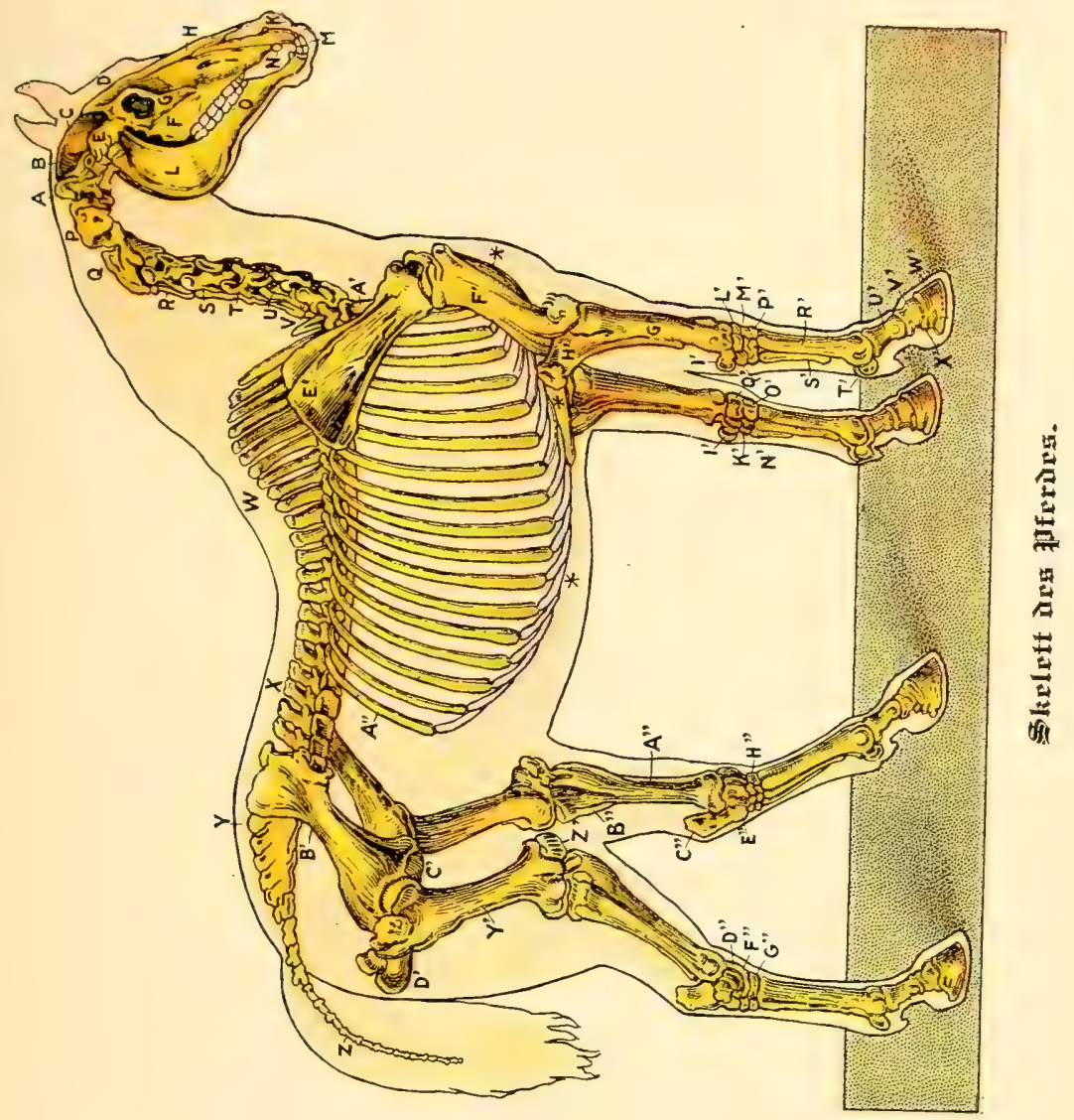



Thuf jeber Seite ber Sdjulter befindet jidj ein bedeutender Snodjen, Der unter Dem Ramen Sajulterblatt (shoulder blade) be= fannt ift. Er ift untent mit dom Irmbeine verbunden; bon biejem OSclente aus wird or dünn und breit, und zeigt auf derr Mitte der

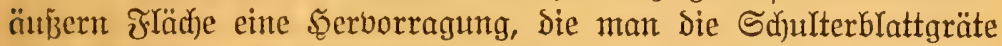

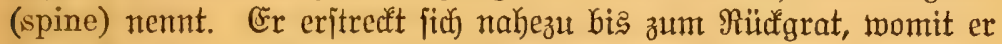
Durd) Musfeln berbunden ijt. Diejer Intodjen ijt zuweilen mit einer furdjtbaren Sranffeit, Sdjulterjdjwund (swinney) behaftet.

Die Rippen, Derent fich 18 auf jeber Seite befinden, geben nirgt

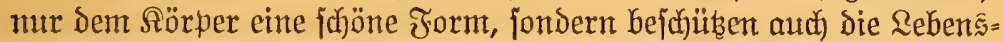
wertzeuge vor äuß̌eren Bciłhäbigungen. Daミ Brujtbein (breastbone) ift aus jedj) oder fieben Stürfen zujammengefest und bildset den

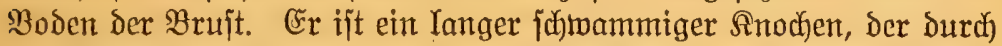

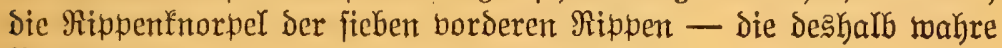
Rippen Geiken - in jeiner Rage erfalten wird.

Die $\mathfrak{M}$ u

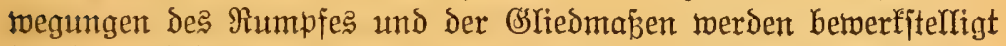

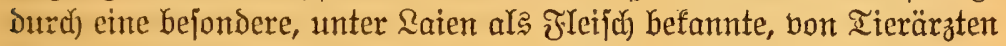
aber als Miugfelgemebe bezeidjnete Subjtanz. Dieje bildset die Şaupt= mafie aller außerhalb der Şirn=, Bruft= und Baudhöble befindlidjen

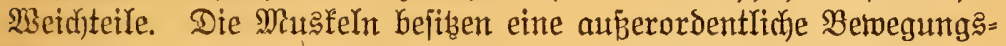
fraft, indem fie aus unzähbligen fleinen Sdynüren bejtehen, bie man Fajern nemt, bon Denen jede einzeln eine eigene elajtijoje und zujam=

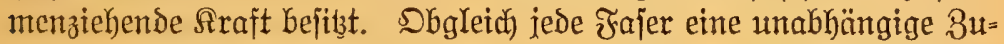
fammenziehungsfähigfeit hat, jo roirfen doch alle zu einer Muafer

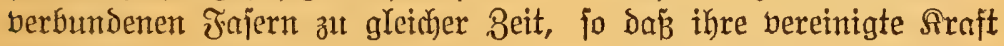
critaumlid) grop ift. Saierbon fann man fid) leidgt eine Boritellung machen, went man bedenft, dä́ Die wunderbare Araft des \$ferdes von den Miusfeln abjängt. Eine bemerfensmerte Eigenjujaft der

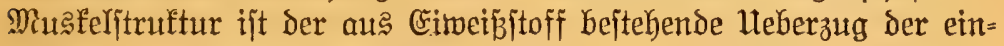

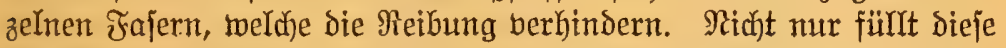

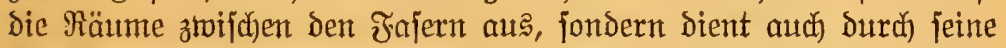
flcbrige twadjartige Eigenjajt als jtarfes Bindemittel Der Fajern und Fajerbündel untereinander.

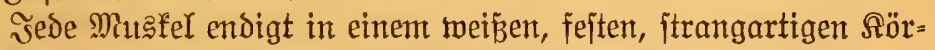
per, Die Sefne oder Fredjfe. (Siełe: Die Sehnen.)

Die Empfindungsfähigfeit Der Musfeln ift unbedeutend. İt

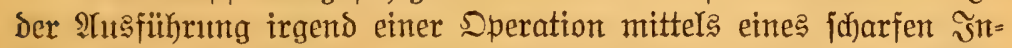
ftruments wirs berbäItnismäp̧ig toenig Scymerz empfunden, nachbem 


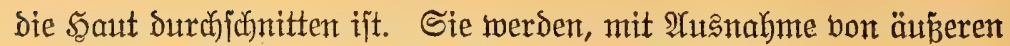
Berleb̧ungen, äuß̌erit jelten von franfhaften Störungen heimgejucht. 3umeilen aber find fie der Sitb bon Gejumüren, die grope $\mathfrak{A}$ n= fajwellung verurjactjen und auberordentlicje grop̈e Duantitäten Citer entladen.

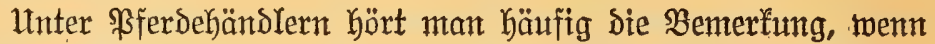

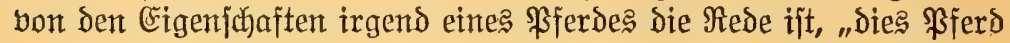

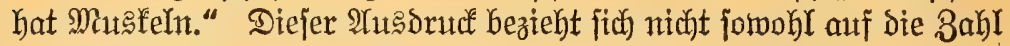

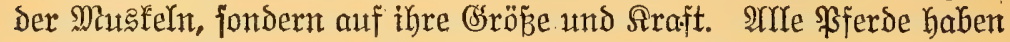
gleich viele Mitsfelı. Nar bezüglich ihrer Biegjamfeit und Elajtizität ift ein Interjchied wahrzunehmen, und zwar mag derjelbe fehr großs fein; eine Szatpturjartje Der gropen Ungleidheit Des Marftwerts ver=

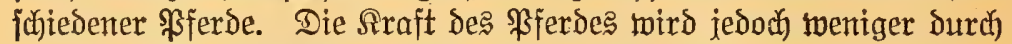
Die Grö̈e der Mußfeln, als durch die Elajtizität und Bujammen= ziehungßähigfeit der Mugfelfajern bedingt, twovon bie gröpere Stärfe und Schnelligfeit gewiljer \$fFerde hauptjächlich abhängt.

Bunahme an Zett fann weder die Mu引feln, noch die Sraft des \$ferdes bermehren. Dadurch entiteht aber bie volle abgerundete Form, weldye fo hod gejuäbst wird und manche bedentliche Fehler ver

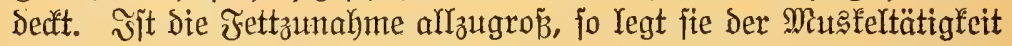
bedeutende Sindernifie in den $\mathfrak{B e g}$. Ein volles abgerundetes $\mathfrak{A}$ eupere ift fein Bemeis für gute Eigenjujaften, aud zeigt Magerfeit nicht Deren Mangel an. Cin gut gefüttertes, gejundes, mageres ßFerd bejist

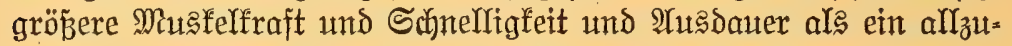

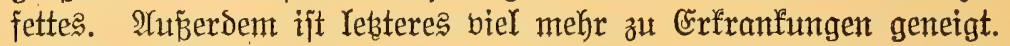
Sbgleidy bieje Iatjactjen allgemein anerfannt find, jo bleibt es nidfts=

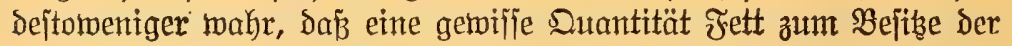
höchjten Sraft und Energie mefentlich notmendig ijt.

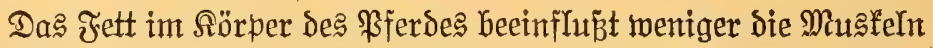
als die Şaut und Die Şaare, deren $3 u j t a n d$ wejentlid dabon abjängen.

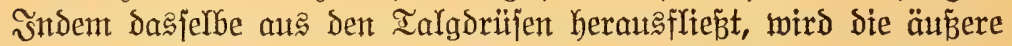
Şaut weid) und gej(d)meidig und die Şaare glatt und glänzend, worin

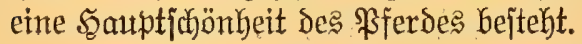

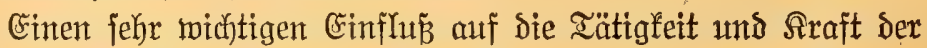
Mitafeln wird ferner Durch) den fifon genannten Eimeibjtoff (albu-

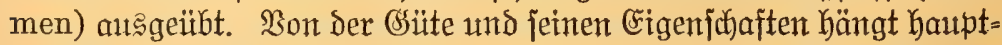

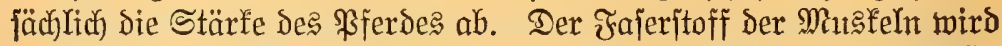
bon Demfelben vollfommen ungeben und in jeiner Rage erhalten. (Fs ift Der in unreifem oder jehr jungem Fleij(h) gefundene wachsartige Stoff, der den Jingern po gern anflebt. Seine Gsüte und Menge find 
bon der Rebenłłraft abhängig, und nehmen baher zu oder ab, je nact)=

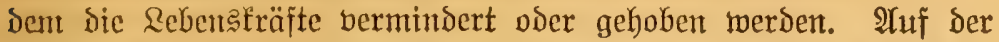

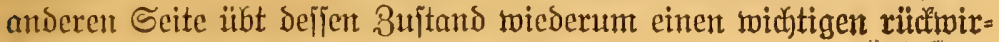
fenton Einfluz auf die Rebenłträfte aus.

Mird ein ßFFerd in Folge einer Sranfheit oder ungenügender

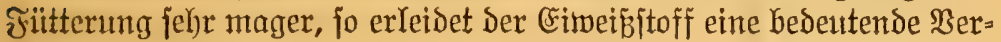
änderung. Ridut nur nimmt er an Duantität $a b$, jondern mird auch) fepter und flebriger. Die Fajern rüden in Folge einander jo nake, Daj3 ibre Iätigfeit gehemmt wirb. Der Unterjadied zmijicten ber Reid)tigfeit ihrer Betwegungen im gejunden 3 utande und ber gehemm=

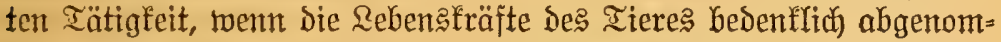
men haben, ift etwa twie Der, Den man wahrzunehmen Selegenheit hätte, wenn man taujend einzelne Sdhüre zu gleidjer Beit erit durdf

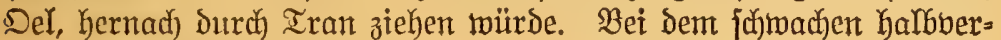
hungerten $\mathfrak{B j e r \delta e ~ i j t ~ c i n e ~ j e h r ~ l a ̈ j t i g e , ~ q u a ̈ l e n d e ~ S Y ~ n i t r e n g u n g ~ e r f o r d e r . ~}$

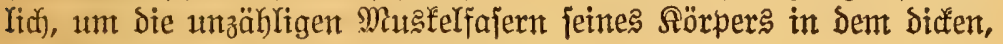
wad)

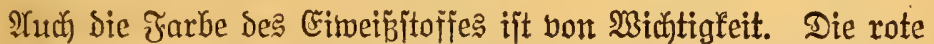

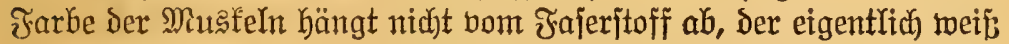
ift, fondern bon Dem in Eimeipitoff befindlicken Farbejtoff. Bet ge=

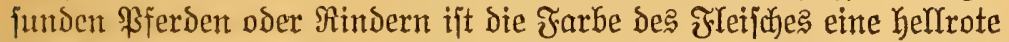

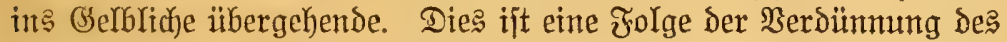

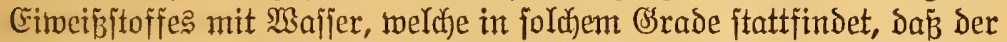

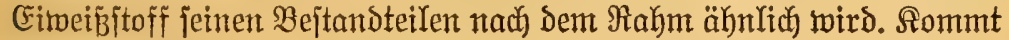
aber Dasfelbe Tier Durch Şunger oder Aranffeit jehr herunter, fo erhält Dą Fleijch eine Dunfelrote, ans Braune grenzente Farbe, und

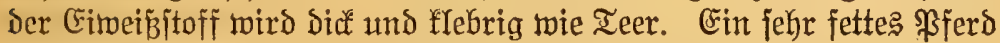
hat twohl zehnmal jo biel eimeipjitoff, als ein jehr mageres.

Wünjut jemand Die Durd dieje zmei Bujtände entjtehenden 14 n= terjuiede zu erproben, fo nehme er in eine Szand ein Stüd mageres

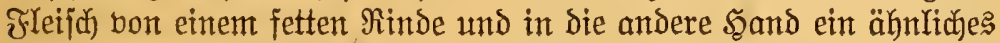

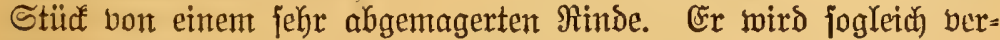
itehen, twas wir flar zu madjen wünjđen. Man hört oft bom Fleijije

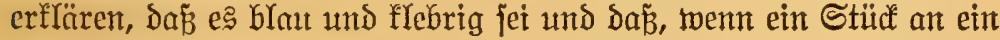
Şaus gemorfen trird, es feit flebe. Dies ift ein Betweis der Atbmage.

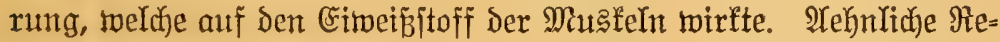
jultate werden Durd) Sranfheit exzeugt. (ङs mag Dem sejer vielleidjt

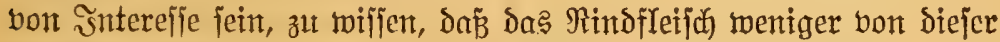

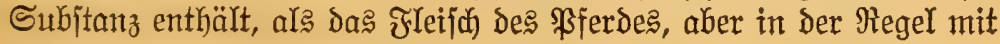
mehr Fett Durchzogen iit. 


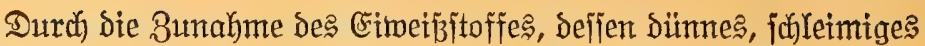

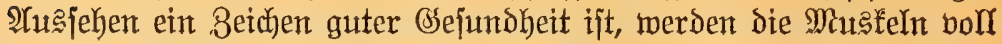
und rund. Die Mußfelfajern werden aufgelocfert und julüpfrig ge= madyt, ihre Elajtizität und Biegjamfeit vergröpert, und ihre Iätigfeit mit bermehrter Energie auggefithrt. IUtch twird die Ernährung des

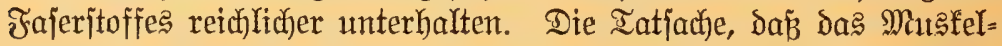
getwebe aus biejen ztwei Stoffen zujammengejebt ift, - Fajerjtoff und Eimeibjtoff — jollte dem Æarmer als Fingerzeig auf das zur Erhal=

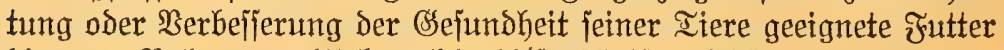
bienen. Rahrungantittel, welde biẹje Stoffe reidylich und in einem Yeidyt verdaulicjen $8 u$ jande enthalten, forlten zur Fütterung jeiner \$fFerde vorgezogen werden.

Die $\subseteq$ ehnen. - Es gibt deren jehr biele; wir fömen bis= jelben jedody ebenjowentg als die Musteln eingehend bejureiben, meil

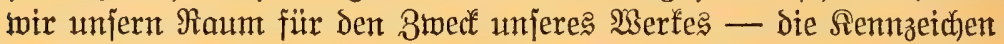
und Seilung der Arantheiten des ßfferdes - nötig haben. Sämtricte Muß̌̉eln endigen in Sehnen, wodurch fie bermittelft des Snorpels mit Dem Snochen nake an den Gselenten verbumben werden. Bum belieren

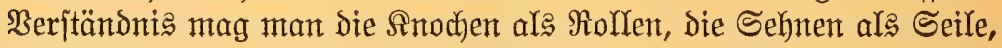
und die Musfeln als die an den Scilen ziehende Sraft betracten.

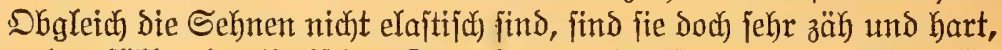
und exfülfen im tierifchen Drganisnus eine jehr wichtige IIufgabe.

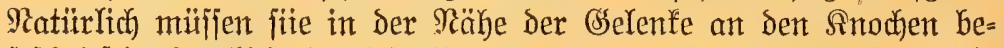
feftigt jein, Da allein burdh jie Bewegungen bewerfftelligt merden. Sie find zu mehreren Rrantheiten geneigt, aber bejonders jener jabmerz.

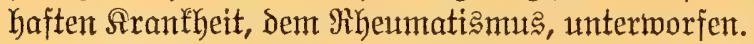

Fijteln, Gejonders die Radenfijtel (poll evil), dieje furd, fuaren ઍeinde des \$ferdes, haben fait allemal ihren Sib in swei widftigen Sehnen. Die Bejabreibung einer Derjelben wird für beide binreidyen, ba fie fich mur himfichtlid ihrer Lage unterjobiden. Die grobte findet man auf Den oberen Teil Der Schulter. Die Fajern Derjelben haben eine eigentümliche Bejchaffenkeit, find blendend toeif und bejizen nicht nur die außerorbentliche Stärfe der übrigen Sełnen, fondern aud cinte merfmürdige Elaftizität. Die Gselehrten nennen Diejelbe serratus major (wörtlid) grö̉e jägenförmige), aber unter den Laien ift biejelbe unter dem Ramen ßeipjleder (white-leather) Kiefannt. Sidi) unterhalb dem oberen Ende des Sdyulterblatts erịtredend,

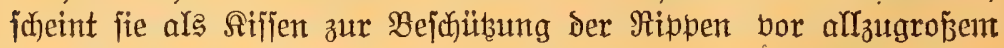
Drute bejtimmt zu jein. Borne ijt diejelbe mit dem $B$ rufftorb and 


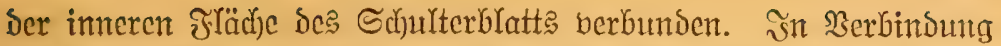

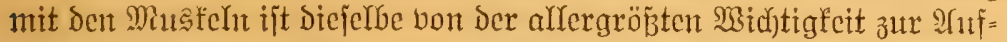
reck)terhaltung Des Sïrpers, bejonders wälirento der Durch gewagte

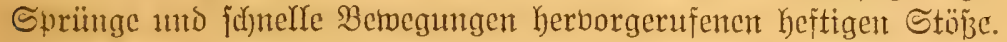

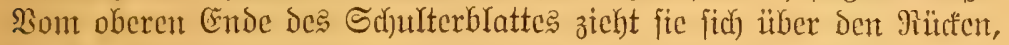

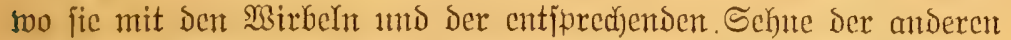

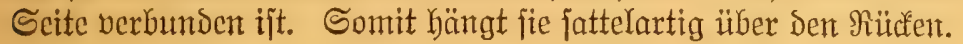

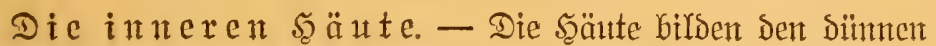
gIatten Heberzug Der Sinodjent und trennen Siejelben bon den Mits=

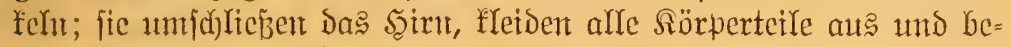

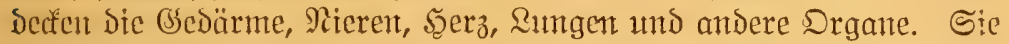

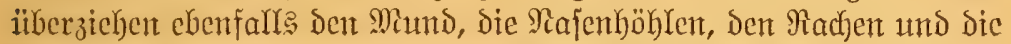
Sichle unt werden an alfen Reibesöffumtent angetroffent.

כ̌e ทtad) ifyrer Rage und den Drganent, Sie fie einfü̈ffen oder über= zichen, find fie bentannt wordent. So nennt ntant dent Heberzug. der:

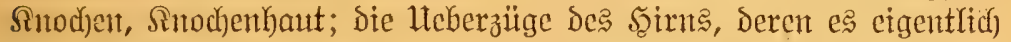

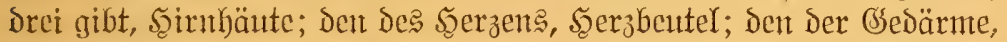

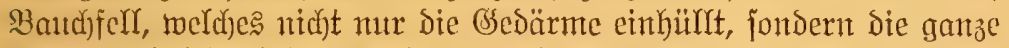

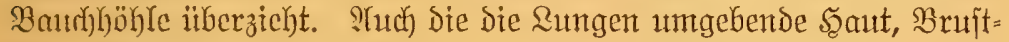
fell, bilsct faft cinen bollfommenent lteberzıtg ১er \$rujthöhle. J̌eder

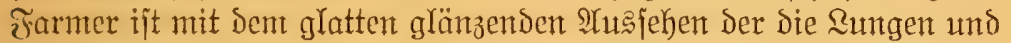

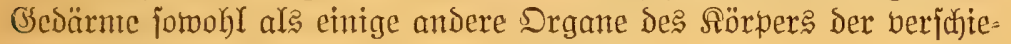
benen Şaustiere untgebendent Saaut befamnt.

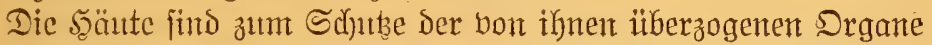

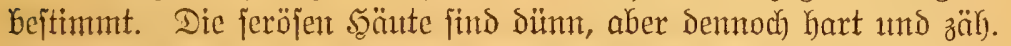
(llnter feröfen Şäuten berfteht mant mur Diejentgen Şäute, Die iłre

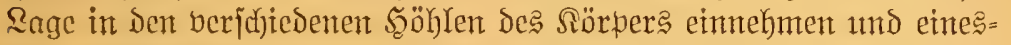

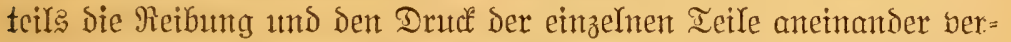
Kintoern, amocrnteils vermöge ifhrer glatten Dherfläche die ßemeglidu= feit Der Drgane an einander unterjtüben.) Sie werden meniger leidjt

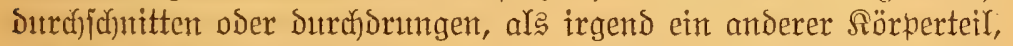

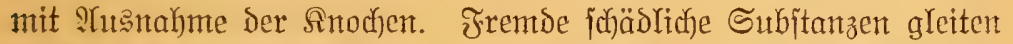
in Folge ihrer glatten $D$ berfläche jehr Yeicht $a \mathfrak{b}$, menn nämlich bie (se=

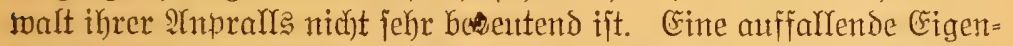

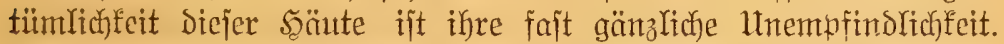

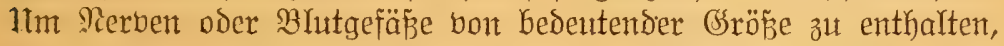
fins fie zu süm; jedoch) findet man derjelben jehr biele gerabe unterhalb der Şäute. Bis jebt fint feine Srantheitent derfelfen befannt gemorden, aber jie fins natïrlich, wie alle anderen Terle, BerYeb̆ıngen unterworfen. 


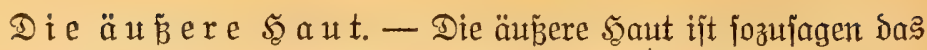
Dach und die Bedectung des ganzen Drganismus des \$ferdes. Die

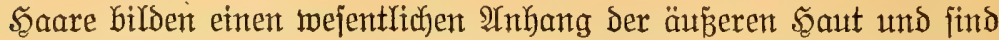
deshalb in Berbintung mit derjelben zu betraditen. Sie find eigent=

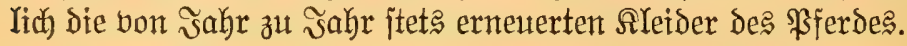

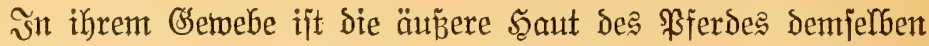
Srgane anderer Iiere ähnlich. Sie bejteht aus orei übereinander Yiegenden Sifict)ten, weldfe wejentlich in ifrer Bauart und Berrict)= tungen bon einander abmeichen. $\mathfrak{A}$ üen findet man bie Şornhaut,

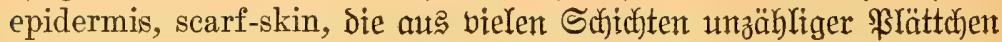
beiteht und über bie ganze Dberfläche des Iieres ausgedehnt iłt. Unterjudyt man die Sornhant mitteljt eines Mifrojtops, jo werden dic

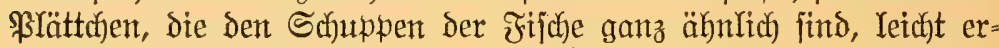
fannt. Durch die Wirfung eines Senfpflajters werden fie bon ber

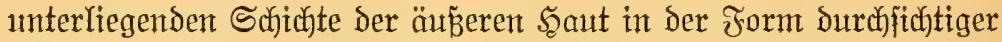

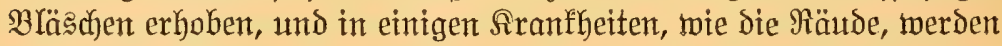
fie als harte, trodfene, weif̉e Schuppen, mowon viele ftets übereinander liegen, abgemorfen. Die Şornhaut ift in jedem Ieile Des §örpers bont unzähligen Poren Durdyzogen, bon welchen einige Den Durdytritt der

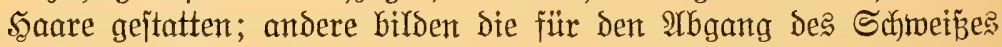

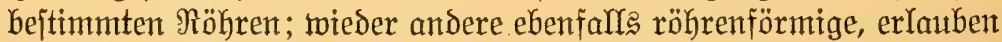

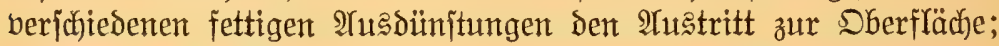

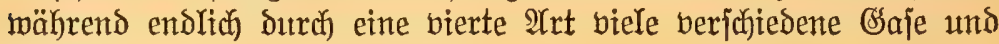
Jriififigfeiten eingejogen werden.

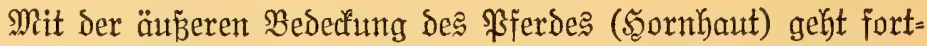

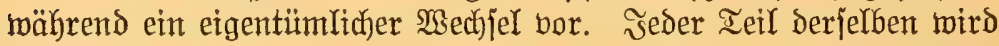
bejtändig umgeändert und erneutert, aber fie ijt mit der unterliegenden Rederhaut mitteljt ber \$oren und jebr vielen fleinen Errböhungen, weldje Berlängerungen der Şautnerben zu jein jodeinen, eng ber= bunden. Die Sberhaut jelbjt ijt gefühllos, ihre widftigite Funt= tion ijt aber die unterliegenden Ieile zu bejüüben, die häufig allzut empfindrich find.

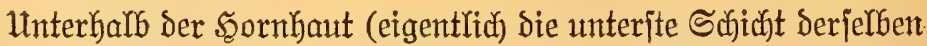
bildend) findet man eine meicte, dünne Subjtanz, Durch melche dic Poren und Erböhungen Der Rederhaut Durdhtreten. Sie wird die Sd) (eimidjidjt genannt (rete mucosum) wegen ifrer gewebten Bauart und jobleimigen Bejtandteile. Sie jabeint zur Bededung und zum

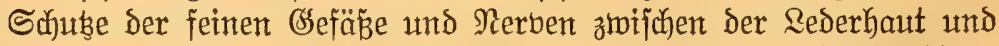
Scornhaut bejtimmt zu jeint. Die Sauntfarbe hat ebenfarls Gier ifren

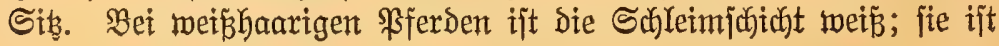


von braumer Farbe bei braumen \$feroen, fujwarz bei ben jafwarzen

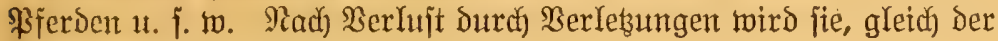
Sornhaut, wieder erneuert.

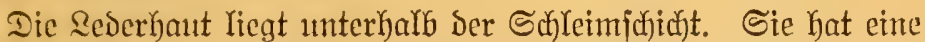

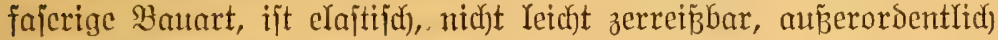
gefäbreich mo jebr empfindlich. Sie bildet ben Teil ber äußzeren

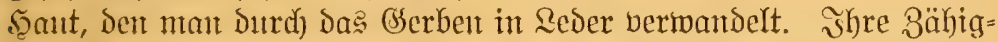

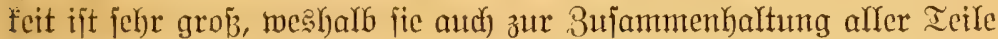
Des Sïrwers bient. Ifn einigen Stellen ift ihre Berbindung mit dent Anterliegenden Drganen fo eng, Daj faft feine Bemegung Derjelben

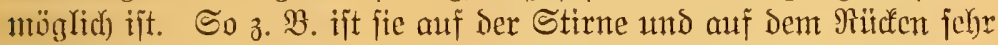
curg mit Den unterliegenden Icilen bereinigt, aber im (Sejichte, Den

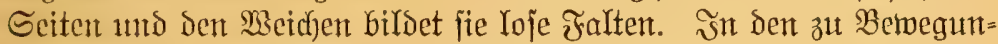

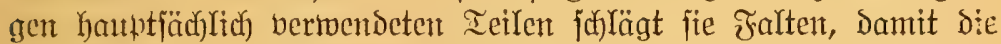

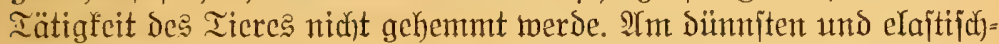
ften ijt bie Sederkant an ben am wenigiten mit Şaren bedectent, oder ganz bon Denfelben entblöß̈ten Ieilen, wie die Rippen, das Maul und

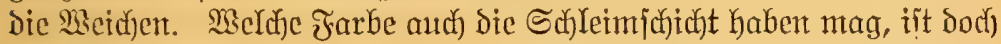

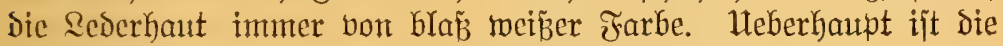
Jarbe der Şaare utd)t von ber Lederfyaut abfängig.

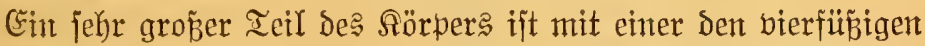
Tieren eigentimlidjen Musfel bededt, Der bei bünnharigen $1 \mathrm{~m} \delta$ Süunbäutigen Iieren biel fräftiger und auggebreiteter ijt, als bei folchen, sie cine ftörffere äupere Bedectung haben. Bom Šinterfopf

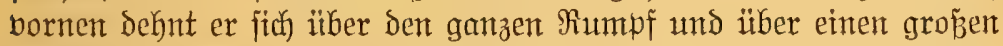

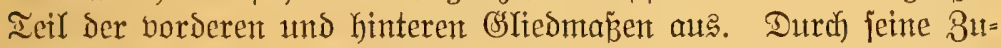

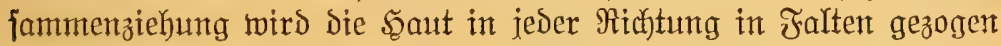

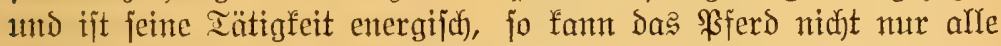

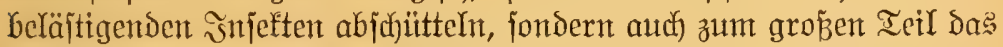

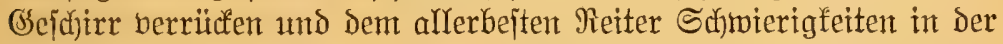
Bebauntung jeines Sites madjen. So weit er fith eritredft, ift er der äıberen Şaut in der Fejtbindung unterliegender Teile behilflidf) und

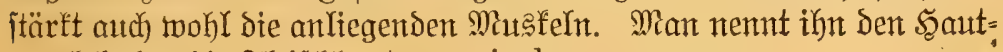

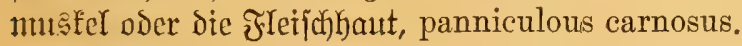

Die äuñere Şaut hat den Doppelten 3reą des Schuthes und der Unteritïbung Der bededten Ieile. Mo eine enge ßerbindung ber Teile untereinander nötig ijt, flebt fie jehr feit an. Zum Beifpiel, die Siniefnodjen und Die Feffeln und Sronbeine, fowie Die Sehnen Der Beine, die oft gropen IYnjtrengungen auggejest find, werden ourch bie änßzere şaut eng und fidjer verbunden und in ifrer Rage gehalten. 
Bon ihrer gropen Stärfe haben wir vielfache 'Betweije jowohl in Iebenden als toten, Tiere. Şhre Jajern find mit einander nad) allen

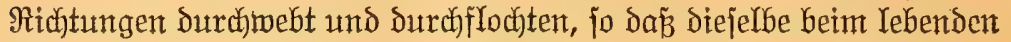

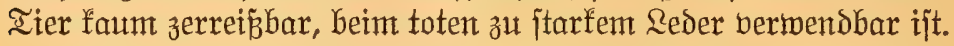

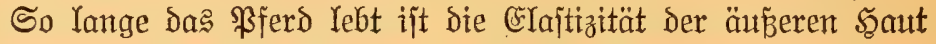

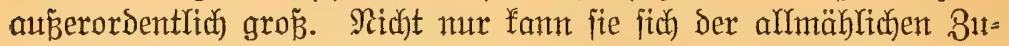

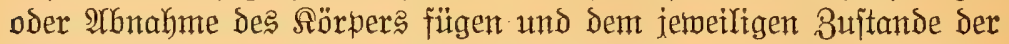
Fettleibigfeit oder jeletettartigen arbmagerung gleich gut anpajjen, fondern wenn irgend ein bejonderer Ieil derjelben bis zum bödjiten Grade Durch Musfeltätigfeit ausgedehnt worden ijt, ziebt er jich augenblicflich) zu feinem getwöhnlichen 1 mifang zurürd.

Dieje Elajtizität bejist jie hauptjächlich in Folge ber bon unzäh= Yigen fleinen Drïjen ausgejonderten fettigen Flïfifgfeit, welche bie

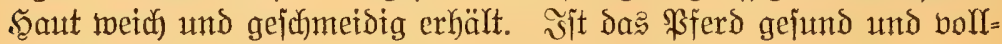
jiebt jedes Drgan feine Junftionen richtig, fo wird eine gewifie Dutan= tität diejes örigen Stoffes auf der Dberflärbe der äuß̌eren Şaut ange=

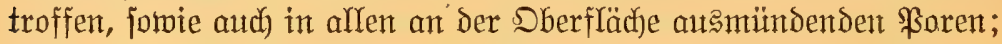

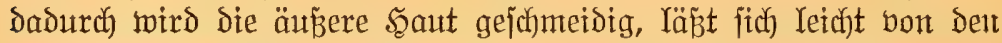
unterliegenden Ieilen auffeben, unto zeigt jente eigentümlidfe nach)= giebige Meichlyeit und exajtizität, die für den guten 3 ujtand oder die bolffommene Sefundheit des ßferdes das beite fiennzeichen liefern.

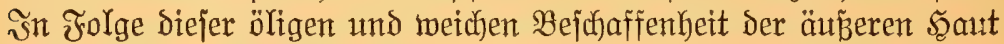
Iiegen bie Saare glatt und bejizen einen jehr jofjönen (Slanz. Sommt irgend eine bejondere Störung ber Gejundheit bor, bejonders ber Berdaunngsorgane, fo dap die Ernährung Darunter Yeidet, jo merft man bald den Einfluz auf Der Dberfläche. Das Del gelangt niçst mehr zur Sberfläche; die äubere Şaut berliert ihre W̉eidheit und

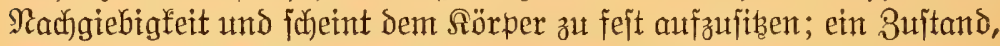
ben man mit dem $\mathfrak{A}$ usoruct "angewactjen" (hide-bound) bezeid)net.

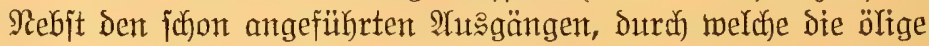
Flüffitgfeit zur Dberfläche gelangt, gibt es andere in noch grö= Berer $\mathfrak{A} n z a h \mathfrak{l}$ vorhanden, die eine grobe Suantität wäfjeriger Flüffitg.

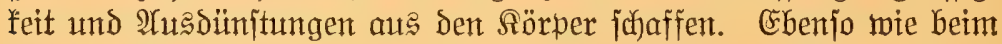

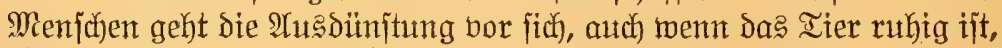

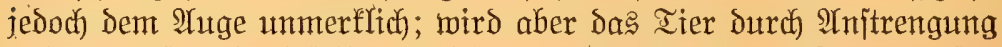

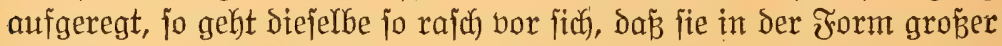

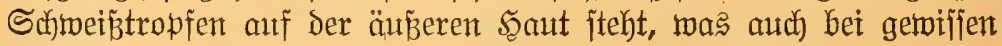
franffyaften 3uptänden Der Fall ijt.

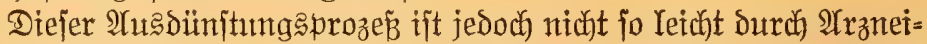
mittel zu beeinfluffen, wie Geim Menjchen. Wir fennen feine Medizin,

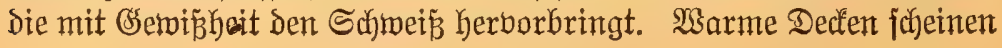




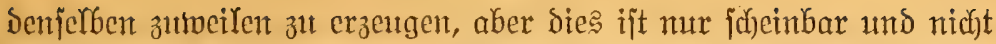

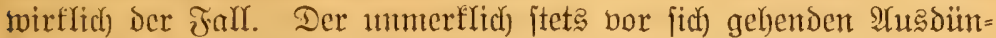

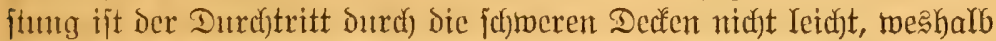

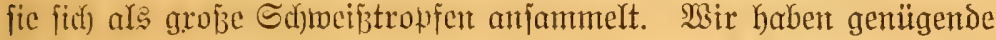

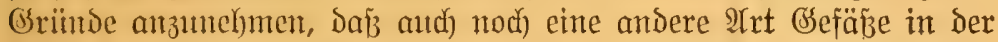

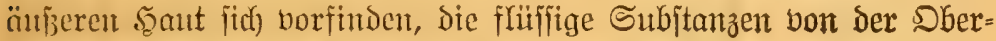

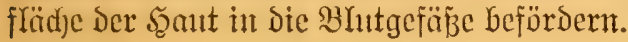

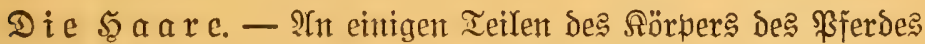
madjjen grobe, ftarfe, fteife Şaare, hauptjäctilich am Salje, wo jie die Mähne bilden, und am Sdjwanze.

Sher bon weit größerem Interefije ijt ung die allgemeine Şaar=

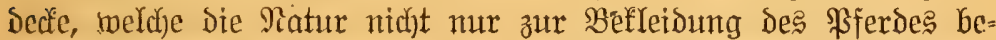

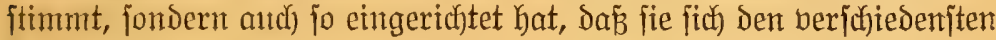

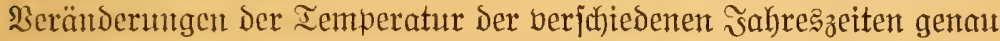

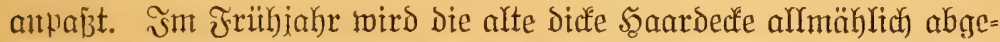
worfen, währent fid eine neue, ctwa einten halfen Bolr Iange bereits 3um Erjake ber alten borfindet. Dieje Saare find biel feiner und Diimer, als Die abgeworfenten, und für Den Iemperaturwedjel aujer = ordentrict) gut geeignet. Sit bas \$fferd gejund, jo haben fie ein glattes, glänzendes șisjehen und find toeich und flaumig. Tritt bie falte Mitterung wieder ein; fo fommt eine neute, biel dicfere und grobere Sajut zum Borjulin. Die Sommerhaare fallen jedoch nicht

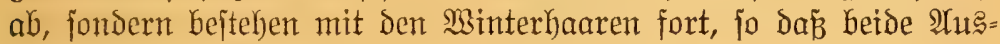

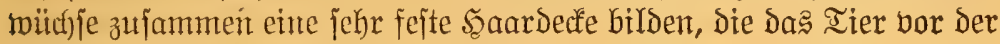
ftrengiten $\Re$ älte zu judüben vermögent.

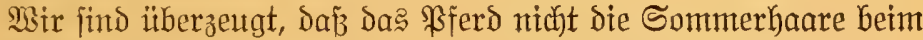

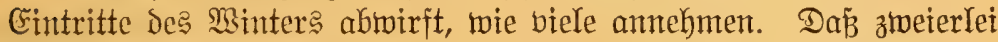

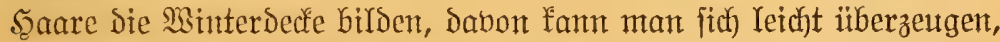
wenn man fich bie Mïlye gibt, eine genaue Unterjuchung vorzunehmen.

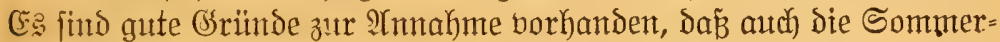
haare bei ber ?lmäherung ber Rälte aufg neue madjjen. Shne Bmeifel hat das ßferd immer zweierlei Saare. Selbjt im Sommer triffit man unter ben längeren und gröberen Şaaren eine viel feinere. Sorte bon flaumiger Befchaffenkeit an. Die eriteren werden im Spätjahr abgemorfen; Die Yebteren jisen bis zum nächjten Frühjahr, bilsen aber indefien die groben Saare des Minters, während der

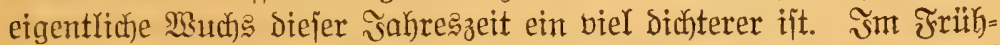
jahr wird der alte $\mathfrak{A}$ (1) Des neucn, Da fonit bie Şant eine viel jtärfere Bedectung erbielte, als 


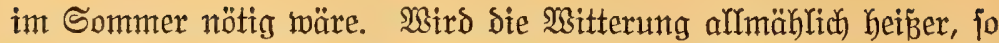
wird die alte S(f)idfyt von der neuen berorängt. Somit fängt die im Spätjahr erforderliche Saardedte int Jrühjahr zu wadjen an, und int Spätjahr die im nächjten Frübjahr nötige. Durch dieje meisliche Ein= richtung wird das ßferd immer gut und anjtändig befleidet.

Die oft wiederholte Behauptung, dap̉ das \$ferd während bes

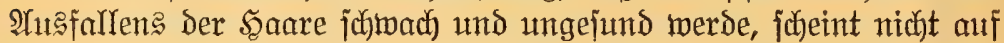
Iatjachen begründet zul jein. Sommen bei irgend einem ßsferde wäh=

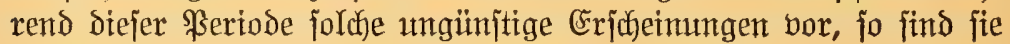
wohl mit viel mehr Redft entweder bem zu diejer Beit borfommenden

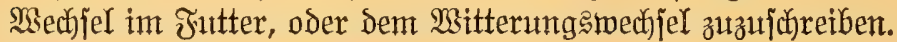

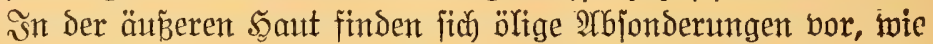
jujon bemerft wurde, weldye fith bei guter Gejundheit des ßsferdes über die Saare ausbreiten und innen jenen bon allen \$ferdelieb=

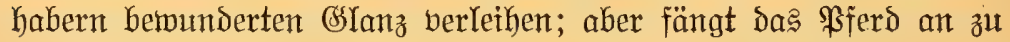
fränfeln, fo werden dieje Delquellen verjtopft, Die Dberfläche nimmt

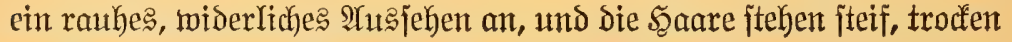
und borjtenartig zu Berge.

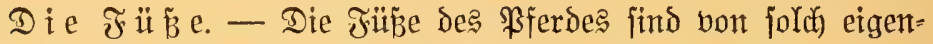
tümlicher Bauart, ihre Reiftungen find jo wichtig und die fie befallen= ben Sranfheiten fo zahlreich), baz wohl ein ganzer Band ihrer $\mathfrak{B e}=$ trachtung gemionet werden fönnte. Biele ifyrer Rranfheiten gehören unter bie hartnäcfigiten und bedenflidjiten, benen das $\mathfrak{B f e r d}$ unter= worfen ijt. Âtn diejer Stelle joll mur eine allgemeine Bejchreibung ber fomplizierten Bauart Der ßferdefüß̈̈ gegeben merden, Die dem ¿ejer leichter verjtändlich fein wird, wenn er bie betreffenden Arbbildungen zur Şand nimmt.

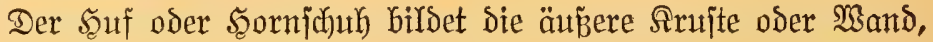
weldte den Yebenden empfindenden Ieil einfichließ̈t und von Den Saaren

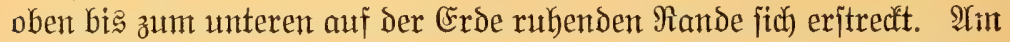
rängiten ift er vorne, wo ber untere Rand mit Dem Ramen "Behe" (toe) belegt worden ift. Seinten ijt er offen; hier endigt derjelbe in einer bicfen, fichnammigen Saat, weldhe Ginten am Fune Durch eine Spalte oder Siluft in Der Mitte getrent und zu beiden Seiten als herborragende ßölbungen auggebreitet ift. Dieje zujammen bilden

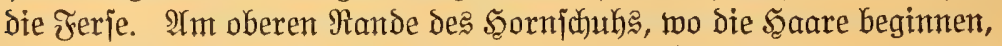
ifi eine didfe, foftwammartige, ringförmige Subjtanz, bon weldher aut

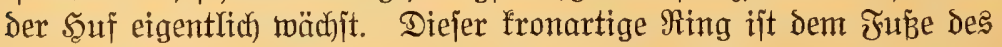

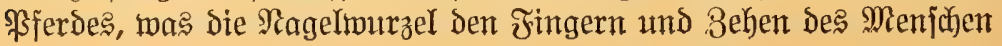




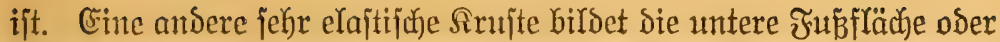
Sohłe, Derent untere Der Erod zugemanote Fläche leidgt ausgehöhIt poer fonfav ijt. Sointen an Jube ift eine hornartige, Dent Budd= ftaben $V$ ähnliche Servorragung, Deren Deffmung Der Jerje zuge= wentsct ift. Die Seiten biejer Şerborragung, welche einen Winfel von ctwa 45 Graden miteinander bilsen, werden Ecfitreben (bars) ge=

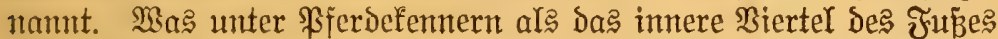
befannt ijt, liegt an ber inneren Seite bes Jukes auberhalb den $\mathrm{E}$ ftrcbent. Das äußzere Biertel befindet fich auf ber entgegengejesten

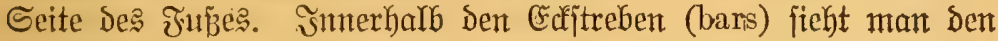
Sornjtrahl (frog). Diejer hat Die Jarbe bon jatwarzem (summi, Dem

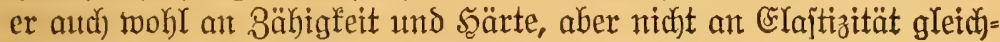
fommt. Der Sonnitrah) bejibt fein (Sefühl, aber etwa einen halben 3oll höher ftöjt man auf ben Fleifajtrahl, ber außerordentlich empfinolid) ift und mit unzäfligen fleinen Rerven und \$lut= gefäß̋en angefüllt iit.

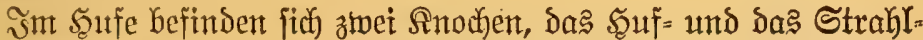
bein, weldje zutweilen bon jehr hartnädtigen Sranfheiten befallen wer= ben. Dieje nebmen faum mebr ars die Şälfte des im Şufe befino=

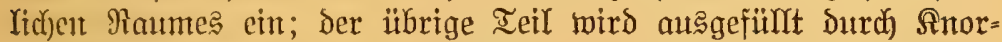
peln, Schnen und Mitzfeln, in tweldjen verhältnismäpig mehr fleine Rerven und Blutgefäpe ifren Berlauf haben, als in irgendeinem

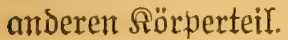

Eine fehr widdtige Sebne (bie Beugejefne) erjtredt jid bom bin= teren Teil bes Sronbeins und Sutfeins über Das Ende des Strahl= beins, wo fie fich in ztwei Ieile trennt, weldje auf jeder Seite der Ferje 11nd Des Somitrabls Ginablaufen und jich an ben unteren (Enden des Sufbeines befejtigen. Dutrh das Strahnbein und dieje Sehne, weldfe unmittelbar anf dem empfindlichen Fleijofjtrahl liegt, wird eigent= Yich Die Sgervorragung Der Ferje gebildet. Folglid werden $\mathfrak{B e r}=$ Yesungen bes Fleijhitrahls fajt allemal aud dieje Sebne und Das tweidje Strahlbein treffer.

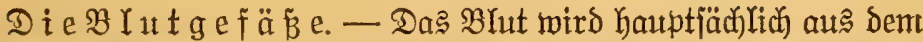

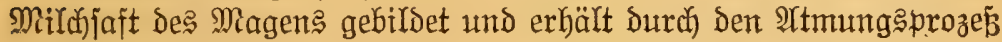
widjtige Eigenjudaften und wird in Der \&unge fortwährend aufge= frijut. Die Durch Das Scerz Getwirfte Birfulation des Blutes treibt

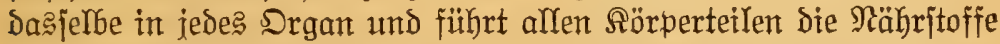

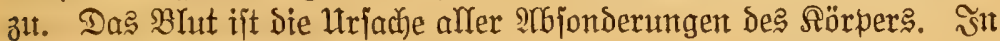

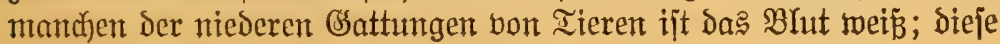




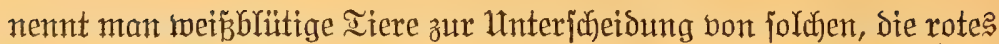

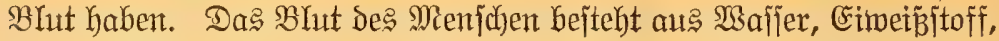
Fajerjtoff, Farbejtoff, etwag Jett und mehreren Salzen. Das Bhlut in Den Sulsadern ift bon einer hellroten Farbe; das in Den blauen Bhutadern hat eine braunrote oder dunfelrote Farbe.

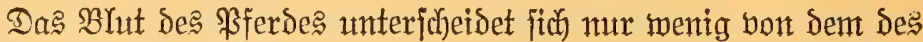

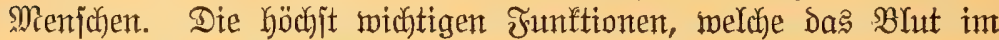
Sörper berridytet, find junon angezeigt in der Mannigfaltigleit jeiner

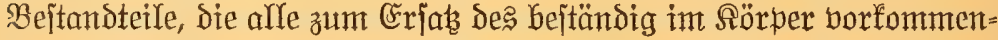

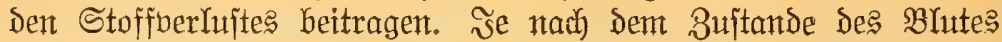

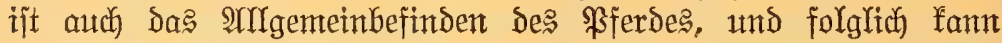

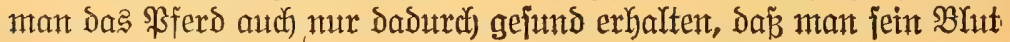
rein und nahrbaft erhält.

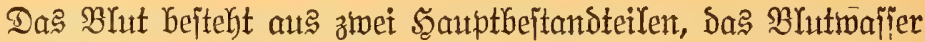
und der Blutfucter. İm Iebteren findet man die roten Sörperchen,

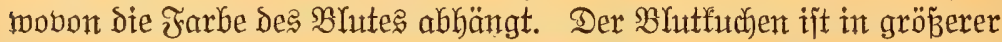
Menge vorhanden, als das Bhytwafjer. Šedermann fann fith Yeidht

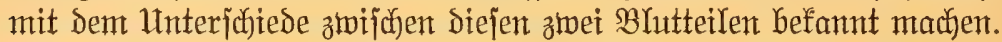
Richts weiter ijt nötig, als eine fleine Duantität frijubes Błut einige Minuten Yang mifen zu Iajjen, Damit es gerinnen fann, wodurdh die zwei Ietle von einander getrennt toerdent.

Der Sreislauf des Bhutes läßt fïch mit einem See vergleichent,

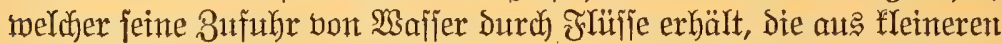

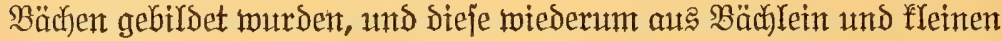

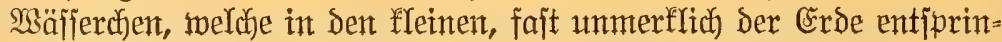
genden Iropfen ibren Utrjprung Gaben; Damn fith wieder verliert Durch

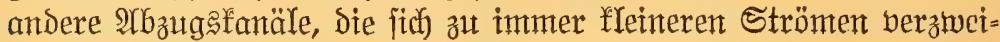
gen, bis fie fich zulebst unter Der Sberfläche berlieren. Dennod) aber findet Da? Maffer mieder jeinen Iropfen erjdheint, weldje fich zu immer gröB̈eren Strömchen 1 tnd Fłïbichen bereinigen, und endlich twieder den See anfülYen. Wiederum

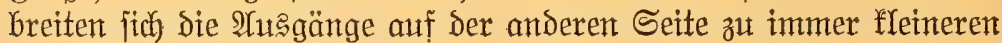

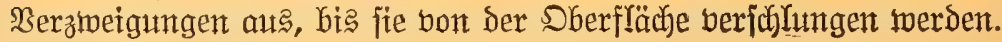
So wiederbolt fitch der Sreislauf bejtändig.

IUtץ ganz ähnliche : Da马 Šerz ift der Behälter. Die Bhutadern find die zuführenden Früjfe. Die \$ulbadem die auf Der anderen Seite ableitenden Ströme.

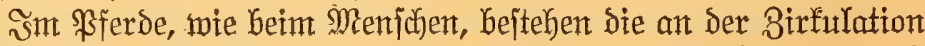
beteilitgten Drgane ebenfalrs aus Serz, \$ulsadern, Bhutadern und

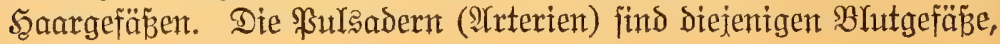


Sic bas rote, mit Sanerftoff angefïllte Blut bom Šerzen nach allen

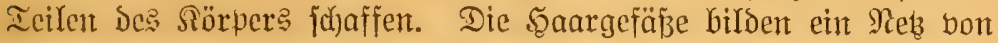
äußzerit feinen (sefäben, bie fich Durd) alle Drgane zichen; fie find in

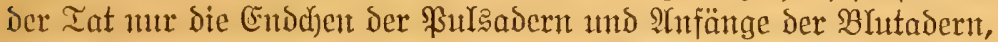
obtwohl fie getwöhnlid) als cin eigenes (sefäbinjitem betrad)tet werden.

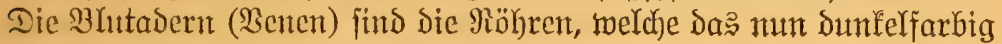

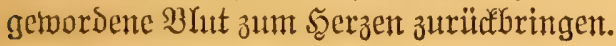

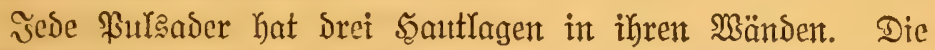

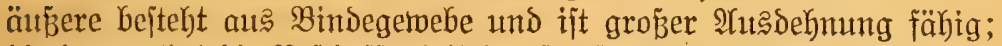
Die inture hat Die Bejuaffenheit ber jeröjen Fä̈ute, und ijt auf ibrer

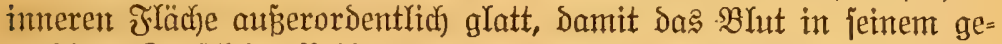

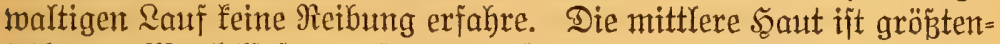

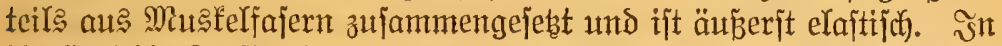
ihr liegt die Iraft, ohne welche der Blutfreisłauf faum denfbar wäre,

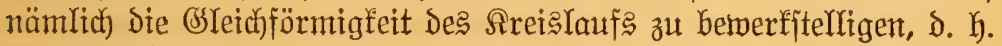

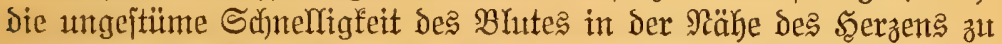
Yemmen, aber jeinen হauf in weiter Entferming von Der groken Bentralpumpe des §örpers zu bejo)leunigen.

Die Blutadern haben ebenjo viel sautlagen, ibre Sände find aber biel bünner und joftwäcther. Sie find biel zahlyeicher als bie

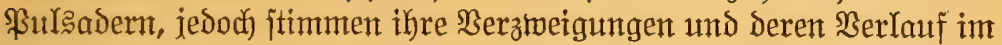
allgemeinen mit leb̧teren überein. ŞGr innerer Flächenraum beträgt fajt soppelt foviel, als ber ber \$sulsadern. Sie ftehen natürlidy nicht joviel unter Dem Einflub des Şerzens, folglich pulfieren fie nicht, aud

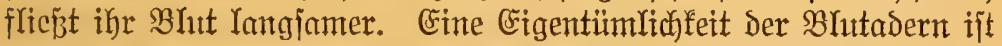
Der Bejiz von Slappen von jehr verjutedener Somitruftion, die daق

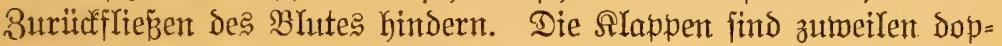
pelt, und hie und da aud wohl brei= oder bierfach miteinander ber= Gunden; in Den meipten, jedoch nicht in ben größ̈ten ßlutadern find Slappen borfanden.

Mir haben foweit nur den allgemeinen oder groß̈en Sreiglauf

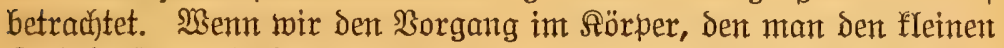
Sreislauf nennt, betradten, jo finden wir ibn fajt umgefebrt; die ßungenpulaader jufafft nämlich das unreine, dunfle Blut aus der red)ten Serzfammer in bie 2ungen hinein, to es gereinigt oder mit eingeatmetem Sauterjtoff berjehen wird. Diejes verbefferte Blut,

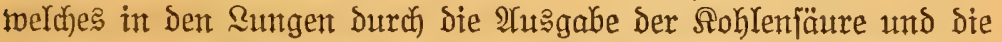
शhufnahme bon Sauteritoff in ein hellrotes bermandelt worden ijt,

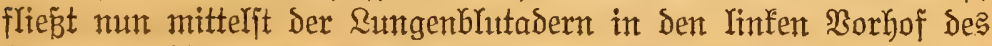
Serzens. Itikerordentlid interefiante Ericheinungen findet man 


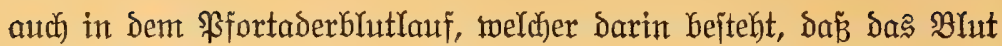
Des Speijefanals mittelit der \$fortader in bie Reber gejhafft und nad) borrendeter Reinigung bon ben Reberblutadern in bie untere Sohlader befördert wird.

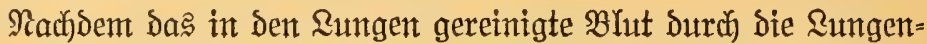

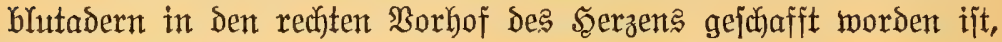
fließst es in die rechte Sorzfammer, beren aus ftarfen Musfeln be=

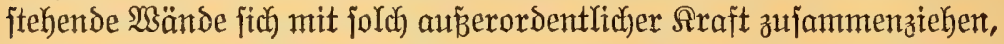

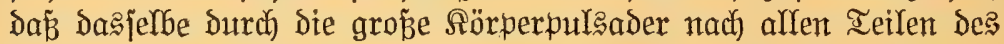
Sïrperg jtrömt. Die groß̉e Rörperpulsader zerteilt fich nach furzem Berlauf in zwei grope $\mathfrak{A}$ ejte, bon denen der fleinere, nach bielen $\mathfrak{B e r}=$

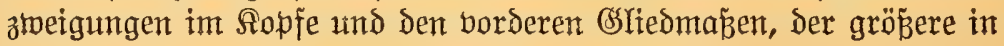

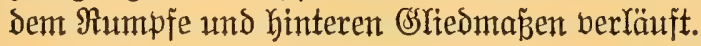

Das fo von Szerzen ausgetriebene shut enthält die mannigfal= tigent Stoffe, wellbe zur Seritellung bes Subjtanzberluftes ber ber=

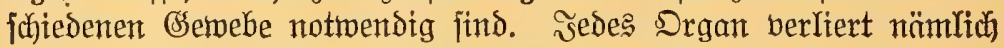
Durch jeine Iätigleit gewifje Ieile, welche Durch das in allen Drganen feinverbreitete $\mathfrak{B}$ hut wieder erjebt werden. Diejen veriüngenden \$ro=

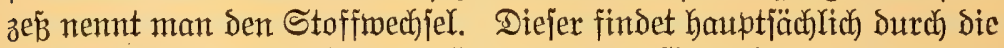
Szaargefä̉e itatt, die fleinen bünnwandigen (Sefäp̧chen, in denen die

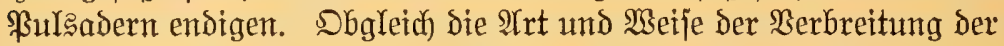

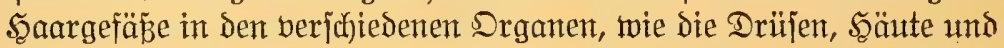
Mugfeln ziemlich mannigfaltig ift, fo haben fie Dod) in allen Drganen Diejelben Berridytungen zu erfüllen. Dieje find nidyt mur die Bufubr Dę zur Ernährung der SSetwebe nötigen Stoffe, jondern die Âtunahme ber alten abgeitorbenen Gemebsbejtandteile, damit bieje Durch den

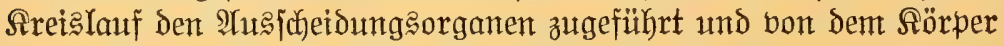
entfernt werden. Durch diejen Stoffwedfel berliert das ghut die in den \&ungen gewonnene hellrote Farbe und wird dunfelrot. YYuth wird

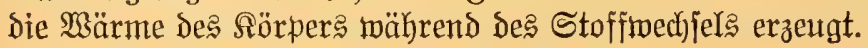

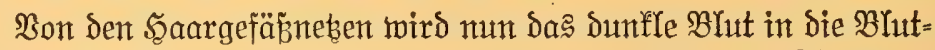
abern befördert, und von Diejen ins Serz zurüdfgeleitet. Die BYut= adern bereinigen fich untereinander immer mehr, je täher fie bem Serzen fommen, bis fie enolich als ztwei groke भrdern, die man bie

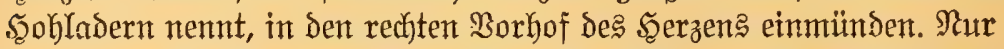
eine dïnne 3wijhyentwand trennt mun das Bhut bon dem IInfangs: punfte des Sreislauf's in Der linfen Serzfammer. Alber in biejer 8mi=

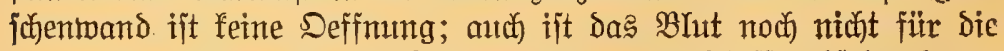

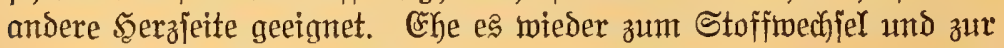
Erzengung der Wärme des Rörpers dientich jein fam, muß ę ge= 
reinigt werben. Nidjt nur müifen bie bon alYen Drganen aufgenom= menen alten Sseweb引beitandteile abgejondert und entfernt werdelt,

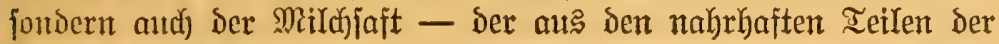

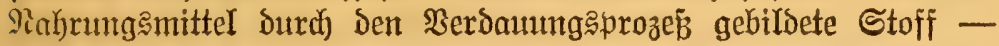
nแm einer weiteren Bearbeitung unterworfen werden, ehe er gans wafiend ijt, den immer jtattfindenten Berlujt an Bsemebsbejtandteilen

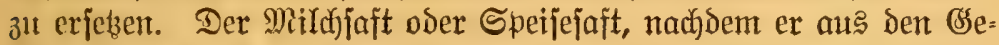
Särmen in bie Saugabern übergegangen ift und in Den Interleibs= briifen eine weitere Borbereitung erfahren hat, wird bon bem Milch): bruitgange, in ben bie Saugabern endigen, in eine der gropen Şohl= abern, fomit in ben Bhutitrom gegoflen.

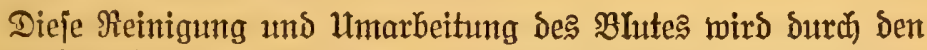
fleinen Ireislauf bemerfitelligt. Die \&ungen, wobon fich eine auf jeber Seite im Brujtforbe befindet, haben ein jojnammige马 Semebe, das hauptjäd)lich aus unzähligen fleinen \&uftzellen oder Bläßłhen befteht. Die \&uftzellen find bon einem äuberit feinen Saargefäвnebe umponnen. S̃ndem das dunfelfarbige unreine Blut Durch dieje

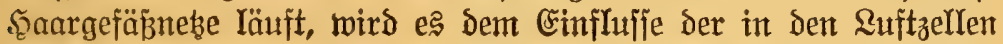

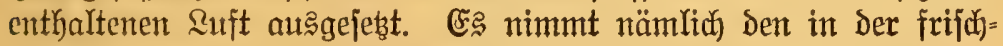
cingeatmeten \&uft befindichen Saueritoff in fich auf, teilt aber zu gleicher Beit Ser Ruft eine groß̉e Duantität ßohlenjäure mit. Die

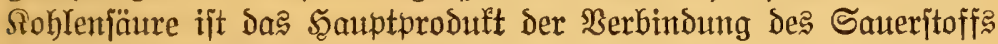
mit Den alten (semebsbejtandteilen, folglich audf) ber unteine, wenn er

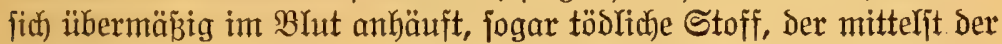

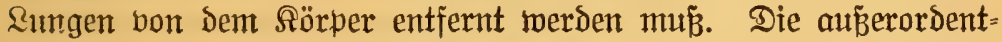

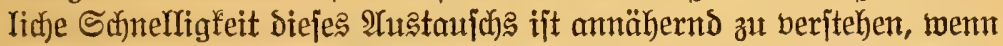

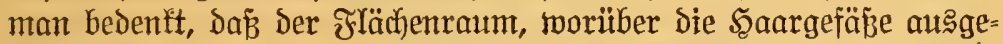
breitet find, etwa zehn= bis zwölfmal fo viel beträgt, als die ganze Sberflärye Des Sörpers.

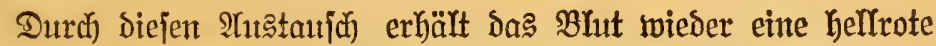
Farbe und wird nun bon ben \&ungenblutabern dem Serzen zugeführt, ım aufs neue Den Sreislauf zu beginnen. Wieder gelangt e马 nach

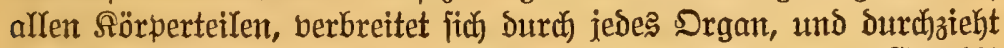

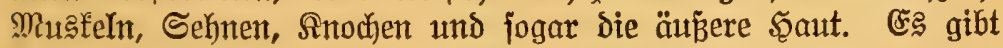
feinen Ieil, fei er auth nod jo flein, entfernt oder unbedeutend, der

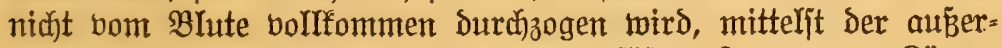

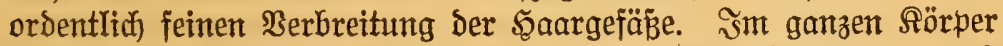
gibt es fein đsemebe, weldhes nicht die zu feiner Ernähnung und

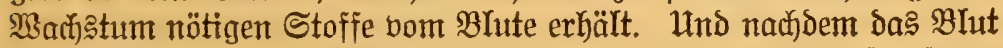

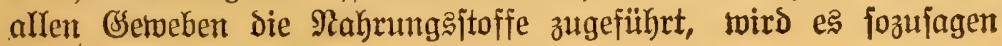




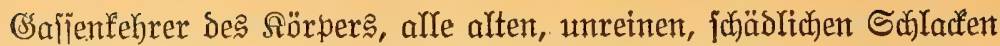
fammelno, und den $\mathfrak{A}$ (t) Dem Sïrper entfernt merden fönnen.

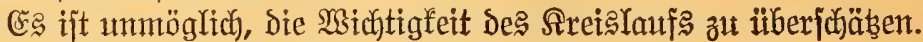
Dhne denjelben fönnte feine einzige Junftion vollzogen toerden und bas Reben jelbjt mürde jatnell zu Ende gehen. Und Dennoch mag ber

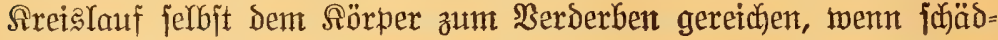
riche giftige Subjtanzen in das Bhlut gelangen. Deshalb follte grope und beitändige Sorgfalt auf Die in ben Magen eingeführten Mah= rungamittel oder Medizinen verwendet werden, da jie fo junell und ficher in bas Bhut übergehen.

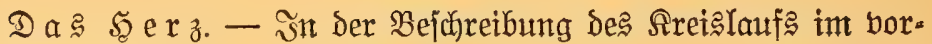

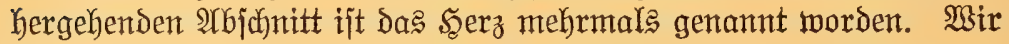
Gaben hier jeine Bejchaffenheit und Junftionen näher zu bejareiben. Dasjerbe fteht als Mittelpunft bes shlutfretzlaufs in umunterbrodje=

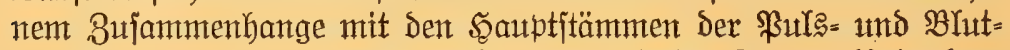
adern, und Yiegt in der $B$ rujthöhle ztwijchen beiden Rungen binter dem Bntitbeine, umgeben von einemt dïnnwandigen Sade, ben man Serz= beutel nennt. Der Şerzbeutel exbält bas Şerz in jeiner natïrlithen

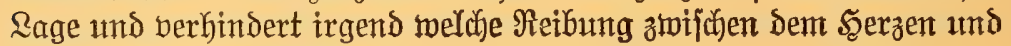
den angrenzenten Ieilen.

İm Şerzen befinden fich vier Şöhlen, zwei oben, die Borfam. mern, und zmei unten, Die Şerzfammern. Die fleijhigen Mände der Syerzfanmern find biel didfer als bie der Borfammern; auth find bie

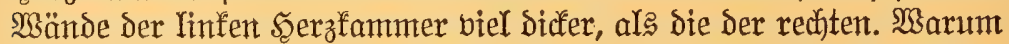
Diejer Unterjoficd in der Stärfe der Wände vorfommt, ît leidht aus

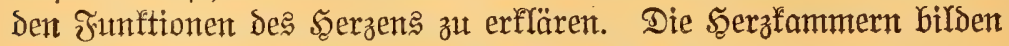
den Ieil dę Serzens, den man Şerzipibe nennt.

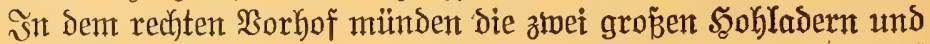

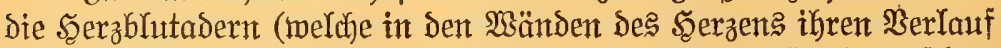

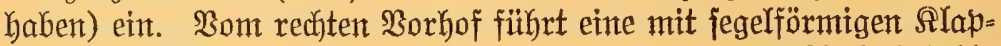
pen berjebene Deffmung in bie redjte Serzfammter. IUth hat die rechte Serzfammer eine runde Deffnumg, efienfalls mit Slappen ver=

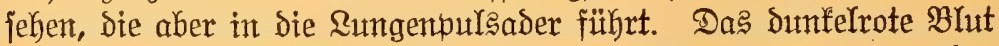
ber redften Serzjeite wirs mittelft jtarfer 3 ujammenziefungen der rechten Serzfammer Durch Diefe \&ungenpulsader hindurch in die \&um=

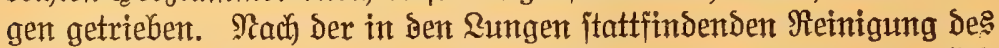

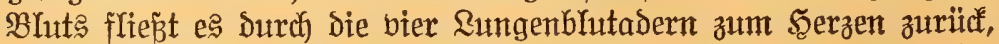

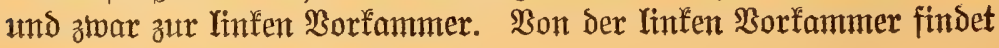




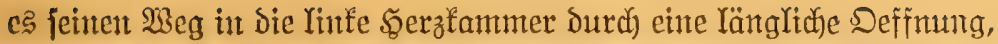

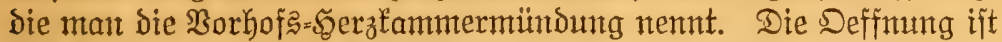

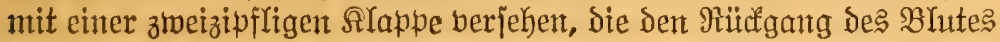

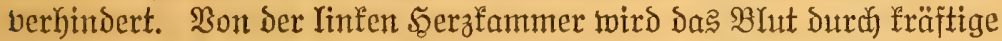
3ufammenziełungen ifrer Mände in die groß̈e Rörperpulaader ge= trieben, un durd) die mannigfaltigen Berzweigungen biejer ben Saargefäpen aller Teile des Rörpers zugeführt zu werden, von wo

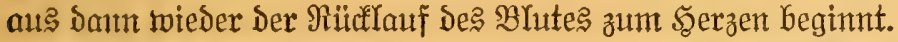

Siteraus folgt, Daj in Der 3twijdyentwand zwifchen ben beiden Seiten bes ફerzeris feine Berbindung a finden ift. Dadurch wird die Sraft Der Bujammenziehungen, welche auf beiden Seiten gleichzeitig ftattfinden, umt vieles erföht.

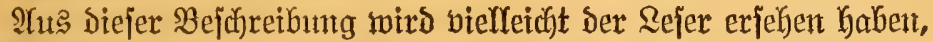

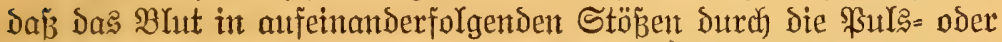

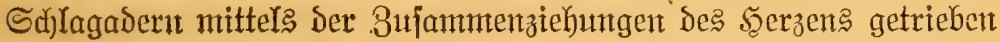

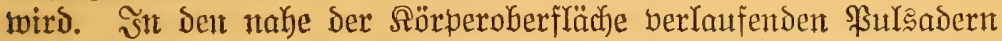

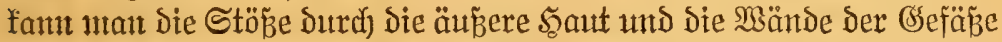
Dcutlid fehen, oder Dodj mit Den Fingern wahrnehnten. Scieraus

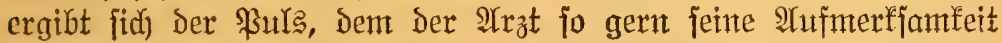

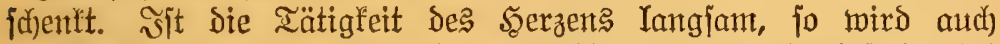

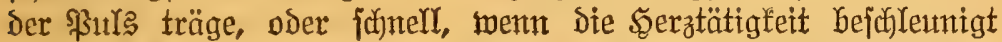
iit. Das \$uljieren fimmt aljo gam mit den bas slut austreibenden Şerzłod)lägen Ḧberein.

Das đSefirn und bildung auf ber nädfiten Seite, weldhe den jenfredhten Duteridhnitt

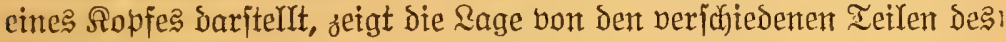

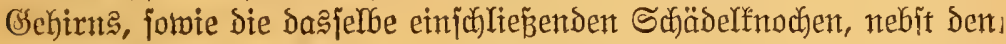

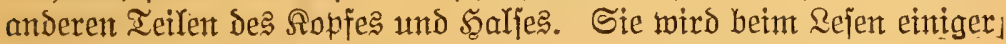

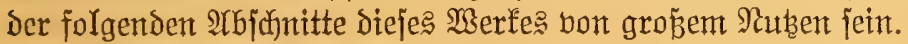

a) Das Rajenbein.

b) Stimbein. Die unterliegenden Şöhlen werden Stimbählen genannt.

c) Die đräte des Dorderhauptbeine马.

d) Das Şirnzelt oder die fnödjerne 3wijujentwand zwijhyen dem grozent und Dem fleinen Esebirn.

e) Das Dberfautptabein.

f) Das Racfentand (white-leather), wodurch) Ser Ropf haupt= fäd)lidu in jeiner Stellung erfjalten miro. 


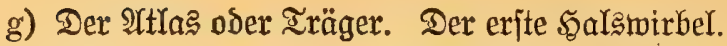

h) Die Âtuje oder dex żweite Şalsmirbel.

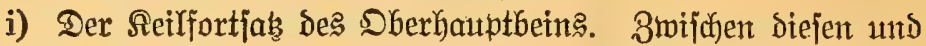
Dem dutrdf e bezeidunteten Ieil liegt das groß̉e Dherhaupts= Ioch, twą zum Dutrdigang des verrängerten Marfes oder Rürfenmarfę Dient.

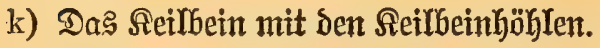

1) Das Siebbein mit den Siebbeinzellen.

m) Dą grop̌e đsefirn mit ber weiß̄en und grauen Rerben= jubjtant.

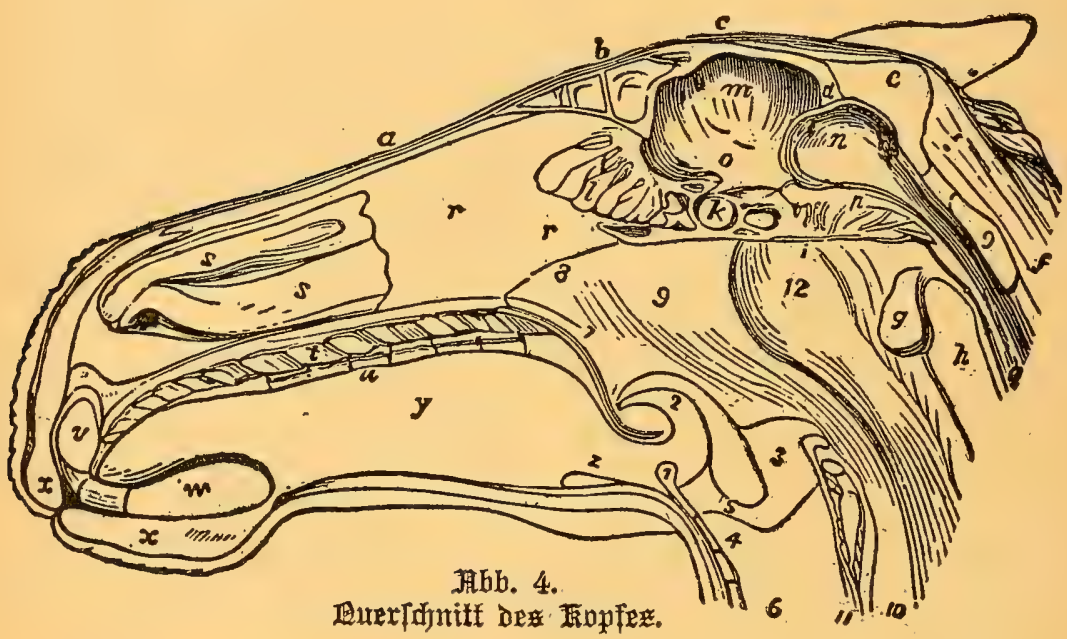

n) Das fleine Ssefint.

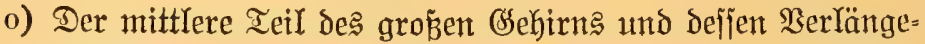
rung, wobon Die meiften Rerven entipringen.

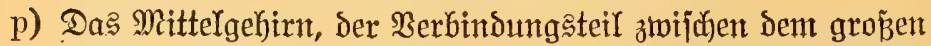

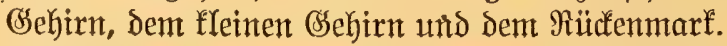

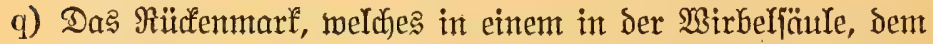

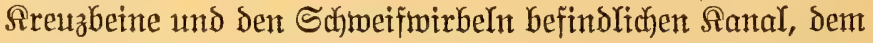

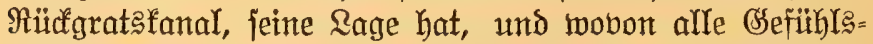
und Betwegunganerven mit $\mathfrak{A}$ ustahme der Ropfnerben ausgeken.

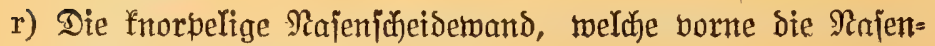
Gäble in ztwei Sälftent trentit. 


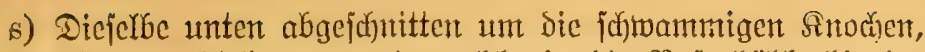

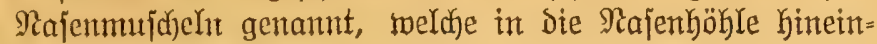
ragen, zu zeigen.

t) Der Garte Saumen.

u) Die Bacfenzähne.

v) Die Hemen Sicferbeine mit Den Sdyneidezähnen. Der Şaten= zalyn iit bon ber 8unge berdectit.

w) Der Szinterfiefer mit ben hinteren Sanneidezäbnen.

x) Die Rippent.

y) Die Bunge.

z) Ein Teil de马 3ungenbeins.

1) Sdjildfnorpel Des Sehlfopfs, weldjer die widjtigiten זeile der Reble einjultiebt und bejchübt.

2) Sefldedel, weldyer zum Sthube Der Stimmribe Dient.

3) Die Siebffannentnorpel, zwijhen weldhen fich bie Stimm= ribe befindet.

4) Die Stimmbänder.

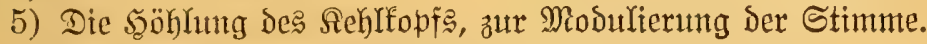

6) Die ミnftröhren mit ihren Intorpelringen.

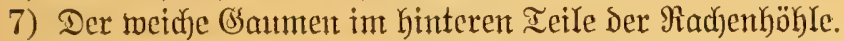

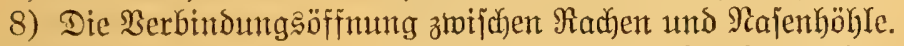

9) Ein Den Eingang Der Shrtrompete bebectender Snorpel.

10) Die Speijeröhre.

11) Der Ringfnorpel de马 Rehlfopfs; unten und hinten ijt er mit dem Siditbfntorpel verbunden.

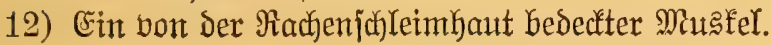

Irle in ber Errhaltung Des tierijuchen Rebens beteiligten Drgane wären für diejen Enozmed ganz unbraud bar, wenn nidjt ihre Iätig= feit Durd eine betwegende Sraft angeregt und geordnet bürde. Einte joldje anregende und oronende Araft juhuf Der gütige Stjöpfer in ber

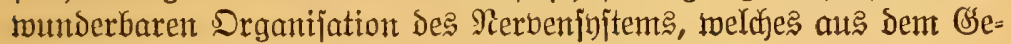

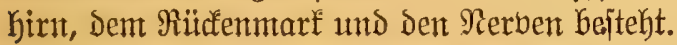

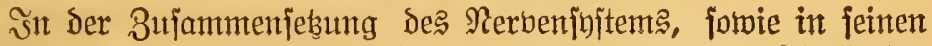
Berridjtungen gibt es noch vieles, das den gelehrteften Iierärzten Dumfel ijt. כedoch fann der aufmerfiame sejer einen jebr guten $\mathfrak{B e}=$

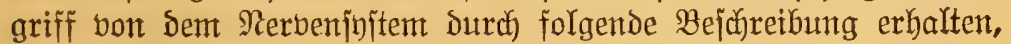

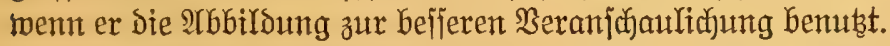

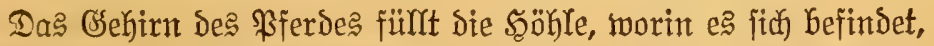
vollfommen aus. Seiner Form nach ift basjelbe länglidjunt und abgeplattet. ¿s bejteht aus zmei ungleid) grop̈en Ieilen, Dem groß̉en 


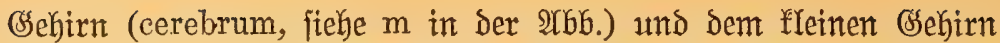
(cerebellum, $n$ in Der $\mathfrak{A b b . ) . ~ S B e i ~ b e m ~ M e n i c h e n ~ l i e g t ~ D a s ~ g r o ̈ ̉ e ~}$ (Gehirn oberhalb des Heinen; bei dem bierfüígen Itere hat sas trente

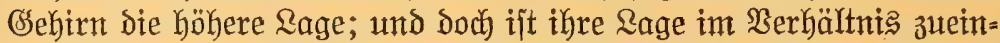
ander in beiden diejelbe. Diejes ift Darauf begrïndet, daß̉ beim Men= fchen Das Soutpt jenfredyt über dem Rumpfe jteht, während es bet den

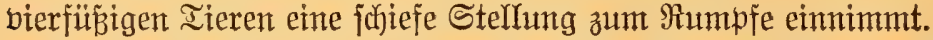

Unterjudyt man зum eriten Mal bas Gsebirn des \$ferdes, fo wird man durch den verfältnismäß̈ig fleinen Unmang des= felben ïberraj(x)t.

Durchjicheidet man bas SEefirn, fo fonmen zmei ganz berjchie=

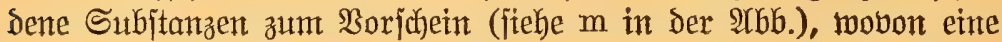

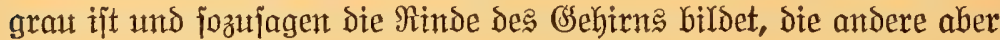
eine weipe Farbe hat und den inmeren von der grauen Subjtanz um= gebenen Ieil des Sehirns bildet. Sbwohl bieje zmei Subitanzen anteinander liegent, fo bermijhyen fie fich nicht miteinander, fondern bleiben getrentut in ifrer Rage, fowie fie in ihrer Bejofjaffentheit und Berridutungen bon einander wejentlich berjüjeden find.

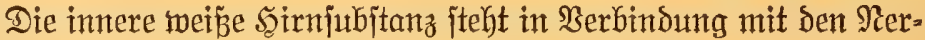

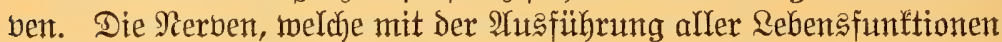
beauftragt ịno, müiffen aIs Berlängerungen der weí̉en Şinnjubjtanz

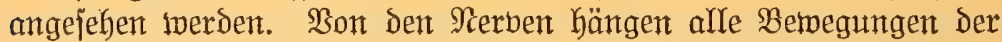

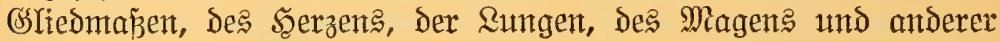
Drgane ab. Durdf Diejelben werden äupere Einorütfe dem Şe. Girne mitgeteilt.

Die graue Şimjubjtanz hat nidyt nur eine andere Farbe, fondern auth eine ganz andere Bejchaffenheit. Miandje haben angenommen,

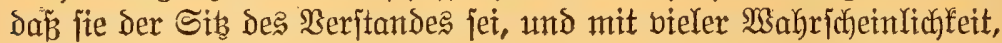

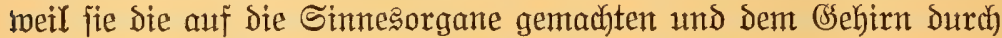

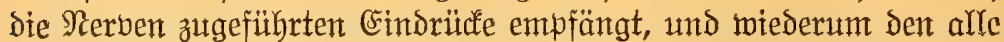
S̈̈rperbetwegungen oronenden, überwachenden Einflü ausübt. Şier= mit übereinjtimmend, wirð höhere šntelligenz in ßerbindung mit einer großzen Entwidflung der grauen Subjtanz gefunden, während die weibe Subitanz verbältnismäß̈ig überhand nimmt, wo tierijabe Sraft und jtarfe finnliche Iriebe herbortreten. Bei Dem ßjerde findet man

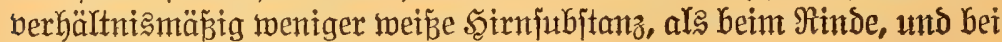
Dent Şunde mentger, als bei dent \$rerde.

Bon Der weï̉en Rervenjubjtanz gehen gemijje ftrangartige $\mathfrak{B e r}=$ Yängerungen aus, Die man Merben nennt. Dieje find die Träger oder Seiter Der auf bie Sinnesorgante gemadjtent Eindrible, weldje fofort 


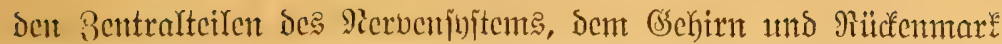
mitgeteilt werden. Niur dutrd) Die Rerven fam aljo Das Tier fitd mit Dent ungebenton Segenftänden befannt madjen und Die Freube ober Schmerz crzengenton Eintrüffe empfantgen. Einer Der Nervent ift in

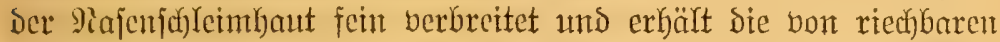
Sïrwern gemad)ten Eindridde, cr riedft; ein anderer ift im binteren Icil bes ?hgapfels ausgebreitct und jieft durch die auf ifn gentad)ten

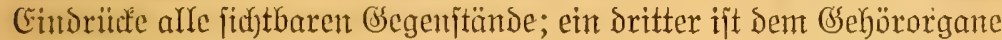
mitgetcilt, wo er bie Cintrïdfe börbarer Töne empfängt und bent ose-

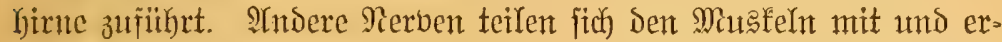

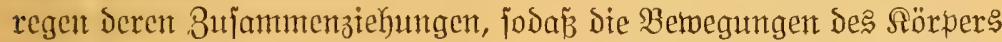
ftatffinden; mährent noch) andere in ber äuñeren Şaut äuß̌erjt fein verbreitet find und Diejelbe зu Empfindungen befähigt.

Cin fehr midhtiger von ciner Berlängerung des Gsefints inner=

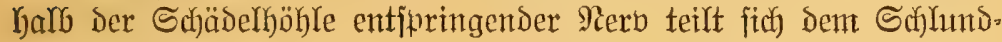
1utD Sichlfopfe, Der \&uft= und Speiferöhre, bejonders aber den \&un= gen, Dem Scerzen und Dem Magen mit und wird baher audf Rungen=

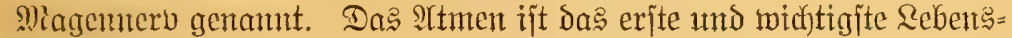

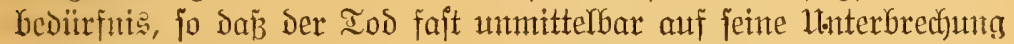
folgt. Die Iätigfeit Der \&ungen, fomie des Serzens, geht des=

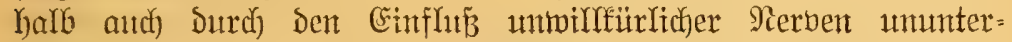
brodjen wor fich, fowohl während des jablafenden als wadjenden 3utandes des Tieres.

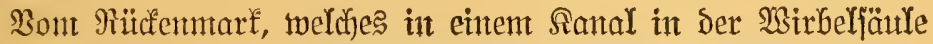
liegt und alङ eine Berlängerung Des Befing anzujeben ijt, Yaufen jebr viele Nerben aus, Die fich in fait allen Sörperteilen berbreiten.

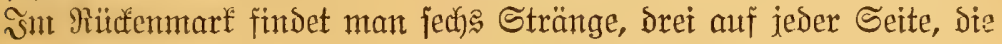
cug miteinander verbunden, aber Durdh Die zu betbent Seiten feidft, aber oben und unten tief eindringenden Einjudnitte zu unterjcheiden fint. Die zmei oberen Stränge find mit Denjentgen Ieilen des Gse= hirns verbunden, in weldyen Empfindungseindorïffe wahrgenommen

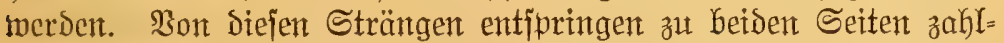
rcidje Perbenfajern, Die fich miteinande* verbinden, ourch eine fleine BcrgröBerung oder einen Rerbenfinoten hindurchlaufen und fodann cinten Empfindunganerv bildon. Bon Den unteren Strängen, welche insbejondere der Inregung bon Bemegungen gemiomet find, Iaufen antore Fajern aus, weldhe fich ebenfalls untereinander, aber zur

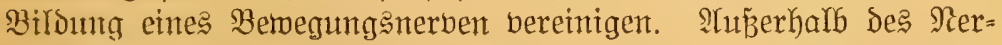
venfnoten bereintgen jich Dieje zmei Rerbentourzeln zu einem gentein=

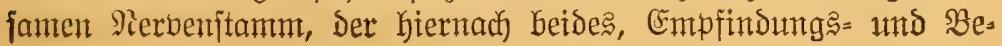


megungsnerben, enthalten muß̈; fie find zmar unter einer Siullle miteinander berbunden, aber Dennod getrennt, ba jeder Rerv bon einer eigenen jebnigen Scheibe ungeben ijt, und feine bejonderen Funtitionen verrichtet.

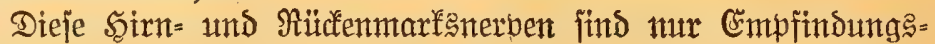
und Bemegungenerven; aber es gibt nod) andere Nerven, Deren $11 r=$

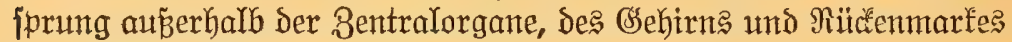
Yiegt. Dieje billon das "Snmpathijhe Rerbeninftem", weldhes jo ge= nonnt wurde, weil es den Sympatfien zu ormunde liegen follte. Sic entppringen bon Inoten, Sanglien genamnt, welche längs ber vor= Deren Fläche Der Wirbeljäule herablaufen. Sie teilen jich Den Serzen

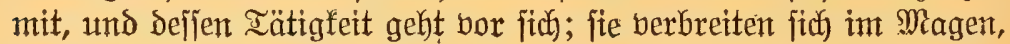

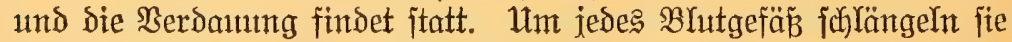
ihre feinen Rese und der Brutjtrom geht unaufhaltjam weiter; Die Wände ber Şaargefäpe jind von ifnen äuperjt fein umjponnen

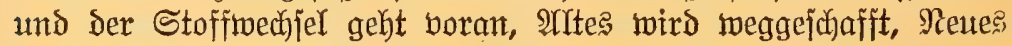
binzugefügt; fie bejisen feinte Empfindung und find ganz $\mathfrak{u t}=$ abhängig vom \$rillen.

Ehe wir auf Den nädhiten SSegenitand ïbergehen, wollent wir die Gebinnhäute betrachten. Es find ihrer brei übereinander gelagert,

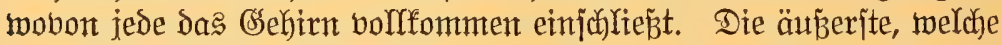

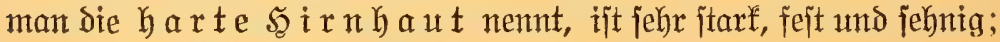

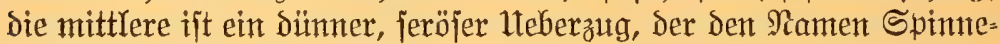

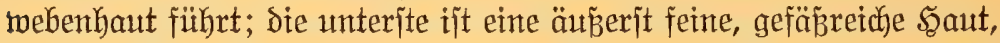
bie wegen ifrer Yeidyten Berreiß̄barfeit, die weiche Şirnhaut genannt wird. Da Yebtere dem Shehinn am nahejten liegt, ift fie wentger

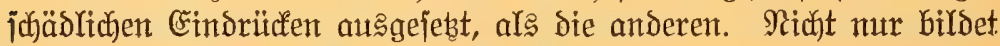

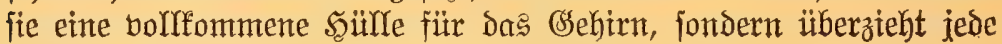
Erböhung und oringt in jede ßertiefung Ginein.

Die $\mathfrak{A} t \mathfrak{m} u \mathfrak{g} g \mathfrak{w}$ er $\mathfrak{f}_{z}$ e $\mathrm{g}$ e. - Die widtige Funftion des Pltmens findet burch die Bewegungen ber Altmungsmusfeln in Den Rungen und Rajentöblen und den dieje Teile verbin= denden Ruftröhren itatt und ftebt unter ber bejonderen IYrbeit Der $\mathfrak{A}$ tmunginerben.

Die sungen find von einter feinten, glatten Saat befleidet, das Bruitfell, weldies nutr bas innere Blatt eines überall geidhlojienen Sarfes Gildet, defíen äuñeres Blatt die Bruftmand und den Šerz= Geutel überzieht. Sie haben eine fegelförnige Sejtalt, beitehen aus einem jehr lodferen fdymamigen Semebe mo liegen bie eine in ber 
redjten und bie andere in ber Yinfen Brufthälfte. Sie werden Durub

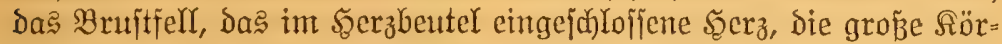
perpulsaber und bie untere Sgohlvene bonemander getrennt. Dic

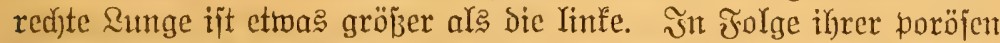

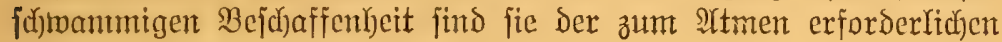
Iubdehnung und Berengerung fähig.

Das Rungengewebe hat in gejunden 3ujtande eine fehr fajöne, Gellrote Jarbe. (E: ift äußzerit weid), zart und fein, jedod fo jtarf

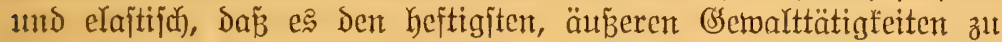
wideritehen bermag. Interjucht man das sungengetwebe genau, fo findet man, dá̉ es aus fleinnen Srbteilungen, Sappent genannt, bejteht, wowon jedes bon allen anderen bolffommen abgejulofifent ift. Die aIs Dämpfigfeit oider Seudjen befannte Rranfheit (broken wind, heaves) wird Durch) Die 3erreip̈ung ber Rappenwände verurjacht.

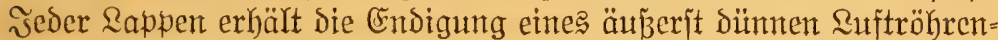
ajtes, tomit biele länglid runbe, traubenförmig miteinander ber

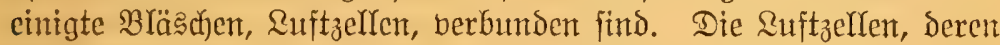
ç beim Menjudy gegen 1800 Miłrionen gibt, find mit einer äuß̉erit

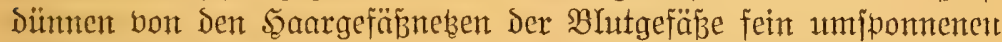

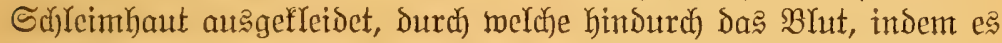

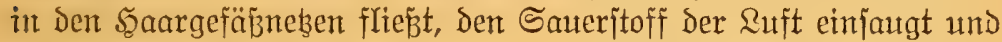
Dafür Die bom Dunfelroten Blut aus alfen Rörperteilen in die হum-

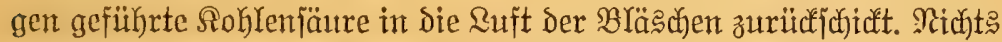
ijt Dem Reben berderblicher, als bie Sohlenjäure, weshalb audb die ausgeatmete suft jo twiorig und unangenehm ijt.

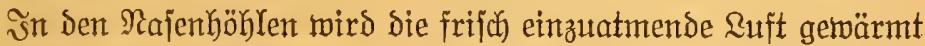

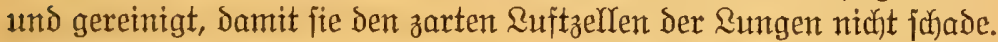

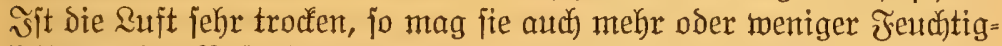

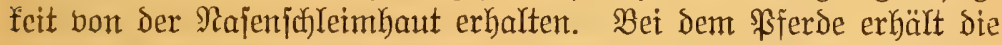
Suft mur Durd) Die Rajenlödjer 3utritt zu Den ßuftwegen, da Der

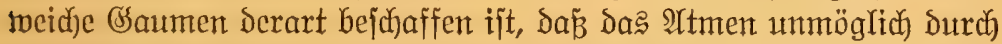
das siul jtattfindon fann; aber dennod) vermag dasjelbe mit bedeu= tender $\mathfrak{Y}$ nitrengung Durd) Şujten bie eingeatmete \&uft aus Dem Maule zu entfernen. Die Najenlödjer und Rajentjöblen find mit einer zarten S(b)leimbaut ausgefleidet, die burch) Beränberungen in ihrer Farbe und Feututigfeit Dem Iierarzte als unjwäbbares Renn= zeidjen bon ber osegenmart eines fieberhaften 3ujtandes und Defjen ßerlaufes bient.

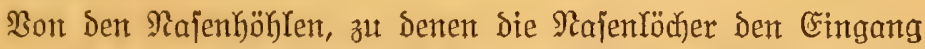
birfen, Dringt bie eingeatmete ßuft in Den Reflfopf, Dann in Die Ruft= 


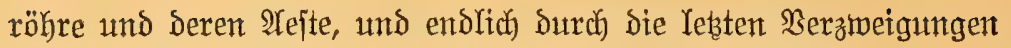

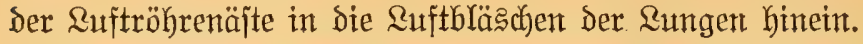

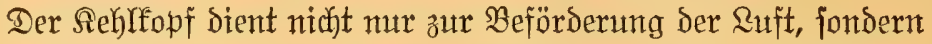
auth zur Bildung der Töne, weldje berjctiedene Iiere bon jich geben fömen. Dieje Töne find jehr einfach bet bem \$fferde, weshalb dieje

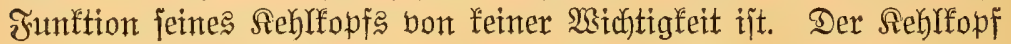
befindet fich) gerade Ginter und unter den Rajentöblen und bejteht au fünf jtarfen, Durch Bänder aneinander gehefteten Snorpeln. Finer Diejer Snorpeln ijt ber merfwürdige flappenähnliche Siefldectel (2 auf

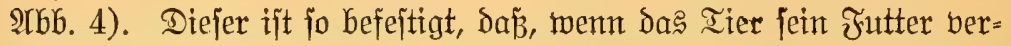
f(c)lingt, er fick nach inten und hinten brängt und fo bie Siehlfopf = öffmung volffommen j(c)liept. Dadurt) aljo wird das cindringen des Futters in Den Reblfopf gehindert, weld)es mun in den S(f)lund ge= langt (10 auf $\mathfrak{2}$ bb. 4); Der Sehldectel aber mirb jogleich Durdh bie

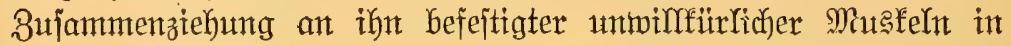

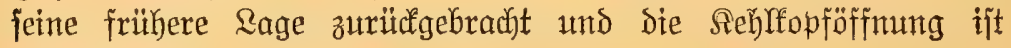
wieder frei.

IIn jeinem unteren Ende jteht Ser Seblfopf mit Der ßuftröhre in

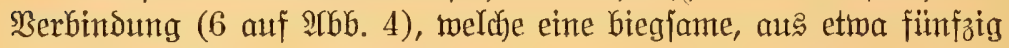
Durch eine ftarfe elajtiphe Şaut aneinamber befeitigten unborl= fommenen Inorpelringen gebildete $\Re$ öhre Darjtellt. Dieje zerteilt

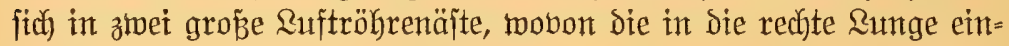
bringende am weiteiten ift. Dieje groß̌en \&uftröhrenäjte berzmeigen

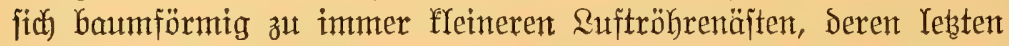

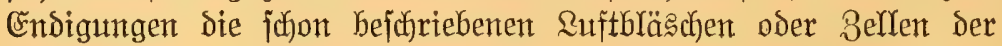

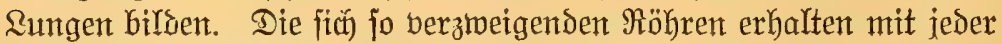

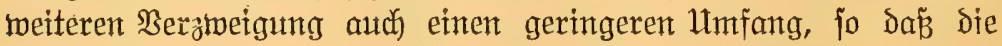
fleinjten \&uftröhrenäjte wohl nicht mehr als 1/25 3oll im Durct)= mejier haben.

Dent Borgang beim Ptmen baben wir fichon in Berbindung nit dent Bhutfreislauf exträrt. Die in Plmen jtattfindende : Iätigfeit Der SYtmungsorgane Yäßt fid gut mit den am Blajebalge vorgebenden Beränderungen vergleichen. Durch) die Bujammenziehungen ber Ytmungsmusfeln, weldye teils am Bruftforbe, teils im Bauche firk be= finden, wird der Bruftforb blajebalgähnlich) ausgedebnt, modurch die Ruft in bie Rungen hineingezogen wird. Şierin bejteht das Ëin= atmen. Nach bem fodjon bejofriebenen (sasaustaujch erfolgen $3 \mathfrak{u}=$ fammenziehungen anderer YYtmungamusfeln, wodurch ber Bruft= forb berengert und die Rungen zujammengedriblt werdent, was die 


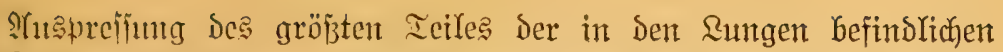
Enft zur Folge Gat. Diejen Borgang bezeidnet man als IH Satmen.

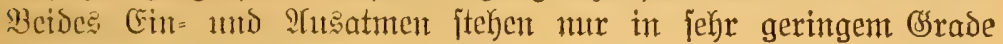

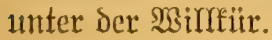

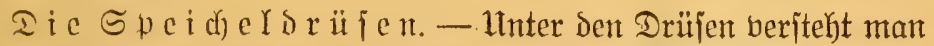

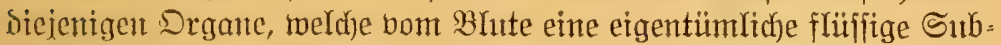

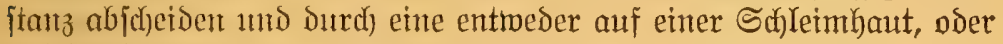

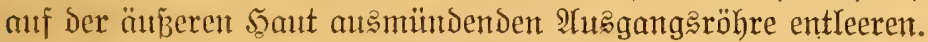

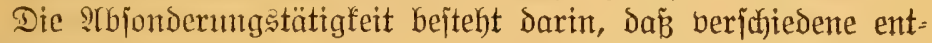
weder brand)bare ober volritündig unbrautubare flüjifige Stoffe bout dem Błute abgejondert werden, und bie burdi die Drïjen fo erfalte= nen Friiffigfeiten merDen Stbjonderungen genannt. Der 3weaf Der Srbjonderungen ijt ein Doppelter: eritens werden fie zu irgend einer anderen Iätigfeit im Sörper berwandt, oder żweitens merden fie als

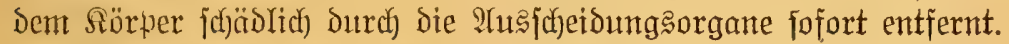

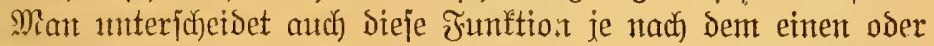

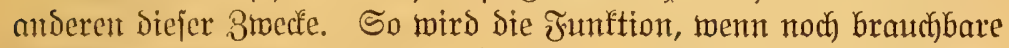

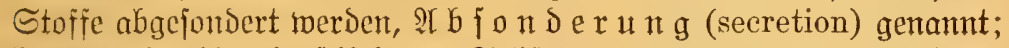
fümtct aber bie abgejütedenen Subjtanzen nicht mebr innerhalb bes Sïrpers verwenset merDen, mïifien fie bom Sïrper ganz entfernt mer=

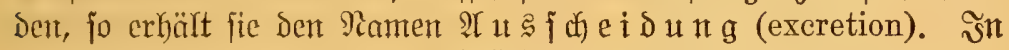
bicjem Sinne twerden dicje $\mathfrak{A}$ th

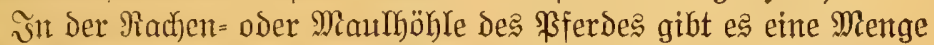

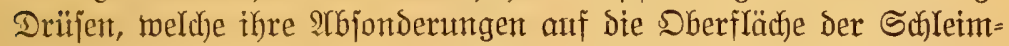
hout ars Speichel entreeren. Shbohl Die Duantität Diejer Frlüffigteit

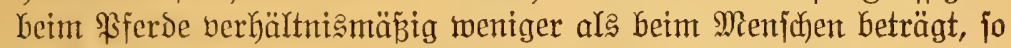
ijt thre Mienge, sie auf nicht meniger als 4 bis 5 Gsalfonen in 24

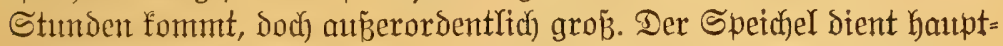

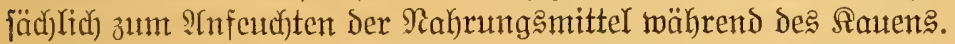

Die midytigite Der Speidelorïfen ijt Die Dhripeidgeldorifje, weldye

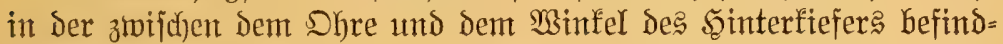

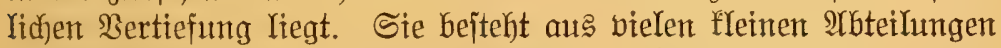

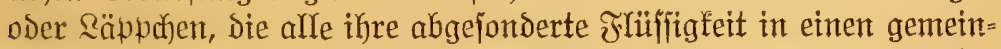

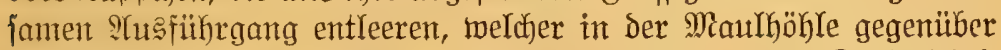
bom zmeiten oberen SBadzahne ausmüntot. Der vont Der Shripeidfel= Drïfe alfein abgejonderte Speidjel wird auf nidyt wentger als ein \$int jede Stunte und mährend der Berfauung des Futters auf dop=

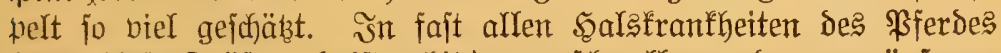

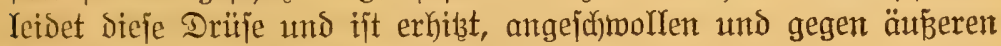

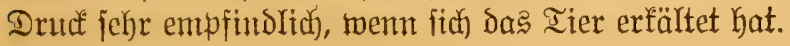




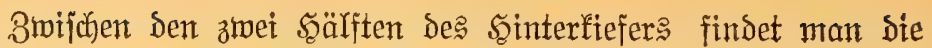
Sointerfieferorïjen, weldye fich ebenfalls durd einen gentinjamen Fugführungggang in die Maulhöhle nahe der 3ungenwurzel uno Ginter ben unteren Sdyneidezähnen entreeren. gumeilen fibinillt Dieje Drüje jtarf an und find Dann ifre Räppatten als fleine תörner Deutlich Durchzufühlen.

Bon ben bedeutenden Speicheldrüjen ijt dic Bungenjpeicheldrüje die freinjte. Sie hat ihren Sib zmijcten den mittleren Ieil ber 3unge und der Seitenfläche Des Sinterfiefers ınd münoet Durch mehrere fleine $\mathfrak{A}$ haführunggä̈nge, Deren Deffmungen fleine Saut= falten oder Bläschen Darjtellen, im jelben Ieile der Maulföble wie

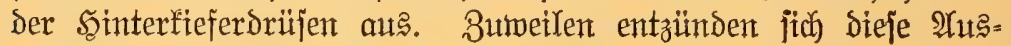

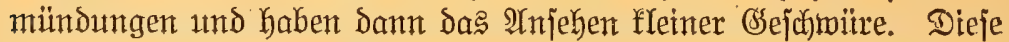
heilen gewöhnlich fornell durch die Raturträfte allein; follten fie je=

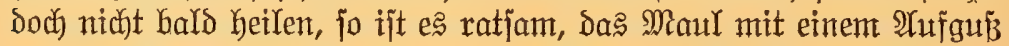

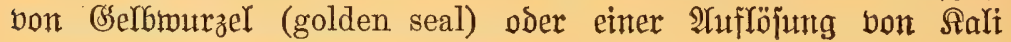
(chlorate of potash) auszumajicten.

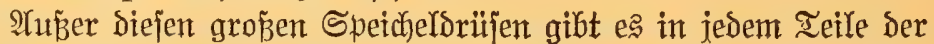

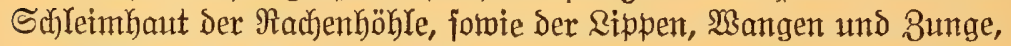

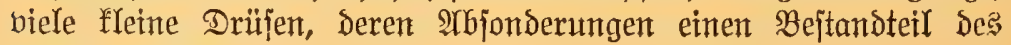
Speichers bildent.

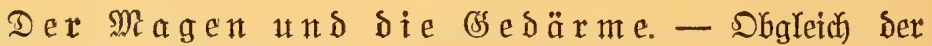

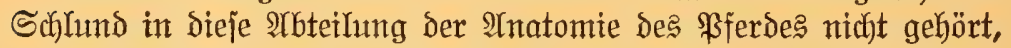
fönnen wir ifn boch vielleicht fier in Berbindung mit ben Ber=

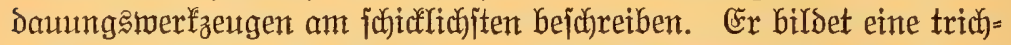

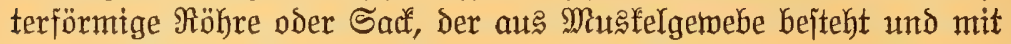
einer Schletmlyaut ïberzogen ift, meldye ber bie Maul= und Rajen= höhlen auझfleidenden Salleimbaut ganz ähnlich fieht. Dben ijt ex

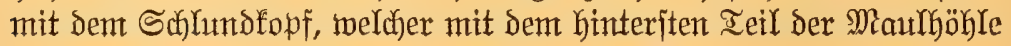
zulammenfängt, unmittelbar berbunden, berläuft dann abwärts und nach hinten Durch die ganze \$Bruthöhle hindurch, oringt ourd eine Deffunt im 3werchfell und bereintgt fith mit dem Magen. İm Infange jeines ßerlanfes Yiegt er gerade Ginter Dem Rehlfopf, nimmt aber weiter unten eine etwas zur linfen Seite gewendete Stellung 孔tr Ruftröhre ein.

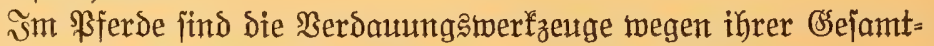

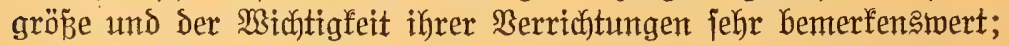
Die fie fehr häufig befallenden Irantheiten ftellen fich fo plöblich ein

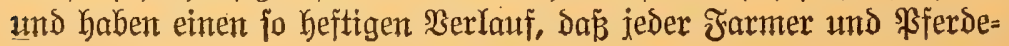




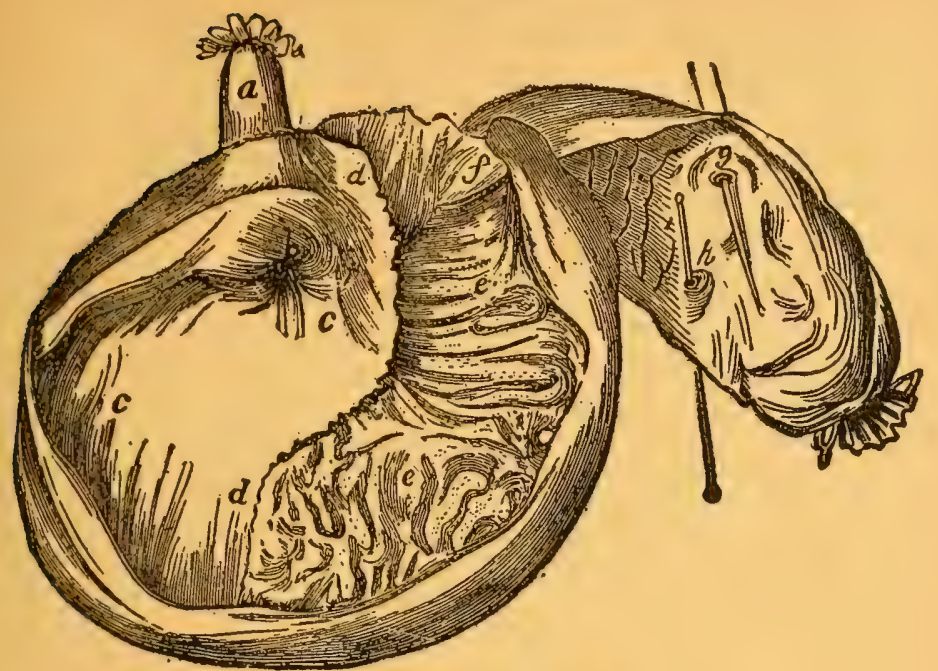

Mbb. 5- Dax Thagen.

a Der Soflums (gullet), weldter zum Magen fülbrt.

b Der Magenmund. (Einmündung des Sc)lumbes in sen Ma= gen). Die in Der Form mamigfacher Ringabidnitte fich um Dan Magenteingang lagernden Mitæfeln find jehr dick und ftart, amb vermöge Der 3ujammenziehung imitande, ben

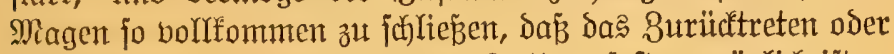
Erbrechen bes bereits genoijenen Futters faft unmöglich ijt.

c Der Ieil Des Magens, weldfer mit ber unernptindlidfen Şaut= lage (cuticle) verjeben ijt.

d Die Cinjunürung, welçe die beiden Magenjäcfe, Sen mit ber unempfindlichen und ben mit der jamtartigen Saaut= lage, trennt.

e e Der mit Ser Schleim= oder famtartigen Saut berjehente Ieil Des Magens, in weldjem Das Jutter batptjächlich ber= baut wiro.

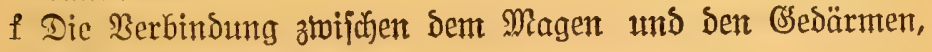
Bförtner genamnt.

$\mathrm{g}$ Die Deffnung, Surch meldye Die Sarle und bie Drüjenabjonde= rung in bie Ssedärme tritt. Die beiden Stäbe bezeichnen bie fier berbundenen Röhren.

h Eine fleinere Deffnung, Durd welde die Drüfenabjonderung in bie đéärme tritt. 
befiber einen ridjtigen Begriff ibrer Struttur und Junftionen fich anzueignen fuchen follte. Bum befferen ßerjtänonis Der hier gegebe= nen Befureibung forlte man bie auf ber vorigen Seite einge= fichaltete Arbbildung des Magens zur Sand nebmen. SBei Den Er: färungen der ßerdautungorgane wird auf Die betreffenden Stellen jener Arbbildung hingetwiejen.

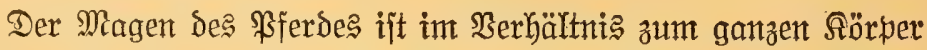
voer autch im Bergleich mit bem Magen des Menjuden jehr Hein.

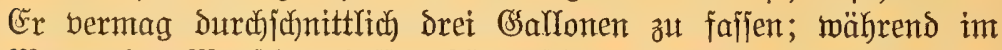

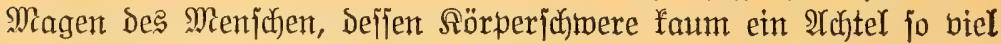

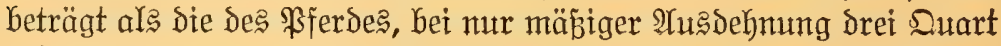

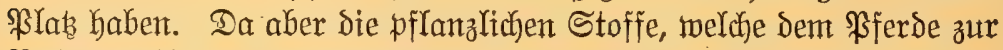

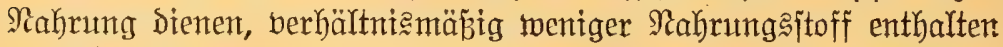
ałs Fleijd und auth diejes Wenige ihnen jumer abzugewinnen ijt, jo

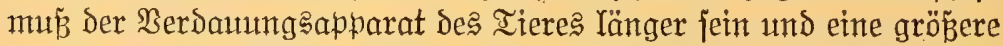

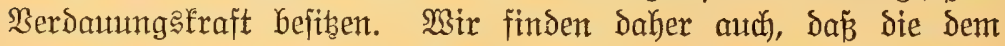

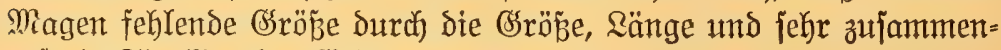
gejebste Struftur der đsedärmte ergänzt ijt.

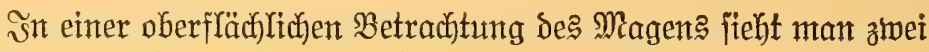
Deffmungen und zwei jactartige Crmeiterungen. Die obere Deffnung jteht mit Dem Schlunde oder der Jutterröhre in Berbindung. Man

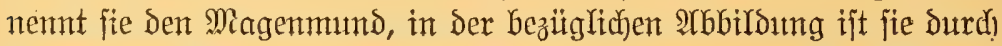
b bezeicfnet. Wo Die Futterröhre in Den Magen übergeht, hat fie eine

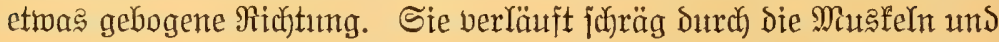
Shleimbat, aber bald legen fich ihre Fajern um den Magenmund herum. Bsenaue 1tnterjuthungen haben erwiejen, dap̧ fie fich in bor

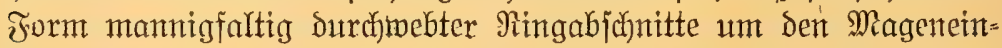
gang Yagern und Durch ifre 3ujammenziehungen benfelben bollfom=

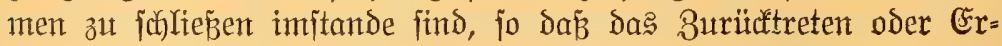
brechen jajon genofjenter Rahrungsmitter fajt unmögling ift.

Durch bie zheite Deffmung berbindet fich ber Magen mit Den (se=

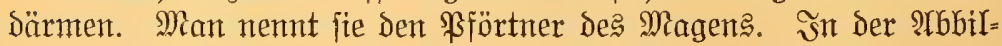
ding ijt fie etwas unvolfommen dargejtellt, fiebe f. Âtn der unteren Magenöffmung oder dem ßPförtner find die Musfelfajern ebenfalls in

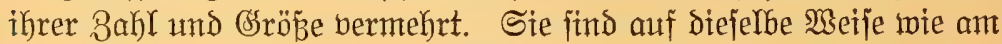
Magennunde angeoronet und itart genug, dem Drud de马 3merch)= felles zut mideritehen und Den Mageninhalt fo lange in Dem Magen zu

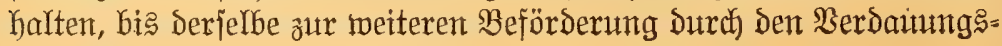
prozes Ginreichend zubereitet ift. 


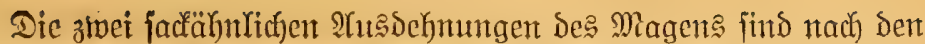
Magenöffumngent benamnt mordent. Dieje Berteilung Des Magene

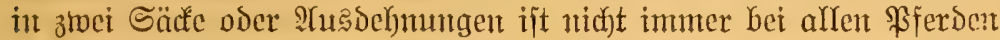

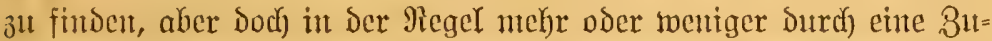

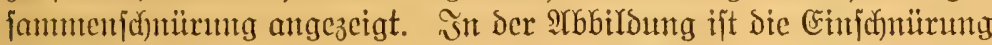

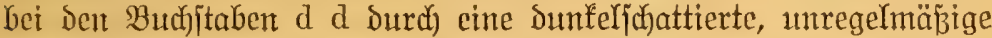
Sinte 3mifhen c c und e e angedeutet. Die obere, Dem Magenmuns

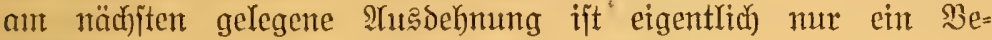

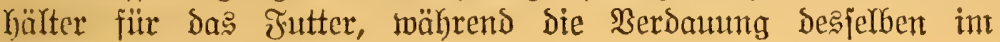
zweiten Sacfe bonftatten geht.

SIl Den Magentwandungen findet man drę Şautlagen. Dic ätberite ijt eine feröje Şaut, bie aus einem Teile des Baudfferfs be= fteht, weldje alfe in Der Baudjhöhle liegenden Drgane, fowie audi die

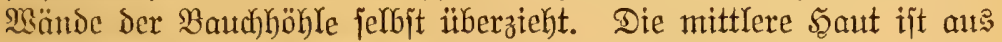

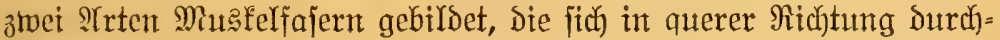
freuzent und badurd bie 3u[ammenziehung feit sieje马 Heberzugę bedentend bermehren. Durdi) Dieje Fantlagen befibt Der Magen Die fujpingenden, wellenförmigen Bewegungen, $\mathfrak{w o}=$ Durd) Der Mageninfalt Dutrdfeinander gemifaft und bortwärts ge=

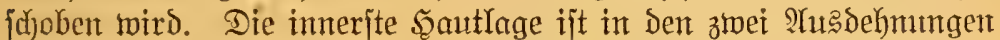
des Magens etwas verjofjiedent. Int Der oberen Ermeiterung hat fie

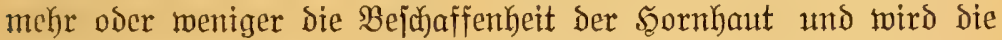
umemipfindriche Sautlage genamnt (fiełe c c in der 2 rbb.); mährent fie im unteren Sacfe als bie famtartige Syaut Doer Schleimhaut befamt ift (fiebe e e in Der $\mathfrak{A} b 6$.).

Der hornhautähnliche oder untempfindlide Heberzug iit pinc

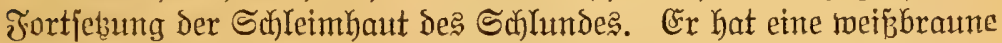
Farbe, ift jehr zähbe und verhältnißmäßig tročen. Nur etwa ein Drit.

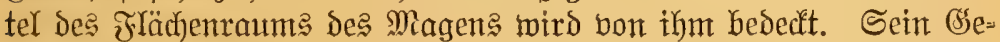

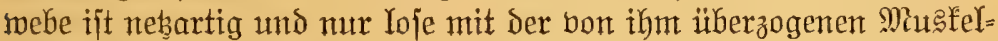

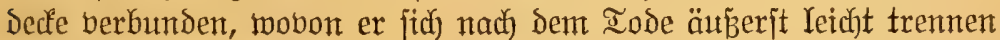
läbt. Er hat, nadjoem er gewajichen und gereinigt wordent iit, da?

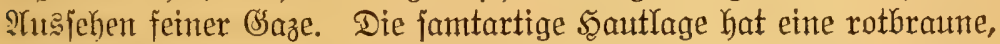
mit helleren Safattierungen burdyzogene Farbe und befibt ein außer=

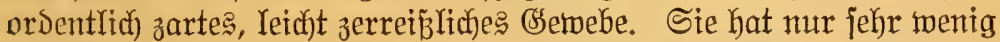

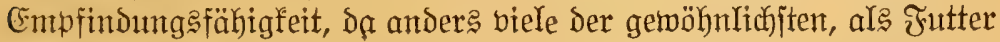

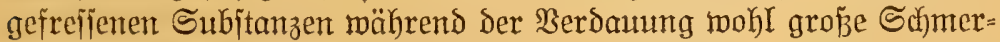

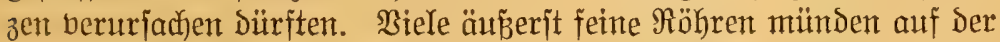

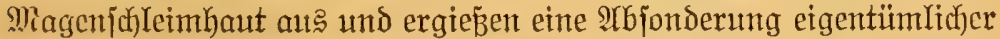

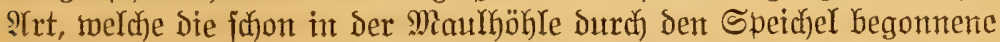
Ermeid)ung Des Futters fortjebt. Dieje Friufifitgfeit, Die einen faurch 


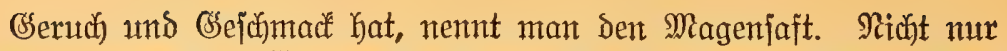
trägt er zur Berflüfjigıng De马 Jutters bei, jondern befördert Durd)

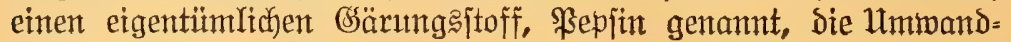
rung des Magenintyaltes.

Dae genoffene Futter wird aljo Durch den Magenjaft berfliujfigt

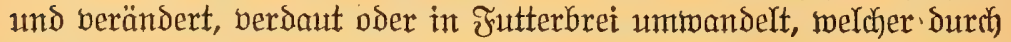

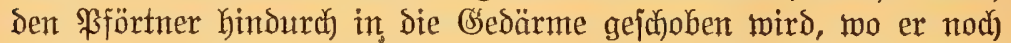
weitere Utmmandlungen erleidet und endlich als Futterjaft oder Milldf= faft bon den Saugadern aufgejogen und mitteljt des Mirldb)bujtgang? in Den Blutitrom gejuafft wird. Der unverdaulidje, unnahrhafte Ieil des Futters, Der nidht bon Den Saugadern eingejogen werden fant, wird Durd die twurmförmigen Betwegungen mit anderen bom Bhute abgeichiedenen, 1mbrauthbaren Stoffen weiter gejubben und endrich Durch Den Majtסarm aus dem Sörper entfernt.

Die BSedärme bilden eine hohle, in jallangenförmigen Mindun= gen in der Baudjhöhle fith hinauf und herab, Ginüber und herüber

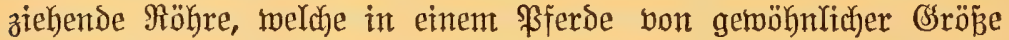

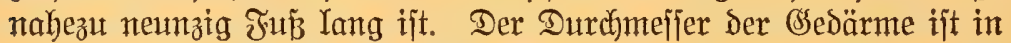
Den verichiedenen Ieilen Durchaus nicht derjelbe. Wie der Magen, fo haben auth die OSedärme orei Sautptlagen in ifrer Struftur, jedoch befibt der innerfte Heberług nirgends eine hornhautartige $\mathfrak{B e}=$

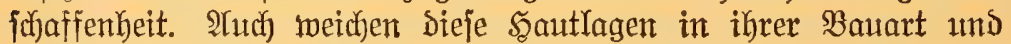

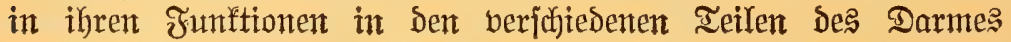
voneinander $a b$.

Die mittlere Sautlage oder Die Mugfellyaut bejteht aus ztwei itach

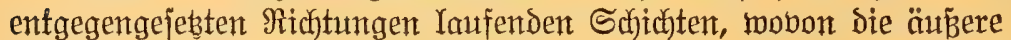
längs Dem Darmfanale Kinabläuft, Die innere aber ringförmig fïch)

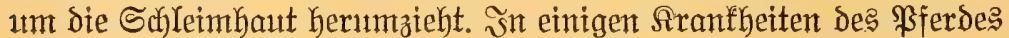
ift die Mugfellyaut der Sib jehr heftiger, frampfhafter Bujammen= ziehungen, weldye die fogenamnten Strifturen berurjactien. Inn der interiten Scautlage ober Der Schleimbaut befinden fid unzählige an Der Sherfläche ausmïndende Satgabern, welthe die berdatten, zux Ernährung des Rörpers tauglichen Stoffe einjaugen und in den Blut=

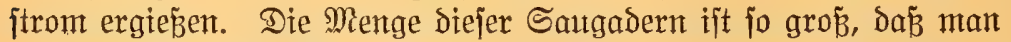

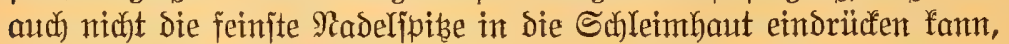
ofye eine der Saugadern zu berühren. Unter gemifien Berbältnifjen wird die Tätigfeit der Saugadern Iangjam und träge, meldjes bald Den Şungertod zur Folge hat, wenn burch die geeignete Behanolung eine höhere Iätigfeit der Saugadern nicht gemedt werden fann.

Der Darmfanal beiteht mur aus zmei natürlichen Arbteilungen, Der Dünndarm und der Diaf́darm. 


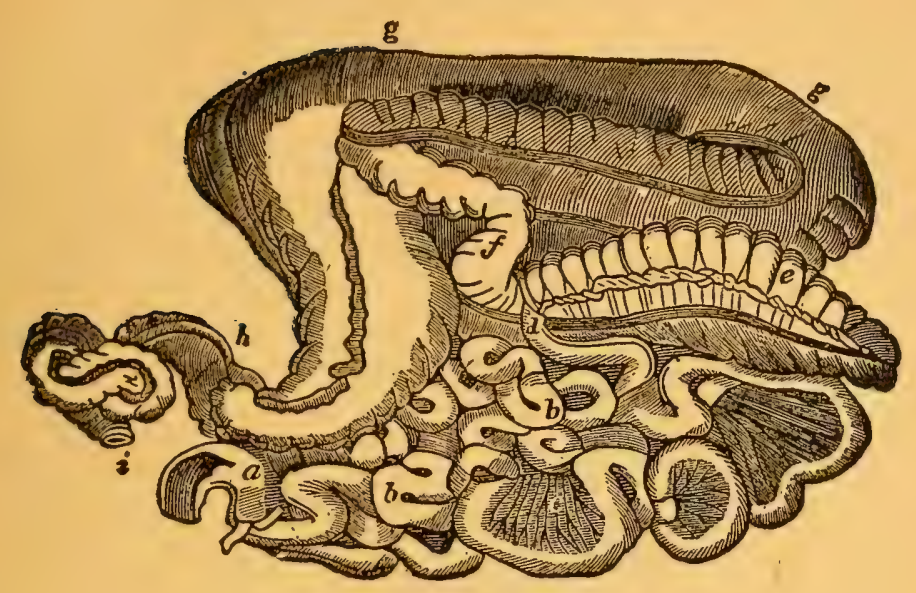

Fbb. 6-Die Gedärme.

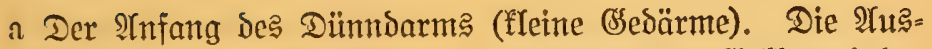

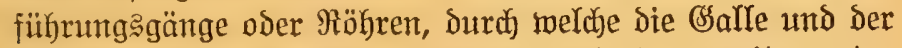
Bauchipeicfel in Den Darm eintreten, find etwas meiter unten angedeutet.

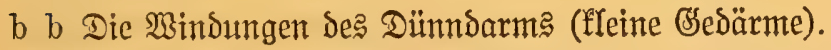

c Ein Ieil des đsefröjes (mesentery), eine groß̌e Falte des

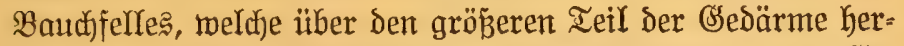

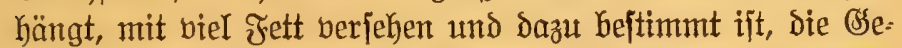

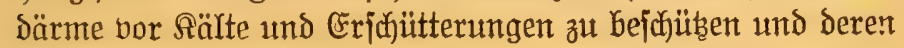
Iätigfeit зu befördern.

d Die Mündung des Dünndarms (fleine SSedärme) in ben BIindoarm.

e Der in Bellen geteilte Blindoarm.

f Der $\mathfrak{A n f a n g}$ Des Srimmbarms.

g g Die Fortjeb̧ung und Erweiterung Deక Brimmbarms, ber fier ebenfalls in Bellen abgeteilt ijt.

$\mathrm{h}$ Die Mündung Des Ssrimmbarms in Den Majtoarm.

i Die Mündung Des Majtoarms in Den $\mathfrak{X}$ fter. 
Der Dünndarm madjt etwas mehr als zmei Drittel des ganzent Darmfanals aus, da feine Ränge von jectzig bis fiebenzig Fú be= trägt. Er ijt jedoch jo viel enger als der Didfoarm, daß̧ er mur etroa halb jo viel zu faffen bermag. Wird er bollfommen ausgedebnt, jo

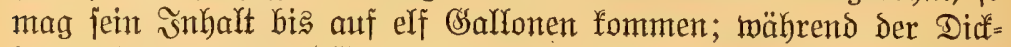
Darm etro neunzehn Barlonen fajt. Redjnet man zu biejen Duan= titäten Die brei bom Magen gehaltenen Sallonen, jo ijt die Menge,

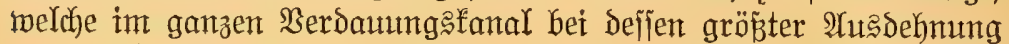
auf einmal \$lab hätte, nidyt mentger als oreumboreipig Bsallonen.

Die orei Ieile, in twelkye nach den meiften Iierärzten der Dünn=

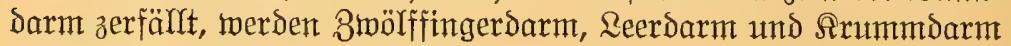
genannt. Der 3wölffingerdarm twurde fo genannt, tweil er im Men= ichen ungefähr die হänge von zwölf nebeneinander gelegten Fingern hat. Beim Gaul ift er etwa zmeiumbzwanzig 3oll lang. Er eritreclt

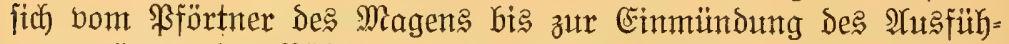

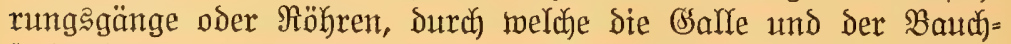
ipeichel in den Darm gejhafft werden (fiebe a in Der 2 rbb. 6).

Der Reerdarm erfielt jeiten Ramen, weil er nady dem Iode des Tieres fait immer leer gefunden wird, was wohl bon bem IImitande

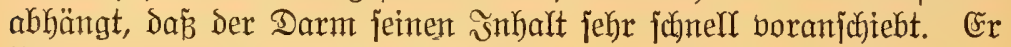
ift etwas enger als der 3tölffingerdarm, fann fich aber viel freier in Der Bauthböhe bemegen als diejer, weil er nicht fo feit an die Bauch), wand Durch das Bauchfell angeheftet iit.

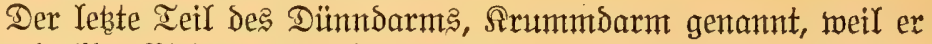

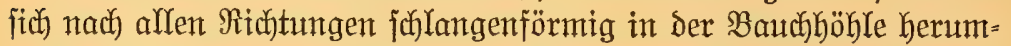
windet, ift den andern Teilen des Dïnndarms ganz gleidf bis auf jeine Musfellage, weldye didfer und jtärfer ijt.

Der Arummbarm endigt in ben Blindoarm, Den erjten Ieil de马 Dicfdarms. Die ๔inmündung des Srummdarms findet nicht am ITnfange des Błindsarms jtatt, jondern nahe dem Ende desfelben, wie

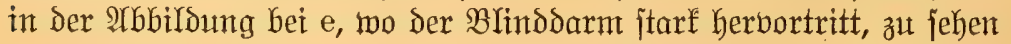
ift. Alus diejer Einridytung folgt notmendigerweije, daj der Darm= inhalt zweimal die ganze Sänge des Błtndoarms durthquert; anf Dem Rürtwege geht er an ber Mündung des Sirummoarms vorüber, wird aber Durch eine eigentümliche Slappe bon demjelben abgejchloj=

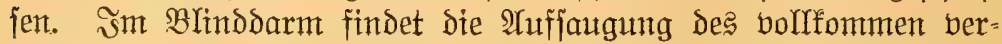
dauten Milchjaftes vorługemeije itatt. Das vom \$sferde gejoffene Sুaffer gelangt pofort in dieje Irbteilung Des Darmfanals ofne wei= teren $\mathfrak{A}$ ufenthalt im Magen und Dünndarm.

Der Błinddarm ift mit dem näd)iten Ieile des Didfdarms (fieke

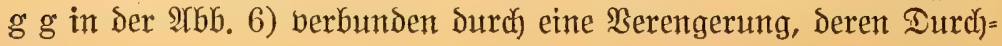


ntefier aber immerlyiu nod) bedentender ift, als ber bes Dünndarms.

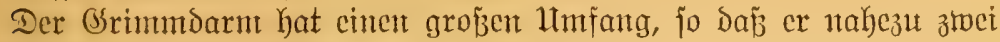
Jïnftel ber Baudbhöhle ausfüllt. Man findet immer mehr oder we=

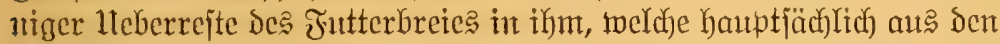

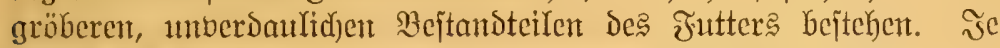

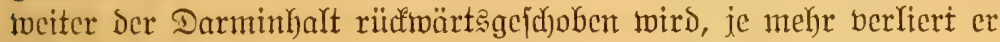
alle fliiffigen und nahrhaften Stoffe und gelangt enblid als immer

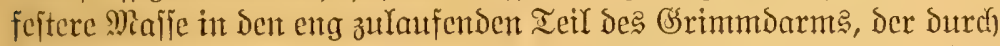
Freiaförmige in ben Darm Kineinragende Bänder Der Schleimbant in

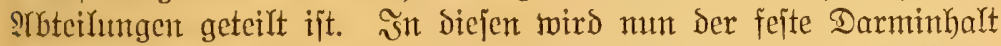
in runde Mafjen geformt, bie immer weiter und enolich in Den Majt=

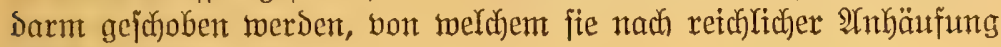
ałs Düngex ausgejtop̉en merden.

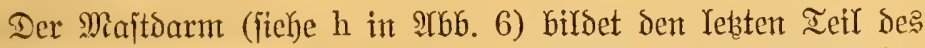

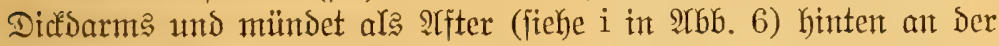
Sïrperoberfläche aus. Er ijt bicl fürzer als der Brimmbarm, audf iit fein Ilmfang tohl um orei Biertel geringer. Da feine weitern nahr= haften Stoffe зur 2 luffaugung übrig find, wemt die Jutterüberrejte in Son Majtsarm gelangen, fo hat audh jeine Sd) leimbaut feine Saug= aberut. Er ijt hinreidjend groß̉, Den Dünger bis zu jeiner Entleerung aufabcwahren. Damit bie Entleerung Des Dïngers ntht zu jeder

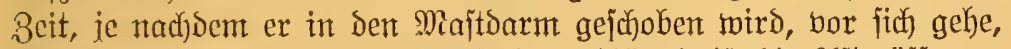

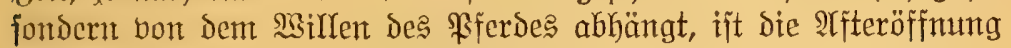

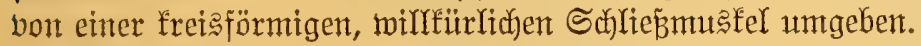

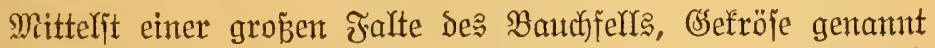

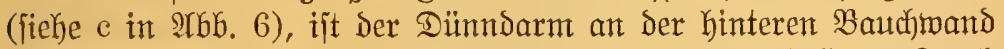
befeitigt und in jeiner ztwar fehr betweglicjen হage gefalten. Durch andere Falten find bie übrigen Teile Des Darnfanals it threr

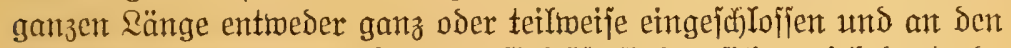

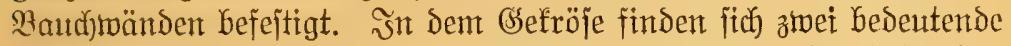

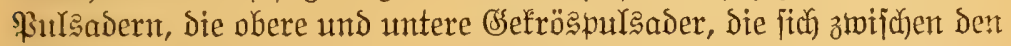

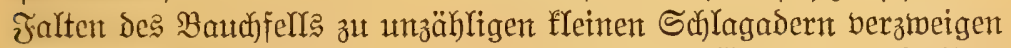

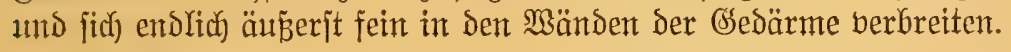

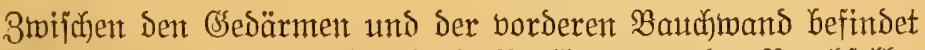

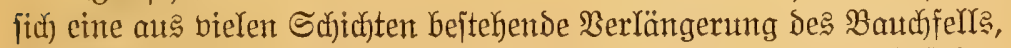

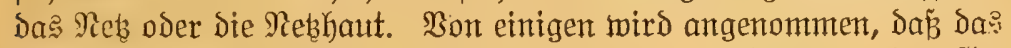
Nes als meicfes \$oljter zur Berfütung bou Berlebungen Der ose=

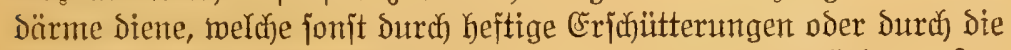

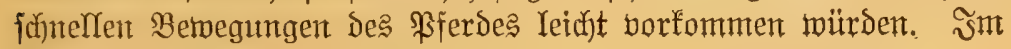
Bferbe ijt es gewöhnlid nur furz. 
Die seber. - Die Reber bollzieht ofne 3weifel im ß̧Ferde Siejelben Fumfionen wie beim Menjuen; bieje find jebod nod) immer nicht bolffommen erfannt. Bon dem dunfelroten venöjen Blut, wel= ches fie von den (Sedärmen durch den \$fortaderblutlauf erfält, jondert jie die Salle $a b$, Deren $\mathfrak{B e j t a n d t e i l e , ~ w e n n ~ f i e ~ n i c h t ~ d u r c h ~ b i e ~ R e b e r ~ a u s ~}$ Der Birfulation entfernt würden, wohl Den ganzen Rörper bergiften fönnten; welcher aber mit Dent Jutterbrei vermijoft, zur Beförderung

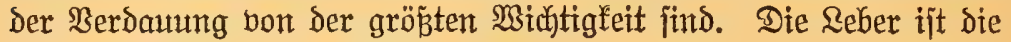
größ̈te Drüje im ganzen నörper.

Die Reber hat ihren Sib hauptjächlich in der rechten Seite, wo fie an Der hinteren fräche des Bwerchfells Yiegt. Sie bat eine eigentïn= liche braume Farbe und bejteht aus orei Rappen. In ihrer Bauart untericheidet fie fich von alfen anderen Drganen. Die Galle wird in

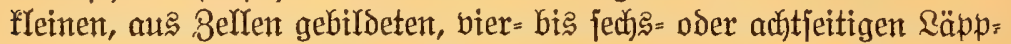
chen bom Blute abgejondert. Schneidet man die Reber auf, fo findet man überalf lleine Röhren, aus weldjen eine dünne, gelb=braune

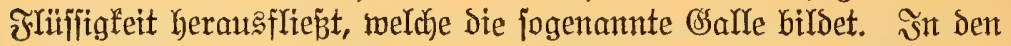
meiften Tieren wird an Der unteren Flärfje der Reber einte länglitude Gallenblaje gefunden, bie zur $\mathfrak{A}$ uffetwakrung der Sfalle dient, bis

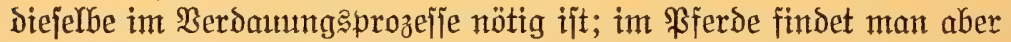

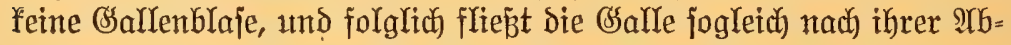

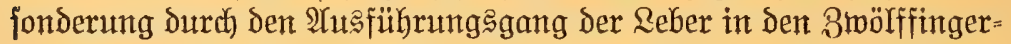
barm, einige Boll unterhalf dem \$Förtner (jiehe a in 2 rbb. 6) hin=

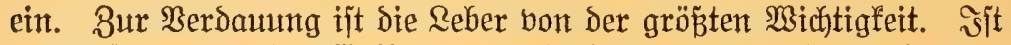

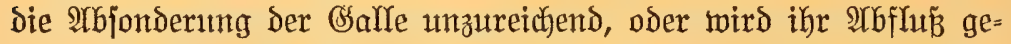
hindert, jo leidet der ganze Drganismus darunter. Şört aber die Gallenabjonderung ganz auf, fo twird das B̧lut durch die BeibebaI= tung jüäblicher Subitanzen alfmähylich vergiftet und die Berdautng

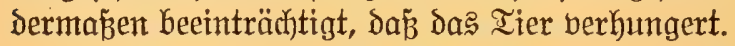

Die Reber wird beim \$ferde nicht fo oft bon Srantheiten betrof= fen, wie bei andern Şaustieren oder beim Menticten. Sistoeilen ift fie Der Sib von Entzündungen und andern Aranfheiten. Şie und da wird infolge von Störungen ber Sebertätigfteit ein ber Selbjuct int Menjajen äbnlicher 3ujtand berurjadyt. Diejer fann Yeidjt an der

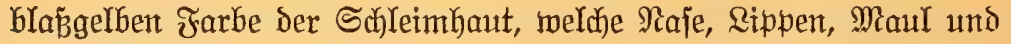
3unge überzieht, bejonders burch bie veränderte, ins (selbe Yaufende Farbe ber $\mathfrak{A} u g e n$ erfannt werden.

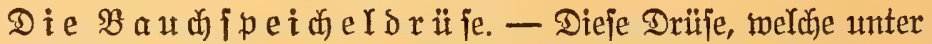
dem $\mathfrak{B o l f e}$ den $\mathfrak{N a m e n}$ sweet-bread führt, hat ifre \&age zwijd)en Dent

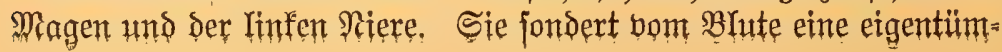




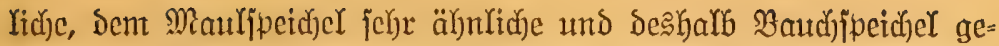

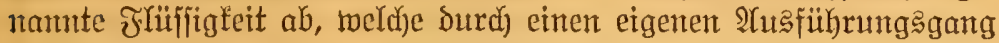

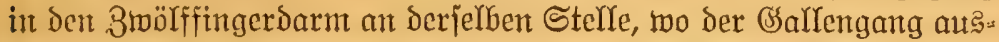

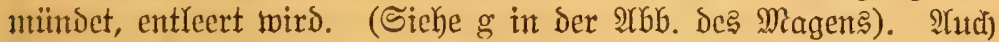
sient Der Bautdjpeid)el zu ganz ähnlichen Bmeưfen wie der Maul=

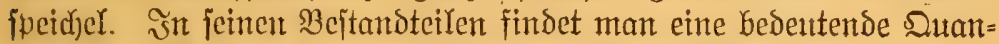
tität Eimeißß̄itoff und eine geringe Menge freier Säıre.

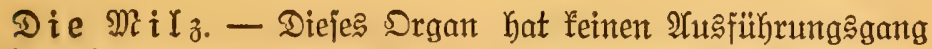

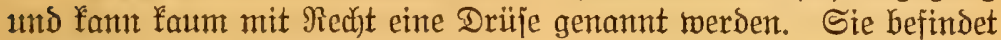

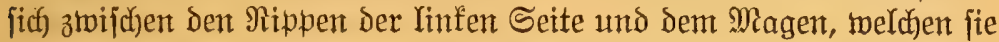
jehrr. feft anliegt. Sie ijt bon länglicher Form, breit an cinem Ende, am anderen aber beinahe zugepist. Jatre Farbe ijt Dunfel= oder

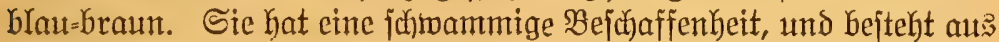

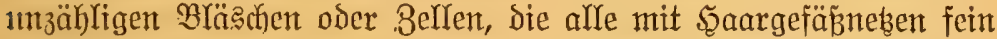

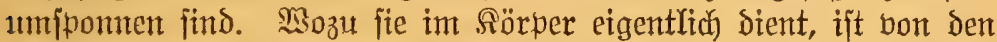

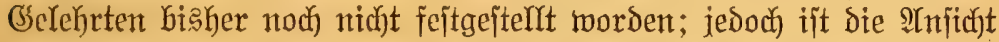

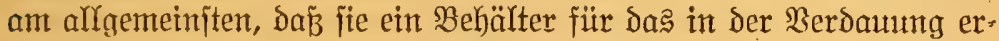

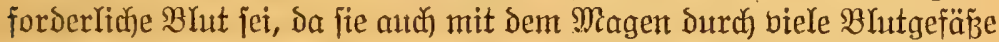

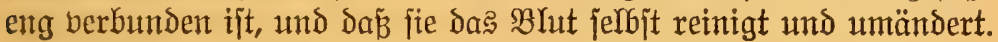

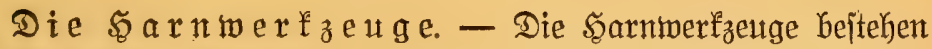
aus Det Rieren, Der Sarnblaje, Den Sarnleitern und der Şarnröhre. Die Nierent fajetden den Utrin oder Şarn bon dem Blute. Sie bejtehen aus zmei Drüfen, deren $\mathfrak{A}$ uf gabe es ijt, von Dem Bhute den Şarnjtoff

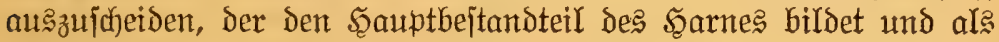
jujnellmirfendes (sift bald ben Iod verurjacht, wenn er nidjt bom Bhute entfernt wird. Die Rieren haben beim \$rferbe eine attBer= ordentYidje ơröß̈e; fie Yiegen in Der Rendengegend; Die redyte interhalb dor Reber, aber etwas meiter nadif borne als bie linfe, weldye binter

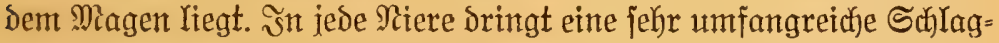

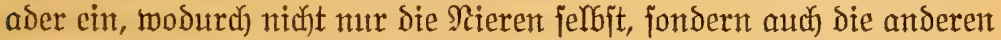
Sarntwerfízeuge mit $\mathfrak{B}$ Tut berjehen merden. Man findet in dent Rieren, wie in allen anderen Drüjen, weldje bon BYute Stoffe augffreiden,

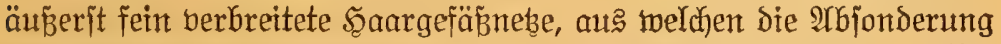

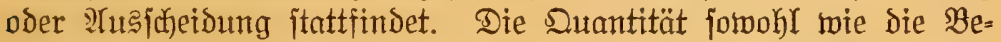

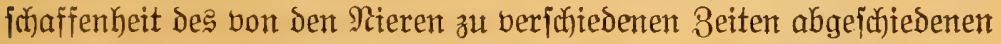
Şarns ift groß̌en $\mathfrak{B}$ eränderungen bet allen Iierent untermorfen, aber bielfeidyt beim \$serde in einem nod höheren srade als bei irgend 
einem anderen Iiere. Der Şarn wird fofort nad) jeiner গ̂tb fonderung tropfentweije bon ben Sarnleitern, wowon einer mit jeder Riere ber= bunden ijt, in die Saarnblaje gejuafft.

Die Sarnblaje ijt ein länglidłrunder, häutiger Sad, weldher als

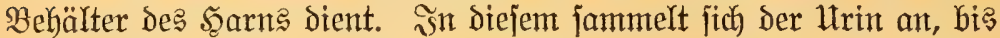
er Durch) feine Duantität $\Re$ ejochwerden verurjactjt, alsoann wird er, Durd) eine willfürliche $\mathfrak{A}$ nitrengung des Iieres, entreert. Die Blajen= wand hat brei Szautlagen, wovon die äuperite, welche Der bom Baudf)= fell erhaltene jeröje Ueberzug ijt, nur etwa bie Şälfte der âukerent Fläche einfiullt. Unter biejer Rage findet man die Mußfellage, welche am unteren ind hinteren Ieile der B̉aje bie auch äußere Dberfläche der Blaje bildet; fie bejteht aus zimeierlei fich freuzenden Fajern. Der innere Uleberzug Der Sarnblaje ift eine Salleimbant, welche auth die innere $\mathfrak{B a n d}$ ber Sarnleiter ausfleidet und ber alle Scoblorgane aus= fleidenden Schleimbaut in ihrer Bejuaffenheit ähnlid ijt. $\mathfrak{A} m \mathfrak{B I a}=$ jenthalje beginnt die Şarnröhre, durd) weld)e der Şarn entleert miro. Der Blajentals fann vom \$fjerde mittelit eines Mubfels, der Blajen=

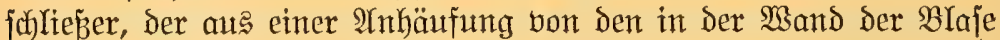

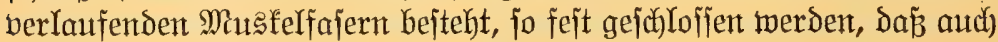

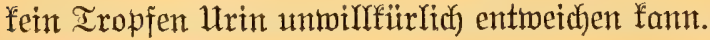

Die Şarnwerfzeuge werden Ieidyt bon gemiffen Aranfheiten be= fallen, die wir am geförigen \$lake nach ifrer Widftigfeit beiprechen werder. 


\section{Kayifel.}

\section{Daz Crffenten ber Tierfranflyeiten im allgemeinen.}

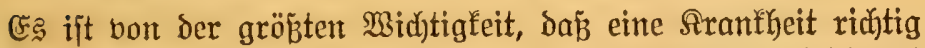
erfannt werde, nur Dann tönnen bie geeigneten Seilmittel bejtimmt werben. Das Erfennen äußjerficher bietet meijten's feine bejondern Sdfwierigfeiten; inneren Sranfheiten gegenüber jteht aber Der Far: mer meiftens rat $=$ und hilflos ba und hört in jeiner Inficferheit auf

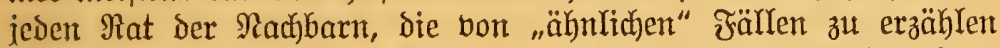
wiffen, wo dies oder jenes Mittel "ganz fither" geholfen habe. Dem

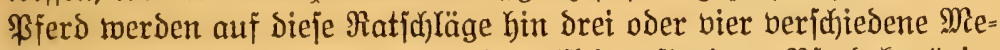
bizinen eingegeben, bon benen eine allein oft eine "Pferdefur" im id)limmiten Sinne des Mortes ijt und im Berein mit den andern Ŷr lung hätte gerettet werden fönnen. Wie foll man aber innere Irant= heiten erfennen fömmen? Das Iier fann ja nidft jpredjen! wirb als Entjdurdoigung für bie Miī̧griffe und deren üblen Folgen angeführt. Es fann aber behauptet werben, baß̄ der Tierarat nicht fajledjter

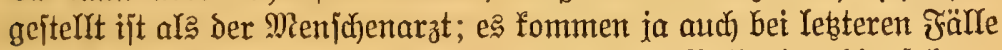
bor, die trok ausführlidjer Erflärungen bes Patienten die folgen= idfweriten Mibzriffe begangen werden. Es tommen allerding bei Tieren wie bei Menjujen Sirantheiten bor, Deren Erfenten auf Den eriten Blide nidjt leidft ijt und weil ein Tier nicht jagen fann, wa马 ifm fehlt, jo glaubt man, das ફ̧in= und Serraten bei ber Bebandlung franter Tiere jei ganz am \$labe. Das ift aber ein Jrrrtum. Ein Beifpiel möge zeigen, daß̉ trobs des Mangels ber Spradje das Er: fennen einer Tierfranfheit nidjt fujwer hält.

Ein Rind hat Magenbejumerden und Durchfall, der Irppetit

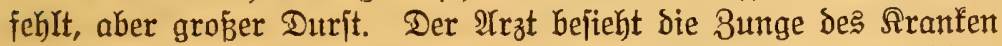
und findet bieje mit einer weiblicjen Majje belegt. Das Aind leidet unbedingt an geftörter Berdauung.

Das \$ferd hat Den Durdjfall, e马 entleert oft einen bünten, mäj= ferigen Dung; Das Tier hat Seu und Safer in Der Arippe heute nod

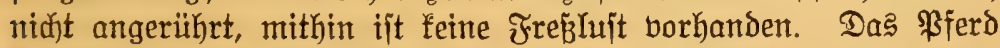
fäuft bon dem vorgehaltenten $\mathfrak{M a j l e r}$ mehr als jonjt und hat jomit groken Durit. Die aus dem Maule herborgezogene Bunge ift nicht

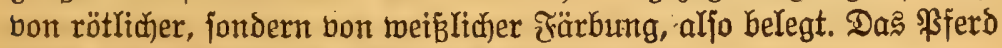
Ieidet aljo offenbar an geitörter Berbauung. 


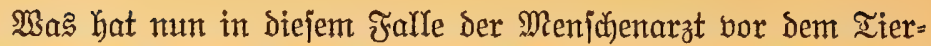

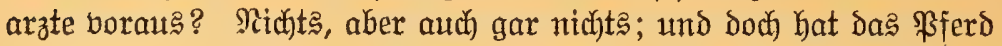
eine innere Rranfheit und fonnte feinent Raut bon fid geben. Der

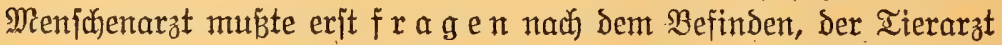
fonnte alles je he numb - "Sehen geht vor's Sagen".

Bentes fich um die Erfenntnis einer innern Srantheit handelt,

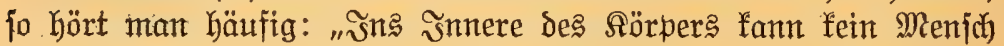

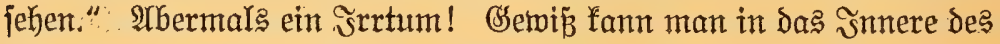
నörpers ohne Magenjpiegel und $\Re$ öntgenftrahlen jehen, wentgitens in den meiftent Fälfen; wur gehören dazu bie rechten Slugen und bie rechte Brille. Freilich fieht mant ohne bie modernen SilfFmittel nidgt wirf $=$ lich ins snnere, fondern immer nur auf bie Dberfläcthe; aber für den

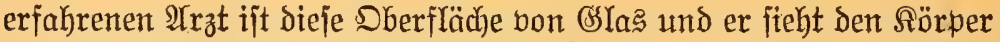
Durch und Durdi. Die Sberfläche fagt uns, waß in šnnern borgeht, und fennen wir bie Rage der Srgane und jedes Drgan und deffen

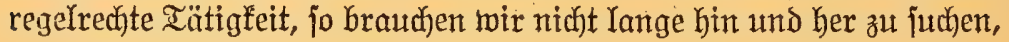

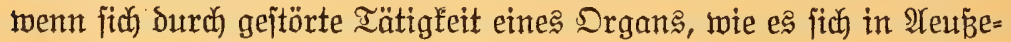
rungen bon S(f)merz beim Befüblen oder in andern Beichen, z. B. im Dunge oder Utrin zeigt; wir wiffen alsbald, too die Srantheit ihren

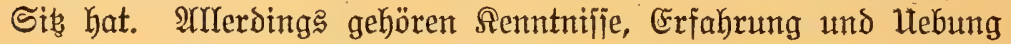

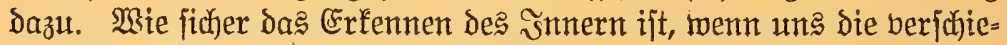
Denen Ieile desfelben befannt find, möge ung mieder ein einfaches Beifpiel zeigen: bon einem Ei jehen wir nur bie Sherfläahe, Die

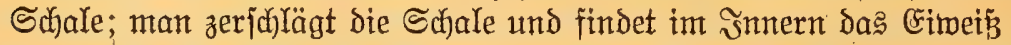
und den Dotter. Das Berifjlagen eines Eis ift aber fo oft miederfolt und fo oft derjelbe כ̃nhalt gefunden, dä jeder bie innere Bejdaffen=

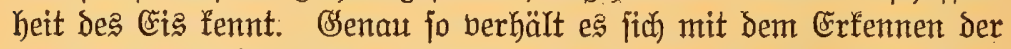

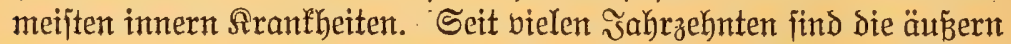
Sranfheitรinmptome beobactjtet und dann bie toten Tiere von Iier= ärzten geöffnet worden; fo wurben Die Utrjact)en Der Rranfheitserjufei= mungen erfannt, bejürieben und in 2HbGildungen bargejtellt, und wir

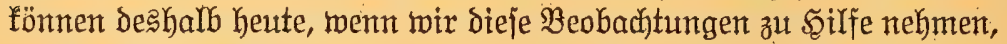

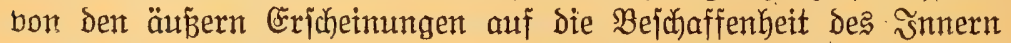

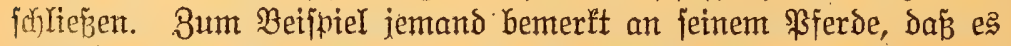

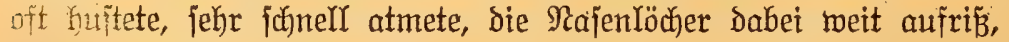

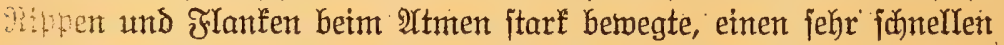

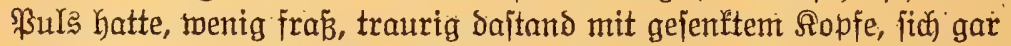

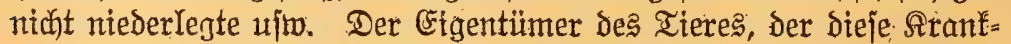

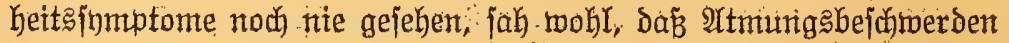
borhandent waren, fonnte aber bie wahre Bejuaffenheit Der Srantheit 
midjt genau beurteilen. Das \$fferd verendete und ber Eigentümer öffuete den Bruftfaften des toten Tieres; er fand die Rungen fdyer 1mid feit, bergrößzert, von jutwarzroter Farbe; im Brujtfajten befanden

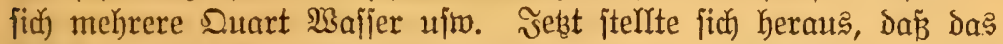

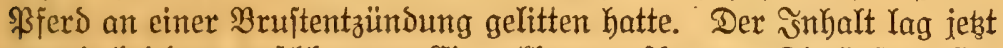

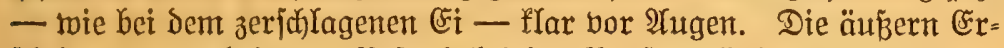
fdjeinungen und innere Befund bei Der $B$ rujtentzündung ijt taujend= fach) beobachtet morden und Daraus fitch in dem vorliegenden Falle bas Erfennen, die Mifjenjadjaft gebildet, am Yebcnden \$ferde die Brult= cutziutoung erfennen zu fönnen. So ijt es mit allen Aranfheiten bes

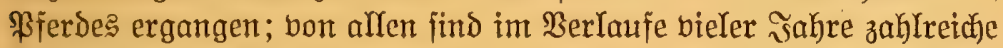
Beobadjtungen der Symptome und die Urjachen Derjelben an toten

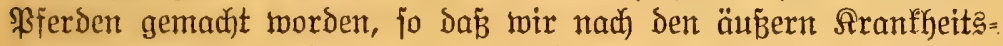
ericheimungen uns ein beutliches sild bon ben innern erfranften Drganen madjen tönnen.

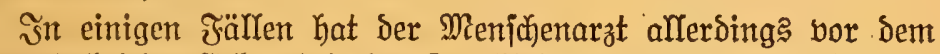
Tierarzte bei der Erfenntnis der Rranfheiten etwas boraus durch Die

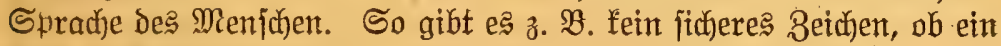
Tier an Sopfweh Yeidet; aud bei IHgenfrantheiten der Tiere ijt nicht genau feitzuitellen, bis zu meldhem (Srade das Sefjermögen geidnäßht ift. Fïr Den Menjajenarzt ijt ferner die Beränderung im Sefichte

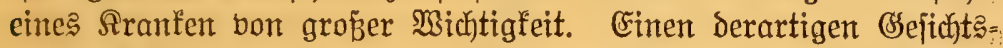

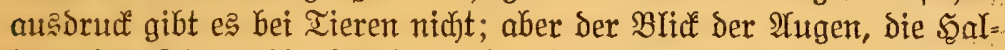
tung Der Dhren, die Stellung oder Rage Des Ä̈rpers, die $\mathfrak{A r t}$ Der. Betwegung ufw. geben meijtens neben andern Beichen widftige $\mathfrak{Y} u \tilde{f}=$

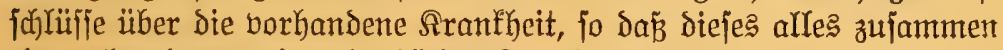
ein mekr oder wentiger deutfiches Rranfheitsbild abgibt. Daggen ijt aber Der Tierarzt Dem Menfibenarzte gegenüber in vielen Fällen im

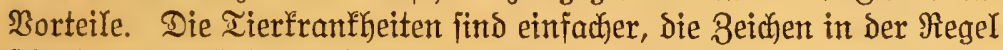
jajarf ausgeprägt, das Tier ftellt fich nicjt frant, wenn es gejund ijt. Die Beurteilung der Aranfheit wird Dadurd beim Tier auberordent= Yich erleichtert.

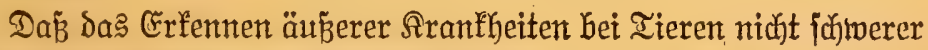
ijt als beim Menjoden, Yiegt auf der Sand. 


\section{Lapiftel.}

\section{Bomt Cingeben ber $\mathfrak{2} \mathfrak{r} \mathfrak{z}$ teien.}

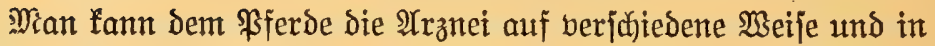

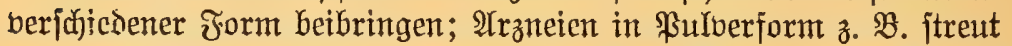
man Dem Pferde entweder trodfen unter furzes Futter ober mijudt fie unter Safer und Rleie, weldye etwas angefeudbtet werden. Starf wirfende, fehr riechende ind joldje $\mathfrak{A}$ rzneimittel, bei Denen es darauf

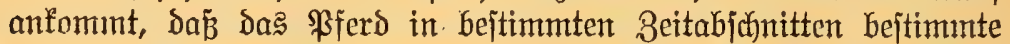
\$ortionen befommt, gibt man entweder als \$illen oder als Brei (Iat= werge) oder auch als eringūb.

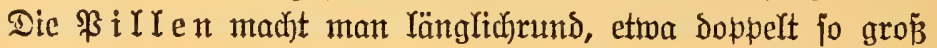
wie cin Şühneret, und gibt diejelben in folgender \$3eije ein: man jtellt

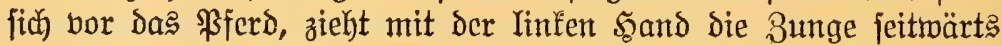
etwas heraus und jectt mun in das geöfïnete Maul die \$ille und legt fie foweit hinein auf bie 3unge, wie möglid, entweder mit dem bloben Prm voer mit Silfe eines dünnen Stucfes, auf Defien Spibe die \$ille geitectit war. Es gehört einige 1lebung zum Cingeben der \$illen, benn es fann wohl vorfommen, daß̉ die \$ille im Şalje jtedfen bleibt, wodurd Dann gefährlicbe Bufälle herbeigeführt werden fönnen. Da=

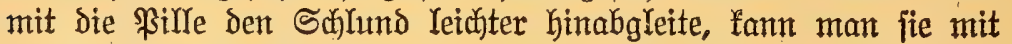
irgendeintem Jett beitreichen.

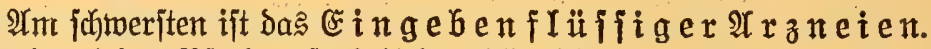

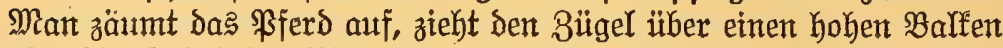

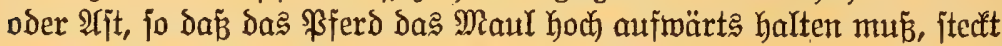
Dann ein Stüct Solz, weldyes noch einmal fo bict ijt wie der Flajdjen= hals, zwijhyen die Zähne, aber jo dả jich die 3unge frei bemegen fann,

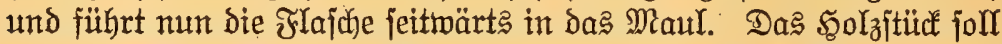

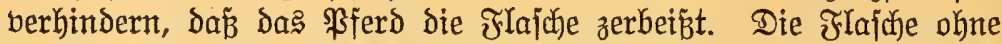

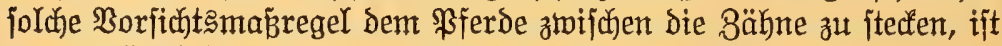

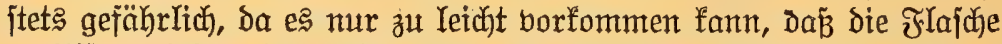

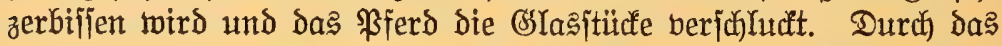

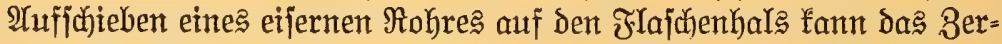
beipen her Flajkje ebenfalls verhütet werden. Das junelle Fingię̧en

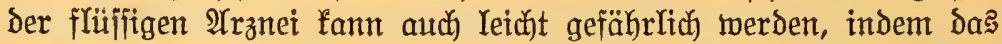

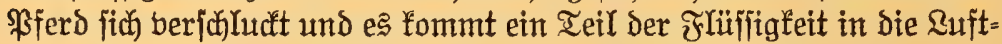
röhre (in die "unrechte Rehle", wie man gewöhnlich fagt), wobur(h) Dann eine gefährlicje sungenentzündung entitehen fann. Das Şer= 


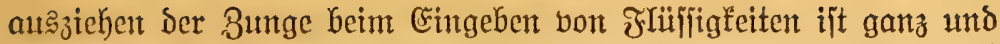
gar vertwerflid); bem das \$ferd fann bann nidft foflucfen und liegt bie (sefalyr jehr nahe, Daß Dann and cin Teil ber Flüjfigteit in bie

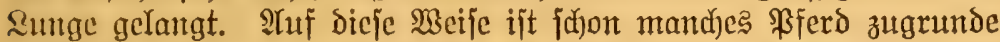

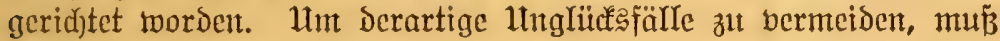
mant äuperjt borfidjtig beint Eingeben flüjfiger :Irzneien jein; man giç̧⿻ mur immer fehr langjam und nur geringe ßortionen auf einmal in Das Maul ein und lafje Das \$ferd exjt bieje verjh)ludfen, bevor mehr

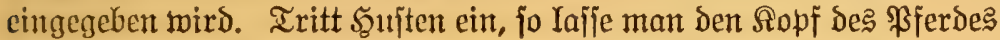

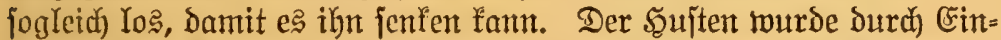
dringen Der Medizin in die Ruftröhre verurjacht und da: \$ferd ver=

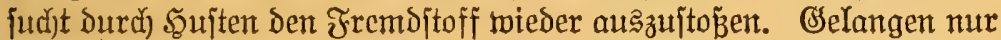
Ivenige Tropfen tiefer und in Die Runge, jo ift eine \&ungenentzünoung Die fichere Folge. Fajt in allen Jällen fönnen flüffige $\mathfrak{A} \mathfrak{r}_{3}$ neien Durd)

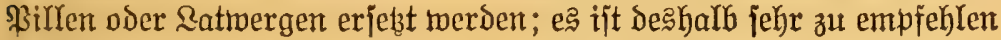
die feiteren Formen vorzuzichen und Flüffigteiten nur Dort zu ge= braudjen, too idjnelle Mirfung, twie etwa bei Solif, erzielt werden joll.

Die beite, bequemite und zmedimäpigite Form bleibt allemal bie L a t tr e r g e ober Breiform; weßhalb ifre $\mathfrak{A}$ ntwendung für alle Fälle anzuraten ift. Die Ratwerge jollte die Bejuaffenheit bes Samalze? oder ber $\mathfrak{B}_{\text {utter }}$ haben. Um fie einzugeben, bedient man fid eincs

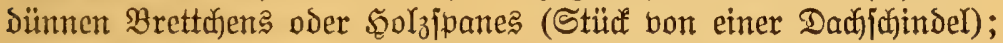
bas eine Ende biro Iöffelartig breit, das andere zu einem Stiel 3urechtgejdnitten. Mit Dem breiten Ieil bringt man ein wenig bon Der Ratwerge, etwa jo biel twie ein Şühnerei auf Den hintern $\mathfrak{I}$ eil bet: 3unge Des \$ferdes, nat)dem man mit Der Yinfen Sand Die 3unge weit aus Dem Maule herborgezogen hat.

(ङ马 gibt nod) andere Metfoden, 2(rzneimittel in ben tierifjen Sïrper zu bringen, indem man bie Flüjfigfeit unter die Şaut jpribt ober indem man Dämpfe mitteljt bejonderer $\mathfrak{A p p a r a t ~ e i n a t m e n ~ l a ̈ p s t ; ~}$ boch erfordert bie $\mathfrak{A}$ nmendung biejer Methoden eine geübte Sand und follte deshalb Dem Iierarzt überlafien werden. 


\section{4. 篗apritel.}

\section{Bom Ziefren des F̨arajeils (seton).}

Ein Saarfeil oder Eiterband wird gezogen, um Entzündungen,

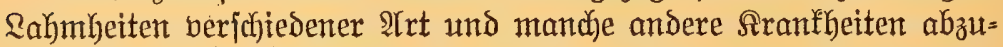

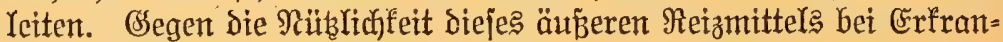
fungen innerer Drgane find mandhe (Einwendungen zu erkeben uns

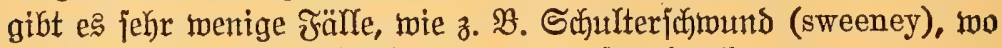

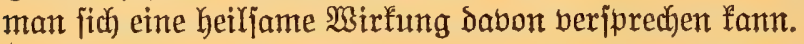

Ein Szarjeil oder Eiterband wird in folgender \$Beife gelegt: an ber Stelle, wo daşelbe liegen foll, zieht man mit der linfen Szaut in eine Räng Darin; Die Entfernung zwijhen beiסen Duteridnitten gibt bie balbe

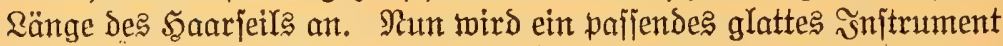
(Röffelifitiel) in ben oberen Suerjdyntt gejtect't und nach Dent unteren

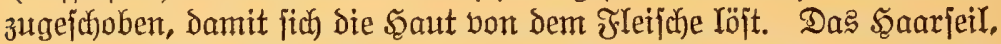

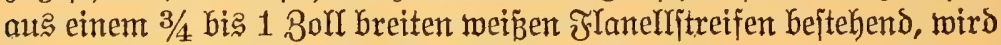
mit Ierpentin getränft und Dann mittelít eines ŞoIzlpanes bout dem oberen Duerïdnitt nach Dem unteren geführt, Gier heraußgezogen und bie beiden Enden zujammengenäht oder =gebunden. Ess erfolgt eine

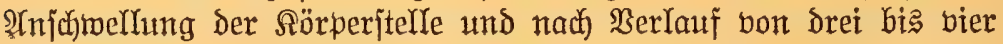
Iagen tritt eine jtarfe Giterung ein. Bei biejer ijt bann weiter nidyts

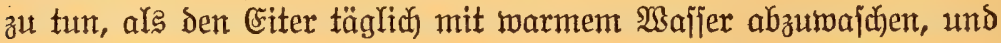
Das Eiterband unter der Şaut etwas bin und her zu jüieben, wobei e马

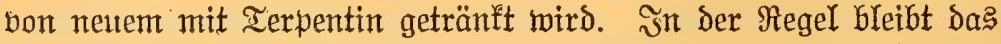
Saarjeil ztwei bis vier \$Bodjen liegen; foll es entfernt werden, jo wird

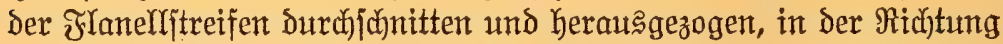
von obett nadi) unten ber fich) unter der Şaut befindende (Eiter herauts=

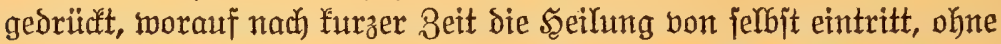
eine bedeutende Rarbe zu GinterIaffen. Statt des franellytreifen fann

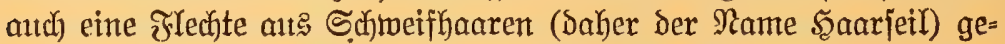
nommen werden; Dod) ift Der weike flanelYjtreifen vorzuziełen. 


\section{Haprifel.}

\section{Bom Deffinent einer Blut= ober Eitergejöjunlit.}

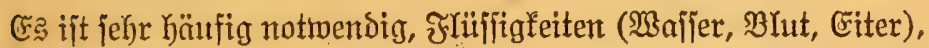
Die fid) unter ber äuß̉ern Sgaut de马 Sörpers angejammelt haben, burd)

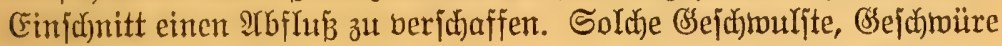
und Eiterbeulen finden fich red)t oft auf der Schulter, am Reblgange, an ben Sinten und andern Sörperfterlen. Das beborjtehende $\mathfrak{2}$ uf $=$

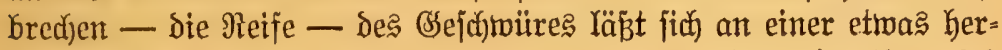
bortretenden weidjen Stelle erťennen, beren Färbung bunfler wird

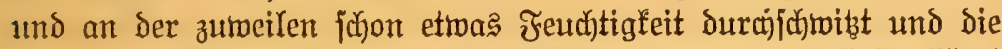
Shaare ausgehen. Das Deffnen Des Gsejufwüres mit dem Meifer fürzt Das Reiden bes Tieres um mehrere Tage $a b$, verfintort das tiefere Eindringen des Citers und andere jüäblidue Folgen; es iłt beshafb in

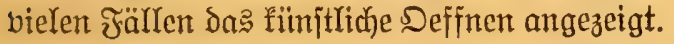

Das ridjtige Snjitrument für foldje Speration ijt bie Ranzette, Deren Slinge man zwijđjen Daumen und Beigefinger nimmt und Deren

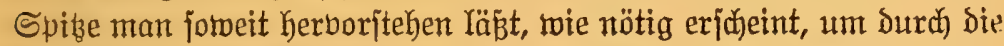

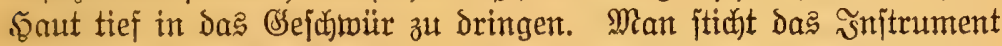

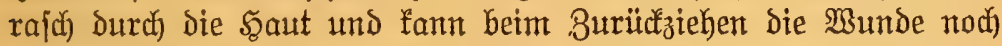
nötigenfalls vergrößern. Die Deffmung mú jtets, weil Der Citter

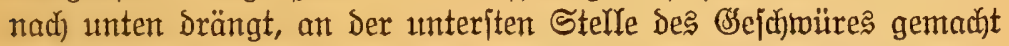

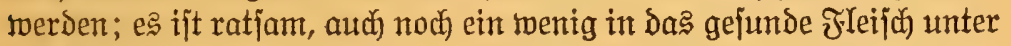
ber Deffnung einzujdneiden, Damit jïb Der hier anjammelnde Eiter

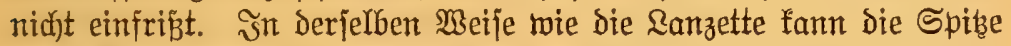
eines Tafdenmeifers vertwandt werden. Die snitrumente find vor

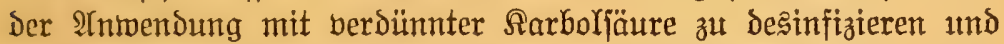

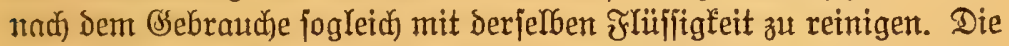

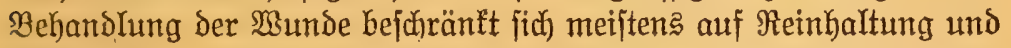
Dffenhalten. Mitunter wird das SYL Den Fłüffigfeit erforderlich fein und miro dies bei Der Bejureibung der ZäIIe an Den betreffenden Stellen angegeben twerden.

Bei empfindlicten \$ferden wird es bei Siejer Speration, wie ïberfaupt in alfen Fällen, wo man ifnen Sd)mer子 verurjadyt, wie

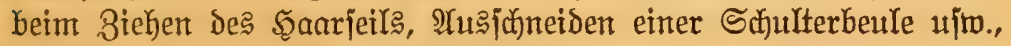
meijtens nötig fein, fie vorher fügjam zu machen und burd Eržtgung 
eines heftigen Shmerzes ifre 2 Hfimertjamfeit bon ber Dperation ab=

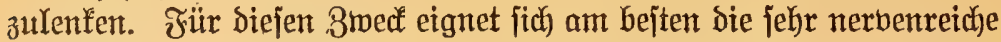

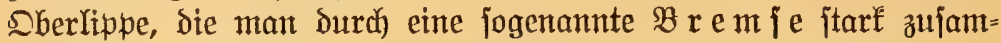
menprést. Fine joldje Bremje fertigt man jich am einfachjten aus

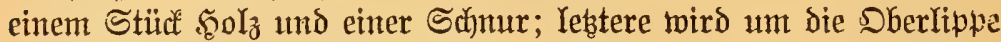

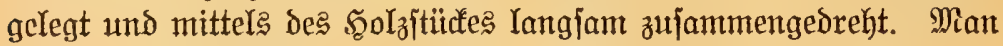
vergelie aber ja nidjt, die Bremje jogleich zu entfernen, fobald die Dperation beendet ijt, um dem Tiere unnötige Sdumerzen zu criparen und um jonjtige üble Folgen, twie 2lbjterben ber Dber= Iippe, zu verhüten. 


\section{6. 算apiftel.}

\section{Bon bent Brentuct.}

Das (słüheijen wird in zahlreidyen Fällen angetwanot, z. B. bei Spat, Sd)ale, Ueberbein, bösartiger Jijtel ujw. Nadjoem dem \$ferbe cntweder cine Bremfe angelegt oder Dasjelbe zu Boden getworfent ijt,

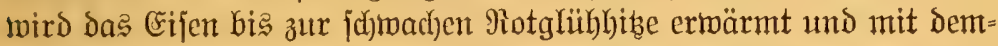
jelben über bie zu brennende Stelle letcht hingefahren, oder wenn man \$untte brennen will, mur mit einem gelinden Drutf auf bie Şaut gehalten. Buerịt merden nur die Şaare berjengt, jodann wirft da? Eijen auf bie blobse saut, wobei e马 notwendig ift, das oslübeifen öfters aufzukeben und wieber gelinde auf bie Branditelle zu halten,

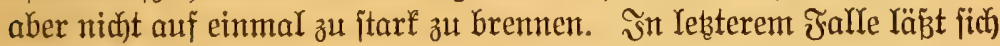

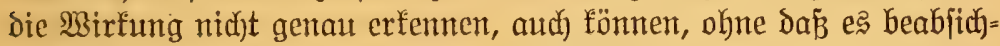
tigt wird, unter ber 5̧aut liegende Teile zeritört werden. Ĩm allge= meinen gilt Die Piegel, folange Das Eijen unter öfterem $\mathfrak{A} u f$ heben auf diejelbe Stelle zu halten, bis die Bransjtelle cine hellgelbe łärbung

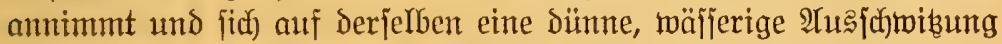

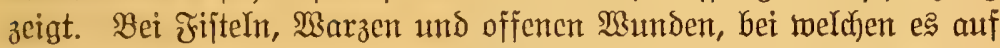
Bernidjtung ber franten Teile anfommt, Grennt man jo jtarf, wie e马

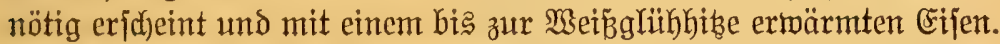
Beim Brennen auf Der Saut fann nach) etwas Del oder jonjtiges reines (nid)t gejalzenes oder getwïrztes) Jett auf die gebrannte Stelle geitricken twerden.

Die Eijen, Deren man fich beim Bremnen bedient und die auझ weichem Stabeijen angefertigt werden, haben berichiedene Formen, unter benen bie bielectigen, punftförmigen, mej̃ex = und fegelförmigen bie gebräudfilichften find.

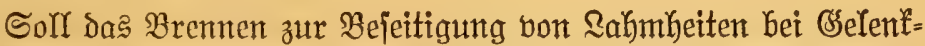
und Snochenfehlern günitigen Erfolg haben, fo mülijen die gebrannten

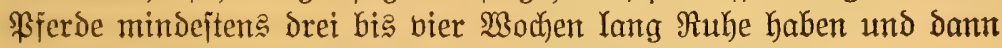
nod) einige 3eit bor Heberanitrengung bemafyrt werden.

Das Niedertwerfen des \$ferdes zum 3medfe des Brennens und

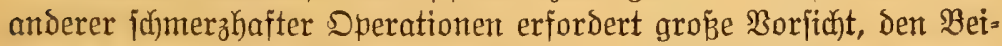
ftand mehrerer zuverläffiger (Sh)hilfen und eine bejondere Borrichtung 3um Niedermerfen. Eine jehr pafjende Borrichtung bejteht aus vier gut gepoliterten, 20 Boll Iangen und 3 Boll breiten, mit Sdfnalle und 
Ring berjehenen Yedernen Fefjelriemen, aนt einem 20 Fun Iangen, ftarfen Seile, einer Giurte und jtarfen Stricken. Derienige Freffel= riemen, an Dem das Seil befejtigt ift, wird an denjenigen \$orderfuß gelegt, Der oben zu Yiegen fontmt; Die übrigen Fefijelriement werdent um Sie andern rejfelgelenfe gelegt. Soll das \$Fferd auf bie rechte Seite fallen, ijt eine gute Streu gemtadft, Das \$Ffers hingefübrt umb an jei= nem Siopf ein zuberläjfitger SSehilfe gejtellt wordent, fo legt mant den

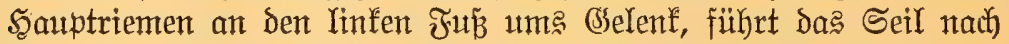
Ginten bon antient nach innen burch Dent Ring des Riements an Dem

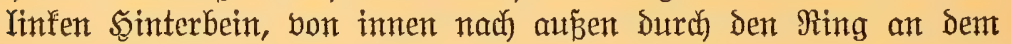

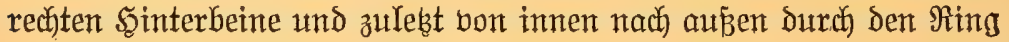

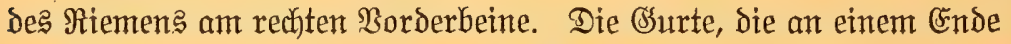
eine Deje Kat, Yegt man mit Diejer um Den oberen Ieil Des Yinfent $\mathfrak{B o r}=$

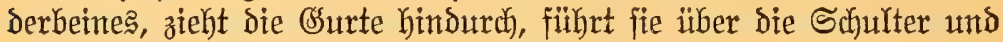

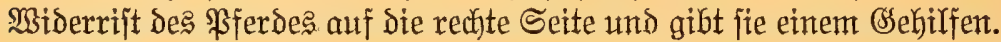

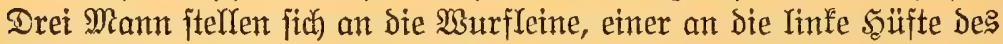
\$Ferbes und auf ein gegebente Beichen ziehen die brei Mann bie Beine

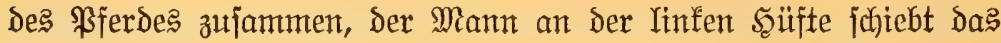

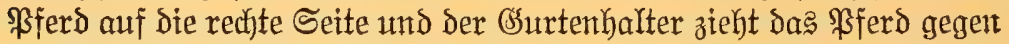

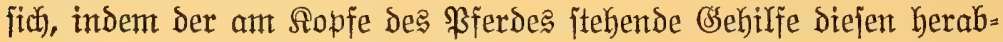

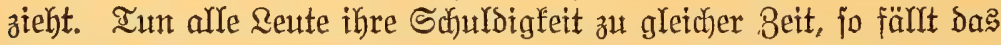

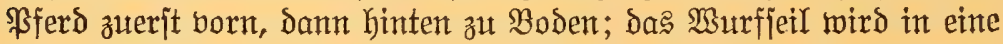
Sableife doppelt ztjantmengezogen, in die man eine Şand boll Stroh

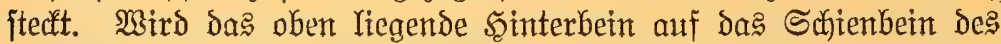

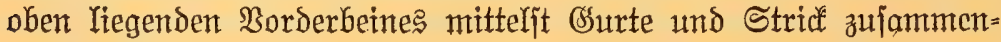
gebunden, jo liegt dą unten liegende Sinterbein jebt frei da und fam

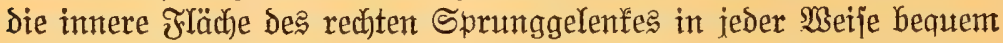

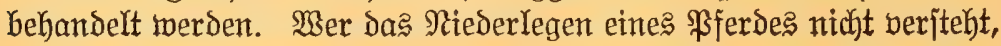
forlte fict Damit jowenig wie möglich befaffen. 


\section{7. 筑apiffel.}

\section{Bom Silitier.}

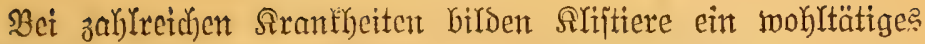

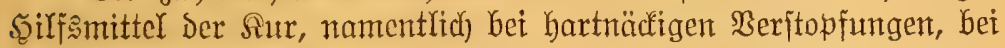

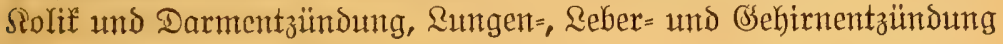

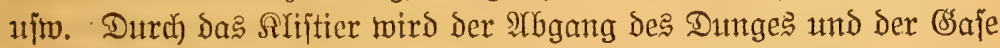
crleidjtert und bejdylennigt. Eine bejtimmte Bujammenjekung Der Sliftierflüffigfeit ift nicht bon jo groper Midutigfeit, wie man gewöhn=

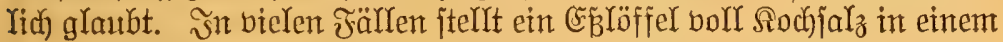

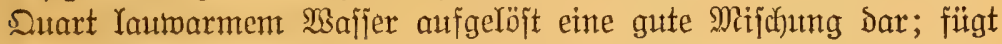

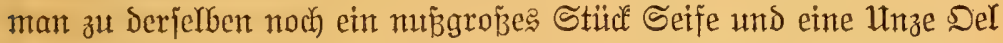
(sweet oil), jo ift biefes noch wirfunggabller. Bet fehr hartnädtigen

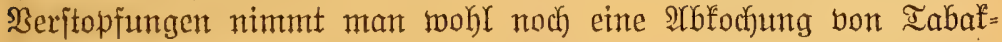

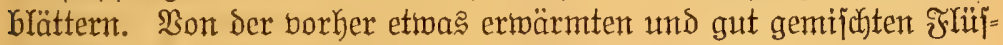
figfeit merden Dem \$fferde, je nach Errfordernis, alle halbe bis zmei Stundert, ein bis zroci Eprib̧en boll in Den Iffter eingejpribt. Solfte Sie Flïffigfeit jogYeid) und ohne \$irtung wieder abgehen, jo ift bie

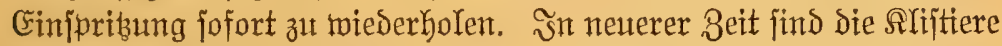

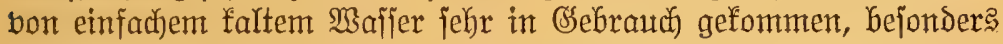
bei SiolifanfäYlen. Man fant fich der Saltwajier=Slijtiere namentlich bet Beritopfungæ. two es Darauf anfommt, mehr reizend auf den Miaftbarm zu wirfent.

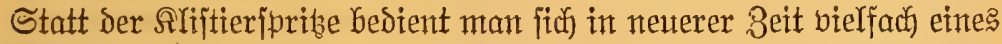

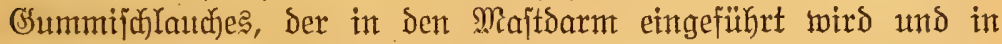
melchen mittelit cines gemöhnlithen Iridjters beliebig groß̈e Mengen Flüffigfeiten gebradft twerden fönnen. Man nahm an, Dap̉ auf Diefe

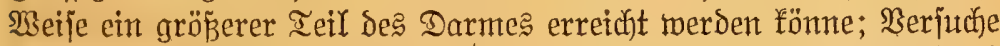

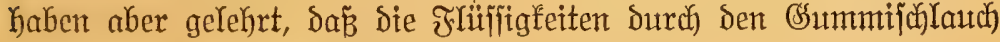
nicht forweit bororingent, wie mehrfach behauptet worden ijt. 


\section{8. 篗aputfel.}

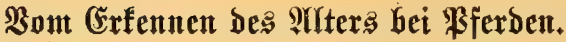

Das einzige, aber audi nidyt immer zuberläffige Sennzeidjen, nach

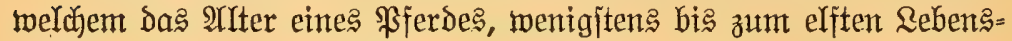
jabre, mit ziemlidjer Sidjerheit angegeben twerden fann, findet man in ber Bejuaffentheit ber Bähne und namentlid) an ben borne in

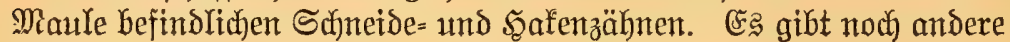

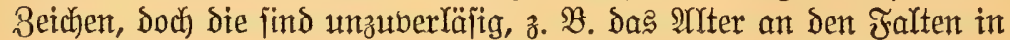

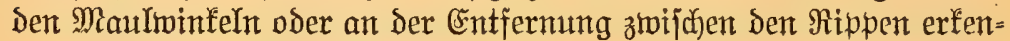
nen zu wollen. Einige Merfmale geben aber boch wertwolle $\mathfrak{A n h a l t z =}$ punfte für die 2rrterabejtimmung und follen fier deskalb er= toähnt werden.

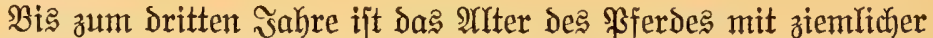

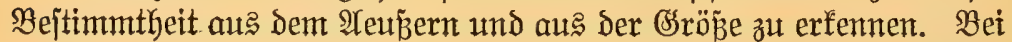

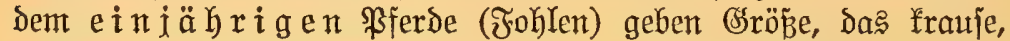
wollige Saaar, bie furzhaarige, meiftens gefräujelte Mähne und ber mit ebenjoldben Szaaren bejebte Sdjmeif, meldyer faum bis zum Sprunggelenfe herabreicht, eine fait fichere Beurteilung des 2riters ab.

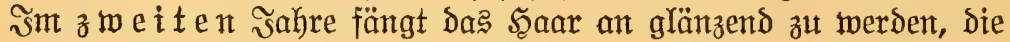
Mähnen = und Sdjweiffaare find Yänger und jallidter und lebstere reichen bis zum Sprunggelent herab.

F゙erner haben junge Pferde eine mehr rundliche Frorm des Sopfes, ihre Stirn ijt gewölbter, Die fpäter Gerboritebenden Inochen

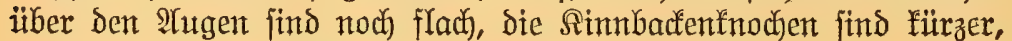

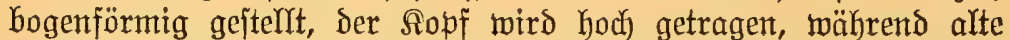

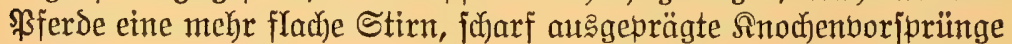
über Den Yltgen, Yang auggezogene fladje Rinnbadfenfinodjen, einen bertieften 囚ehlgang bejtien und den Ropf öfters hängen Iajjen. Bei alten Tieren erjcheinen weibe Scaare um die PHgen, auch an andern

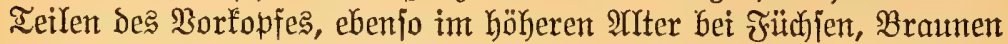

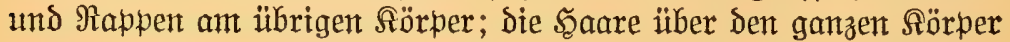
werden gröber, itachelfaarig. Die jogenannten $\mathfrak{A p f e l = ~ m u \delta ~}$ Fliegen:=

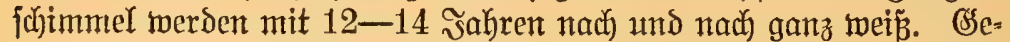
nauere Sienntnis des artters geben nur, wie gejagt, Die Bähne. Es ift

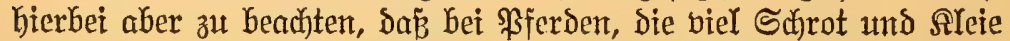
erhalten, die Bähne fich langjamer abmuken, die "Ânden" oder "Bohnen“ (marks, kernels) bleiben beutlidjer und länger erfennbar, 
Inährend Dagegen bei ßFerden, die unr Sönnerfutter erhalten, bejon= Dere aber bei joldjen Tieren, bie viel auf jandiger Weide gehen, ton

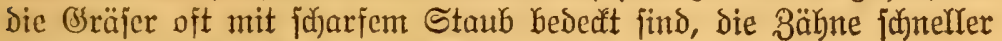
abmulsen mo bie "Siunden" früher berjd)twinden.

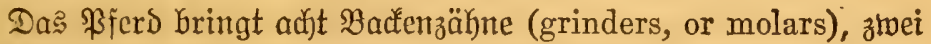
anf jeber Seite oben und unten, mit auf Die Melt, ober e? zeigen fith bicjelbent ztwei bier brei Tage nad) ber OSeburt. \$3enn bier Sdjneide= ober Borbcrzähne, ztwci in Sber= und ztwei in Itnterfiefer, völlig

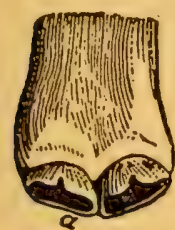

Jabb. 7.

Bähne xine 6

đage alfen

In IfIEnts.

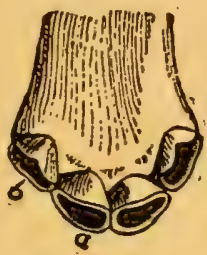

Jibb. 8.

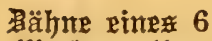

20) odjen alfer Foylentar.

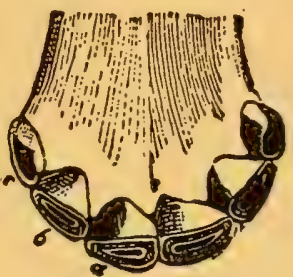

\аb. 9.

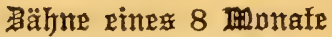
alfen Folflents.

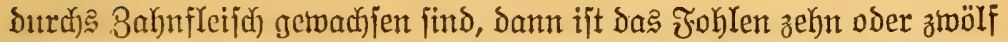
Iage alt; und went nod) bier weitere herauggetwarfjen find, einer auf jeber Seite, die andern in beiden Siefern, fo ift das Fohlen beinahe einen Monat alt. Das Seraustreten Der Caf́zähne - Dies ijt des

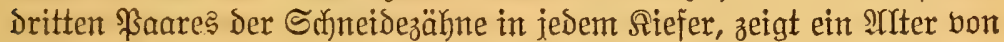

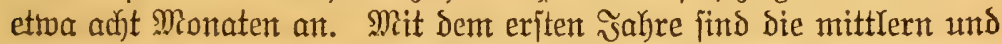

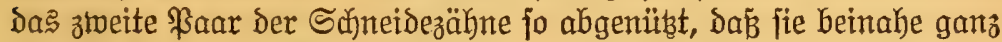
eben find, was mit bem Edyahn, ber nun ebenjo lang getoorden als feine Nadjbarn, aud bald der Fall ijt.

Da马 zmeijährige Fohlen hat Den Sern (mark or kernel), Die Dunfle, Garte Subjtanz in Der Mitte Der Zahntrone, ganz und gar

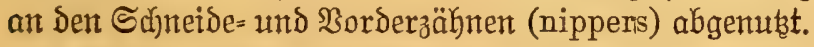

Bisher Yeijteten die Milluzähne Dem Tiere alle erforderlidjent Diente, mummehr aber ijt es anderer, fejterer und in jeder Beziehung Dauerhafterer benötigt, und hierfür forgt bie Ratur, inden fie Dieje

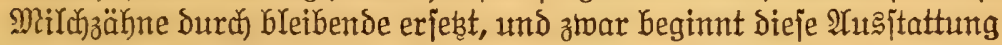

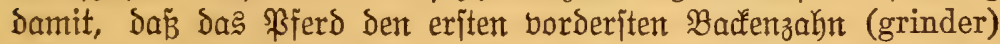
befommt. Da jebodh dieje Backenzähne zu weit zurüd in Maule angebracht find, jo mun man auch fernerbin zur Beptimmung des

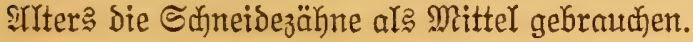




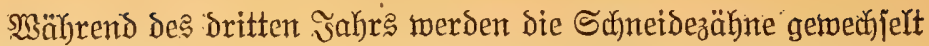
(shedded, shifted), und bỉ diejes vollendet ijt, ijt das mittlere ßaar derjelben beinahe anggemartjen. (Siehe das Bird, twelches die Bähne Des Dreijährigen Fohlen daritellt.)

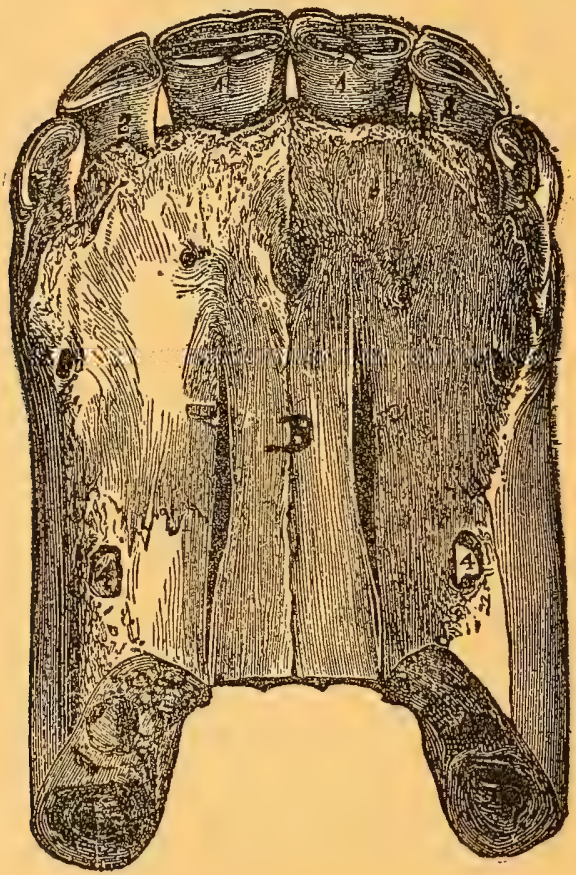

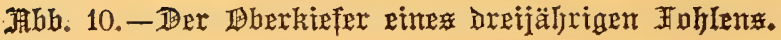

B, Sorderer Siteferfnoifen.

1 1, mittlere, bleibende, beinahe auggemarfjene Suneidezähne (nippers).

2 2, Milchzähne, ab́gënübt.

3 3, Eufähne, an meldjen noch der Sern (kernel or mark) zu jeben ijt.

4 4, כัn Siefer berborgene Şafenzähne (tushes). 


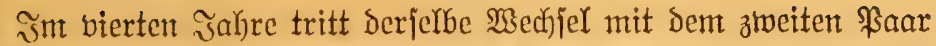
ber Sd)neidezäbne eit und gegen bas Ende desjelben und mit $\mathfrak{I n}=$ tritt des fïnften fommen dic Şafen= oder 3aumzähne deutlich 3um నorjachein.

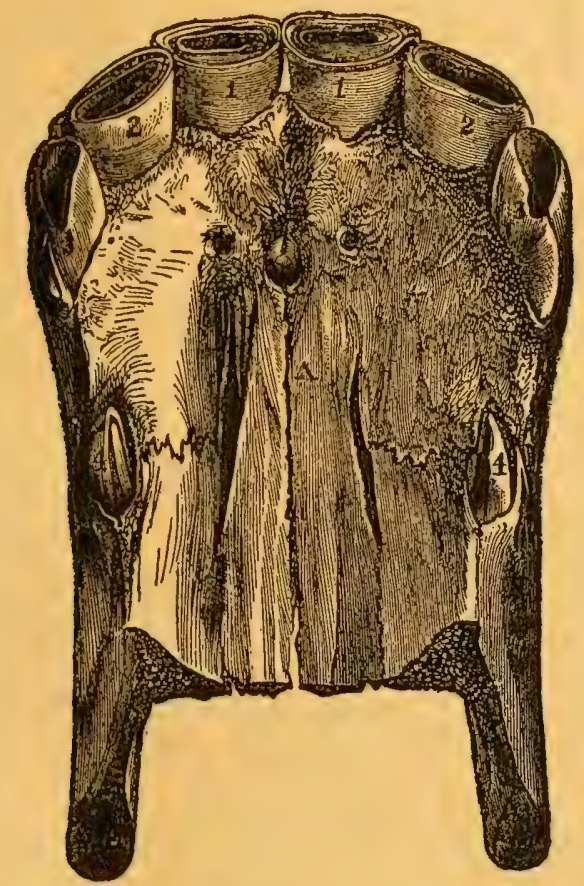

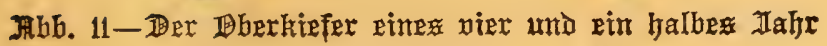
alfen pferdex.

A, Borderer Sieferfinodjen.

1. Mittlere, żemlich abgenütųte Schneidezähne.

22 , Das nädjite böllig entroidelte und an Den Sd)neiden etwas abgenübte ßaar.

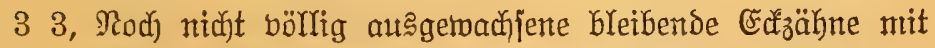
furarfen Sdjneiden und jefr beutlichem Sern:

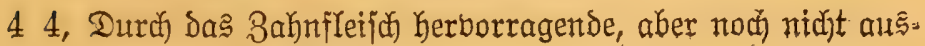
getwacjiene ฐafenzähne. 


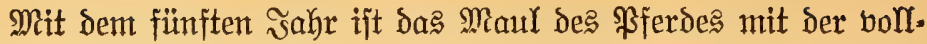
ftändigen $\mathfrak{A} \mathfrak{n} z \mathfrak{y}) \mathfrak{l}$ Bähne (a full mouth) berjeben, und mit dem fechjten jind die Sdnneidezähne des Itnterfiefers dermaß̈en abgenübt,

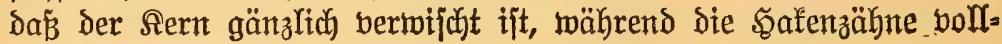
fomment ausgetwadjen find.

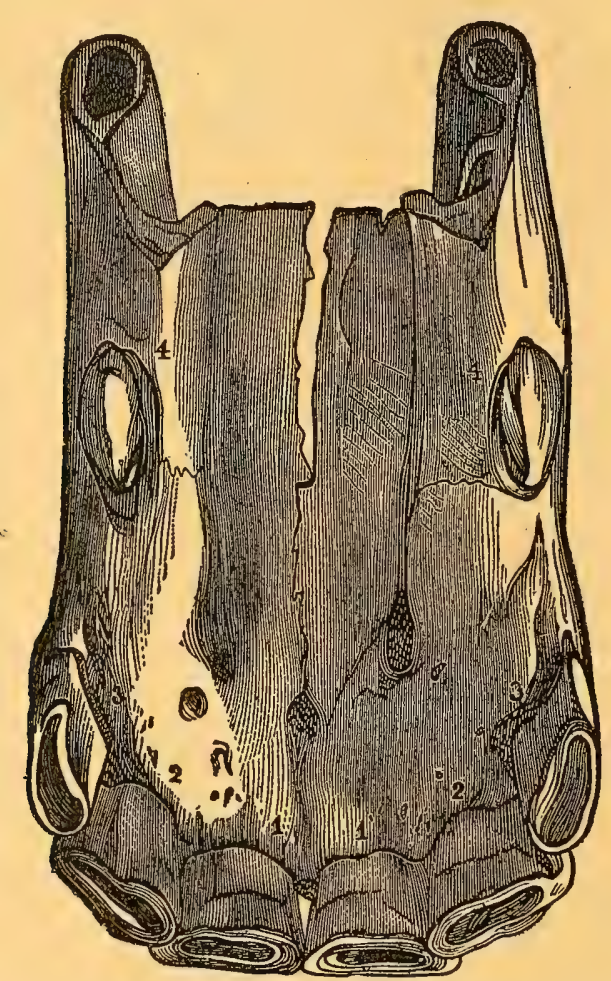

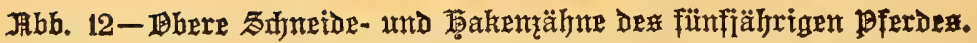

1 1, Mittlere Sdyneidezäfne, mit nody unberwijudtem Sern.

22 , Die diejen zunäbjt jtehenden Sdneidezähne, mit nod) dent: licfer herbortretendem Яien.

3 3, હałzähne, mit jehr mentg abgenübsten Sdjnetøen.

4 4, Bollfomment entwicfelte Şafenzähne, an beren äunerer Seite die 2โughöhlung noch deutlich wahrounehmen ijt. 


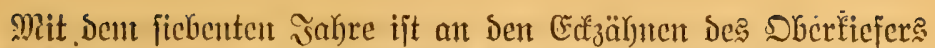

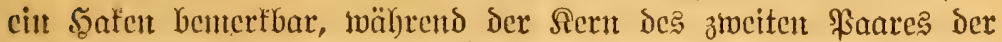

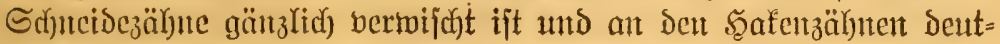

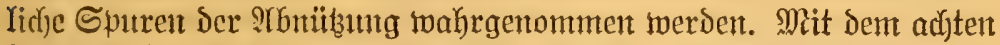

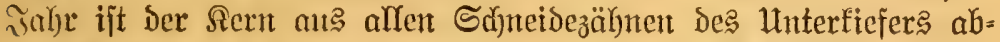

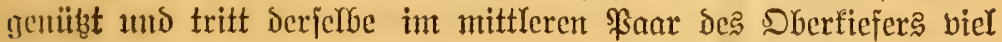
sveniger Deutfid) herbor, oder derjelbe ijt bei bem \$Ferde, Das mur im Stall gefüttert wirb, aud gänz

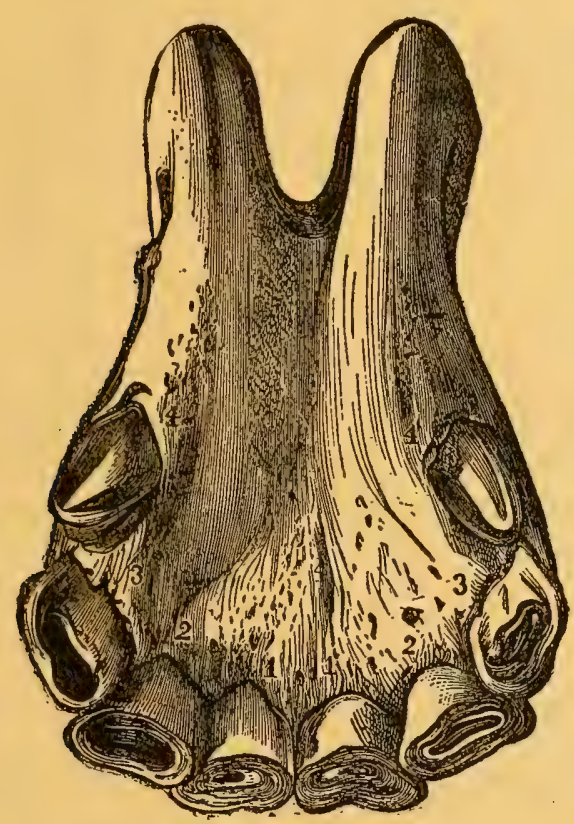

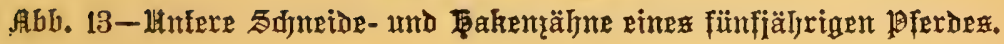

1 1, Mittlere Sdyneisezälyne, Deren Sern beinalye abgenü tat iit.

2 2, Die Demjelben zunädjit jtehenden Sdjneisezähne, mit teil= sweife abgeniußstem Rern.

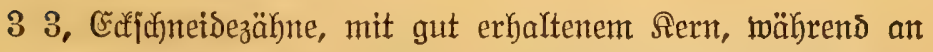

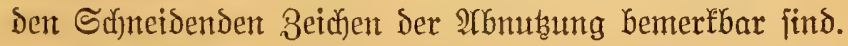

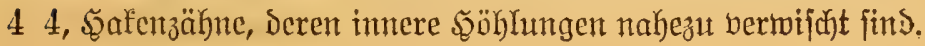




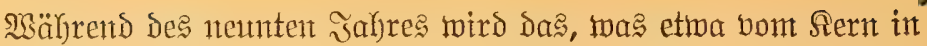
Dent mittleren \$aar Des Dberfiefers übrig geblieben ift, abgenütst,

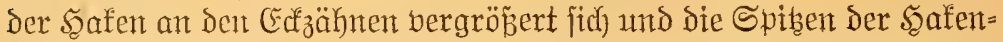

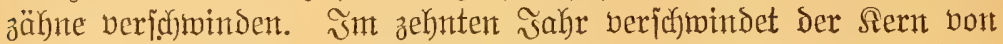
Dem zweiten \$aar ber Sdnteidezähne an Sberfiefer und im elften

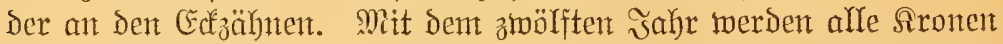

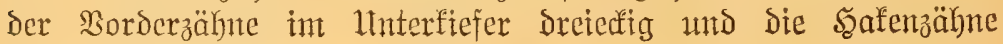
find jebr abgenübt.

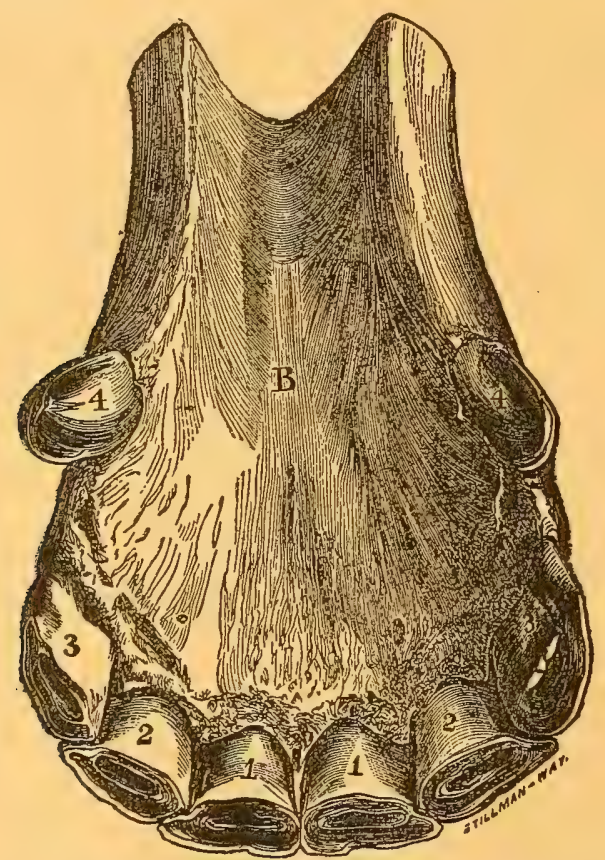

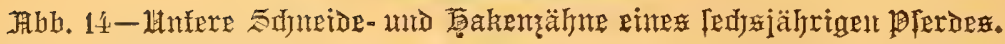

B, Der Itnterfiefer.

1 1, Die mittleren Schneidesäfne, mit abgenübtem Sicrnt.

22 , Die Denfelben zntäajt ftehentont Sdyneidezälne, mit teil= tweije abgenübtem §ern.

3 3, Die Eaffonneidezähne, an weldyen der Sern Deutlid) zu jehen ift, die Sdfneiden jeodof bedeutend abgenübt find.

4 4, Die 3/4 Boll langen Şafenzähne, mit nut swentg abge= ftumpften Spiben. 


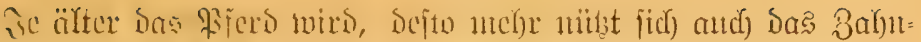

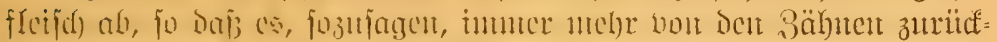

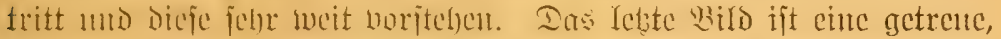

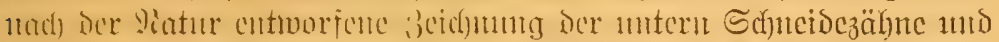

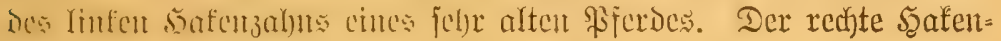
zahut ift, wie зn fehen, antsgefălyent.

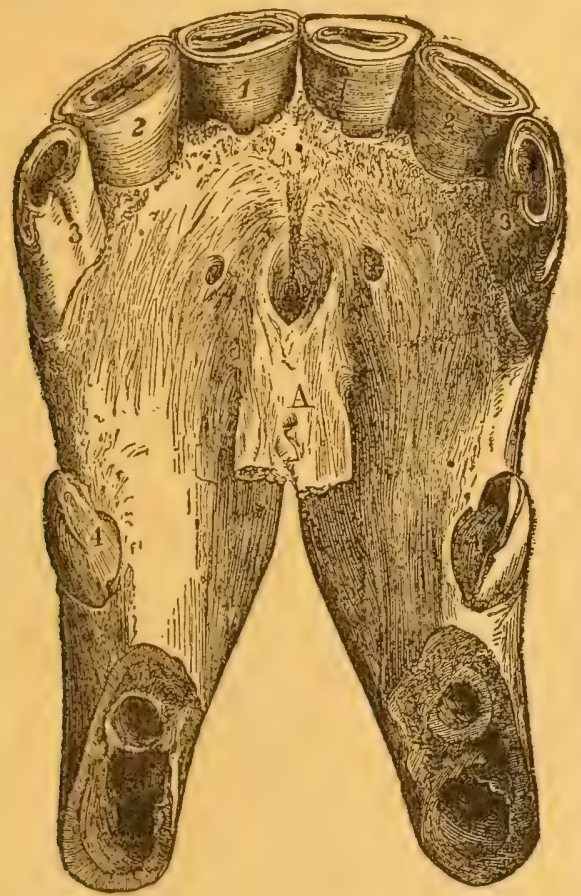

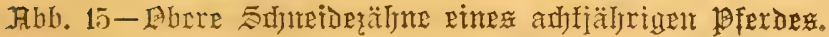

A, ßoroercr Sileferftnodjen.

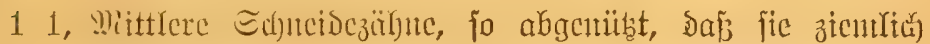
eben finto.

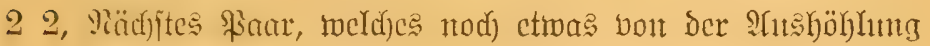
zeigt.

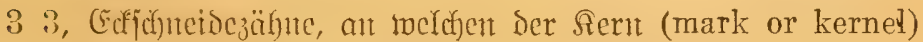
tod) Dentlich) zu jehent i it.

\pm 4 , safenähnc, dic nehr abgenübt find als die im Interfiefer

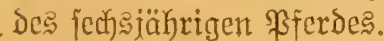




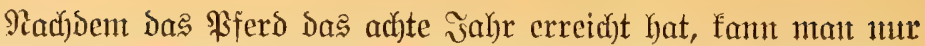
antühernd deffen âter beitimmen, obgleich erfahrente \$Fferdebändler

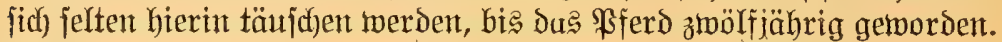
Bom zwölften sahre an aber fönnen wir, aujer dá̉ fehr lange her: boritehende 3ähne ein hohes Irlter anzeigen, fein fentzeidynende? - Merfntal mehr angeben. Mit den Bähnen mandher Bferde geht, nachdem fie das neunte sahr erreidjt, mur jebr twentg ßeränderung

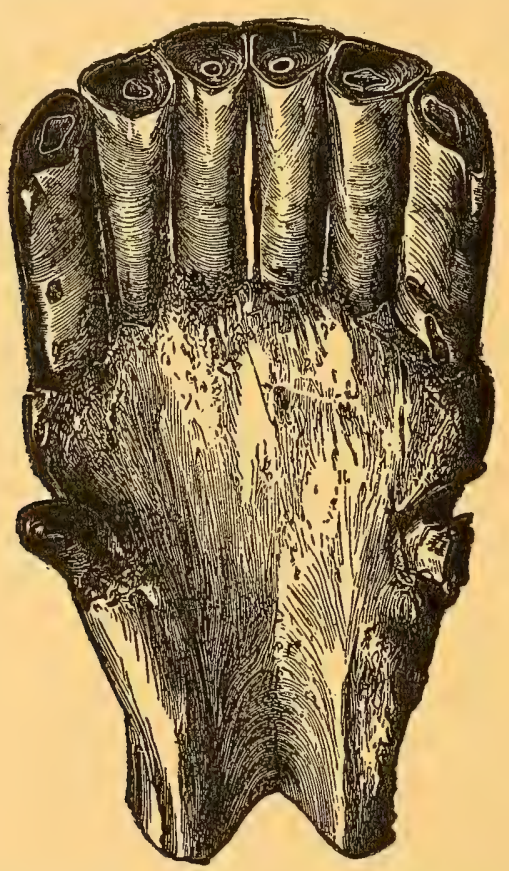

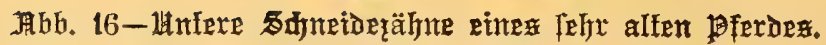

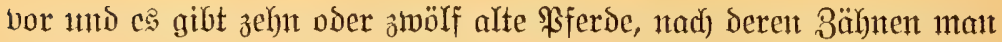

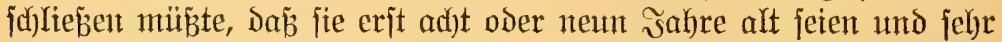

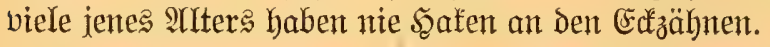

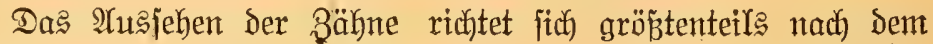
Futter, welutes das \$ferd frip̈t, forwie nach ber Bodenart, auf welcher

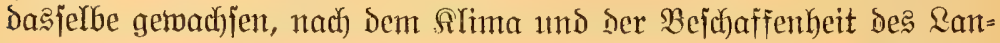

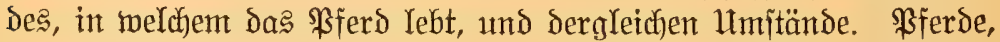
welcje ftets auf einer Beide find, bie auf fandigem Boden angelegt ijt, nüben ifre 3ähne janell ab, weil bie öfters mit dem Gras bermifidten 
Sansförner beitändig zermalmt merden, mosurd) ben Bäfnen früh)=

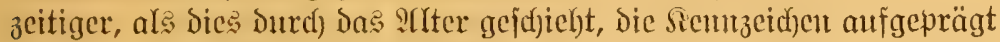

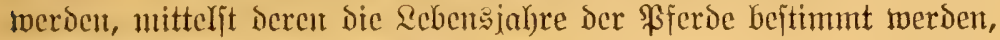

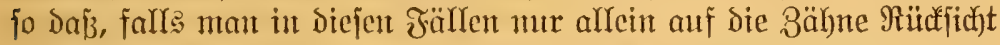

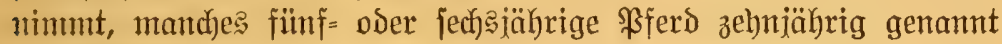
wersen miijste.

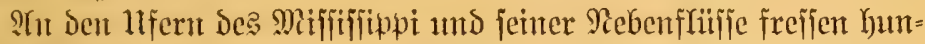

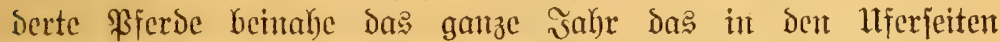

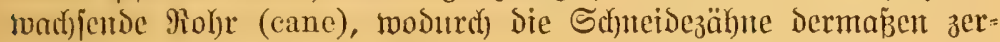

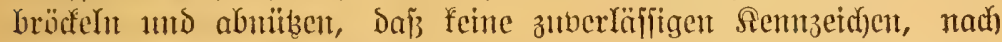
weld)en man bas sflter beftimment fönnte, wal)rzumehmen fints, und bic Erfzälnne bicjer Prerde haben, gleich denen Der eben ange= fiilyrten, feine ฐ̧aten.

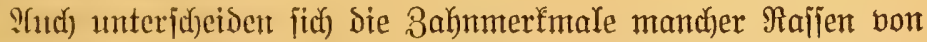

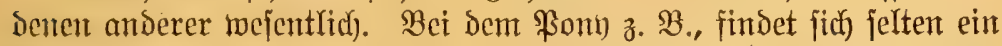

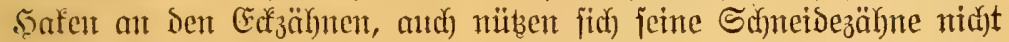
fo fadnell ab, als sies gemöhnlicf) Der Fall ijt. Ebenjo jadrumpft jein

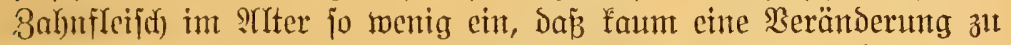

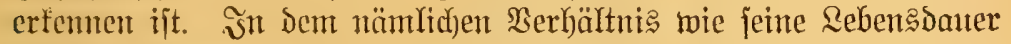
cine biel größzere ift, als dic anderer \$fferde, erbalten fich auch jeine 3ähne \änger. Dicje Bemerfungen mögen aud in gemiffem (Śrade auf Pferde verj(f)tedener Form und Rörperbilloung angetwandt werden. Die 3ähne grober, fnod)iger Tiere benten auf ein viel böheres arter hin, als biejenigen fleinerer, geonängter gebauten, und ebenda:jelbe

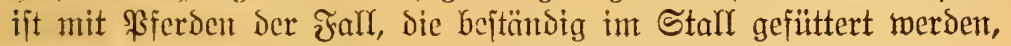
gegeniiber Denen, welche bie meipte Beit auf Der \$eide Iaufen.

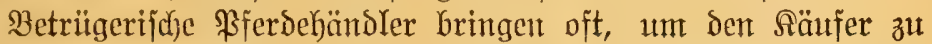

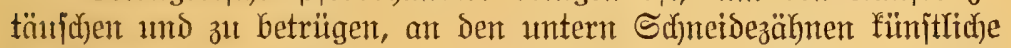
Mierfmale an. Dieje aus England ftammende Betrügerei wird folgendermaßzen bejurieben:

"Man nemut Dicjen Betrug nach dem Erfinder, Der Denjelben aterit benübte, "Bifhop" (bishoping). Das acht= voer neunjährige

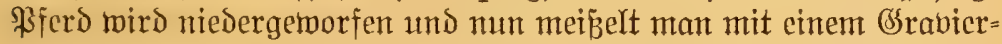

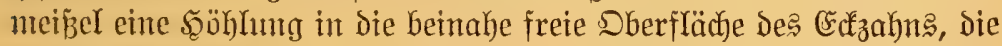
bezïglid) Der Sejtalt und Form Dem Rern (mark or kernel) Des

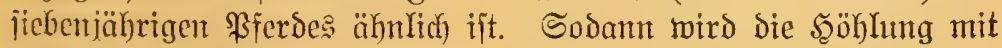

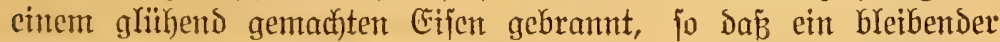

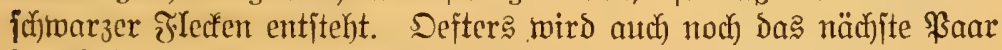
Der Sâneidezähne eit menig gebrannt. Itnwiffende werden Durch

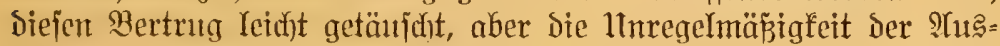

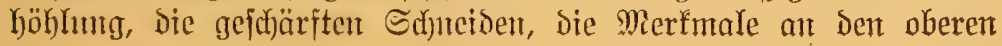




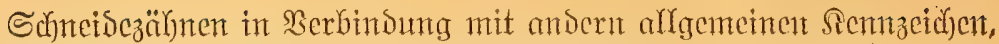
fönnen eitten anfmerffamen Reobad)ter nienals irre fitlyrent."

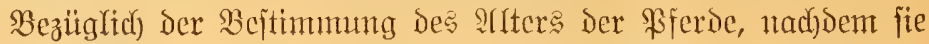
bas achte sabr zurïdfgelegt haben, jagt derjelbe Sfutor: "Die Safen= zälyne find der arbnübung verbältnismäbig in mur geringem Brade

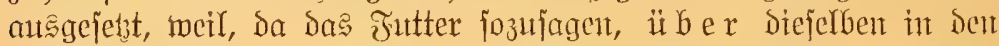
Sulumb geht, fie nur geringer Sieibutng ausgejebt fint. Deshalb fant man ats der mit ifnen borgehenden Beränderntng, obgheicl) fic getwöhnlich in ser bon unts bejuchrebenen Meije itattfindet, nicht mit

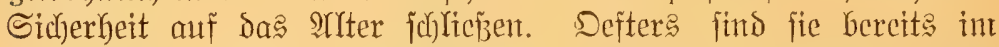
adften sabre ftumpf, mandfmal aber aud nod) im adjtzchnten ganz gut erfalten. Die obern Sgafenzäbne, obmokl fie bic jüngeren find, nüben zuerit ab.

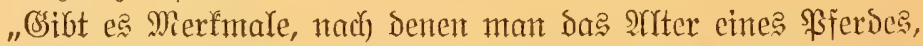

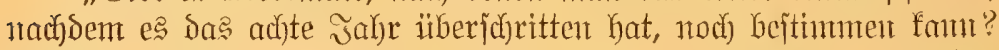

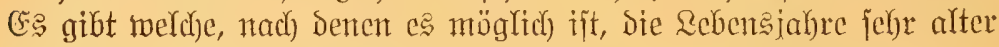

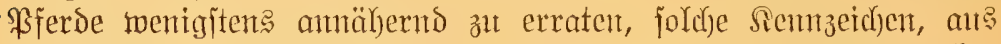
benen man mit einiger Sicherheit Sorbiifife zieben fömute, find aber nidyt mehr borbanden, und man fann bout mut an jeine Bermutungent nur auf bie sseitalt der Bälnte grünsen. Mit bem achten sahre finto

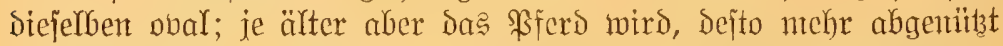

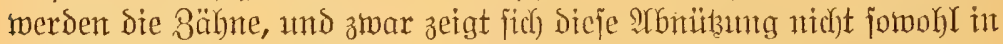
Der Diffe als in der :

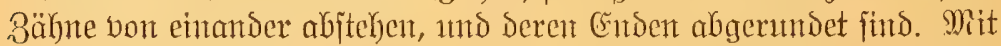
bem vierten sahre ijt Sies an ben mittleren Sulneidezähnen bentlict) wafyrzmelymen. Mit bent zehnten wird bas Doal ber andern fïrzer; mit Dem elften find Die Enden des zweiten ßaares ber Sdynetdezälynte

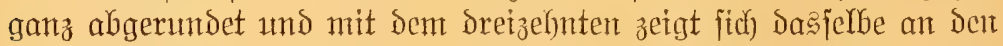
Erffichneidezähnen. Mit dem bierzehnten Jahr merden Die Serne Dor:

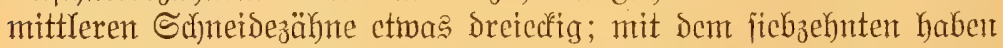
alle Dieje Form. Mit dem neunzehnten bagegen fund bie Ecten twicocr abgenübt und die mittleren Bähne find wieder oval, mur dais das Doal eine umgefehrte Rage hat und nicht melor bon rechts nach Yinfs, font= bern bon autzen nach imten liegt, und mit bem zmanzigiten haben arre

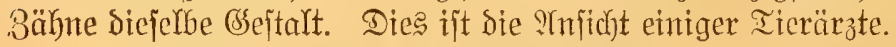

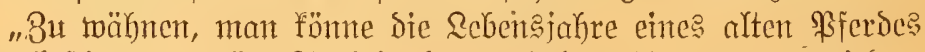

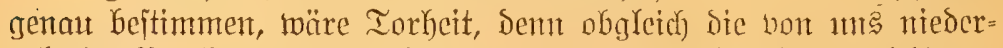

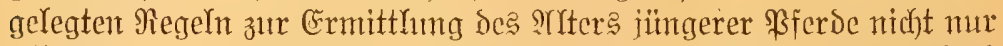

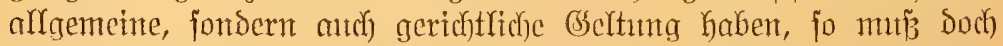

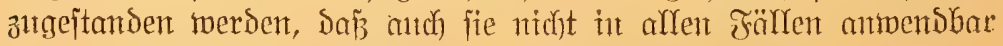
find. Die in Stall gefütterten ßFferde mïben Den Sern (mark or 


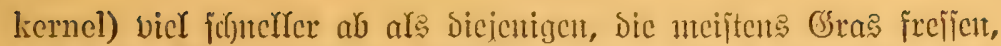
IIII) Der "Siriphenbeijer" (crib-biter) ntag faffon int critcu oder

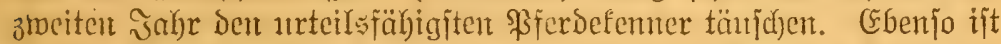

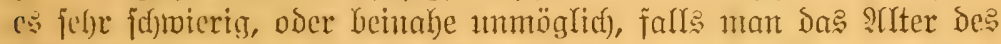

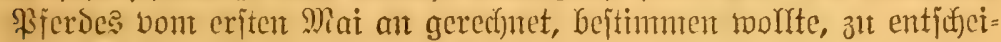

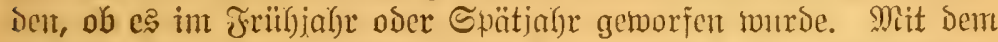
nemuten ober zehntent Jahre find bie Iräger (hars), Ieile Des fiefer?,

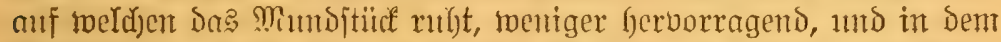

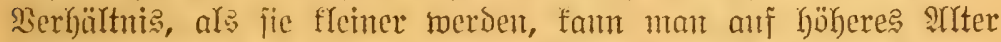

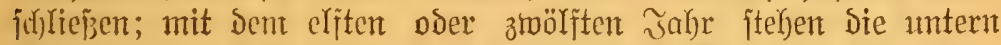

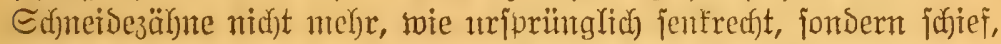

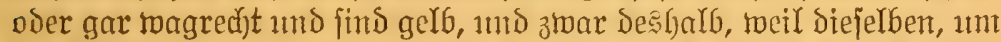

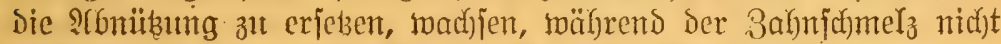

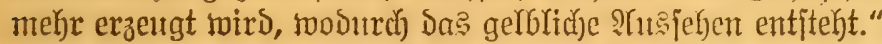

Die 2 ippen. - Die Sippen weifen zwar feine Merfmale

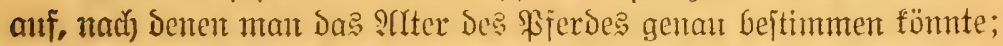

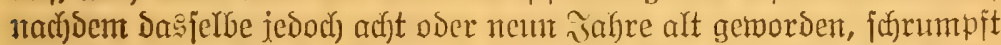

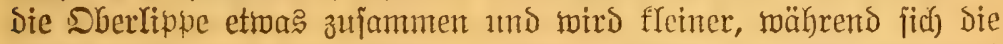
Intere verYängert, herabfängt, oft in Der Forn einer Sdjale boriteht

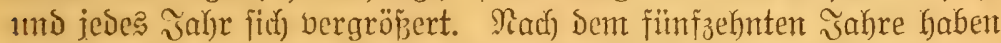

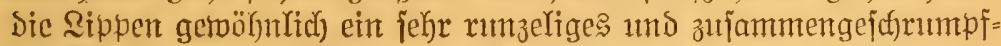

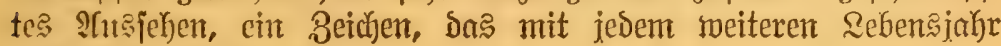
mehr herbortritt.

Die Sca a re. - Die Szare zeigent in mehriadyer Beziehung

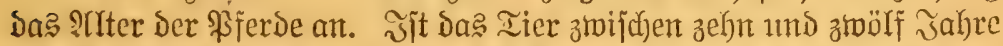

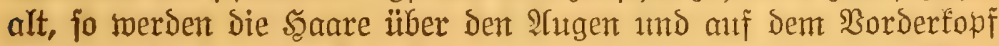

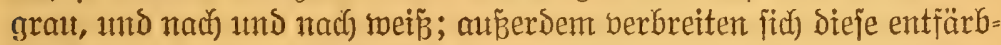
tent Sgare auff Die umliegenden Ieile, und mit Demt fünfzehnten Jahre

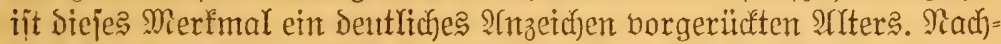

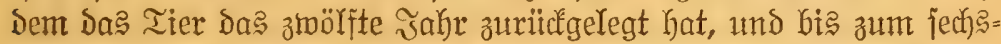

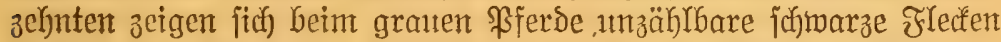

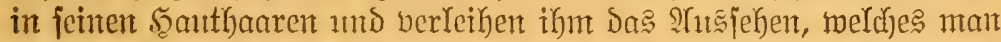

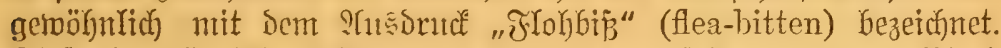
Dieje eigentümlidfe Eridjeimung zeigt firf) mtr jelten bei einem \$rjero

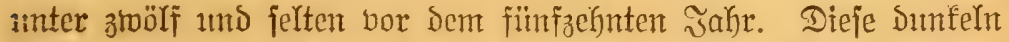

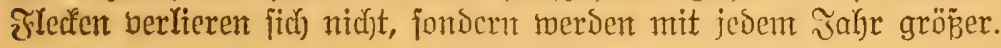

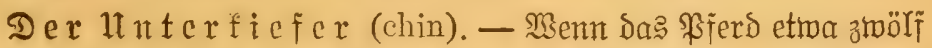
כahre alt ijt, wirb ber lluterficfer (chin) jpitig amo an feinem Ende

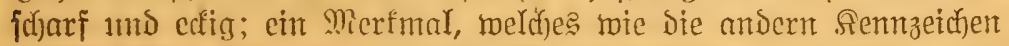

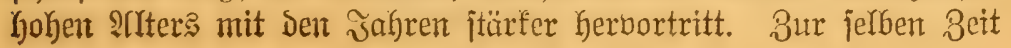




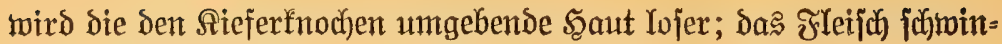
Set, bis jich amitatt ber im fünften und jechiten Jahbr mahrzunefmen=

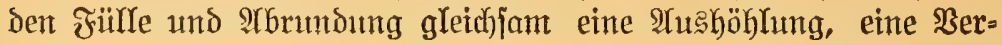

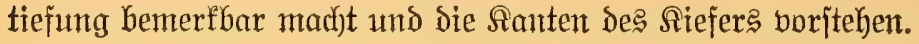

D) i e $\mathfrak{A}$ u g e n. - Die $\mathfrak{A}$ ugen verlieren mit zunebmendem arter

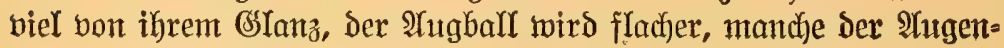

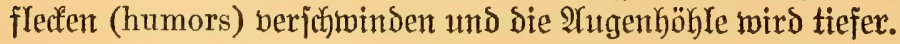

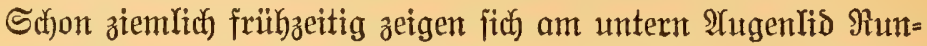

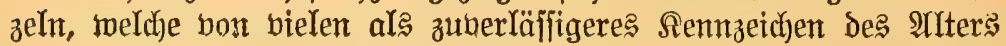
angejeben werden, als die an ben Bähnen auftretenden Merfimale; ja

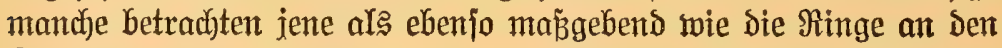

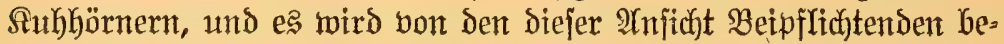

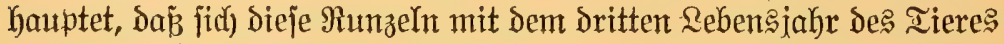

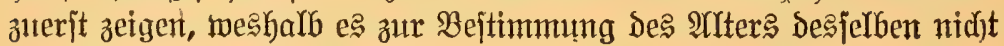
weiteres als Bählung Derjelben bedïrfe, zıt weldjer Bahl man Drei

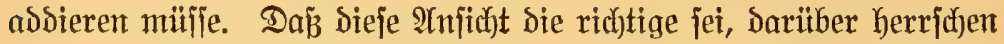

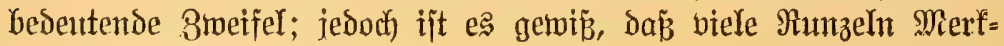
male hohen Irlters find. 


\section{9. 筑apitel.}

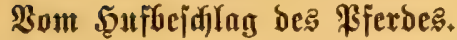

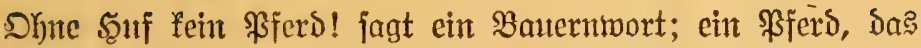

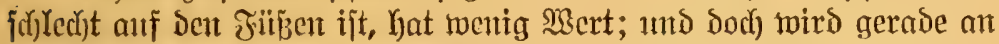

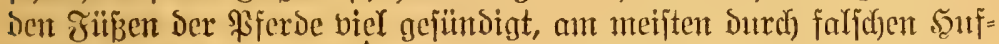

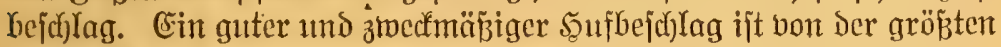

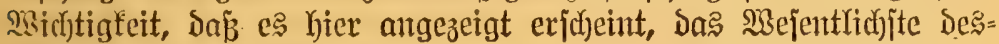
felben in Sürze mitzutteilen.

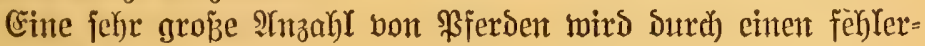

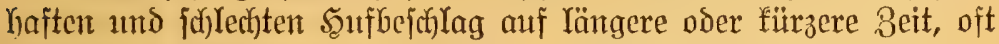
fiir immer unbrautebar, und bejonders ift dies auf bem Rande umb in

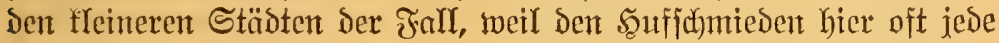

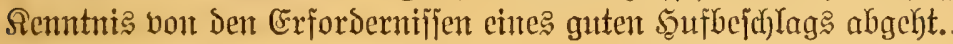

Rotwendigfeit und 3 we de

Bon Ratur fint die శüne des \$ferdes zwar mit fintreid)ender

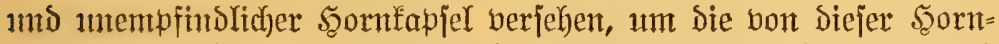
j(d)ale eingeid)lofjenten, empfindlidjen Ieile gegent $\mathfrak{B}$ erYebungen unto

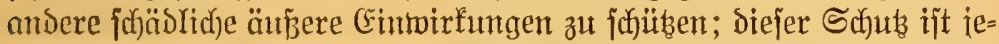

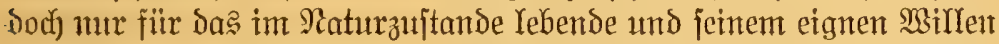
jiberlafjene \$fero finreidjend, nidjt aber für das gezälymte, unter ser Serrifjajt Des Menjuden jtehende und in Dejien Dienjt arbeitende

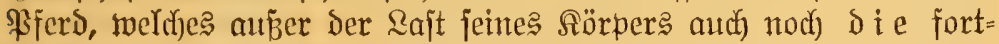
fdjaffen mutz, weldhe man ifm auflegt ober weldhe es ziehen mur

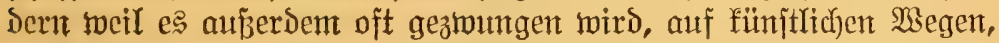

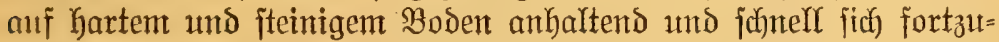

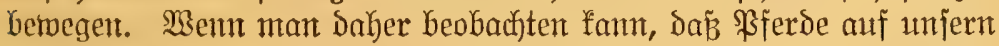

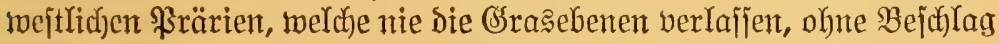

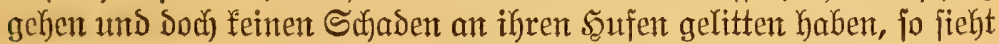

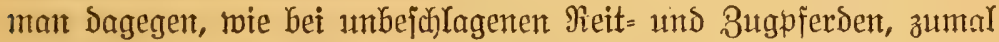
wenn fie auf hartem Boden oder gesflafterten Straß̉en oft faum einen cinzigen Tag, ja mitunter mur einige Stundent gegangen find, fich Der

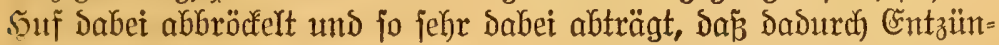

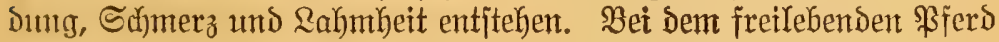
miro jedod) nidjt mehr Şorn abgemtbt als fortwährem wieder nad)=

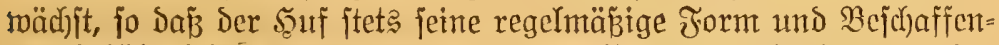

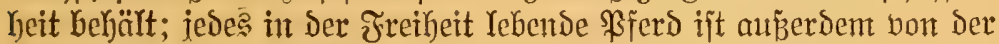

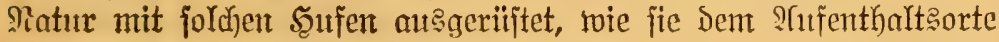
entipredyen. So hat Das anf Bergen, fteinigem und trockenem Boben 


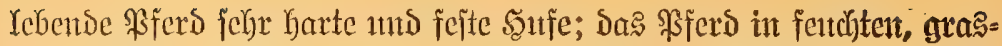

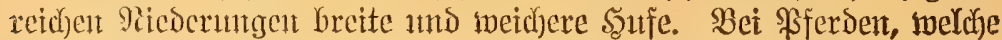

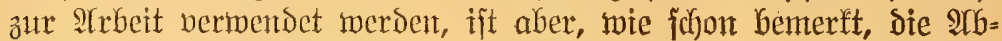

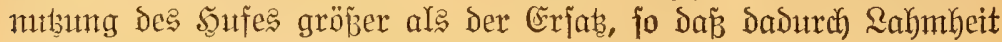

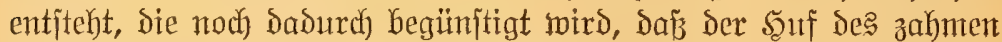

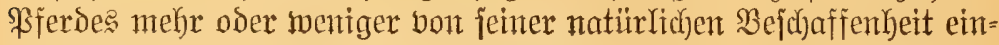

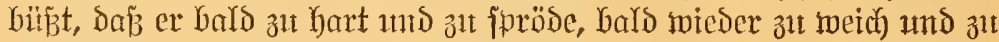
mürbe wird, mo baj jelbit der natïrliche llmfantg mebr ober wentger berloren geht. Inerläßliff iłt es daher, bie Sufe des \$sferdes, Gejon. Ders went es auf hartem, fteinigem Boben geken joll, bor zu groper

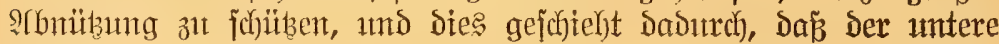
Szufrand mit Eijen bebedt, oder wie man furztoeg fagt, be= fif)lagen wird.

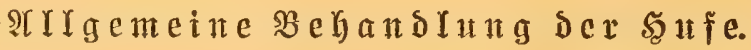

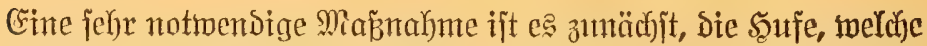
Die natürliche Feud)tigfeit mehr ober meniger berloren haben, öfter

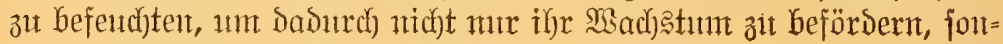

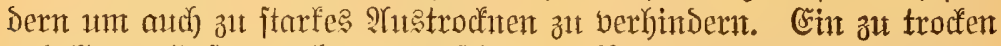

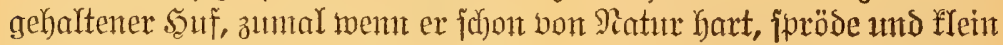

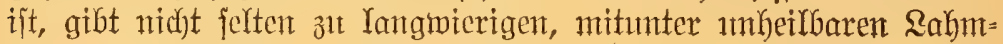

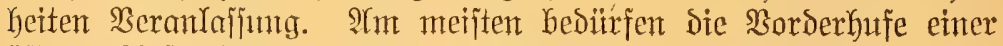

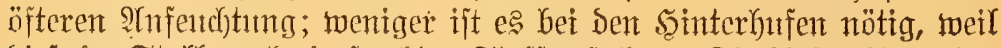

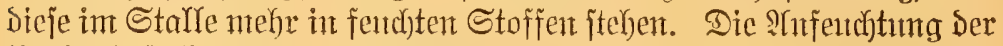
Sorderbufe foum anf berfdyiedene Irrt bemerfferligt werden. Sehr

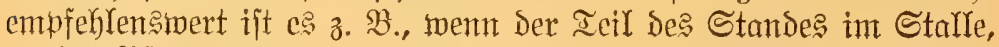

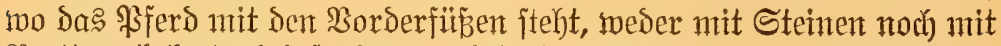
Brettern belegt wirs jondern unbedect bleibt, Dagegen mit Rebm und

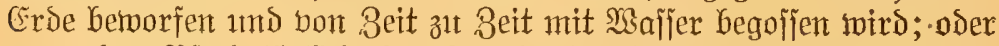

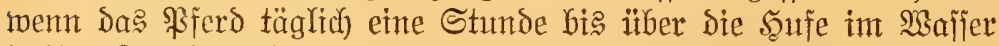

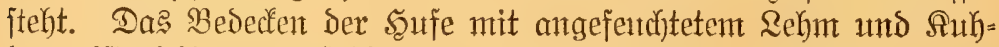

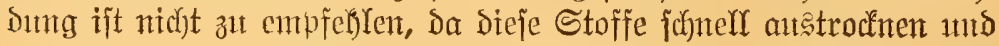

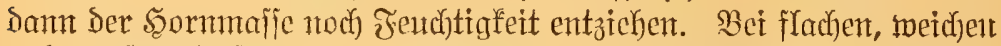

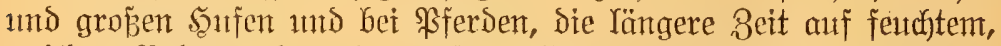

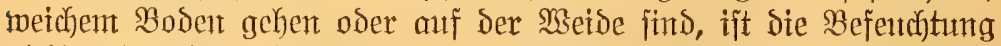

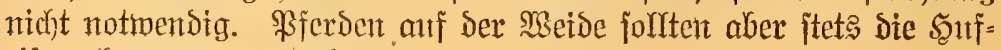
eifen abgenomment werben.

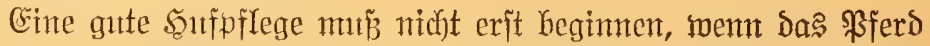
zur Srbeit eingejtellt werden forl, fondern fichon Den Suffen Der Foh)= Ient min, befonders wenn fie biel im Stalle gebalten werden, eime

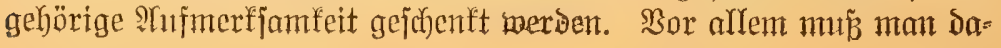




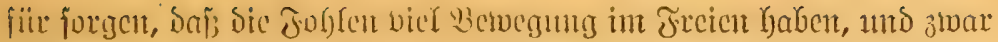

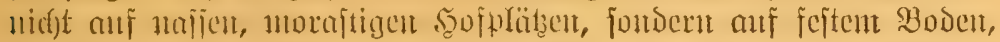

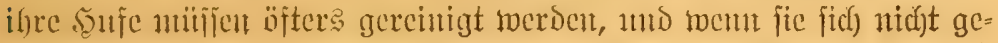

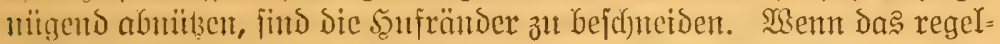

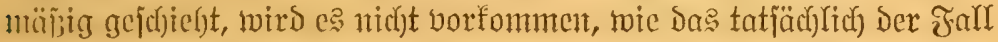

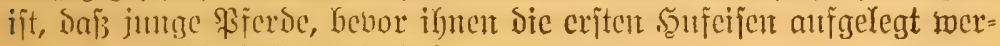

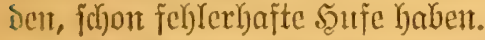

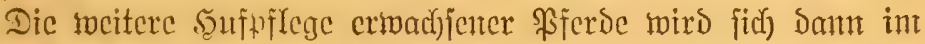

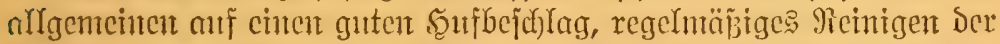

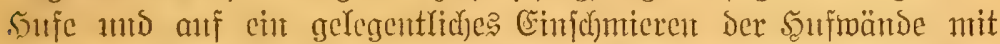

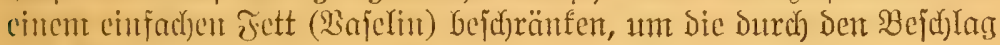

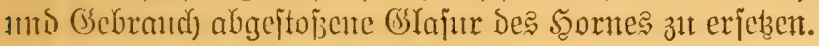

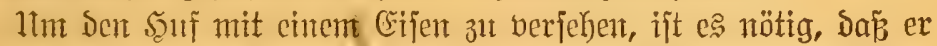
worker in sie nötige Form umb Bejuaffenheit gebracht werde. 31t=

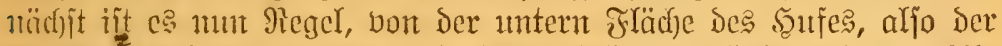

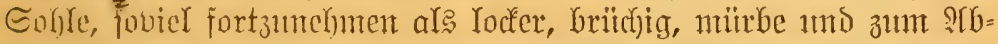

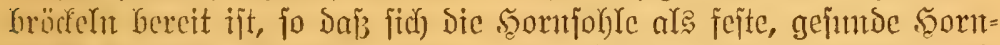

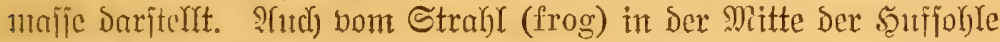
fint mu fajerige mo Grïdjige Teile 3n entfernen; Das Bejuneiden

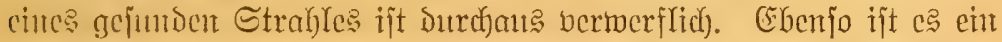

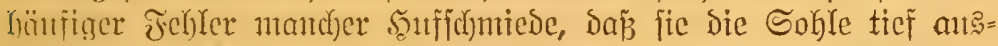

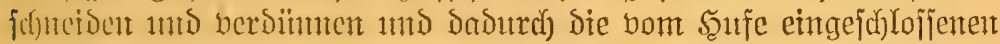

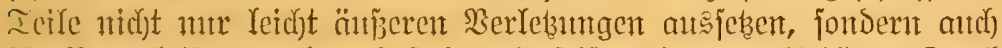

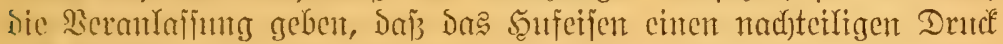

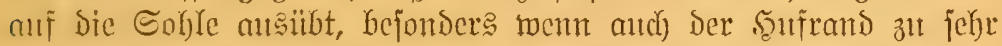
niesergefuntutten wirs. Nian halte Deshalf itreng Daranf, Dap̃ Der

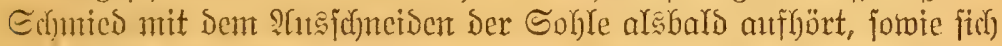
bie criten gejunden Şornfpänte zeigen, und man Yafje Den alten,

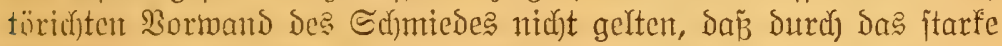

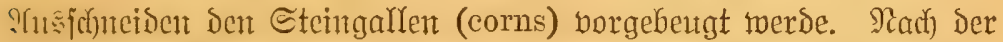

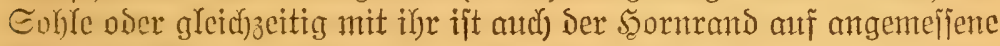

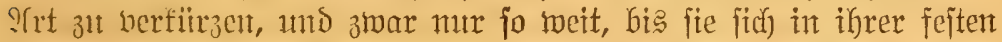

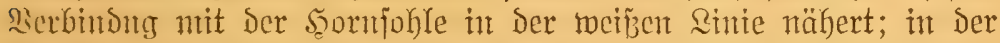
Piegel läßjt man dic äutjere Şornmand $1 / 16$ Boll über bie Sornjohle

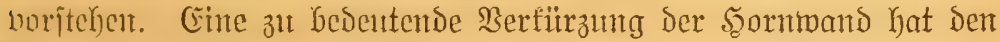

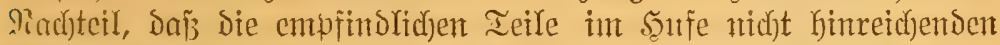
E(f)ub behalten; ferner füts bie Eijen auf folchem furzent Souframbe micht ficker gemig an befejtigen, wenigitens nidft, ofne bie Sohle zut

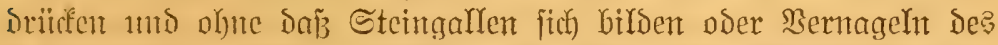

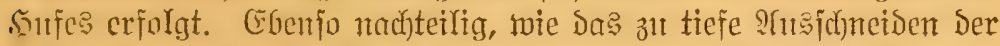
Eoljle ijt das des Etrahlyes; Dadurd wird Derjelbe nicht mur äunern 


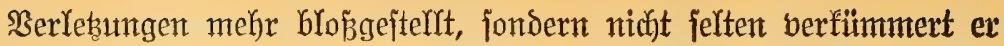

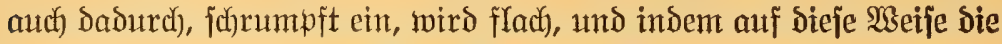
elajtija)e $\mathfrak{B}$ erbindung der $\mathfrak{B}$ allent beeinträdftigt wird, entite ht 3 wang=

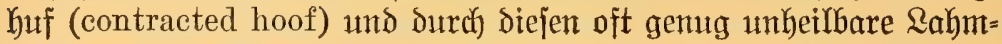
heit. Es darf bom Strable daher mur wie bei ber Sohle das zum

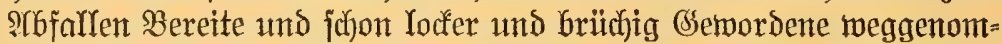
nten werden; ttmötig berffeinert Darf er dagegen nie werden, jondern ift möglicfjit boll зu erfaltent.

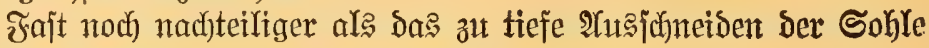

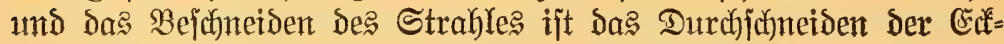
itreben (corners); e

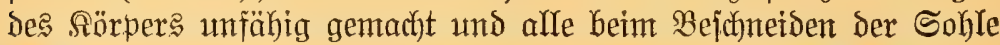
imd des Strahles angefüufhten Fehler werden dadurch vergröpert.

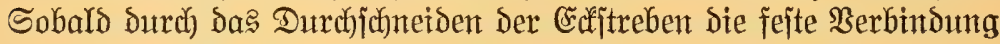

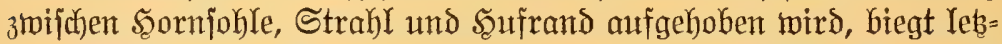

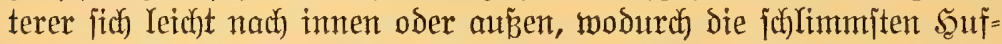
übel entiteben fömnen. Sebr häufig hört man bie Meimung ber=

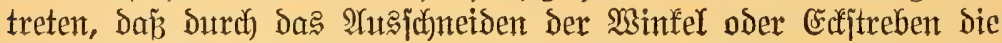
5઼ufe erweitert, 3manghufen und Steingalfen borgebeugt oder abge= holfen werde, umb bod ift da? Durdfichneiden, bejontoers bei einwir= fender Irodfenheit, bie vorzüglidjite §uelle der genannten Heber.

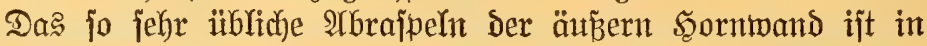

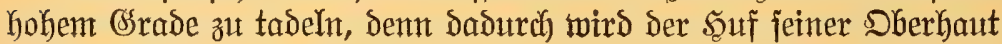

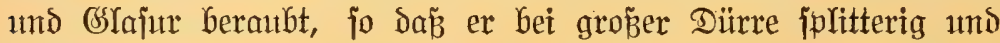

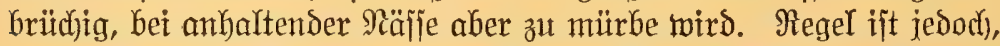

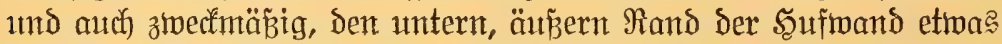
abzurafpeln, Damit berjelbe beim Ireten auf Garte Gsegentände mididt abjplittert.

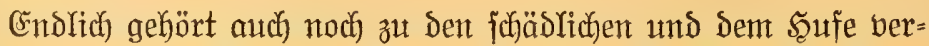

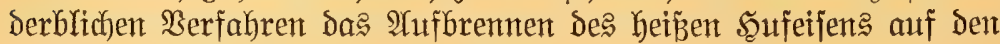

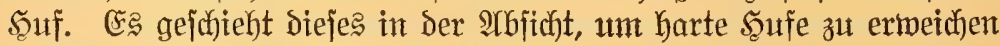

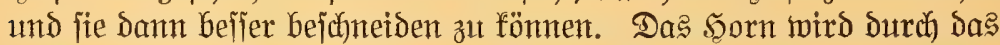

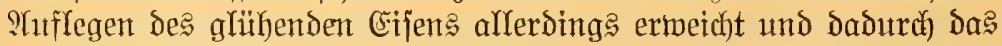

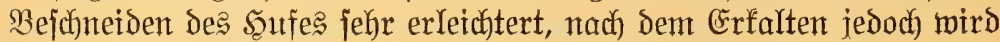

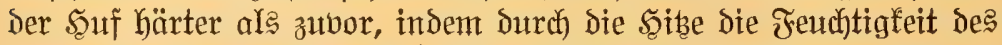
Şornes berloren geft, wodurd) bie Claftizität besfelben verringert wird.

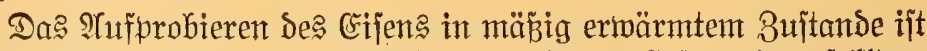
bagegen jtatthaft, Damit, mo fich fleine Febler am Eijen zeigen jollten, bieje fofort abgeäntort werden fömment, und weil jiti) Dabutrch am Ëijen

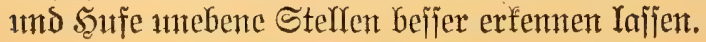




\section{0. 筑aypifer.}

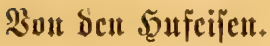

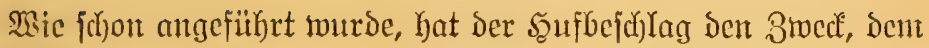

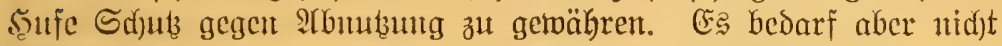

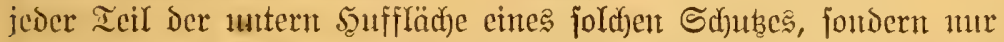
serientige, Der ant nteiften abgemubt wird, und das ift der Tragrant

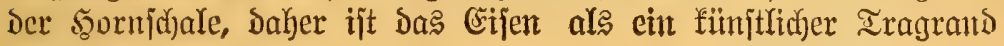
引ेt betradjten.

Da Borber $=$ tmo Seinterbuf einen verfifjeden geformten Irag=

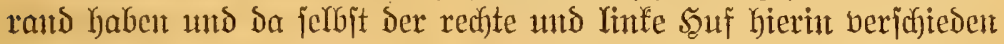

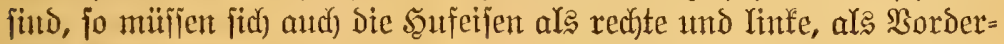
ober Şintereifent Deutlid) bon einander unteridjeiden Ialjen. (Siebe ?trbildungen.)

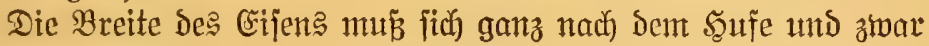

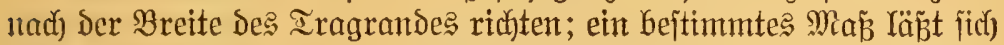

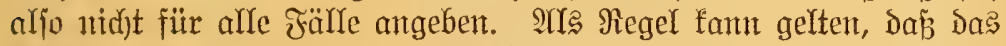

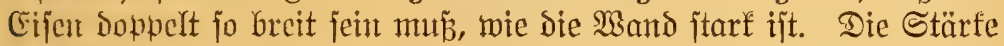
Der : Stollen= oder srififfende.

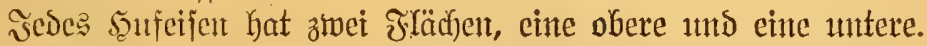

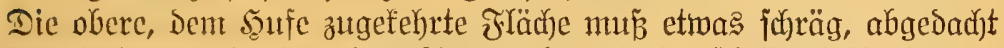

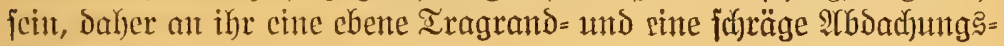

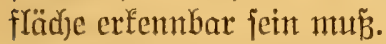

Die Tragrandfläd)e, ๖. h. Derienige Teil Des Eifjens, weldjer mit

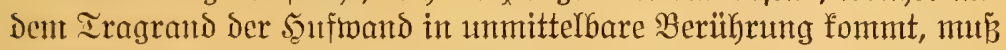

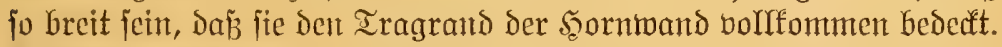

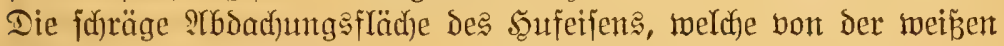

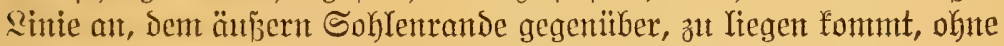

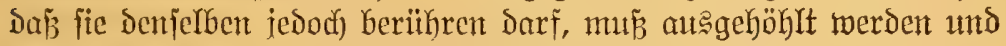
Deutlidi) vout Der Tragrandflädje abgegrenzt jein.

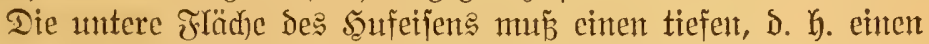
mentigiten Drei $\mathfrak{B i e r t e l t e i l ~ D e r ~ E i j e n j t a ̈ r f e ~ D u r d j o r i n g e n d e n t ~ u n d ~ m o ̈ g = ~}$ Yidfit weiten, bon einem Ente zumt andern Ende Iaufendent (Finjunitt ober Far $\mathfrak{z}_{3}$ Kaben, in melchem die Rageflöcher angebracht merben. Ein

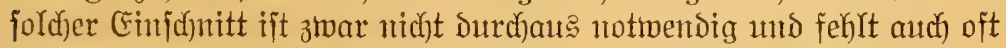

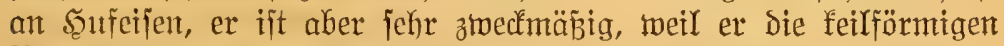

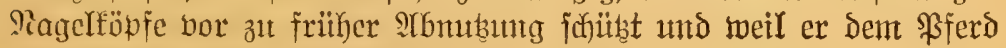
Sidjerfeit anf juflitpfrigent 


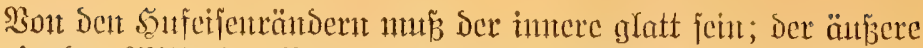

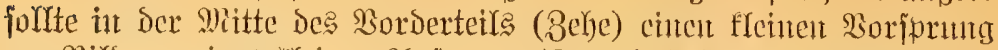

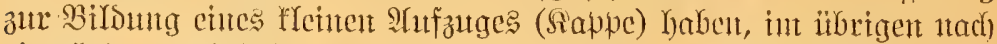

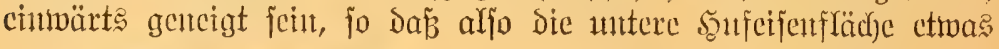

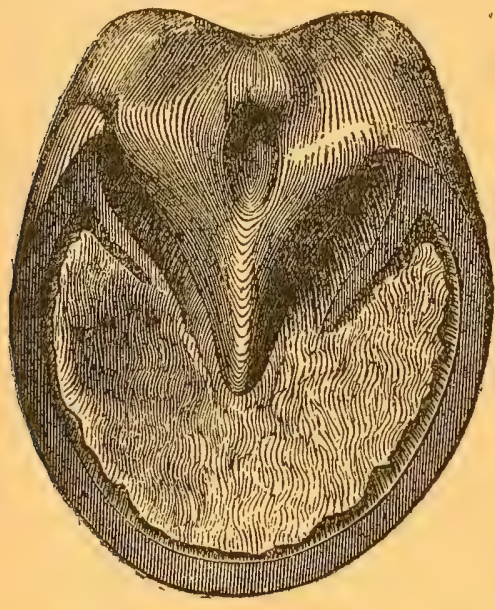

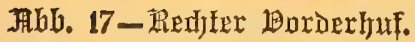

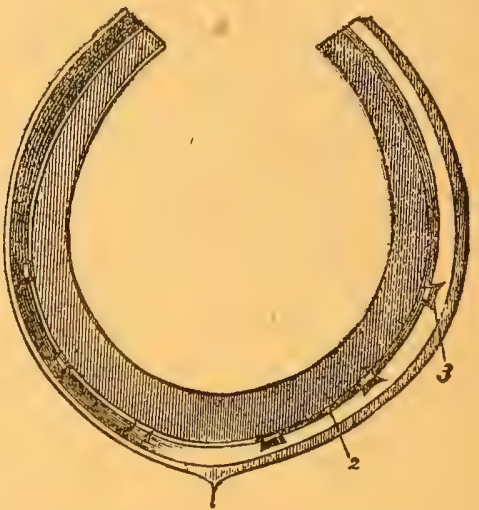

Jabb. 18- Redfles Dordereiten von unfen geleljen.

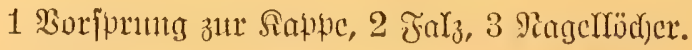

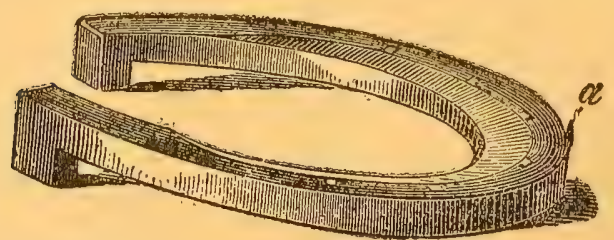

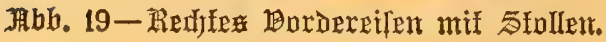
a Sappe.

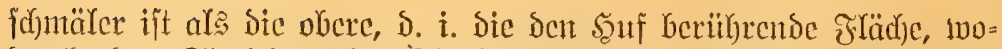
Dutrd) Da: Streichen (catching) und fonitige Berlebungen ver= Gïtet meroen.

Die Storlen, die won manthen als zum Sytfeijen notwendig

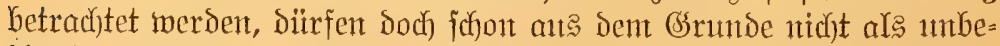

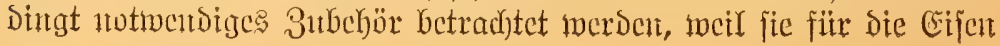




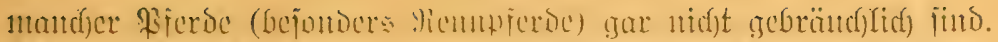

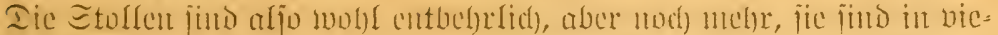

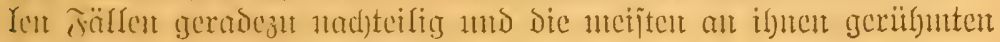
3orteile lafien fidy leidyt wiserlegent.

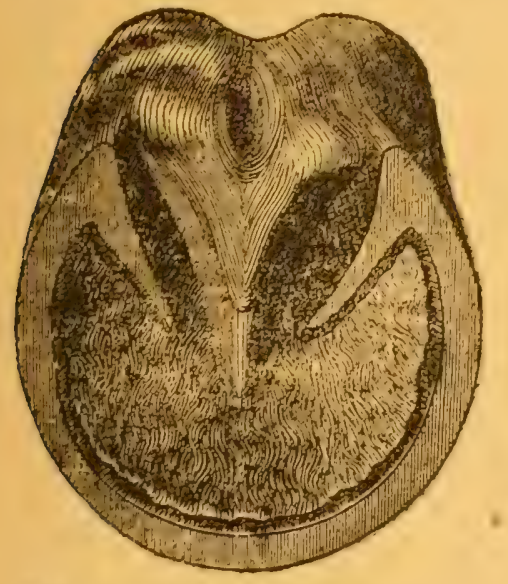

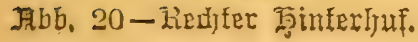

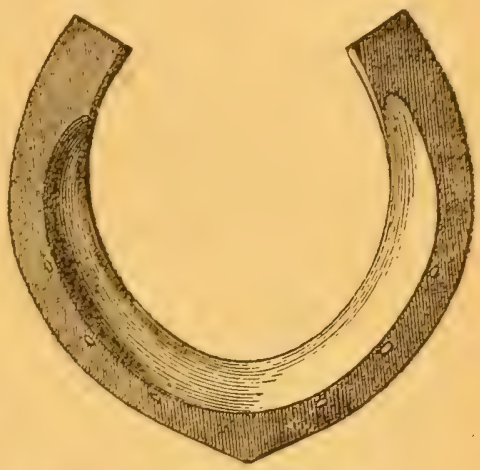

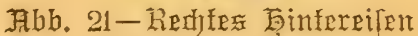
von oben gelelter.

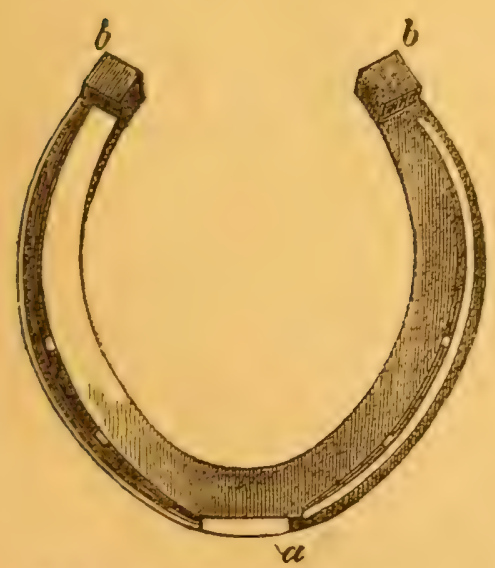

Flb. 22- hipdyfes Dinfereiren. a Grift, is Etollen.

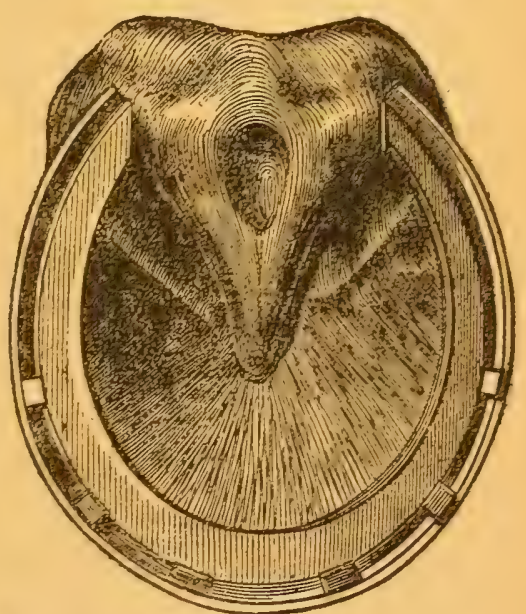

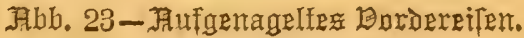


Bei \$FFerden, die Eijen ofne Stollen tragen, ijt Stellung uns

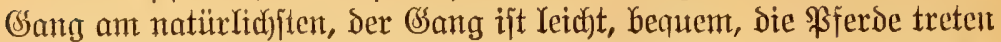
regelmäp̈ig, misen alfo die cijen an gleichmäßjigiten und wenigiten ab. Das Gsegenteil vont alledem findet bei Şufeijen mit Stollen ftatt.

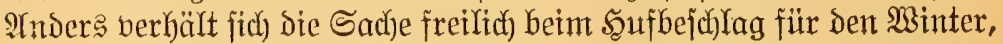
Gei diejem werden Stollen meijtens nicht zu entbefren jein.

$\mathfrak{W}_{\text {s }}$ die Stollen jelbjt betrifft, fo mülien diejelben, wenn fie

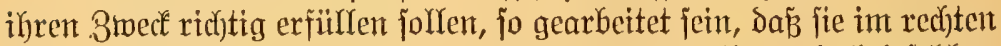

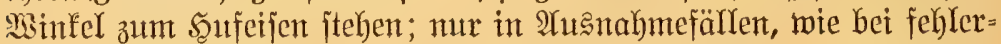
hafter Stellung des Sufes, oürfen die Stollen judxäg, o. h. im jpiben Minfel zum Sufeifen itehen. Die Stollen milifen ferner vierfantig fein, fpibs zulaufen und höchjten $1 / 230$ fll hoch jein.

Den an der Borderfite, dem Behenteile des Şufeijens, ange=

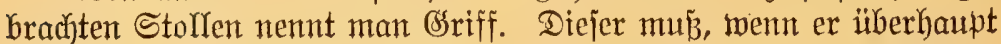
notmendig ift, mit dem Stollen greidje Şöhe haben. Fïr den Winter= bejula lag eignen fich am beiten forgfältig gearbeitete Sdyraubjtollen, die je nach Dem erforderntis als jicharfe ober jtumpfe Stollen zur $\mathfrak{A}$ n= mendung fommen.

Cine Crifindung, bie bejonders in Stäbten vielfach benubt wird,

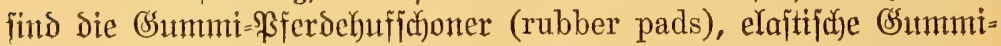

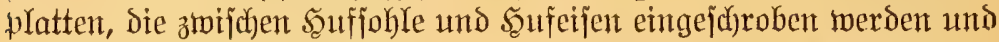

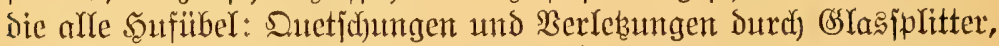

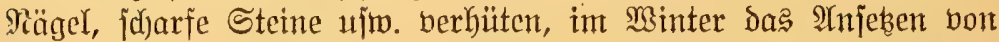
Sdyncebarren 1mmöglid) und das Sdjärfen der Şufeifent bei \&latteis umnötig madłen jollen.

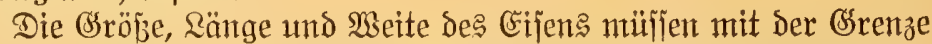

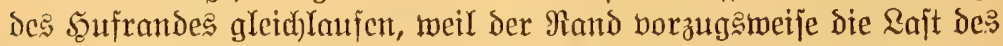
Siorpers und Den बsegendrtad des Eijens und Boden zu tragen hat.

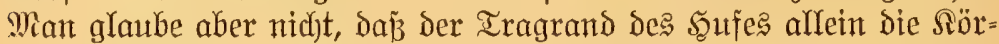
werlait zu tragen bejtimmt ijt, jeder Ieil Des Şufes trägt das Scintge

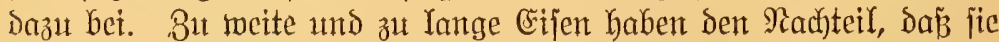
ficf) Yeid)t abtragen ober losreiben; fernter mad)en fie den (Sang Des

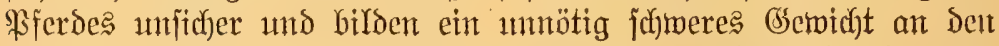
Jitizen des \$fferdes. 3u enge und zu furze Safeifen haben Dagegen

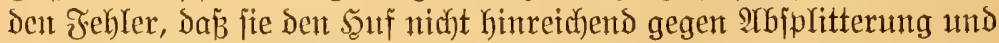

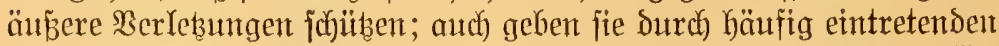
Drut auf bie Sohle nidjt jelten Beranlajiung zu Rahmbeiten. Gse= wöbnlich merden bei zu fleinen Eifen die überjtehenden Soufränder weggejdyitten oser abgerajpelt, wodurch jedoch ber Šuf nidjt nur

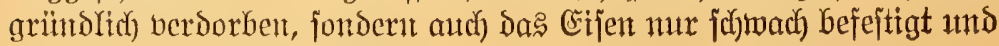
ber Suf Yeicht vernagelt wiro. 


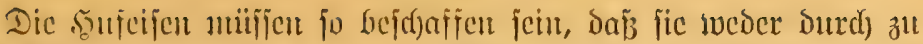

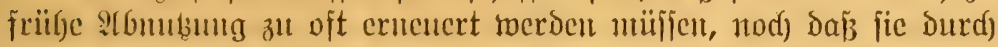

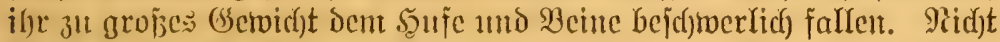

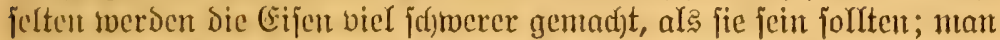
glaubt, das Eifen fömte dam lünger getragen werden, aljo es werde (Beld gefwart. Die Erjparnis gejdieht auf Rojten bes \$ferdes; der bang des Tieres wird nicht uur dadurd) erjoftoert und crmübend ge=

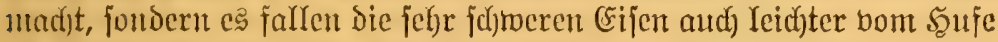
ab, insen bie Rägel bie Eijen nidgt fejthalten fönnen. Mithin ver=

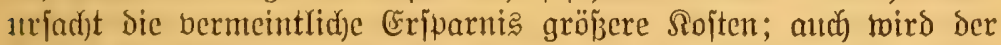

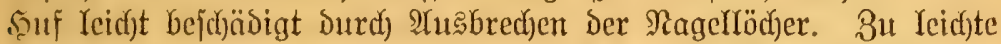

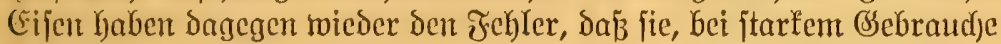

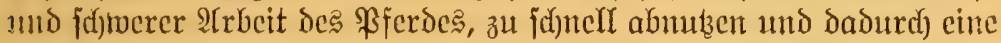

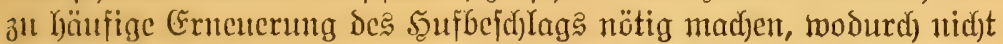

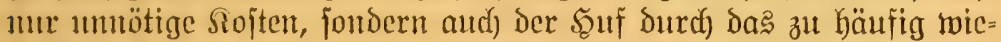

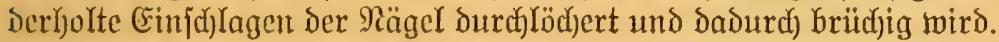

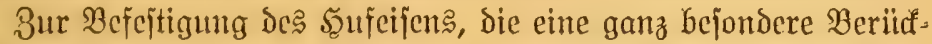

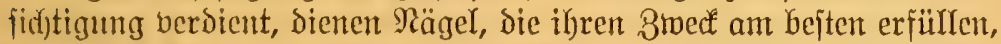

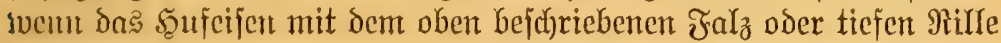
weriehen ijt, and wenn bie Ragellödjer gehörig barin berjenft find.

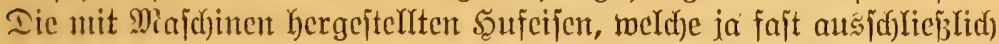
Gier vermentet merden, haben bielfach eine zu flact)e Rille; bie herbor:

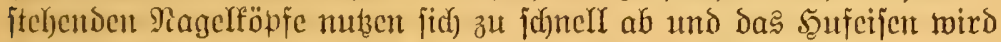

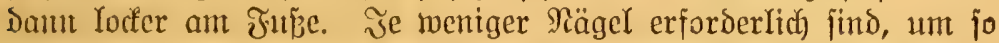

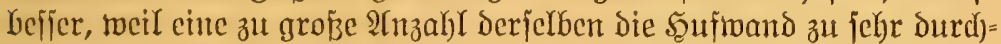

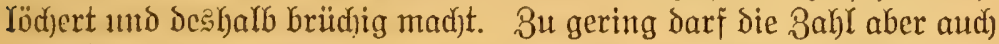

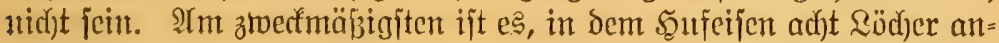
3ulningen, aber mur ficben Nägel einzufd)lagen, bier auf ber äuß̄ern 1utD Drei anf Der innern Scite; für fleme Satfe gentügt ein Eifen mit

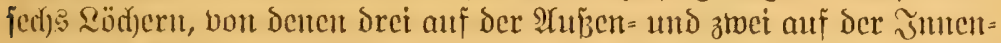

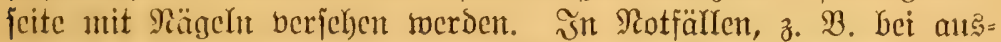

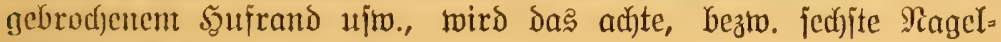
Iod) benutbt.

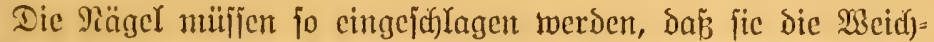
ftelfen Mid)t verlelsen, Die Szorntwand nid)t zerjplittern und die Elajti=

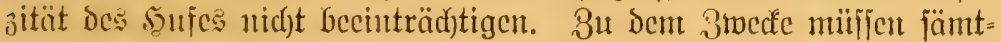

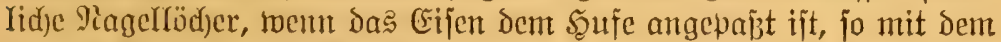

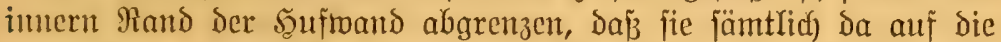
weibe Sinie zu jtehen fommen, too Dicjelbe an oen Tragrano ber Scorn=

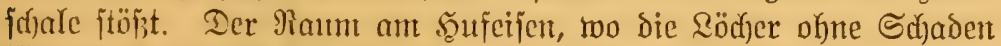
fiit bie Elaftizität bes sufes angebrad)t twerden fönnen und ange= 


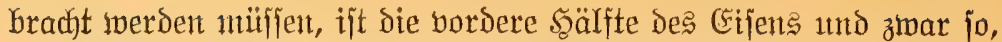

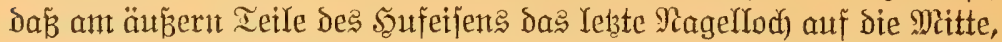
am innern Teile aber $1 / 2.30$ ll vor ber Mitte in eine Rinie zu liegent

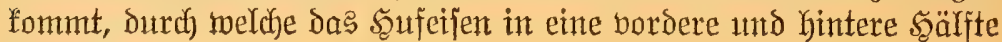
geteilt wird.

Ein jehr wichtiges Erfordernis fïr einent gutent Soufbejulag find endrich noch die Sufnägel jelbjt. Sie müljen nidyt mur vom bejten, biegjamiten Eijen angefertigt jein, fondern autch bie gehörige Form

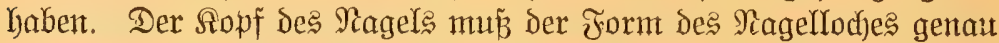
entjprectjen. Der Ragel mú ïberall eben, gerade und glatt jein, und barf nirgends Splitter oder Brüche zeigen. II jeiter Spibe erbält ber Magel eine jujiefe Prbfladung. Die Spibe darf weder zu furz, 1tod) zu lang fein; i ît fie zu lang, jo fommt fie entweder gar nidjt oder

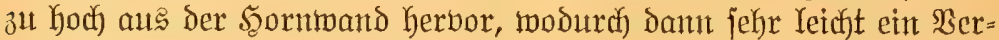

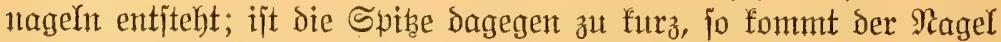
zu niedrig an der 5̧ornmand heraus und fant alsdann bas Şufeifen natürlich nidgt Ginreidyend befejtigen. Die Dem Şufe zugefehrte oder

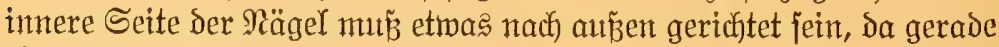

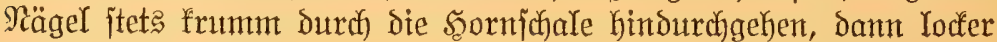

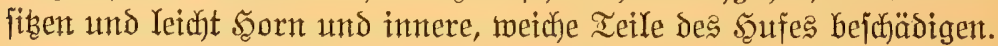

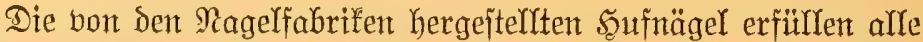
Snforderungen aufs bejte und find den bandgentadten unbedingt vor孔孔 ieken. 


\section{Kaypifel.}

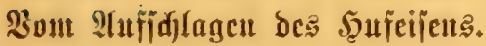

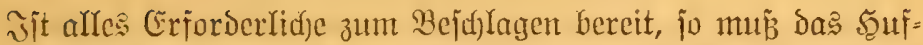

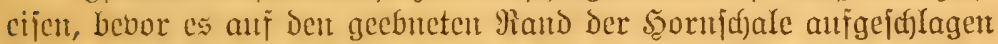
wird, 3twor genau geridjtet werden. 3u Dem 3toefte twird das Eifen

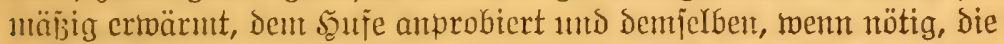
rid)tige Form gegeben. Inter humbert vorrätigen (Fijen wiro fich felten aud) mur cin cinziges finden, weldjes genau zu ber Form bes

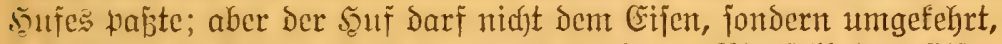

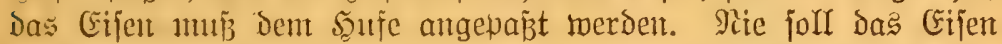
glühent auf die હohle gelegt toeroen, weld)es bei geböriger Fertigfeit nuld llebung in Bejulage audf Ieid)t vermieden werben fann. Bei Dent Ŝn

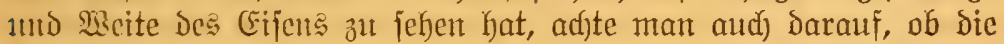
liagellöd)er bie rid)tige Bejdaffenheit bejiben, unto ob es nidjt not=

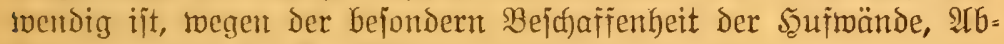
änderungen ant Den Piagellödjern borzunehmen.

Sit alles in gehöriger Dronung, fo werden bie Eifen an beut Shufen befeitigt, wobei folgendes zu beadten ift: man bringt bas Eifen

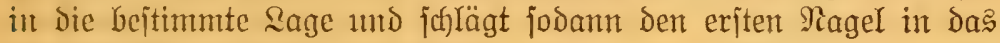
mittlere Magellod) Der innern 厄eite, Darauf eimen Mittelnagel an ber

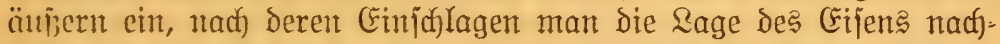

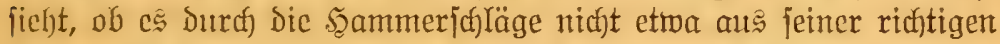
Zage verjubben ijt. Sind bie Berjujiebungen des Eifents mur gering, jo twird cs durd) jeitlidje Şammerjuläge wieder in jeine bejtimmte

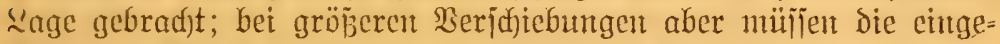

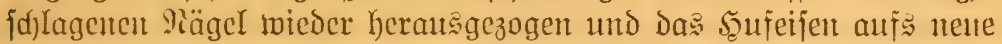

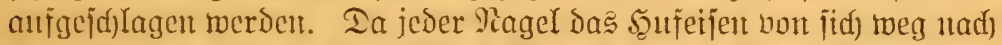

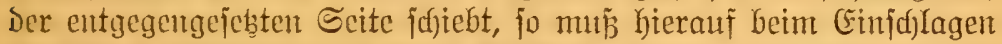
Der Rägel, bcjonders des erjten, Rïidfidjt genommen werden, und da man Das Eijen am alferwentgiten an ber J̈nnenfeite über Den innern Piand - wegen ミtreidjen und Sostreten - voriteben Iajien Dari, jo ijt es pafiend, die inmern Nägel zuerit einzujd)lagen, umb dann werfjeltweife die äupern. Jeber Ragel wird in Der weipen Rinie angejest umb jolange zroijajen ben Jingern jeitgehalten, bis man jid bon jeinem ridftigen Sang überzengt hat, wobei jowohl das Sefühl

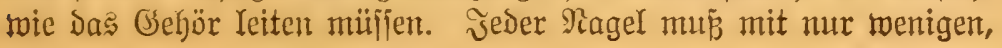




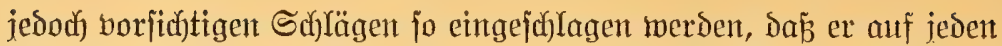
S(f)lag etwa $1 / 4$ Boll vortwärts bringt. Rägel, meld)e it einter Itefe bon ungefähr 3/4 3oll ntod) meidf) gehen, fict) jeb̧en oder fonit sem \$ferde Sd)merz berurjadjen, müijen fofort herausgezogen werden.

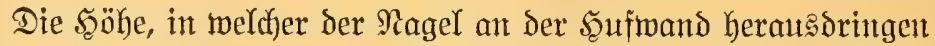

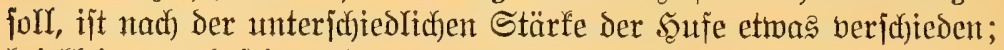
bei fleinten und feinen Şufen fann fie $11 / 4$ 3oll, bei gröperen $\mathfrak{y} u f e n$

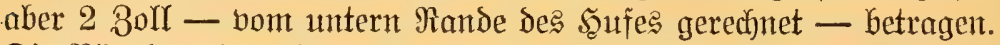
Die Rägel an dem Behenente fönnen wegen der Didfe des şufteiles

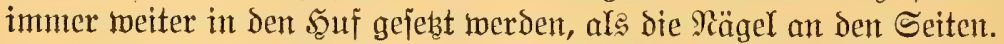
Die burd) die Syornwand Kerausgetriebene Spibe des Ragels wird fogleid) nad) abwärts gebogen, um fowohl den S(t)mied als aud bas

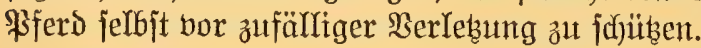

Sind alle Rägel gehörig eingejoblagen, fo jollten biejelben mitteljt untergejebter 3ange feit angezogen werden, Damit alle Ragel= föpfe tief in bie Berjentung einoringen, und bamit burd) $\mathfrak{A b z}$ twident

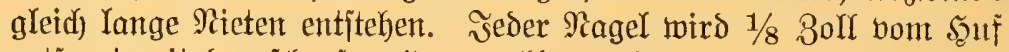
entfernt mit ber jafarfen Şammerflante abgeoreht, fodann mit ber

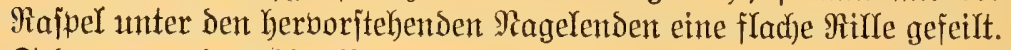
Sodann werden die Magelenden mitteljt untergejestem Rieteijen Durch) ein paar fräftige Şammerjud)läge auf bie Ragclenden abwärto

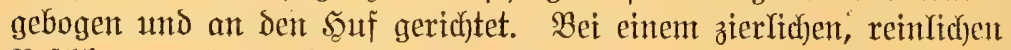

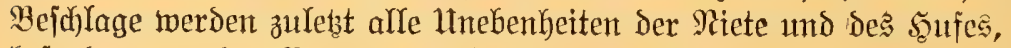
bejonders un den Rand des Eijens Durfh die Rajpel tweggenommen,

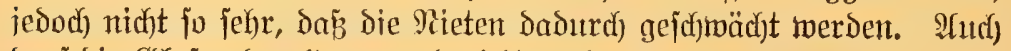
barf Die. (Slajur der 5ornmand nicfst berlekt werden. 


\section{2. 集apitel.}

\section{Sranffyeiten ber Berbantmugernane.}

Bei ciner Bejpreshung bicjer Sranfheiten uns Dent Sintweifen,

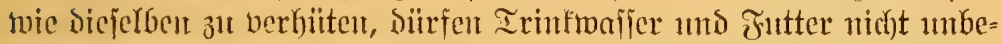

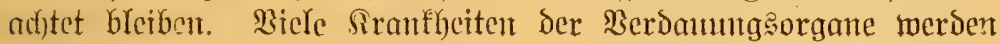

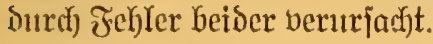

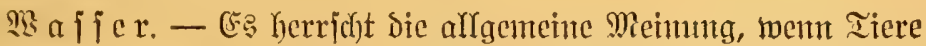
פisajier antebmen, fo jei bas ein Beid)en, Dasjelbe jei eintwandfrei.

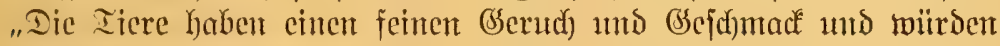

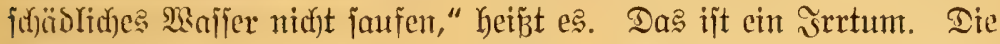

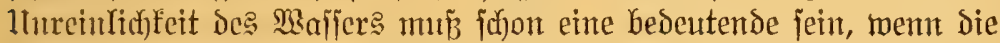

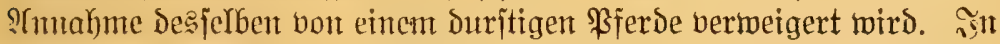

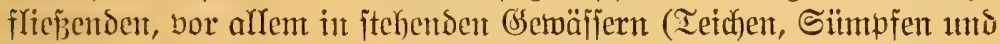
Seen) finden fids itets berfaulte PfIanzemitoffe in geringer oder

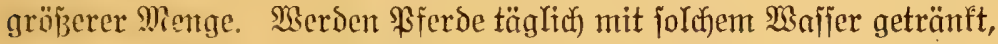

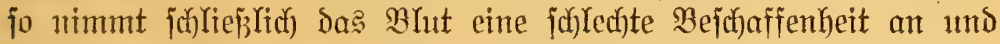

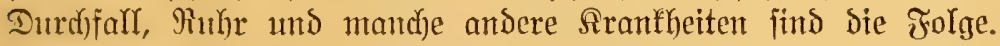

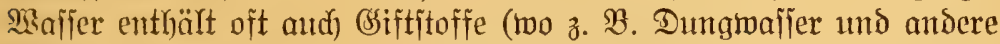
Etoffe in umbidste Brumnen gejdymemmt werden), wodurd) ein iffineller Tod herbeigeführt werden fann.

Beantworten wir zuerit Die Frage: Bieviel \$aljer foll ein \$ferd

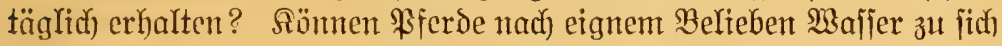

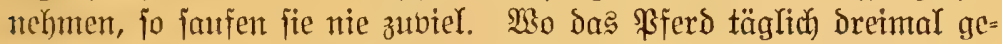
tränft twird, find ungefähr 8 (Gallonen pro Iag erforberlid), Dą

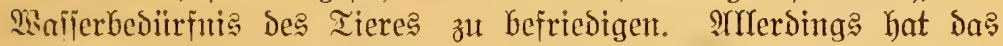

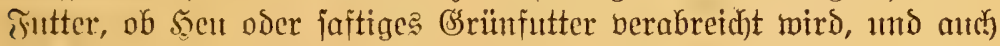

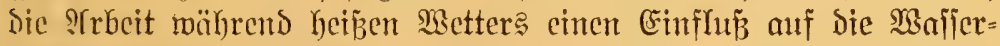

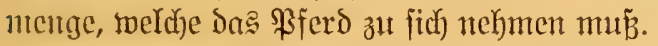

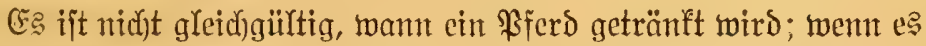
midut abreitet, geniigt Dreimaltges Iränfen twährent eines Iages; bei

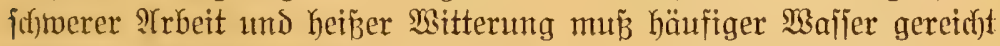
werbert. STrs allgemeine Regel gelte: Bib mur fleine Miengen, aber

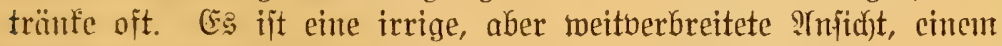
crhibten \$ferde bürfe fein

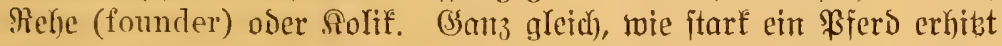

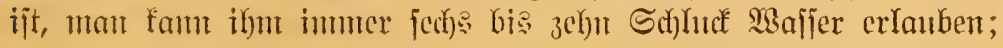


fommt bas Iier gleich in ben Stall, jo gebe man fofort ein ober zmet

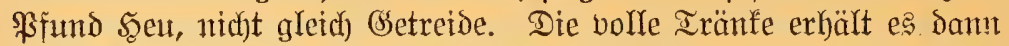
eine Stunde nad) dem Fïttern. SBird ein duritiges \$ferd, ohne ge= tränft zu werden, an bie Srippe gebrad)t, jo fehlt oft bie Jreß̉hit oder es füuft fpöter mur wenig Mafjer. Die Sefahr liegt bei erfibten

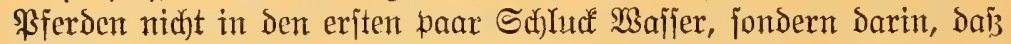
ifm erlaubt wird, zu biel Majjer in jolrfem 3ujtande aufjumebmen.

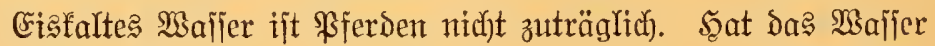
an jebr falten $\mathfrak{B i n t e r t a g e n ~ l a n g e ~ i m ~ I r o g e ~ g e i t a n d e n ~ u n d ~ i f t ~ m i t ~}$ bededt, fo genügt es nicht, bie Eisdecte zu zerjulagen, fondern fie müijen mit Keißzem $\mathfrak{3 a j j e r ~ a u f g e t a u t ~ m e r b e n . ~ D i e ~ I r o ̈ g e ~ j o l l t e n ~ f o ~}$ jtehen, Daß̃ fie bon der Sonne im Winter bejujienen merden.

Die Reinheit bes Tränfmaffers ijt bon erjter Wichtigfeit. Da: Wafjer aus bidjten, tiejen Brumnen, aus Duellen und junell fließ̈en= Den $\mathfrak{B a ̈ b j e n ~ f a n n ~ i m ~ a l l g e m e i n e n ~ a l s ~ g e n u ̈ g e n d ~ r e i n ~ b e t r a c h t e t ~}$ werden; bagegen liejern flache, undichte Brumnen, ftehende und lang=

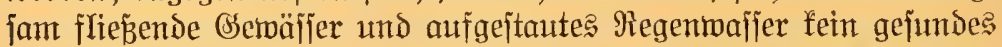

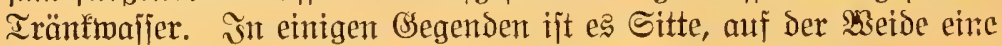

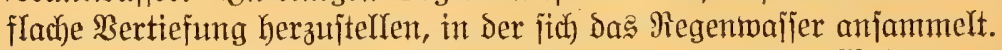
Der Untergrumb bejteht aus Ton oder Refm und läß̈t fein Wafjer ver= ficfern, fo jtebt da: $\mathfrak{B a f f e r}$ in foldher Bertiefung wie in eimer Schale und fann nur surch Berdunjtung vermindert werden. Stürme und Regen bringen viełe \$fflanzenjtoffe in bas \$affer, wo fie verfaulen.

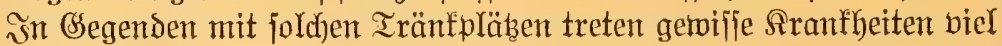
hänfiger auf als Dort, wo ßferde gejundes Iränfmalfer erhalten.

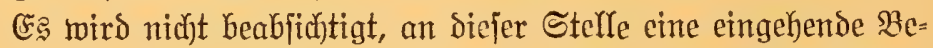
handlung über Futteritoffe und Füttern zu geben; das Ihema ijt zu ımfangreich und bejiben wir barüber ja aud jefr wertwolre Bïcher. Sanz unberïdfict)tigt bürfen beibe aber audf) nicft bleiben in einem

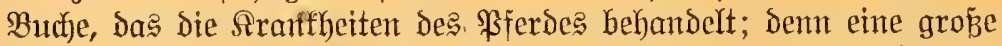
IInzahl Erfranfungen der Tiere find eine Folge verdorbener Futter= ftoffe oder fehlerhaften Fütterns. Für den \$fferdebejiber ift es aljo

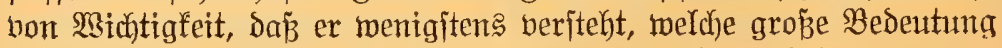
Futteritoffe und Füttern für Die SEejundheit der Iiere hat.

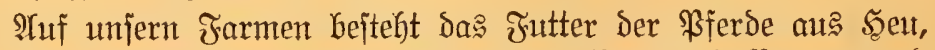
(Sras, Maisfutter, Murzelfrüdten, Şafer, Mais und Roggen und

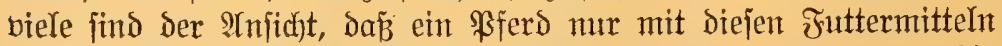
ernährt werden fömte. Sehen mì aber nach andern ¿ändern, too die

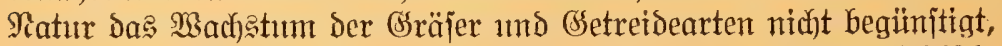

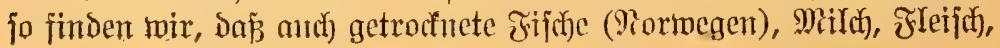




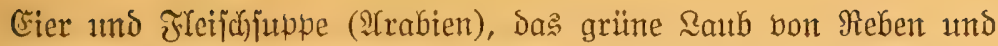

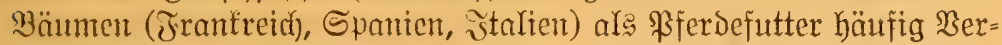
wenoung finden.

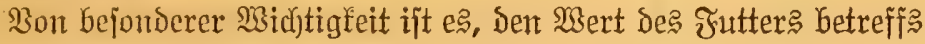

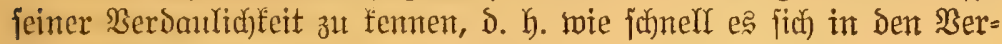

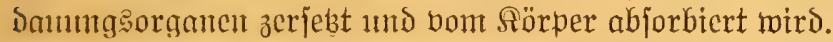

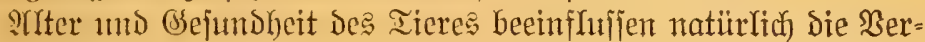

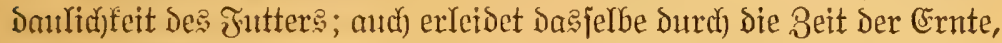
Durd) S(uffemahrung umb Durd) Gefoudere Bubereitung einen höheren ober geringerent (orrad Der Berdantichfeit, und müffen bieje \$unfte bei

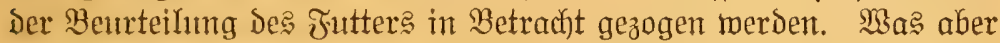
and) gefiuttert twirs, jedes Futtermittel mur rein und fehłerfrei feir. Die Jintterzeiten milffent gentan eingehalten merben; bet unreger=

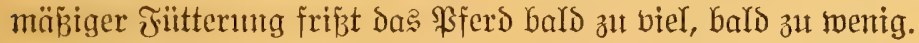

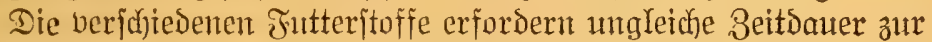
Serdaunng. Şelt und Stroh gehen fanneller Durd) Dent Magent ale

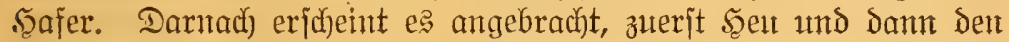

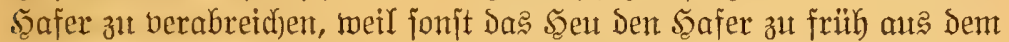

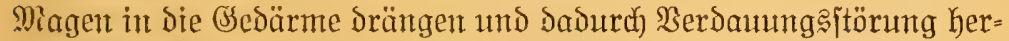

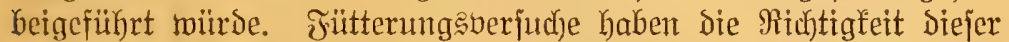
Sinfidst bemiejent. Es gibt nod) einent antoent midytigent (Srumb, warum seu zuerft gereidyt merden forlte, bejonders ment das \$ferd fehr.

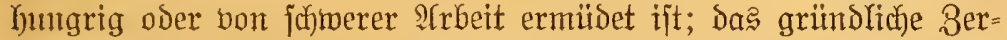

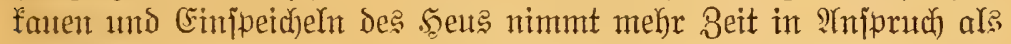

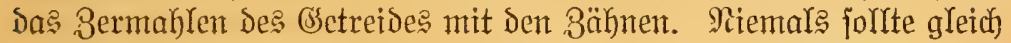

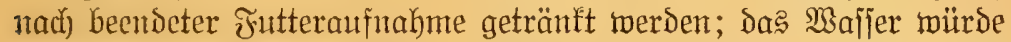

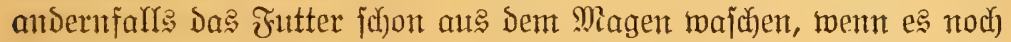
nidjt geniigend fïr Die SerDaung int Den Eingemeiden vorbereitet ijt.

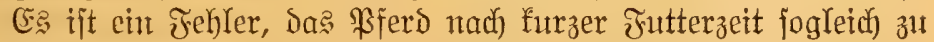

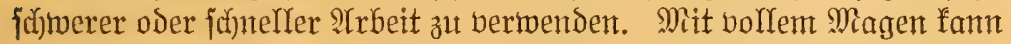

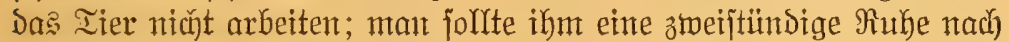

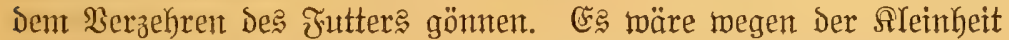
Des Miagens Dem \$feroe biel zuträglidjer, wem itatt Dreimal, vier= oder fünfmal töglidu gefüttert und jedesmal mur eine fleine Futter= menge gegeben wiübe. Der fleine Miagen Des Iieres und die groß̉e

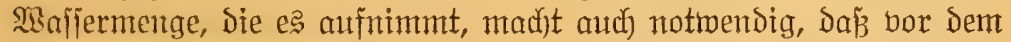

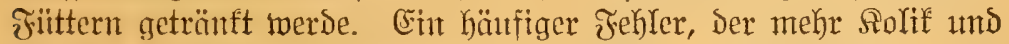

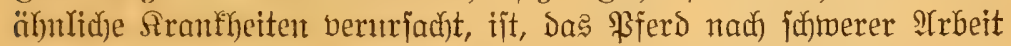

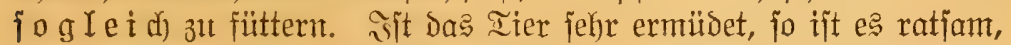
irnt vor Dem Jüttert ein \$int reidyung des Fntters aber mindeftens eine Stminde zu warten. Ein 


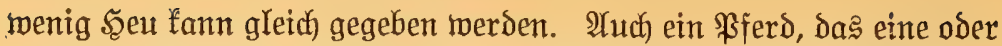
mehrere Jutterzeiten überjoflagen mußte, jollte in gleicher $\mathfrak{B e i j e ~ b e = ~}$ handelt werden. In Iebterem Falle follte aud nicht gleich bie volle Ration verabreicht twerden; das gierige Freijen hat Dann febr leidjt Solit im Ssefolge.

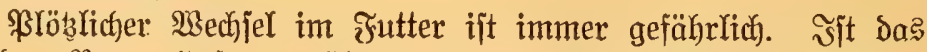

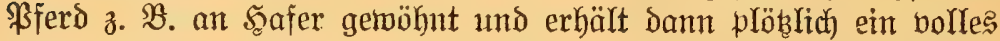
Futter Mais, jo fühlt es jich untohl. Soll mehr und fräftigeres Jutter gegeben werden, jo jollte das allmählidf geichehen. Die Jutter= menge jolfte immer im cinflang mit der $\mathfrak{A r b e i t}$ itehen, melkyes das

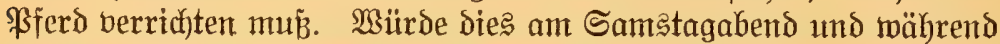
bes Somntags beobauthtet, fo wïrben die franfen $\mathfrak{B f e r d e}$ am Montag= morgen jeltener jein.

Fehlerhafte Jutteritoffe, bejonders foldie, die mit Sifimmel behaftet find, follten nie berabreicht merden. Dämpfigfeit (heaves) und Rungentrantheiten find fait immer auf verdorbenes Jutter 孔urüd

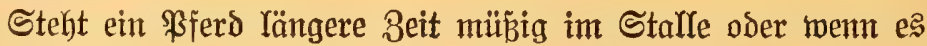

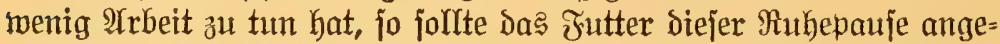

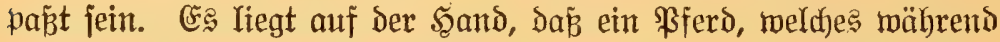
mehrerer Wocten ober gar Monate menig oder gar feine $\mathfrak{A r b e i t}$ zu verridjten hat, nicht dasjelbe jabmere Futter bedarf, wie ein fiftwer= arbeitendes Iier; der fiorper des erjteren hat feine Bermendung fïr

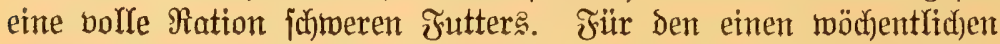

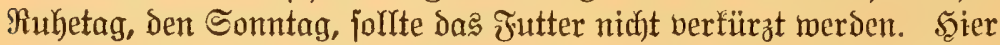
wird aber häufig ein anderer Fehler gemacht; man will den Tieren etwas zugute tum und läßst fie im Sommer während des Sonntaģ

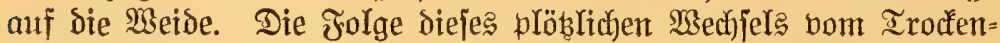

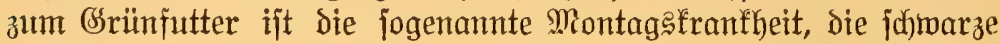
Şarmwinde (Azoturia), von ber die \$rerde plöblich) Gefallen werden und die fajt immer mit dem Iode endet. Ein $\Re$ ferd, weldhes

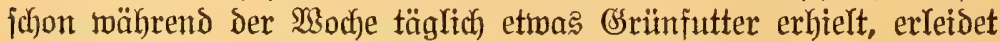
feine Shäbigung bon dem Meidegang am Sonntag.

Den allgemeinen Bemerfungen über Jüttern ufw. mögen einige Morte über die berjdiedenen $\mathfrak{J}$ ut $\mathrm{t}$ e $\mathrm{x}$ it o f f e folgen.

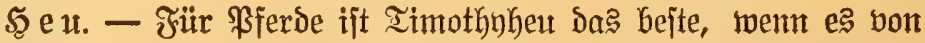
grünlicher Farbe, rein und frifo ijt und einen angenebmen Seugeruth hat. Sfit bas Şeu jefr alt, jo hat es viel won jeinem :Bert verloren;

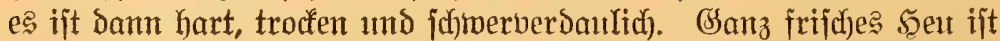
ebenfarrs jafwer zu berbanten uno berurjacht oft jtarfen Speichelflutis, 


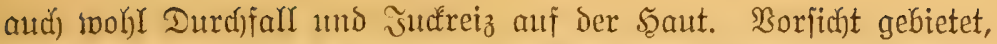

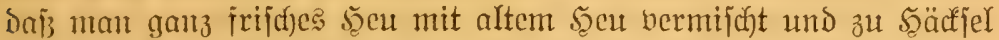

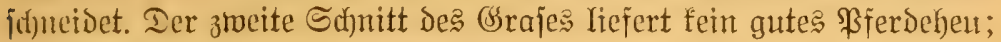

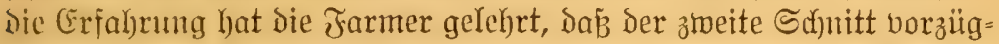
Iiches Siubgeu ift. Der Nährwert einer Seujorte iit nidyt immer der= felbe, er hängt von der Beit, waum Das Sras gemäht tourde, von Dem

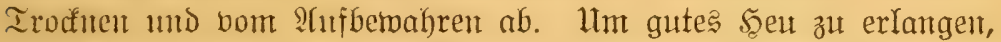

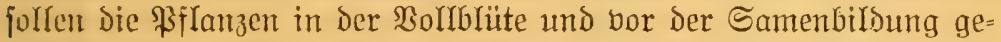
mäht merDen. Mit ber Samenbildung merben die Braßhalme holzig und Die Blätter verlieren an Mährwert. Der Şauptpunft bei Der

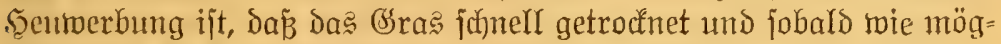

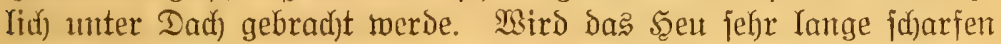
Sommenitrablen ausgejebt, fo berliert es an Farbe und (Gejumadf.

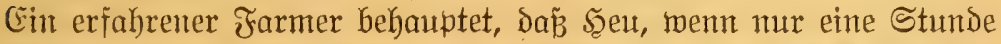
länger als nötig Der Sonne auggejebt wird, 15 bis 20 \$rozent an

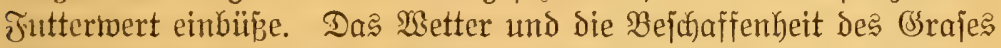

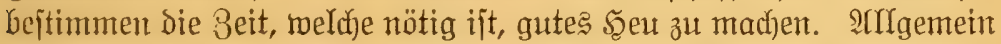

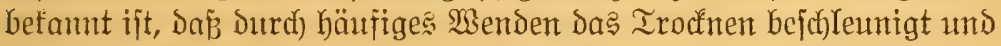

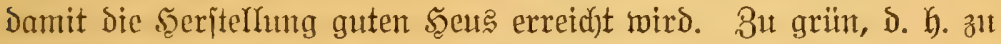

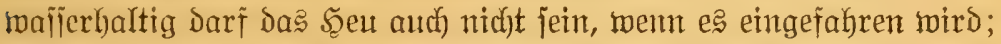
anternfalls würde es juimmelig twerden oder "berbrennen". Der=

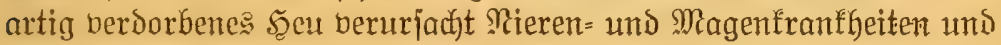
Die \$ferde werden mager dabei.

Erfält ein \$rerd volles Getreidefutter, fo fann es mit 10 bis 12

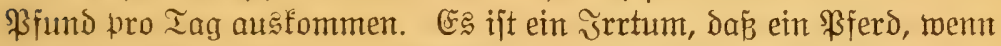
es mur leid)te Irbeit zut verrichten hat, an Seeu allein gemug habe unt feil (Setreibe gebrautd)e. Soldhe Tiere befommen jehr bald einen 5 eu= baud), fallen ab uns gedeihen nidyt. Bei Fohlen treten die üblen

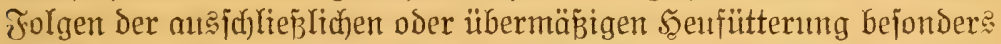
j(t)arf hervor; Die jungen Tiere bedürfen zum Ifufbau itres S̈̈rpers ciner täglichen Getreisezugabe, menn ein gejundes, fräftiges Irbeits: pferd daraus twerden joll.

Stroh. - Es mird hierzulande wentg Stroh an Itrbeitspferde berîittert, mur bie jungen, ein= bis breijährigen Tiere müijfen vielfach) fic) am Strohhaujen während des \$3inters ernähren; wird nicht reidd)= Yid) Siörnerfutter nebenher verabreicht, jo leidet die förperlidje (Ent=

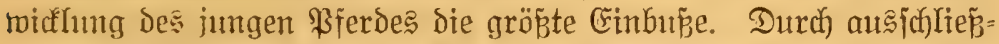
lidfe Strohfiitterung Der im Marfstum begriffenen Tiere treten in=

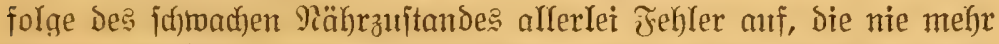
hejeitigt werden fömnen. Coll ๔troh an jumge ober alte Bferde ber= 


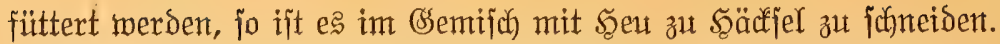
Roitfreie马 Saferitroh ift Das bejte Futteritroh, Damn folgt Weizenjtroh. Roggenitroh jollte mux als Einjtreu Bermendung finden. Son den Stroharten der Scïljenfrühyte ift Erbjenitroh dem Bohnenjtroh be= Deutend vorzuziehen.

凡aff o jorlten Den \$ferden nie gegeben werden; Die Gramten (beards) Diejer Getreidearten jeben fid nidyt jelten im Maule und ber Sehle feit und

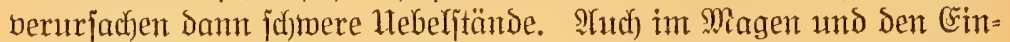
gemeiden jeben fid) bie (sramen mitunter fejt unb haben gefährlid) Entzündungen зux Folge.

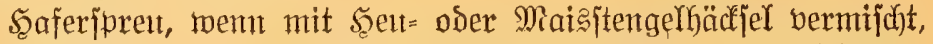
wixd bon \$fferden gern gefrefien; in grö̈erer Mafie barf es nidyt ver= abreidft werben, sa Dam gewöbnlid itarfer Durdffall - auth bei Sïken - erzeltgt miro.

(us etreide. - Safer verdient won arfen Gsetreidearten den

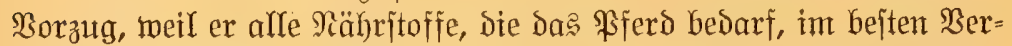
hältnis zuteinander enthält and weil er am leidhtejten berdaut wirs,

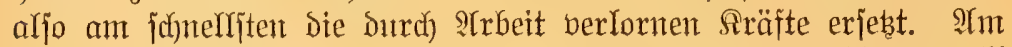
geeignetiten ijt Der Şafer, wemn ex ein sahr alt und die Aörner voll und furz, rein bon Stanb und jüb von (serud) find. Neuer Safer ijt

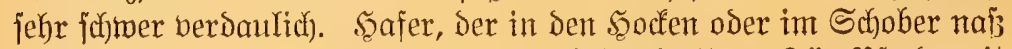
wurbe und anfing zu feimen, ift gefährliches Futter. Für ßfferde mit guten Bäbnen find Die ganzen Sïrner am zuträglicljiten; für alte

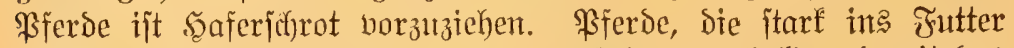
"Glajen", follten ilgr Futter in groß̉en Sriphen erbalten, Dantit Da? osetreide bünn ausgebreitet werden famm.

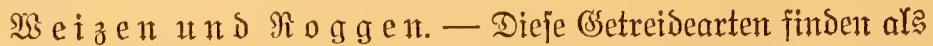
Pferdefutter felten ßerwendung, höchitens in fleinen Duantitäten and mit andern (Setreidearten bermifht. Merden fie allein und in

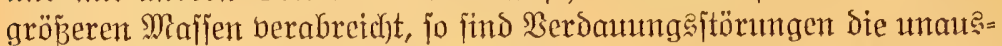

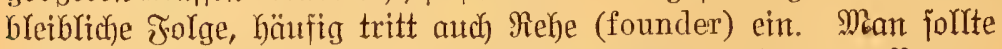

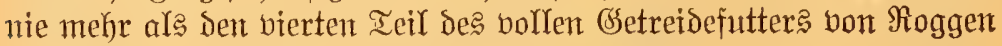
ober \$seizen nehmen umb fie mur gejuyroten geben.

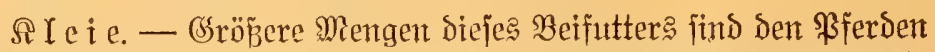

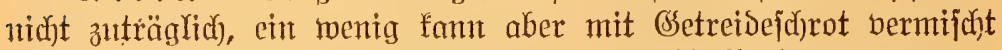
swerden. Sileienfutter in geringer Menge regt Die Berdanung an.

Mi a i s. - Fïr junge \$ferde ijt Mais allein fein zuträgliches

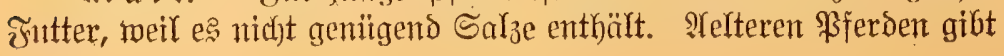




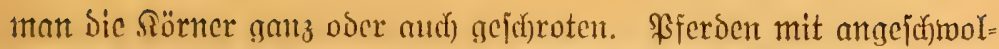
Yencm 3afufYeijad) (lampas) gibt man die ganzen Maisähren. Die

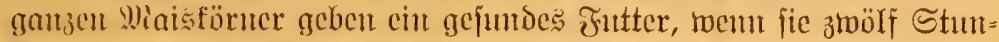
ben in reintent Wajajer, Dem in Der Sommerzeit cine fleine Szant boll

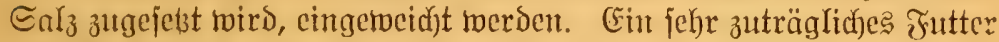

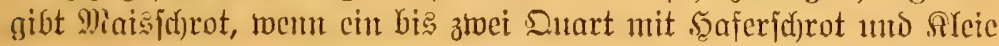

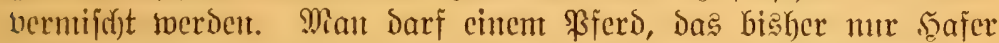

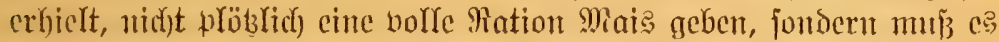

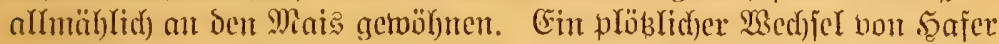

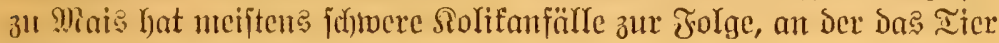
getwöhnlich) 3ugrunto geht.

F【a d)

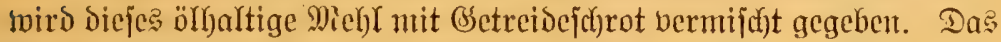

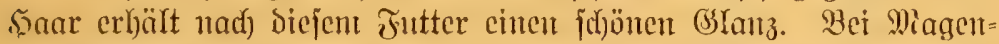

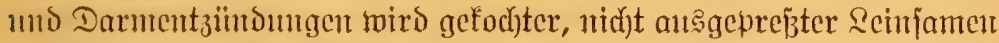
mit ßorteil alミ Iränfe gegeben.

SartoffeIn. - In Gegentsen, wo Der Sartoffelban im

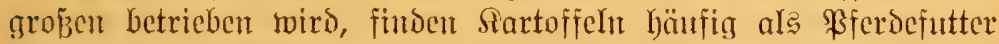

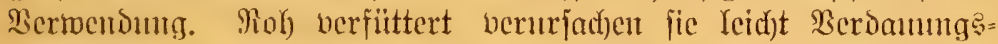
bef(d)werben, währeno fie gefod)t ober gedämpft unto in fleimen Men=

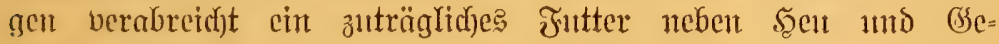
treise bilsen.

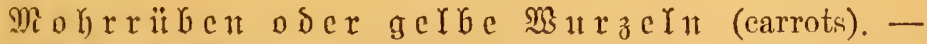
Dicje Wuntzelfrucht ift ancertamntermaßen cin ganz borzügYides

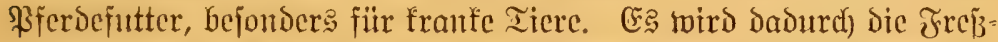
Init angeregt und Dic Tätigfeit des Miagens jebre gümitig beeinflü̧t.

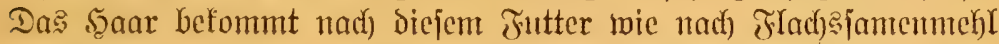

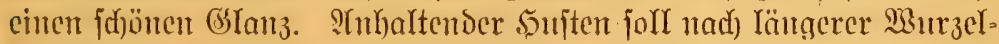

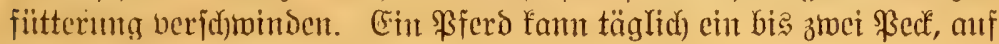
brei Mahlzeiten berteilt, erhalten.

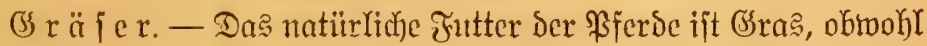

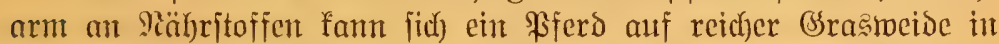

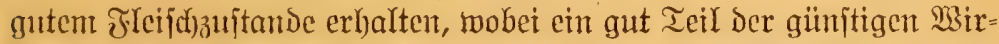

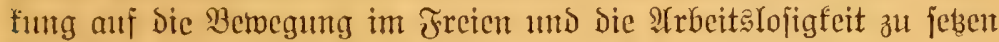

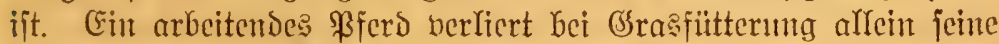

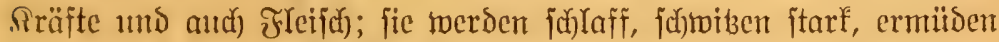

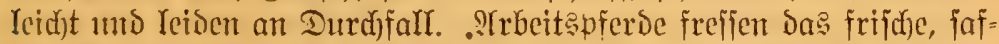

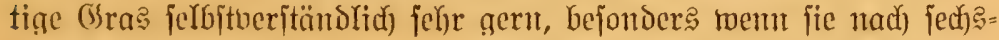

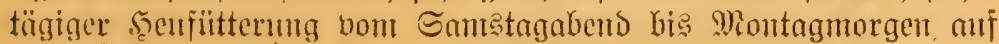


Die ßeide fommen. Cin Tierfreund glaubt hiermit jeinen \$fferdent

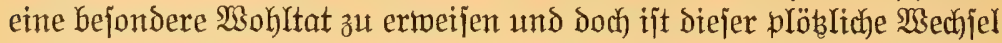

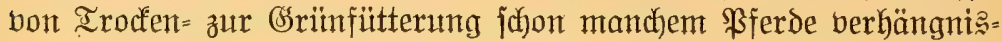
boll geworden; anjtatt ant Miontagmorgen frijc) und munter für bie

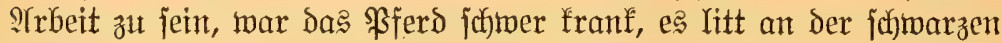

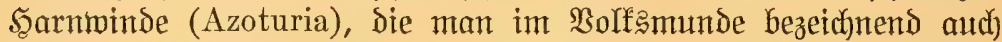
Montaggfranfheit nennt, ein Rierenleiden, Das Durch das jaftige Futter und 9 rrbeitsruke herbeigeführt wurde. Unbedingt mokytätig wirtt bas (śrasfutter, went es in geringer Majie neben Seu täglid) werabreidyt twird. Machben der Magen allmäblich an jaftiges (Sras= futter gemöhnt, follte jedem jufwerarbeitenden Iier jährlid) eine

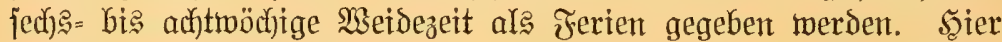

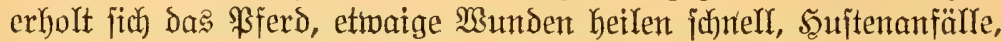

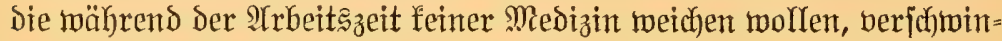
Den ganz und die Şufe - natürlidh ohne Scufeijen - eritarfen unt ieren zahlreidye 1tebel heilen aus. Eine geringe Osetreidegabe mui autcl während bicjer Rubezeit täglidf gegeben werden,

\section{Sranfrgeiten ber 马äfnte.}

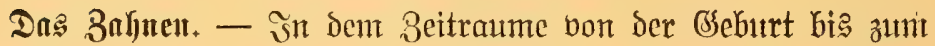
fünften Rebensiahre befommt bas Fohlen feine eriten Bähne umb werbjelt fie bann für bie Danterzähne. İm brittent Jahre find dic eritent ober Milldyzäfhne erit bollitändig entwickelt; bald daraulf beginnt

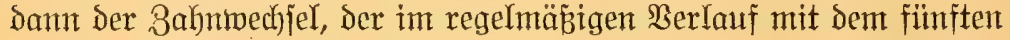
כahre volfendet ift. Das Durdjbredfen Der Mitldh= oder Fohlenzähne geht gewöhnlid) ohnte S(f)werigfeiten bonjtatten, während fitch beim

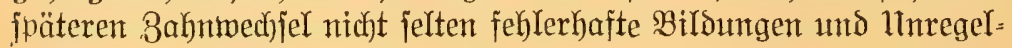
mäpigfeitent einftelfen, bie dem Iicre Schmerzen bereiten und oft da? Berfauen Des Futters unmöglidid madjen. Farmer und jelbit Ticr=

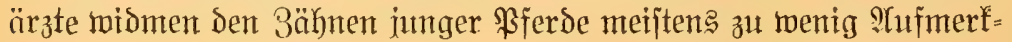
famfeit. Das Bahnen, wohei nahezu breiştg 3ähne ausbredsen, ift

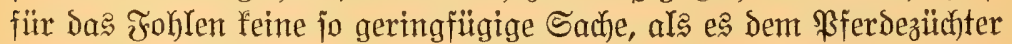

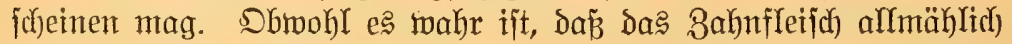

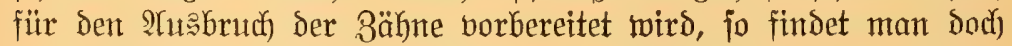

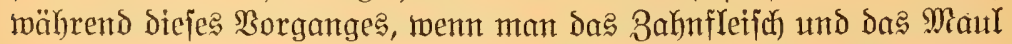

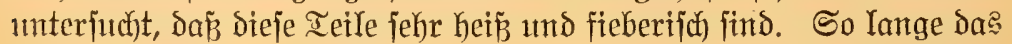
FohYen noch faugt, werden die unangenefmen Folgen des Bahnens

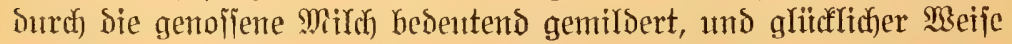

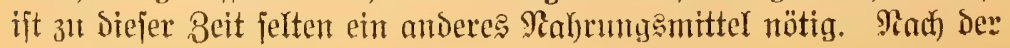


Cutwöhnung ift bas junge Tier viden Itnannelymlidj)feiten, fo Yange

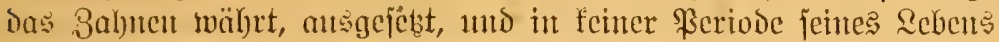

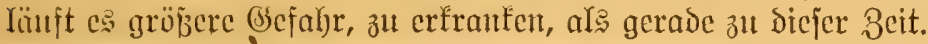

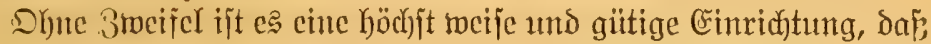

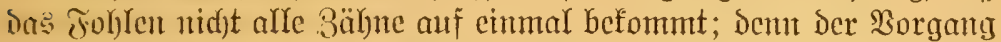

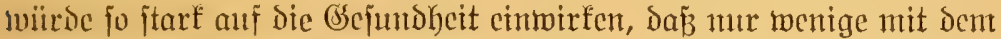

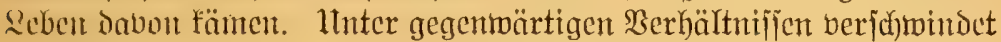

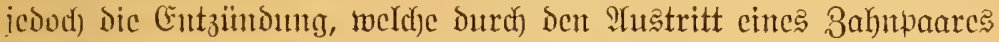
nerurjad)t wird, uns bas Bahnfleifdy fehrt 孔u dem gejunden Bujtanis 3uriac, che wicder weldje surchtreten. Das Bahnen hat aber im all=

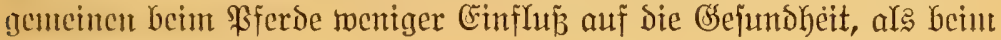
Sienjaden und Sुumbe.

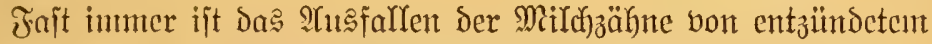
und wumben 3ahnfleijach begleitet und mähreno ger ganzen Daucr

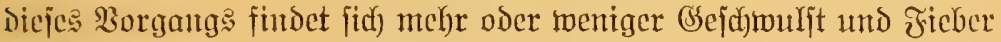

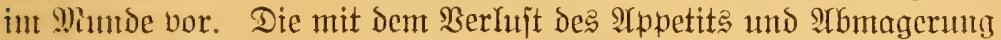
verbutnoene Störung ber allgemeinen Sefunoheit bei jungen Fohleu ift fajt immer anf biejen Umptand zurüdzuführen, toovon man jiơ. jehr

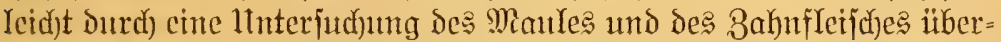
jentgen famt. Die IPpetitlojigfeit ift jconch nicht die einzige oder

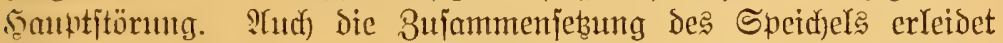
infolge des ficberijden 3ujtandes im Maule eine franfhafte $\mathfrak{S e r}=$

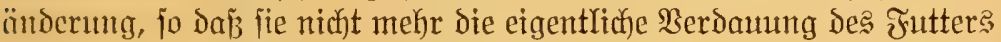
befördert, fonbern den Magen jebr bald in llnordnung bringt.

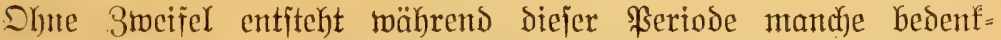

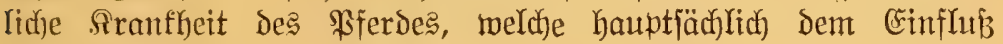
Des 3ahntwedjfels zuzuforreiben iit.

Bcha

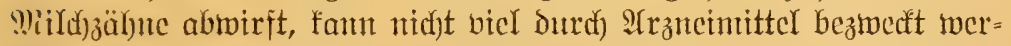
icu. Wian Iente bie IIfmerffamfeit vorzugsmeije auf eine gut gr= wäl)Ite Diät, Dent die Jütterungsmittel vermögen einen unverfent= baru Einfluí anf Diejen 3ujtand auszüben. Sebr feite 1410

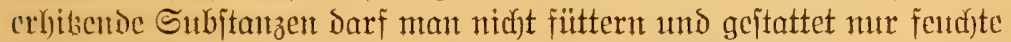
Icid)te Fütterung, wie fie in \$Binter Durd) Şäcfel, Şcu und Safar her3uftellen, und während des Sommers auf ber Meide, weldje das allerbefte Futter für alle Berbältniffe bietet, zu finden ift.

in Sen Baummollenitaaten, wo die \$Beiden felten und un= crgiebig find, ijt es fajt unmöglidu), ein Fohlen ohne auferordentlidje Sorgfalt zu erzichen. Dort werden Die jungen Tiere gemöhnlich mit Miais gefüttert and Die Jolge Dabon ijt, da bie Mefrzahl Derfelben 


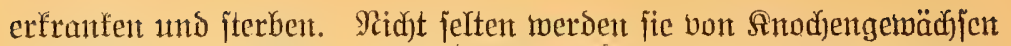

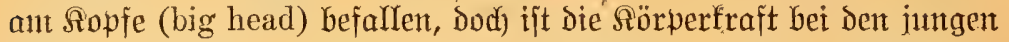

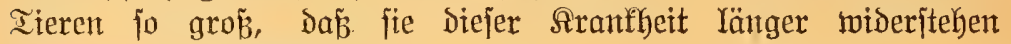
fömtten als alte Pferde.

Man vergelie bas Salz audid nidjt, Denn ç ift bas beite $\mathfrak{U r z n e i m i t t e l . ~}$

1turegelmänige Bäfuc. — Dicje finden fidf oft bei \$fferden, befonvers bei älteren Tieren; am häufigiten trifft man fajarfe

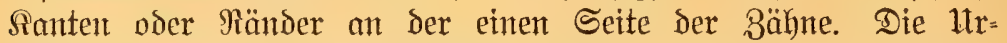

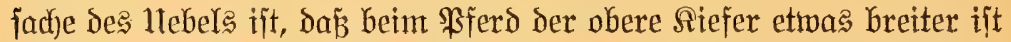
als der intere und die Bähne deshalb nicht genaut aufeinanderpaffen,

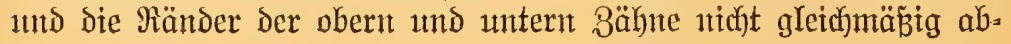

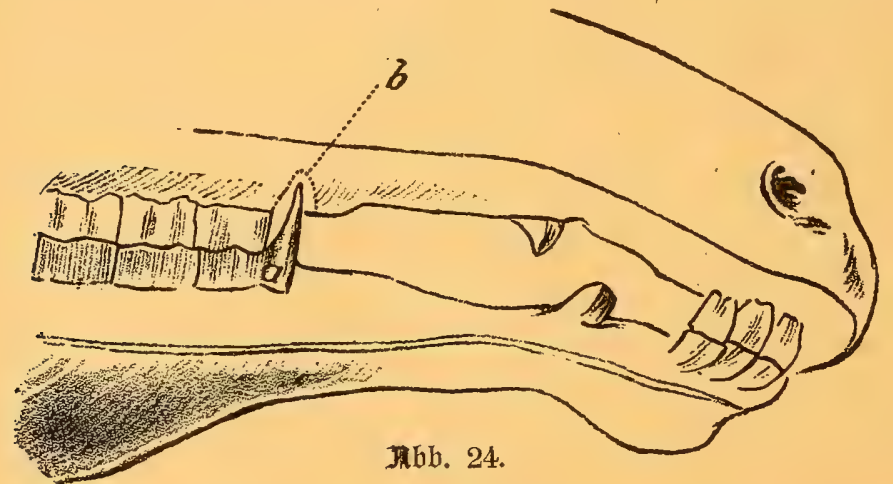

a Unvorritändig abgeriebener erjter Bacfeitzahn, Defien itebent geblie=

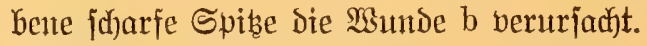

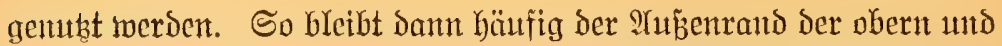
ber snnenrand Der untern 3ähne als eine jajarfe Sante iteljen, dic

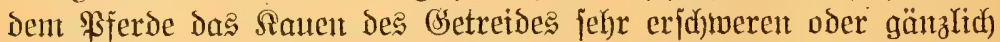
untmïglid) madjen. Durd) Entlangitreidjen mit dem Finger über die Bahnränder lajjen fich die fafjarfen herborjtełenden Santen Yeidjt entoecten.

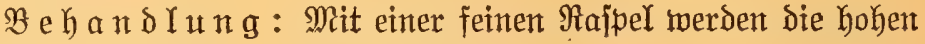
Ränder entfernt.

Mitunter iteht der erite und Yeste $\mathfrak{B}$ actenzalyn zu hoch herbor, wodurch bas Aauen bes Futters unmöglich gemadyt wird. Fin Iier= arzt fann mit Meípel und Säge den Hebeljtand bejeitigen. 
Starfer Speidjelflıb̆, Jallenlafien des eingelpeidyelten Jutters

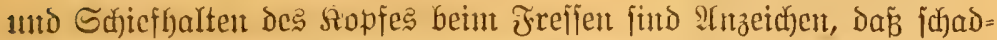
bafte oder unregelnäßjige Bähne Dem Tiere Sdymerzen bereiten oder

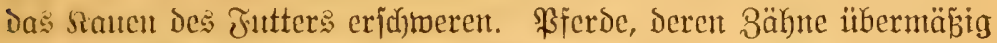
fd)arfe Mänder haben, ziehen im (Sejuirr nad) einer Seite und folgen

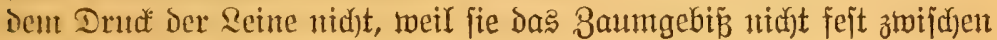
Den Bälnen halten fönnen.

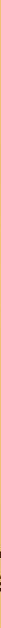

Thbeilen ciner itehengebliebenen Spibe a bes eriten Bactenzahnes. ?IIf Diejelbe Weije werden aud) Die jd)arfen Ranten der übrigen Bacfenzähne abgefeilt. Es ift aber notmendig, dab man vorker einen Sicil zmijhyen bie 3ähne der anderen Rieferreihe jtedt.

Sadjobrjafte 3ärne. - Infolge angefaulter 3älute Yeiden \$jerde zแweilen an 3ahnjumerzen. SBein Jreffen werfen Die Tiere sen siouf plöblid) in bie Şöhe แnd öffnen das Mianl, als ob fie auf cincu juarfen (Segenjtand gebifien; anth) beint Irtufen faltent $\mathfrak{B a f f e r s}$

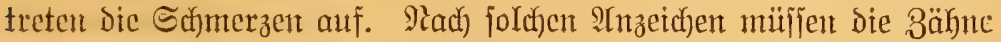

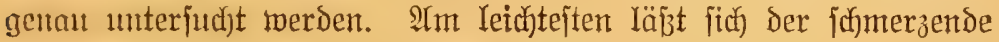

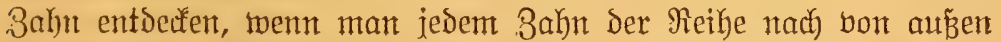
cinen Yeidten Schlag mit einem fleinen Şammer gibt; wem Der:

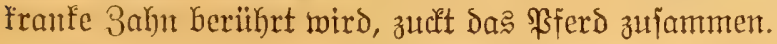

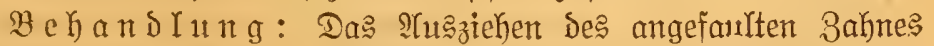
bictet die cinzige Ŝbhilfe und fann mur von cinem Sacfberitändigen mitteljt geeigneter șnitrumente auझgefübrt toerden. 


\section{Sirauffjeiten bes Miules.}

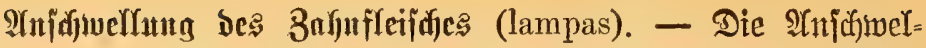

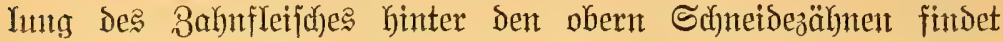

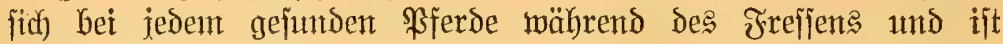
cine Folge des ftärferen Bhutandranges beim Sauen Des Frutters.

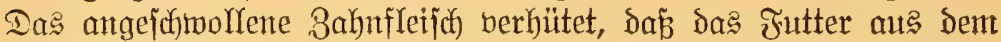

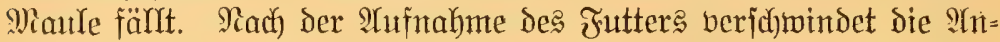

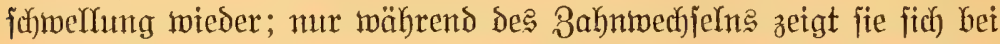

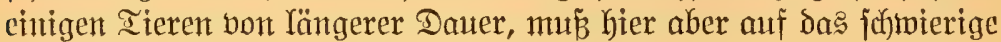
Durchbredjen Der Bäfne zurüdf́gefübrt werden. So oft alfo bon "Ramtpas" als einer franfhaften Erifheinung gejprochen wiro, jo ift

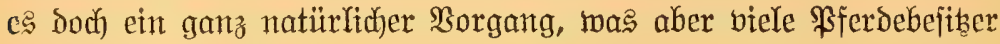
nidyt glauben toollent.

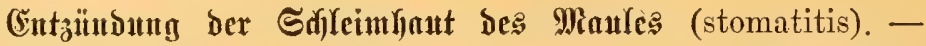

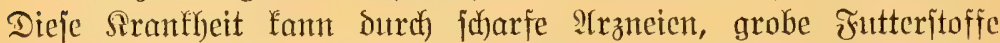
uíw. Kerborgerufen meroen. Mitunter tritt itarfer Speidjelffuis

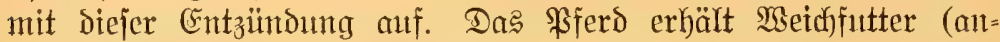

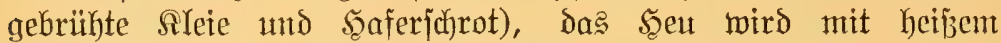
Majjer ïbergofjen. Beigen fich BYajen und Gsejumüre im Miaule, fo

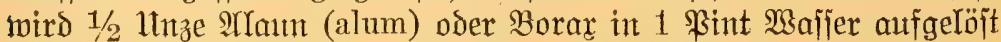
ınঠ das Maul täglidu mehrere Male damit ausgemajd)en.

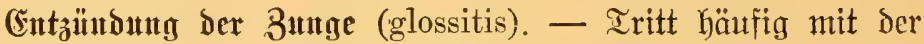

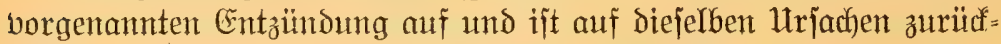
zufühyren; fie wird mit demjelben Mittel behandelt.

Speidfelffut (plyalism). - Schadhafte oder unregelmǟ̋ige 3ähnte, Entzïnonngen Der Maulfjuleimbaut oder ber 3unge

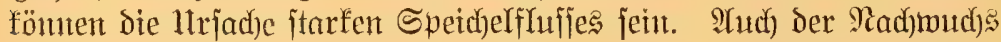

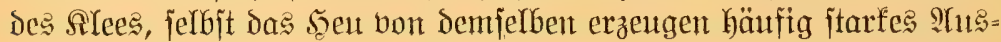

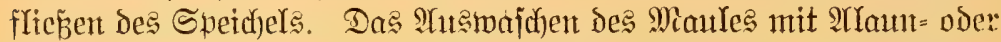

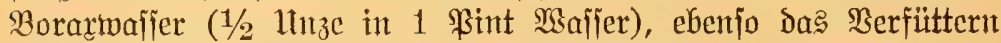

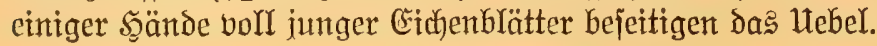

\section{Siranffyciten bes Mingens unb ber Gedärme.}

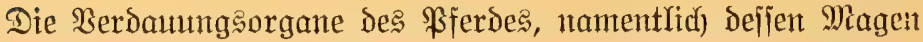
utto Gedärme find mehr aIs andere Rörperteile vielen Iranfheiten unterworfen, und diefe find jofwerer zu erfenten, weil man mit ber Rage, Struftur utto ben befonderen Futntionen, welde Magen und (sedörme zit verridyten haben, meniger bertraut ift, ars mit irgend 


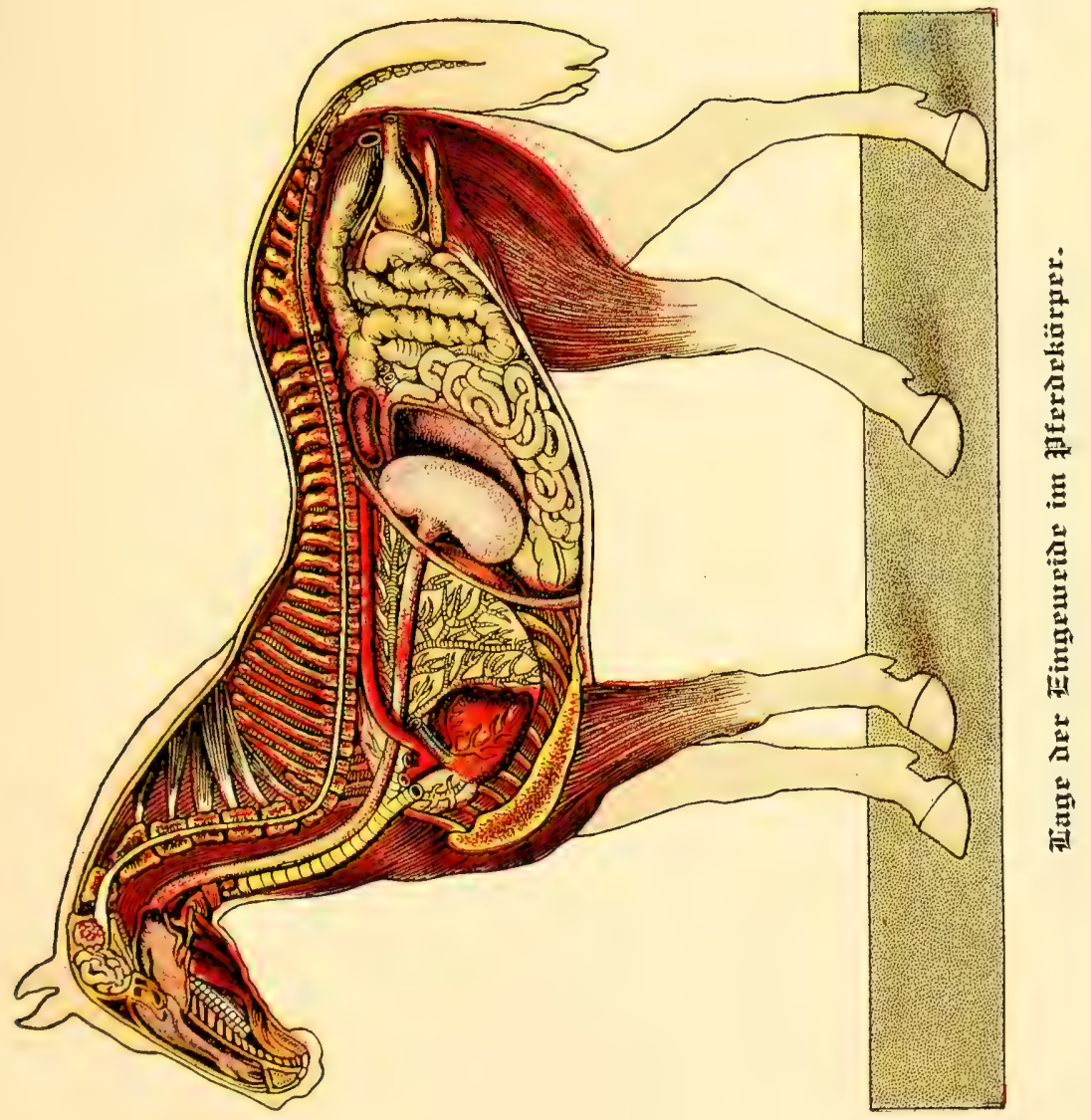



andern Drganen. Meben bicjen Untitante find auth Die Gei Magen=

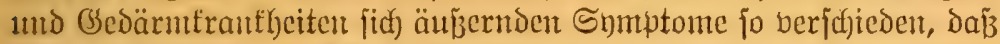
man badurd) oft in (sefalyr fommt, hinfidftich) der Natur und $\mathfrak{B e}=$ fdjaffentyeit ber Srantfyeit ganz und gar irrgeführt zu werden.

Der Magen ijt nidjt allein Der Jutterbehälter des Tieres, jon= Sern nuß aud alles, twas ihm Ilntwifiende und Suadfalber ein= зwäugen, aufuehmen; und nur 孔 oft werden bie eingegebenen Mittel gerabe die Urjadje zu mandjerlei Sranfheiten. Der weije Sdjöpfer hat bie innere Magenlyaut mit ciner Unempfind lichteit ausgerüftet, Die, obglcid) fie nidjt imitande ift, alle llebel zu verhindern, in biejer झezichung Dod) bedcutendes Yeijtet. Und doch ijt die jtarfe Magen: Yaut nidjt immer imitande, den Drganismus vor den bem Magen

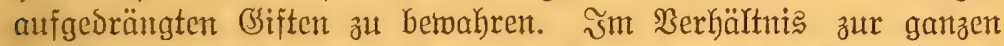

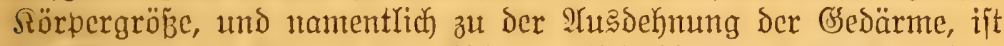

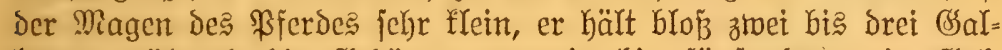
Yonen, twährend die Sebärme ztwanzig bis fünfundztwanzig Gsal= Ionen z̊ falien bermögen.

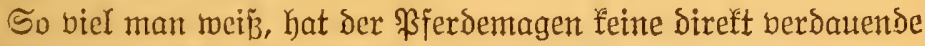

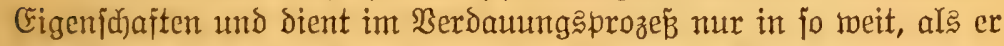
das Futter ertweicht. Die übrigen Funftionen Der Berdaunng werden bon Den (scdärmen verridjtet, welche vermöge ihrer gropen হänge

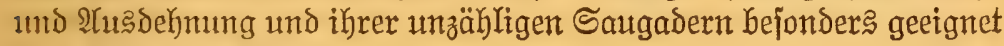
find, Dies auşufïhren.

Der veriäuerte Magen (sour stomach). — DaS Langfutter Des \$FFerdes fann im Maule nicht geförig gefaut werden und wird beshalb bon bem Speichel auth mur teilmeije ourchfeuchtet;

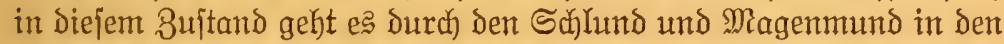
Magen, wo es mittelit ber in jenen Ieilen fid befindidjen Miusteln

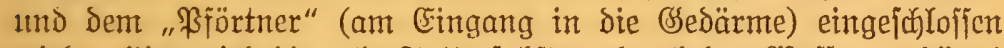
wird. Şier wird bie roke Jutterjubitanz Durch das Wajier veroünnt und in eine breiartige Maffe, Den Jutterbrei, verwandelt, zu Deffen

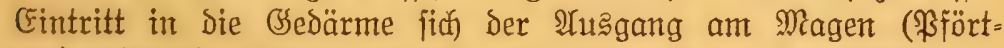
ner) zeitweilig öfñet, worauf jener (Der Magen) wiederum nad) Jutter begeljrt.

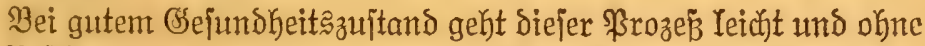

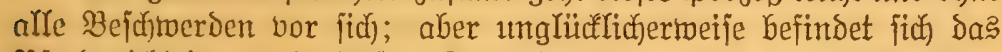

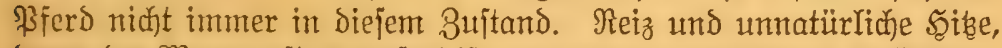
Denen ber Magen oft ausgejebt ijt, erzeugen im Jutterbrei oft Gsärung und ๔äure. Und diejes fann zu irgend einer Beit Durch das Freijen

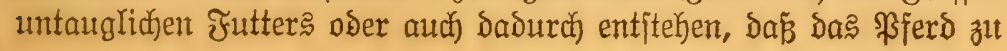




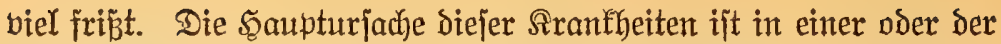
andern Störung der ßerdauung:merf jondern auth in ben sedärmen, zu juthen, und daher rührt bie $\mathfrak{B i l}=$ dung jener (Gaje, Deren Borhandenjein Durd das jog. Magenfmurren und andere $\mathfrak{I}_{n} z e i d j e n$ angedeutet mird, was inmer $\mathfrak{U n r u h e}$ und Sajmerz unto mandimal aud) Windfolif (flatulent colic) herborruft.

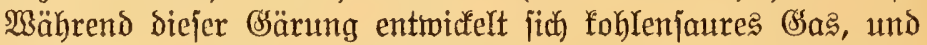
zmar öfters mit foldher Bsejthwindigfeit, dá̉ eine frampfartige Bujammenziehung bes "\$Förtners" jtattfindet. Der Magen wirs

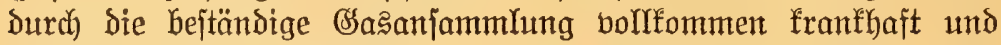
berurjaḑt biele Sajmerzen, und ber Eigentümter erfennt bald, Dáp jein \$ferd bon der

Solif (colic) befallen murbe. Man verjteht unter Solif eine

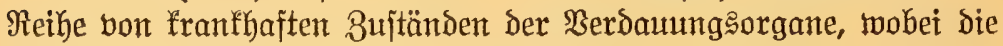

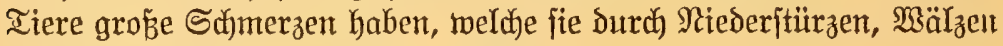
auf Dem Boden ıim. zu erfennen geben.

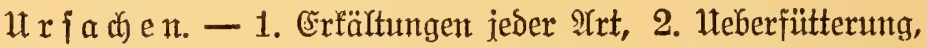

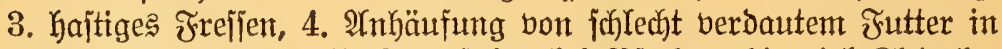
engen Darmpartieen, 5. Darmiteine bei \$ferden, Die viel Sleie be=

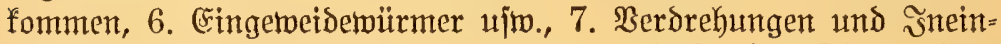
anderjujtebungen des Darmes (Twisting of the bowels), 8. Cin= jodnürungen des Darmes ujw.

E $r$ j d e inu $n$ gen.-Die franten Iitere werden unrubig. Sie jehen fich nadh Dem Baudje um, treten hin und her, fuarren mit ben Borderfü̈вen, Iegen fid̆ nieder, wälzen fid), fpringen wieder auf und Yegen fidf fofort twieder nieder. S̃n juffweren Färlen hört man aud ein

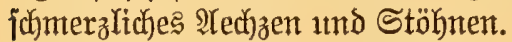

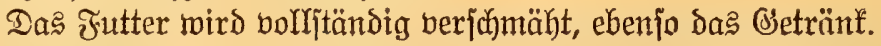

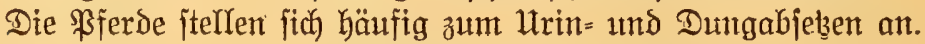
Regt mian das Dhr an bie Baudbrandung an, dann hört nan in der

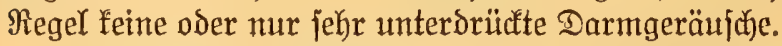

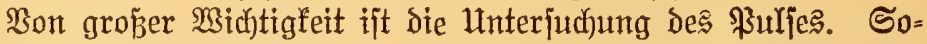

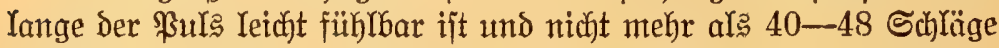
pro Minute beträgt, beiteht menig Gefahr. Went aber der $\mathfrak{B u r g}$ be $=$

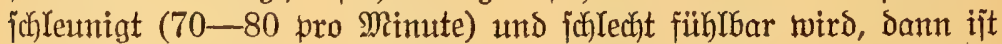

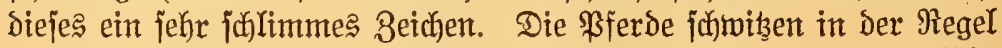

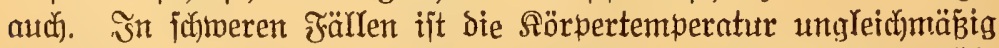
berteilt. Die Dhren find bald falt, bald warm. Eifigfalt fidd anfüh=

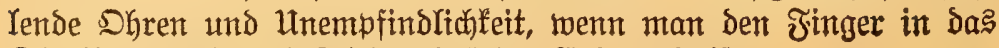
Dhr Gineiniteclt, find Beidjen, Dás Das Ende nahe ijt. 
Seltene Erfadjeinungen fint Bredjbemegungen, Sic nad̆ Miagen= beritungen borfommen; Sizen auf bem Şinterteil, fogen. Şundeitel= Iung, oder frummes Stehen mit dem Sinterteil und mit den Border=

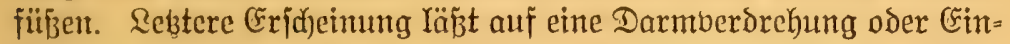

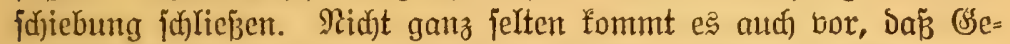
burtamehen bei träd)tigen Stuten mit Rolif verwed)jelt merDen.

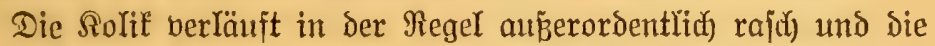
Srantheit bauert oft nur wenige Stunden (bis zu 24 und 36 Stun= Den). Rur bei Berftopfungsfolifen ober nad) Heberfütterung mit

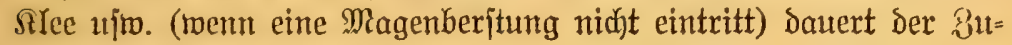
jtand nidut jelten $3-6$ Tage.

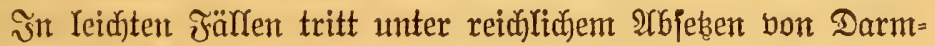

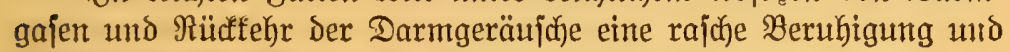

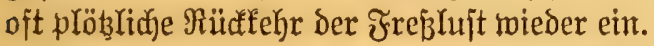

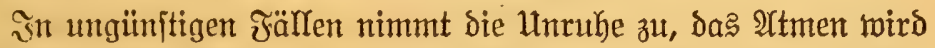
bejd) Yeunigt, bie Tiere berraten groß̉e $\mathfrak{A n g}$ it. Später werdent bie $\mathfrak{P a}=$

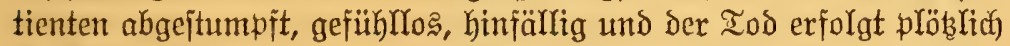

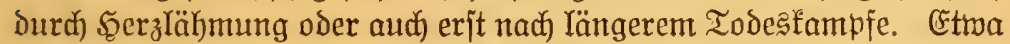
40 \$rozent aller verendeten \$ferde gehen an biejer Sranfheit zu

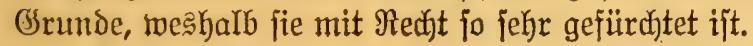

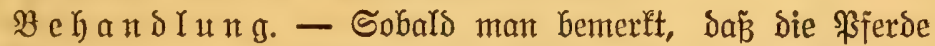
Soliffjumerzen zeigen, reibe man fie fräftig mit Strofmijuden an Flanfe uns Baud) alf beiden Seiten ab, etwa 10 Minuten Yang. Midjt felten tritt nad) fräftigem Âbreiben facon eine Befferung ein.

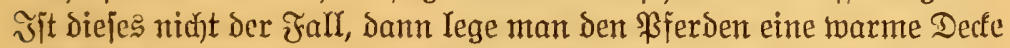
auf und verbringe fie an einen geeigneten \$lakg. STm bejten eignen

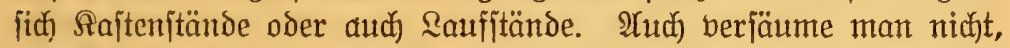

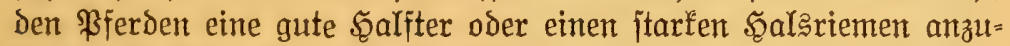
Yegent. Sind bie \$ferde ftarf aufgetrieben und gehen bon 3eit zu 3eit in geringer Menge Darmgafe ab, Dann madhe man innen $\mathfrak{W a j f e r =}$ fliftiere bon Iaumarmem Baffer.

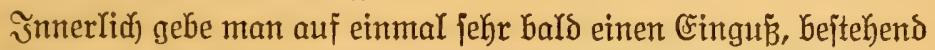
entrweder aus $1 / 4$ Duart warmem Bafjer oder warmem Bier mit 1 Ulnze Soffimannstropfen. Stellt fid nadi $1 / 4$ Stunde feine wejent= lide Befiferung ein, Dann tann man die Dofỉ miederfolen oder man

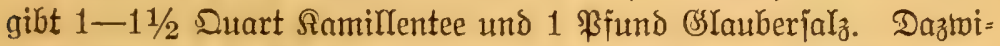

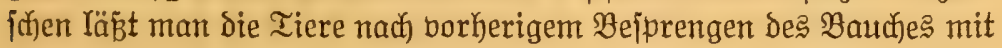
Sampferipiritus wieder abreiben. ITud jebt man ifnen alle $1 / 2$

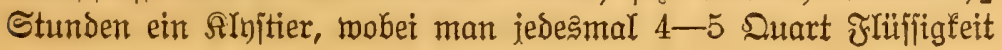




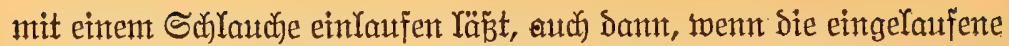

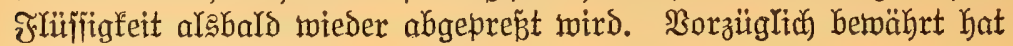
fich folgende Medizin:

1. Unze Dpium (tinct. of opium),

11 tnze $\mathfrak{A}$ ether (sweet spirits of nitre),

1 Unze Tinct. of asa foetida.

Die Mijanng wird in 1 ßint warmem $\mathfrak{W a j j e r ~ a u f ~ e i n = ~}$ mal eingegeben.

Sann man die \$ferde Yängere Beit auf Den Beinent erfalten, fo empfieblt es fith), biejelben im Sdyritt oder Irab zu führen oder auth zut reiten. Dabei mur aber ein bernünftiges Má̉ eingebal= ten werben.

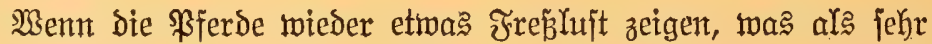
günitiges Beichen aufzufafjen ift, gebe man ibnen fchleimiges Bsejoff

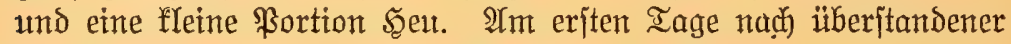
Solif halte man die \$Fferde nod jehr fnapp im Jutter.

Das Einjpamnen der \$ferde ummittelbar nadh Dem Heberjtehen Ser Solif ift nidyt rätlidf. Eine \$Betwegung im Sdyritt ift am erjten

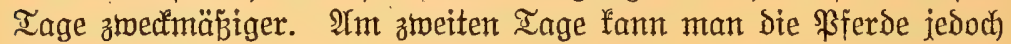
wieder zu jeder $\mathfrak{T}$ rbeit bermenden, wenn fie bolrjtändig munter exjojeinen.

Scarnfolif. - Sie ift im allgemeinen nidbt ganz jeltent. SYlm Gäufigiten fommt fie bei mämnlichen \$Pferden vor.

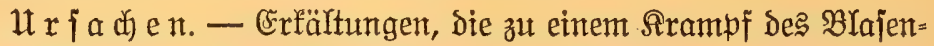
Galjes führen, oder nidjt Beit Iafjen zum Utrinieren während des

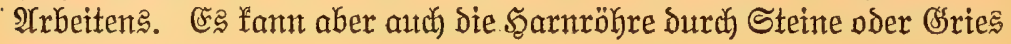
berjtopft werden:

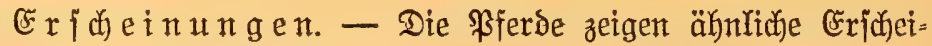
nungen wie bei der Solif. Sie legen fid nieder und fpringen wieder auf und jtellen fich bergeblich zum Itrinieren an. Jührt man bie Şand in den Majtoarm ein, Dann fühlt man bie jtart angefüllte und itraff gejpannte Blaje.

(ङ马 Iann aber nach einiger Seit bon jelbit noch Entleerntng er= folgen, momit dann bie Unrubericheimugen nachlaffen. Scidyt felten fommt ę zu einer Beritung Der Blaje, was nack jebr furzer Beit Den Iod herbeifiligrt.

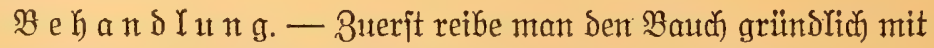
Strohrwifucen ab. Sehr häufig erfolgt aud die Sgarnentleerung twie= 
Der, went man Sen \$FerDen bie Stren ridjtet und jüüttelt, oder wenn man die \$ferde in einen Sdjafitall ftellt.

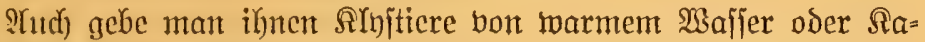
millentec. Sehr borteilhaft ift es, wenn man bie Şand in dent Majt= Darm cinfiilyrt und am Scheitel Der Blaje mit der flact)en Şand einen Druck auf Die Blaje ausübt. Man adjte aber Darauf, baß̉ Der Majt= Darm nicjt berlebt wird.

Эัnnerlid) gebe man $3 / 4$ Duart Ramillentee mit $1 / 3$ Utnze Dpium= tinftur (tinct. of opium).

Sifuarze Garnwinde (Azoturia). - Dieje fo gefürdftete Sranfheit fommt am häufigiten in der rauben sahreszeit und

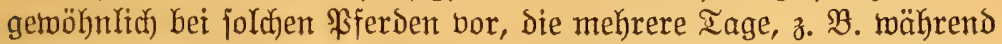
Regentwetters oder wälyrend Sonntag, in Stall gejtanden baben, wes= harb fie Montagstranfheit genannt wird.

Die Aranfheit Geitebt in einer rajd eintretenden Rähnung bes

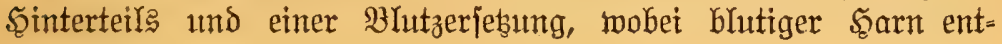
leert toird.

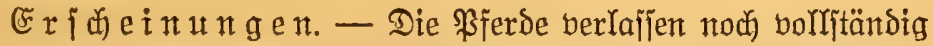
gejumb und munter ben Stall, beginnen aber damn nach einţger Beit ॐu lafmen oder unjicher zu gehen, ein Umitand, ber häufig ber Iräg= heit infolge de马 Yängeren Stehen im Stalle zugejabieben wird. Merden Die \$ferde trobsem noch meiter fortgetrieben, Dann mird da: S(j)wanten itärfer, łngleid) beginnt ein reidjlicher S(jweipausbruch.

Bringt man Die \$̧Ferde in Diejem 3 ujtande rajd) in einen warmen

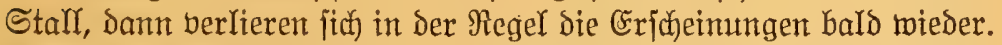
Dauert die Iranfheit Yänger, Dann entiteht eine brettartige Spanmung

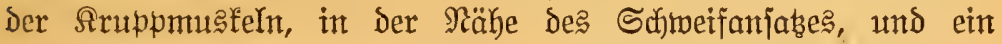
Dumfelroter bis tintenjànarzer Urin wird fpäter unter Drängen und Stöhnen entleert.

Bringt man jie gleid) im $\mathfrak{A}$ nfang ber Ertrantung in einem Stall unter, dann find fie in Der Regel gerettet. Berjäumt man diejes, fallen fie um und bleiben fie auf Der Straßje liegen, Damn find bie

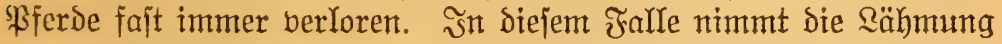

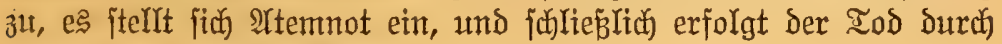
Serz= oder \&ungenlälymung.

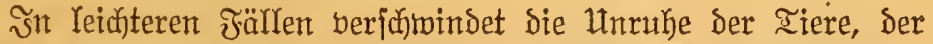

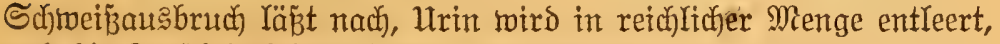
und Sie Freß̧luit fehrt wieder. Die sähmung Des Sinterteils fann bann entweder bald oder erit nad) mehreren Iagen berjhtwinden. S̃m 


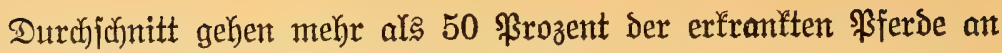
Diejer §ranfleit zugrunde.

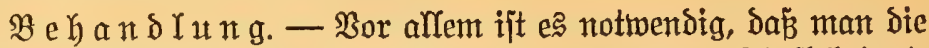
befallenen Pferde jobald als möglict in einen nahen Stall bringt. эe früher diefes gejdehen fam, Dejto wentger Ssefahr befteht für bas ¿eben des Iiteres.

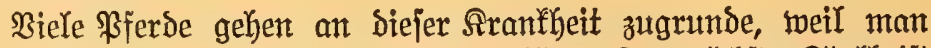
fie nock) naç Saauje transportieren wollte. Der nächjte Stall ijt Gier ber beite.

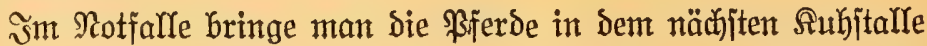
unter. Sind die \$jerde pajiend untergebracht, dann reibe man fie

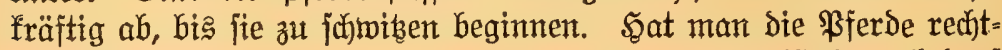
zeitig ausgejpannt und an einem warmen Drt eingejtellt, Dann bedarf es jehr häuftg auß̉er fräftigen Irbreibens feiner weiteren Behand= lung, und in jehr vielen Fällen fann man bie Pferde in einer Stunde wieder eimpannen.

Doch ift eร empfeblensmert, wenn man Sen Iieren, 1tm die Şaut= tätigfeit anzuregen, eine Mijhthung berabreidjt bon $1 / 4$ Duart Raffee mit etmas Brandy oder nod belier 1 Duart Fliedertee mit $1 / 2$ \$Fund •

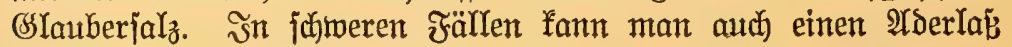
berjutifen.

Sdjarjreizende Einreibungen von 1 Teil Terpentin und 10 Ieilen Rampferipiritus (spirits of camphor) in der Nierengegend

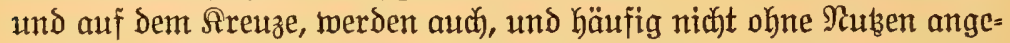

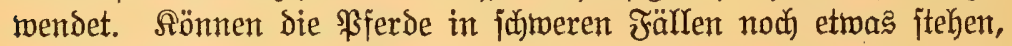
bann bringe man fie balo in eine $\mathfrak{A}$ uffängeborrichtung hinein. Dazıt

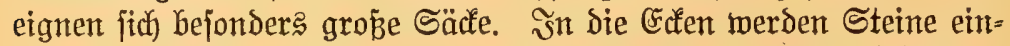
gelegt, bamit man bequen einen Strid an den 3ipfeln befejtigen

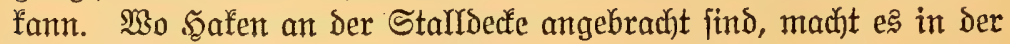

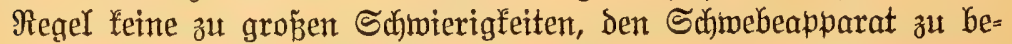
feitigen. Sełr gut ijt es, wenn die Säcfe mit Şäcfjel, Şolzmolle,

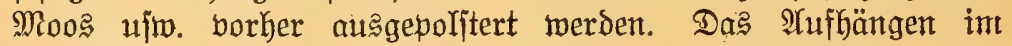
Sch)mebeapparate hat aber geringen $\mathfrak{W e r t , ~ w e n n ~ b i e ~ T i e r e ~ D a ̨ ~ g a n z e ~}$ Rörpergetwidyt in Denjelben Iegen und fid gar nidjt mehr zu ftüben jucjen.

\section{Dutrdfall (Diarrhoea).}

$\mathfrak{U} \mathfrak{r} j a$ d) e n. - Erfältungen jeder $\mathfrak{I} r t$, Saufen von zu faltem Mafjer, AHfnahme bon jauer getwordenem Futter, gefrorenem Bras, gefrorenen Sartoff́eln, jafimmeligem .Selt, Mais oder Safer. 


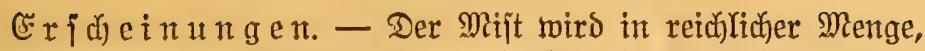
tweid) odcr ganz dünflüfitg im Bogen abgejebt ober ausgefpribt. Die Dberidjentel und Dor Sdjweif, jowie bie Sprunggelente werden itart beid)must. Dabci hört man häufig ftarfes 'Poltern im Reibe, nicht jelten bejtehen auth mekr oder weniger jtarfe 2eibjümerzen. Îtd) fann niedriges Fieber vorhanden jein.

Der $\mathfrak{A}$ ppetit ift im 2 rnfange und in Yeidjten Fällen wentg ber=

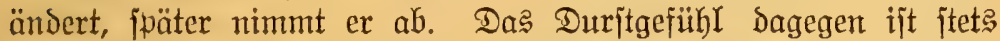

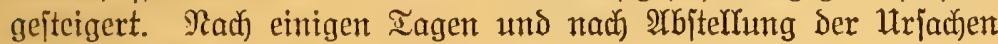
werden die Arulleerungen twieder fejter.

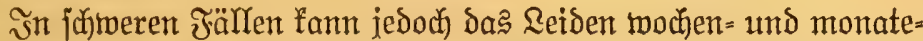
Iang Dauern, und bie Iiere fönnen an Erjdjöpfung zugrunde gehen. Rang andauernde Durchfälle find ganz bejonders bei jungen Tieren bedenflich.

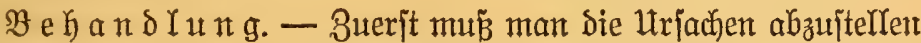
judjen. ITud) joll man bie Iiere toarm halten. 2luberdem reibe man

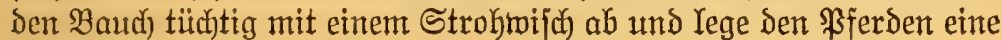
wollene Decte autf.

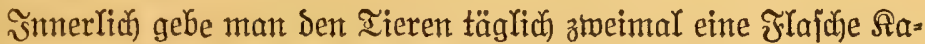
millentee mit 1 Pint $\mathfrak{B r o m b e e r w e i n ~ ( b l a c k b e r r y ~ w i n e ) . ~}$

Bei anfaltendem ftarfem Durajfall gebe man oreimal täglich jesesmal

2 drams powdered opium

$1 \mathrm{oz}$. subnitrate of bismuth

(Fohlen Sie ફ̈älfte). Bur Fütterung verwende man gutes Şeu und guten, alten Safer. IIIS SSetränf́ gebe man fein faltes, jondern Imt= toarmes Bafjer.

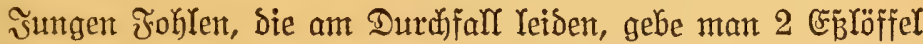
von $\mathfrak{M e i z e n m e h l ~ m i t ~ D e r ~ M i l d y ~ b e r ~ S t u t e ~ z u ~ e i n e m ~ T e i g e ~ a n g e r u ̈ h r t , ~}$ Der auf einer heiben Dfenplatte jtart geröjtet wird. Der geröjtete Ieig wird zu \$ulver zerjh)lagen und Dem Iter in einem halben \$int Samillentee eingegeben.

Bremijenlarven (bots) int Magen. - $\mathfrak{m}$ Magen fait aller

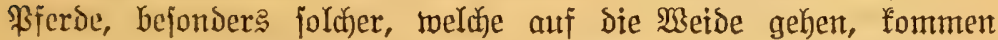
Zarben Der ßferdebremje vor; fie fiken oft zut vielen Duben= Den auf der Sdyleimbaut bes Magen?. Mur wenn die Rarben fidt in Mafje \öjen und Rlumpen in Den Bsedärmen bilden, werden jie Den

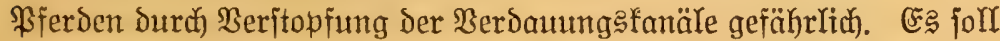

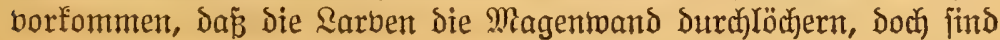


fold)e Fälle, went fie überbaupt je borgefommen, äıberjt feltent. Den

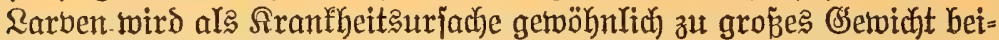
gelegt; fie Yöjen jich, wenn fie ihre volle Grö̈̈e erreidht haben, bon jelbjt und gehen mit bem Dung ab. Âtraneien, burd) weldye bie

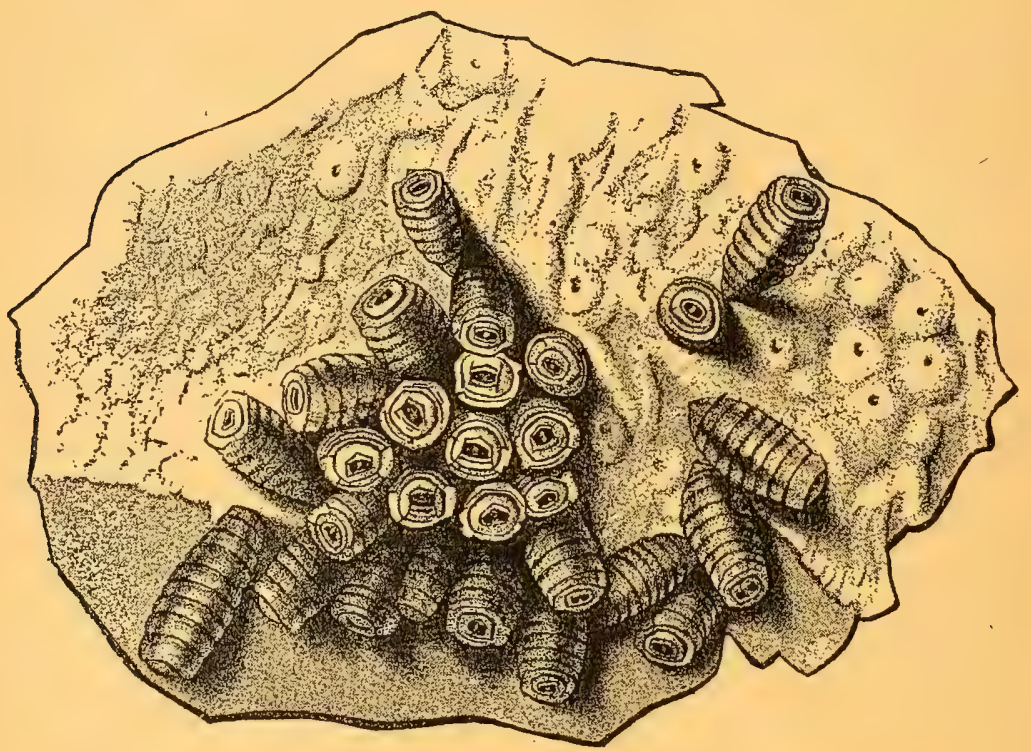

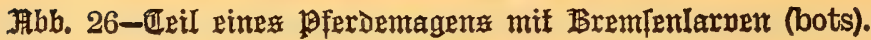

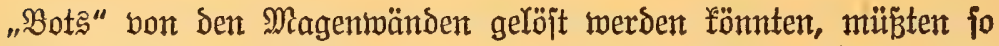

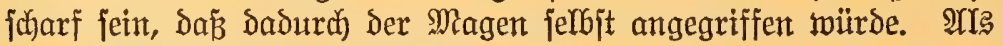
bejtes Mittel foll fich Der Saft roher Sartoffeln betährt haben, von dem man bem Tier je morgens and abends ein \$int eingibt. Sicherer:
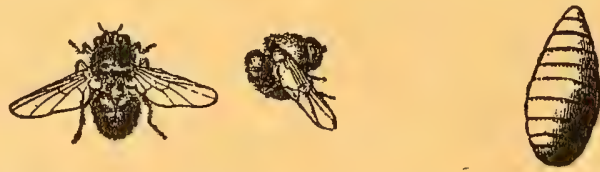

Hab. 27-19ferdebremfe und Tarne (bot).

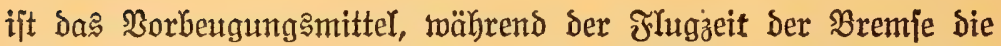
SBeine und Schultern der \$fferde wöbentlich mehrere Male mit Jett (Sthreinejamalz) einzureiben, jo Dap die Bremjeneier nicht haften bleiben. 


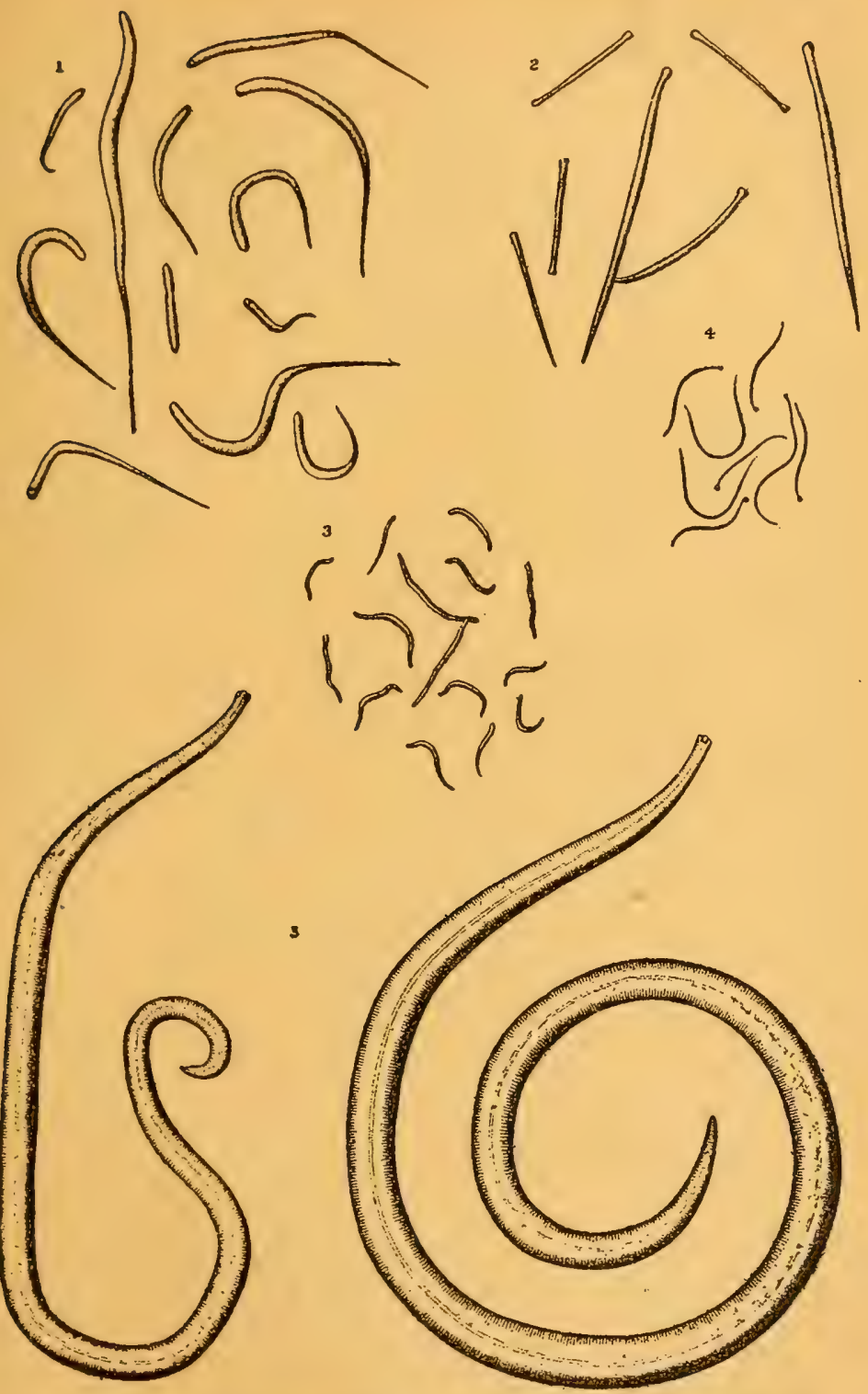

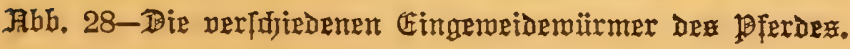


Cingeweibemiitmer (worms).

Ut $\mathfrak{r}\{$ a Futter, Meidegraje und Irinftwajןer auf.

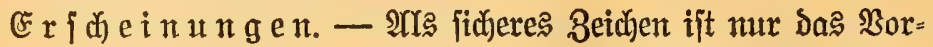
fommen Der Cingeweidewiirmer im Dumge anzujehen; rauhes Saar

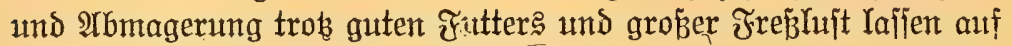

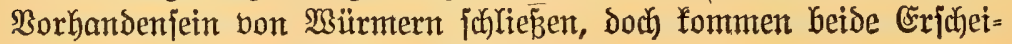
mungen aud bet anderen Srantheiten bor.

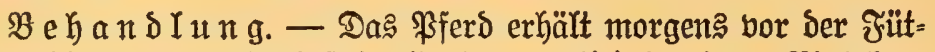
terung $1 / 2$ Unze $B$ rectyweinjtein (tartar emetic) in einem $\mathfrak{B i n t}$ Iaut= warmem $\mathfrak{B a f j e r}$ eingegeben; am nädjjten Morgen erbält es biejelbe Dojį und fünf Stunden fpäter $1 / 2$ \$fund OSTauberjalo ir 1 \$sint Majler. Fohlen erhalten bie Şälfte.

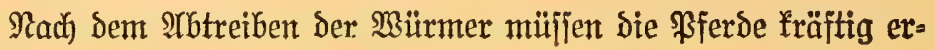

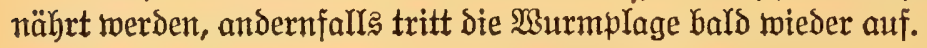




\section{3. 筑angifer.}

\section{Sranffeiten ber Reber આnd 5̧arnorgane.}

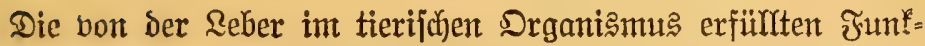
tionen gehören zu ben allerwidftigiten, denn die đsepundheit des

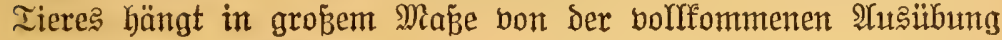

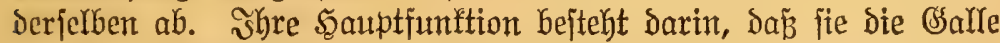

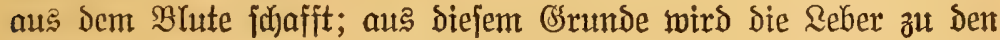
Drüjen gezählt, unter weldjen fie bei weitem die größ̈te billdet. Die

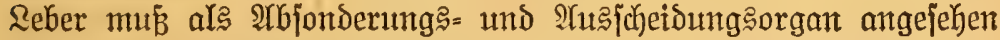

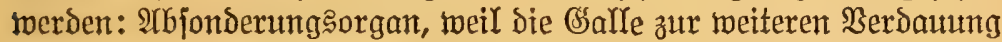

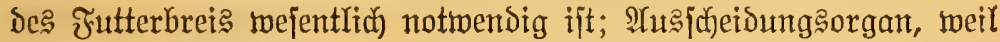
die Ssalle, farls diejelbe mur mangellhaft aus dem Blute entfernt wiro,

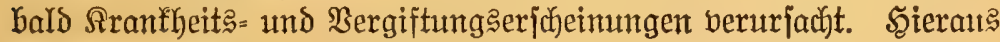

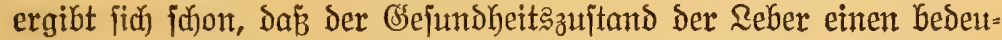
tenden Einfluí auf Die allgemeine Sejundheit des ̊örpers ausübt.

Das Pferd hat feine Sallenblaje, jomit mup die Galle, jo jant fie in ber Reber vom Blute abgejondert wird, in bie đsedärme gejdjafft

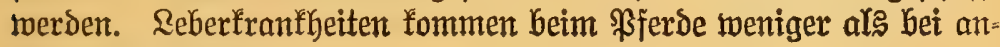
beren Saustieren vor.

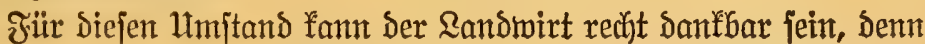
unter ben bielen Sranfheiten gift es wohl feine, Deren Symptome in gröp̈eres Dunfel gehïllt und die deshalf jufjwerer zut erfenten find, als gerade die Rebertranflyeiten. Selbjt die erfahrenjten Iierärzte fönnen mur Durdh die Seftion mit annähernder Ssetwibheit die Ratur ciner Reberfrantheit entderfen.

Benn man Durth andere Sranfbeiten zugrunde gegangene झ̈Ferde, die nicht über fünf sahre alt jind, unterjucht, fo findet man in

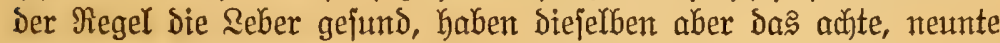
oder zehnte Sahr erreicht, jo zeigt die হeber gemöhnlid einen größeren Ilmfang, hat bie Elaitizität eingebü̈st und ein förniges, zerfallenes Susjehen angentommen. Das Bhut ourdforingt wentger leidst ifre Sefäße, fatwibt baher mehr voer minder aus diejen heraus und häuft fich in den Baudfhöhlen an, oder wird von Den Baudffell einge= jajloffen. Diejer Bujtand mird aber im 2 Infang Durd feine bejonderen Snmptome angefindigt. Das \$FFerd befindet fich wohl, fript jo viel wie jonjt, ijt nicht abgemagert und fann bejtändig arbeiten, obgleich 
eine unbeilbare Berjtönung in Diejem hödjft widjtigen Drgane ftatt= findet; ałer mit der Beit reist plöblich Der. Heberzug Der Reber; Das

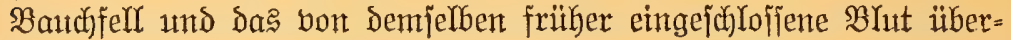

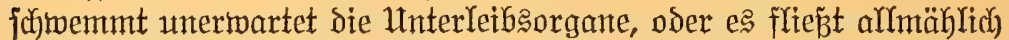
eine Ginreichende Duantität in die Baud)höhle, um die Funftionen der darin Kefindlichen Drgane beinake aufuheben.

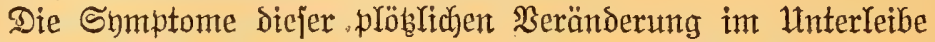
jind: Scfarrent mit den $\mathfrak{B o r d e r b e i n e n , ~ o ̈ f t e r e r ~} \mathfrak{B}$ edjjel der Stel=

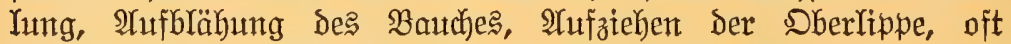
miederboltes tiefes Seufzen, blajie Srbleimbaut der Naje und

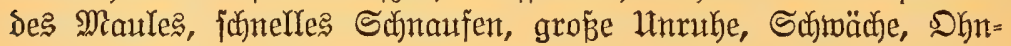
macjten $\mathfrak{m} \delta \mathfrak{I D d}$.

Deffnet man die Baudhöhle, jo findet man die Gsedärme mit dimflem $\mathfrak{B l u t}$ überj(f)menmt. Die Reber hat entweder eine hellgelbe Dder braune Farbe, ijt äuberit Yeidjt zerreiß̧bar oder ganz zerfallen.

Giallenfieber, Belbjudut (jaundice or yellows).

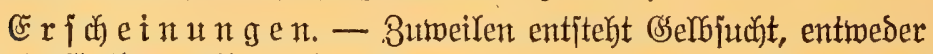
weil die త্রalle in allzugroper Duantität abgejondert wird, oder weil fie in ifrer 8 ujammenjebung bom normalen 3ujtambe abgemichen ijt,

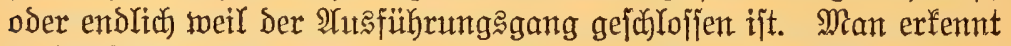
Diejen 3 uftand Yeidjt an Der gelben Farbe Der IYugen, Des Maules und ber äußjeren Şaut, wo diejelbe nicht mit Saar bedecltt ijt. Der Mijt ijt hart und wird in Ileinen Ballen auggejondert; Der Hrin hat eine

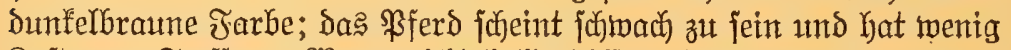
¿uft zum Jreffen. Went nidjt bald Scilfe gejuafft wird, zeigt ber Saul gemöhnlich eine unberfennbare Itnrube; wird aber zut anderen

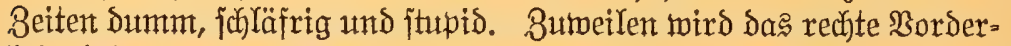
bein Iahm, twas man, toie die Sdymerzen in der redyten Sabulter beint

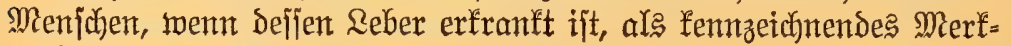
mal zu betradjten bat.

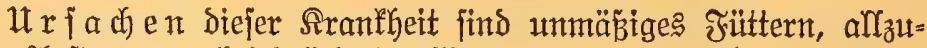

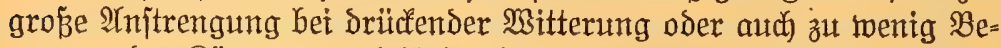
wegung des Rörpers; auch ift fie ein Snmptom bou Entzündung und anderen Sranfyeiten Der Reber. Sor allem ijt es notwendig zu unter= jucken, ob dieje 2eberiranfheit nidyt infolge Des Bujammenhanges der হeber mit einem anderen erfranften Ieil entjtanden ijt; Denn nicht felten begYeiten fie Entzündungen Der Sedärme oder audb ber ßungen.

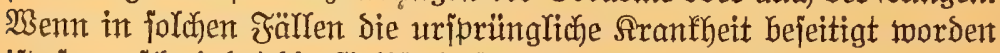
iit, jo veridhwindet die (sselbjucht fofort. Sollte fich aber feine andere Sranfbeit vorfinden, fo wird es ratjam fein, den natïrlicken 2 IKgang 


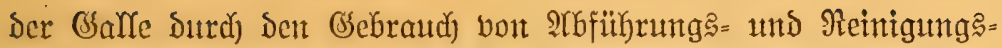
mitteln, ment möglid) herzujtellen, die aber nicht in allzugrojent

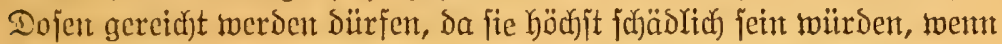
cinc uncrtante 2ungen = oder Darmentzündung im Gsang fein follte, aber man wicderbole fleine Dojen Derjelben in furzen Brofidjen=

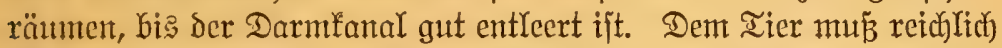

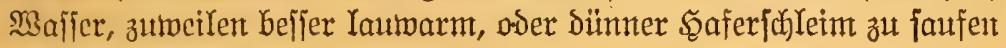
gegeben werben.

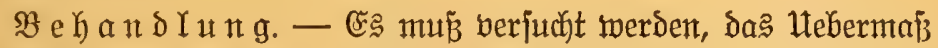

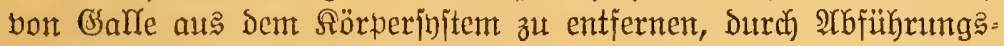
mittel, weldye anf die Rcbertätigfeit wirfen, wird dies am beiten crreidyt. Man gebe Salomel (calomel) 2 Dradjmen (drams) mit

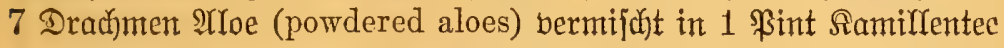

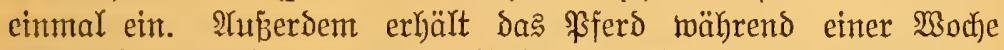
ztweimal täglich je eine Şandooll Grlauberjałz mit bem Futter ver=

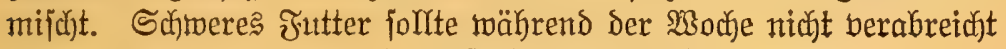

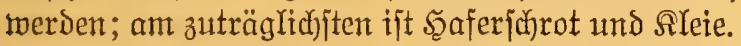

\section{Mlierenentaindung (inflammation of the kidneys).}

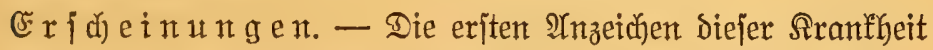
find gemöhnlid die des శiebers; aber bald wird der Sib Der Srant=

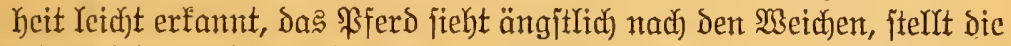
Sinterbeine weit auseinander und fperrt diejelben beim Bseben, Yegt (iç) jehr ungern, empfindet Samerz, wenn es fich oreht, fährt zujam= men, wenn man die Meichen orüht, bie heiper als andere Äorperteile find. Der Urin wiro in Kleinen Duantitäten abgelafjen; Derjelbe ift gewöhnlicf hochrot und zumeilen jogar blutig. Der Drang zum $\mathfrak{3 a j =}$ ferłaffen mird ftärfer, und die entleerte Duantität bermindert fid, biß ber Drang höbjt fantherzhaft und heftig wird und mur ganz Yleine Mengen fochroten und bremenden Sarn entleext werden. J̃m erjten Stadium Der Sranfheit ijt Der \$uls fannell, hart und voll, wird bald

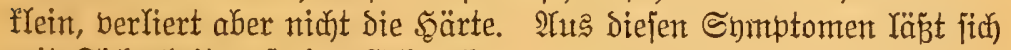
mit Sidjerbeit auf eine Erfranfung ber Sarnorgarte jüließ̧en; aber

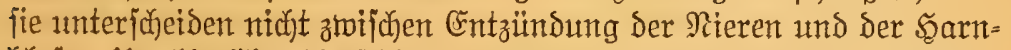

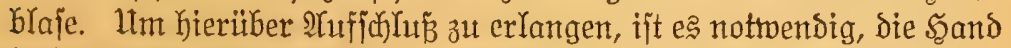
in sen Maftoarm zu führen. Fühyt fich die Blaje boll und hart unter= halb bes Maftsarms an, fo ift eine Blajenentzündung borbanden; findet man oben die Blaje leer, zeigt fie feine Sd)merzempfindung bei Dem Drud, und ift fie nidjt heifier als die angrenzenden Ieile, fo riigren bie Symptome bon einer Nierenentzündung her. 


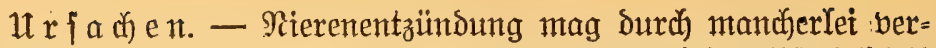

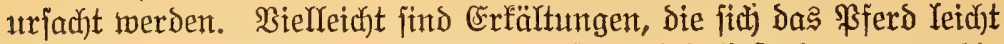

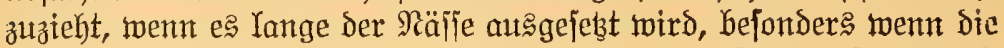

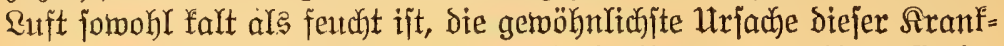

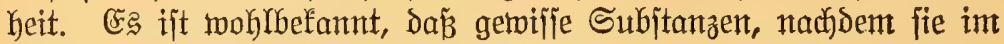
Magen berdaut worden find, groß̧e Störungen der Rierent herbor= nufen. So entijtehen bäufig Rierenfranfheiten infolge vont jüimmes

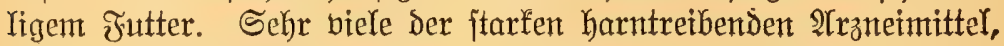
beren fid untwiffende \$erjonen gern bedienen, haben gleidfalts einen

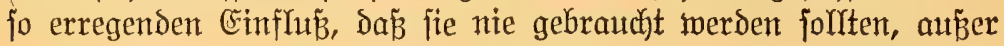

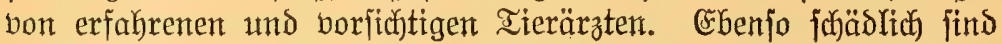

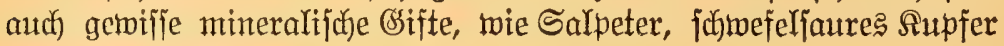
und Eifentitriol.

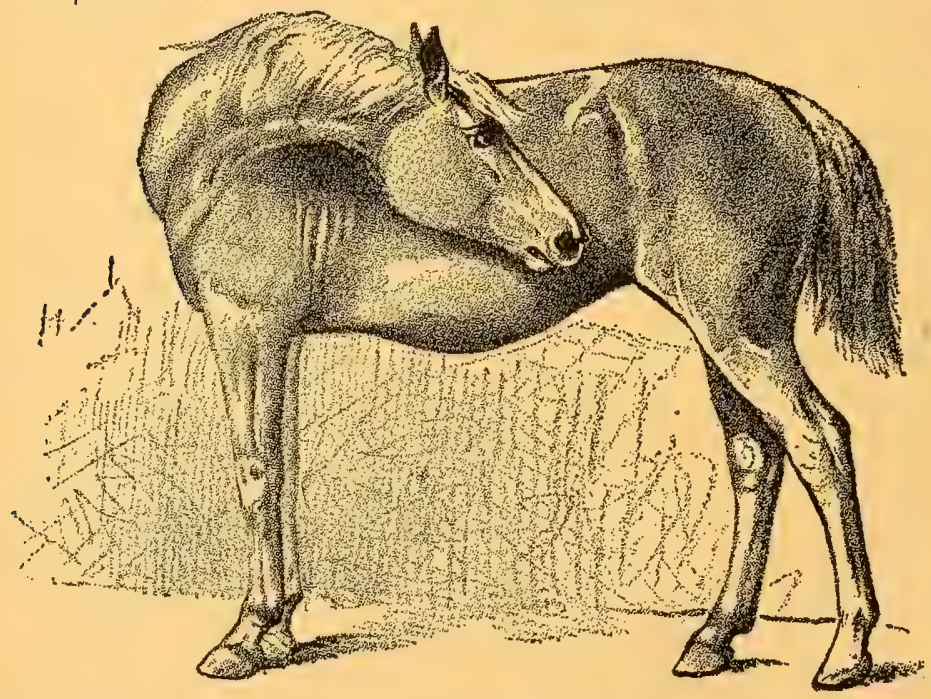

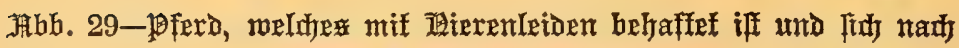
Dem 酒infexleib umlieff.

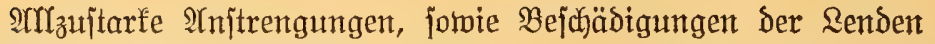

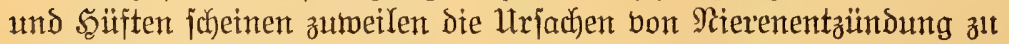

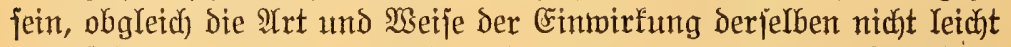

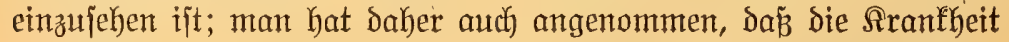

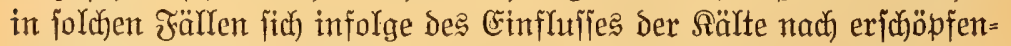
Der Înitrengung entwickelt, oder Dáz irgend ein fleiner 3tweig Der

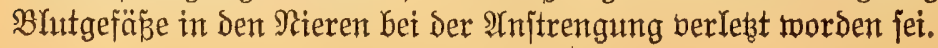




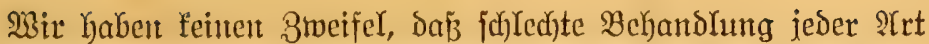

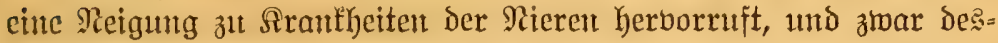

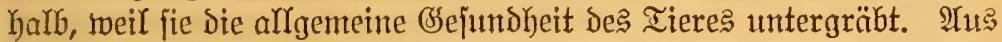

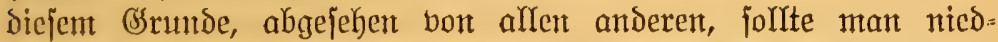
rige itnd feuddete Stärle meiden und poldje faule und berpejtete Ruft,

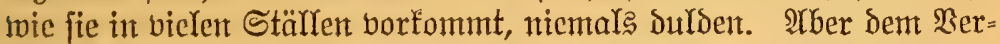

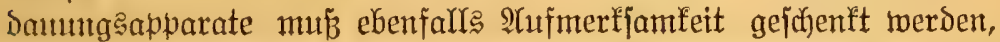

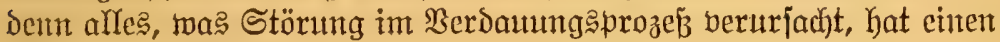

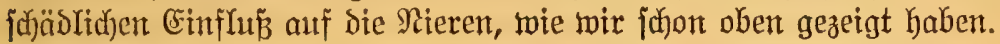

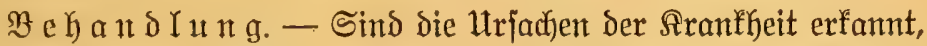

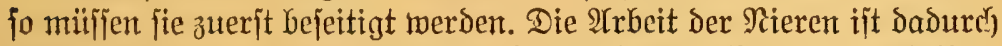

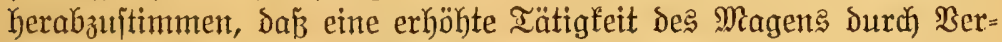

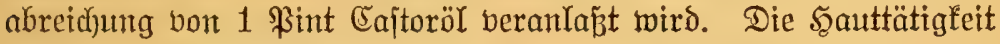
mird Durd) Bedecfent Des Rörpers mit twarmen Deffen angeregt. Die Rierengegent (bor Dem Sreız) wird mit gemahlenem Senf, der mit

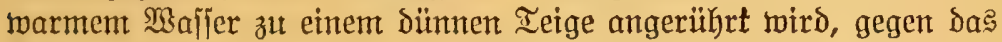
Şaar eingerieben und mit einem Bogent \$apier bedect. Die Ein= reibung follte mindejtens eine halbe Stunde fortgejebt merden.

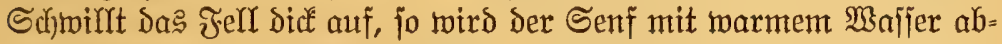
getwajdyen und eine Decte aufgelegt. Innerlid) gibt man tägfid einmal 1 Sfrupel (scruple) Nux vomica und 4 Dradjmen (drams) Enjianmurzel (powdered gentian root). Dag $\mathfrak{B f e r d}$ ift gegen $\mathfrak{E}=$

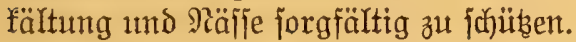

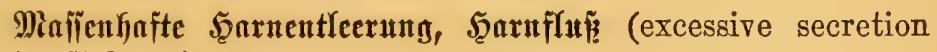
of urin, diabetes).

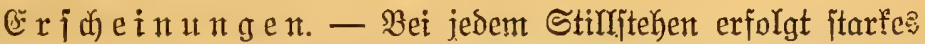

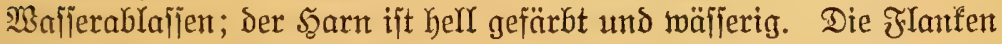
cricheinen emporgezogen, Das Tier magert ab, bas Fell fühlt fich zäh unt trocen an und liegt fejt auf bem Sörper (hidebound), Die Saare

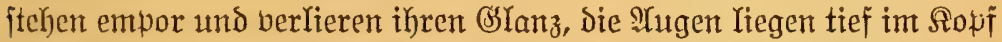
1mi haben einen trïben Blict, das Tier zeigt graßje Sdjwädhe und fajmibt ftart bet ber geringiten 9Trbeit.

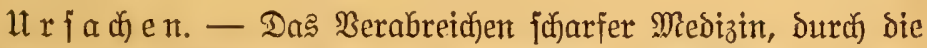

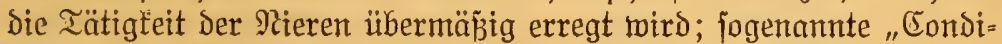

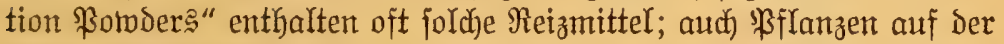

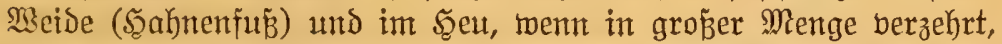

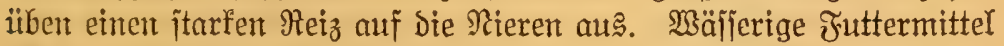

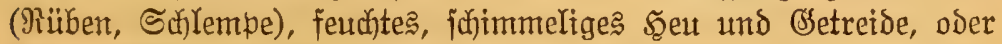

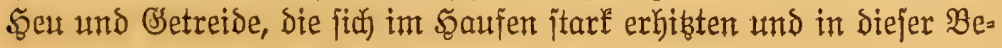




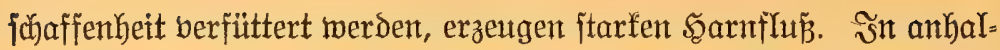

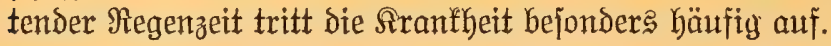

$\mathfrak{B}$ e $\mathfrak{h}$ a $\mathfrak{n} \delta \mathfrak{I} \mathfrak{u} \mathfrak{g}$. - Die Ulrjaden, wenn belannt, find zut be $=$

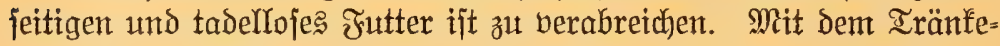

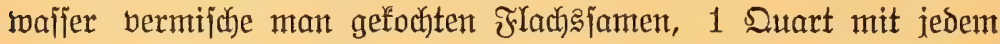

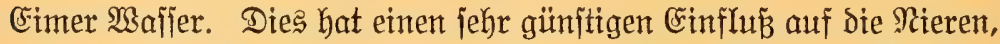
indem e马 Das Grift aus denjelben entfernt und die überreizłe Iätigfeit herabitimmt. Morgens und abends gebe man jedesmal mit Sadrot= futter vermifint 2 drams sulphate of iron $\mathfrak{u t b} 4$ drams powdered Peruvian bark.

\section{Bhatffarnen (bloody urine).}

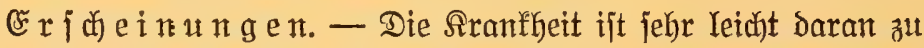

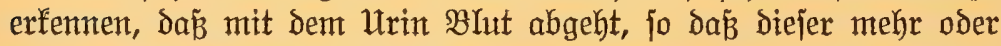

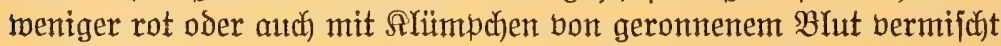

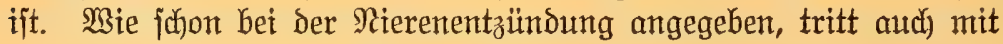
Siejer Sranffyeit błutiger Utrin auff.

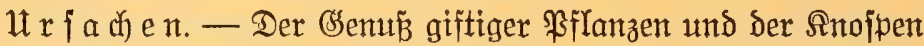
junger Fithten, Errlen und \$appeln, fann Blutharnen herworrufen.

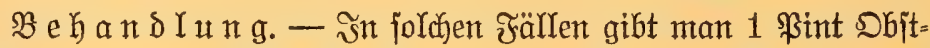
effitg (cider vinegar), nidht ben fiimftlich aus jacharfen Säuren herge=

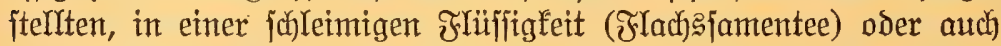
mit SpeifeöI (sweet oil) ein. $\mathfrak{B}_{0}$ dą Bhutharnen jehr lange ange-

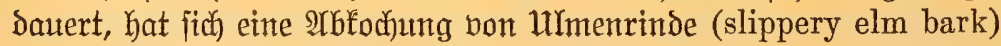

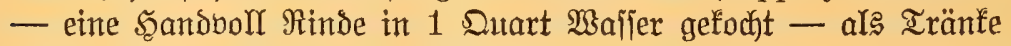
gegeben, bejtens bemährt. Sn jubmeren FälYen gibt man 1 oz. oil of terpentine.

\section{Sifleimfinntut (thick and albuminous urine).}

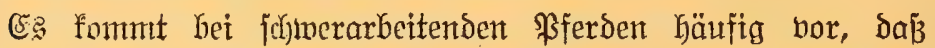

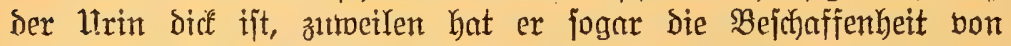

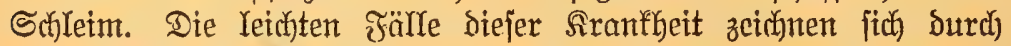
einen, im Înfang ber EntTeerıng, bicfen rotbraumen Sarm aus, Der aber bals eine natïrlidjere Farbe annimmt, Julest aber mei

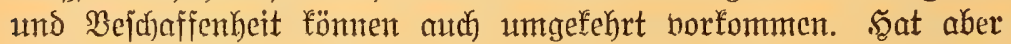
Die Sranffheit längere Beit beitanden, fo ift Der ltrin burchgängig Dict und bon bunfler Farbe und gibt häuftg einen ftarfen, unange= nefmen (Gerudi) bon fidf. Shne Bweifel haben viele meiner Rejer F̧älle ber Sirmffheit geịchen, in benen Der Sarn wie ein biffer Strom bon Sirup zur Erde fiel unt beinahe fo fatmer war. 


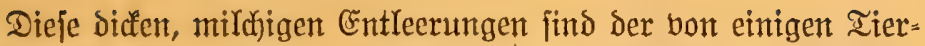

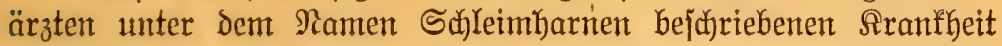

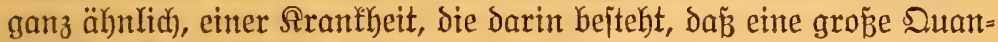

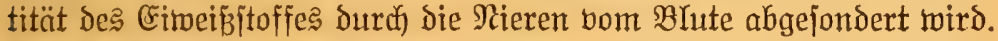

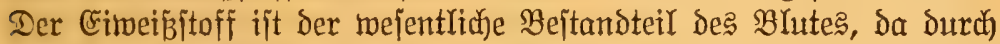

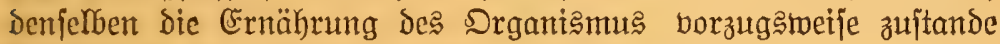
fommt. Man hat ign fo genannt, weil er feiner Matur nady dent int (Ei befindlid)en weipen Stoff bollfommen ähnlid ift.

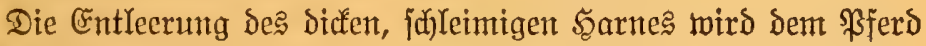

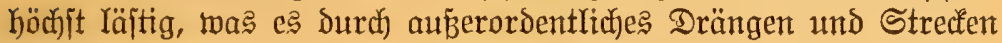
bejonders Der Borderbeine, funtotut. Gscmöhnlidf ift das Hebel von mehr oder meniger Steifheit der Şüften und Şinterbeine begleitet,

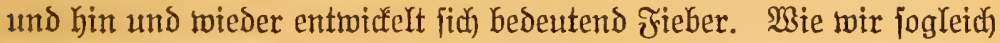

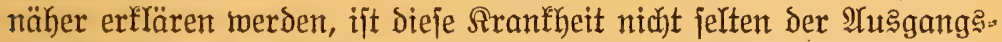

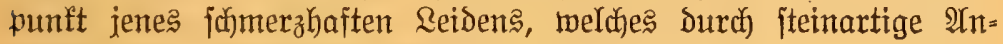
Gäufungen in Den Rieren ober Blaje berurjacht twiro.

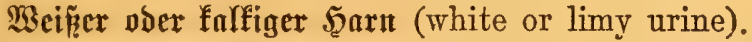

YHud in ben gejundeften Sarnentleerungen finden fith falfartige Subitanzen, bie, menn fie ungeitört bom Rörper entfernt merden, nicmals Bejhiwerden verurjadjen. Selbjt im Falle siejelben in $1 \mathfrak{m}=$ natïrlich großer Menge borfanden find, entiteft dadurd feine eigent=

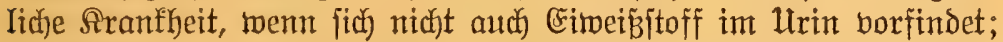
im Yesteren Falle aber merden die falfartigen \$artifelchen burdh bie

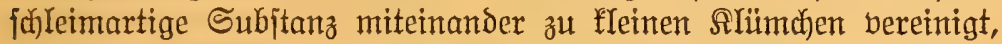

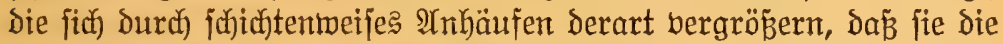

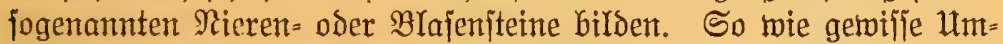

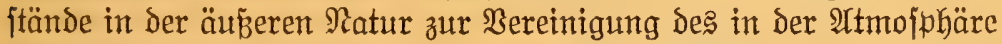

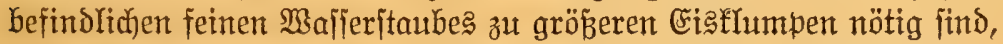

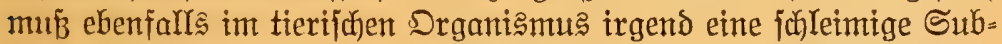

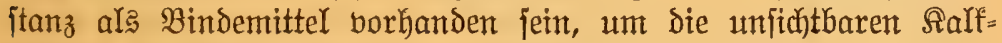
teil(hen zı gröBeren Steinen zu bereinen. Dię fübrt uns auf eine näłere Befpreffung der

\section{BInjeniteitte (gravel, or stone in the bladder).}

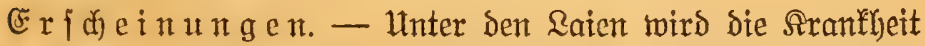

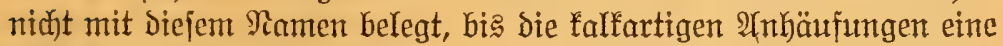
Gedeutende (šröße erreidyt haben und furdjtbares Reiden verurfachen;

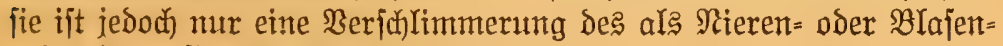
gries (gravel) befanten 3uitandes. 


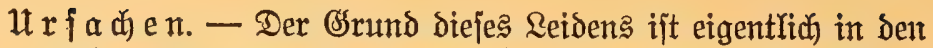
Nieren zu juthen; Dent obgleidy man häuftger Steine in der Blaje alঙ

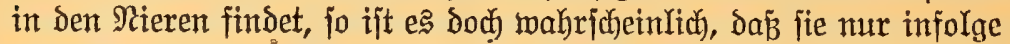
eines unnatürlidyèn Bujtandes des durd bie Nieren ausgejonderten

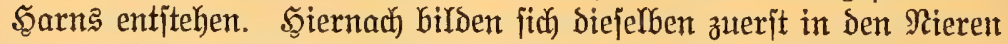
und werden mit dem Sarn durch bie SarnIeiter, ehe fie einen groß̈en Ilmfang erbalten haben, in die Blaje geffhafft, two fie alşann immer

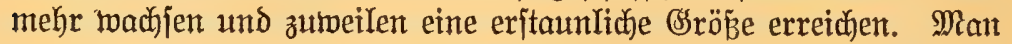
hat Durch operative Berfahren Steine aus der Blaje entfernt, dic

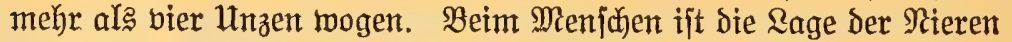
beinahe jenfredjt über ber BIaje, modurdh fdyon bie Sdjwertraft den. IYGgang ber falfartigen Maffen beförbert. Dies ift aber nidyt ber Fall beim ßferde. Die SarnYeiter haben bei Demjelben eine beinake

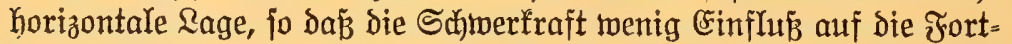
idfaffung frembartiger Rörper hat, bie fich in den Nieren gebildot. haben; Daher bleiben Steine nidyt felten in den Rieren Des \$Ferde:,

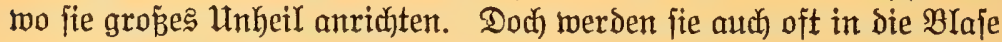

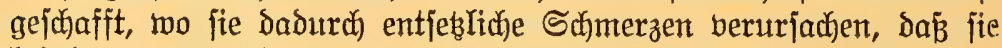
bei den Şarnentleerungen an Den Blajenhals geiffwemmt merden

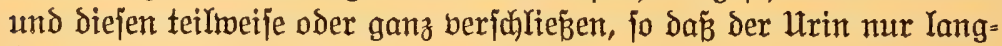
fam oder gar nidjt abfließsen fann.

Man fann nicht mit Beptimmitheit auf bas Borhandenfein von Nierenjteinen jafließ̈en; menn aber ber ફarm unbolffommen entleert wird und wir biejen $1 \mathfrak{m}$ itand auf feine andere Sranfheit der Blaf:

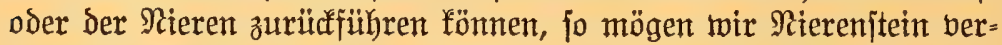
muten. Sind fie aber in ber BIaje, fo fann man fich Yeidjt dadurd)

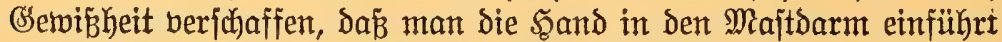
und mit Den Fingern Den Stein in Der Blaje fühlt, weldje unterbalb

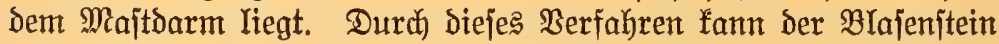
immer entbect werden, menn er nidjt zu flein ijt.

Die Durd) Rieren= oder BYajenjteine berurjadyten Sdymerzen fint

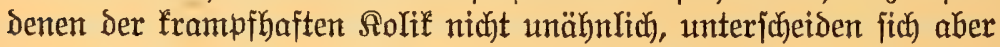

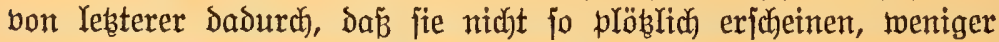
heftig berYaufen, und bie Betwegungen bes Tieres auf eine meiter

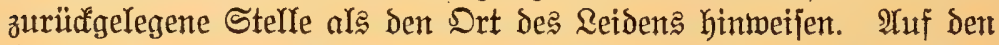

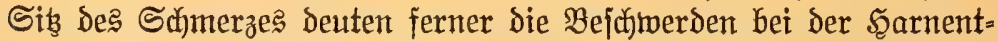
Yeerung, bie gemöhnlidi mit dem heftigiten Drängen und itarfen Sd)merzäukerungen begleitet find, und wie wir fidjon bemerft haben,

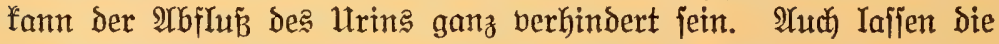

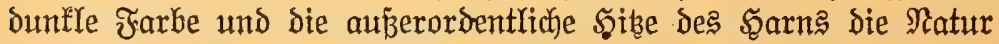




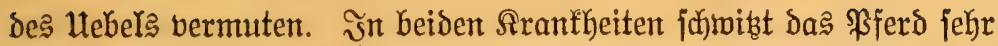

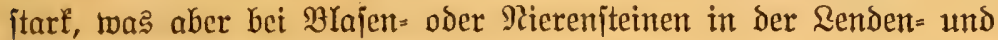
Meidjengegend am jtärfiten borf́ommt.

Die Sdjmerzen, weldje Blajenjteine verurjachen, find von ber

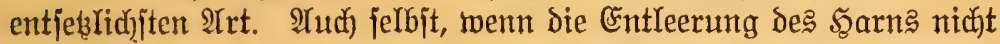
fehr behinbert ijt, fo entitehen bod fidon von ber (Srö̈̈e und Schwere

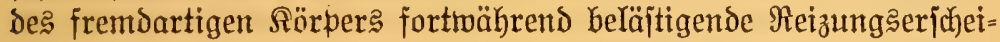
nungen, und nidyt felten wird bie empfindlidje Sdjleimbaut der Blaje Durdj) die rauke, unebene Sberfläche der Steine bedenflich verwundet.

(słüdfidjerweife fommen joldje Fälle nur äuß̉erit jelten vor, aber fie gehören 孔 Den hartnädigften aller \$ferdefrantheiten. Selbit in Den Ieidhten Fällen bergeht eine geraume Beit, ehe fich Befferung einjtellt, und in Den jaflimmern trobst die Arantheit jeder Behand=

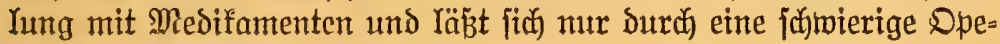
ration, ben Steinfornitt, bejeitigen.

$\mathfrak{B}$ e $\mathfrak{h}$ a $\mathfrak{n} \delta \mathfrak{l} u \mathfrak{n}$ g. - Wix wenden ztwei $\mathfrak{A r z n e i m i t t e l ~ a n , ~ w o b o n ~}$ beide heiljam gewirft, beide aber audi oft ganz erfolglos waren, was jich bon jeder Methode behaupten lä̈t. șm Folgenden werden wir das Mittel zuerit anführen, welches fich in unjerer Praris am bejten bewährt hat.

Die erite Medizin beiteht aus Sted)apfeljamen (jimson seed). Die Dojis diejes Mittels ijt eine Unze oder ein jtarfer EBßöffel boll

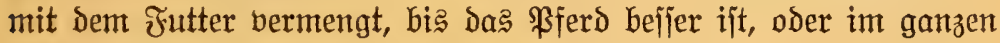
fünf bis jedjs Dojen eingegeben jind. SSleidjzeitig gibt man jefr jaft=

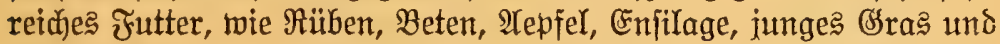
dünnes Brühfutter. Sann ein mit BIajenjteinen behaftetes ßfero mehrere Monate auf ber Meide bleiben, jo ift bas in den meiften Fällen bie bejte §ur zur Entfernung ber Blajenjteine und der beiden vorker genamnten franthaften Erjudeimungen bes Urins.

Sarnberitopiung. - $\mathfrak{U}$ s Symptom des Blajeniteins haben wir

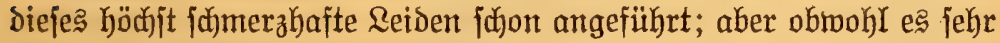
oft bon bem Blajenjtein abłängt, jo fommt e马 Dod) aud häufig unter

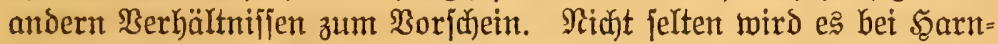
röhrenberengerung beobachtet, die oft infolge bon Berlebungen ent= fteht. Die Sarnröhre führt von Dem Blajenhals bis zur Dberfläche

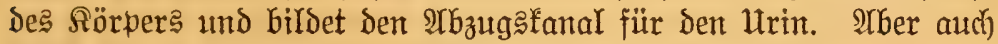

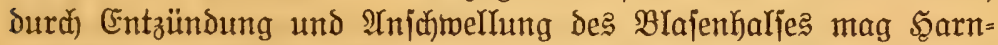
veritopiung entitehen. Was auth die Urjache diejes Ulebela jein mag, jo ijt es immer von den entfebslidjiten Sdjmerzen begleitet. 


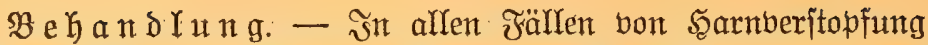
gebe man 1 ltnze Salpeteräther (sweet spirits of nitre) in einent

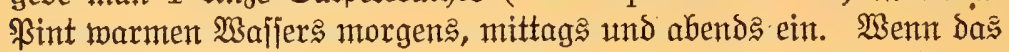
Hebel infolge bon Rieren= oder Brajengries entitanden ijt, jo follten aud) Die übrigen für die Rranfheit angegebenen Mittel angemantst werden. Sind die betroffenen Sörperteile jtart angejdyworlen, jo

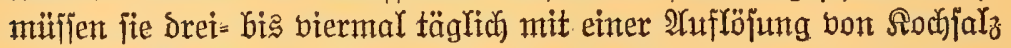
in faltem Majjer getwajden werden.

Blajenentzïnoung (inflammation of the bladder).

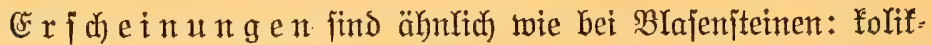
artige Sa)merzen, Steifheit in Den Şinterbeinen, Drängen zum Sarn= Iajien ujw. Beinahe immer wird Blajenentzünoung ourd) Blajen= grię oder Blajenitein verurjadyt, entiteht aber zumeilen ohne borher= gehendes Blajenleiden. Ssemöhnlich wird nur ber Blajentals von ber Srantheit betroffen und jelten bie im šnnern ber Blaje gefundene S(hleimbaut oder aud die äubere Mußfellyaut.

It $r$ ja d) e n. - Mehr oder wentger Entzündung fommt beim

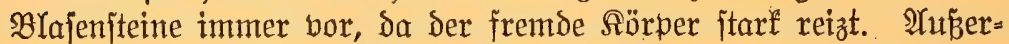

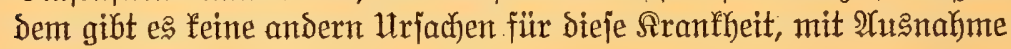

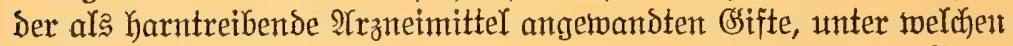

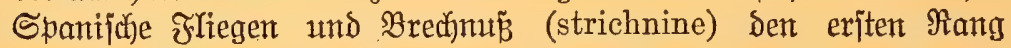
einnehmen.

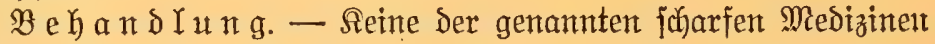
(ङpanifche Fliegen, Ierpentin ujw.) Darf mehr eingegeben werdent. Der Urin mußs aus Der Blaje Durdh Einfüfrutg einer Röhre (catheter) entfernt werden; nach Der Entleerung wird Durch die Röhre Borarwafier (1 Unze Borar in 1 Duart $\mathfrak{B a f j e r}$ aufgelöjt) eingeführt. Dies ift täglich oreimal auszuführen. Wenn die jutweren Rranflyeits=

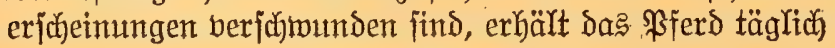

Buchu 1 dram,

Powd. nux vomica 1/2 dram;

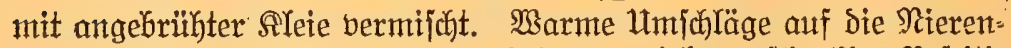
gegend mildern bie Sdymerzen und tragen viel zur janellen Bejeiti= gutng ber ๔ntzünoung bei.

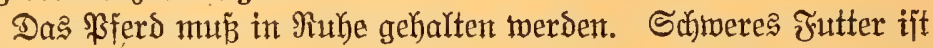
ifm auf Yängere Beit ganz zu entzieben, und menn Der Figentümer

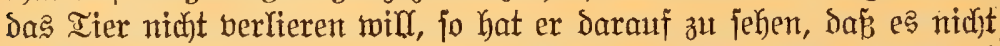
mit fifjimmligem Seu oder andern verborbenen Futterjtoffen gefüttert wirs. Non Mais ift auf löngere Beit nur ein jehr jparfamer Gse= braudf) 孔u macken. 


\section{Bantuber Sdjlautd (foul sheath).}

Der rumbe Sablauch ift ein fprechender Beweig für bie Sorg.

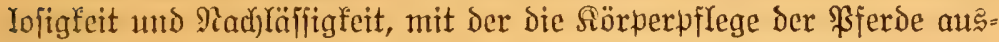

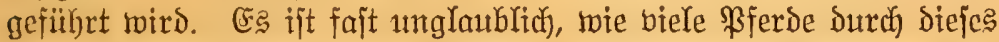
11ebel herunterfommen umb zumeifen fogar zugrunde gehen; und nidjt minser jelten berurjacht es andere heftige Sranfheiten. Sthon mandjes gute Bferd ift durdh 1tnachtfamfeit in diejem \$unfte auf Iange Beit und viele lebenzlänglich unbrantchbar getworden. Das fo

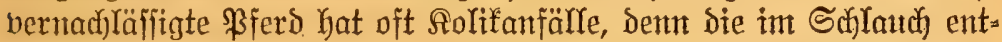
itandone Entzündung gibt fich bald burch einen unberfennbaren cin= fhủ auf die Gsedärme fund.

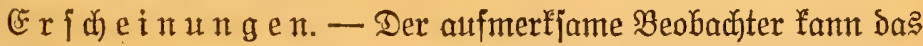

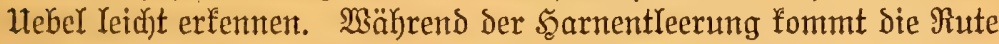
nicht mehr aus dem Schlaudhe herbor, und ber Utrin juheint aus biejem

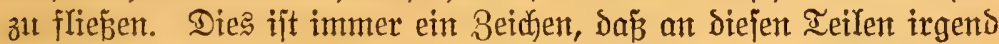
ein franfhafter 3 utand fich borfindet. Da? Tier jobeint Sifmerzent in Sen Yeidenden Drganen zu empfinden. Die Şüfen find fteif and die Sinterbeine werden weit außeinanier gehalten, samit die entzün=

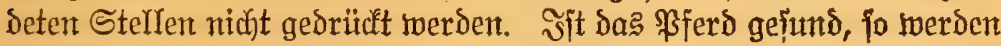
Die Şinterbeinte nach binten und zur Seite auggejtredt, und jelbjt in

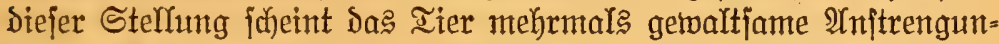
gen machen zu müfjen, ehe ber Şarn in einem reidjlichen Strom

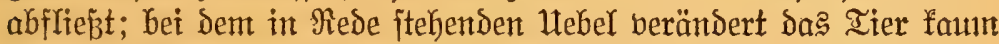

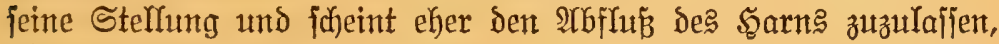
als Durch Drängen herbeizuführen. Dies findet barin feine Ertłä= nung, daßj jede Bemegung und bejonders 3ujanmenziehungen ber mit diejen Drganen in $\mathfrak{B}$ erbindung itehenden Musfeln Dem Iiere Sd)merzent verurjacjen.

Ut rfa disen. - Das Hebel bejtebt in einer 2 Anbäufung bon

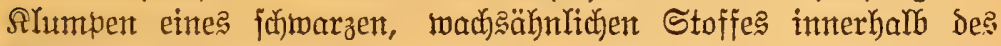
Sdflauthes. Bumeilen findet man mut einen Slumpen, gemöhnlixh

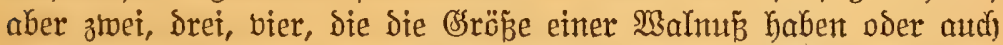
ben IImfang eines groß̉en Szühnereis erreidjen. Menn diejelben

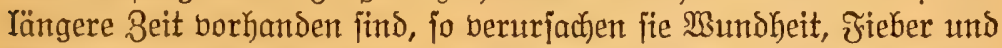

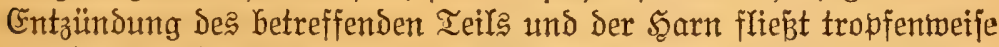
aus Dem Shlatude herbor. Bald fangen die entzündeten Stellen zu

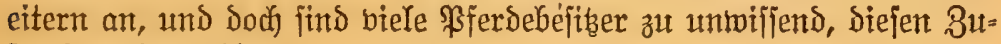
ftand зu beurteilen.

Der wumbe Shlaud ift eng mit Fieber und andern Sranflyeits= erjodeinungen ber Sgarnorgane berbunden und wird oft von denjelben 
Gerborgebrad)t. SIber nod, hälffiger verurjad)t Derjelbe andere Befduwerben. Bei alten \$ferden trifft mant bas Ulebel häufiger als bei jungen an, biclleid)t weil ber Stoff, weldyer abgejondert wird, unt

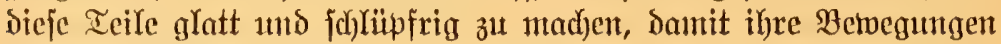

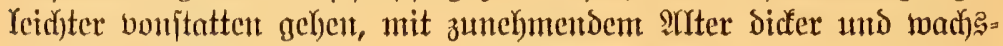
ähnlidjer twird.

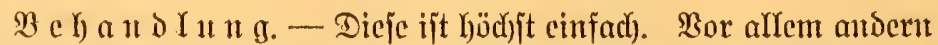

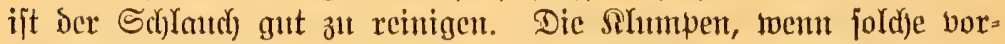

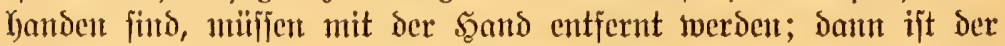

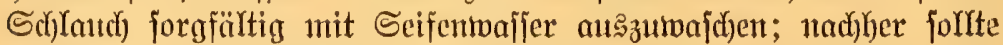

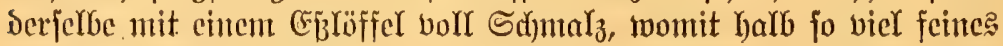
Iodjjalz gemijut worden ijt, eingejumiert wersent. Diejes bringe man jorgfältig mit Der gauzen immeren Fläd)e bes Sdjlaudfes in $\mathfrak{B} e=$

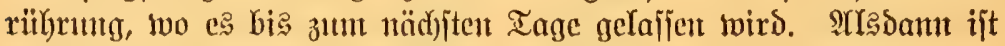
ber Schland nodymales mit Scife und Maffer zu reinigen und mit

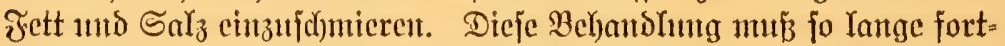
gejest merden, biz bie betreffenden Teile gejund fint, oder bis ber

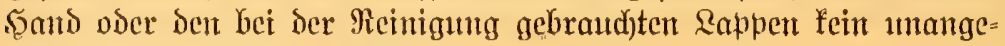
nefmer (Sserutd) melyr anthängt.

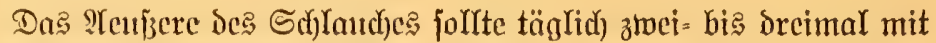
falten $\mathfrak{B a f j e r ~ g e m a j d e n ~ w e r b e n , ~ w e n n ~ c s ~ S o m m e r ~ i j t , ~ a b e r ~ i m ~}$

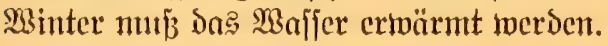




\section{4. 筑apififel.}

\section{Sranfyeiten bex Itmunģorgaue.}

8u Den Drganen, weLd)e zux Einatmung ber Suft und berel ßeiterführung in ben Siörper Dienen, gehören: Die Rajenöffnungen

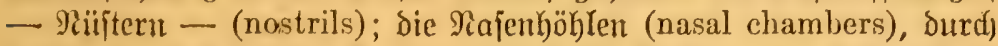
weld)e bie Ruft in den Sropf geleitet twird; Radjen oder S(t)lundfopf (pharynx); Der Siehlfopf (larynx); die 2uftröhre (wind pipe); die

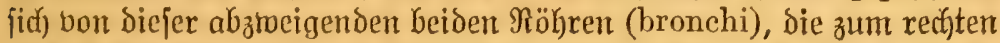

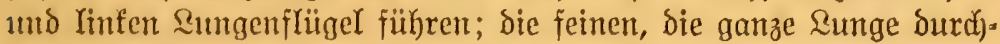

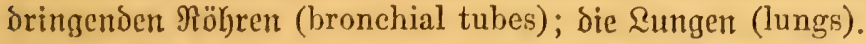

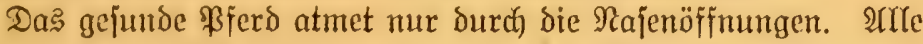
ITtmunģorgane find Yeidjter und mebr Siranfjeiten ausgejebt, alj irgendrwelde Drgane, die mit andern Seörperfunttionen in Berbin.

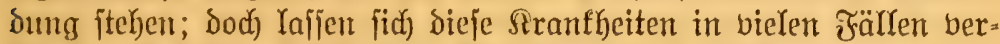
hüten und jollte es fidf) jeder $\mathfrak{B f e r d e b e j i z e r ~ d e s h a l b ~ a n g e l e g e n ~ j e i n ~}$

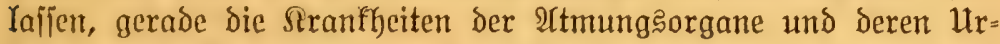
fadjen genau fennen zu Yernen.

Eine gewölnulidje Erfältung, toenn bernachläffigt, mag in eine sungenentzïndung ausarten, bie töblid) berlaufen fann. J̃m Früh. jahyr und Serbit, wenn die Tiere das Şaar wedjfeln, find fie bor allem zu biejer Siranfheit geneigt, und jollte beshalb ganz bejon. Dere Sorgfalt auf die Pflege ber Pferde in biejen Jahreszeiten berwendet twerden.

Ställe mit fdjled)ter, oumpfer ミuft, aljo ohne gute Bentilation, find häufig Urjache bon Sranflbeiten Der Attmungsorgane. Mant nimmt tookl an, Daß̧ Ställe auf ber Farm im allgemeinen gejunder jeien alङ bie in Stäbten; das ijt ein Jrrtum, denn bie Stallungen auf Den Farmen find nidjt jelten jo fehlerhaft gebaut, baßj ein (Ent=

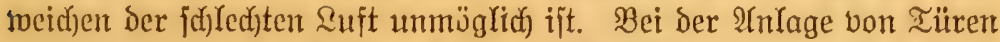

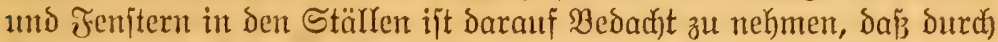
die Deffnumgen die einjtrömende falte suit bie Tiere nicft trifft. Nur burd) gute Bentilationsborridjtungen fann bas Finitrömen reiner Sult erreidjt werden. Salte, geid)lofiene Stallräume habelt jtetફ

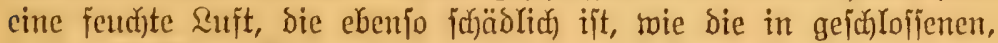

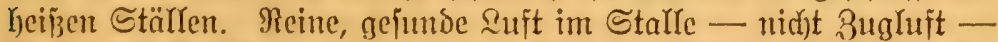

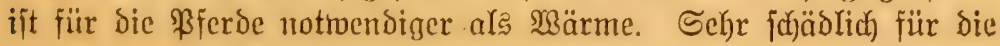




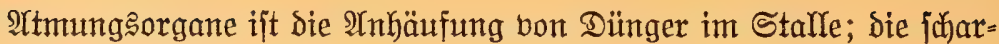

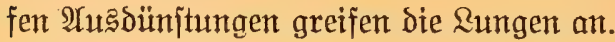

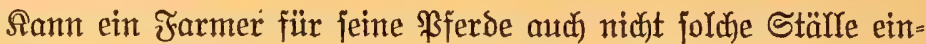

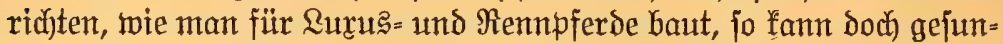

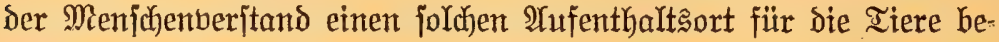
jüaffen, baß̈ beren হeben nicht gefäbrdet ijt. Borteil.

Der \$ferdebejiber hat von einem guten Stalle den größten

Bumben an Den Rilitern (wounds about the nostrils).

Nidjt felten läuft ein \$ferd gegen joharfe Begenftände im Stall oder

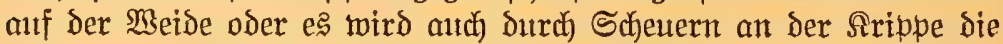

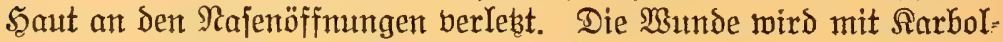
wafịer - 1 Teil Sarbolfäure (carbolic acid) und 40 Ieilen Waffer

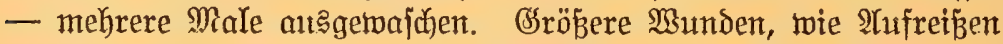

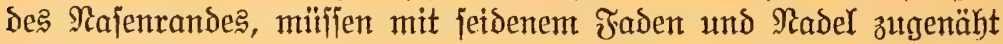

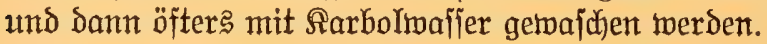

\section{(Sejd)müre in ber Naje (tumors within the nostrils).}

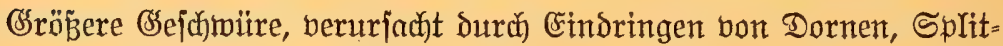

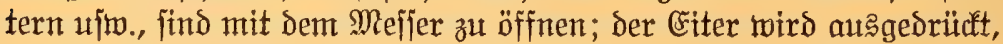
nachdem der vorhandente frembe Segenjtand entfernt torden ijt. Durch) Itustwajchen mit Sarbolwaffer wird bie Munde rein gebalten.

\section{Rajenfatarrf (nasal gleet).}

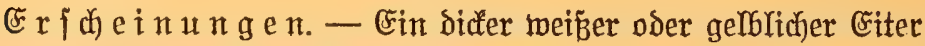

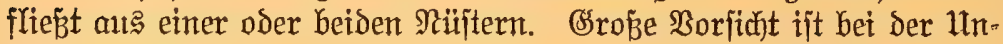

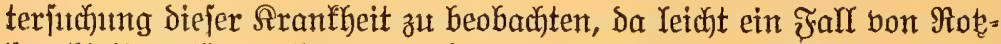
tranfheit borliegen fonn und lebtere auf Menjuen übertragbar und unheilbar ift. Ssewöhnlicher Rajenfatarrh ift nicht anjtedend, weder für Menjuen noch fïr Pferde; doch ijt er oft febr jobierig zu heilen. Bemöhnlich find nicht mit bie Niiftern, jondern aud höher im Ropf Yiegende Ieile angegriffen und bie Drüjen ztwifhen und unter bett Simubadenfnodjen zeigen dutrd) (Sejumulft ihre Entzündung an. Das Ifuge an ber Seite, deren Driifen entzündet find, mag ein merfmür:

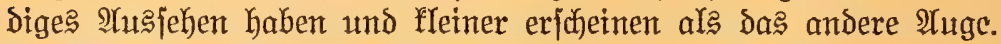

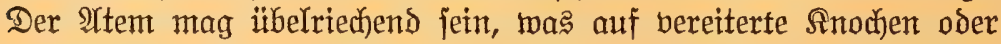

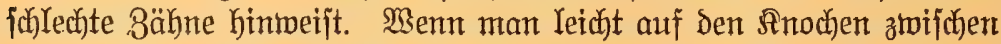
und unter Den $\mathfrak{A}$ ugen utnd aut Den Sinnbactentnodjen hinter Den obern Badtenzähnen flopft, jo gibt es einen hohlen, trommelartigen Ion. Das Saar über Den angegriffenen Stellen mag ftruppig erjodeinen. 


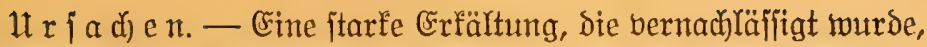
ift die häufigite 1lrjache des ఇajenfatarrhs. Seltener wird die ßrant: heit Durd) Berlebung - Sdjlag oder Stop̉ - Der Rntodhen (Najen= Geine) und ber Sdhleimbäute odcr burch jujashafte Bähnte her= borgerufen.

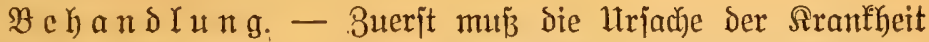
feitgejtelrt werben, bevor man zur Behandlung derjelben jarreitet.

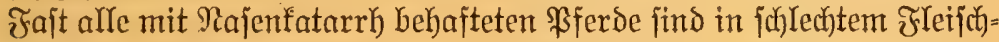
3ujtande; fräftige Ernährung uns Betwegung im Freien - nidjit Yrbeit - ift beahalb nötig. Der Futterfajten follte auf ber Erde

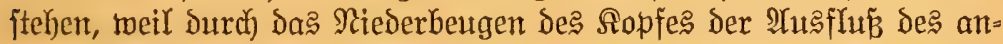
gejammelten citers befördert wiro.

Bci bielen, bejonders bei veralteten Entzündungen biejer $\mathfrak{A}$ rt ijt eine Entfernung ber angegriffenen Inodjen Durch Speration not= mentig. Seidjtere Fälle verlangen eine lange $\mathfrak{B}$ ehandlung mit $\mathfrak{A} \mathfrak{r}_{\mathfrak{z}}=$

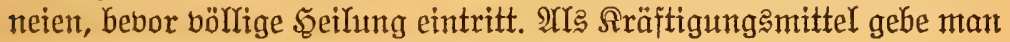
reduced iron $3 \mathrm{oz}$., powdered nux romica $1 \mathrm{oz}$.

Die Mijudung twird in 16 ßulver eingeteilt und erhält das \$FFerd morgens und abends je eins der ßulver mit dem ssetreibefutter

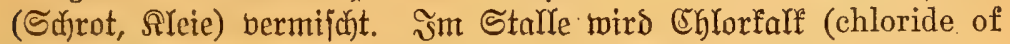

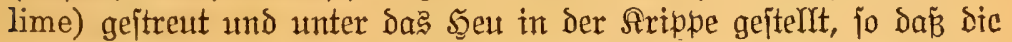
auştrömenden Saje bon sem Iiere eingeatmet werden müfíen. Die

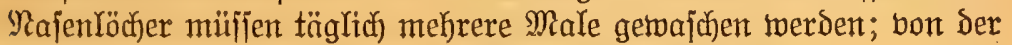
Srippe ift Der Eiter vor jeder Fütterung abzuwajden.

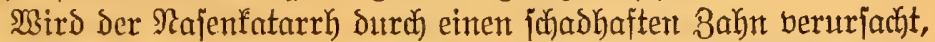
fo muß derjelbe ausgezogen merden; Sie Eiterhöhle twird dadurh ge= öffnet und farn die (Entzündung ourd) Finfpribung bon SInzerin (glycerine) (1 Iein und listerine (2 Ieile) jidnell geheilt werden.

शnjenbluten (bleeding from the nose).

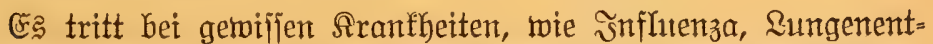
zündung, Rosffranfheit ujw. auf; Doch fommt es aud unabhängig bon andern Sranfheiten bor, beranlapt Durch Berlebungen beᄅ Sopfe马 ober ftarfes Riejen, wodurd fleine Irdern zerriffen wurden. Da?

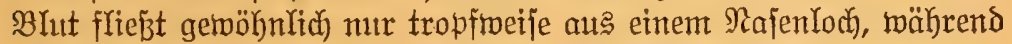

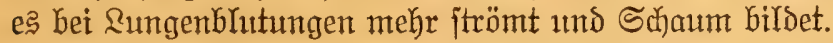

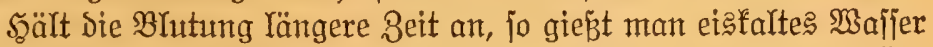

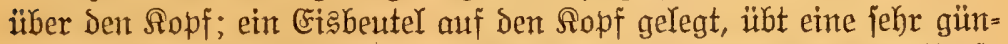

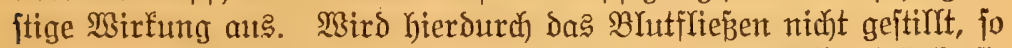
nimmt man ßatte, jadnürt einen Bindfaden um diejelbe, tränft fie 


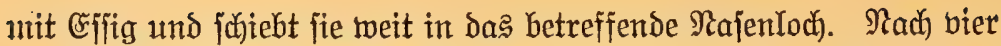
oder fünf Stunden fann der Baummollpfropfen an Dem Bindfaden herausgezogen werden. Wenn das Bhut aus beiden Najenlödhern

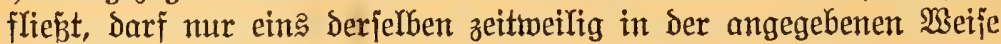
verjd)lofien werden.

(Sntz̈̈ndung des Reflffopfes, Şuften (laryngitis).

Der Rehlfopf (larynx) liegt zmijhen den beiden Rinnbacten= fnodben unmittelbar finter ber Bungenwurzel. Die Entzündung

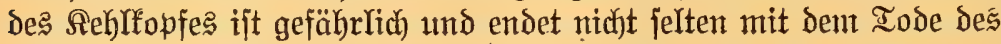
Iieres; gewöhnlich Defnt fich bie (Entzündung aud auf Den Sd)lund= fopf (pharynx) aus.

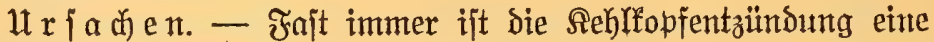
Folge bon Erfältung, bie durch längeres Stehen in faltem Regen oder jatjarfer 3ughtuft herborgerufen wurde.

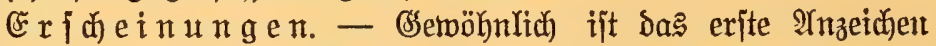

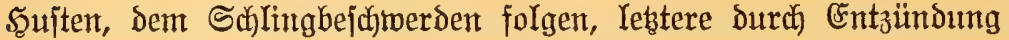
Des Sd)lundfopfes berurjadit, über den Jutter und Trinftwajjer hin= weggleiten müij̄en. Ĩn mandjen Fällen twird das Sd)ludfen unmög= Iich und Futter und $\mathfrak{B a j i e r ~ I a u f e n ~ a u s ~ d e n ~ R a j e n l o ̈ c h e r n ~ h e r a u s . ~ D i e ~}$

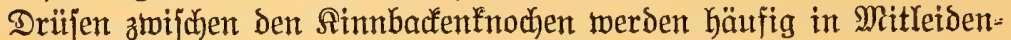
jifaft gezogen und jind angeictwollen. Der Sopf wirs bortwärts ge= jtrect't ud jteif getragen. Die Sd)leimhaut der Najenlörber erjheint

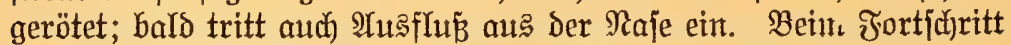

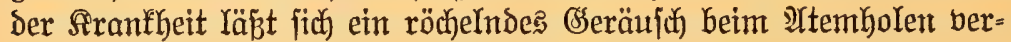

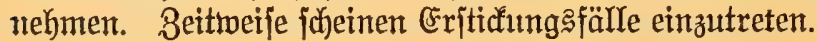

$\mathfrak{B}$ e $\mathfrak{h} \mathfrak{a} \mathfrak{n} \delta \mathfrak{l} \mathfrak{u} \mathfrak{g}$. - Einatmen von $\mathfrak{B a j j e r \delta a ̈ m p f e n ~ w i r f t ~ j e h r ~}$ günjtig; in foblimmen Fällen follte jede zehn oder fünfzehn Minuten ein frijher Eimer mit fodjendem $\mathfrak{B a f f e r}$ unter Den fopf Des Tieres geitellt werden. In jeden Fimer wird ein Eहblöffel boll Terpentin

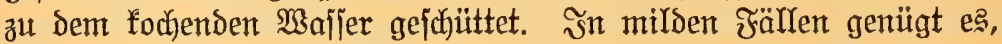
wenn bieje Behandlung fünf= bis jiebenmal täglth borgenommen wird; in jđjweren Fällen müb das Einatmen ber Mafferdämpfe ftumbenlang ohne Unterbrechung angewandt werdent.

Das Rjerd pollte in einem bequemen Stand jtehen; bor allem ijt für reine Ruft im Stalle zu jorgen. Da马 Jutter follte aus angebrüh= ter Sleie, angebrühtem Şafer und Reinjamentränfe bejtehen.

Mit einem Riniment, bejteheno aus

2 oz. olive oil,

$1 \mathrm{oz}$. solution of ammonia,

$1 \mathrm{oz}$. tincture of cantharides. 
(gut zu jujütteln vor sem Ssebrauch) wird die Riphlfopfgegend bout einem Dhr bis zum andern und jed) Boll an Der Ruftröhre, fowie

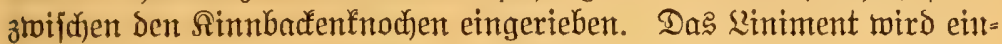
ntal täglich ztwei oder orei Iage hintereinander angetwandt.

Sieuden, Bfeifen (thick wind, roaring, grunting).

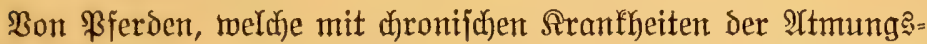
organe behaftet find, twodurd beim ritmen cin itarfes, umatüriches (Geräu (d) herborgebrad)t wiro, jagt man, fie leiben an Reuthen oder Pfeifen (niç)t zu vermechjeln mit Dämpfigfeit - heaves.) Berichic=

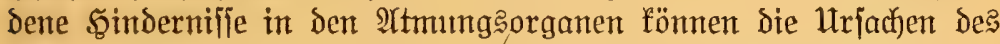

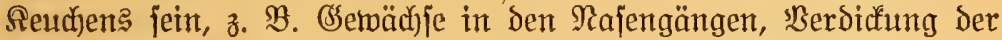

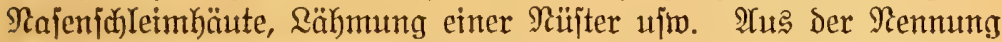

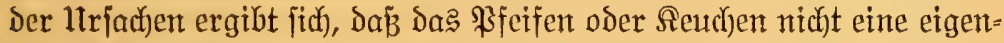

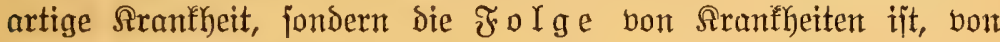
Denen bie verjufiedenen IYtmunggorgane befalfen werden. Es girit

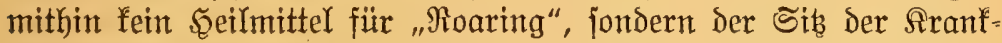

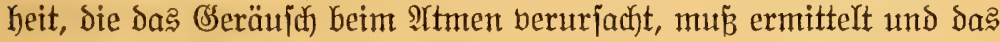

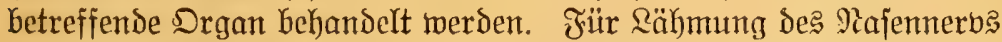

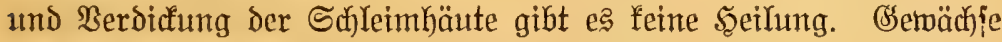
in ber Raje oder andern ITtmungstwegen fönnen nur Durch Speration bon fachtundiger 5̧and entfernt werden.

\section{\&ungenentänoung (lung fever, pneumonia).}

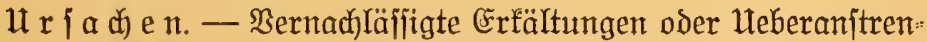
gung des an Erfältung Ieidenden İeres jind die häufigiten Ulrjachen der Rungenentzïnoung. S(f)led)t ventilierte Ställe, in denen durth Infäufung des Düngers eine fđarfe, ungejunde Suft erzeugt wird, find eine Der Saatpturjachen diejer Sranfheit, indem die Runge Da= Durd) angegriffen wird, fo Dap̉ die geringite Erfältung oder fidwere Urbeit eine Entzünoung in bem empfindlichen Drgan herborruft.

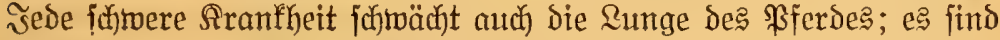

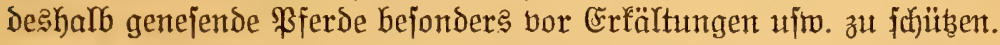

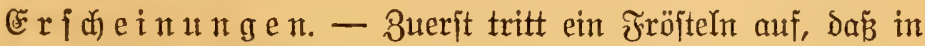

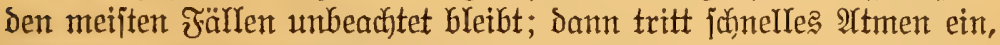
Das Tier läpt Den Sopf hängen und madyt in jeiner ganzen Erichei= nung einen traurigen Eindruct. Das Maul ijt heip und fühlt fith

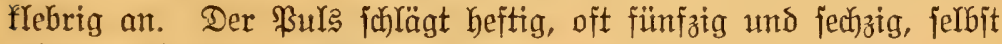

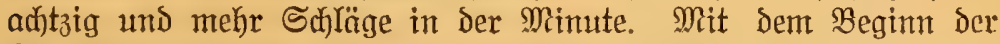
Sranfheit tritt aud fajt immer ein trodner Şujten autf. Nidjt felten ift der Najenaugfluß mit BIutitreifen Durchjest; in andern Fälen ijt 


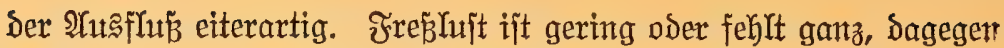

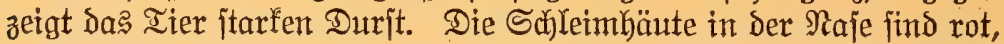
anfänglich trodfent, werden aber jpäter feudst. Die Beine find falt. SartYeibigfeit ift faft immer borfanden, und was ant Dumg abgeht, ijt mit einer fafleimigen Sout überzogen. Der Sarn gebt in fleinerer

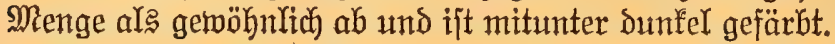

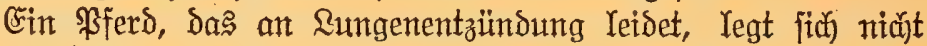
nieder; tritt aber nod) Brujtfellentzündung (pleurisy) hinzu, wie $e^{2}$

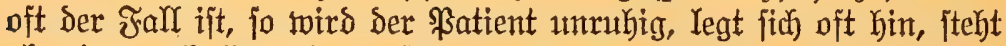
aber immer bald mieder aurf.

Ein gutes Erfennungszetden der Rungenentzündung ift, wemt

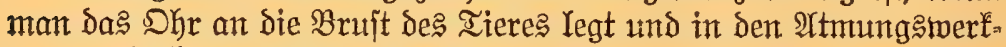
zeltgen ein Iautes, f́nifterndes (šeräuj hört, etwa jo, als wenn man

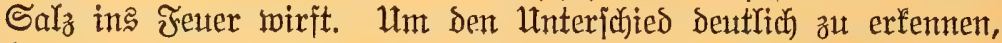

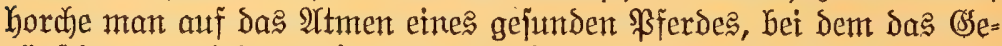

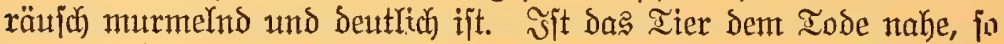
treten alfe Srantheitsericheimumgen in beritärftem Mape auf: bie

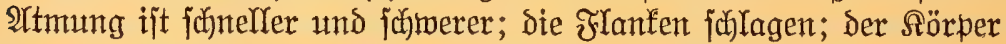

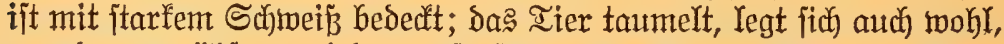
um bant mühjam wieder aufăltehen; es jojmanft hin und her. Soldye Beichen treten nad) zehn bis zwanzig $\mathfrak{I} a g e n$ auf und Deuten das nafe Ende ant. Mendet fich die אranfheit zumt guten, fo ift bas

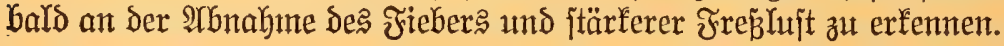

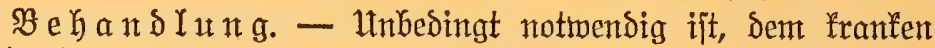

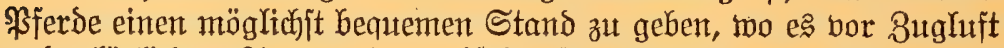

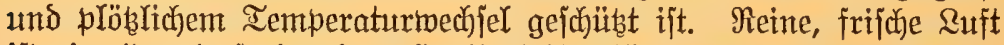

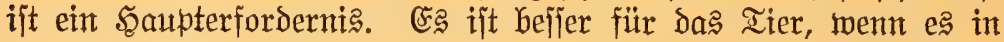

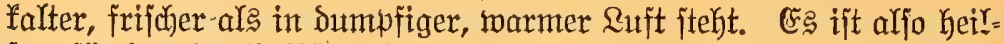
famt für das franfe \$fferd, in falter \&uft - nidft 3ugluft - zu ftehen

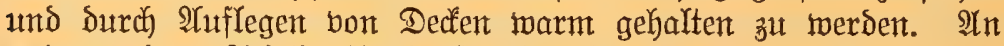
gutem, reinem Trinftafjer Darf es dem Iiere nie fehlen. Die Beine find folange mit dent Sä̈nden zut reiben, Gỉ fie warm gemordent und

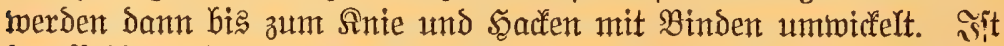

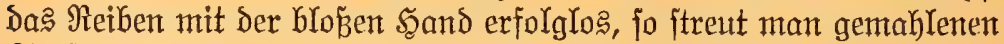
Senf̣ auf Die Sout und reibt diejen ein. Die Binden find täglich ab=

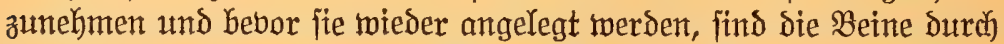

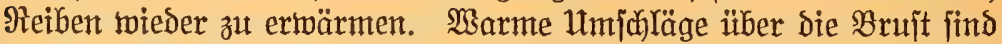

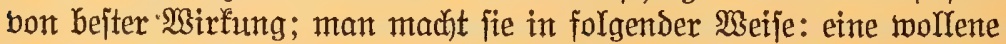

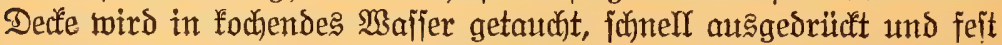

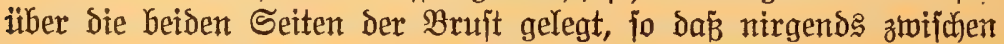

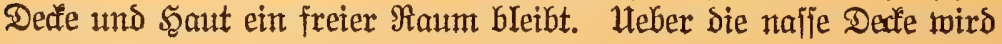




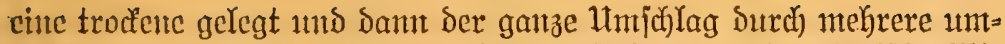

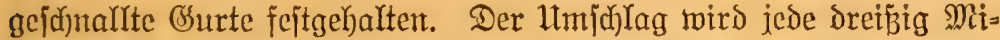
muten toälyrent brei Stunden erneutert. Den Eimer mit bem fochen=

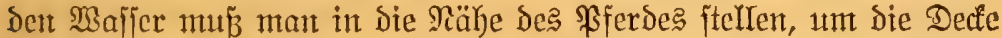

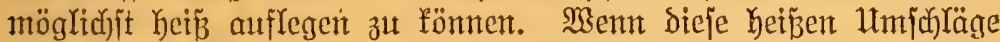
rechtzcitig angetwandt und brei ober vier Iage natjeinander wieder = Golt werben, fo twerden bie meiften Fälle bon 2ungenentzündung ba=

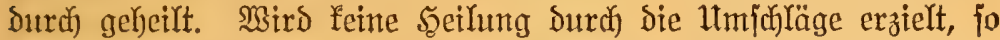
werben Senfpflafter - 1 \$3fund gemahlener Senf mit warment Waijer angerïhrt - unmittelbar Ginter die Sctulterblätter gelegt. Der Senfbrei wird aufgeitrichen, nicht eingerieben, und bann mit einent Bogen \$apier bededt, Darüber eine Decfe. Nact) ein bis ztwei Stunden wirs \$flaiter und Dedfe abgenommen. Banz verfehrt ift es,

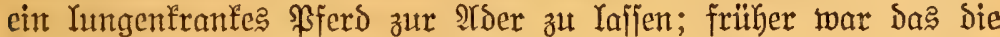
Sauptfur und manches \$fFerd ijt daran zugrunde gegangen, Dap durch ridjtige Behandlung hätte gerettet werden fönnen.

(Fin Fehler ijt e马 auth), Dem \$ferd gewaltjan Shrottränfe eitt=

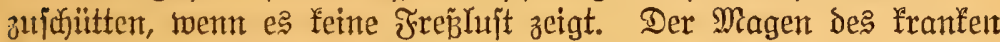
Tieres ijt zu jubmad), irgendetwas verdauen zu fönnen; aljo Rräfte werden ifm daburch niaft gegeben, fondern bie Sartleibigfeit mtr

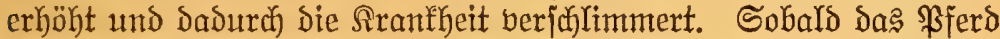
SYppctit zeigt, gebe man ifm Yeidjtberdaulidjes Jutter, wie angebrühte STeie, angebrübten Safer, Reinjamentränfe und gutes Şeu. Itm bas 5ुer子 zu fräftigen, gibt man jeøe oret Stumben 2 drams of tincture

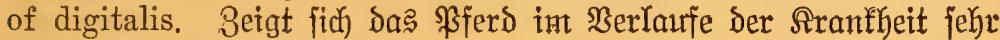
fatwad), fo gibt man ifm

$$
\begin{aligned}
& \text { rectified spirits } 3 \text { oz., } \\
& \text { spirits of nitrous ether } 2 \text { oz., }
\end{aligned}
$$

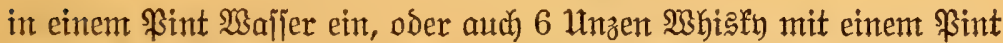
Wafjer verdünnt. Dieje Ssaben f̈önten nach fünf Stunden wieder eingegeben werden. Sit die Rranfheit überitanden, jo muß das \$Fferd allmählich an fräftiges Futter gemöhnt und gut ernährt twerden, um

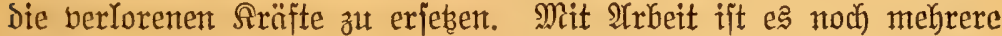
Modjen ganz zu verjofjonen, bafür aber biel Bewegung, went das Metter eミ erlaubt, im Freien zu geben.

\section{Rippenfell= voer $\mathfrak{B r u j t f e l l e n t z ̋ ̈ n d u n g ~ ( p l e u r i s y ) . ~}$}

šeser ¿ungenflïgel ijt nit einer jehr feinen, glänzenoen Şaut

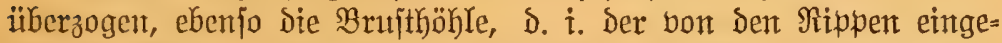

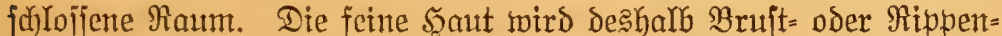
ferr (pleura) genannt; fie jondert im gefunden Bujtande fortwährend 


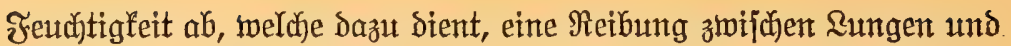
Rippen zu verhüten. Die \&unge debnt fich bei jeder Einatmung bon

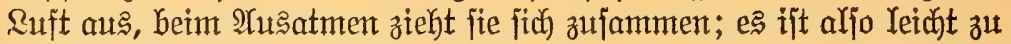
beritehen, Daßj infolge diejer andauernden Betwegung der Runge ge=

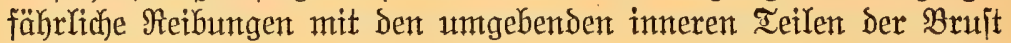
ftattfinden mübten, wenn fich zmijhyen beiden nicht ein Stoff befände,

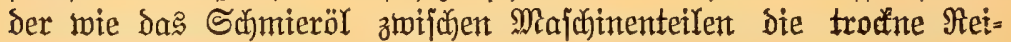
bung berhüitet.

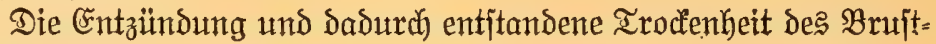
felles wird immer auftreten, wenigitens teilmeije, wenn die Runge entzündet ift, und ungefebrt, Denn beide, \&unge and \$ruftfell, find ja eng miteinander verbundent. ITm häufigften tritt die $\mathfrak{B r u j t f e l l e n t = ~}$ ॐündung an ber redften ̊örperjeite auf.

Er $\mathfrak{j}$ d

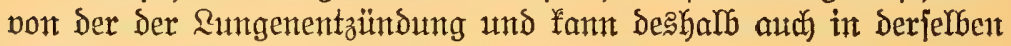
Meije twie dieje behandelt werden.

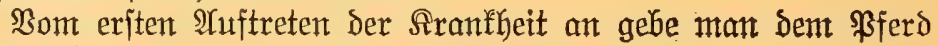
tägYich alle jechs Stunden folgende Mediłin ein:

$3 \mathrm{oz}$. solution of acetate of ammonia,

$1 \mathrm{oz}$. spirits of nitrous ether,

3 drams bicarbonate of potassium,

1 pint of water.

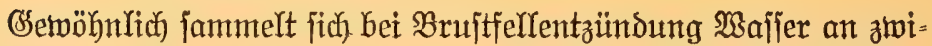

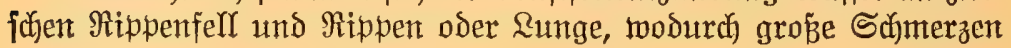

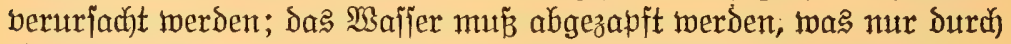
eine Speration bon fachfundiger Şand ausgeführt werden fann.

Däntpfigfeit (heaves. broken wind).

(Éficinungen. - Dieje Srantheit, auch Dampf, Eng=

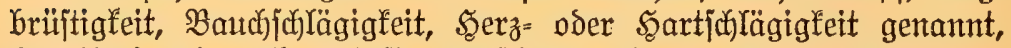
bejtegt in einer łranfhaften Bejaffenheit des Îtembolens ohne

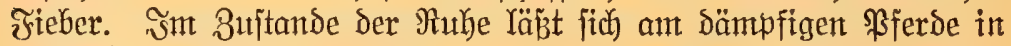
vielen Fällen nidyts Sranfyaftes wahrnehmen; hat das Hebel indejjen einen jehr hohen (srad erreidht, fo machen fid aud fidon im Stande Der Rufye Die Beidfen Der Aranfheit mehr oder wentger bemerffar: das 2 ttmen ijt fichtbar angeitrengt und häufiger als in gejunden $31 t=$ ftande; Dasjelbe mird mit auffallenden Betwegungen ber Flanfen unt Rippen auggeübt, bejonders dann, wenn das \$ferd furze Beit vorker gefreffen hat. Ridjt jeltent ift bon Beit zu Beit aud ein flanglojer, Dumpfer, trodener Şuften wahrzunehmen (trodfener Dampf), 孔u=

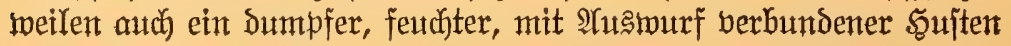




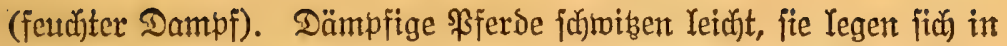
ber Regel nicft ober nur für fürzere Beit und dant gewöfnlich mit

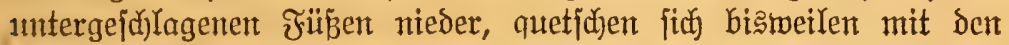
Stollent Der Eijen die EMenbogenhöcter, woourd die jogenannten Stolfenbeulen entitehen und madjen fich mitunter f(t)on hierdurd fenntlich. (Sanz entjofieden und Deutlid tritt bie Dämpfigteit in der Regel erit bann hervor, twent bas mit ihr behaftete \$ferd einer

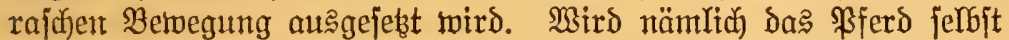

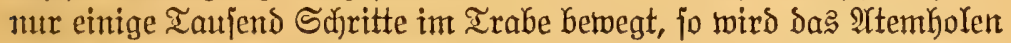
fdjon hierourd) auffallend häufig und angejtrengt, indem jich, wenn

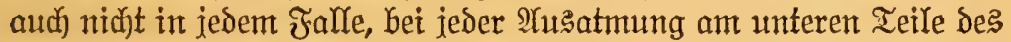
Baudjes eine tiefe Rinne, Die jogenannte Dampfrinne bildet; die Flanten rerden dabei jebr jtart bewegt und ber 2 ffer macht bei dem Fin= und IYlabatmen meiftens eine Bewegung abrechjelnd nach bor.

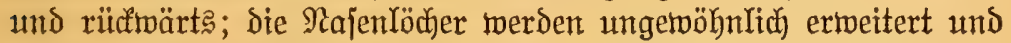
nadj einer jebr rajdjen und ankaltenten Bewegung fommt das ßFerd

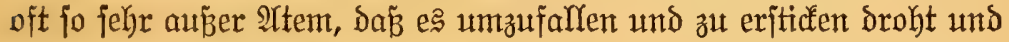
oft einen röchelnden, funnaufenden oder pfeifenden Ion hören Yäpt; dies namentlid) Dann, ment es an Derjentgen Form des Dampfes

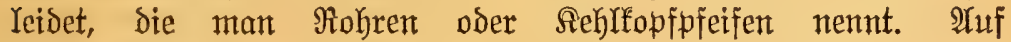
gleidje Weije wird das Irtembolen berändert, wenn das dämpfige

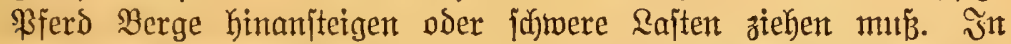

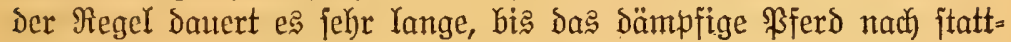
gehabter Bewegung wieder zu ruhigerem SYTtem fommt. Meijten? hat

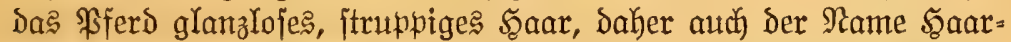

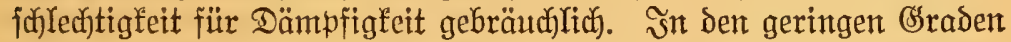

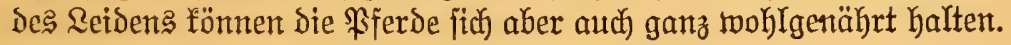

Ut r fa di en. - Die Urjachen der Sämpfigleit find nicht in jedem Falle genau zu ermitteln; vorangegangene \&ungenentzündung,

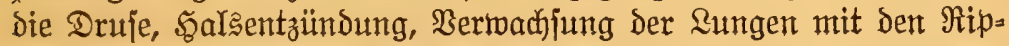
pen, Erweiterung und Erjoflaffung der \&uftzellen, Rajenpolypen, Berengerıttg Der Stimmrike infolge bon teilmeifer 2ähmung ber

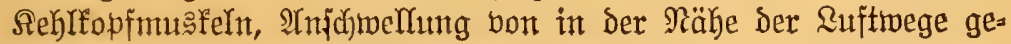
Yegenten Drüjen, Fehler in Den Rlappenapparaten Des Şerzens ujw. gebent nidjt felten ミeranlafiung zu Dämpfigfeit. Damn f้ann audh biejelbe hervorgebradjt merden burd anfaltendes und übertriebenes

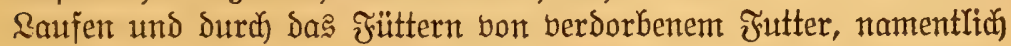
von jujimmeligem und dumpfigem Қeu. Manchmal wird die Dämp= figfeit wie beim Menjiben Durdh eine übertriebene Fettleibigfeit und

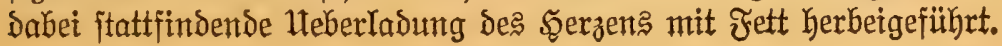




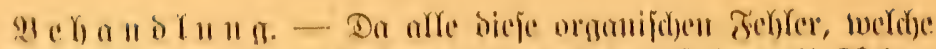

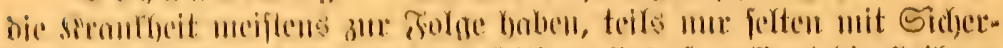

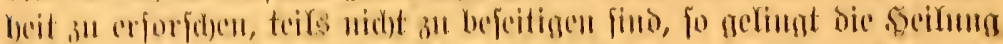

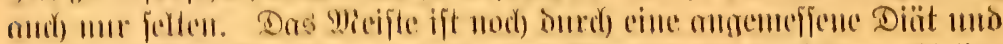

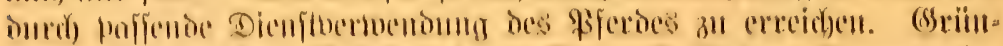

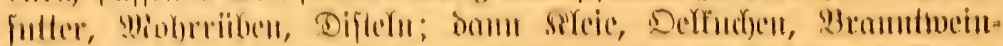

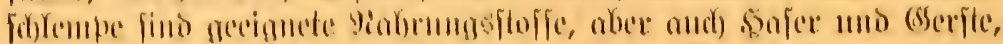

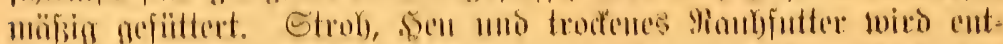

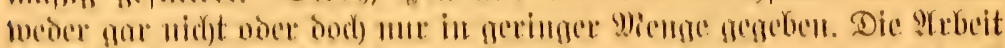

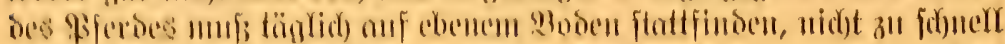

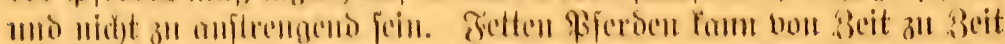

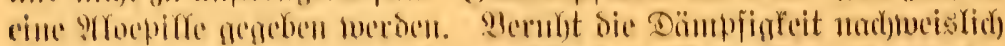

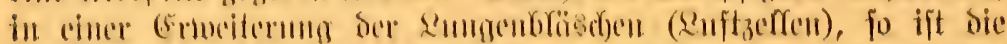

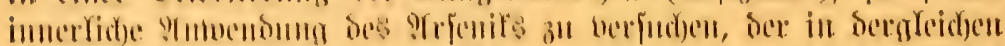

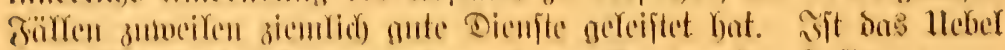

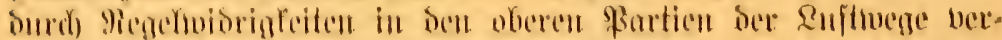

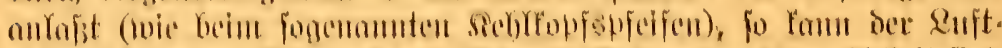

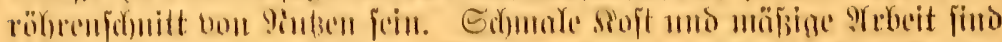

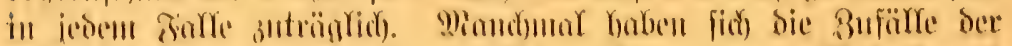

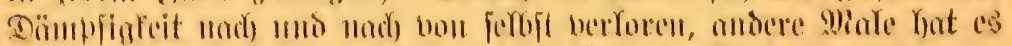

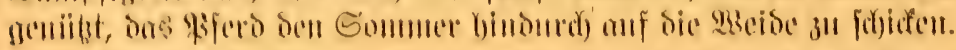

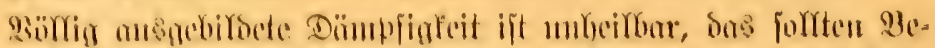

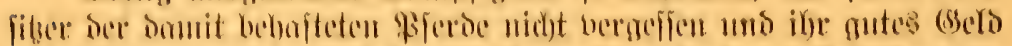

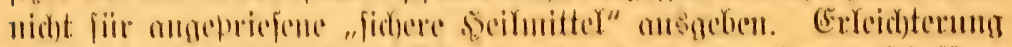

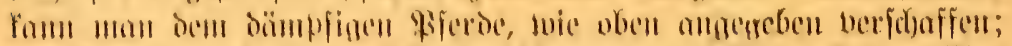

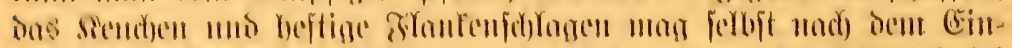

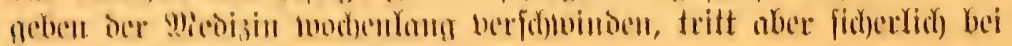

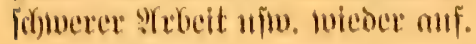

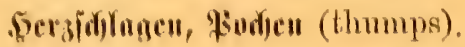

(E) r f

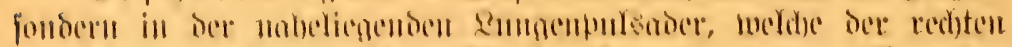

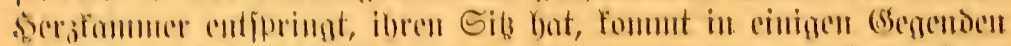

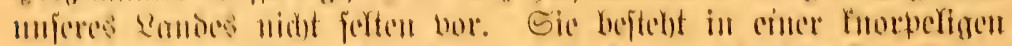

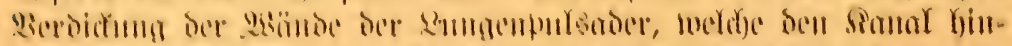

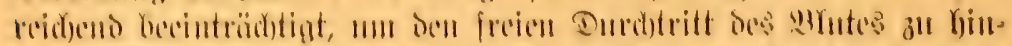

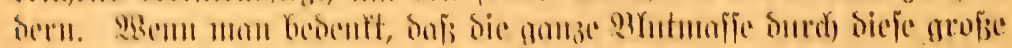

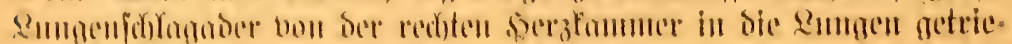

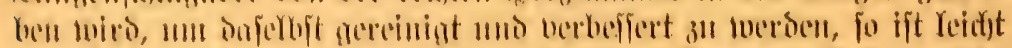

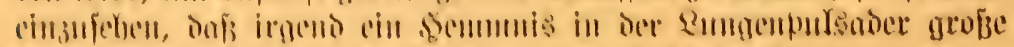

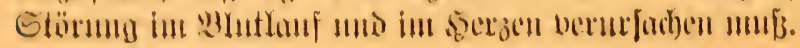




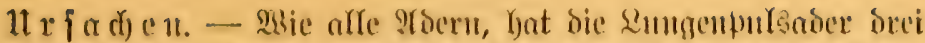

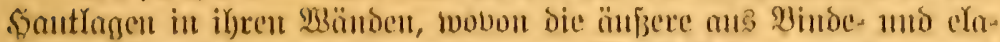

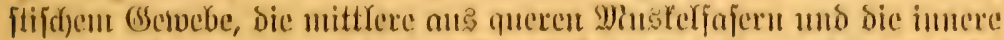

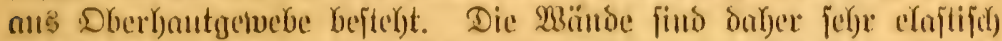

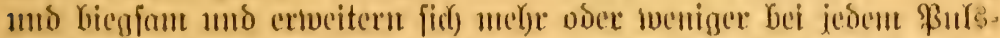

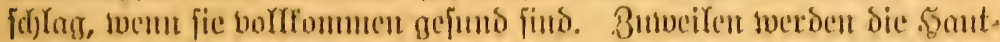

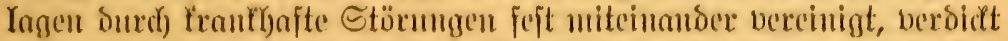

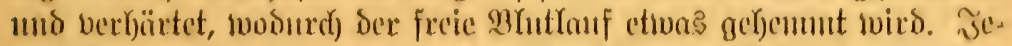

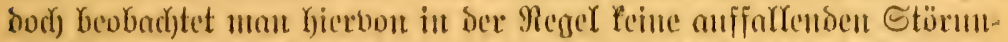

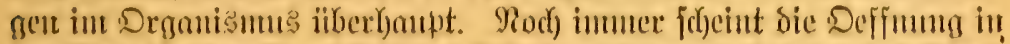

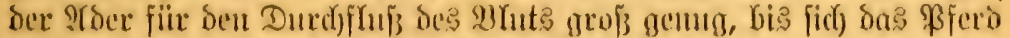

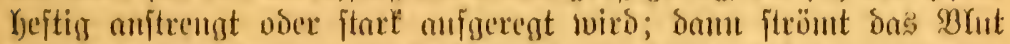

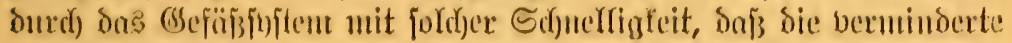

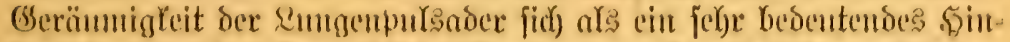

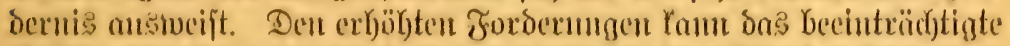

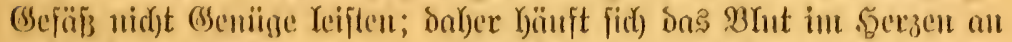

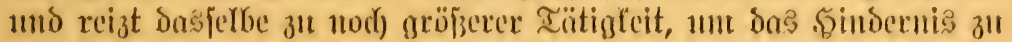

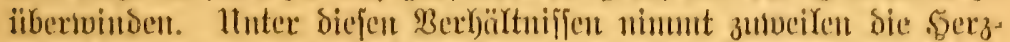

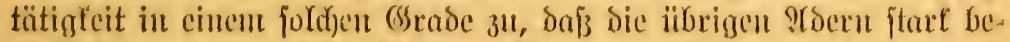

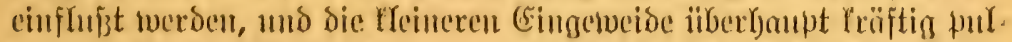

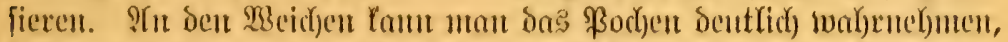

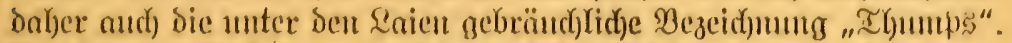

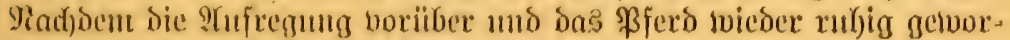
ben ift, Yjört bas heftige \$ulficren auf.

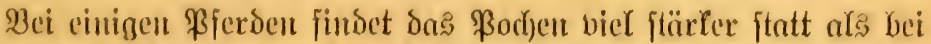

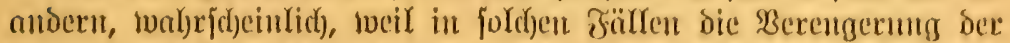

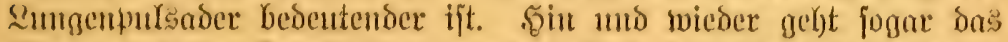

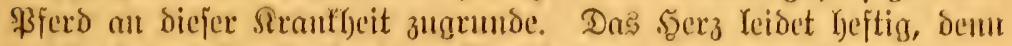

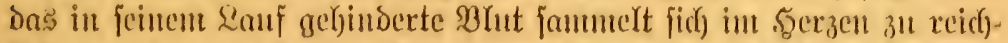

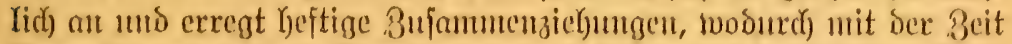

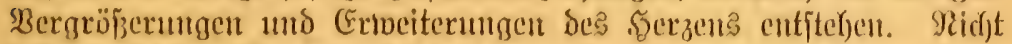

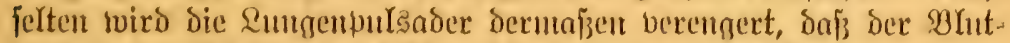

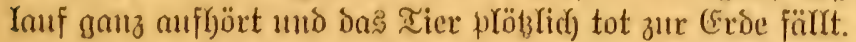

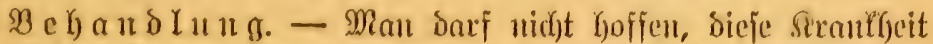

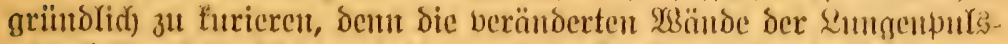

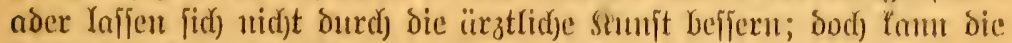

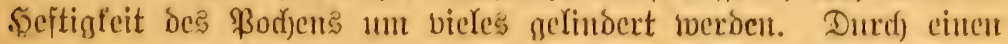

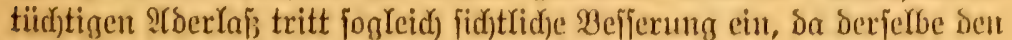
פglutIanf um vieYes verntindert; jedod) ift vout bicfen Mittel unt in

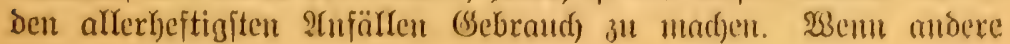


Sgeilmethoden nidjt genügt haben, fo fann man zulest autd zum Yrderlä greifen.

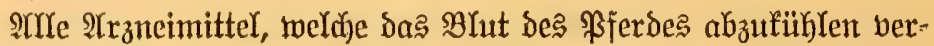

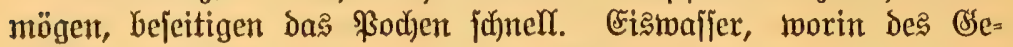

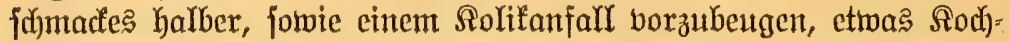
faly aufgelöft worben ift, fdjafft nadd einigen Mimuten Sindorung. Dies wirs ala das bejte und fidjerfte Mittel anempjohlen. Das bon cinem $\mathfrak{A}$ nffall ergriffene \$fers jäuft bą Eismaffer jehr gierig, felbjt

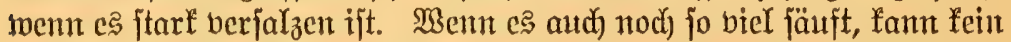

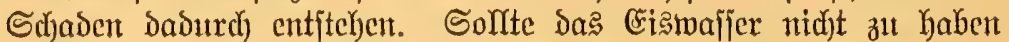

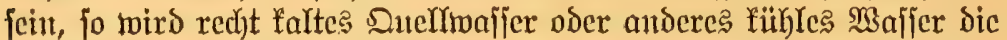
Befdjwerben ebenfowohy bejeitigen. Das \$odjen läpt jeondy in ber

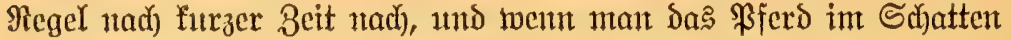

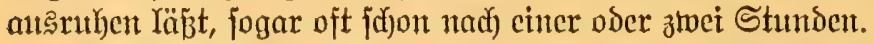

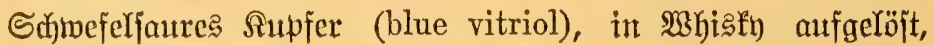

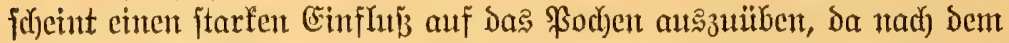

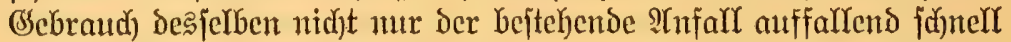

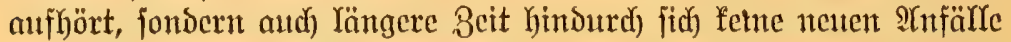

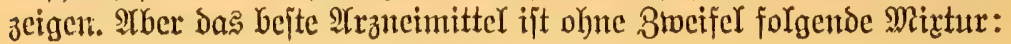

$$
\begin{aligned}
& 2 \mathrm{oz} \text {. blue vitriol, } \\
& 2 \mathrm{oz} \text {. asa foetida, } \\
& 2 \mathrm{oz} \text {. jimson seed; }
\end{aligned}
$$

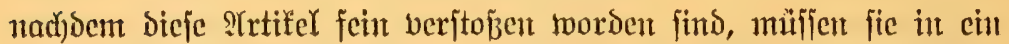

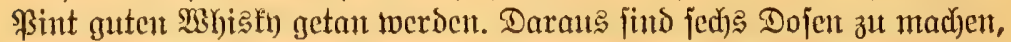

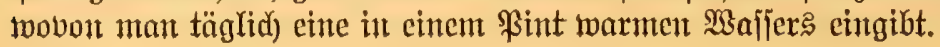




\section{5. 筷apifer.}

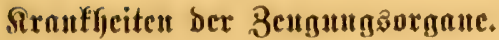

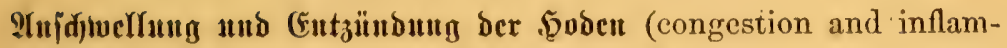
mation of the testiclas).

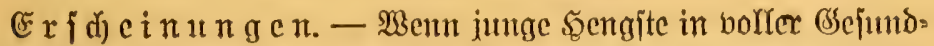

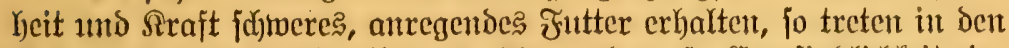
Soden mitunter $\mathfrak{2}$ (1)

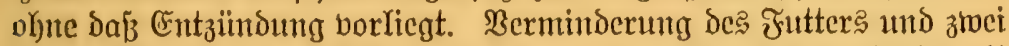

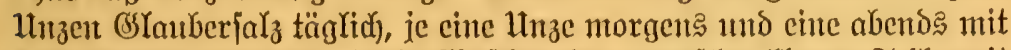
bem Futter vermifd)t, fotwie $\mathfrak{B a j}_{\text {djen }}$ ber angej(y)ollenen Teile mit Iautwarmem SIantwaffer $-1 \mathrm{oz}$. alum in 1 quart of water - bes jeitigen bas Hebel.

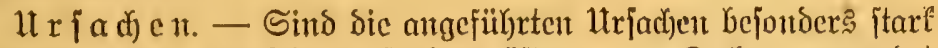
borhanden, wirs das Tier außerden öfters zum Deden berwendet

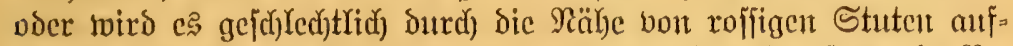

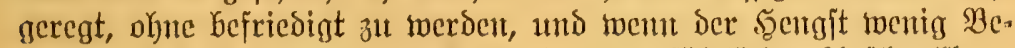

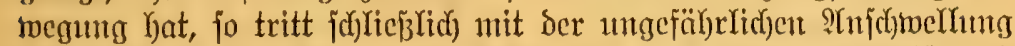

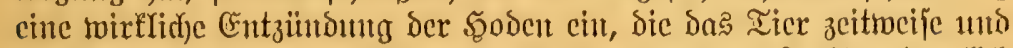

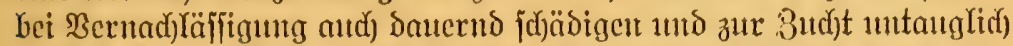

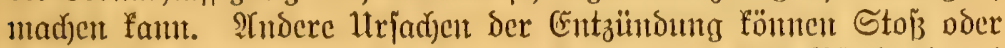

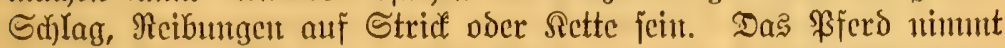
einent 1 mfid)ern BSang ant, fpreizt Die Sointerbeine und hat Schmerzen int Baudfe, Die es burd) Itmbliden nadj ber Flante fundgibt. Bei

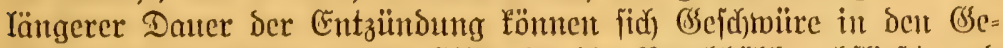
fd) Ied)tsteilen Gilden, deren Eiter in bie Baudjhöhle abfliept und fadwere Ertrantung łur Jolge haben fann.

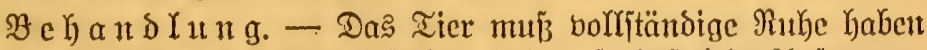

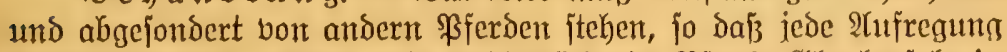

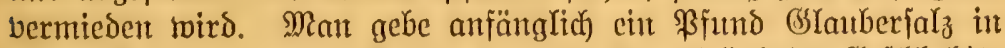

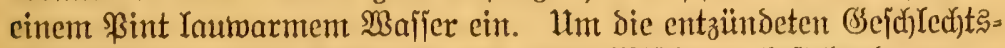

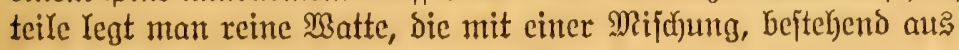

2 drams acetate of lead,

2 drams extract of belladonna,

1 quart of water,

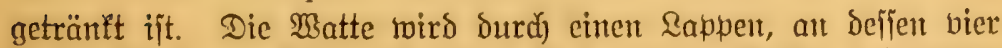
Enden fid) lange $\mathfrak{B a ̈ n d e r ~ b e f i n d e n , ~ \delta i e ~ a u f ~ b e m ~ \Re u ̈ u d e n ~ z u f a m m e n = ~}$ 
gebumben werden, in ifyer \&age gebalten. Bollen fidf Gefdumüre bilben, bie fich als weidse Stelfen beim Befüh)(en mit ben Fingern erfenmen Yofien, fo toerden twarme Reinfamemm for)läge gemact)t. Ein

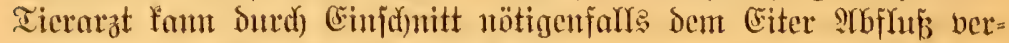

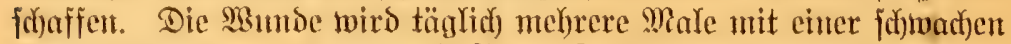

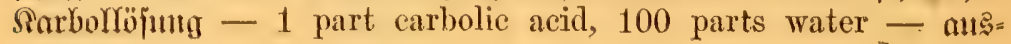
gejpritst.

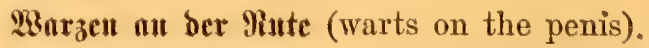

Dieje Yaffen fich Yeid)t mit Beigefinger uno Daumen aborehen voer fie fömen mit einer Sdjere abgefonitten uns bie 93 mbjterfe mit Sörrenitein (lunar caustic) betupft werden.

(Belun̈d) แn ber Mute (degeneration of penis).

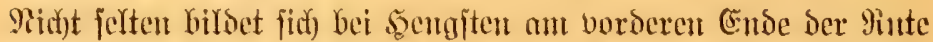

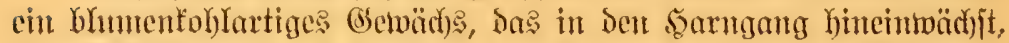

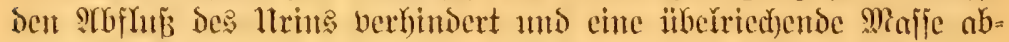

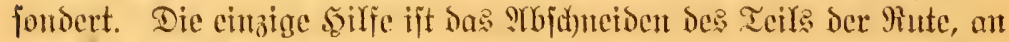

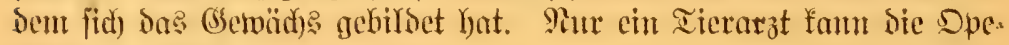
ration mestilfren.

Saftricen ber sengite (castration of stallions).

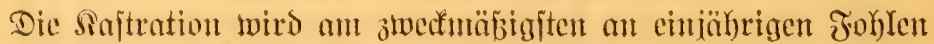
borgenommen; fie fom ant ansgefiifyrt werben an ganz jungen Tieren, wemt fie ein ober stwei Mionate alt fint, es wird babutrif) aber

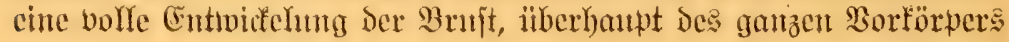

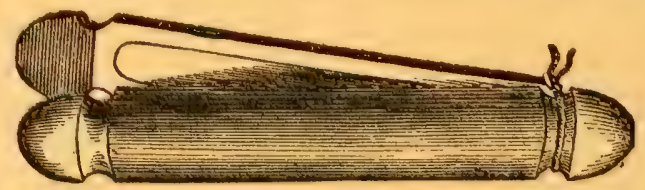

Mhb. 30- Ellammer für Kaffrafinu.

verbinbert. Se fpäter die Saftration borgenommen wirs, "etwa int

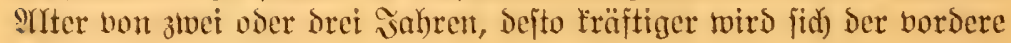
Sörperteil ausbildent.

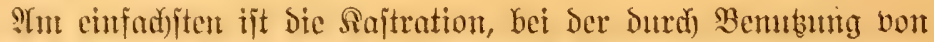
freinen hölzernen SIlanmern bie SYbern un Samenjtränge abgepreß̈t

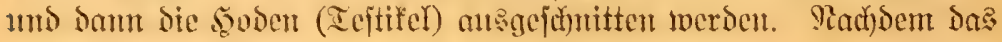
jumge Bferd gebumben unb anf bie linte Seite getworfen (fieke 6. Sia=

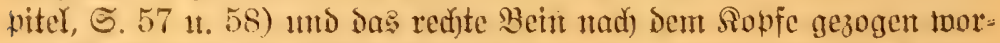

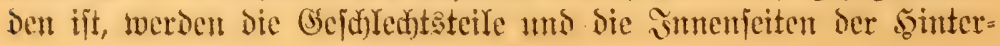


beine mit Seife unt Bafjer, Dem auf 1 ßint 1 Unze Dijterine zugejeet murde, jauber gemajdjen. Arrer Sdymub, Irujten ujt. find jorg= fäItig zu entfernen; vor allem find ber Schlaudf utnd Soodenjad grïnd= Iich) zu reinigen. Die STammern (ficke 30. STbb.) find borber aus Sartholz gejdynibt morden; jedes Stüa erhält in Der Mitte an ber

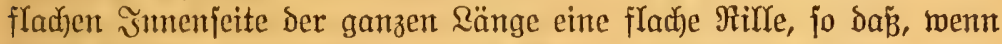
beise Stïlfe zujammengelegt, bie Riłlen aufeinander pajien. Dic Rillen find von Midytigfeit, fie exfürlen einen ooppelten Btoef: eriten fibt Die Slammer infolge Der Aruah̆̈hlung feiter; zweitens wird bie Rime und die s̃nnenjeiten ber beiden Stüde mit einem antijeptijoben

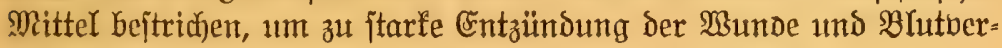
giftung zu berhüten. Das antijeptijaje Mittel bejtełt aus

$$
\begin{aligned}
& 1 \text { dram sulphate of copper, } \\
& 1 \mathrm{oz} \text {. vaseline, }
\end{aligned}
$$

beides gut vermijut. Die Rillen in Ser Alammer müljen mit biejer Salbe ganz angefüllt werden. Die Slammer murbe fachon bor ber Dperation an einem ende mit einer bünnen, itarfen Sdyur mehr= mals ummunden und jither zugebunden. Die Shmur wird ebenfalls

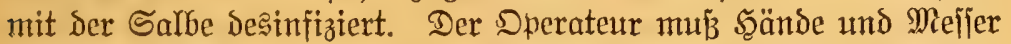
borher mit $\mathfrak{M a f j e r , ~ D e m ~ a u f ~} 1$ Suart ein halber Ieelöffel boll Rarbol=

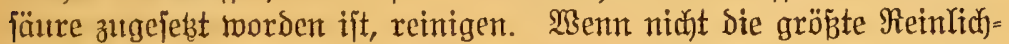
feit bei Der Dperation beobachtet wird, fo tritt regelmäbig eine bö: artige Entzündung ein, die meijtens erit bemerft wird, wenn fie in Den Rörper eingeonungen ift, woran das Iiter gemöhnlich Jugrumbe geht. S̃it alles in Bereitjofaft, jo ergreift Der Sperateur mit Der

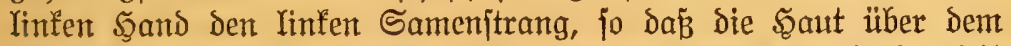
Stein ftramm liegt. Der Srriff muß fejt fein, Damit ber Stein nicht

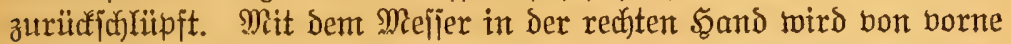

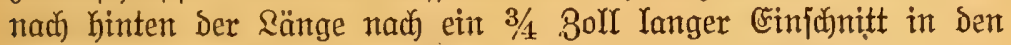
Şodenjact gemacht, tief und lang genug, um ben Stein hervortreten 3u Yafjen. Die Iinfe Sand mub jest den Samenitrang bejonders fejt= halten, weil jonjt ein Burühipringen des Steines ftattfindet und der= jelbe in die Baudhöble eindringen fant. Nach jefundenlangem Fejt= halten ift die Sefahr borüber und jest wird ber Samenitrang durd jafnitten. Der Stein hängt mun fohlaff herunter. In Serjelben Meife twird der andere Stein herborgeholt; beide jotweit herunter=

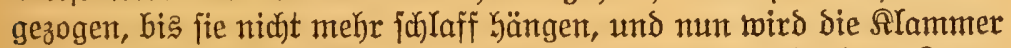

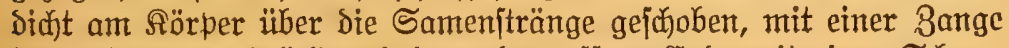
feit zujammengebrült und bann bas offene Ende mit einer Sd)mur umbidfelt und zugebumden. Nadjdem die Rlammer befejtigt ift, wer= Den $1 / 2$ bis 1 Boll unter berjelben bie Samenjtränge mit ben Daran= 
hängenden Şoden oder Steinen abgejanttten. Der Samenitrang

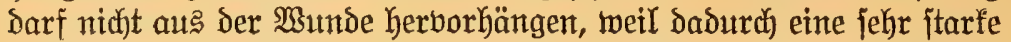

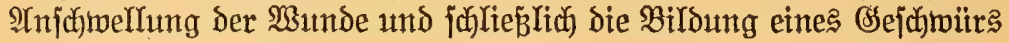
verurjacht merden fann; Der Samenitrang follte nady Der Speration

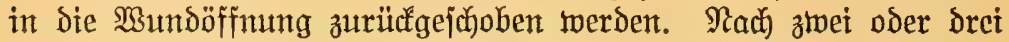
Iagen fann nadh dem Berjuneiden der umgemidelten Schnur an einem Ende die Rlammer abgenommen werden. Die Wunde follte am zmeiten Tage einen weiben Citeritoff abjondern, bei faltem Metter tritt die Afbjonderung exjt am dritten Tage ein; bon jebt an geht bie Sceilung jifnell bon jtatten.

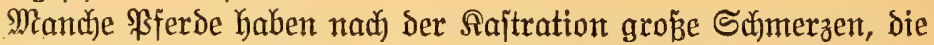

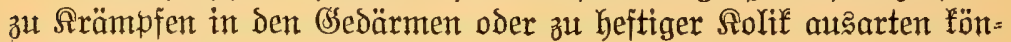

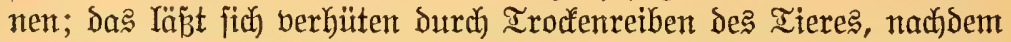
es aufgejtanden und durh langlames Serumfülyren. Safjen die S(f)merzen dann nidjt nach, fo gibt man einem einjährigen Fohlen

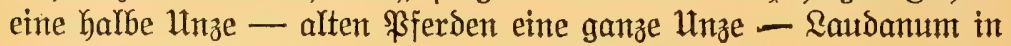

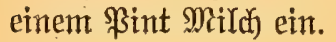

\section{Sterile Sengite and Stuten (sterility).}

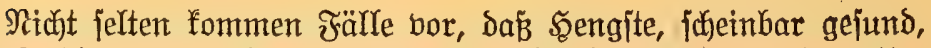
feine Fohlen zeugen fönnen; diejem Zehler fönnen verjhiedene $\mathfrak{u r}=$

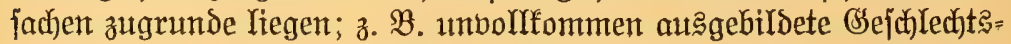
teile, Deren Entzündung, berfettete Entartung ber Steine infolge zu

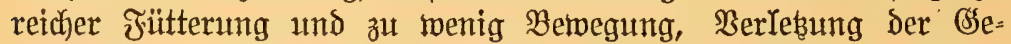

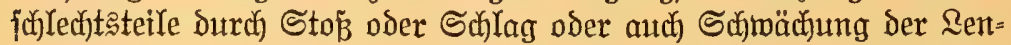
Denmußfeln als Folge von Aranfheiten (jd)twarze Şarnwinde u. a.).

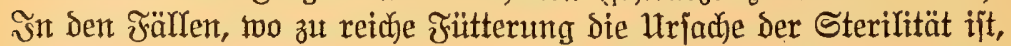

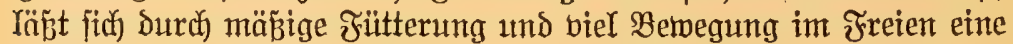
Iräftigung herbeifiibren; in Den andern Fällen ijt jelten seljerung zt ermarten and jind jold be Sengite zu fajtrieren.

Rod) häufiger als bei den männlichen. Iieren findet fich $3 u(t) t=$

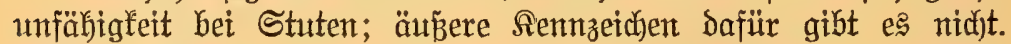
Areltere Stuten, Sie unter judwerer $\mathfrak{A}$ rbeit abgemagert und j(ftwad)

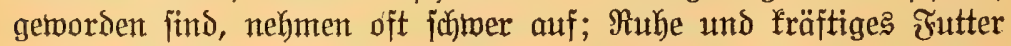
find Gier die bejten Seilmittel. S̈nnere Jehler find in den meiften Fällen unheilbar.

\section{Merfinale ber Trädtigfeit (indications of pregnancy).}

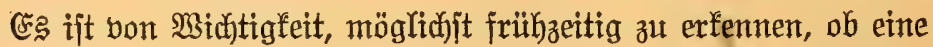
Stute tragend ijt, um fie zu jajonen und bot allem gegen Fallen,

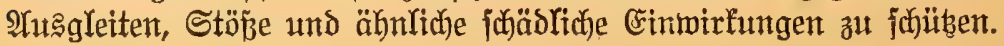


Menn fid) in Den nädjiten Bodjen nad) Dem Decten feine Brunit Gei Der Stute cinftelYt, fo ijt bas ein bemerkensmertes, aber bod) immer nod) fein fidjeres 3eidjen Der Trädytigfeit; Dent es gibt Stıt=

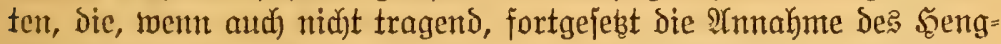
ftes verweigern. Trorerjeits fommen auch Fälle vor, jedod) find

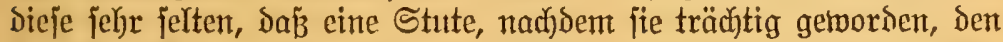

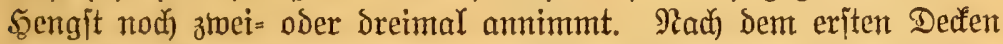
follte bie Stute nod) twäbrend cines Monats toöchentlich einmal zum Sengit gebrad)t werden; wenn fie in biejer Beit bie $\mathfrak{A}$ mnahme $a b=$ ja)lägt, fo famm man mit ziemlicher Sicherheit auf Trärdtigfeit des Tieres fujliçen.

Mird eine bösartige oder fehr Iebhafte Stute nadh dem Dedfen

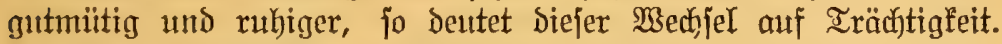

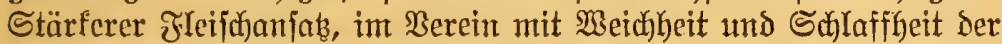

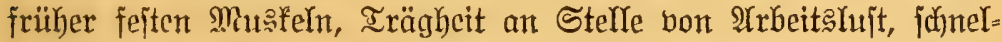

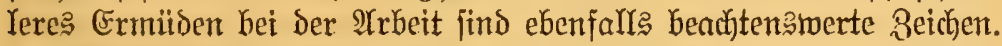

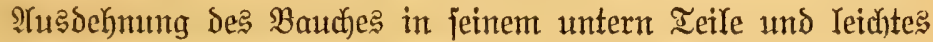

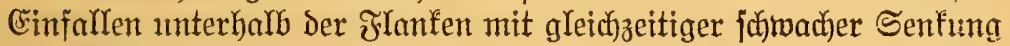

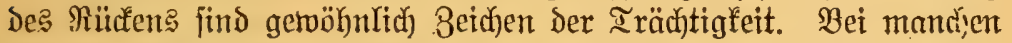

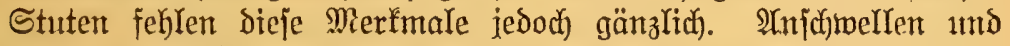

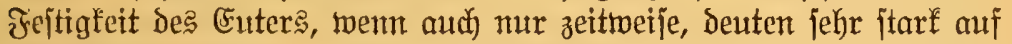

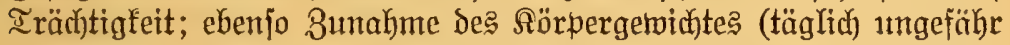
$1 \frac{1}{2}$ \$fund) im bierten und fünften Monat. Bom fiebenten und adjten Monat an fann beim vorfichtigen Drüden mit Der flactfent . brängt Dả Fohlen nach Der entgegengejebsten Seite, fliegt aber jo-

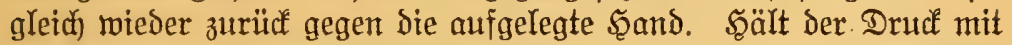

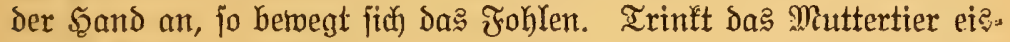

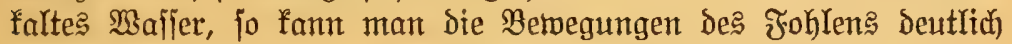
jehen; Dod) follte eine derartige Probe bermieden werden, tweil $\delta \mathfrak{a}=$ Durd) Berwerfen Kerbeigeführt werden fann.

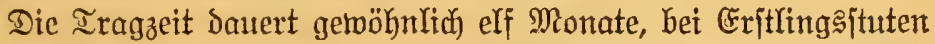
aber aud wohl ein bolles Jahr. Fohlen waren lebensfähig, wenn nad) ciner Tragzeit bon breihundert Iagen geboren, in andern Fä̆lYen fam ba马 junge Tier erit nad bierhundert Iagen zur Belt. Sengit= fohlen werden gewölynliư) Yänger getragen als Stutenfohlen.

\section{Berjandłung ber träđftigen Stute.}

Die träd)tige Stute follte nidft muinß̧ig im Stalle ftehen, $\mathfrak{B} e=$ wegung ift Reben; fie beförsert ben Stoffmedfjel im Rörper, Sie Błut= ernetterung, uno deșmegen follen gerabe träd)tige Stuten bis zum 
Ietten Iage bor bem Irbfohlen ein gewilies Maß̉ bon Bemegung haben. (sröbere 2 nitrengungen und namentlich Fahrten auf ge=

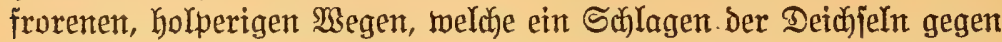

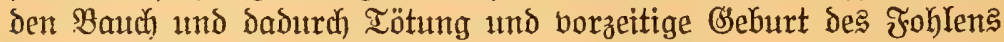
herbeifübren fönnen, find zu bermetoen. Wenn fonit feine Irrbeit vorhanden ift, Dann follen bie tragenden Stuten wenigitens eine Stunde auf dem Soofe, abgejondert bon andern Iieren, fich $\mathfrak{B} e=$ wegung madken.

Die Fütterung hod)trädtiger Stuten foll nicht zu majfig, aber

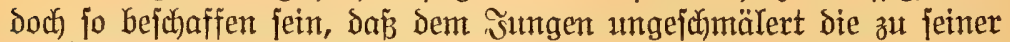
regelmäbigen Entwicfelung nötige Rahrung zufommt. Şafer, nicht

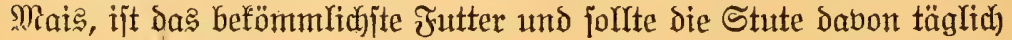

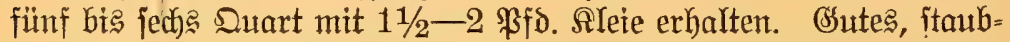

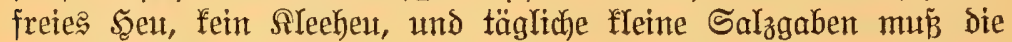
Stute unbedingt in ben rebten Monaten erhalten und gegen Ende Der Irärbtigfeitszeit follten die Şeugaben etwas berringert, Dagegen ein menig mehr đsetreide gegeben werden. Recht häufig fommt es bor, Daß́ Die Stuten gegen Ende Der Iragzeit an Berdauung: gen, bejonder' an Sartleibigfeit Yeiden; in jolthen Fälren empfiehlt

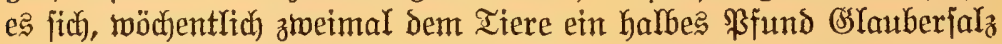
in 1 \$int Yautwarmem $\mathfrak{B a j f e r ~ e i n z u g e b e n . ~ S a n n ~ m a n ~ D e m ~ P f e r d ~}$ täglicf) ein halkes Dubend mittelgroße Mohrrüben reichen, jo ift da? ein vortrefflicher Erjab für (SIauberjalz. 3u dem Wohlbefinden des Iiteres trägt eine frijabe, reine Stalluft viel bei; diejelbe foll nicht zu falt, noch biel weniger aber zu warm jein; 50-55 osrad ift bie richtige Stalltemperatur. Şit es jehr falt orauben, jo muв man beim Deffnen bon Tïren und Fenjtern jehr borjichtig fein, Damit łeine 3ugluft da: Iier treffe. Stuten, die in einem angigen Stalle itehen

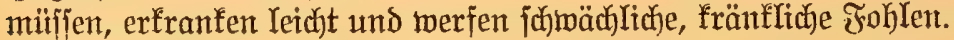

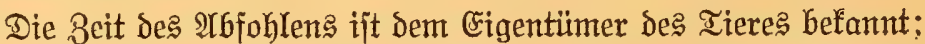

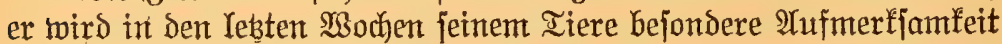
fibenfen und genau auf alle Beichen ber heramnabenden (sseburt adjten. (5r wird hauntfäb)lich das Euter beobarften; Dasfelbe nimnt all= mäblich an ulmfang zu, wird zulest itramm und feit und an den Bibenenden zeigen fich) Yleine harzähnliche Iröpfduen bon gelblicher Färbung; bet manchen Stuten fließ̈t die Milch fathon borker aus.

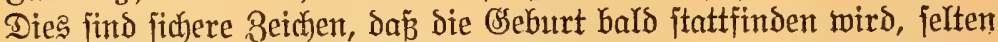
bleibt fie Dann nod) länger als zmei Iage aus. Ein weiteres $\mathfrak{A} \mathfrak{n}=$

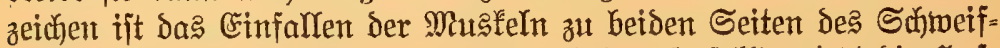

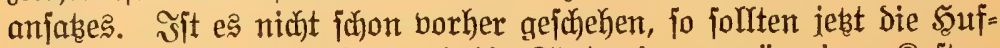
eijen abgenommen werঠen and bie Stute einen geräumigen Rajten= 
ftall, in sem fie fret umbergehen fann, erhalten. Das Tier während bes Seburtsaftes angebunben halten, ift ganz bermerflich. Selbjt= verjtänolich ijt, Dá ber Stand mit reichlich reiner Streu berjeben jein

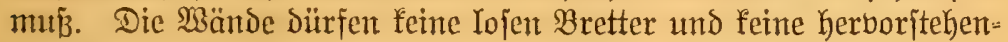
ben Rägel haben, an denen Stute ober Fohlen fich) verleben fönnten. Säufig tritt bei ben Fohlen eine $\mathfrak{A}$ (nja)

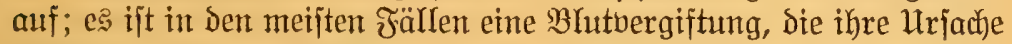
in sem (Einoringen föböblicher Stoffe in den Rabel hat. Ene Szeilung

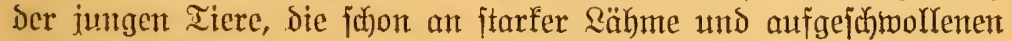

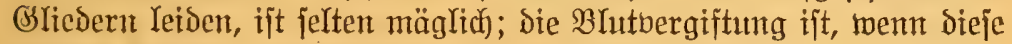

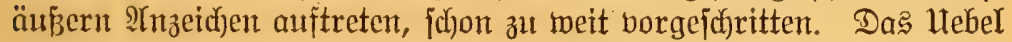
lanm aber jebr wohl bei einiger Borficht berhütet werden. Wir wifjell, Daß̧ Stroh, mag cs nod) jo rein und jauber erjofinen, allerlei Staub

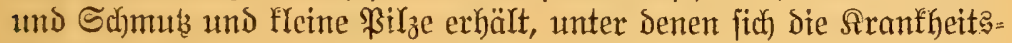
erreger befinden. Ias neugeborne Fohlen follte alfo nidft mit dem Stroh in $\mathfrak{B c r u ̈ h}$ rung fommen, fondern auf einem reinen Iudbe auf= gefangen werden; Darauf wirs es Dann mit einem zmeiten reinen Iudje abgerieben und bemubt man fierbei eine Mifatung bon 2 Itnzen Rifterine und 1 Suart Iautwarmem Maffer. Die Nabelwunde wird bejonocrs samit abgetwajhen umb Dann mit Sollobium (Collodion) überpinfelt. F̧ierdurch) wird bas (sindringen füäblicher Stofje in den হabel verkütet.

Wenn bie Seburt regelmä̈ig vor fich gegangen und bą Foblen abgetrodinct ijt, bringe man es zum Saugen an bie Stute. Fs ijt

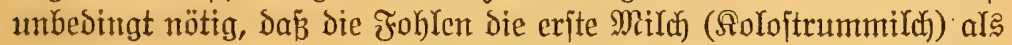
Rafrung befommen; Diejelbe ijt jehr reich) an Salzen und besharb geeignet, Magen und Sedärme des jungen Iieres bon dem foge= nannten Darmpert) zu reinigen.

ê: gibt nun Stuten, bejonders junge Iiere, welche bas Fohlen niajt jaugen lajien wollen. Man darf hier niabt mit Gsemalt ein= grcifen, jondern burch Streicheln, Siebfojungen und namentlich) mehrere Modjen vorher, went die Stute als bösartig befamnt ijt, Durd) Berühren, Streidjen und janftes Sneten des Futers bie Stute beruhigen. Beht es auf diefe Irt Durchaus nicht, dant beriuche man cs mit gleidjzeitigem Iränfen der Stute mit Iaumarmem Rleten= waffer, um bie Îfmerfjamfeit abulenfen; erit ganz zulebt bringe man bie Bremje in श्Ynmentung, namentlich twenn bie Stute beipen und jud lagen will.

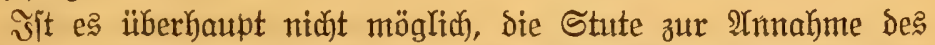
Fohlens zu bringen, ober geht fie an einer Aranfheit zugrunde, Dann

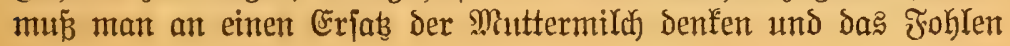




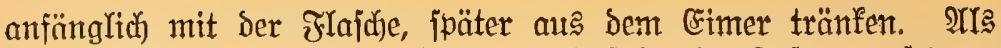
bejter (rrjab für stutenmil(d) hat (ïh folgende 3 ujammenjebund ergeben: 5 Ieile Submildy), 1 Ieil \$ajfer, auf 1 Duart biejer

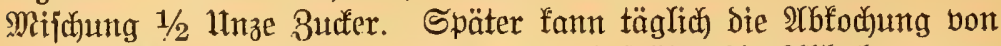
ztwei Eplöffeln boll Reinjamen und noch jpäter die Yrbfoctung von

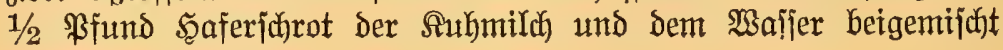
merden.

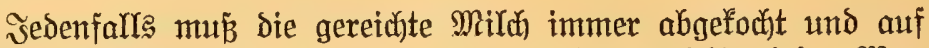
95 Brad abgefühlt jein, wenn fie dem Fohlen gereicht wird. Man

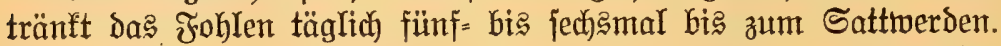
Der Eimer ober Sie Flajche muz jehr reinlich gehalten und barf ber Inhalt nie jauer werden, jonit gibt es Durbfall; und was ber bei Fohlen bedeutet, weiß wohl jeder, der \$fferde aufgezogen hat.

Die fäugende Stute füttert man mur mit gutem Seeu - jeder gute Bür)ter hebt ja immer für feine Stuten bas bejte Şent auf -,

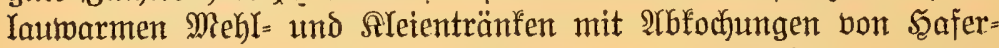
oder (Seritejachot, aud ein wenig Reinjamen, namentlich menn man amnehmen muñ, daßz die Stute nidyt gemug Mild hat. Es emprieflt fid), milldarme Stuten täglich brei= bỉ viermal am Baudje umb am

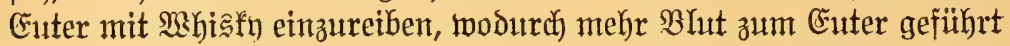

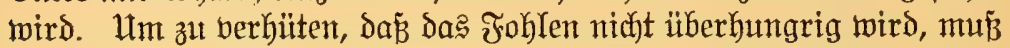
man dasjelbe, menn die Arlte arbeitet, was aber erjt brei Wodjen nach)

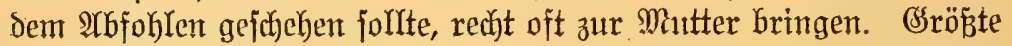

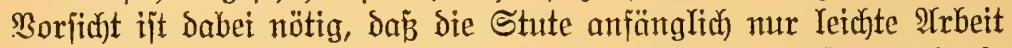
verrichtet und das Fohlen nidft an der erfibten Stute faugen darf;

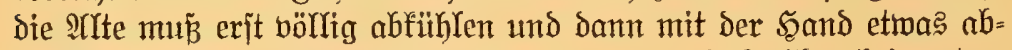
gemelft merden. כ̌edenfalls follten Stute und Foblen bei gutem Metter fobald wie mögrict) ing Freie.

Und mun nod) einige $\mathfrak{B}$ orte über bie Bermendung Der Stute zur weitern Budft. Befanntlich) nimmt bie Stute am neunten Iage nact) bem Arbfohlen am ficherjten wieder auf. Weldyer Sengit foll da auts=

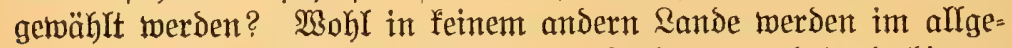
meinen jo biele untauglidye Sgengite zur 3udht vermendet wie hierłu= Iande. Die Mahl wird getwöhnlid Durd bas Gilligite Dedfgeld be= itimmt. Wie berfehrt das it, zeigt der geringe Mert der Machfommenjifift joldher Tiere. Die fümf oder zehn Dollars, die als Dedfgeld für ein reinraffiges männlid)es Budtttier mehr bezahlt merden, bringt

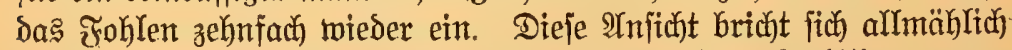
Bahn und haben Farmerbereine gute, reinraffige 3udttiere ange= inafft; aud Durch Sejebe wird jest in einigen Staaten barauf hin= 


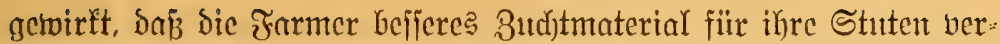
Iventen, jo baf zu ermarten ift, wir werben im Berlaufe der safhre befiere \$ferde auf umfern Jarmen jehen, ałs bisher.

\section{Berwerien (Abortion).}

Mit $\mathfrak{B}$ er to erfen bezeicfnet man eine Geburt, sie fo bor=

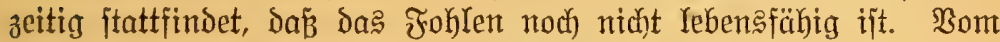

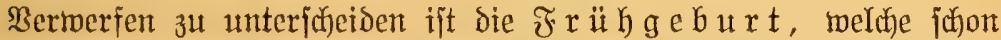
mit Dem zeknten Monat (Dreifhundert Iage) Der Irächtigfeit eintretent fann und das junge Tier lebensfäbig zur Welt bringt.

Das Bermerfen fann herborgerufen twerden burch irgend eine jtarfe Cintwirfung auf Den אörper Der Stute, z. B. Durch) Keftige Ent= zündung widbtiger innerer Drgane, wie Magen, Nieren, Blaje oder Rungen. Starfer Durdffall und fodmere Sartleibigfeit fömen eben= falls Uriache bes Berwerfens jein; ebenjo heftige Rolifanfälle und IHfblähungen. Stöße und Schläge auf den হeib, fcharfes Reiten voer sagen, bejonders went bas trächtige Tier in julled)tem Jutter=

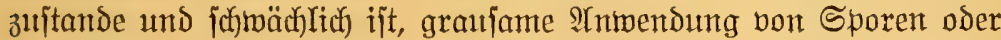

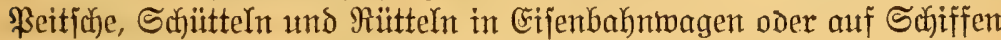
find gefährlid) für eine träd)tige Stute. S(h)

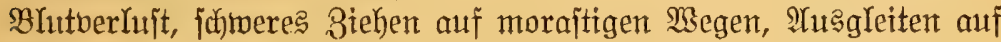

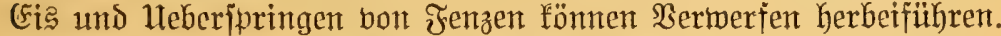

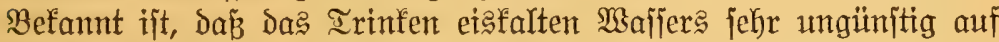
ein trächtiges Iier wirft, was burdh bie Geftigen Bewegungen des

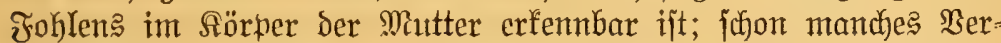
werfen ift daburd) herbeigefiilyrt worden. IUth gefrorne Iutteritoffe, Seu, Maisjtengel und bereiftes Meidearas wirfen in Derjelben Beije,

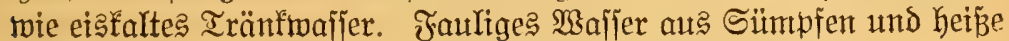

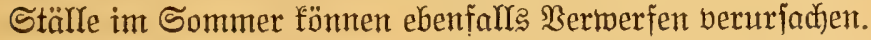

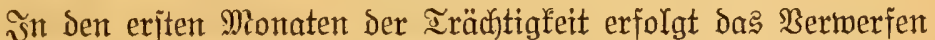

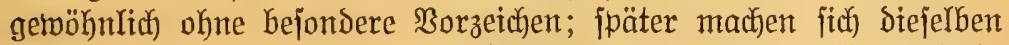
Înzcichen wie bei ber völlig abgelaufenen Iragzeit bemerfbar. Sehr oft findet man bei beborjtehendem Berwerfen einen oder mehrere

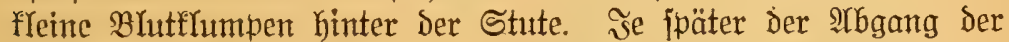
Frudft eintritt, Dejto jujwerer ift die seburt and um jo mehr greift e? bie Stute an.

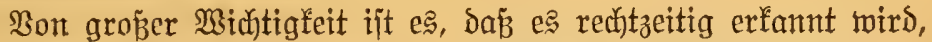
wenn eine Stute berwerfen will; es Iäß̈t fich Damn manches tun, ben Seburtsaft zu bertïrzen und dem Iitere Scymerzen zu erjparen; mit= unter famn bas ßerwerfen audif nod) berfiltet werden. Mird ein alf= 
gemeines Unmohljein, für daş feine erfennbare Hrjachen borliegen, bei einer trächtigen Stute beobadjtet, jo follte bas Beranlafiung jein, fogleich eine Unterjuchung anzujtellen, ob bie Scheide angejchnollen und ob Sch) Yeim aus derjelben fYieß̄t, bejonders ob fich şlutitreifen in lebterem befinden. Soldbe Borzeichen im Berein mit folifartigen Schmerzen, Drängen - wenn es auch ganz f(f)wach auftritt - Iebhafte Bewegungen der Frudyt und angejubolrenes Euter find Merf́ = male des beborjtehenden Berwerfens.

Eine gute, forgjame Befandhung, woourch bie genannten Ur= fachen bes Berwerfens ferngehalten werden, jolrte jeder träb)tigen Stute zuteil merden, um damit Der 2Tbortion borzubeugen. Bejondere

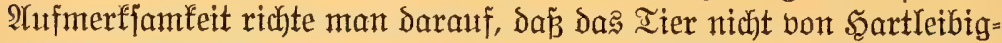
feit, Durchfall, Berdaung引bejđmerden und Blähungen heimgejucht werde. Scharfe Medizinen follten feiner träbtigen Stute eingegeben

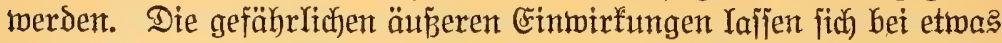
Borjicht vörlig bermeiden.

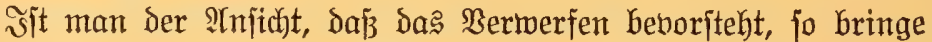
man bie Stute in einen bunflen, geräumigen Einzelftall. Das heftige

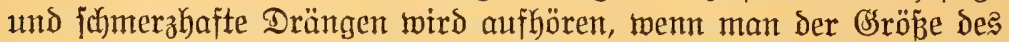
Iieres entfprectjent eine ober zroi Unzen Laudanum in etwas Iaut= warmem Maffer eingibt. Die Gabe fann nach zmei bis brei Stumben. wieberkolt werden, wenn notwentig.

Menn trob der angemandten Mittel Das Berwerfen boch eintritt, fo bleibt nichts weiter zu tun übrig, als bie Frühgeburt burch Fnt= fermung des Fohlens zu unteritïben. Das 2rbgeken der Nachgeburt erfolgt getöbnlich fehr jpät, nicht felten erjt am nädhjten Iage. Iritt Der 2 Ggang micht nach mehreren Iagen ein, jo müfifen, um eine 3er=

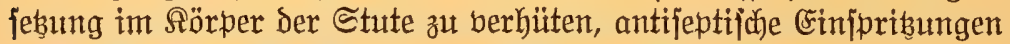
(2 Ieelöffel boll Sarboljäure in 1 Duart Mafjer) gemacht werden. Die \$Flege der Stute nark Dem Berwerfen bejtebt in Der Berab=

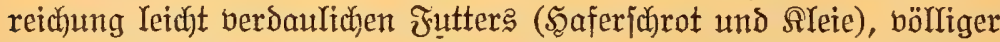
Ruthe während einer $\mathfrak{B o c h}$ und viel Bemegung im Freien. Solangi

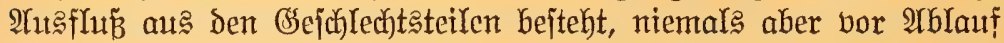
eines Monats jollte die Stute wieder zum Sengjt gebradht werden.

Bei Stuten, die einmal verworfen haben, tritt redht oft während.

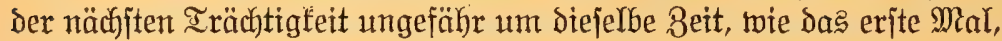
wieder eine Frühgeburt ein. Man gebe um Dieje Beit Der Stute einen Iag un den andern abends

$1 \mathrm{oz}$. fluid extract of blackhaw, 20 drops of pure carbolic acid, 
in einem \$int ßaffer cin. Beim geringiten Beichen bon IInruhe uns

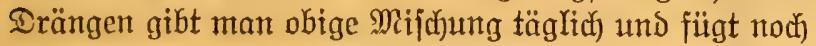

$1 \mathrm{oz}$. fluid extract of cannabis indica

hinzu. Ĩn vielen Fällen hat fid) dieje Medizin als ficheres OSegen= mittel gegen öftere? Bermerfen einer Stute bemährt.

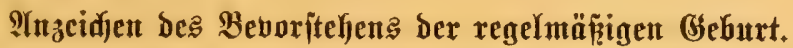

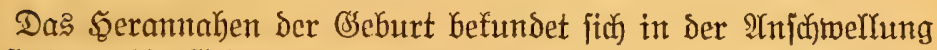

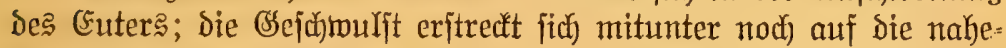
Yiegenden äuß̈ern Ieile des Bauches und beiber Şinterbeine. Ilnge= fähr cine Moche borker tritt ans den Stricten eine Flïifigfeit herbor, Die fid) an Den Stridjöffnungen als eine gelbe, wad jäbnlidye Majic anjełt; bierundzwanzig Stunden bor der sseburt fließst aus ben Stricken eine weike, mildyartige Flüffigfeit, die herabfällt und oft an Den unteren Ieilen der Sinterbeine Yeidt erfembar ijt. Die Sdjeide

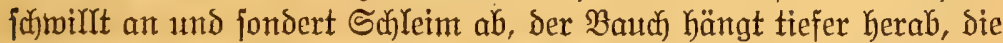
Flanten fallen ein. Die Stute wirs fajlieblich unrubig, fript nicht,

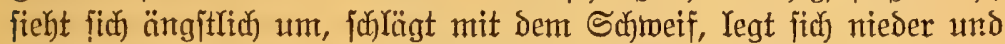
jteht gleid) wieder auf; Dorf) nidft alfe Stuten erheben fich) gleich) mieder, mandje bleiben bis zum Seburtsaft Yiegen. Nun treten frampfrafte 3ujammenziehungen des Baudjes aur, die Majjerblaje fommt hervor und zerplakt, gleich Darauf erjobeinen bie ßorderfüße

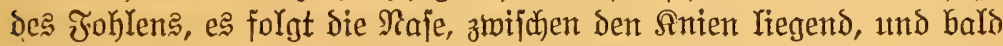
ber ganze Rörper des jungen Iieres. Nicht jelten bleiben Stuten während des ganzen Sorganges itehen. Der Sseburţaft mag nicht mekr als fünf bis zefn Minuten in Ilnjprud nefmen. Die furze Dauer und das Bejtreben der Stute fich Der Beobarbtung zu entziehen, erflären es, daß̧ jelten jemand Beuge der Seburt des Fohlens iłt.

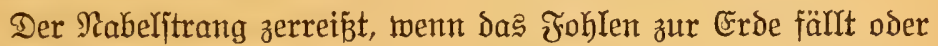
wenn bie Stute auffiteht; er jollte jobald twie möglici in einer Ränge bon żei bis orei BoIr bom Rörper entfernt, abgebunden und die Deff =

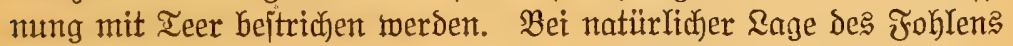

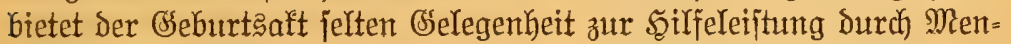

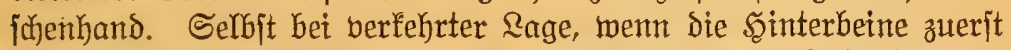
fommen, wird Dą Fohlen fid)nell zur Melt gebradft. Iritt dagegent

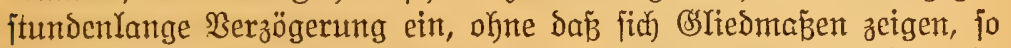

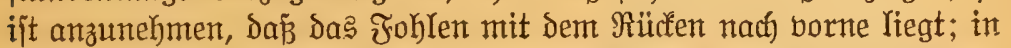
foldyen Fällen iłt sas Ilmorehen des Fohlen’ mittelit cingeführter eingeölter Sand notmendig. Siann in joldjen Jällent ein Iiterarst 
fifnell herbeigeholt merden, fo ift bas unbedingt anzuraten, da burch)

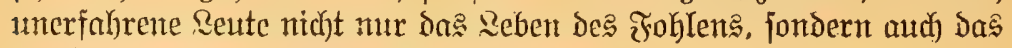
des Muttertieres in Gefabr gebractit miro.

\section{SBeifintulus (Leucorrhoea).}

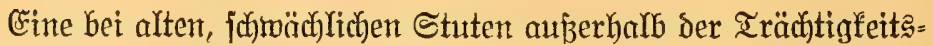
zeit nicht jelten auftretende Iranfheit: eine aus der Sibeide andauerno

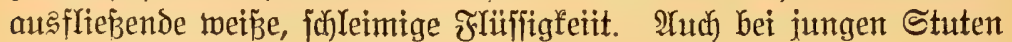

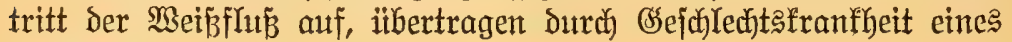
Sengites.

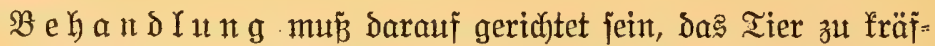
tigen. Die Stute Darf nidft zur Budft verwandt werden; mit jojwerer

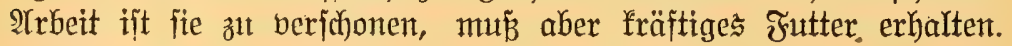

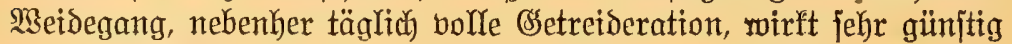
auf foldje Stuten. Ŝrs innere Medizin gibt man täglidu

3 drams sulphate of iron,

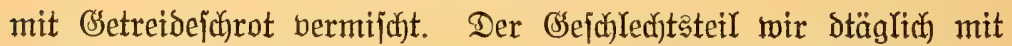
marmem Wafjer auggemajhen und folgt darauf eine গYY mit einer Mijchung, beitekend aus 2 Ieelöffeln toll Rarboljäure (carbolic acid) und einem halben Dram Iannin (tannic acid) it

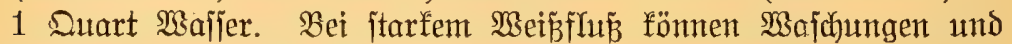
IHsjpribungen breimal täglidy borgenommen werden.

Sranffeiten bes (5uters und bor Stridje (diseases of the udder and teats).

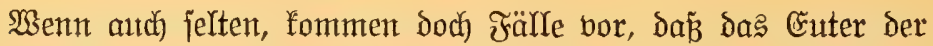

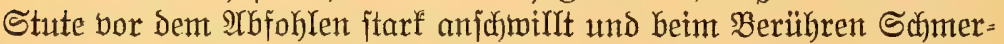

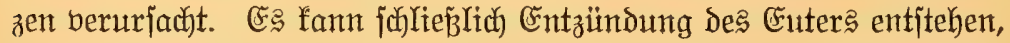

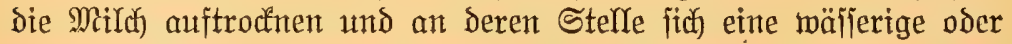
rötliche Flïffigfeit bilden, bie nidyt jelten einen üblen Gerudi ber=

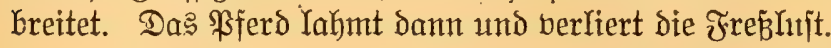

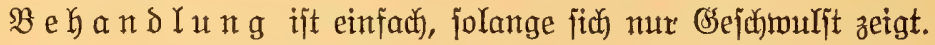
Borjichtiges, anfaltendes Einreiben mit Sdmalz (beljer ijt camphor-

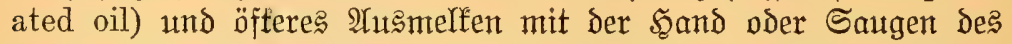

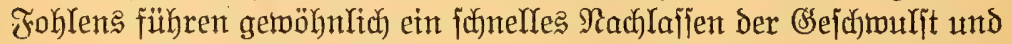
Sdymerzen herbet. Şat fich bereits Entzündung eingeitellt, fo jint Bäder mit marmem saffifer, jedesmal eine Stunde während, von

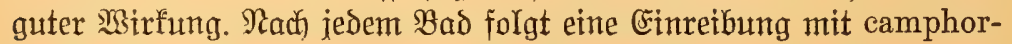
ated oil, dem ein wentig Doppelfohleniaures Ratron (carbonate of 
soda) und eintge Tropfen Belladonnaextraft (extract of belladonna)

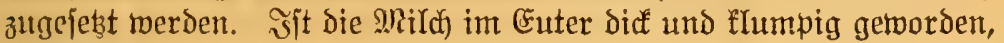
jo werden

20 grains of carbonate of soda,

10 drops of carbolic acid

in einer Unze Maffer aufgelöłt und bieje Mifichung in bie Striche gefpribst.

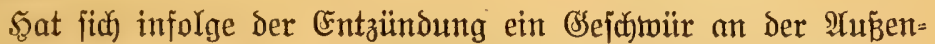
jeite bes Euters gebildot, fo wird es mit bem Meffer geöfrnet und

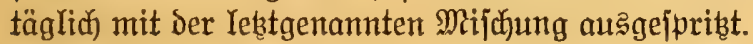

Wunbc Etridje, Rifle unb $\mathfrak{B a r z}$ en an ben Stridjen (sore teats, eracks, warts).

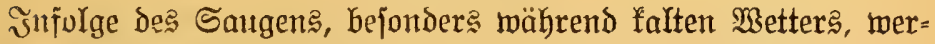
Dent bie Striche am Stuteneuter oft wumb amb befommen Riffe mit

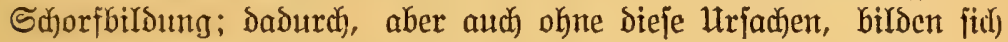
Şarzen an ben Stridjen, die dem jaugenden Fohlen hinderlich und ber Stute jamerzhaft find. Die $\mathfrak{B a r z e n ~ f o l l t e n ~ m i t ~ e i n e r ~ S d j e r e ~} \mathfrak{a b}=$

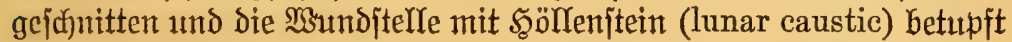

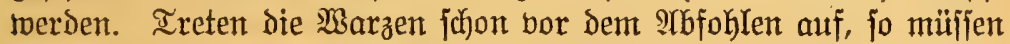
fie jogleid) bejeitigt twerden, damit Şeilung eintritt, bebor ba: Fohlen faugt. Ssegen wimbe Stridje mendet man folgende Salbe an:

$1 \mathrm{oz}$. vaseline,

5 grains balsam of tolu,

5 grains sulphate of zinc. 


\section{6. 笟apitifel.}

\section{Srmuffeiten Des Rervenifyitems.}

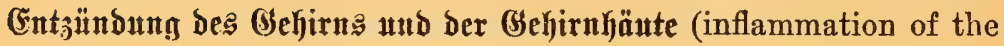
brain and its membranes).

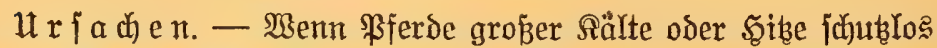
ausgejest morden find, nach extremem Iemperaturmedjel, birefte

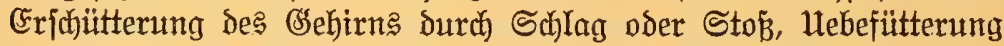

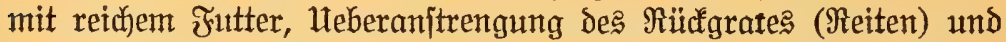
ïberbaupt Heberanjtrengung Durd andauternde fiuswere $\mathfrak{A}$ rbeit fömmen Bsebirnentzündung erzeugen.

Er $\mathrm{r}$; d e inu $\mathrm{ng}$ en. - Das \$ferd zeigt grope Erregung, der pröblid) Erift)laffung und Mintlofigfeit folgt; oft zeigt fide eine auf=

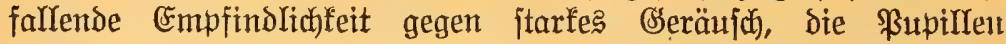

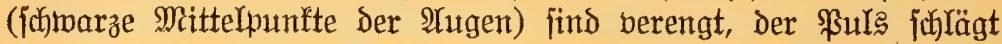

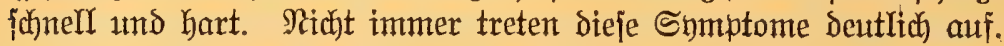
Bald zeigt fich aber ein Bittern oder Drehen der Muß̌teln, frampf=

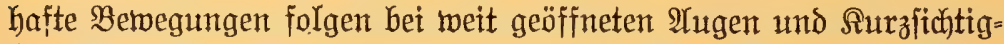
feit. Das Tier jucht ängftlidy auszumeidjen, wenn jemand den Ropf

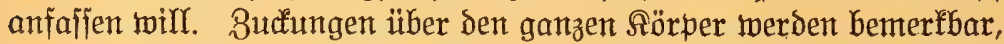
verbundent mit [mpfindung weifes Toben und Shlagen ein, Dann folgt große Mattigkeit und jujwaches 9 Atmen.

$\mathfrak{B} \in \mathfrak{h} \mathfrak{a} \mathfrak{d} \mathfrak{I} \mathfrak{i t} \mathfrak{n}$. - Da die genannten Symptonte eine Frolgc

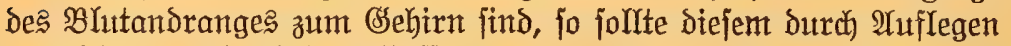

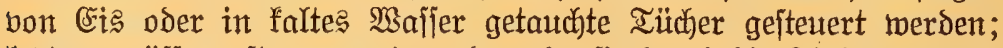

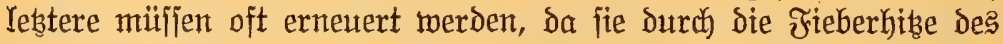

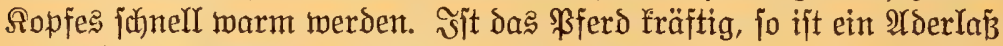

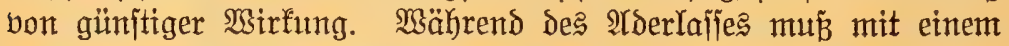
Finger der \$ulsjablag gefüblt merden; jobald diejer Iangiamer twird, barf fein Blut mefr abgezapft merden. Şat fich bas \$Pferd darnach ein mentg erfolt, fo gibt man ifm einmal folgende Medizin ein:

powd. aloes 7 drams, calomel 2 drams, powd. ginger 1 dram, tincture of aconite 20 drops. 


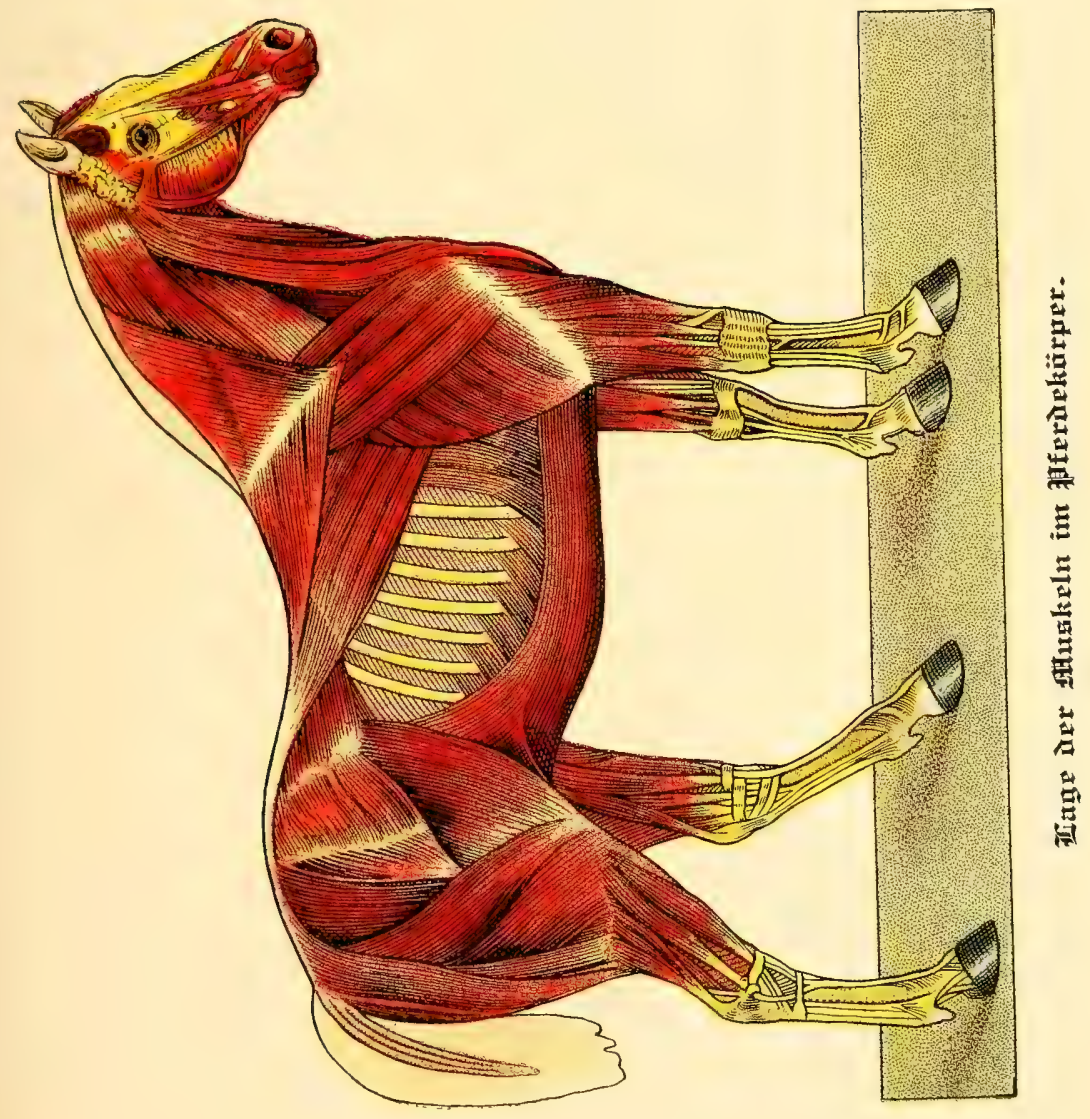



Da? Tier wird in cinen Hülylen, Dunflen Stall gebrad,t, wo e马 bor:

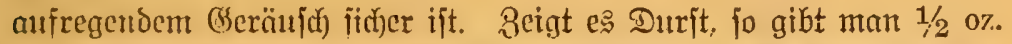

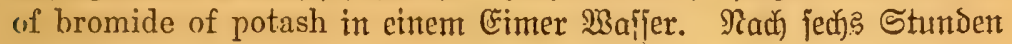
fant es cine zweite Dofis erhalten. SYijtiere mit toarmem $\mathfrak{B a f j e r}^{2}$ jind öfters alzuroenden.

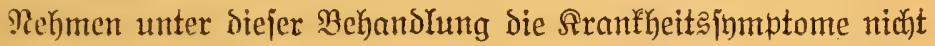
ab, jo ift Die Entzündung berartig, Daß́ mit Eingeben der Medizin nichts mehr antsgerichtet merden fann; ein Tierarat foll bann Ergotin=

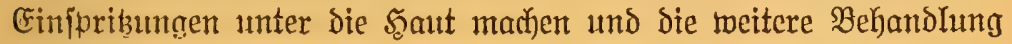
ïbernefymen.

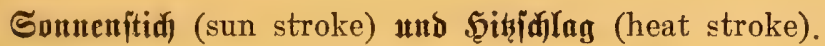

Beise Sranffyciten werden oft verwerbjelt oder man hält dic

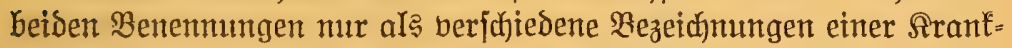

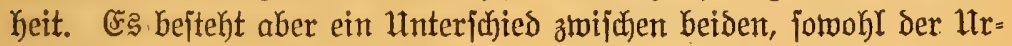
fache twie ben Symptomen nach.

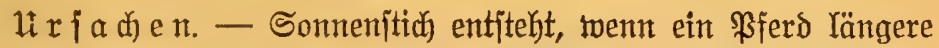
Beit Den jujarfen Sonnenitrahlen auggejekt mird. Sajwere $\mathfrak{T r b e i t}=$ pferde, wenn ihnen f́eine Erholungspaujen im Sdiatten gewährt wer= Den, Kaben am meijtent vom Sonnenjtid zu Yeiden.

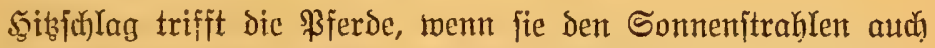

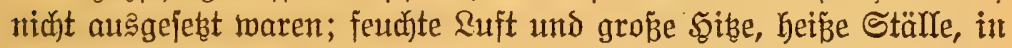

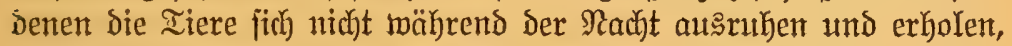

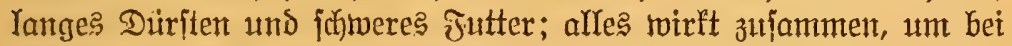

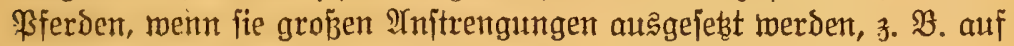

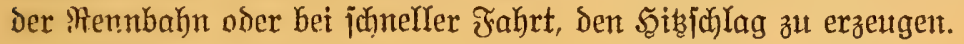

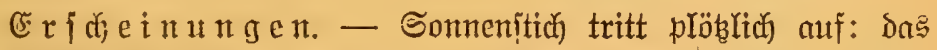

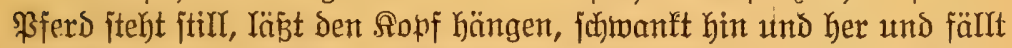
betwußtros um; Der Stem geht fehr jofiner, Der \$uls ift faum fühlbar,

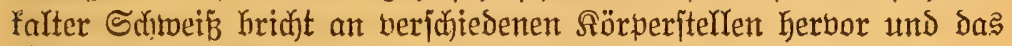
Tier verendet, ofyne twieder auf bie Beine zu fommen.

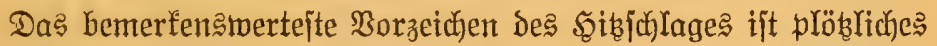

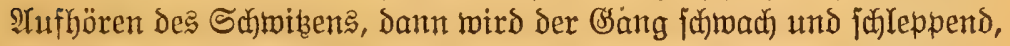

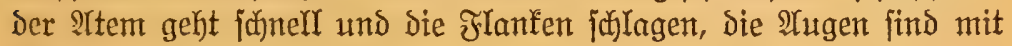
Blut unterYaufen, bie Riiftern find aufgeblajen und hodhrot gefärbt, Pula geft fajnell, ijt aber menig bemerf́bar, Das Sgerz jajlägt heftig, Bewubtlofigfeit folgt und dann tritt Gald der Tod ein. 


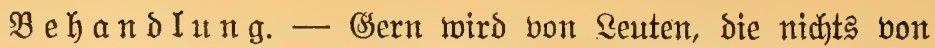

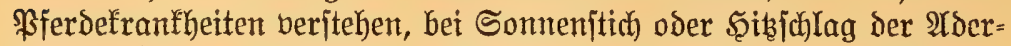
Iaß̉ angewandt. Nichts ijt verféfrter; hätte das Iier unter richtiger Behandłng noch gerettet werden fönnen, fo wird bieje Möglichleit

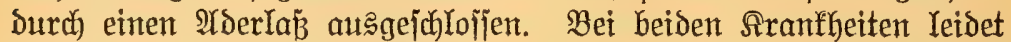
das Pferd an groper Sdymäche; die mird Durd den geiteigert. Man bringe das $\mathfrak{\$}$ ferd an eine jhattige Stelle, liegt es bereits, jo erridjte man eine $\mathfrak{2}$ rt Beltbart) aus Stöden und Iühjern.

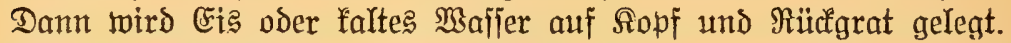

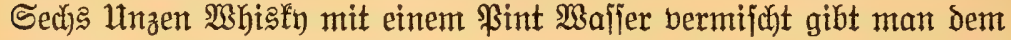

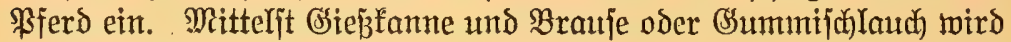

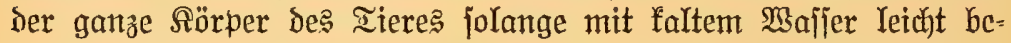
iprengt, bis die Jieberhitze zurühgegangen ijt. Das Dauert 45 bis 60

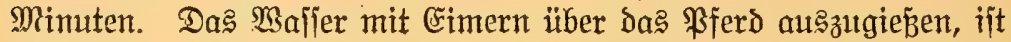
nidjt ratiam. Srjarfes und anjaltendes Einreiben ber Beine mit Rampferipiritus wirft günjtig. Eine Stunde nad) dem eriten Ein=

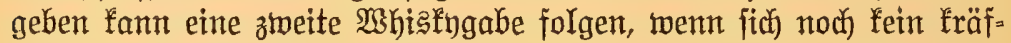
tigerer \$ulsjichlag eingejtellt hat. Unter ber angegebenen Behand= lung ift die Gsefahr innerbalb zwei Stunden vorbei. Böllige Gse=

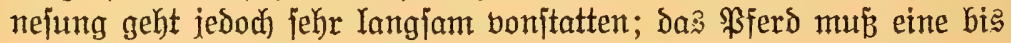

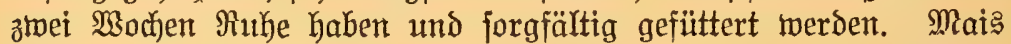
follte es nicht erhalten, jondern Saferjidyrot (3 Teile) und Aleie (1 Teil). Morgens und abends wird mit jedene Futter folgende \$ulvermijuchung gegeben:

$$
\begin{aligned}
& \text { sulphate of iron } 1 \text { dram, } \\
& \text { powd. gentian root } 3 \text { drams, } \\
& \text { powd. red chinchona bark } 2 \text { drams. }
\end{aligned}
$$

Sonnenjtich und Sitbichlag fönnen Yeidjt berfütet meroen; man befeitigt einen najien Subwamm ober einen "Sonnenjfyirm" auf bent Sopf des \$ferdes, jo daß̉ die \$artien zwifhen den Shren und die Stirn gejüübt find. Da' Wafjer im Sdjwamm muß öfters erneuert

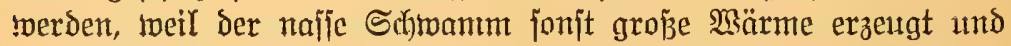
mehr Schasen als Nuben jtiftet. Der Somnenjutrm mup fret liegen, samit bie Ruft barunter zirfulieren lann; fejt aufliegende Shirme

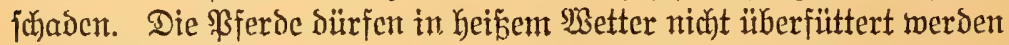

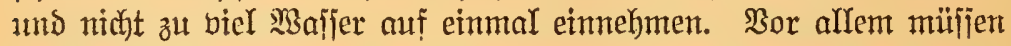
Die Ställe tühl jein; ein an allen Seiten offener \$retterjuhupen ịt häufig ein befferer Sommerjtall, wie der getöbnlich dumpfe und enge

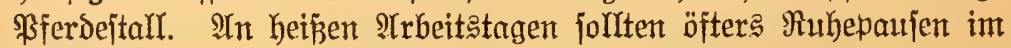
Schatten gemactit und die ß3ferde bäufig getränft werden. 


\section{Bergiftung סurd) Futter ober : Bafijex}

(spinal meningitis, blind staggers).

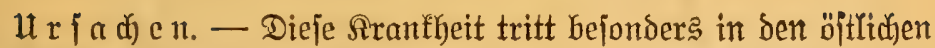
unto fübridjen Staaten häufig auf und werden mandje Segenden jähr = (id) Dabon heimgejudjt. Sie bejteht in einer Bergiftung und Bejajäbi=

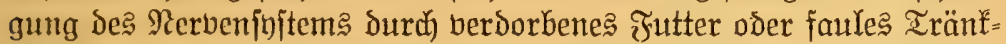

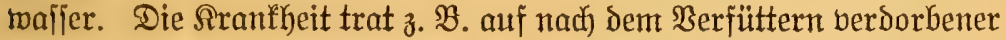
Enjilage, muffigem Şeu und nad) dem Tränfen aus Sumpflödjern, in benen fich berfaulte Pflanzenjtoffe befanden. כ̧n Birginien und andern Siibjtaten jifreibt man bie Entjtehung ber Sranffeit Dem Berfüttern von wurmigem Mais zu.

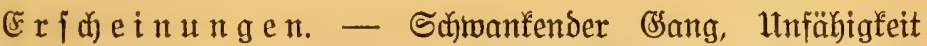

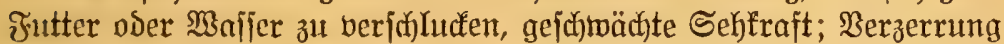

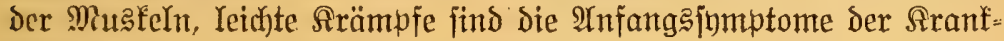
heit; Darauf ftellt fich böllige \&ähmung des ganzen Rörpers ein; Das \$FFerঠ fälnt und mitunter macht fich Delirium bemertbar, baj fich in

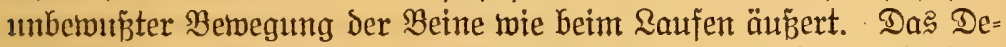

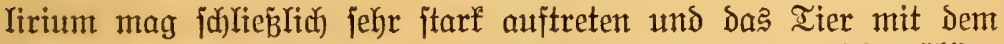
Sopfe hin und her fd)lagen; in ben meijten Fällen herrjut böllige Empfindungs= und Betwustlofigfeit bi: zum Eintritt des Todes, Der nad) bier bis bienundzanzig Stumben nad) Den exiten Aranfheits= erfideinungen erfolgt.

Mandjes \$Ferd überiteht den eriten 2Infall, bleibt aber längere

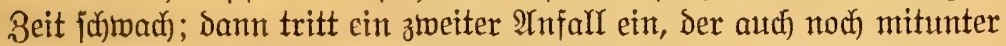

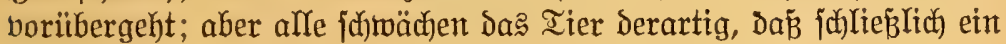
verhältnismäbig leidjter $\mathfrak{A}$ fall das Ende herbeiführt.

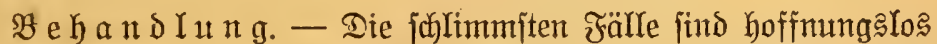

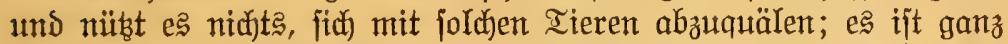

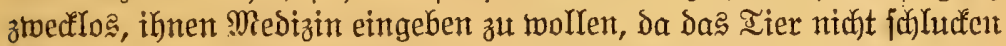

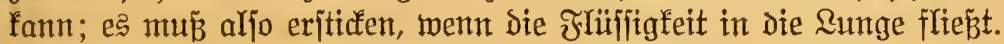

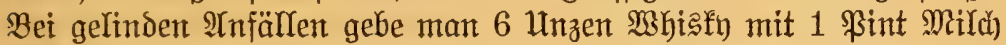
vermijat ein. Die Betwuktlojigfeit verjdyindet meijtens, ment mait IImmoniat (ammonia) auf einen Sdymamm gießst und Dem Tier bor

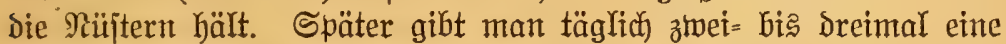
Dofis von 2 Sran Strichnin (2 grains of strychnia). Die Medizin wird mit Sonig und Mehl zu einem $\mathfrak{B r e i}$ angeridftet und mit einem Solzjpan hinten auf die Bunge geitridjen. Sobald Bucten ber Sdutt=

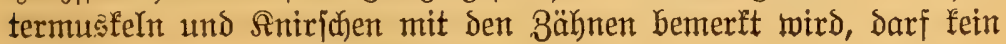
Stridinin mebr gegeben werden. 


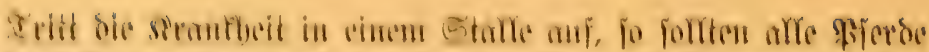

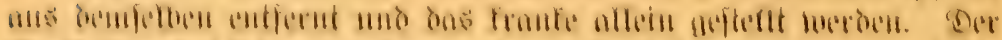

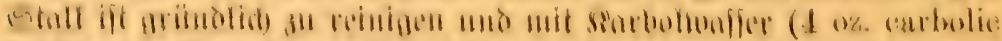

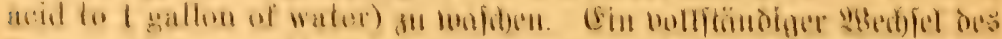

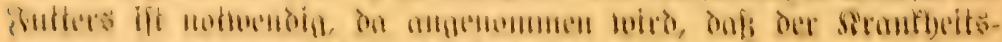

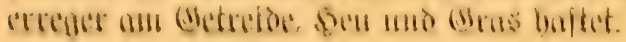

\section{Donbuentritt (string halt).}

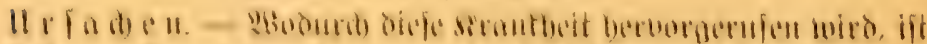

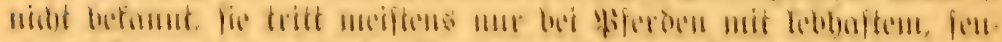

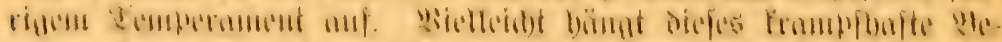

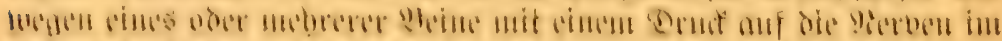

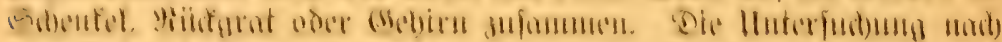

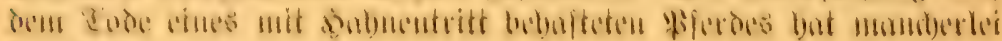
trontbofte Bierändemunen ergeton.

(5)

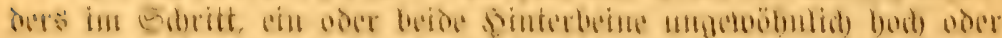

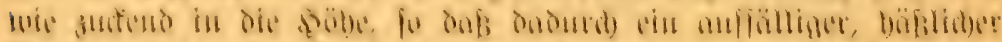

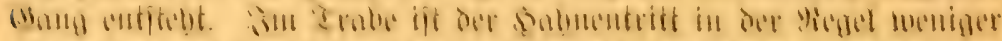

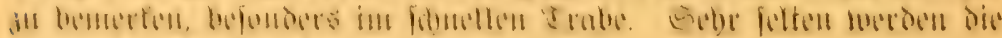

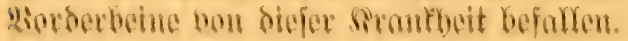

ㅂ.

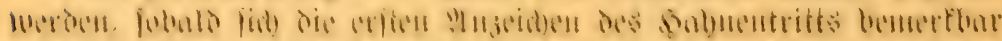

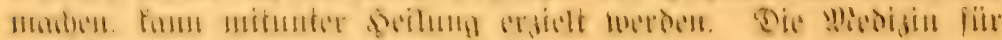
polbe Eärle ift:

iontide of iron 1 dram,

powd. unx romica 1 dram, powd. seutellaria 1 oz.

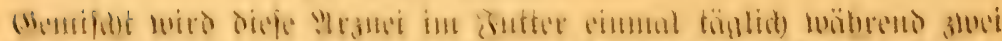

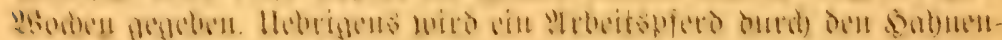

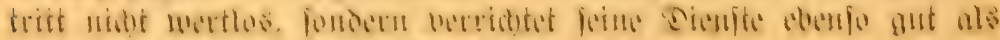

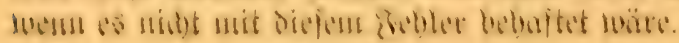

\section{Tarlund (opilepsy, falling fits).}

If

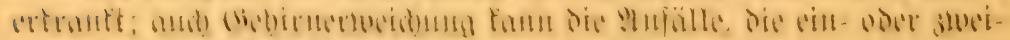

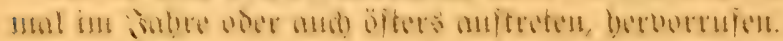

(5)

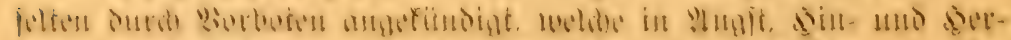

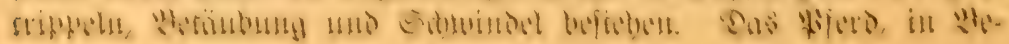




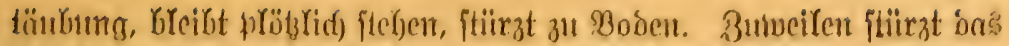

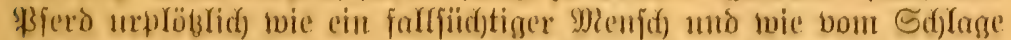
getroffen zu Buden; bier liegt basferbe zuerit einige Minuten ganz

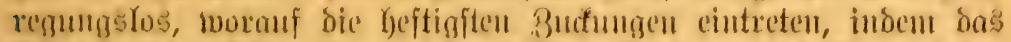

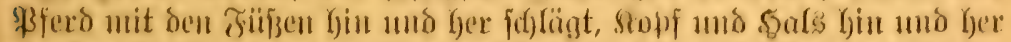

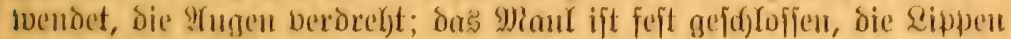

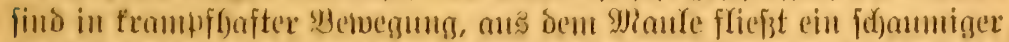

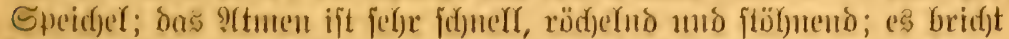

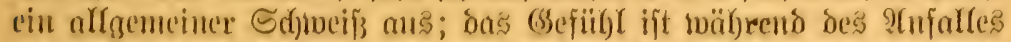

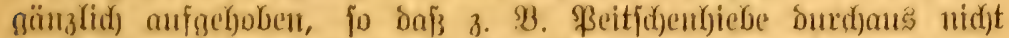

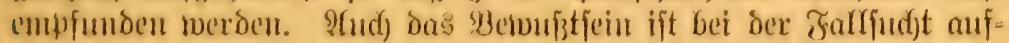

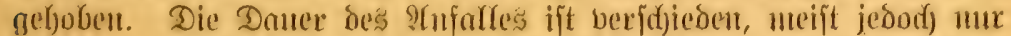

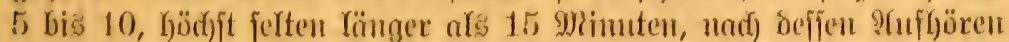

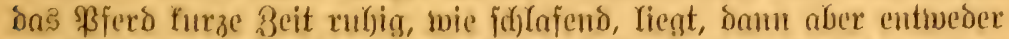

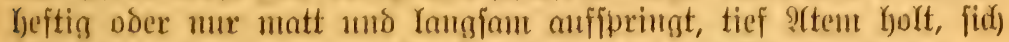

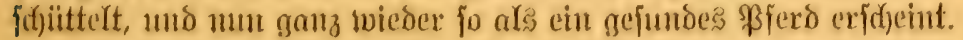

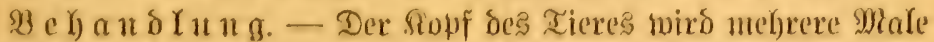

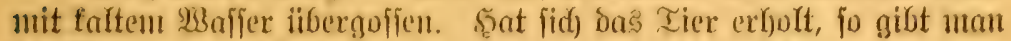
Die SMif(d)ung, weld)e beim s.jaf)nentritt berabreidjt wiró.

\section{Sđjuintol (giddiness),}

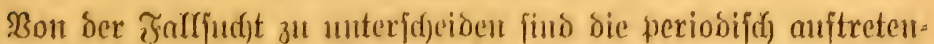
ben Sdjunindelanfälfe, Mervenleiden, Die olyne Fieber auftreten. Foft nie oder bod) mur feiten, wiro das \$fero im Etaffe bout Sd)mindor befalfen, wentigftens viro der Itnfall hier (eid)t überfehen. Dagegen

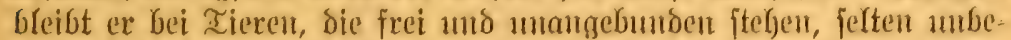

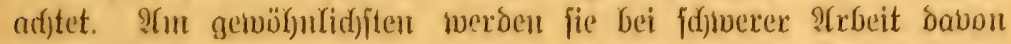
iuberrajdjt.

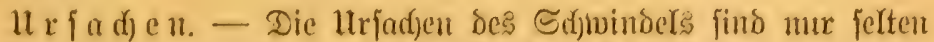

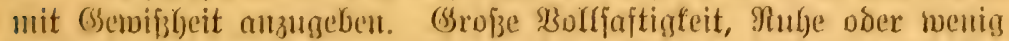

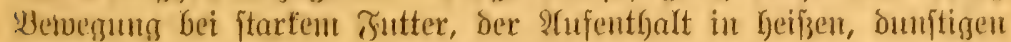

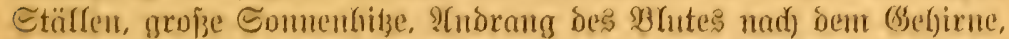

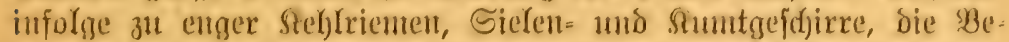

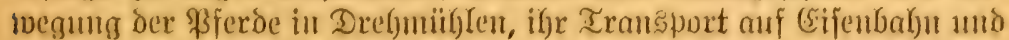

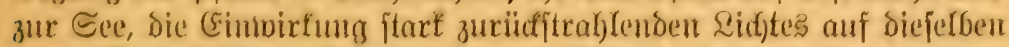

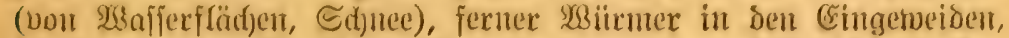
bürften zu ben hänfigften Beranlaffungen zu zäblen fein. Der

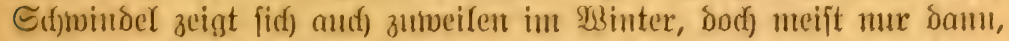

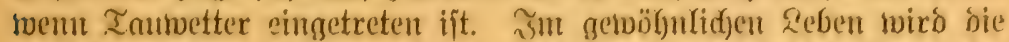

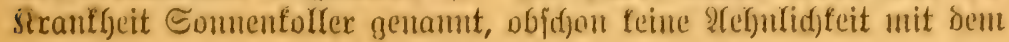


Soller bejteht, und beide Sranfheiten nidjts mit einander gemein haben. Die Borkerjage beim Sdymindel richtet jith nady Den Urjachen, Die ihn beranlä̧ten.

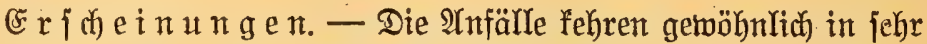

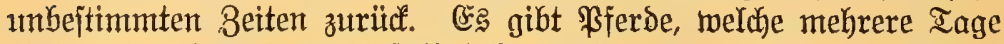

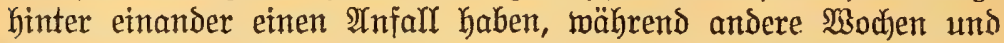
Monate hindurch befreit bleiben. Ereignet fich ber $\mathfrak{A n f a l l}$ rährens

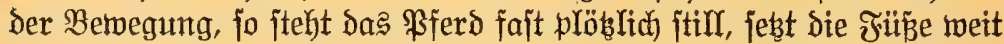
auseinander, taumelt, hat 3uchungen an berjudiedenen Ieilen, zumal ant den Rippen und am Şalje, hält Den Sopf jeitlich und hoch in die Söbe, zittert, fällt jedoch mur in jeltenen Fällen zu Boden. Mird dą

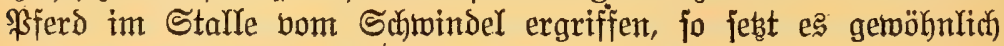

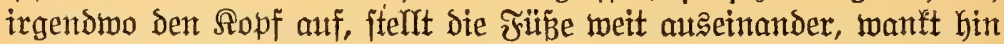
unto her, tritt rüctwärts unt legt fich jo jtart in Den Şarfter, Daß biejer

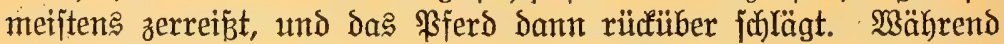

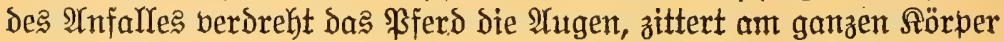

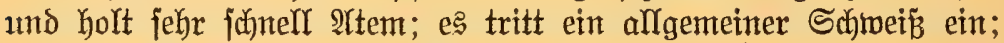
Dung und Utrin gehen babei oft untwillfürlich ab, 'morauf 5 bis 10

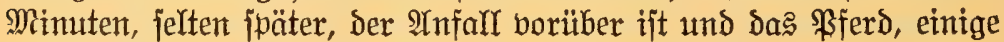
Mattigfeit abgerednet, wieder ganz gejund erjueint, jo wie dann

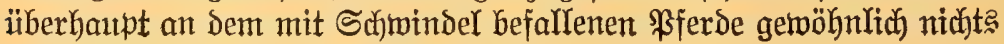
Siranflyaftes weiter zu bemerfen ift.

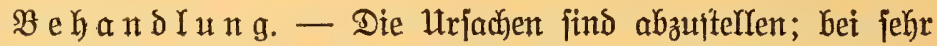

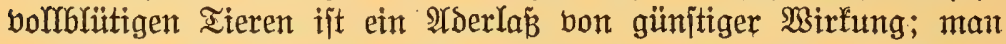

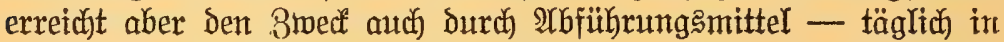

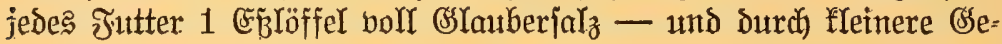

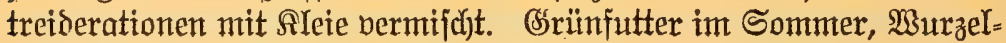

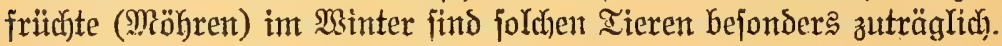
Das 3aumzeug mǘz nadjgejehen werden, ob die Rehlriemen Iodfer genug fitzen. Mo Glendende Sonnenjtrah)len (vom Maffer oder S(f)nee) die S(j)windelanfälle verurjadjen, wirft man dem \$ferd ein Iuci ïber Den fopf. Sotwie der $\mathfrak{A}$ nfall vor bem $\mathfrak{B a g e n}$ eintritt,

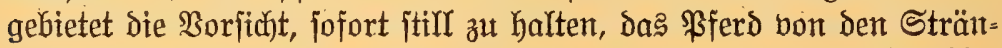
gen und ber Deidfel zu befreien und bann ruhig bas ende bes $\mathfrak{A} \mathfrak{n}=$ falls abzuwarten.

\section{Arämpfe (spasms, cramps).}

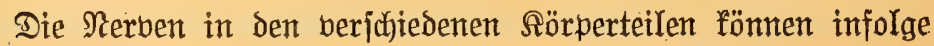

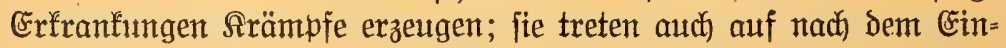
geben joxarfer $\mathfrak{Y}$ rzneten. Die Şillfe in joldjen Fällen bejtebt in ber 
Behandłung Der innern angegriffenen Teile, wie bies bei deren ber= fdjicbenen Iranfleiten angegeben ift. Sier follen nur bie bäuftg borfommenden, pröbzlich auftretenden Srämpfe ber Şinterbeine be= iprodien werden.

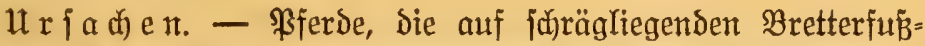
böben im Stalle ftehen, werben bejonbers während falten Metterg bon Srämpien in Den Sinterbeinen befallen; audi nach jabtwerer IIrbeit treten bie $\mathfrak{T}$ nfälre auf́.

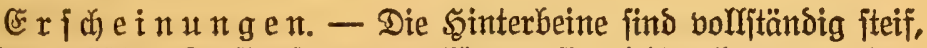
mit ber größ̈ten Sraftanjtrengung fönnen fie nidbt gebogen werden. Da马 Pferd jtebt auf ben Beinen, ijt aber unfähig, fich fortzubewegen.

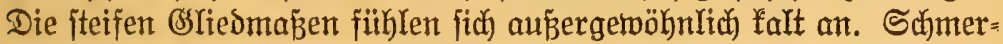
zen jujeint diejer Starrframpf nicjt zu berurjachen oder boch nur Dann, wenn Das \$ferd fich betwegen will. Der Rrampf mag mur ronige Minuten anhalten, fann aber auch mehrere Tage bauern. Nidht jelten wird ber Starrframpf für eine Nerrenfung Des Şüft= gelents gebalten. Das Erfennen einer Berrentung ijt jedoch Ieicht; Das \$ferd fteht Dann nidjt auf Den beiden Sinterfüßen, jondern Da?

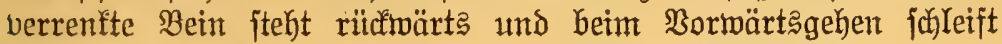
es nack).

Behand I $\mathfrak{n} \mathfrak{g}$. - Eine Cinreibung der frampfitarren Mus= leIn mit einem Riniment, beitehend aus

chloroform 1 part, soap liniment 4 parts.

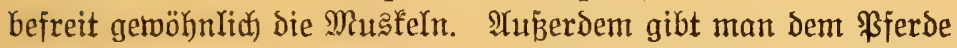
chloral hydrate $1 \mathrm{oz}$.

mit einem halben $\mathfrak{B i n t}$ Mild bermijht ein.

Starrframpf, Mauliperre (lockjaw, tetanus).

U r f a d e n. - Der Starrframpf tritt am häufigiten als Folge einer offnen ßertwundung auf, bei weldyer eine Berunreintgung ber Munde mit Ietanusbazillen oder mit erde, Staub ujt. itattfindet.

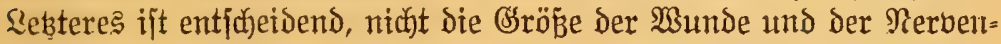

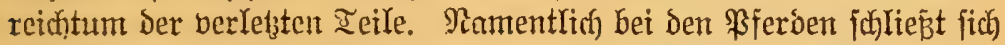

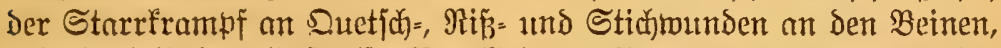

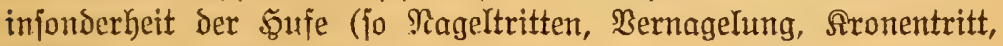
Findringen frember Rörper, Rnod)entwunden) an; ferner an bie Sta= itration, bei der unreine snjtrumente und Alammern benutst wutrden, ebenjo toie unreiner Stalrboden die Rranfheit erzeugt. 
Durct) Berjuctje ijt Dargetan, baß̈ jich der Starrframpf von Tier

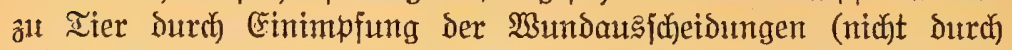

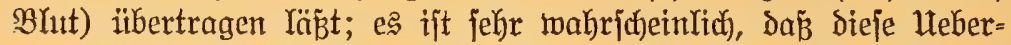
tragung aud) in Mirflid)feit burd) unreine şnjtrumente bei Dpera= tionen, Sseburtghilfe ujw. exfolgt. Bwijhen Berwundung und offen=

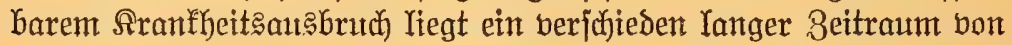

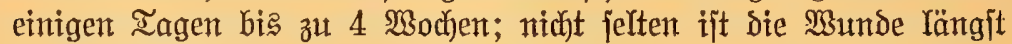
abgebeilt. 3umeilen entwicfelt fich ber Starrframpf, ohne dá̉ eine Bermundung borautsgegangen wäre. Bisher wurden derartige, gemeinfin aud) milloer verlaufende Jälle auf (Ertältung (rheumati= ficher Starthampf) zurülfgeführt, Doch bürfte aud) bier eine ver=

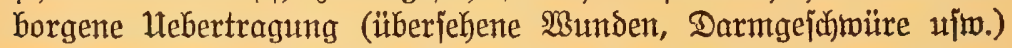
zugrunde liegen.

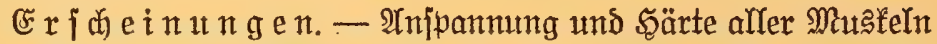
in mehr oder weniger itarfem srade und infolge dabon jtärfere $\mathfrak{A} u s=$ wrägung ber Mußfeln, Steifheit und Sd)twerbetweglidffeit aller Ieile.

Die Rranfheit entwidelt jich janell oder langiamer; zumeilen beginnt Ser Arampf an einem Sörperteil und breitet fich bon dort weiter aus. Der ganze Rörper hat eine iteife, geftredfte Saltung, Sopf und Şals ijt meiftens geradeaus geitrectit, Der : siucfen jteif, un= Bemeglich, ber Sdjwanz aufgeridjtet und weggeitredt, ber Bauch ge= fpannt aufgezogen. Die Scjentel jteif und jtarr, bejonders bie Sin= terglieomaß̉en gejpreizt, baher eine jägebodkartige Stellung. Bein osehen find die (selenfe jomer beweglid, fönnen nidbt gebeugt werden, baker ein mühjamer, gefpannter Şang, fo bá̉ die Tiere wie altf Stelzen gehen, Ieidht anjtoizen, ftolpern, jujwer zurüdftreten ober wenden. Die Tiere legen fich jelten und fönnen fich fidwer oder gar nicht erheben.

Das Maul ijt feit gejolofien oder mur wenig zat öffnen, die Siefer fibmer beweglich und die Siaumuteln bart und angejpannt (Mauljperre). Die Jutter $=$ und (Ssetränfaufnahme ijt jomit erjahtwert oder ganz unmöglich, ebenjo ijt das Schlingen erjobwert und daher meititens Speicheln und Gseifern zugegen. Die in ber Mautböhle zurüafbleibenden Futtermaljen und ber Speidjel zerjetgen fich und riechen übel. Die Alugen find fatwer bemeglidh, itier, in bie Söhle zurüdfgezogen. Beim plöblichen Emporricten Des Ropfes tritt der Blinzfnorpel über bas গ্lıge weit herbor. Die Shren find iteif aui= gerichtet und die Najenlödjer wibernatürlich) (ectig, trichterförmig) erweitert. 


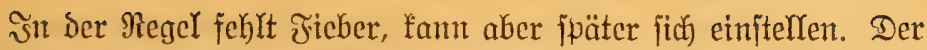

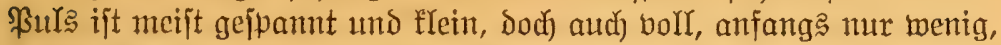
fpäter jtarf an 3ahl bermehrt; Iemteratur ziemlidf normal, erjt bei

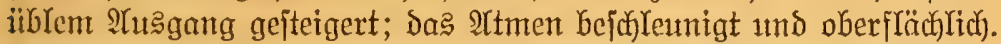
STppetit und Durrft borfanden, aber Freffen, Saufen und Saflingen

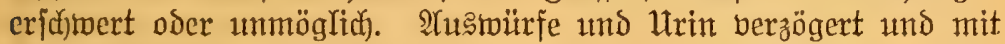
3twang entleert. Das Betwuṕtfein ungetrübt, aber $\mathfrak{A}$ ngit berratender Blid. - Dabei find bielfadf bie Tiere überaus reizbar, jidrecthaft, jo

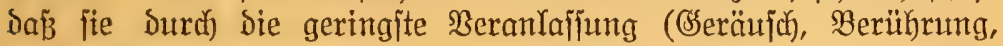

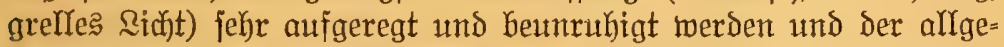
meine Srampf an Seftigfeit zınimmt. Îtrhaltende, ftarfe Schmeip̆e find jebr gemöhnulict).

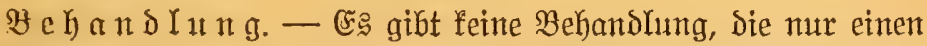

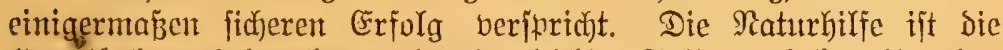
5auptjache und daneben geeignetes Yeidjtes Futter wnd beruhigendes Berfahrent. Dahin gebört geräuf́chlojer, berDunfelter, nidgt zıtgiger STufenthalt mit nidjt glattem Fußboden; furz gefounittenes Streu=

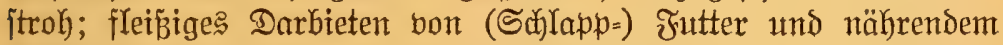

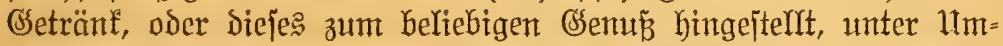

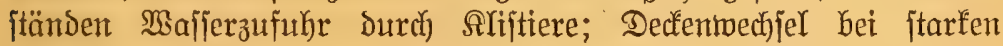
Sdjmiken; Einftellen Der Tiere in Şängegurte beim Stehen, utm daß umfallen зu verbüten, fomeit fie hiersurch nicht aufgeregt merben. -

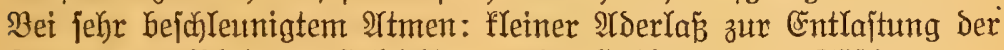
\&ungen bon Błut; zur Erreichterung Der Entleerungen: Artitiere.

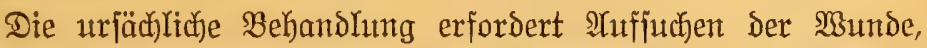

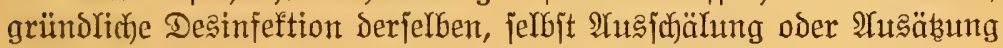
Der Itmgebung; Yeider ift diejelbe jelten Durchzuführen.

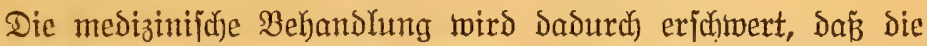
Beibringung innerlicyer Mittel burd Den ßimnbactentrampf ber=

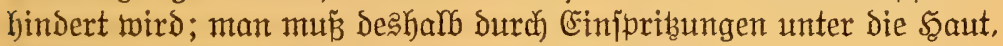

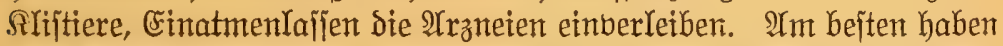
fid) (Finjprib̧ıngen bon tetanus antitoxin, wenn gleid) beim $\mathfrak{A} u \mathfrak{u}=$

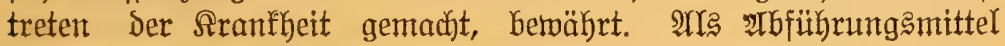
gibt man

\section{Barbadoes aloes 7 drams, solid extract of belladonna 2 drams,}

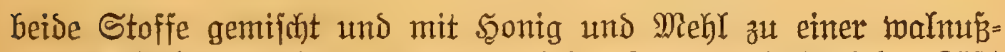

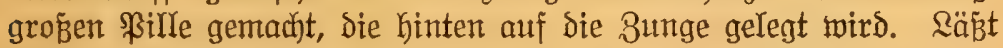

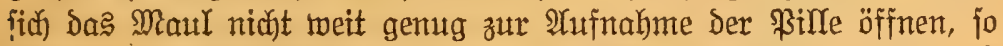
fönnen bie medizinifben Stoffe in 2 Utnzen Slivenöl aufgelọ̈t und 


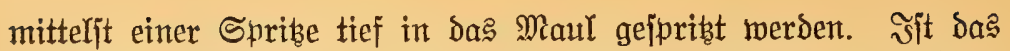
Maul feit gejulofijen, fo verjudje man nidjt mit Gerwalt es zu öfnen.

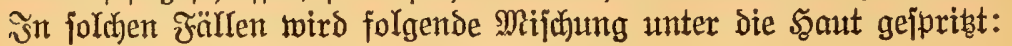
atropia $1 / 4$ of a grain, sulphate of morphia 5 grains,

in 1 Dradt)me (dram) Majjer aufgelöit. Die Cinfpribungen werden öfters wiederholt, um bas \$ferd ınter Dem Einflū der Medizin zu Galten und die Sdjmerzen zu lindern. Semöhnltch tritt bald ein

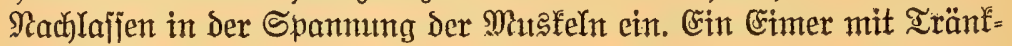

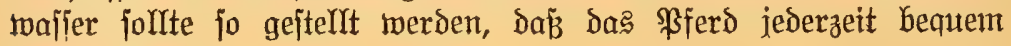
trinfen fann:

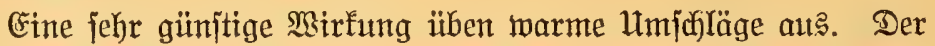

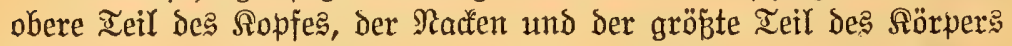
merden mit wollenen Deffen belegt, bie in jebr twarmes

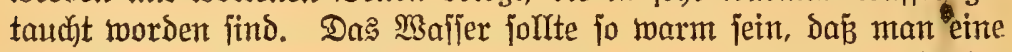
Şand bequem längere Beit Gineinhalten fann. Sind die Deçen

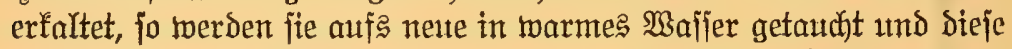
Behandlung mü jechs bis jieben Stumben umunterbrochen andauern.

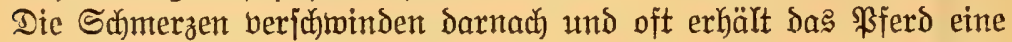

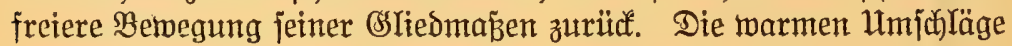

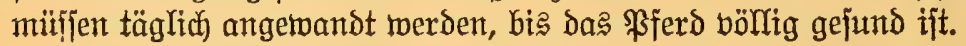

\section{Dummfoller (staggers).}

Fine Iangwierige, fieberloje Simfrantheit ber \$ferde, bemert"

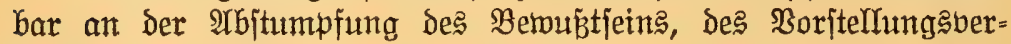

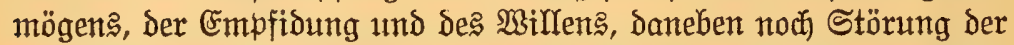

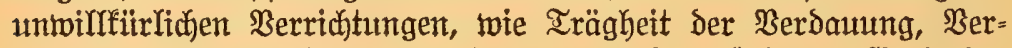

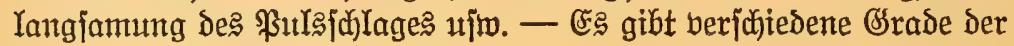
Irantheitsausbilsung.

Die Srundurjache des Dummfollers liegt in einem andauernden

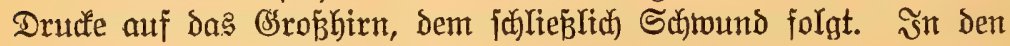
allermeiften Fällen bewirtt diejen Drute eine $\mathfrak{A n j a m m l u n g ~ v o n ~ S a ̈ f ~}=$ ten in bett Sirnfammern, Deren nähere Urjache allerbing? unauf= geflärt ift; jeltener Renbildoungen im Gebirn und Sajäbelber = bildungen.

Il $\mathrm{r} j a$ chent. - Der' Dummfoller entjteht 1. ganz allmählich und unbemerft, oder unter ßoraustritt einzelne jeite Entwidflung

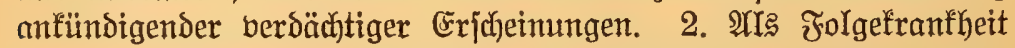

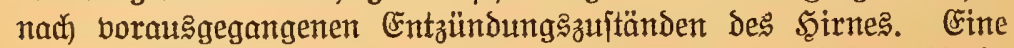

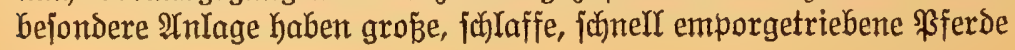


mit jđłmalem Schäbel (mit geringerer šntelligenz), ser gemöhnlichen Raffen. Fernter wird bon bummfollerigen EItern sie Ilnlage bererbt,

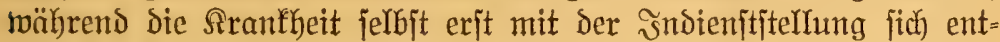

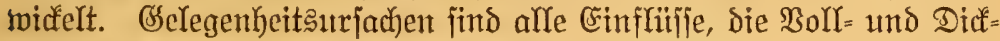
blütigfeit, Indrang bes Blutes nach den Siopfe erzeugen, alfo twie bei (bsehirnentzündung; bornehmlict): ungewohnte, fräftige Fütterung

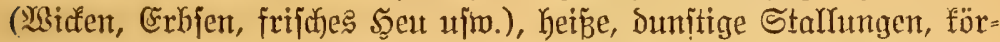

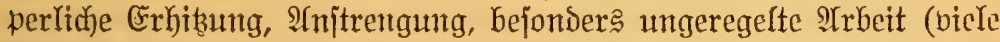

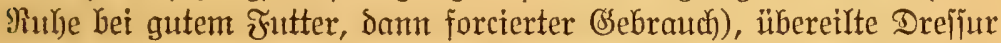

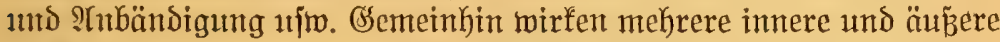

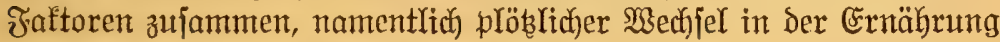
und Der ganzen Rebenstweije.

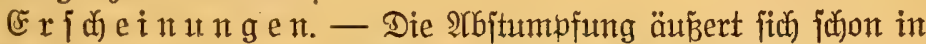

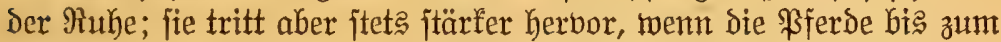

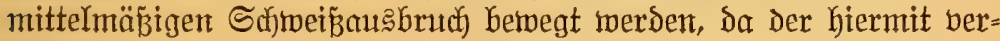
bundene Blutandrang nach) Dem Sopfe Den faton borhandenen (S) birnoruat iteigert.

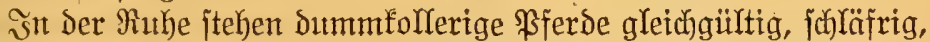
in fich berjunfen da, mit bummem, auรdorudf mäßżgem Dhrenjpiel; Die Siörperhaltung ift nad)läjifig, Der Sopf wirs meift niebrig gehalten, feltener aufgeitübt oder angelehnt, ber Sörper vorgejuoben; Die Stellung Der Fübe ijt oft unregelmäßig und ge=

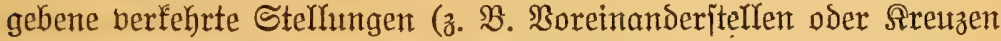
ser Borderfü̈be) twerden längere Beit beibehalten. Weiterbin zeigt

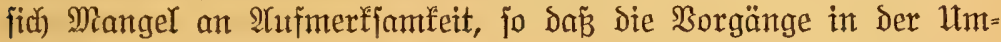

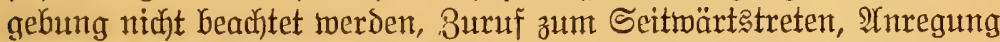

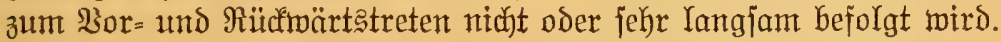
Die Tiere erjaredten Yeidjt bei ungemöhnlichen Einwirfingen; nicht

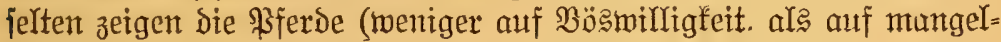
haftem Seritänonis beruhende) Intugenden, namentlick obne irgend= tweldhe Beranlajiung Beipen, Sa)lagen, Scheuten. Fernter findet firch

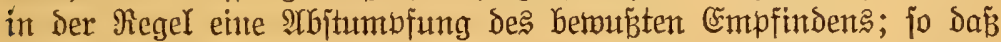

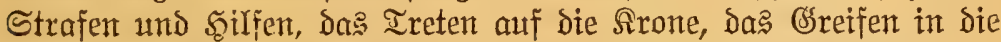
Dhrent, ১as Sdjnellen bor die Stirn, nidyt oder wenig beadjtet werden, an ehejten noch bei plöbliden, nicht aber bei langjameren, jelbjt jehr Itadibaltigen Einmixfungen. Surr in jeltenen Fällen iit bie Emp= findlichfeit überall oder an einzelnen Sörperteilen wenigitens in Der

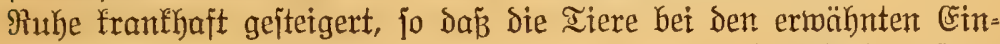
wirfungen ganz ungemöhnlich aufgeregt merben, (chrecthaft zujam= menfakren oder fich jonjt ungebärotg benthmen. Die ß̉etwegung exfolgt naçjläjîtg, träge, tappento. 
Die Futteraufnahme geifjieht langiam oder in Dummer Şait, oft

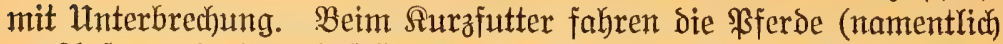

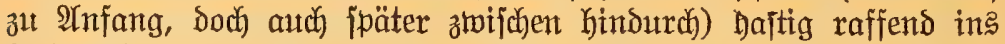
Futter Ginein oder wilfhlen jidnell fauend in Futter herum. Das

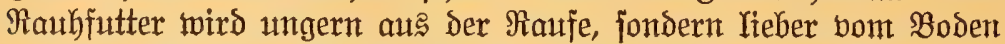

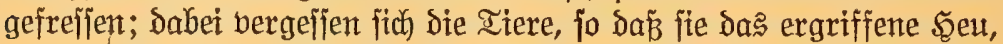

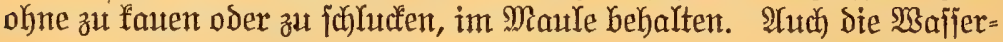

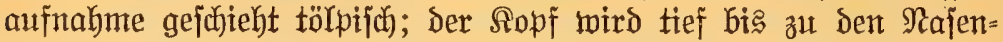

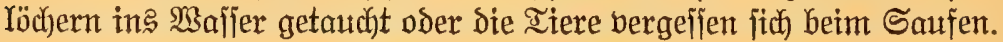
Die SBerdauung ift verzögert, Der Dung meift trocent und fleiner ge=

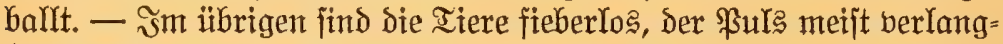

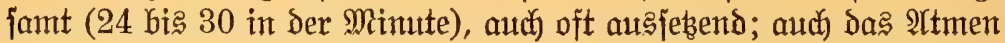
verlangiamt und tief.

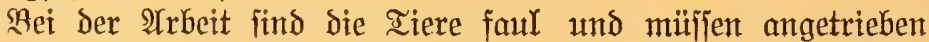
werden; fie gehen mit niedrig gehaltenem Ropfe, legen fich in bie Bügel. Dft brängen fie Dauernd nad) einer Seite, fint füber zut Yenfen; Silffen und Strafen bieiben unbeadytet oder bringen unge=

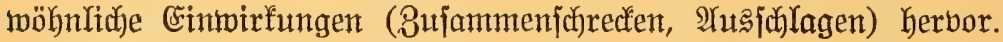

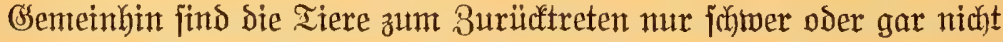

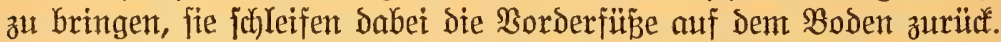
Monn fie warm getwordent, find fie oft nidjt mehr won der Stelle zu Gringen, oder Drängen unauffaltjam unt Glind borwärts vder zut Seite und alle oben erwähnten $\mathfrak{A b j t u m p f u n g s e r j a b e i n u n g e n ~ t r e t e n ~}$ nod) Deutlictjer herbor.

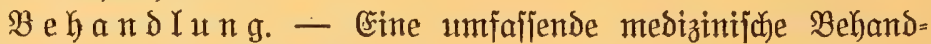
Yung ijt mur bein Sranfheitsbeginn oder bei eingetretener erhebficher Beridflinmerung angezeigt. Folgende Mittel find zu empfeblen:

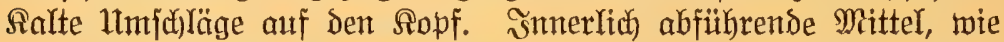

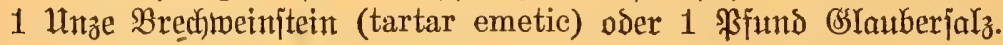
Saarjeile am $\mathfrak{S}_{\text {alje. }}$

Ritctige Prflege ift unter alfen Utmitänden Sie Şautptiache und

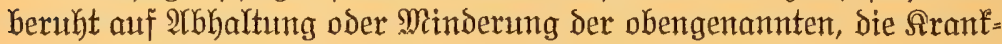
heit fteigernden Berfältnifje. Erforderliư ift aljo: fühYer, Yuftiger

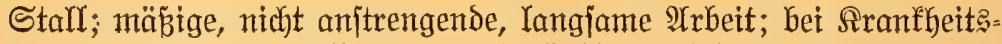

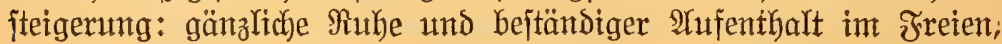
audid) Des Radjts und bei Regentwetter, aber mit Schut gegen bren= nende Sonnentjise. Miäpig nährende, gelind eröffunende, łüblende,

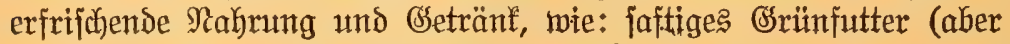

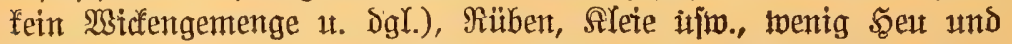

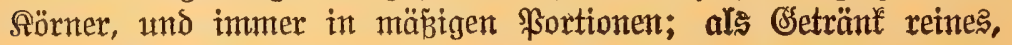

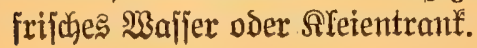




\section{Tolriwut (rabies, hydrophobia).}

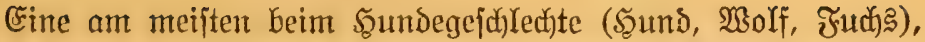
aber audj) bei alYen übrigen Saustieren, felbjt bem B̧eflïgel (uns beim

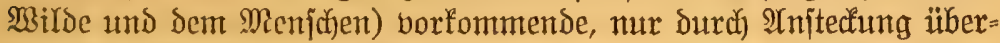
tragbare Siranffheit, d)arafterifiert Durdh auffällig veränderte马 $\mathfrak{B} e=$

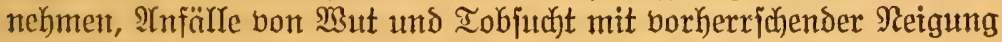

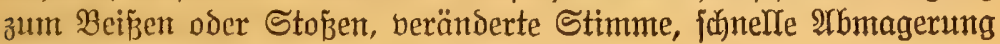

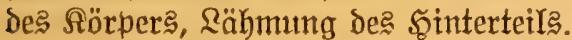

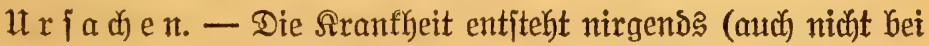

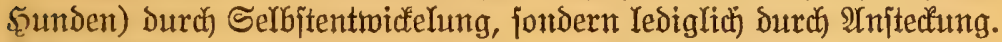

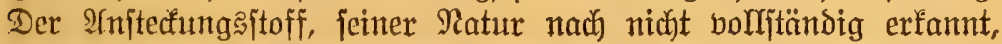

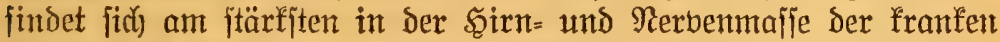
Titere, weiterbin aber mud in beridjiedenen (Speichel=, Tränen=,

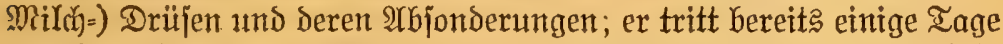
bor Der offenbaren Ertranfung im Epeichel auf. Die natürlidge

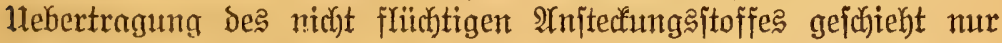
Durd) Einimpfung mit Dem Bifife woutfranfer Tiere, wobei ber mit

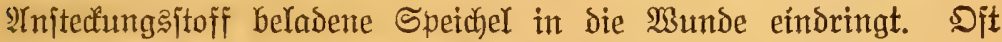

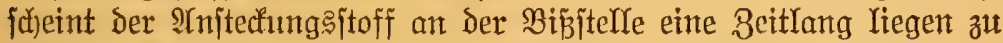

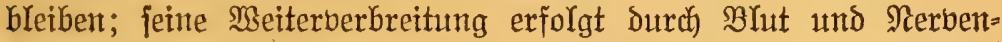

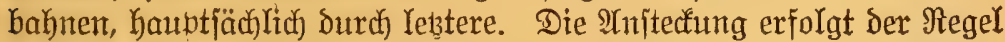

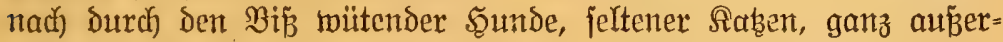
ordentlidj) bereinzelt bon anderen Tieren. Nidjt alle gebifienen Iitere ertrantent, fonvern mur ungefähr 5 bis 40 \$rozent; die Mefrzahl bleibt bon Der Aranffeit beridjont, wohl gewöhnlid, deshalb, weil Dą

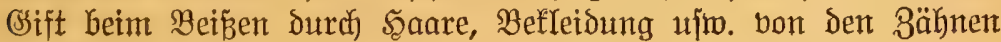

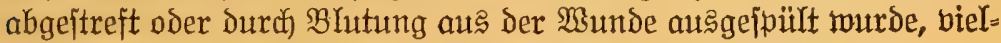
Ieidbt audd zum Ieil deshalb, weil bie Beranlagung fehlt.

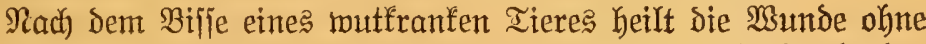

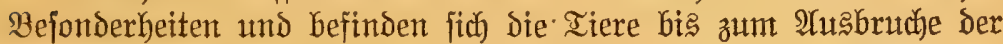

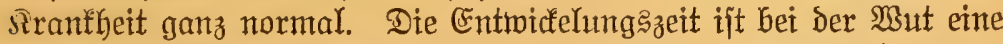

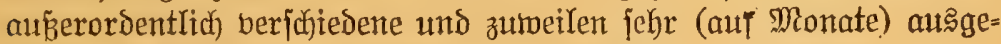

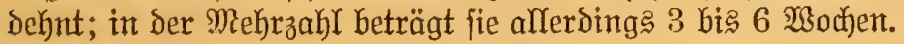

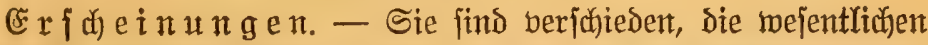
Eridjeinungen aber ïberall gleid), und als folcte zu nennen: $\mathfrak{B} e r=$

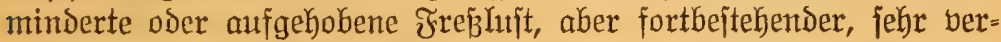

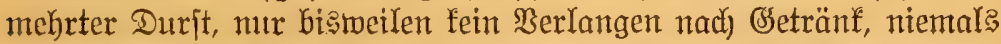

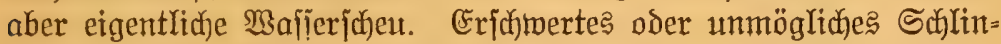
gen. Şartleibigfeit oder $\mathfrak{B e r i t o p f u n g , ~ a u c i ) ~ f p a r j a m e ~ U t r i n e n t l e e r u n g . ~}$

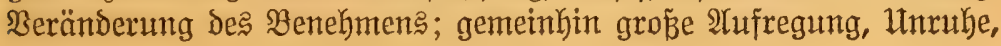


bismeilen mit Sdłrecthaftigfeit, jeltener 2Ubitumpfung. Eine eigen= tümliche Beränderting der Stimme, mebr heifer, Hurz, abgebrochen und bie Iiere Infjen fich häıfiger als jonjt hören. Beitweilige IYnfälle

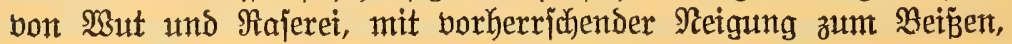

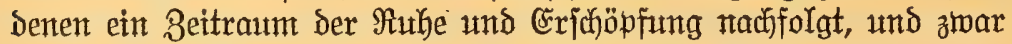
mehmen dieje immer mehr zu, narh Erad und Dauter. Starfes Speicheln und Şeifern. Ein wilder, ftierender Bliat, globende, her=

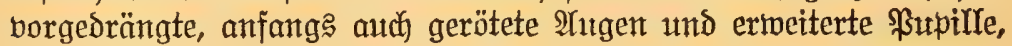
Sin" und Sertrippeln, Stampfen mit Den Fü̈Ben, fteifer, gejpannter

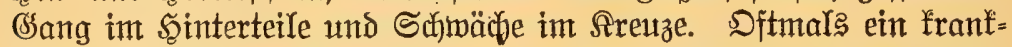

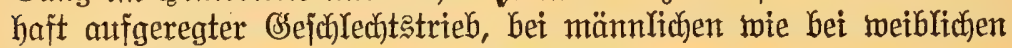

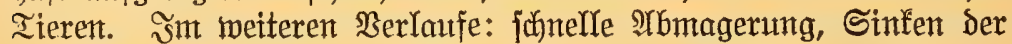

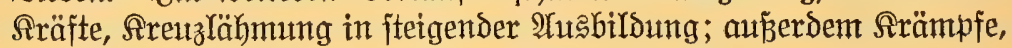
Budungen, Bittern Der Mußfeln, Sehnenhühfen und zulebt unter

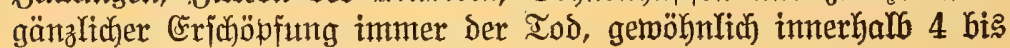
5 Iagen, Doch atth ipäter oder frïher.

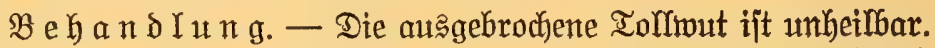
Irre bisher entpfohlenen Berfahren waren ohne Erfolg; Deshalb und

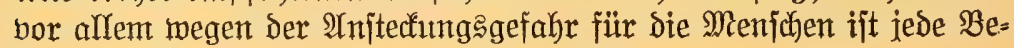

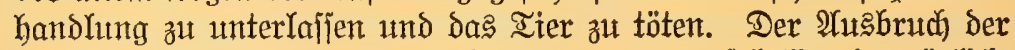
Sranffeit Yäßst fich aber verhindern, went man jobald wie möglich,

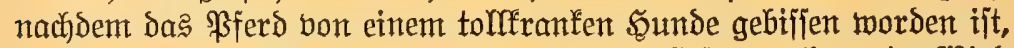

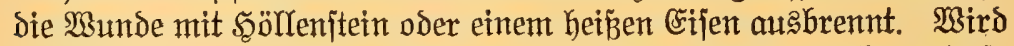
die $\mathfrak{3 u n d e}$ innerbalb zwet Stunden nach dem $\mathfrak{B i p j}$ ausgebrannt, jo tritt die ₹ollwut nicht auf. 


\section{7. 篇apitel.}

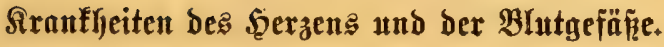

Die Errfrantungen des Şerzens treten jelten für fich allein auf, jondern find gewöhnlidf) Begleiter anderer Aranffheiten. Sie find auberbem jehr jafjwer zu erfennen, jelbjt ein erfahrener Tierarzt

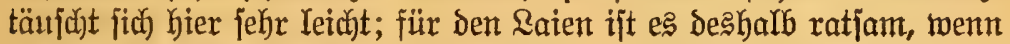
er eine Sgerzfrantheit bet jeinem \$ferbe vermutet, bie Befandlung einem ₹act)manne zu übergeben. Die马 ijt um jo mehr notwendig, ba bie bei Şerzfrantheiten angemandten Mittel fajt alle jtarfe Biffte find.

Selbjtändige Erffranfungen der BIntgefäß̈e find ebenfarls jelten. Bejondere Beadjtung berlangt hier aber bie

Rabelent子ündung Der Frofflen (inflammation of navel by colts).

It $r$ f a dy e n. - Diejer Sranflyeit, bie früher als Fohlenlähnte voer SeYenfanjidmellung bezeidnet wurbe, ftand man jolange ratlos

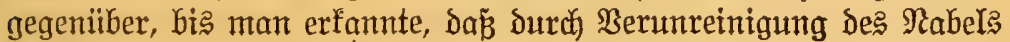
Bafterien in Dą Bhat eindringen. SGierdurdi merden eitrige Ent

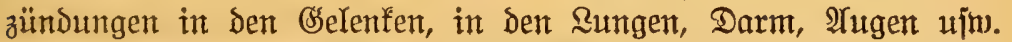

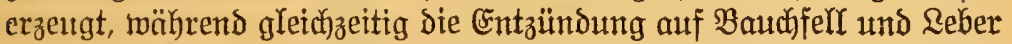

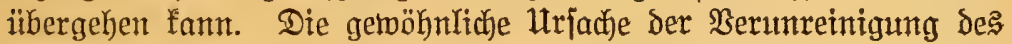

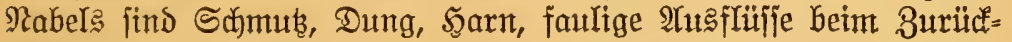

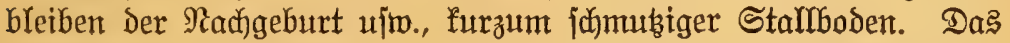

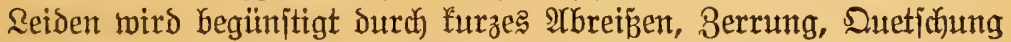

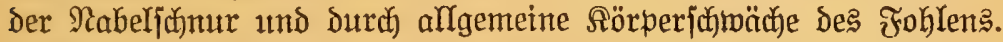

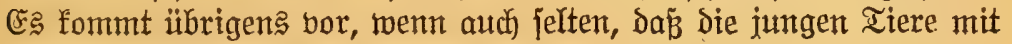
bereitertem Rabelijtrang geboren werden.

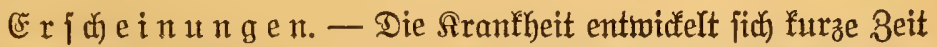

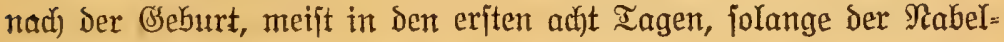
ftrangrejt nidjt eingetrodetnet ijt, felten jpäter als vier : Der Bseburt.

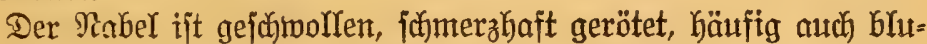
tig. Meiterfin füblt man int Bauthe bom Mabel nact) born (ber

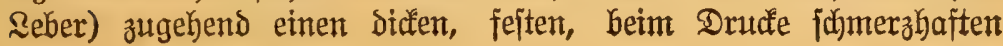




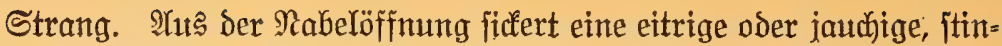

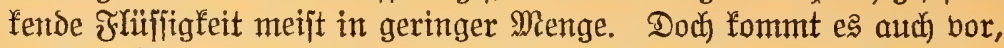

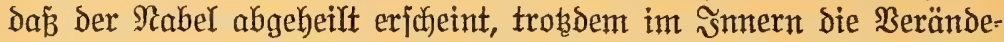
rung fortjichreitet oder dieje wirs überjeben. Fs ftellen fich bein Foblen anfangs Mattigfeit, mangelnoe Saughujt, dann groß̉e

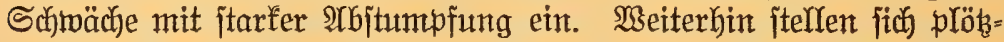

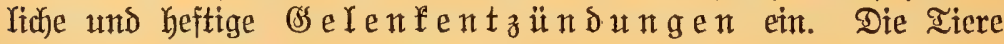
hinfen oder jtehen gar nidyt auf. Die Gselenfe find gejujwollen und weijen erböhte Wärme auf. Jerner gejellen fich Dazu Berjtopfung oder Durchfall, empfindlithfeit des Bauches gegen Drud, juntlles

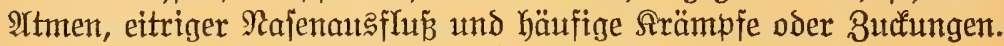
Der Iod tritt zulest infolge allgemeiner Blutbergiftung ein.

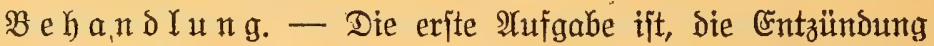

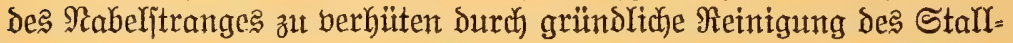
bodens bor Dem Arbfohlen und Einlegen reiner, trocher Streu. Marht

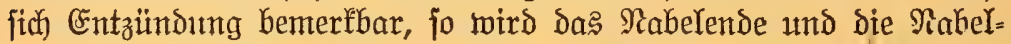
öffmung mit berdïnnter Sarbolïäıre (5:100 solution of carbolic acid) beitrid)en. Sft ijt e? notwendig, die Rabeloffmung mit bem

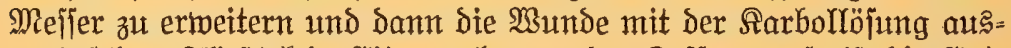

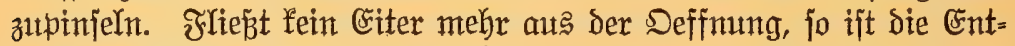
zünoung behoben; nicht jelten bleiben aber nod) Irnjubellungen zu= rituc; bieje werden mit Duedfitberjalbe (mercurial ointment) einge= rieben. Şaben fich sefictwüre gebildet, fo werden fie mit bem Mefier geöffnet. 


\section{8. 筑aprifel.}

\section{firnnffyeiten bes 9Hases.}

Entzïndung ber 9 (ugenliber (inflammation of eyelids).

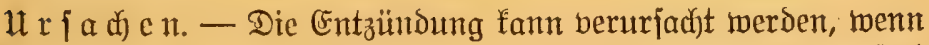

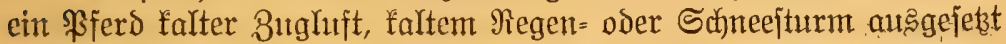
wirs. Die Bifje von Mosfitos, Friegen und anderen Ĩnjeften,

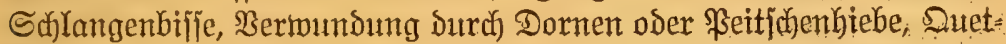
fofungen im Stall ober auf Der Eroe, wie fie beim. Riederitüxzen bei

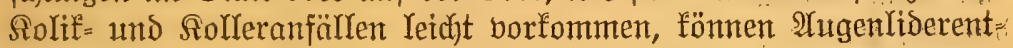
3ündungen herborrufen. Daß́ das Einoringen bon Frembförpern: ( Sand, Staub, Spreu, Osrannen Der Serite uftw.) oft Entzündung de?

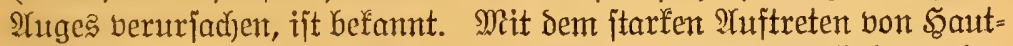
cntzündungen (nettlerash) ijt mitunter auth eine Entzündung ber Iugen berbunden.

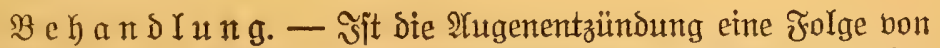
Erfältung ober Erf̌ranfung anderer Rörperteile, jo bereite mant eine fïhlende Flizffitgfeit, Gejtehend aus:

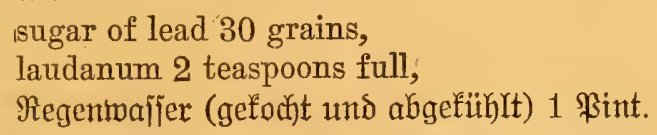

Ein weidjes Stüd Beug wird mit ber Mifánung angejeudftet, über bie

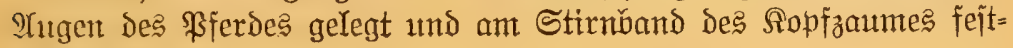
gebunden.

sit bie Sd)leimbaut ber $\mathfrak{A}$ ugenlider mit Heinen förigen

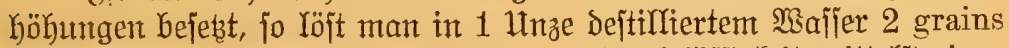
of nitrate of silver auf und betupx mit Der Jłhiffigfeit mitteljt einer

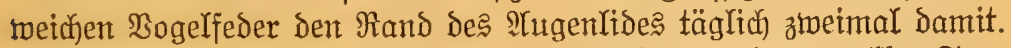

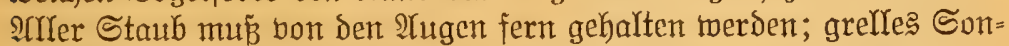
nenlid)t Darf nicht auf Die Ŝtuen Des Tieres fallen. Das Futter nut?

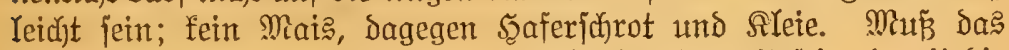
ßferd arbeiten, fo mú dą אumt (collar) jehr weit jein, damit die

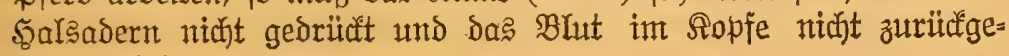
Galten wiro. 
Sit bie Entzündung eine Fुolge bon Frembtörpern im 2 Huge, jo miiffen sieje mit einer weidjen Feder herausgemifjbt werden und ị̂t Darnadi bie oben angegebene fühlende Mijhyıng anzumenden.

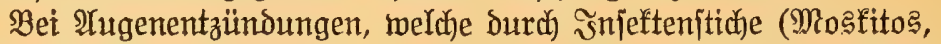
Bienen, ßejpen) herborgerufen wurden, Getupft man bie Iltugenlider

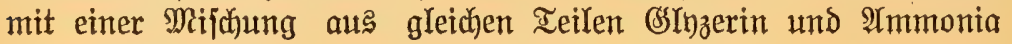
(aqua ammonia).

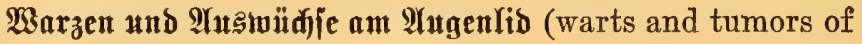 the eyelid).}

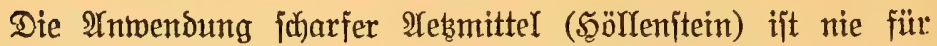

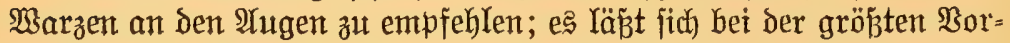

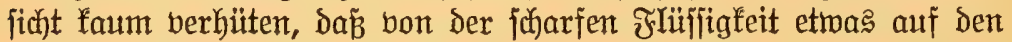

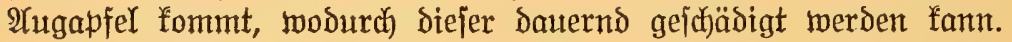
SIm gefahrlojejten ijt das

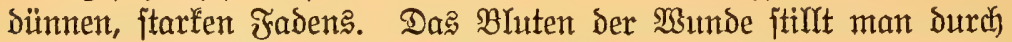
Einreiben Derjelben mit einem Stüd ̊upferbitriol (bluev vitriol). Die Eintreibung wird jolange fortgejebt, biß bie $\mathfrak{B}_{3}$ unde geheilt ift.

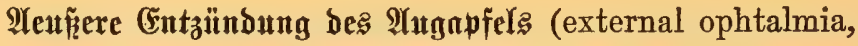 conjunctivitis).}

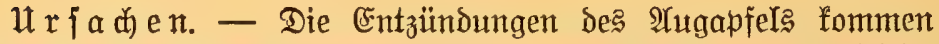

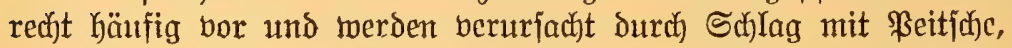

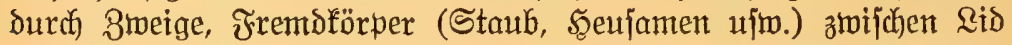

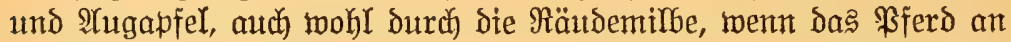

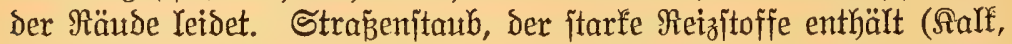
fYeine \$il

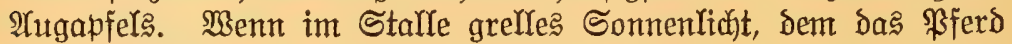

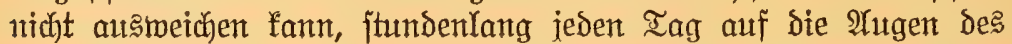
Tieres färlt, fo tann audch badurch bie Entzündung herborgerufen merden. Sie tritt aud in Berbindıng mit Entzündung der Sa)leim= häute in $\Re a j e$ und Maul auff.

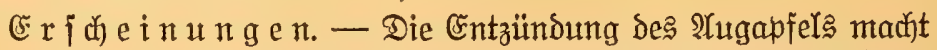
fich fenntlich) burch jtarfes : Tränen, angeidfinollene Rider, auffallente

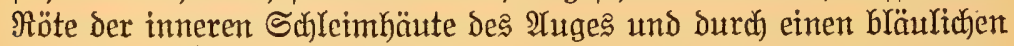

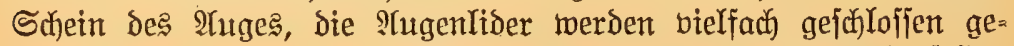
halten; mitunter wird ein weiper freed im Âtuge beobadftet; felten zeigt fict) (Eiterausflü.

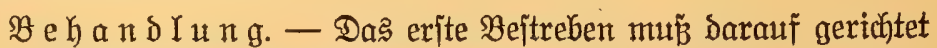

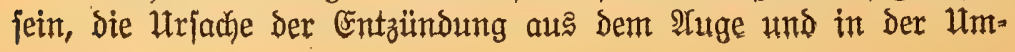


gebung zu entfernen; der Stall muti ftaubjrei jein und bas \$Fero

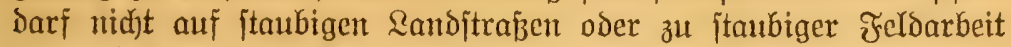

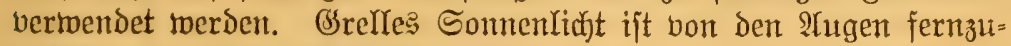
halten, aber aud) völlige Dunfelheit ijt tagşüber im Stalle zu ber= meiden. Das \$fero ift gegen Bugluft und najfe Rälte bejonders zu

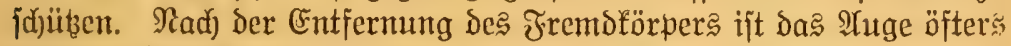
während des erjten Iages mit Yaumarmem Majjer 15 bis 20 Minuten:

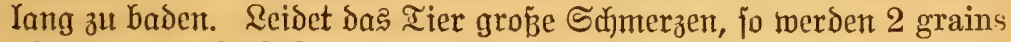

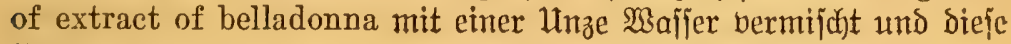

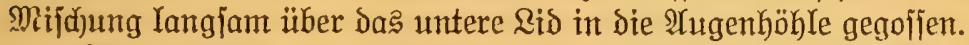

Sit Yierdurd) eine Rinderung der S(f)merzen herbeigeführt, fo

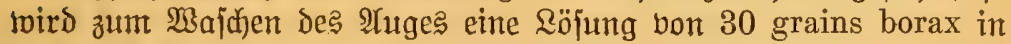

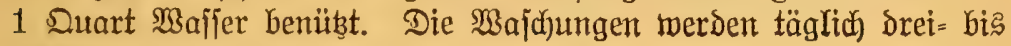
biermal borgenommen.

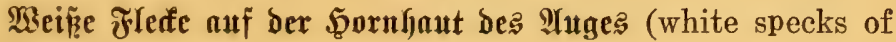
the cornea).

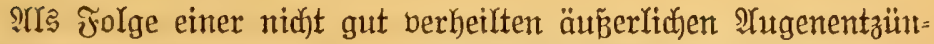

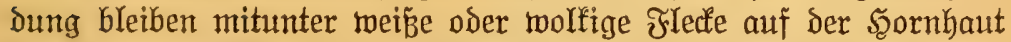
Des গYges zurüd. 3ur Entfermung Der Flede bermendet man eine

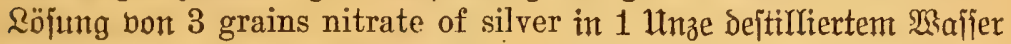

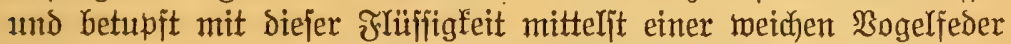
täglid) einmal bie weiñe Stelle. Şat ber weip̌e frlect lange bejtanden

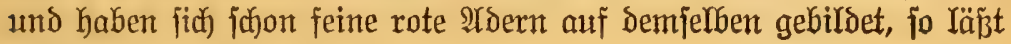
er fidj) nidjt mehr entfernen.

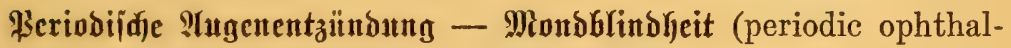
mia or moonblindness).

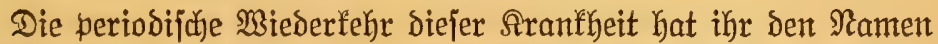
Mondblindheit eingetragen, obmohl Der Mond ohne Einflü auf Das Entitehen und den weiteren Berlauf Derjelben ift. Es i it eine Ent=

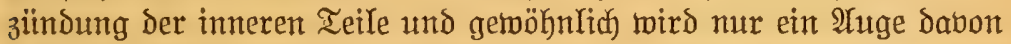
befałlen. Bei Yängerer Dauer twird aud̆ Das andere $\mathfrak{A} u g e$ angegriffett und böllige Erblindung ijt fidließ̧lid bie Folge.

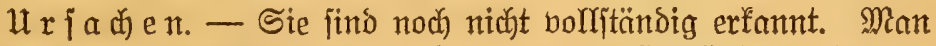

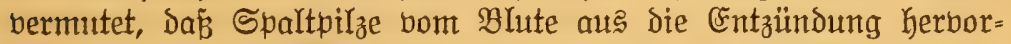

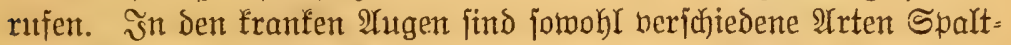

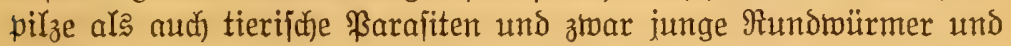
Egel gefunden worden. B̧efannt ijt, Dás bei der Entitehung der

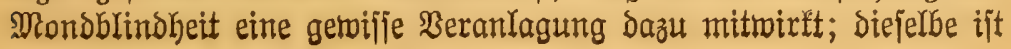




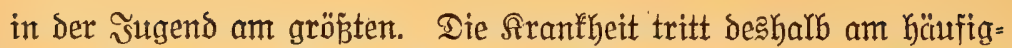

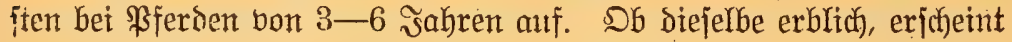
neuerdings zweifelfaft. Die Sranfheit ift borwiegend an gewiffe DertItchfeiten gebunden; fie fommt in bejtimmten Begenden (nament=

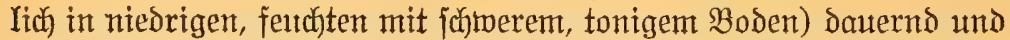

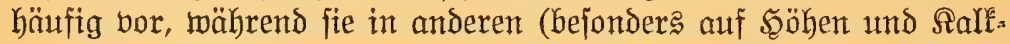

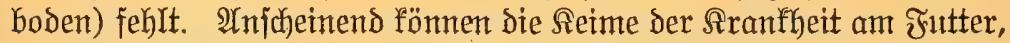
wie am $\mathfrak{B a j [ e r ~ h a f t e n ; ~ F e u r d y t i g f e i t ~ u n d ~ U l e b e r j ( c ) m e m m u n g e n ~ b e g u ̈ n = ~}$ ftigen die Entitefung.

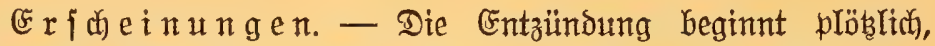

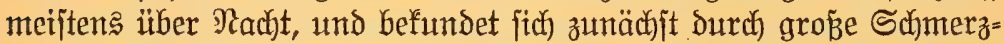

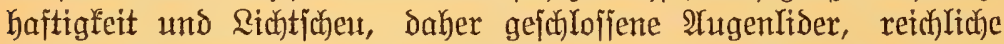
Iränenabjonderung, die beim Deffnen der Âtgenlider ftrombeije herabzuftürzen pflegen; bermehrte $\mathfrak{B a ̈ r m e , ~ f t a ̈ r f e r e r ~ \Im n n e n d r u c t , ~ f t o ̈ r ~}$

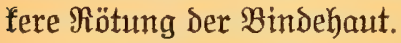

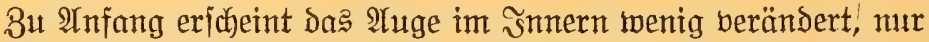
die \$upille ganz und gar berengt. Bald (in 24-36 Stunden) treten

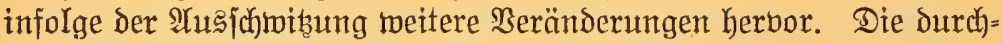

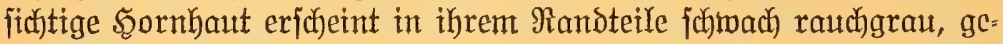

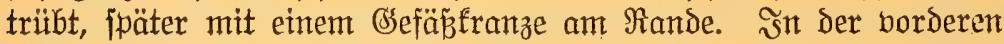
IHgenfammer fammelt fidf, bon unten nad) oben zunehment, ein

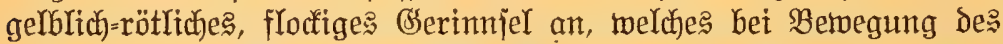

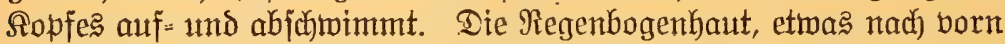

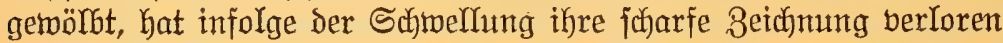

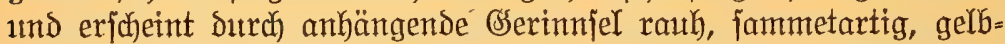

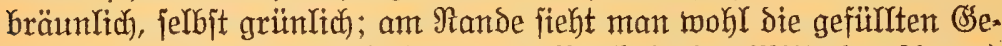

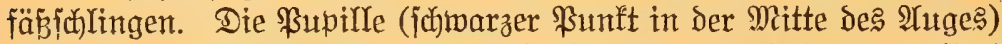

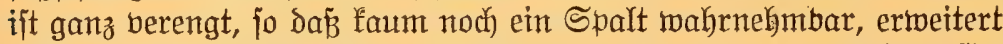

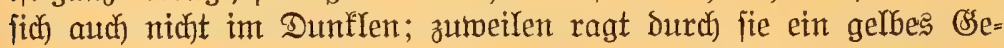
rimmfel aus der hinteren $\mathfrak{A}$ itgentammer herbor.

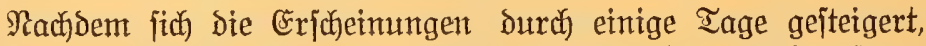
erfolgt zınädhft Minderung der Sdjmerzhaftigteit und Ridhticheu,

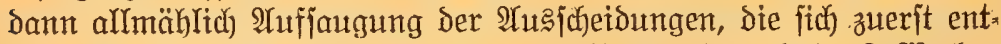
färben, wäfjerig gequorfen zulammenballen, und nadh 1-3 ift jueinbar alles norüber. Bei genauerem 3 ulehen findet ntan jedoct)

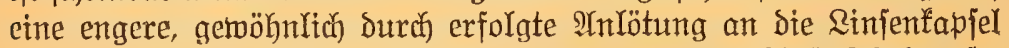
unregelmäßige, felbjt berzerrte \$upilfe und auf ber হinje fłlecten, fo. wie Irïbungen; Dabei Yeidytes Scheuen, untgenautes Sehen.

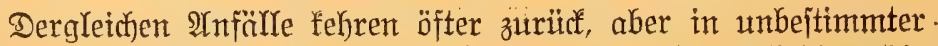
Beit (bon einigen Modfen bis Monaten, getwöhnlich) 4-5 Mochen; bie 
eriteren Iangiamer, bie Iebsteren juneller folgend) und hinterlafien

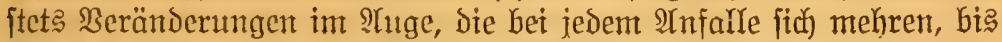

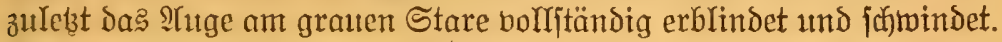

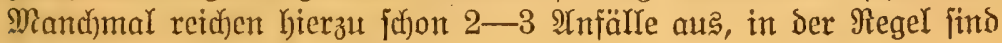
aber beren mebrere erforderfich.

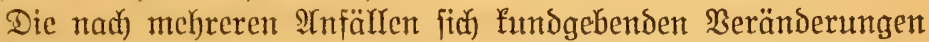

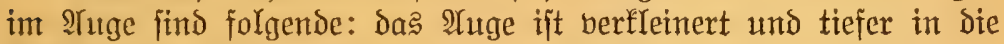

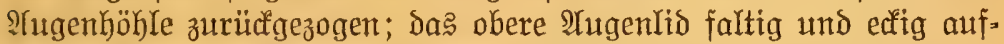

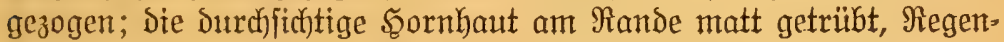
bogenhaut vorgetölbt, ohne forarfe 3eidfmung, fammetartig, roit= farben, Die \$upille meift edfig, nerzerrt; in Der Arijtallinje zeigen fidf) trïbe, undurchjichtige Stellen (Starpuntete), bäufig audo an ihrer bor=

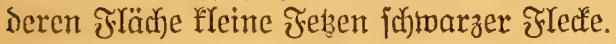

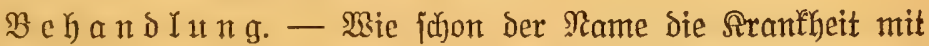
bem Mons in Berbinoung bringt, fo Darf man fid audif nidbt darüber wumbern, Daß̉ alferlei $\mathfrak{B u m b e r f u r e n ~ z u r ~ S ̧ e i l u n g ~ a n g e w a n d t ~ w e r d e n . ~}$

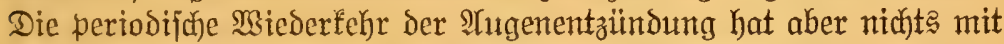
Dem Monotwedjfel zu tun und alle bet abnehmendem und zunehmen= dent Mond angetwansten Mittel haben fith als untwirfjam erwiejen;

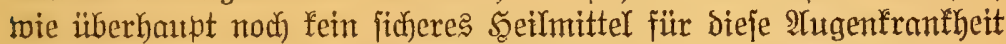

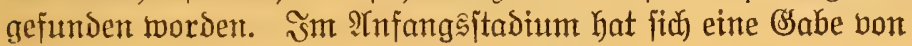

2 drams salicylate of soda,

1 scruple of powdered colchicum,

3tweimal täglich berabreicfit, recht gut betwährt. Die \$ulver merden mit Sirup und Mehl zu einem Brei verriihrt und mittelit eines Solz= ipanes Kinten auf Die Bunge geitricjen.

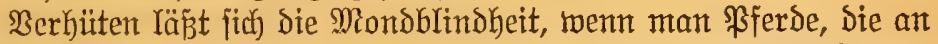
Der Sranfheit Yeiden, nicht zur Budyt vermendet, auf gute Stallungen

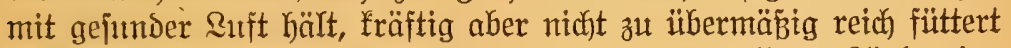
und vor allem \$ferde nicht auf niebrigen, fumpfigen হändereien tweiden läst.

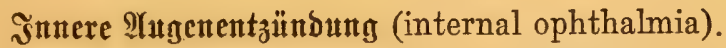

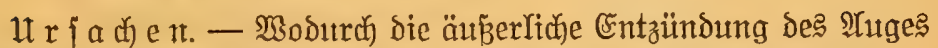

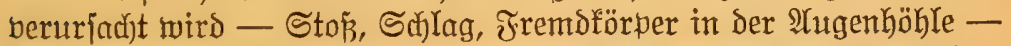
fonn auth), wenn die \$erlebung fohtwer ift, die innere Entzündung her=

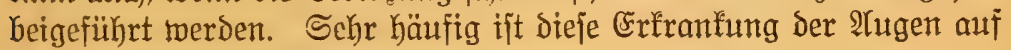

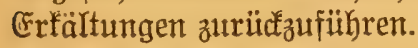

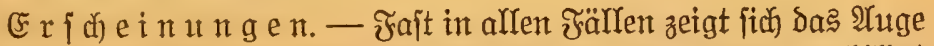
trübe, oft mit wolfigen Flecfen; bei jehr jobmeren Entzünoungen bildet 


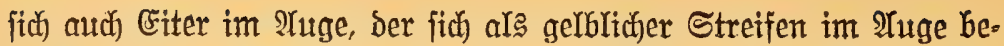

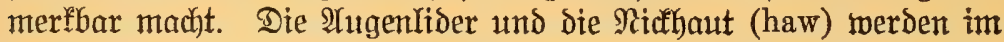

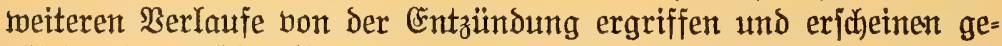
rötet und angeify) wollen.

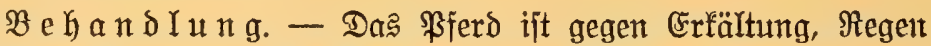
und Bugluft; gegen grelles Somnenlidyt und Heberanitrengung beim

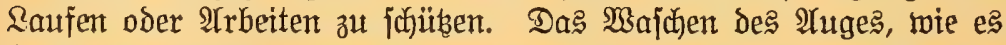
bet äuñerYicfjer Entżündung emtpfohjen, Yeiftet auth hier gute Diemite, bejonders wenn die äuperen Ieile fehr entzündet find. F̌ür bie innere

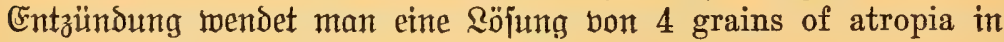

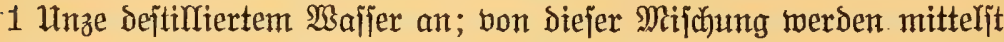
einer meidhen Freder jede zehn Minuten einige Iropfen in bie Stugen=

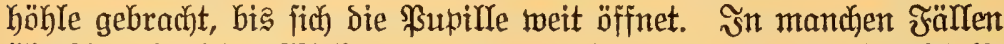

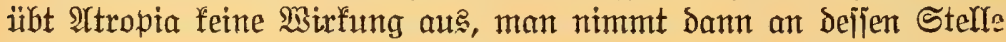

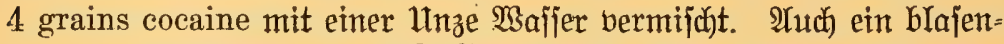
ziełendes \$Pflajter - spanish flies, fertig in IXpothefen zu faufen -

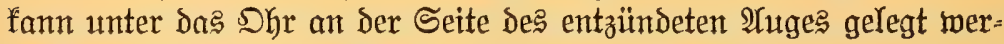

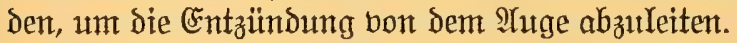

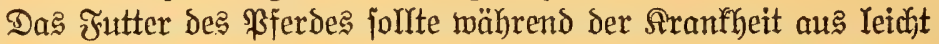
verbaulicten Stoffen (angebriifte STcie und Madjmehl - middlings),

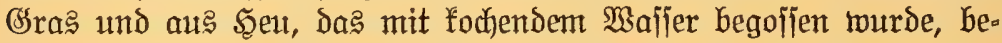
jtehen. Nachdem bie Entzündung geheilt ijt, follte da? Eintröpfeln

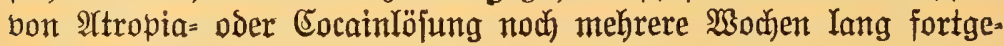
jest toerden. 


\section{9. 位apifel.}

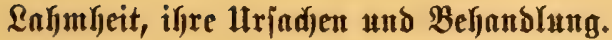

Das Sinfen oder sałmgehen ift eine unregelmäpige Betwegung

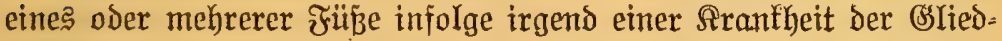

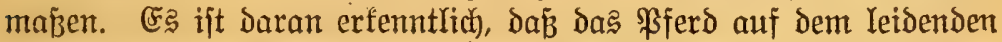
Beine ober Jube fürzere Beit bermeilt als auf bem gejunden und bie

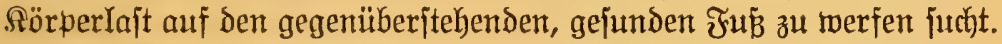

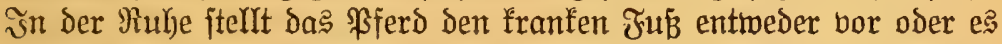
iteht feit auf Demjelben und im geringeren Grade bes Ulebels bemerft

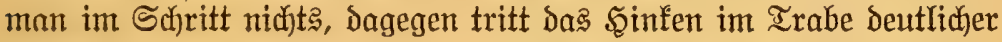
herbor, während es im Sralopp wieder wentger fichtbar wird. Iิn ein= zelnen FäIfen beridfnindet das Şinfen nadh einiger Bemegung, im

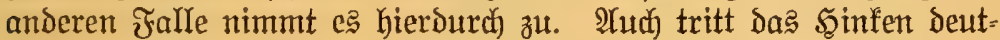
Yicher herbor auf fejtem, hartem Boden und barf baher bie Unter= judfung nie auf weidjem Boben, (Srabboden ujw. borgenommen wer= Den. Mill man ein \$ferd in bezug auf Şinfen unterjudhen, po Iajje man es zuerit im Scjritt an jidf borübergehen, und beobachte genau

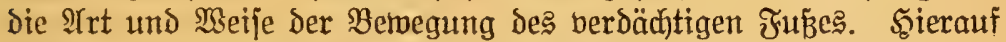
Iafie man es im Irabe an fich borübergeben, dann beim Şinfen auf einem $\mathfrak{B o r b e r f u b e ~ a u f ~ f i d ) ~ z u ~ u n d ~ b e i m ~ S i n f e n ~ a u f ~ e i n e m ~ S ̆ i n t e r f u ß B e ~}$ bon fid fintwegfithren.

Jit es nun für sen 1Ingeïbten in manchen Fällen fafon fatmierig, herauszufinden, auf weld)em Fußse das \$fFerd hinft, fo ift es um fo

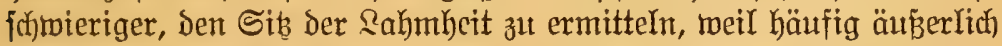
gar feine Iranflyafte $\mathfrak{B}$ eränderung an Dem Yeidenden $\widetilde{F} \tilde{B}$ wahrge= nommen werden fann und man mur aus der Art und Weije des Şin=

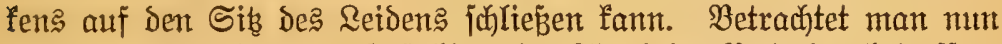

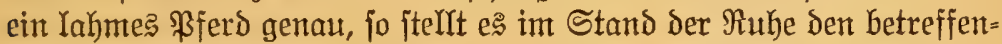

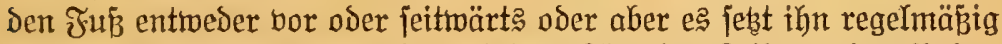
nieber. Dabei berührt es, je nad) Dem Sibe des Reidens, Den Boden mit ber ganzen Sohle oder mur mit ber Zehe oder mit dem Barlen.

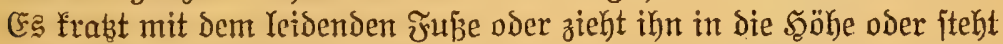
gar nidjt auf bemjelben. Beim Sehen berüfrt ber Juß ben Boden cbenfalls entroder nur mit ber Beke, oder mit bem Ballen oder aud) mit der ganzen Sohle. Das betreffende Bein wird in irgend einem 


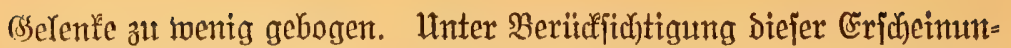
gen wird man Durch die Interjuthung teilmeije jugn ben Sib Des sinfens, ingbejondere aber ermitteln, ob ১ą \$ferd auf einem Border= beine oder auf einem Şinterbeine, ob es auf beiden Border $=$ oder bei= Den Syinterbeinen und endrid) ob es auf allen vier Beinen zugleid hinft und mun exjt fdyreite man zur bejonderen Itnterjuchung.

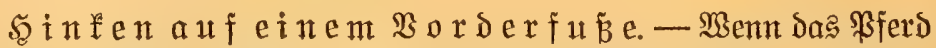

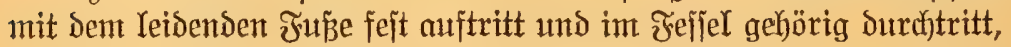
aber Den Fun nidft fo weit aufhebt umb boritreatt als ben gejunden,

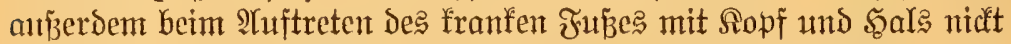

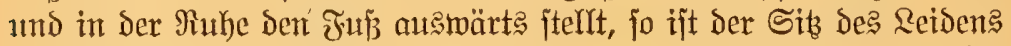

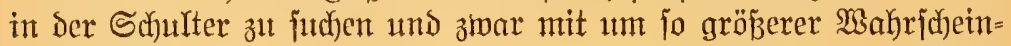

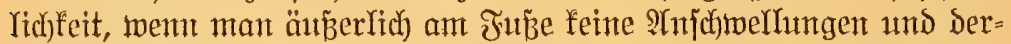

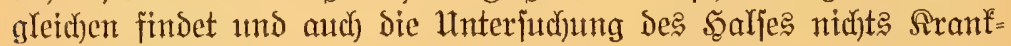

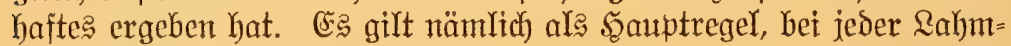

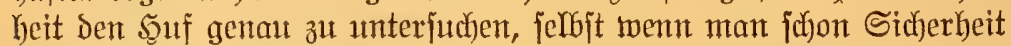
iiber den Sib ses Reidens an einem anderen Ieile des Beines zu haben

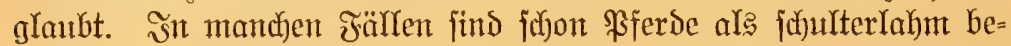

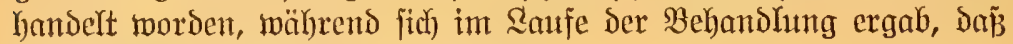
Die Utriadye des Sginfens im Sufe lag.

Sebt aber bas \$ferd im Schritt und Irab Den Fuß nicht fejt auf,

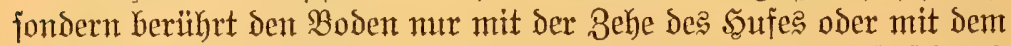

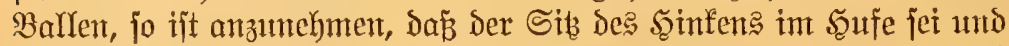

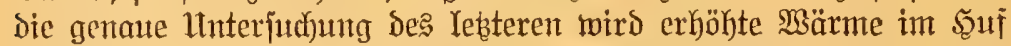

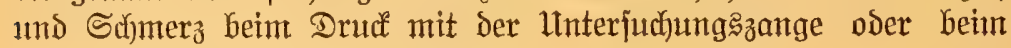
Alopfen mit Dem Soummer ergeben.

Iritt Das \$fferd mebr mit Der Beke auf, fo fann man auf $\mathfrak{B e r}=$

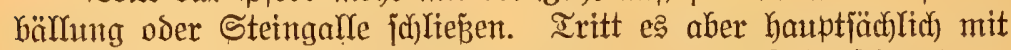
sent Ballen auf, jo ift Der Sib bes Reidens an ber Bebe, fei es mum,

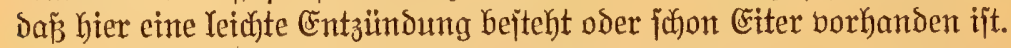

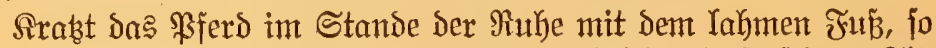

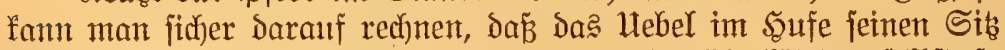
hat. Iritt Das \$fers nicht im Felfel Durch ober überfötet e马 jelbit, fo

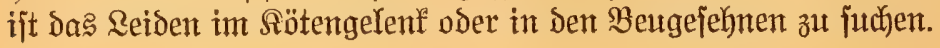

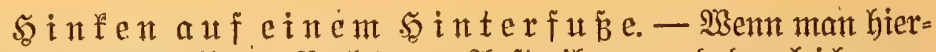

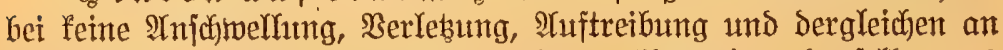
Dem betreffenden $\mathfrak{B}$ eine findet, fo gilt im allgemeinen basjelbe, wa? beim Borberfü über Den Sib des Reidens im Sufe oder in ber S(f)ul= ter gejagt wurbe, mur ijt zu Gemerfen, dab mitunter bas \$ferd mur

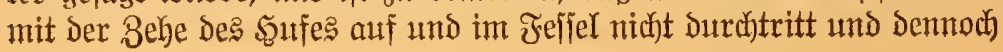




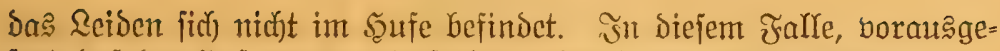

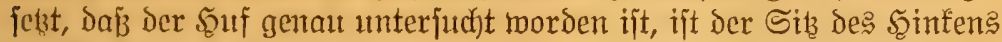
im Sprunggelent zu fudt)en.

Wirs dą Sprunggelent nidjt geförig gebeugt, der Fü zudfend aufgehoben und berliert fich das Scinfen nach einiger Bewegung mehr oder meniger, fo ift der Berbad)t auf Spat begründet.

Bcim $\mathfrak{g}$ infen a f f beiden $\mathfrak{B}$ orderbeinen war= den bie Yebteren jtets nad) vorne gejtred und dic Bemegung gejujteft iteif und ijt jidytlich jumerzhaft. Die Sinterbeine werden dabei weit

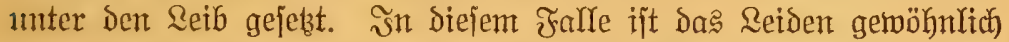
rhemmatijucer Ratur und fann feinen Sib fotwohl in sen Mutfeln als in Den Soufen haben, worüber Die näkere Interjuchung diejer Ieile श्रufichluß geben wird.

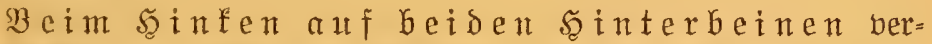
bält cs fid) ganz ähnlid), nur werben hier bie Borderbeine nid)t ge. jtreift, jondern unter den seib geitellt.

\section{Sinodjenerfjöfung unterfjulb bes Snies (splint).}

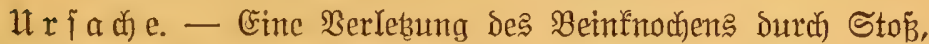
S(f)lag oder Dutrd) den Tritt des Nebenpferdes find bie getwöhnlicken

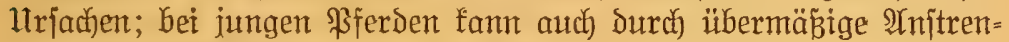
gung eine Berjujiebung unb Daourch eine Bejchäbigung ber Bein= fnochen herborgerufen werden.

(5 $r$ jhe wöhnlid) an Den šnnenjeiten Der Sorberbeine, nicht jo oft an Den

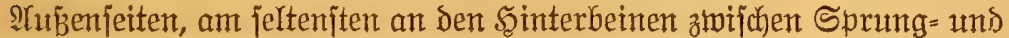

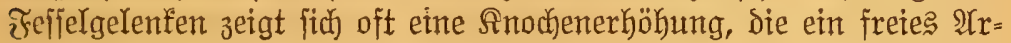

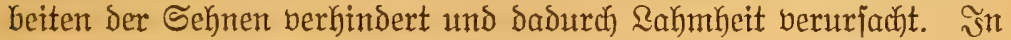

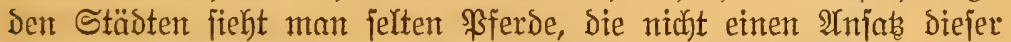
Anodjenerhöhung haben. Die Rahmheit tritt nidft andauerno auf. fontern mad)t fid mur zeitweilig benterfbar, Gäufiger menn das \$ferb warm ijt.

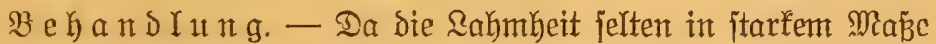
auftritt und ber Febler mithin nidjt bedeutend ift, fo ift es in ben meijten Fällen geraten, feine Mittel anzumenden; zeigt jich aber itarfe Entzündung Der betreffenden Sterle, fo wird bäuftg mit faltem ober

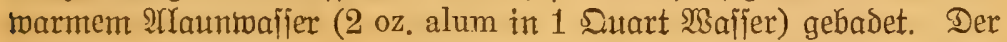

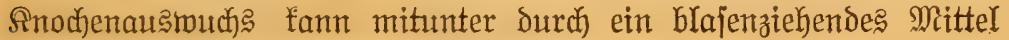
(spanish fly plaster) berhindert werden. 


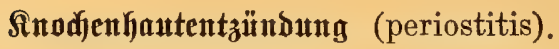

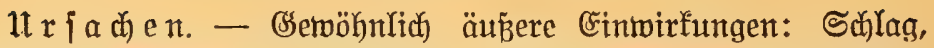
Stö̉ oder Berrungen. Dit friedtst die Entzündung auf benachbarte Teile über.

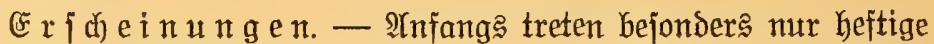
Sibmerzen, namentlich beim Drut und als Folge Lahmgeben auf. Şierzu gejellt fich $\mathfrak{A}$ nj(b) und fejt.

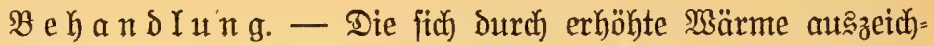
nende Stelle wird durch Baden (mie bei ber Snodjenerböhung ange= geben) täglid mehrere Male abgefühlt. W3enn rechtzeitig angemandt, wird die ๔ntzünoung und Bildung eines Sinochenaustwudjes verhütet.

(Entzïndung bes Sirungelent:s, Sdjale, Reift (ringbone).

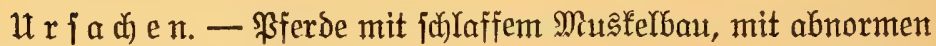
Stellungen (jtarfes Durdytreten, bodenenge und bodentweite Ster= Inngen) zeigen eine bejonbere (auth) bererbbare) IInlage. Sselegen= heitsurjache find Beritaudungen auf holperigem, gefrorenem Boden, bergab unter jobwerem Sewidjt oder andauernde Berrungen bei jajie=

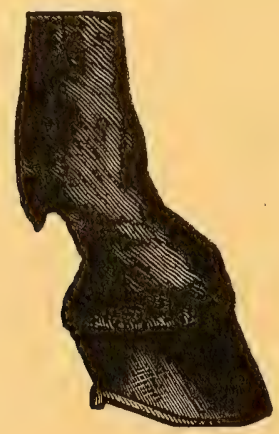

Jhb. 31- Iuf mif Eronenleiff (ringbone).

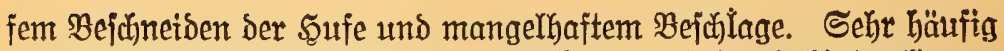
beranlafien audh BerYebungen ber Şuffrone und Der bahinter liegen=

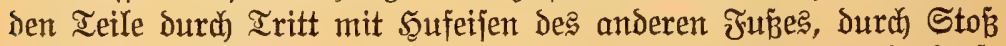

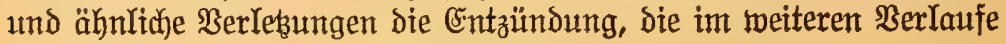
eine Snochenauflagerung im Sisplge hat. 


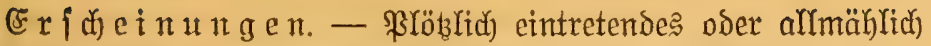
(id) einjtellendes \&ahmgehen mit nicht gehörigem Durchtreten. Die Safmbeit tritt jtärfer herbor im Irabe auf hartem, 1mebenem Boden,

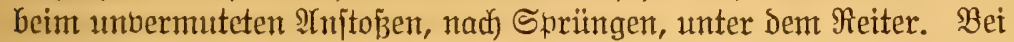
Dem Şerausnehmen aus Dem Stalle gehen bie Tiere oft eine furze Strede weniger, Dann ftärffer lahm; Minderung tritt bei fortgejebter

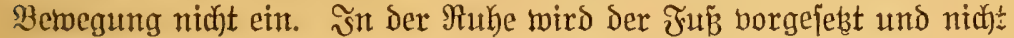
gchörig belajtet. $\mathfrak{A} m$ Arongelenf jelbit (am oberen Şufrande) tritt

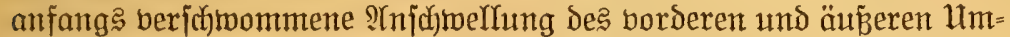
fanges und $\mathfrak{3 a ̈ r m e ~ h e r b o r . ~ S d ) m e r z e n క a ̈ u b e r u n g e n ~ w e r d e n ~ h e r b o r = ~}$ gerufen bei orehenden Bewegungen.

Der Berlauf ift auch bet Der einfachen entzündung ein zögernoer, meijt auf 2-3 modjen ausgedehnt. Rach) borrjtändiger Bertetlung

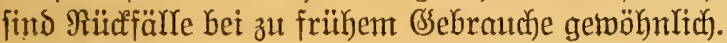

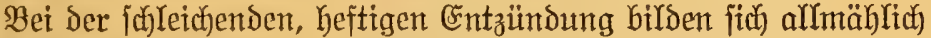
feite Anochenauflagerungen in Der IImgebung des Bselenfes, die man bei Bergleidung fieft und beim Darüberftreidjen füblt; fie find bals

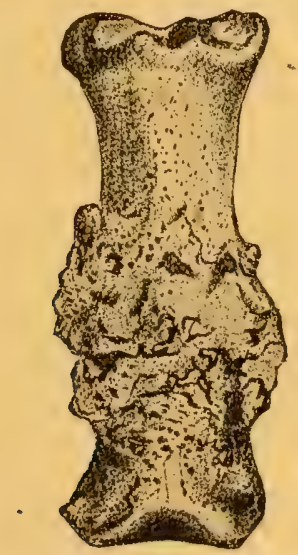

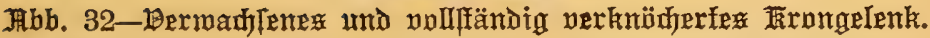

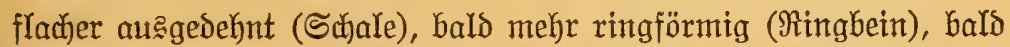
auf einzelne Stellen bejuräntt (Reijt). Später gejellt fich hinzu

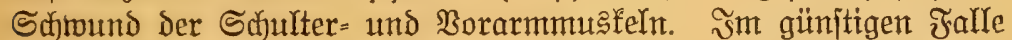

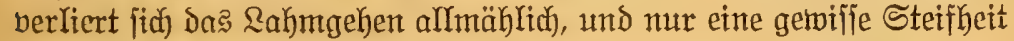
im Sselenfe Ginterbleibt; oder die Rahmbeit dauert umunterbrodjen an, ober fehrt plöblid wieder, wenn fie fich fidjon gänzlidy verloren hatte. Die Imorhenauflagerung erfährt zulebt immer eine Bejuräntüung ihres Madjstums und bleibt dann unverändert jtehen. 


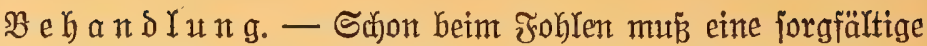

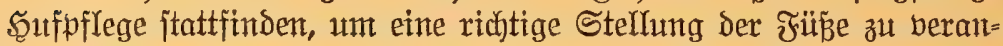

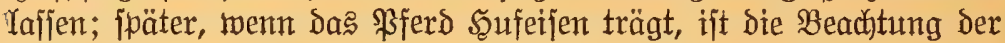

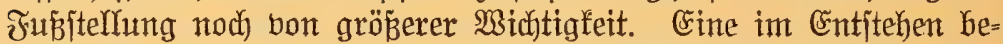
griffene Sironenleijte fann oft Durrob riatiges Bejulagen geheilt werDen. Solange mur Entzündung bejteht, fann butrab ein blajenziehen= dę Mittel:

biniodide of mercury 1 dram,
crystal iodine 1 dram,
powdered cantharides 1 dram,
oil of terpentine 1 dram,

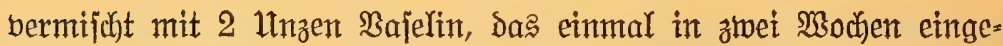

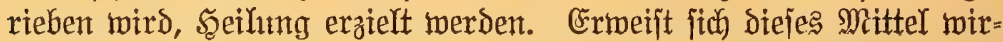

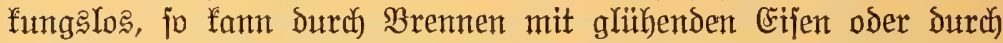

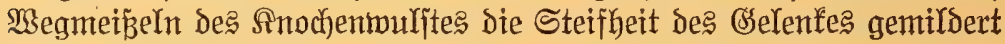
werden. Die beiden Yekten Mittel fam nur ein Iierarzat anwenden.

\section{Spat (spavin).}

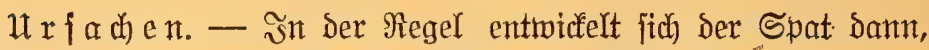

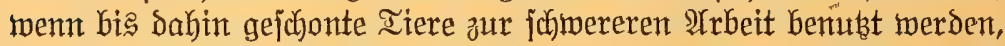

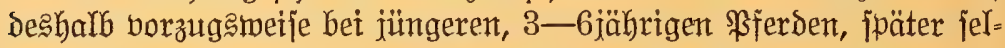
tener und mur nach) jtärfferen ITnjtrengungen. Bet jentent wird die (Ent=

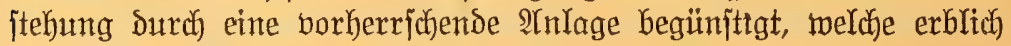
und in mangelfaftem, jufwact)em Bau des Sprumggelentes, abnormen

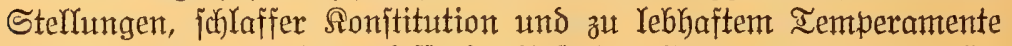

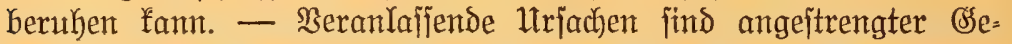

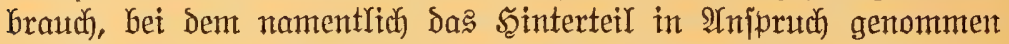

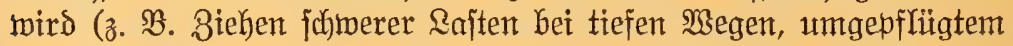

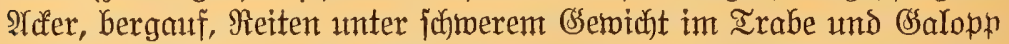

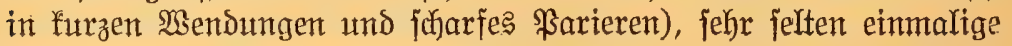
刃̧eritauchungen, bei Fehyltritten.

E $\mathfrak{x} \mathfrak{f}$ w)

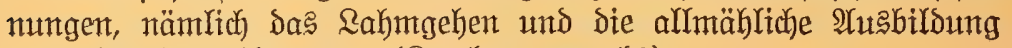

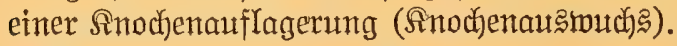

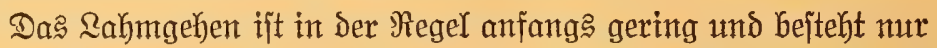
in einem jogenannten Biehen (Sheben) bet den erjten Schritten, wird deshalb oft überfehen. Altrmählid fteigert es fich und zeigt folgende EigentïmIidfféten: e马 tritt am ftärffiten herbor, menn die :iere un= mittelbar aus dem Stalle (namentlich) am Iage nadb borgängiger 
ter Berwegung, bebeutend der Grang, Doch pflegt bas Sinfen umunter= brochen firctbar zu bleiben. - Bulebt, nach sahresfrift und Dariuber,

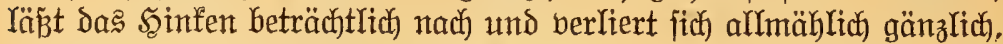
aher ftets finterbleibt eine gemifife Steifheit im Sprunggelenfe. Bisweilen bauert aber aud das Sinten unumterbrodhen an; łehrt plöblich

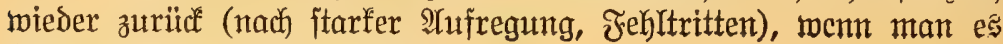

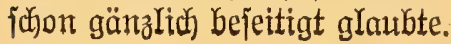

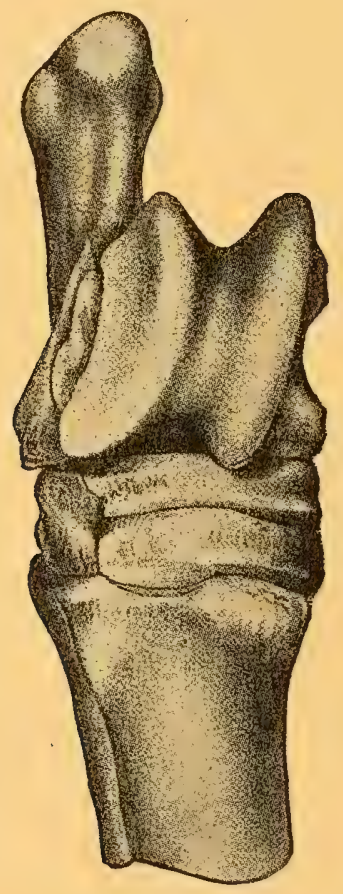

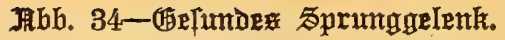

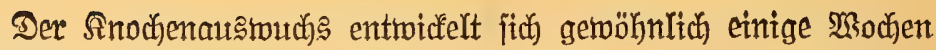

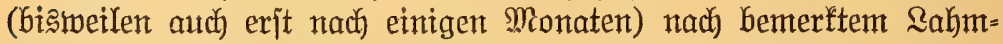
gehen. Er fitst an ber inneren Seite bes Sprunggelefes und nadi bem

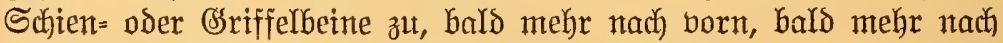
hinten. Ânfangs ijt er jefr gering, faum merffich), Yäuft flach aus,

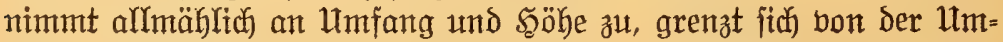
gebintg flach erbaben ab und ijt Dant unberfentbar. Bismeilen

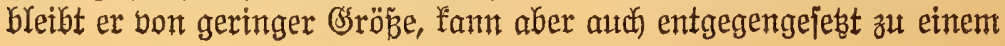


berhäItnismäßjig bedcutenden Umfange heranwadjjen; jehr jelten tritt er gar nicht oder erit fpät herbor.

Sierzu alङ begleitneó Erjoheinungen: vermehrte Märme, fpäter Sdjwumb oben am Sdjenfel.

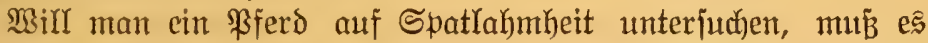
immer crit cinige Beit itehen, Dann jogleid) in Trab gejest merden. 3eigt fich hierbei ein Schentel verdäd)tig, Dann wird bas Berfahren

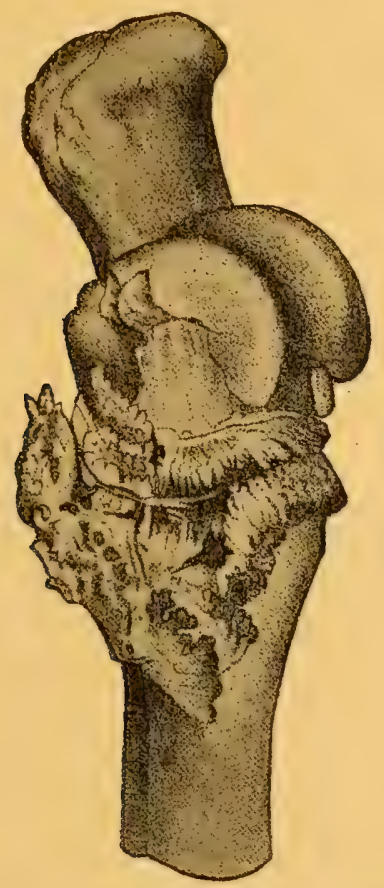

Jbb. 35-5prumggelenk mif 5pat.

roiederfolt, nadjoem jener nod) Durd einige Minuten itarf zufamment= gebeugt hodgehalten murbe. Dann läßst man bas ßBFerd durch einige 3eit traben, um zu jehen, ob Befjerung fid einjtertt.

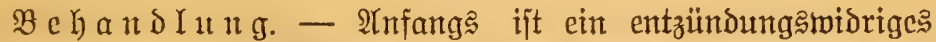
(fiih)lendes und ableitendes) Berfahren am Blabe, fpäter mú ange= ftrebt werden, baldmöglichit Feftitellung ber Gelenfe Dutrd) (selenf:= verwachiung zu crzielen. Şiernad) fommen folgende Berfahren iu

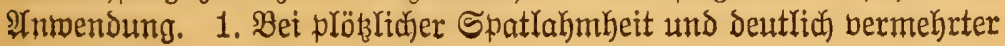


Märme des Sprunggelenfes ît jtets ein fühlendes ßerfahren: Rebm=

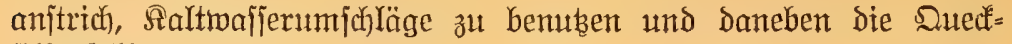
filberjalbe:

$$
\begin{aligned}
& \text { mercurial ointment, } \\
& \text { Sc(j)weinefett, }
\end{aligned}
$$

bon jedem gleiche ̃eile. Iäglidy oreimal einzureiben. şit alle

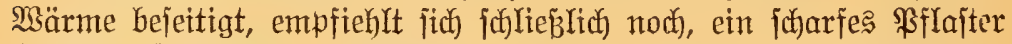
(spanish fly plaster) aufzulegen. 2. (Entridifelt fid) der Spat gan

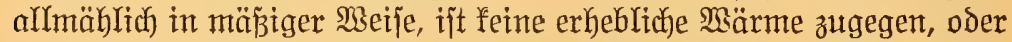
bejtand er fadon längere Beit, Dann findet ein jałarfes \$flajter $\mathfrak{I n}=$ twentung,

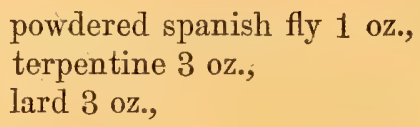

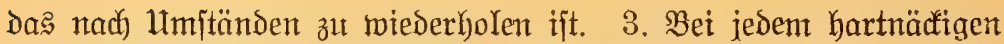
Spat empfieblt fich als lețtes Bufludytamittel das Brenteijen.

Unerläßjiche ßedingung bei jedem Seilberjuche ijt eine umunter=

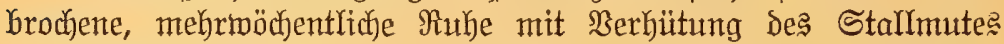

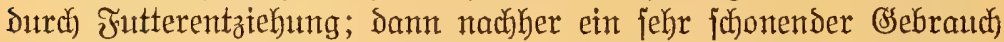
auf ebenen, nicht harten $\Re$ ßegen. - Šit Befferung nicht zu erzielen, Dann fann die Bsebraudfafähigfeit (und jelbjit $\mathfrak{A}$ (usheilung) erhalten

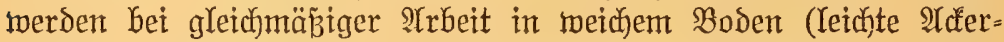
arbeit). IInterjtïkend wirft ein ß̧ejb)lag mit Şufeijen mit etwas erhöhten Stollen und aufgerichteter 3ehe (ohne (Sriff).

F马 find berjutedente Scharfialben (Aanthariden, Euphorbium, Sublimat, Dperment, šoduedfirber ujp.), darunter aud einige ose= heimmittel in Brauch. Seine bejist eine fichere Şeilminfung. Die fräftig und tief einwirfenden Salben hinterlajien leidht haarloje

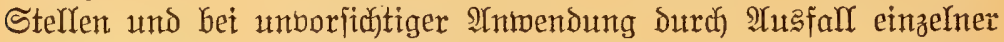

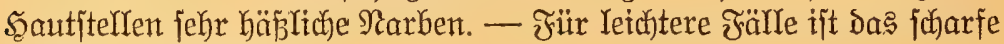
SFflafter borzıı̇ehen.

Das Brenten ift bas beliebtejte und nach allen (Erfahrungen aud das wirfjamite Mittel, wenigitens bie Yetste Bufluctit. Fs fann in Strichen ober \$intuten gejuehen, Sauptjache ift, recht biel Sibe all=

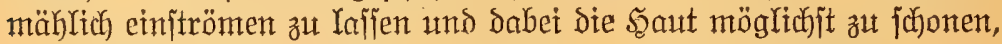
um häßliche Brandnarben zu vermeiden. Deshalb jtets Brenten in feinen \$unften oder Strichen mit rotmarmem Eifen. Šit ber Erfolg ntidt ganz befriedigend, Dann fann man nadher nod) ein jodarfes \$Pfáfter aufferent. 


\section{Snodientoridje (fractures).}

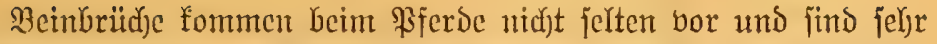

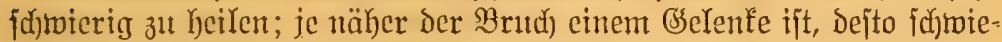
riger ift bie Şeilung. Dic Sctwierigfeit ber Sceilung ift begründet in ber groß̧en Rajt bes Sïrpers, Der ftarfen Musfelfraft und der ge= ringen Befäljigung auf brei Beinen zu jtehen, und infolge deffent

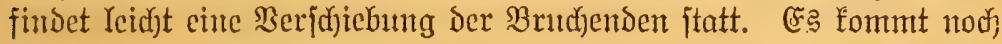

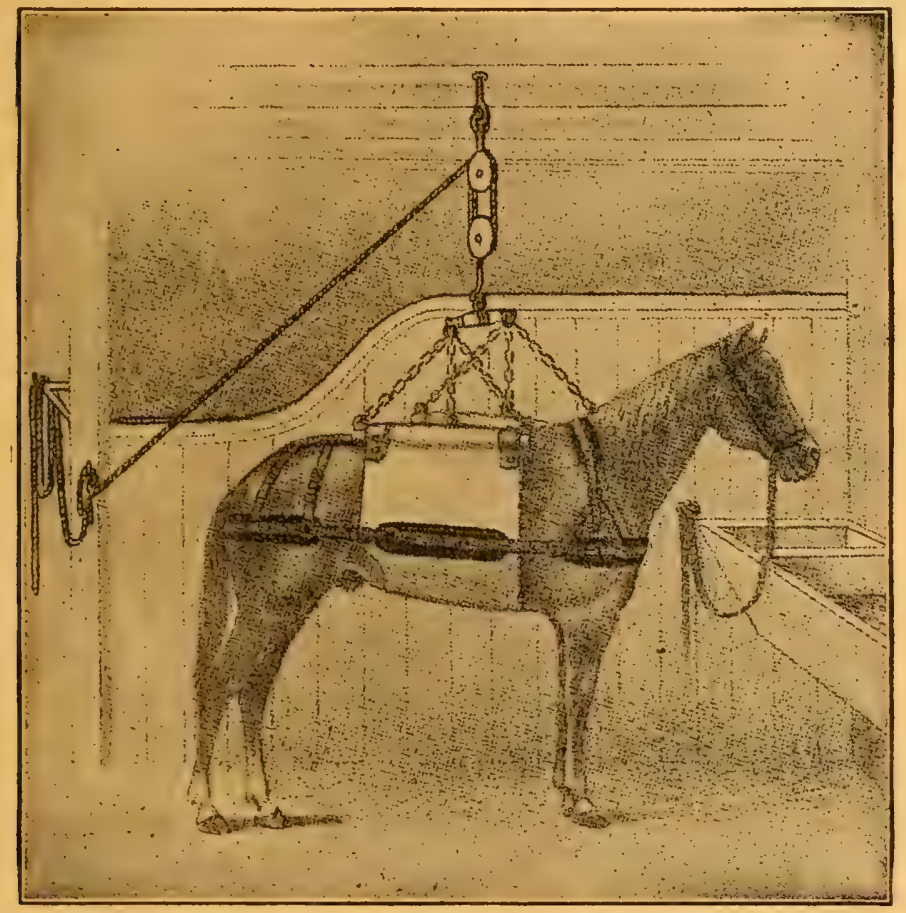

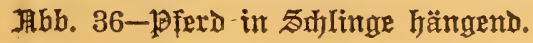

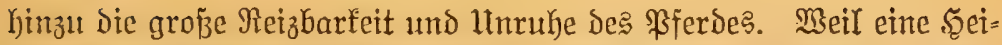
Yung fo umficher ijt, wird fie in ben meijten Fällen gar nicht berjucfst unD Das Tier, wenn ein Beinbrud) über jeden Zmeifel feitgeiterrt iit, getötet.

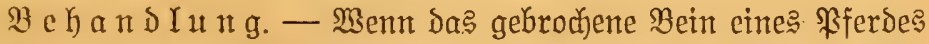

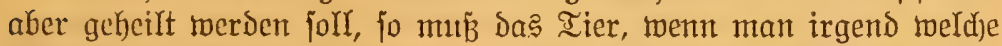
STlEficht auf Erfolg haben will, in eine Sdjlinge gehängt werden, fo 


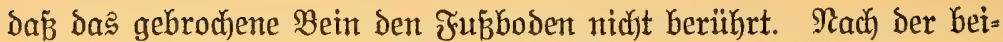
gegebenen 2 bbildoung fann eine foldhe Sdylinge jadnell angefertigt werden. Dann ijt ber Brudd) einzuridften, worauf der Berband angelegt wird.

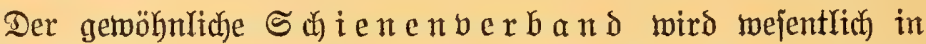
folgender $\mathfrak{A}$ rt angelegt. Das gebrodtene (s)ied mird zuerit mit einer Binde umtwickelt, mit der man unterhalb des Brudjes beginnt, und

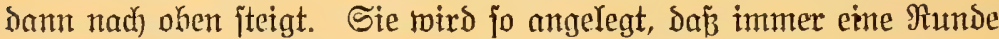

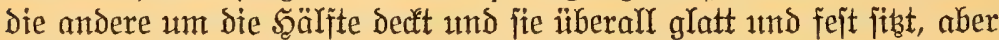

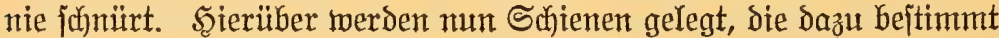

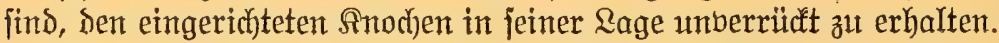
Sie werden aus berjifiedenem Material gefertigt und, je nadid Dem

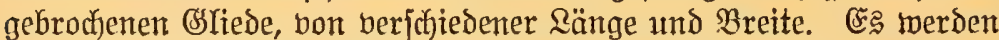
Ineren 2-4 (auf beiden Seiten, Gintent und vorn) angelegt utnd durch

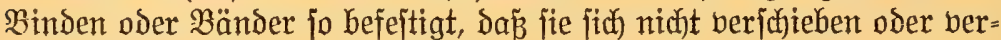
rïrfen fümnen. Bebor fie aber angelegt merden, ijt e? nötig, alYc Itnebenheiten bes (6́liedes, da, wohin fie zu liegen fommen, durd)

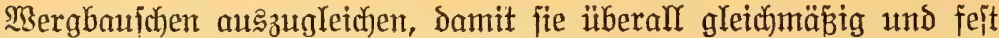
anliegen und feinen Teil ftärfer or büđđen.

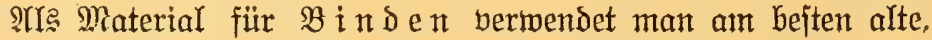
ausgewajidyene Reintwand ohne FaIten und Rähte, ferner gemirfte

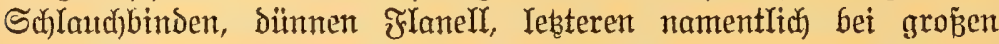
Tieren. Bur bequemeren Sinleging wiffelt man fie borher zu einer Rolfe zufammen.

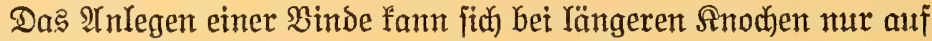
bieje exjtrecten, bet fürzeren Inodjen geft man barïber hinaus, um fo

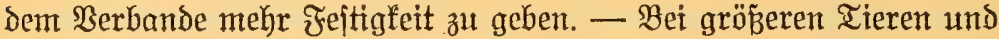
two eine $\mathfrak{B e r j u j i e b u n g ~ d e r ~ B i n d e ~ z u ~ f u ̈ r c h t e n , ~ f a n n ~ m a n ~ b i e j e l b e ~ w a ̈ b ) = ~}$

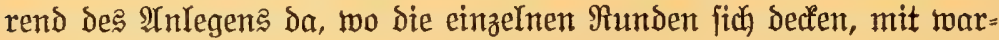
mem $\mathfrak{I}$ ijfiflerYeim bejtreichen.

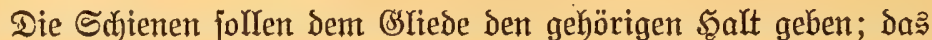

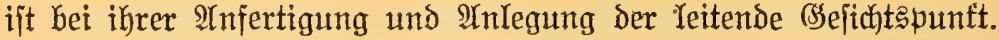
Sie follen fid) dem Rörperteile anj(d)miegen, dod auth mieder bic gehörige Stärfe befiţ̧en.

Die Schienen werden am bejten aus frifhem, noch etwas nach= giebigem (Eichen= ober Şidfort)holz angefertigt; Sdjienen aus hartent,

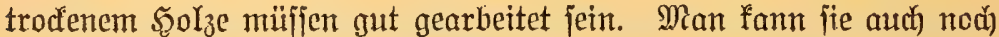

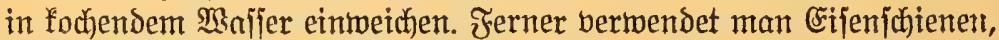

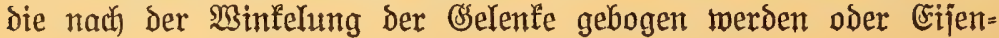
bledjichtenen. 
Der Osip

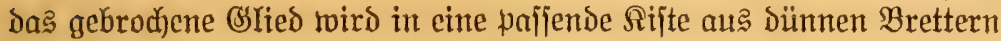
ober BIed), Die an einer Rängşfeite offen ift, gelegt und Dann ringsొum mit (3ip引brei (plaster of Paris) gefüllt.

Bei allen Berbänden ijt in ben näbjiten Tagen forgiam zu unterjuchen, ob biejelben nidjt brüden ober fdunüren. Sobald unter= halb des Berbandes jtärfere oder anhaltende Shtwellung eintritt,

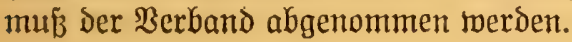

\section{Windgaflen (windgalls).}

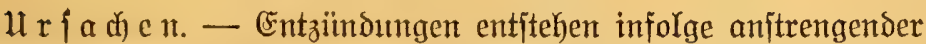
Irbeit, bejonders bei janellen Srangarten und im Sommer; ferner

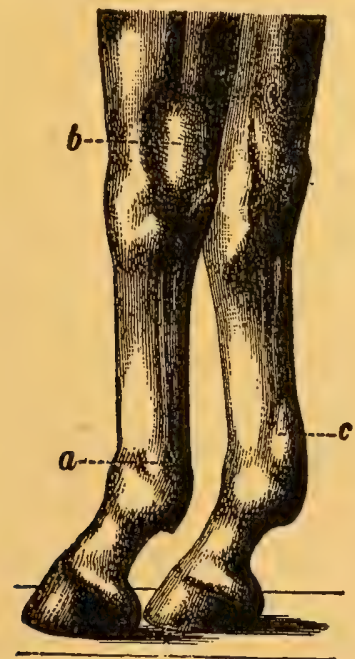

Jbb. 37-Boroerbeine mif Gallen.

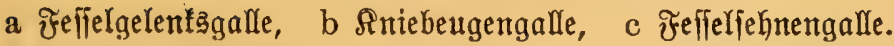

Durd) TYusgleiten, Jehltritte, Sprünge; nach) Ertältungen; ferner

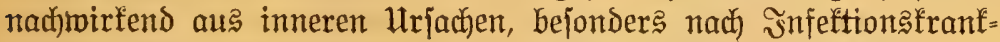
heiten (כึnfluenza), meift ganz plöblich über Nad)t herborbredhend. -

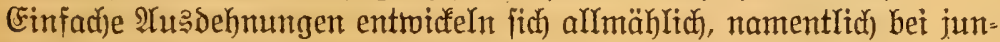
gen, jajlaffen ßferden, bei erjd)laffender, majtiger Ernährung, biel Ruke, ganz von felbit oder bei beginnender $\mathfrak{A}$ rbeit. 


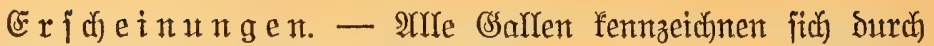
rumblich erhabene, elaịtijich gejpannte $\mathfrak{A}$ njidtwellungen bon bejtinmt abgegrenzter Form im Berlaufe der Sefnen. Bet vorhandenter Ent= zündung beranlaffen fie sahmgeken oder fithonenden Gang, find ftärfer gejpannt, bermełrt warm und fơmerzhaft. Wo Entzündung fehlt, jind fie falt, amjomerzhaft, ohne Rahmbett. Bei verhärteten

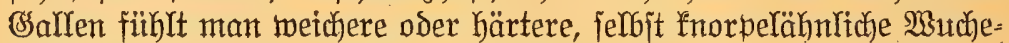
rungen hindur(h), zumeilen aud fnotige, fanmerzhafte (Entzündungen

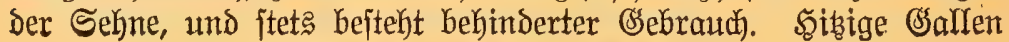

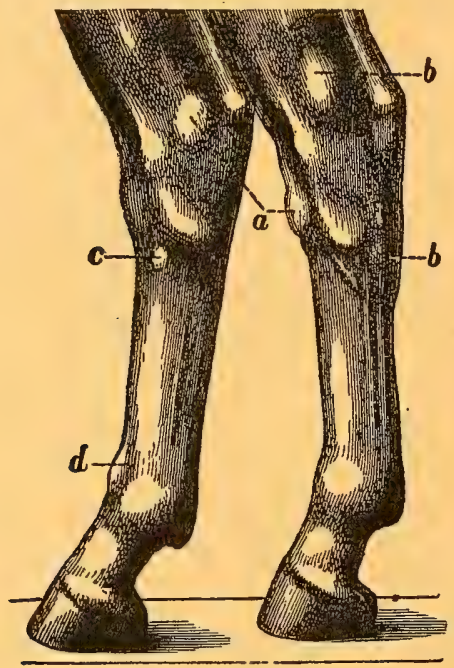

Дhb. 38-
a Sprungsgelenfoalle, b Beugelehnengalle,
c Streâjehnengalle, d Frefielifehnengalle.

entiteken febr jünell, brectjen plöblich herbor. Die Entzünoung uns Rahmbeit bergeht meijt junell, wo anitrengende Arbbeit, Iangiamer, two Errflältung tmo innere Rranfheitsurjachen vorlagen, geivöhnlich bleift $\mathfrak{A}$ tsdehmung zurïct. Reicht fommt es bei anitrengendern

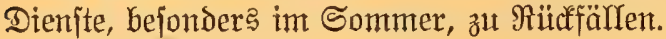

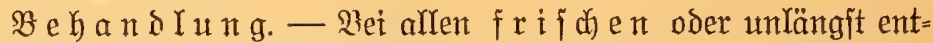
itandenen बisallen, gleidbiel ob bentlidbe entzündungsfälle zugegen find oder nidyt, jomie bei Riudfällen empjeblen fich füh)lend=zujam= menziehende Mittel: namentlich B̉eimaifer, Drufrat, Effig, in Form 


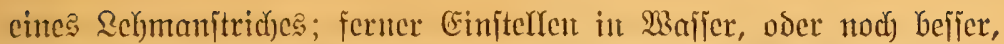

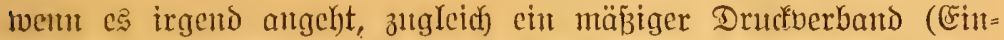

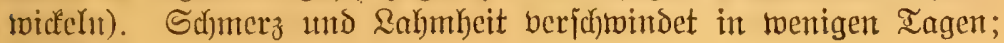
Die Sralle mur Iangiam.

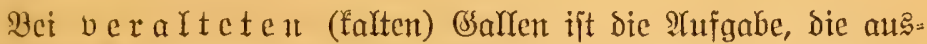
gedehnter (sallen zur Bujammenziehung zu bringen, bie bermehrte STbjonberung Der Sebnenfd)eidenflüffigteit zu bermindern, refp. Die Ergüfie zur STuffaugung ober Bejeitigung zu bringen. Şierzu bienen auber fejten Eintwidelungen: Die zu[ammenziebenden Mittel, nament= Iich) versinnte Schlwefelfäntre (sulphuric acid), 1 Teil S(b) 31 8-12 Teilen Spiritus oder Mafjer, täglich ein= oder zmeimal.

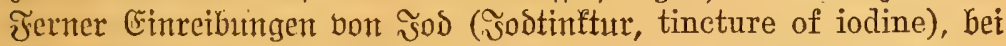

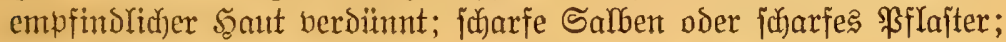
3nlest das Brenten in Stricjen mit rotwarmem Eifen, um 34 jam= menfarumtimg zu erhalten.

Bei verhärteten Grallen ift Erweidhung und Berteilung

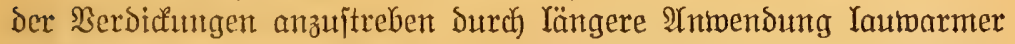

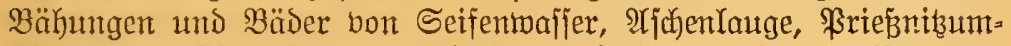
facläge und Einreibuntg auflöjend=zerteilender Salben, z. B. graue Duedfifberjalbe (mercurial ointment) und Sdyweinefett, von jedent

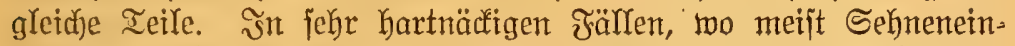

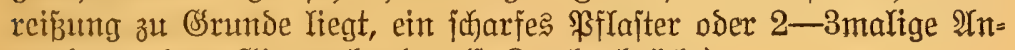
mendung eines ssipsberbandes ( . Anochenbrüche).

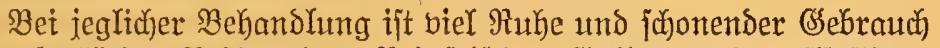
ein wejentliches Bedingnis. Bei frijchen GSallen und bolliaftigen Tieren ijt eine magere Diät, felbjt ein zeitmeiliges ?rbjübrmittel 1 ßĩund (slauberialz - am \$lake.

\section{Giclenfentzïndung (inflammation of joints).}

Il $r$ jadje n. - Sö̈lffig ijt eine bejondere $\mathfrak{A n l a g e ~ b o r b a n d e n , ~}$ bie in allgemeiner S(f)wöche (Iodferer Bau) begrimbet tmb aud) ererbt jein fann, oder durch feblerhafte Stellung bedingt ijt.

(S) legentheitsurjachen find: änf̧ere medhanijche Einwirfungen, StöBc, Sçläge, potwie Dehmmgen und Berrungen, Berrenfungen, Seritauthungen, jodann Erfältungen, rheumatijace (Selenfentzündung.

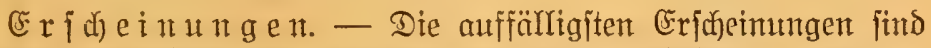

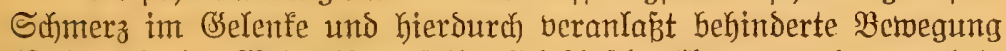

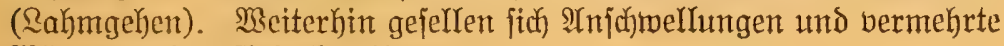
Märme an Den sselenfen hinzu. 


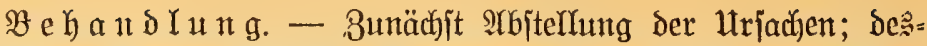

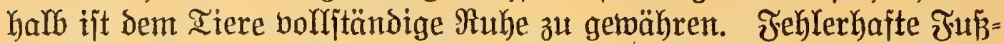
ftellungen find durch entjprechenden Şufbejhlag zu berbefjern. $\mathfrak{Y} n=$ fänglich entpfeblen fich jtets füblende Mittel, namentlid, Beriejeln mit

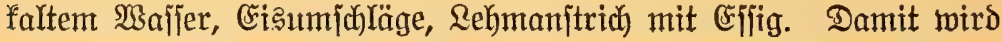
fortgefahren, folange Wärme und Sdmerzhaftigleit andauern; ber=

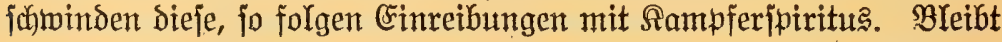

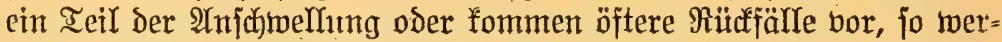

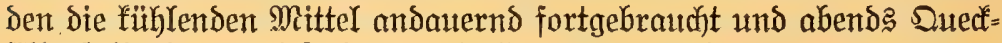
filberjalbe (mercurial ointment) tïc)tig eingerieben.

Sdjulterlafmljeit, Sdjulterjajumtub (lameness of shoulder, sweeney).

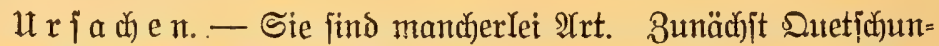

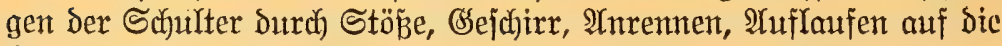
Srippe, jubmeren 3ug. Dann Berrungen, Dehnungen, Erjłütterun= gen beim Springen, 2Ytsgleiten, Fehltreten, bei plöblichen und zu furzen Bendungen, 3ujammenjtürzen, Reiten bergab ujw. Endlit) Erfältungen, Gejonders bet erhibtem S̈̈rper.

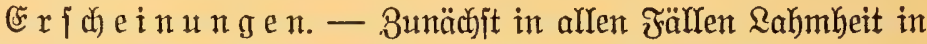
berjujeden jtarfem Grade mit gewifjen Eigentümlichleiten: Die

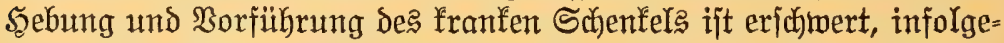
Deffen ift ber Srfyitt fürzer, der Fuß weniger gehoben, ftöß̧ Yeichter an, bie Sdyulter erjojeint gebunden (fommt nicht frei herauts); Der תörper wird mehr bon Dem gejumben Sdjenfel gemorfen und fintt bei

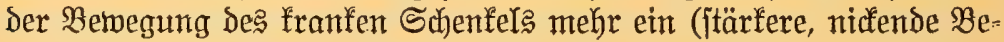

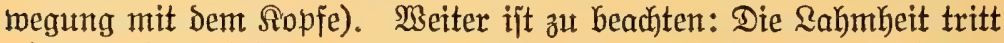
gleid)mäß̈ig auf hartem, wie auf weichem Boden (bei tiefem Sande [tärfer) herbor, fie erjcheint jtärfer beim Iraben im Itmorehen, wenn Der Schenfel fid autzen befindet, ferner in furzen (jog. Şundes) Irabe

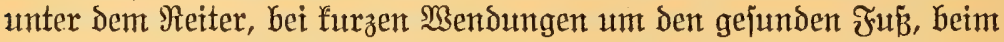
Pieiten Kergab. (Semöhnlich tritt Das Rahmgehen ftärfer herbor im

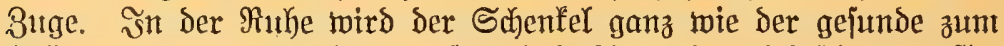
Stüben bermendet, nicht borgejebt (mit $\mathfrak{A}$ tanahme bei jobmeren Yenfveränderungen):

Dertlich) find Beränderungen nicht immer zugegen, oft jedoch) $\mathfrak{A} \mathfrak{n}=$

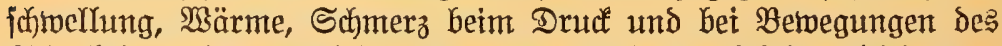

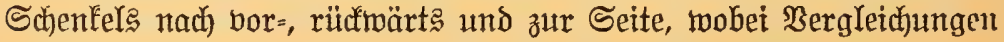
mit ber gejunden Seite anzuitellen find. Bei längerer Dauer pflegt das S(jwinden ber S(f)ultermußfeln nicht auszubleiben. 
Ridjt jelten beobadjtet man einen S(j)wund, ein Einfallen ums Sleinerwersen ber Sd)ultermußfeln (sweenied shoulder) und audn Der SdjenfeImu引łeln. Dies Reiden entifteht nidjt jelbjtändig, fondern ift cine Folgefrantfheit, weldje um jo ftärffer und junteller herbortritt,

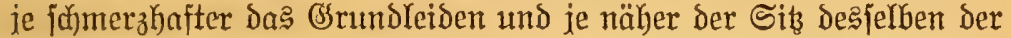
Sd)ulter iff. Demnadi bildet fich biefer Mulłelidumund bäufig und jtart bei Sdjulterlahmbeiten aus, Dod tritt er aud bei berifjiedentr anderen, Yänger andauternden \&ahmheiten auf; er barf Daher nidyt aIS

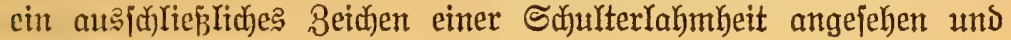
behandelt twerdent.

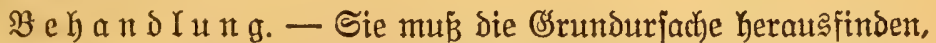

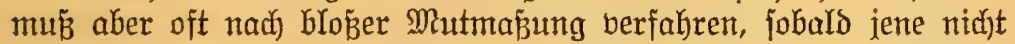

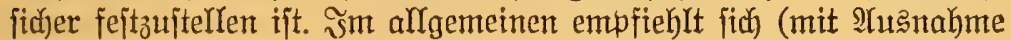
Der rheumatifunen Sdjulterlahmheit) folgende Behanolntngstweife Bei alYent frifad entitandenen Rahmbeiten, namentfich aber deutliden

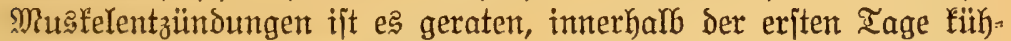

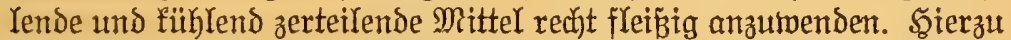
bienen Rehmanitrich mit (Effig, Bajofungen mit einfachem $3 a$ afjer,

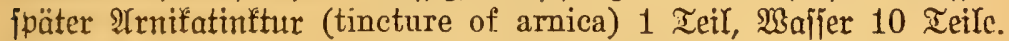
Iritt hierdurd) nad) 4-6 Iagen etwą Beflerung ein, fo bienen zur Stärfung Der Teile, forvie zur vorrftändigen Berteilung $\mathfrak{B a j a j u n g e n ~}$ mit Sampferjpiritus. Bei hartnärtigeren Sdyulterlahmbeiten, nat

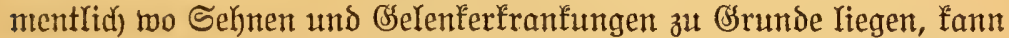
man. fogleid fpirituöfe Bafdiungen antwenden. Bet allen beraltetent oder mieserfehrenden Schulterlahmbeiten fommen bie beritärften ख্ajdungen mit

\section{Rampferipiritus 4 Ûnzen,}

$\mathfrak{A}$ mmonia $1 \mathfrak{U n z} z$,

Terpentinö $1 / 2$ Unzze,

zur $\mathfrak{A n m e n \delta u n g ; ~ z u l e k ̨ t ~ e i n ~ j u j a r f r e i z e n d e s ~ R i n i m e n t , ~ b e j t e h e n d ~ a u s ~}$

¿orbeeröI (oil of laurel),

TerpentinöI (oil of terpentine),

Îtmmonia (ammonia),

Santharibentinftur (tincture of cantharides), boit allen gleidje Ieile,

noer befier .5aarfeile (f. 4. Sapitel, S. 54). Rebterc find bie fuäftig= ften Irblcitnngsmittel, Die oft in furzer Beit Seilung herbeiführen.

Bei rheumatificher S(fulterlahmbeit emptiehlt fich zunächjit eine

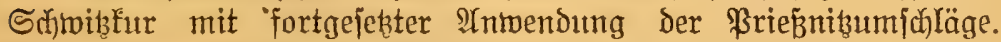

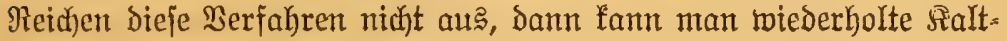




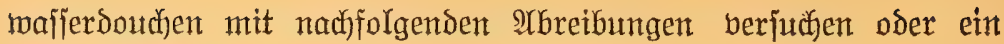
Şarjeil Yegen.

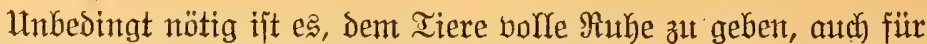
cin gutes Rager und weiten, bequemen Stand zu jorgen. - Nadj bc-

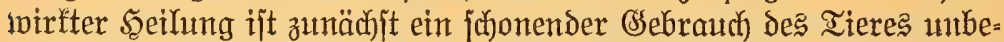
bingt erforderlich. Es Darf nur in Schritte auf ebenem Mege und nidjt ankaltend gebraudit werden.

\section{Şiiftenlafjutheit (hilp lameness).}

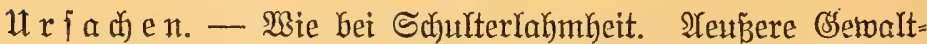
tätigfeiten, z. B. Sabläge, Stöß̉e, Niederfallen, Anrennen; ferner.

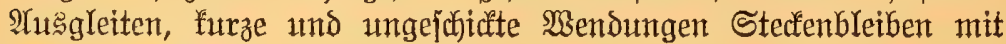

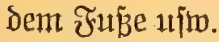

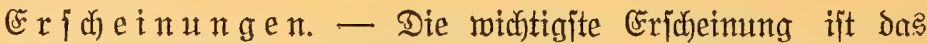

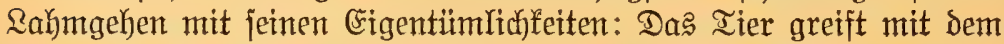
franfen Shenfel nicht jo weit bor, e马 tritt fürzer; Da马 ganze SSlied wird wentger emporgeboben, gebeugt und wentger finnell und exaft borgejest, jondern mehr jajleppend nachgezogen, in höherem (srabe

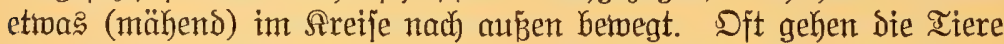

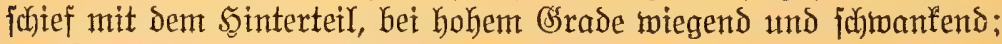
Das Rahmen tritt am itärfiten herbor bei furzen Mendungen nach der franfen Scite, das Iier Inidt' Dann bismeilen förmlich zujammen.

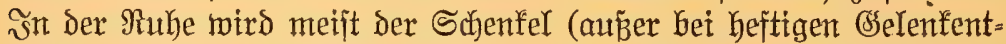

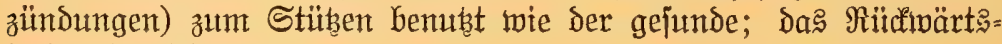
treten ijt erfochinert.

Sertlich find bemerffar: Kei Muglelentzünoung Âtichmellung

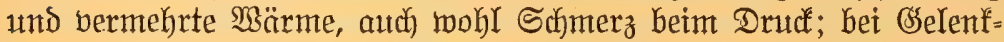
entzündngen Shmerzen bei Betwegungen in Şüftgelent. Ism twet=

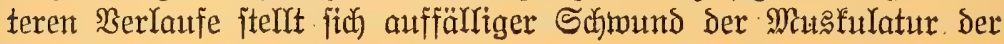
Soufte ein.

Be beften Rebmanitrich mit (sfig) ijt aud hier am \$labe, namentlich wo

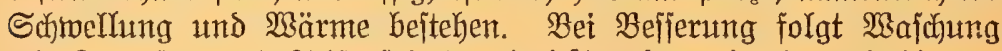
mit Rampfer $=$ und Seifenpiritus (spirlts of soap) gleidje Ieile bon beiden. Bei hartnädfigem Seiden wirb das jharfe Siniment wie bei Srhulterlahmbeit angetwanst. Bei allen beralteten Soüftenlahmbeiten erweijen fich) Şaarjeile (\%. 4. Sapitel, S. 54) bejonderg heilfräftig, eins wirs vor und eins Ginter das Şüftgelent gelegt. Bumeilent ijt aud bie fortgejebte $\mathfrak{A}$ nwendung falter $\mathfrak{B a f j e r u m i j h l a ̈ g e ~ v o n t ~ E r f o l g . ~}$ 


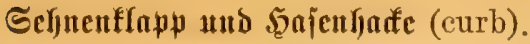

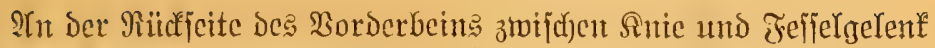
tritt cine $\mathfrak{A}$ nf

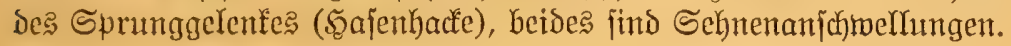

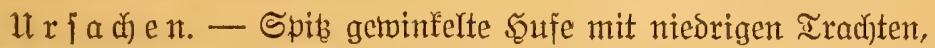

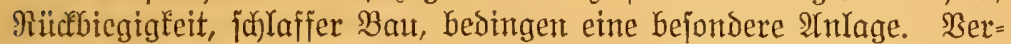

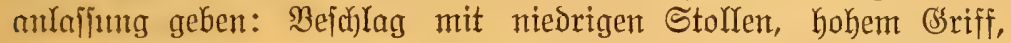

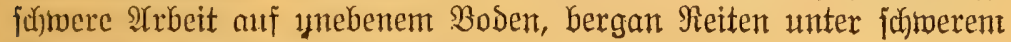
(sctridft auf nadigiebigem $B_{0}$ oden.

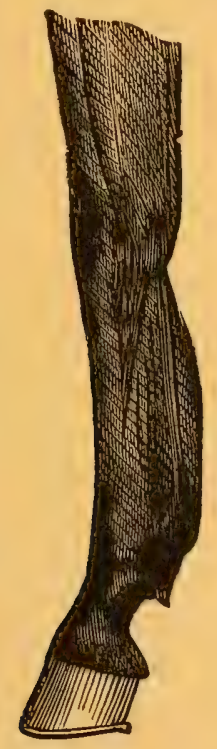

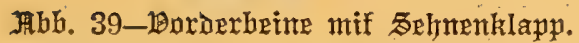

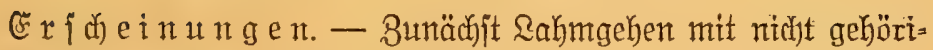
gem Dutrd)treten im Feffer, fteifem Borführen, leidftem Etolpern,

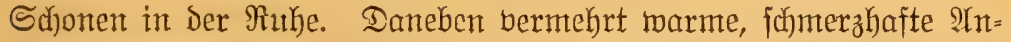

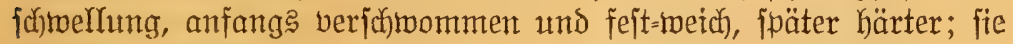
räßst fich am bejten am aufgehobenen und gebeuten zußse feitftelten.

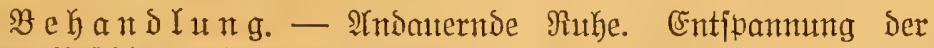

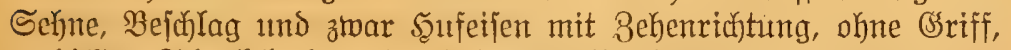
berbicten Schenfelenden oder hohen Stollen je nadh Dem Durchtretert, 


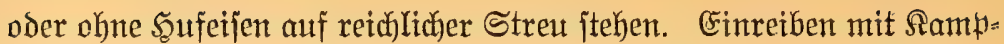
ferjpirttus. Beraltete Fälle fönnen Durch Brennen mit rotglühendem Eijen gemildert twerben.

\section{Stulfbeule, Storliäunamm (capped elbow or shoe boil).}

Sie fommt häıfig vor, hat ihren Sib auf Dem Sörfer (ङIbogen) am oberen Teile des Borderbeins nahe am Rörper und ijt entweder

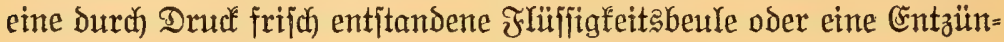
bung bes dajelbjt nicht immer borbandenen Sh) leimbeutels und jei= ner Umgebung. Beide fönnen zur Berteilung fommen, meijt tritt aber infolge wiederholten Drucfes eine Bergrößerung und $\mathfrak{B}$ er= bärtung ein.

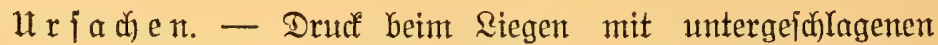
Jü̈pen, namentlidy in engen, unebenen Ständen, bei furzen Retten, wenig Streu. Sejdyäbdte, forwie dämpfige ßferbe neigen bejon= Der: Dazu.

Er $\mathrm{r}$ d) einungen. - Semeinhin entiteht die Stolrbeule

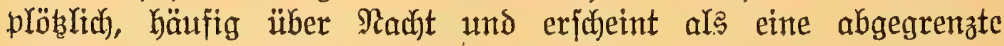

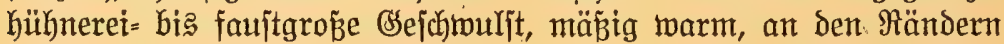
teigig, in ber Mitte verf(c)iebbar. Selten erfolgt gänzliche 3ertei= lung. Meijt bleibt die Beule bejtehen oder wird größer, wobei an ber

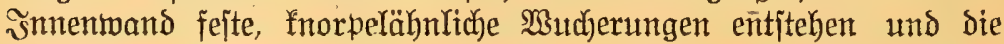
ß3andungen bärter und berber merden. Bumeilen entjteht DrudGrand und nachfolgend Fiterung; bie Âtnjdwellung wird bann größ̈er, wärmer, jehr jumerzhaft, es jtellen fich Entzünoungen ein; dann

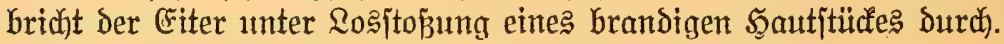
IYuch hier hinterbleibt eine lange 3eit eiternde Ssejurwulyt.

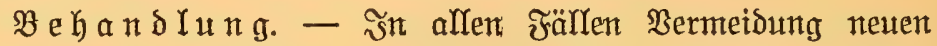

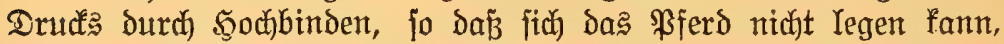
fpäter reidfliche Streu und meiten Stand. $3 \mathfrak{u}$ Infang einige Iage Berband mit tühlend=zerteilenden Mitteln, wie

\section{$\mathfrak{A}$ rniffatinftur (tincture of arnica) 1 Ieil, Mafjer 10 Teile.}

Dann wird mit Dem Mejper geöfnnet, ber Sdynitt nach unten ausge=

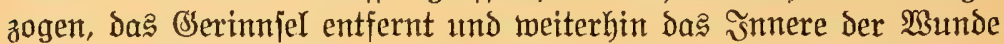
täglich ein = bis zmeimal mit einer Salbe eingerieben, beitehend aus

rotem Duedfiłlłerpräzipiat (red oxide of mercury) 1 I eil,

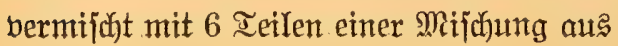


Sidfent Texwentin $6 \mathfrak{1 n z e n , ~}$

5ुonig 12 1tnzen,

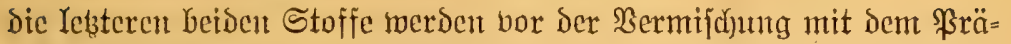
zipiat über Fener bis zur Sुälfte eingedampft.

Beim Entitehen Der Stollbeule Yäß̈t fich Diejelbe oft entfernen, went der Sुuf Des Borderbeines an ber betreffenden Seite gut mit 3eug betwicflt und barïber ein aus altem Reder angefertigter fleiner. Sact gebumben wird.

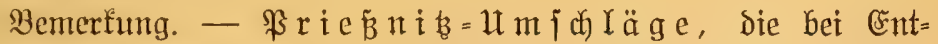
zündungen, Sltetjdungen ujw. als jehr wirfjam empfohlen mordent find, werden in folgender Weife angelegt: ein in faltes Mafler ge=

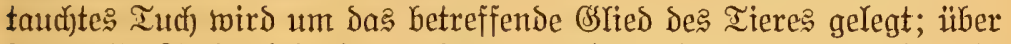

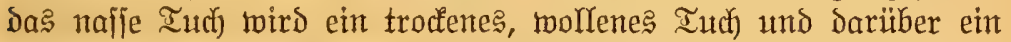

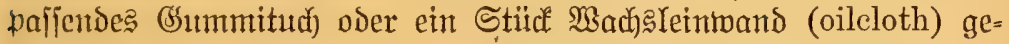

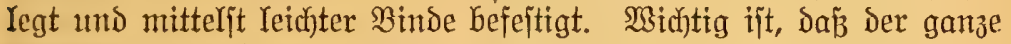
Berband ïberalf feit auffiegt, jo baß feine Ruft an die berbundene Rörperitelle gelangen fann. Beim Îtlegen aller Berbände und

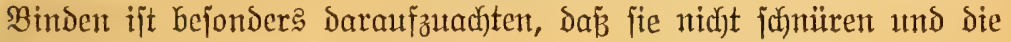
Blutzirfulation nid)t behindert mirs.

\section{Siniejudiunmm (capped knee).}

Sommt an Der vorderen Fläche Des Iniees häufig bor und fam

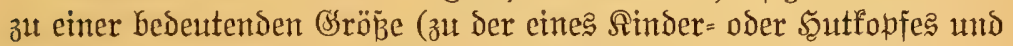
Darüber) herantwachjen, wobei die (sejutwuljt narh dem Schienbeine

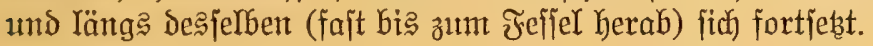

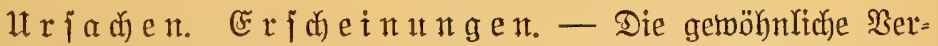

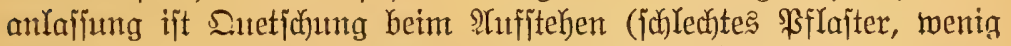
Stren). - Es ijt meijt uriprünglid) eine Jlïffigfeitabeule, Die lange 3eit in diejem 3ujtande verbleiben fann. ("Weicher Sniejumamm".) Gsanz allmählidf berdidfen aber bie Mandungen und ihr snhalt und jo bildot fidj eine mehr Derbe, fejte, an ber Dberflädje haarloje, mit

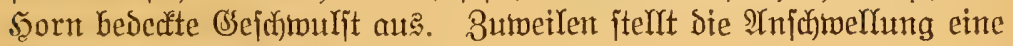
Entzündung Der Sehnenicheiden dar.

Par in erfter Beit beim weidfen Sniejorwamm ift Seilung mög= Iich), aber megen fortwirfender Itrjachen immer unjict)er; jpäter fdjwierig oder gar nidjt zu erreichen. Dafer ijt in vielen Fällen von jeser Behanshung abzulehen.

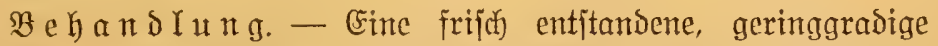
und sünntwandige Sniebeule, wird burd) einen einfact)en (sinfitid) an 
Der tiefiten Stelle entleert und da? Snie mit einer Binde umgeben und gefiuhlt. Es fam die Söhle berheilen, fid) aber aud wieder füllen.

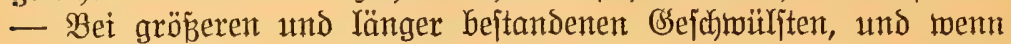
boriges Serfahren nicft genügte, madyt man am unteren Ende der Sejormitljt einen etwa 1-2 3olr Yangen, jentrechten (rinjidnitt, ent=

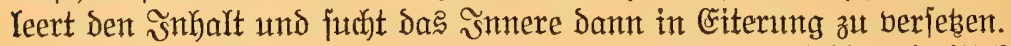

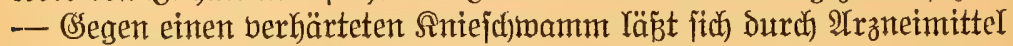
mentg ausribjten, und operatives Eingreifen ift fichon wegen ber Nähe Des Selenfes und der Sehnen unitatthaft. 


\section{0. 位aprifel.}

Sirnuffreiten ber Fefïel (fetlock), ১cr Fefïclgelenfe (ankles) und ber Fiilipe (feet).

Streid)en, (Einfonten, Grreifen (interfering, overreach).

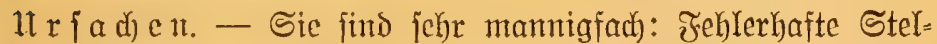
Inny ber Beine, namentlich zehenweite ("franzöitiche"), jeftener bodenentge Stellung und untregelmäp̧iger (Sang, wie fuchtelnde $\mathfrak{B} e=$

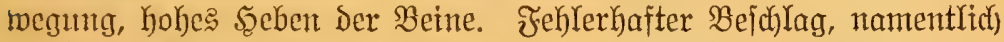

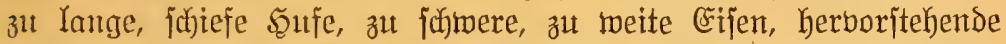

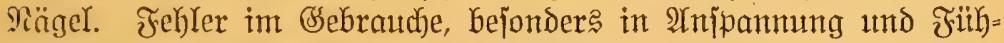

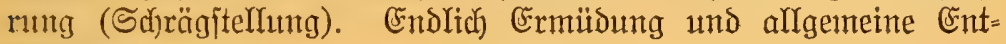
fräftung.

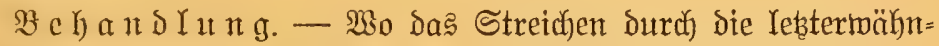

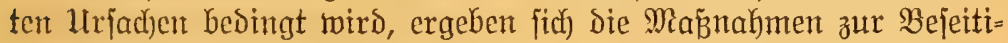

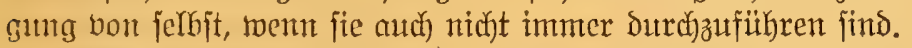

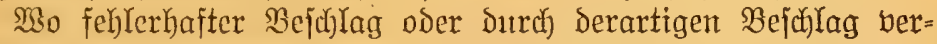
aulabte ober geiteigerte aburme Stellungen borliegen, wirs durd)

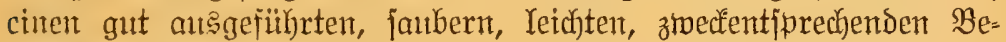

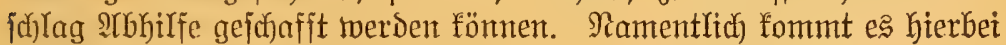

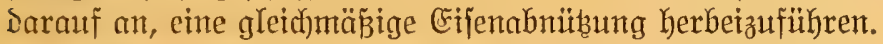

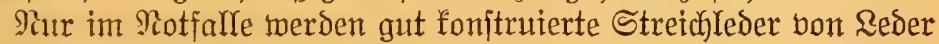
oder Sitmmi berwendet.

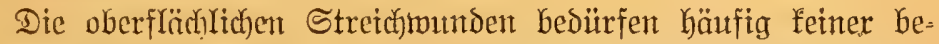

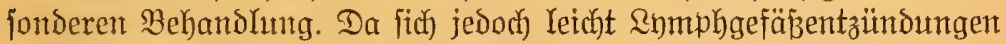

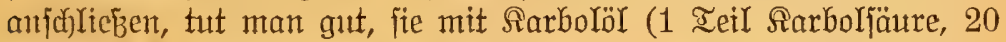

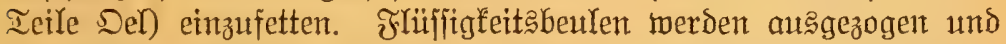
cin mäßig brüdender ßerband angelegt. Streidballen vermindern

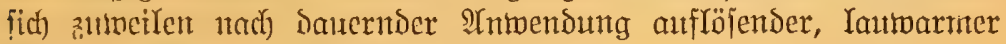

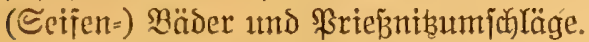

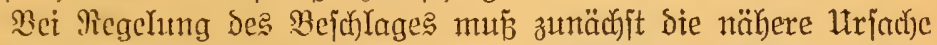

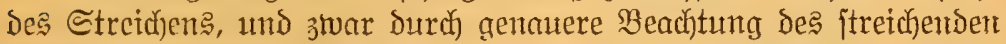

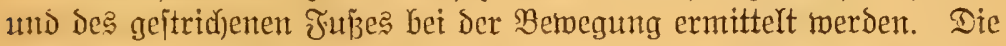

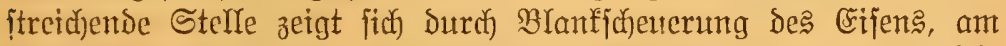

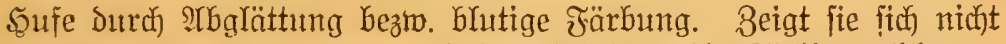
Dentlich, fo madjt mant einent Refmanitrid) an sie Stelle, welche ge= 


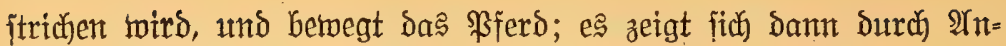
fängen des Rehmes die Stelle, weldhe jireicht.

(semöhnlict) bermeint man genug zu tum, went man ein Streidi)= eijen, $\mathfrak{d}$. $\mathfrak{i}$. ein Eijen, delifen innerer Schenfel in einen hohen jumalen

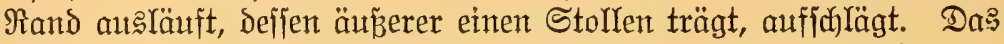
genitgt aber mur jelten bei bodenenger Stellung. Bur Prbjterlung ijt jowohl ber geitridfene als jtreichende Jun zu bearten. Meijt ijt die

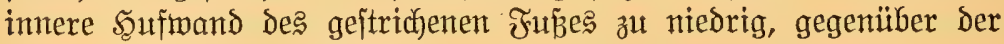

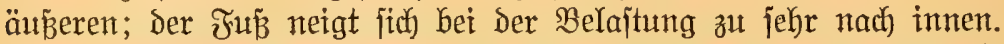

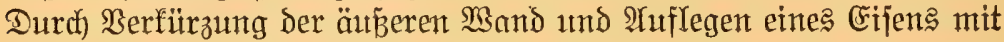
bickerem inneren Sdyenfel, bezw. Stollen, Engridten des äußeren,

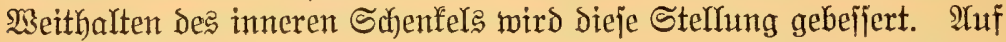

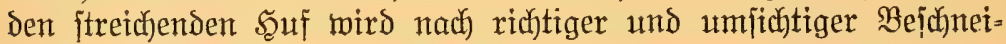

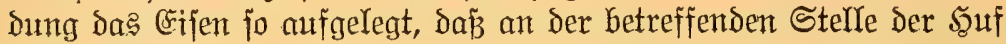

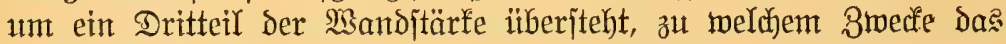

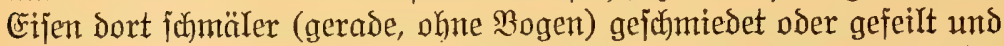

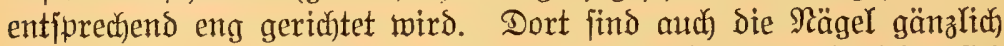

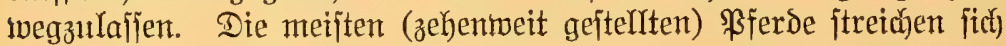
mit der inneren 3eke; Deshalb ift das erijen dort gerabe zu halten und nicht zu Yodjen. B̧ei enggejtellten Scufen verwendet man ein Eifen mit einjeitiger Lochung, §. h. Der intere Shenfel bleibt unge= Yor)t und das Eifen mird ïber die Behe weggenagelt.

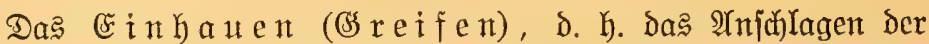
Behe Der Şinterhufe an die Eijen oder Ballen Der Borderfï̈pe beruht entweder in mangelfafter Rörperfraft (jobrwachem Rüdfen, Ermü= Dung), febferhaftem Baut (Ueberbautjein, Unterjtändigfeit der $\mathfrak{B o r}=$ berfü̈e) oder in mangelfaftem Bef(c)lage, namentlich Yangen Behen und zu niebrigen Trachten an Den ßorderhufen. Das Greifen ijt

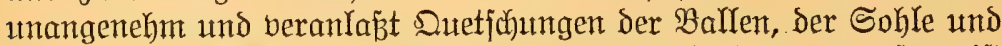

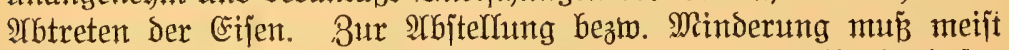
Berfürzung Der Behe und Sdjonen Der Tradjten an ben Borderhufen itattfinden. IVenderung des Bejulages: Sintereifen mit zmei Seiten= fappen und an der Behe jo abgejtubt und abgerundet, dá̉ der Suf $3 / 4$ Der $\mathfrak{B a n d i t a ̈ r f e ~ u ̈ b e r j t e h t , ~ u n d ~ a n ~ d e n ~ B o r d e r h u j e n ~ m o ̈ g l i d j i t ~ f u r z e ~}$ Eijen mit jadräg nach vorwärts geridjteten Stollen verhìten wenig= jtens das 2 (btreten der Eijen.

\section{Berrenfung bes Fefielgelentes (sprain of the fetlock).}

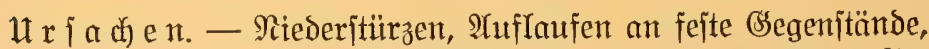

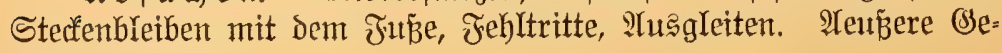
walttätigfeiten. 


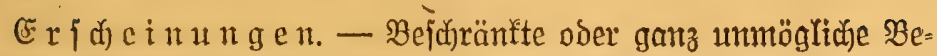

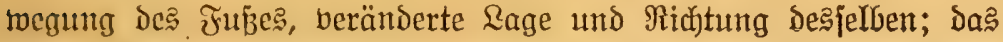

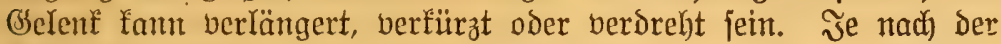

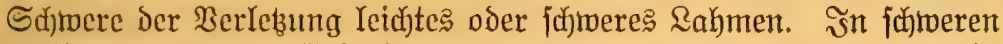

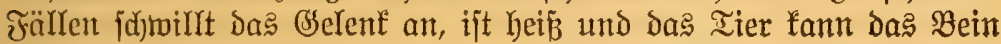
nidjt gebraudjen.

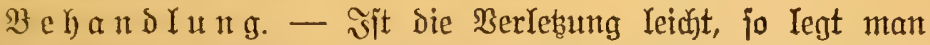
Sinden, Die in faltes Mafjer getaudht wurden, um und gibt Dem Tiere

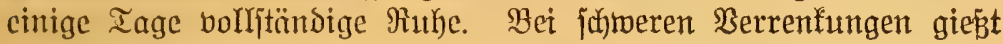
man langfam, aber andauernd falte马 Maffer auf bas verrenfte be=

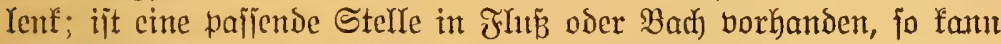

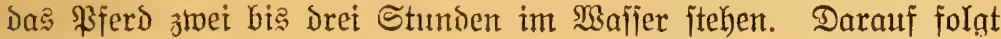
Einreibung mit cinem zerteilenden und fühlenden 2iniment, bejtekend aus

囚ampferfpiritus (spirits of camphor) $2 \mathrm{oz}$,

Salmiat (ammonia) 1 oz.,

따감 $5 \mathrm{oz}$,

Majier $5 \mathrm{oz}$.

Die Cinreibung wird morgens und abends borgenommen.

\section{Strahlfäule (trush).}

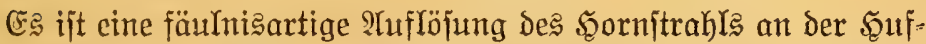
johle. Srommt an allen Füben bor, am bäufigiten aber an ben Sinterfüben.

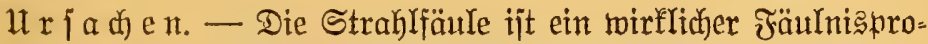
зев, bei ber fid Das Strablyorn in juarfen Flüfifigfeiten (Urin ujw.) auflöft. Die nädjite Urjache ift Demmad) immer Unreinlidbfeit, ins:

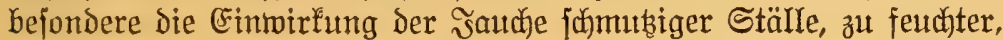
alter Streu. Meiterhin wirfen alle Momente begünjtigens, tweldye Die natürliche Reinigung des Strahles beim Berübren desjelben mit Dem ß̧oDen hindern, fowie jeine gejunde Ernährung beeinträbjtigen. Gierhin gehören: vieles Stehen (bei నuxuspferden), ftarfes Nieder: janteiden Des Strahles, hohe Irachten, Stollenbejd)lag, namentlid aud) Slemmorud infolge eingezogenter Irad)ten (3twanghuf), Şuf= einlagen (ङtrohjohlen ujw.).

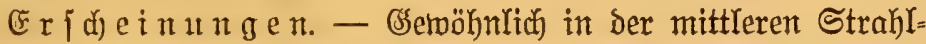
furdje beginnend, Dann aber aud in ben feitfidjen Strahlfurdjen zcigt fid) eine graue bis jojwärzlid)e, jaudjige friuffigfeit, bie einen jehr ïblen Sserud hat. Dabei ijt das angrenzende Strahlyorn ertweidyt 
1nঠ mürbe. I̛n meiterer 3unahme wird der ganze Strahl zerfajert,

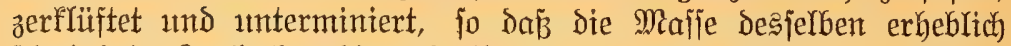

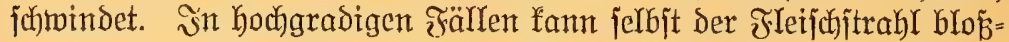
gelegt werden, Dann findet fich auch Rahmheit hinzu, wenigitens wiro ber Brang alt harten Megen etwas Hlammerig. - Bei längerer $\mathfrak{A} n=$

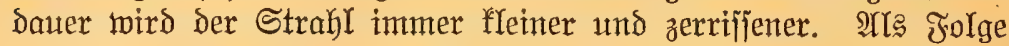

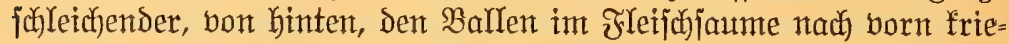

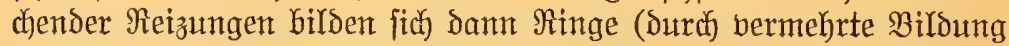
des Saumbandhornes, der (Slafurjichicht), weldye fadräg von finten und unten, nach vorn und oben über die Şufwant berfaufen, fich an ber 3ebe jelbjt freuzen und daz Borfandenjein von Strahlfäule cr:

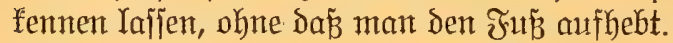

Die Strahlfäule ift ein rein örtlidyes Reiden, weldjes fich Yeidjt bejeitigen Yäß̈t. Es fehrt aber jtets wieder, jobald fich die entfernten Itrjachen nicht abjtellen Iafjen. \$Beiterhin führt es aber auds zu all= mählidfen Berengerungen bes Şıfes, jelbjt zur AYusbildung von Brounghufen und jodiefen Şufen, ferbjt zum itachligen (bang und Stolpern.

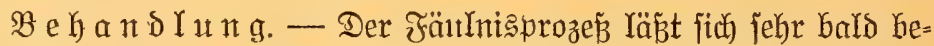

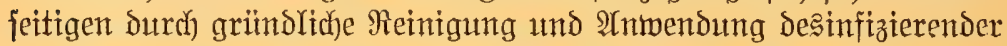
und austrod"nender Mittel. Arres in Röjung begriffene, zerfebte Şorn mird zınäcbit mit dem Mejīer entfernt. Sodann wird eine täg=

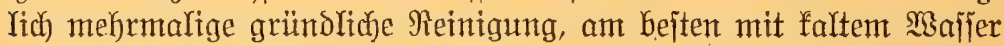
und Büryte oder ßinjel borgenommen. Das fann juon für fich genügen, in hartnädfigen Fällen bermendet man täglich) ein $=b i s$ ztwei=

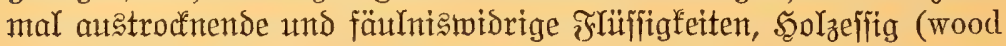

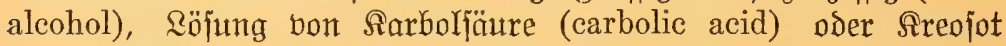
(creosot) in 2rlfohol; man nimmt 1 Ieil Rarbolfäure oder §reofot zut 10 Ieilen 2Hrohol. Ein jefr wirfjames Mittel ijt trodnes falomel (calomel), mit dem ber Strahl (frog) und die angegriffenen Stellen beitrent werden. Daneben reichliche, trodene Streu und viel $\mathfrak{B} e=$ wegung. Itm den atggeheilten Strahl wideritandsfähiger zu machen, bejtreicht man bie gereinigte Fubjohle mit Şolzteer (pine tar), den man ourch Rakehalten eines rotwarmen Eijens einjojmoren läß̈t.

\section{Steingallen (corns).}

Sommen vorzugemeije an Den Borderfiïen, namentlich an der

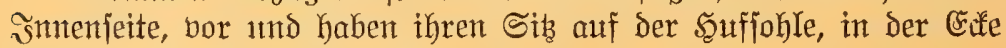
ztrificten Sufrand und Strahl.

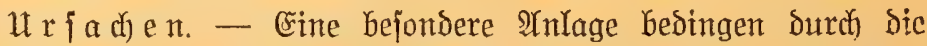
Damit einhergehende, ungleidymäpige Belaptumg fehlerhafte Stellum= 
gen (boientweite, bodenenge, franzöfifuhe Stellung, fehlerhafte Sufe

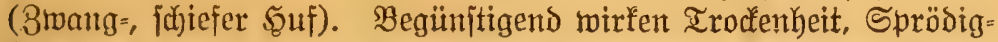
feit Des Sufes, Stollenbefulag und Behen auf hartem Boden. Bei

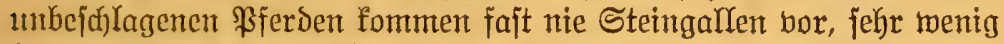

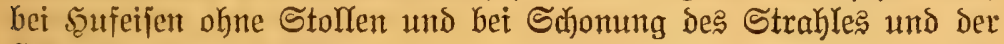
Eifftreben beim Bejulagen.

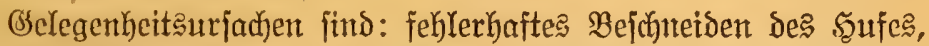

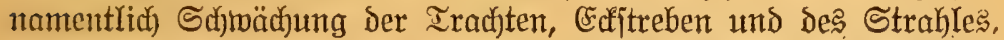
Sdjieffidneisen. Ferner feblerhafter, Drucf und 3errung veranlafíen=

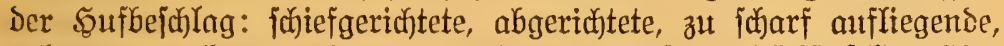
gebogene, zu furze und enge, zu lange Şufeijen. Sö̈djit felten Ein= flemmen bon Steindjen zwifdyen Souf und Eifen.

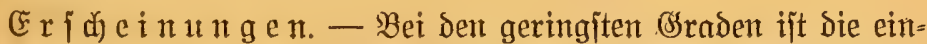
3ige Errjojeinung bie rote, bläulidy)=rote oder gelbliche Färbung be? Sornes im Ecejtrebentminfel, sie an fid ficton bemerfbar ift oder ber= vortritt, wenn einige Şornfpäne hinmeggenommen werben. - Bet höherent Graben find zugegen mehr oder weniger heftiges ¿ahmgehen, bermehrte \$ärme, Sdhmerzen beim Drudt, \$ulfieren Der îrterie.

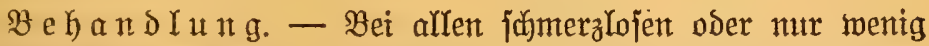
cmipfinolichen (tročenen) Steingallent ijt eine bejondere Behandlung

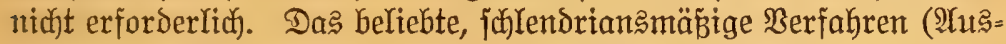

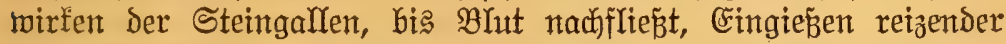

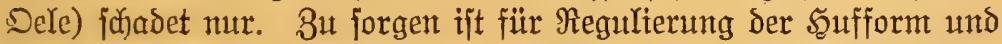
für guten, zweçentipredjenden Şufbejülag, mobei man dent. betreffen-

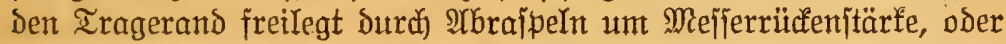

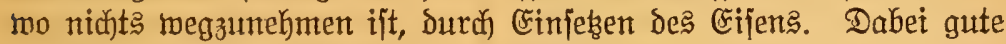

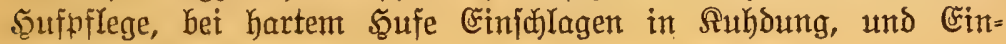
jummieren mit $\mathfrak{s e t t .}$

Nur bie finmerzhaften, entzündeten Steingallen erfordern eine

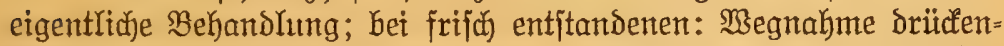
Den fornes und fühylenbes Berfahren; Gei heftigeren und anfaltenden

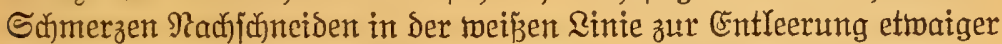

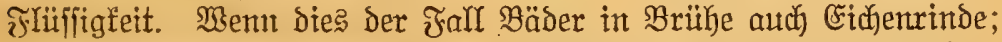

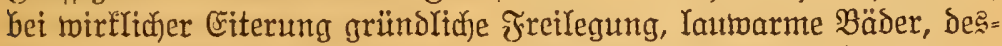

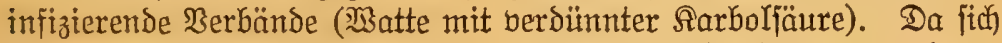
bei ungenügendem Eiterabflü Yeidjt ßnorpełentb̆öß̈ungen bezm.

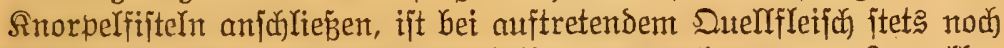

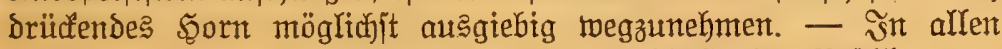

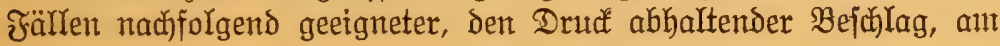


bejten gemeinhin mit einem geinloljenen Eijen. Borhandene Deff= mungen twerden mit Baumbaris zugeflebt.

Irlle jog. beralteten Steingallen fönnen mur ganz allmählid ourch eine umithtige, dem jedesmaligen $3 u$ itande entiprectjende $\mathfrak{B e}=$

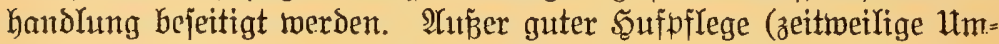
fa)läge, Suffialben), forrefter Befchlag, der namentlich) Den Drucf Dauernd abhält; bei Yeidbten \$fFerden ein Dreibierteleijen, bei jäbere= ren ein gejdlofienes Eijen, an meldyem am betreffenden I radten= jhenfel ein Stüld herauggehauen ijt (gejulolienes Dreivierteleifen).

Die jog. Blauroten Mäler find Glutrote Fledten an ber übrigen Sohlenfläche. Es find Duetjuhungen mit B̧lutunterlaufung, bie gemeinhin nidjts zu jagen haben, unt jelten in Eiterung übergehen. Die Behandung wejentlich wie bet Steingallen.

\section{3wunghuf (contracted heels, or hoof-bound).}

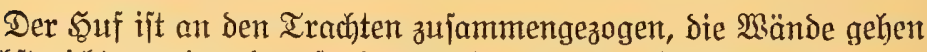
bajelbjt nicht auseinander, fondern nähern fich, Die Erditreben find um= gebogen, der Strahl ijt berfïmmert ober ganz gejdinumben, ebenjo find die Ballen geidnumben und einander genäbert oder übereinander gej(hoben. Meijt find die Irachtentwände hod), bon geringer Stärfe;

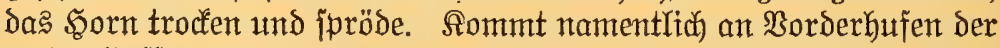
engen Sufform vor. - Die nähere Itrjache ijt die ßerminderung oder

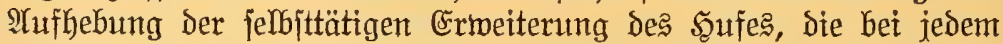
IUuftritt erfolgt, fobald der Strahl den Boden berïbrt. Innfolgedelien fterrt fich 3ujammenziefung und Sdywund ein. Das wird herbet=

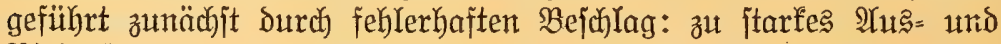

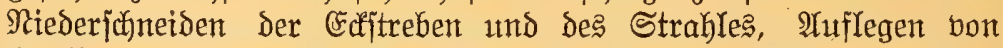
Stolfen, zu weiten, hohl gerichteten und daher einflemmenden, zit weit nach hinten genagelten Eijen. \$3eiterhin Strahlfäule, wentg Betwegung, Trodenheit. Sdymale Soufe neigen bejonders dazu hin.

\$ferde mit 8manghuf gehen zaghaft geppannt und treten nidjt

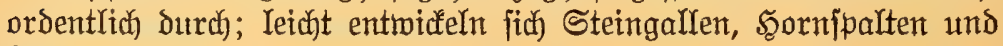
Ectitrebentorüche,

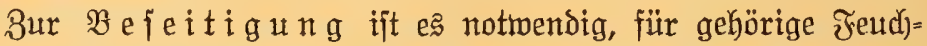

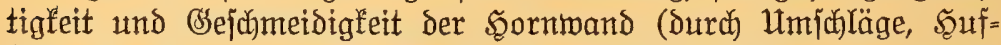
jalben) zu jorgen, dann ferner bie allmähliche Selbjtermeiterung dę Sufes anzuregen Durch Şetwegung und Durch Ermöglichung des (Segendrudfe bom Boden namentlich auf Den Strahl.

(6sanz einfach erreidyt man biejes allez, wenn man bie riere unbe=

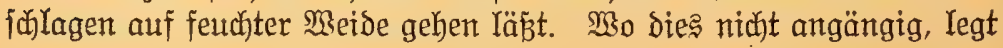


mant citt halfmondförmiges oder Dreivierteleten, oder Eijen ohne Stollen auf, bie nidjt tweit nad) Ginten gelodjt jein biurfen. DDer mant benubt ein gejolofjenes Eijen mit Drude auf Den Strahl, jobald diejer

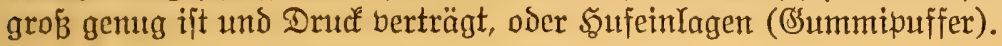

\section{Refe, Berjudlag (laminitis or founder).}

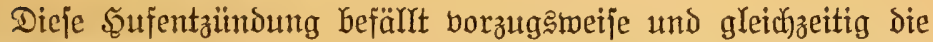

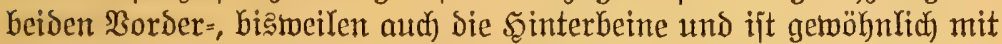
cinem allgemeinen rbeumatifhen und fieberhaften হeiden bereint.

Da: Reiden bejtebt in einer plöblich anftretenden oberflächlichen

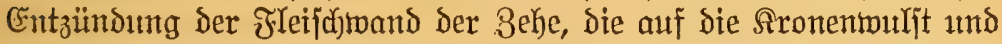

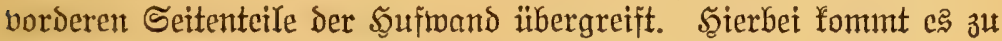

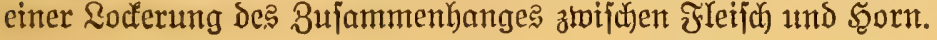

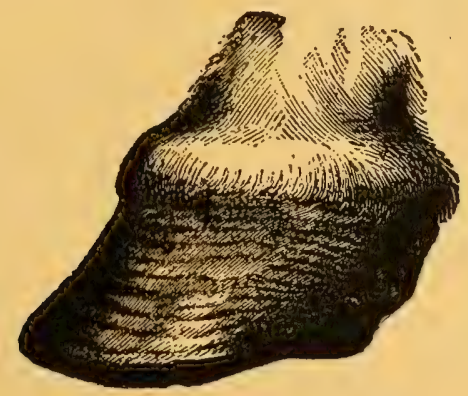

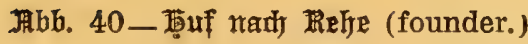

Geht Die Entzïndung balo noriber, fo ftellt fich eine ernente Sornbildung ein; bei längerer Daucr fithrt fie zutr Bildung des

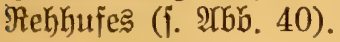

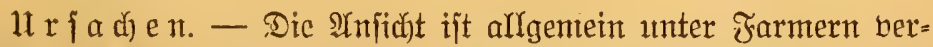

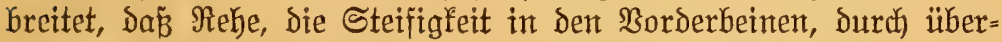
mäßiges Freịjen 1 tnd Saufen (corn-, water-, ryefounder) oder Dutrdi)

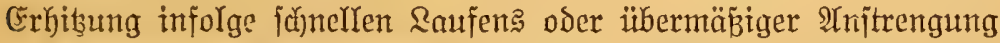

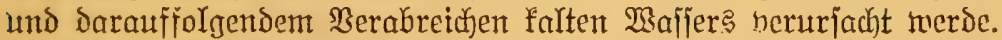

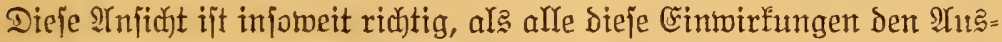
brutch ber Entzünoung bchroleunigen, fait in allen Fällen befteht aber

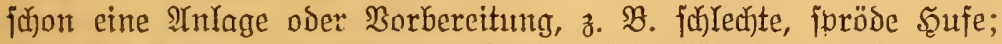

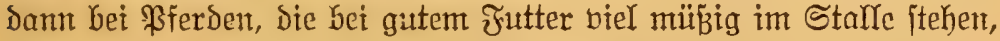
bejonbers auf hartem Boden oder fubon borker an Şufenzinduting 


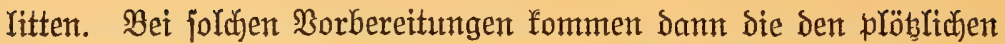

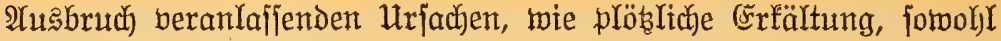
im Jreien als im Stalle burdh 3ugluft, faltes Irinfmafjex, ftarfes

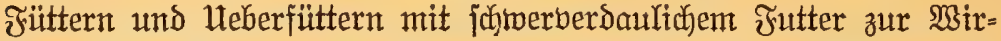

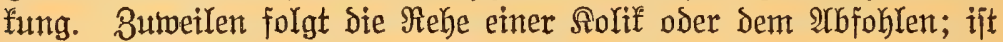
anch) jochon nach heftigen Durchfällen (infolge jtart abfübrender Me=

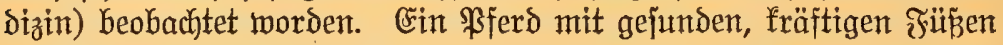

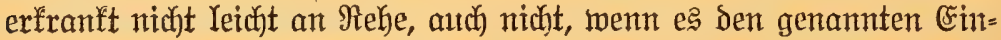
wirtungen ausgejetst war.

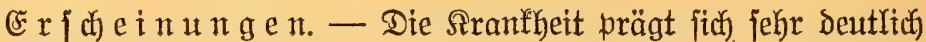
Durch) Stellung und (sang aus, weil bie bedeutenden Schmerzen bie Tiere veranlajien, die franfen Ieile zu entlajten. Beim Stehen jeben.

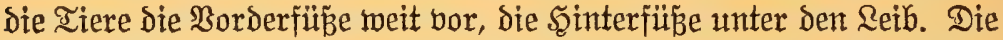
Tiere haben einen blöben, flammrigen, höheren Brabes jehr fläg= Iidfen rsang, bejonders auf bartem, inebenem Boden. Sie gehen

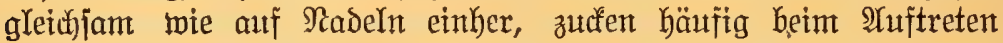
fammerzhaft zujammen, jesen Ballen und Trachten zuerit auf die Eroe und jajonen die Behe. Deshalb twerden die Borderfü̈e weit borge=

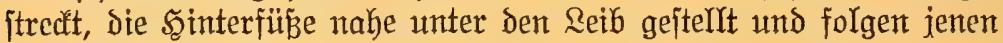
idynell in furzen Sdyritten, wodurch wieder im höheren şrade eine eigentïmlidfe, gelpannte (fabenbudelige) Stellung und Bemegung im

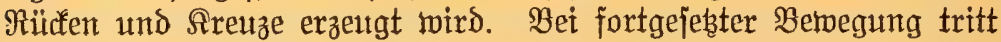

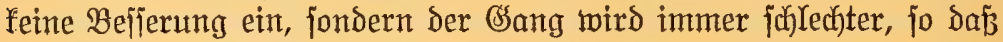
in hod)gradigen Fällen die Tiere faum von der Stelle zu bringen find. Die Tiere Yegen fidt), pobald jie fönnen. Die Şufe find warm, ja)merz=

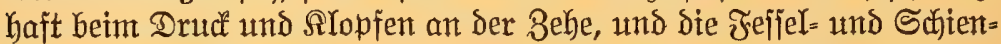

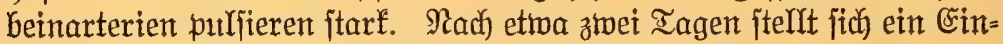

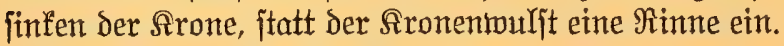

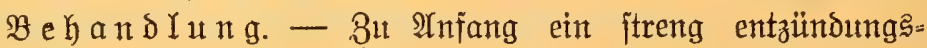

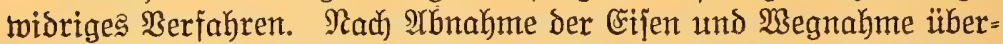
flüjfigen trodfenen Sohlenhornes, etwas Bertürzung der Behenmand Durch) IVrajpeln, andauternde lühlende IImja)läge (von Reinmehl mit Bleiwalfer befeuchtet, bon (Fiミ) oder Bäber und Beriejelıngen mit

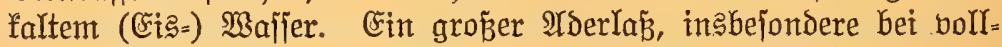
Glïtigen Iiteren. כ̛nnerlich fïhlende 1 nd eröffnende Salze, nament=

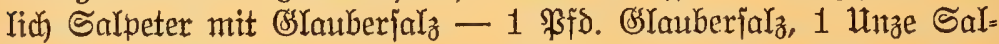
peter -, auth wohl Brectimeinitein (tartar emetlc) - 1 Utnze. -

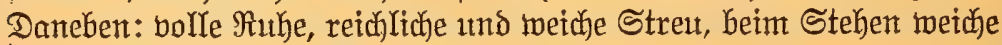

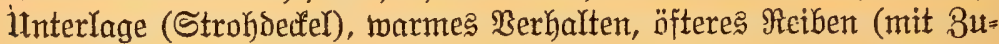

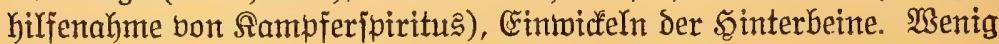
und Yeidjt berdaulidjes, eröffnendes Jutter, berid)lagenes Irinftwafier. 
Radi) cinigen Iagen, wenn bic (sntzündung gemindert, aber bie Berteilung ungeniigent fortj(j)reitet, empfehlen fich namentrich zur Itbreitung fujarfe Cinreibungen mit einem Riniment, bejtehend aus

Rorbeeröl (oil of laurel) 1 oz.,

Terpentinöl (spirits of terpentine) 1 oz.,

Salmiaf (ammonia) $1 \mathrm{oz}$.,

Rantfaridentinftur (tinct. of cantharides) 1 oz.,

oberhalb Der Srone (etwa fingerbreit von Derjelbent entfernt, aber fonjt um Den ganzen Fefiel herum), für Deren andauernde 1 tnd reich)=

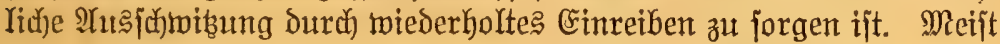

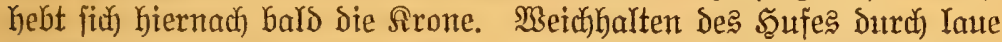

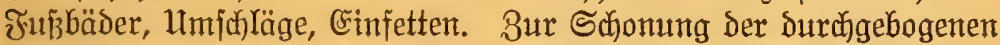
Sohle gut abgedadjte, an ber 3ebe nicft auffiegende şufeifen.

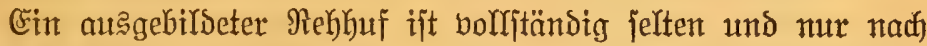
längerer 3eit (6-9 Monate) zu heilent. (E马 handelt finch dezhall meift um Errhaltung der Bsebraudjafähigfeit auf meichem Boden.

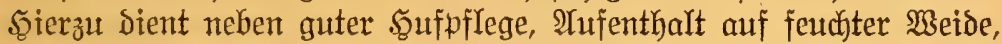

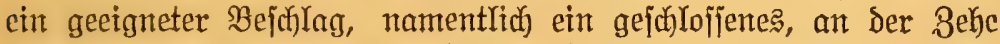
breites und gut abgedantes Eijen mit etwas Behenaufridftung. Beim Befollage foll dasjelbe nur auf Seiten=, Trachtentwand und Strahl arfliegen, sie Behe mird burch vorheriges Arbrajpeln freigelegt und

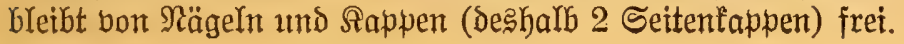




\section{1. 筑apuifel.}

\section{S̨autf́ranffyeiten.}

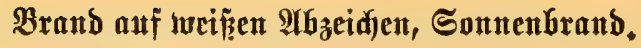

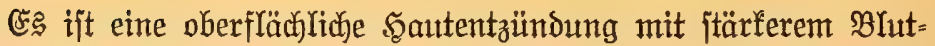
andrange 1 thd geringer mäfiferiger

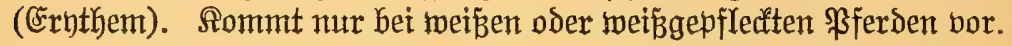

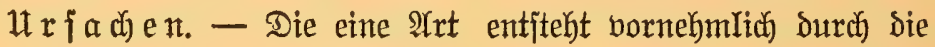
Einmirfung greller Sonnemftrablen. (Sonnenbrand); Die zweite $2 \mathfrak{A r t}$

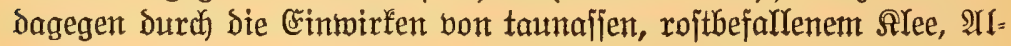

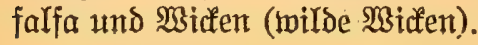

ङ

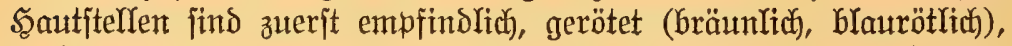

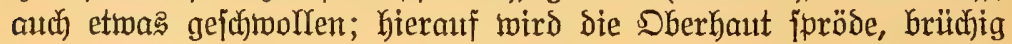

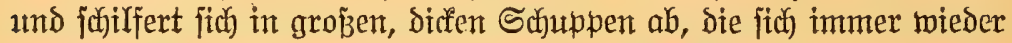

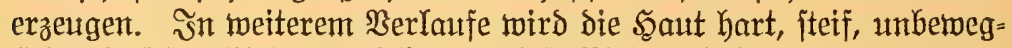

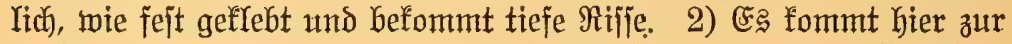

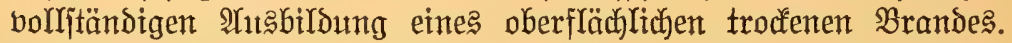
Die Şaut ijt anfangs ebenfals entzüntoet, gerötet und etroas ge=

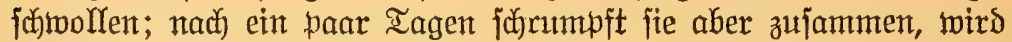

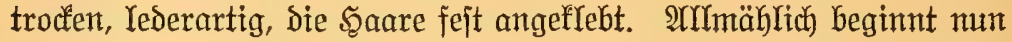
bom Rande her bie 2ostrennung Der oberen abgejtorbenen Saut=

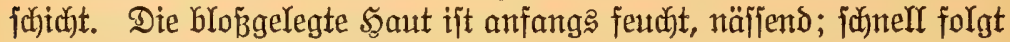

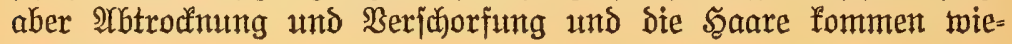
der herbor.

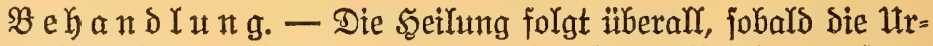
facten abgeitelyt, bon jerbit, wem aud Yangiam. Bet ber e $r$ it en

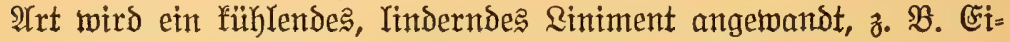

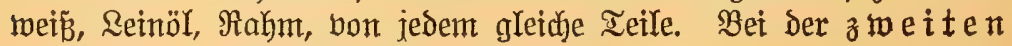
Irt werden diejelben Mittel angetwandt.

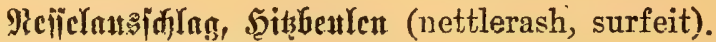

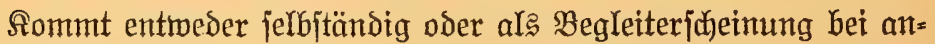
Dern Aranffheiten, wie Drife (distemper) und Staupe (influenza) bor. 


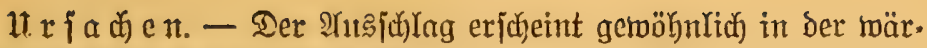

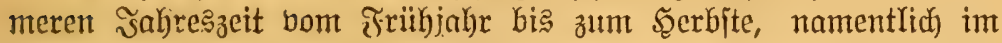

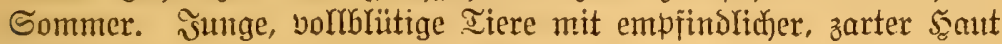
merien bejonders von biejer Sranfheit befallen. Beranlafiung geben

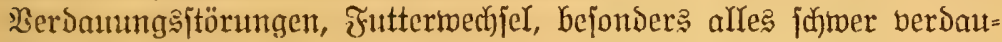
Iiche, fdunell ins Błut übergehende, jaftige Jutter, wie filee und $\mathfrak{I r}=$

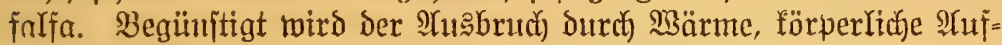

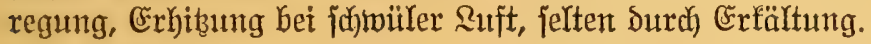

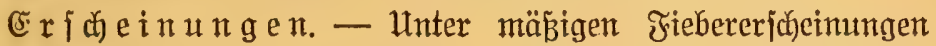
entiteben plöblich und gleidzzeitig an beridjedenen Rörperitellen,

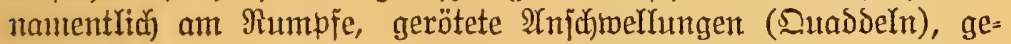

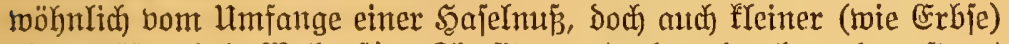

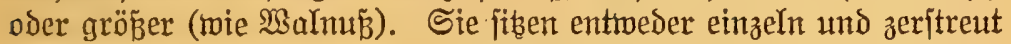
oder bicht gebrängt aneinander, gleidj)an twie ïberjät, pflegen dann

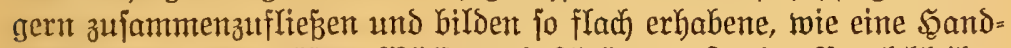

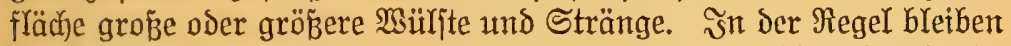

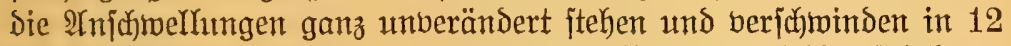
bỉ 48 Stunden; mur bie grö̈eren Sd)mellungen zerteilen fich Yang= jamer. Entweder tritt mur ein $\mathfrak{A}$ nfall auf oder e? findet in fruzer 3eit cine Wiederkolung itatt.

şe ha $\mathfrak{n}$ D I $\mathfrak{n} \mathrm{g}$. - Sit in vielen FälYen gar nicht nötig; Die \$ujteln treten von jelbit zurüde. Sonjt empfiefit fich bie Berab=

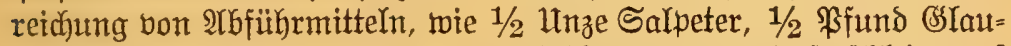

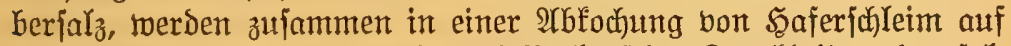
einmal eingegeben und find je nad) Berlauf Der Srantheit an ben fol= genden Iagen zน wiederholen.

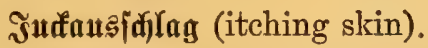

It $r$ j a d c $\mathbb{n}$. - Die nähere Itrjadje ijt unbelannt, man nimmt viclfach) eine unbefannte Schärfe im Błht an. Die häutfigite Ber= anlaffung ift eine fräftige, erhibende, reidylidje Rahrung, bejonders

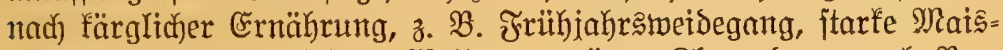

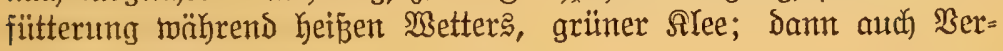
bauungsitörungen.

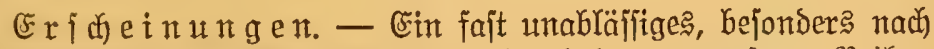

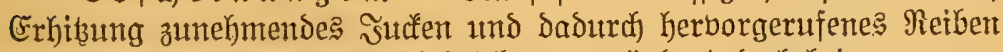
umb Scheuern. Die Şaut erjheint faum berändert, bod beim genauen Rarfjeken bemerft man einzelne, zerftreut jizende, ijebr fleine meidje ober auci) grö̈Bere, flache Sautfnoten, bie ourch bas Scheuern aufge= rieben werben und fich Dann mit nabelfopfgrober, bünner Schorfe be= 
Decten. Die Dauer ijt unbejtimmt, meiftens auf einige Modjen ober Monate beịnränft; im Minter vermindert fich bas Reiden, fehrt aber meijt im Frühjahr wieder.

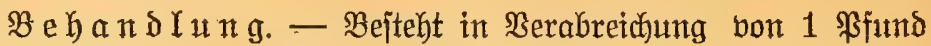

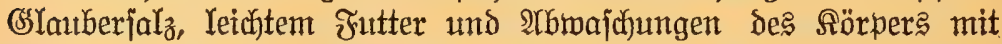
Waffer, bem auf einen (5imer voll (4 Sallonen) ein halbes \$find Salz und 2 Itnzen ?llaun (alum) zugejest werden.

\section{Minuffe (scratches).}

U $\mathfrak{r}$ ja ch e n. - Die getoöhnliche Beranlajinng diejer Entzün=

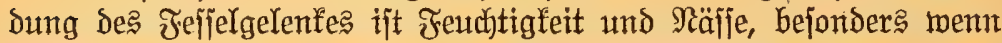

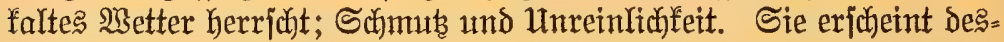
halb gern im $\mathfrak{B}$ inter bei fdymbigen, aufgemeidyten $\mathfrak{B}$ egen, bei Iau=

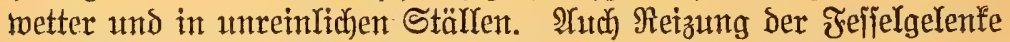

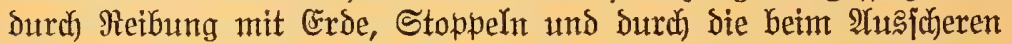
abgeitutsten Saare beranlafien die Maute.

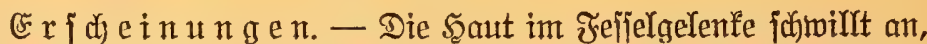

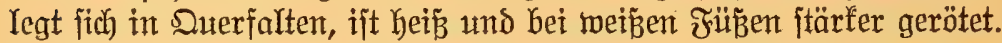

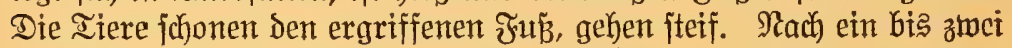

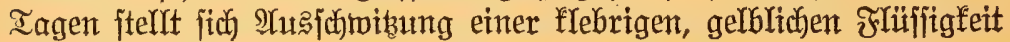
ein, Sie aus offmen Stellen und Duerfalten Kerborquillt. Die Saare find verflebt.

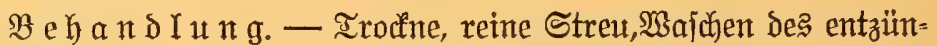
Seten Selenfes mit Yautwarmem Seifenwaffer und Darauf mit witch-

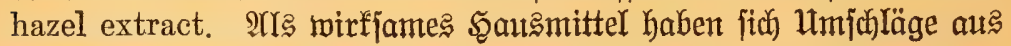
Sautertraut bewährt. 


\section{Liapitel.}

\section{Wimben und beren Befrandlung.}

Berluumbangen ১utrdy Stadjeforaht (cuts by barbed wire).

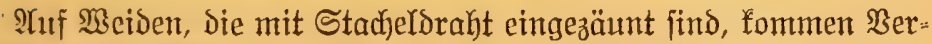

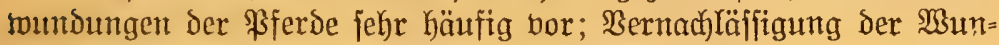
Den füfrt oft 孔 dauernder Sdjäbigung de? Iiere?.

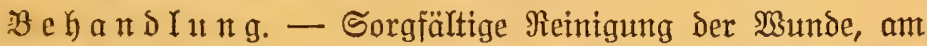

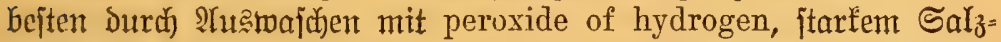

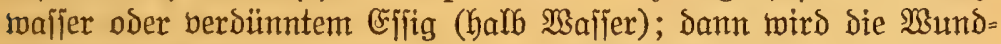

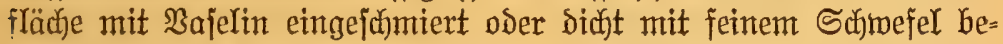

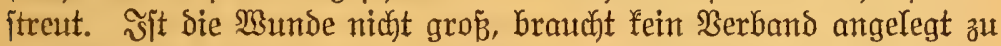

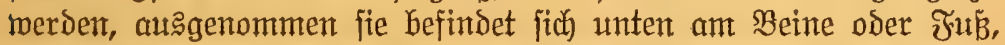

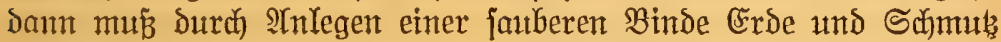

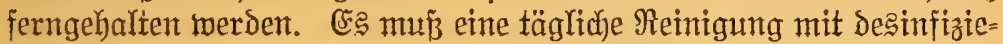
renden MitteYn ujw. vorgenommen werden. Bei gröberen $\mathfrak{B u m b e n t}^{2}$

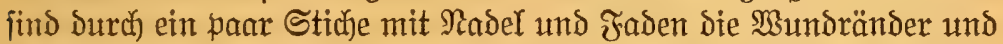

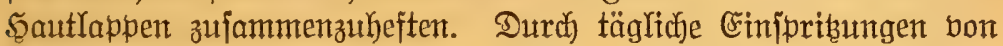

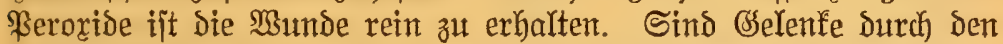

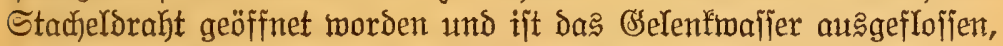

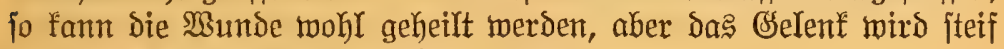
bleibent, aljo das \$fFerd mertlos mactjen.

\section{Wididerriftfiltel (fistula).}

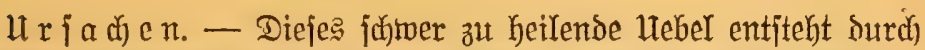

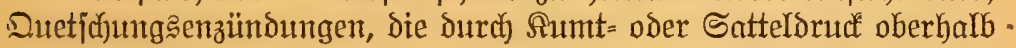

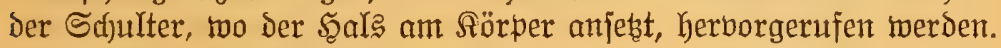

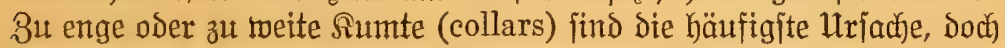
fann and) Sablag ober Stö (an niebriger Stallüre ober an ber Srippe) Die Itrjadje fein. Es entftehen Durd) Dieje Eintwirfungen, Durdi Sie Snochen, Snorpeln und Sebnen an ifrer Sberfläche ent= zündet und vereitert merden.

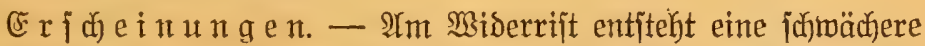
ober ftärfere $\mathfrak{H} \mathfrak{n}$ d)

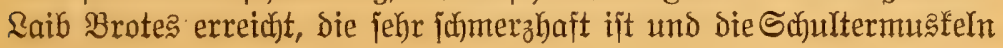




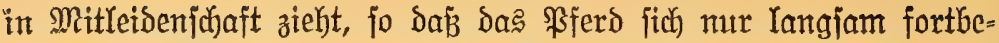

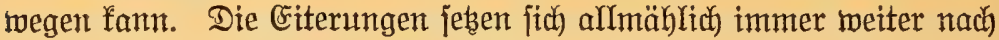
born und zugleidy nad) Der Tiefe fort, und jo fömen lange und weite Stredfen unterminiert merdent. Diejes meitere $\mathfrak{H}$ mjictegreifen ber $\mathfrak{B}_{\mathfrak{i}} \mathrm{i}=$ Derriftfijtel und damit im 3ujammenhange bie jafwierige und nur Ianglame, nact Monaten erfolgende Şeilung ît auf bie bejtändige und

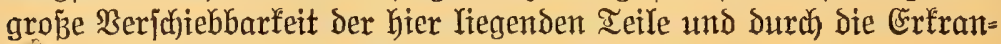

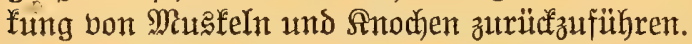

$\mathfrak{B} \in \mathfrak{h} a \mathfrak{n} \delta \mathfrak{I} \mathfrak{n} \mathfrak{g}$. — Eine frübzeitige und bon $\mathfrak{A n f a n g}$ an grïndlidje Behandlung der Ziittel ift unbedingt notwendig; je tiefer Die Eitergänge entIang der Şalsmirbel und hinab hinter das Sajulter= blatt eintoringen, um jo gefährlicher find fie und bejto jafberer zu

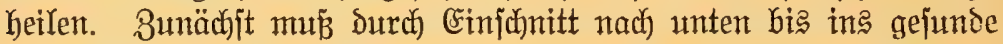

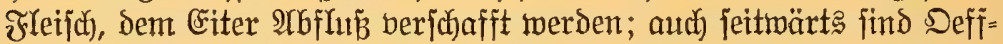
mungen mit dem Meêjer зи madten, utm den gamzen Eiterkerd freizu= legen. Artre ftarf bon Eiter angegriffenen Ieile find mittelft Schere

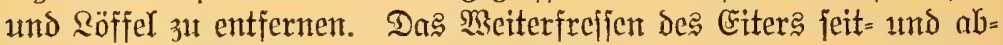
märts madft öftere

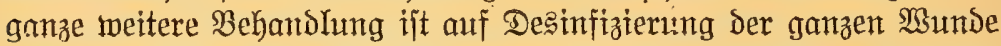
zu ridsten; jobald die Eitterbildung berbjitet werden fann, tritt der

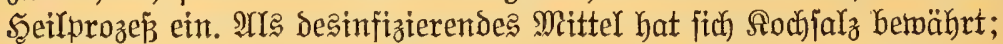

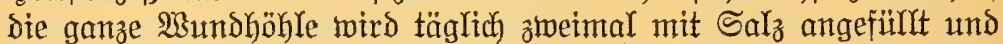
bann ein $\mathfrak{B e r b a n d}$ darüber gelegt. Bor dem Einlegen bes SaIzes

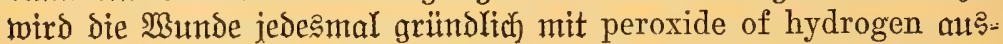

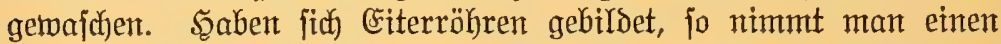
jtarfen Jaden bon entjpredjender Ränge, tränft ihn mit fliuffígem (Gummiarabifum (mucilage), rollt ihn in gepultuertem Duedffitber= fublimat (powdered corrosive sublimate) umb jofiebt diejen Faden in

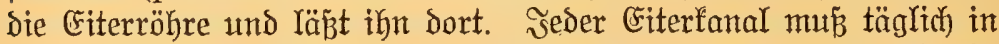

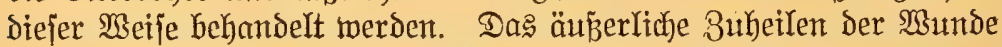

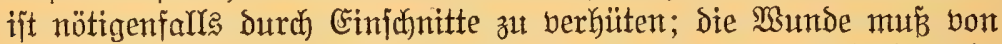
grumbauf heilen, andernfalls billot fid nach) mentgen Modhen ein

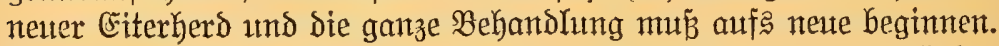

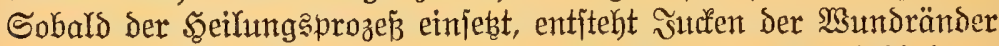

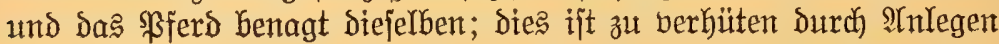

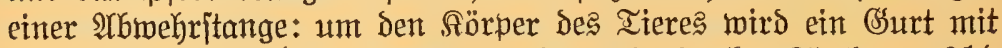

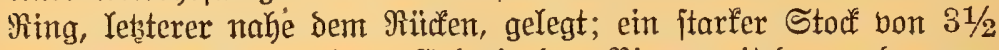

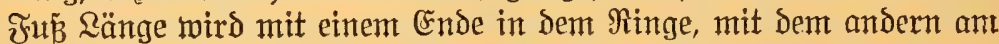
Salfterringe nahe dem Maule befeitigt. - Irfe größeren und tiefen

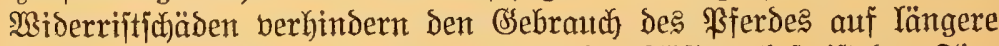

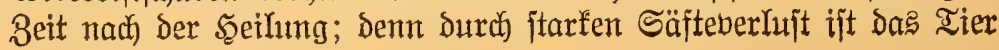


fehr entfräftet uno bie Fijtelftelle berlangt nod) längere Beit größjte Sdjonung; jdon cin geringer Drudt bes Aumtes fann bann eine neute Entzünoung herborrnten.

\section{(Genifififitel (poll evil).}

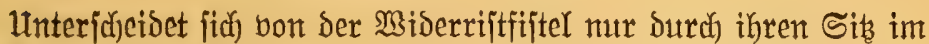
Senide, unmittelbar auf Der obern Seite des \$̧aljes hinter den Shren. IIrFadjen, Eridjeinungen und Behanolung find diejelben wie bei der Miderriftiftel, mux ift die Sheilung nodj bedentend jumieriger und it ben meiften Fällen nicht erfolgreich). 


\section{3. 篗apitel.}

\section{Irrgemeine Siranffeiten.}

\section{Pf̆exठejtaıtpe (influenza, pink eye).}

Utriachen. - Die Sranfheit entiteht mur Durch IInjtedung.

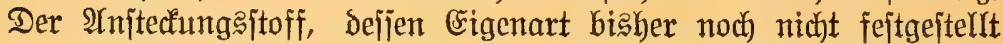

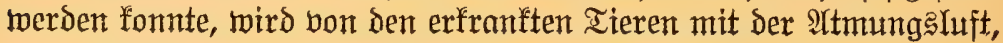
namentlich aber im Dung und Şarn auggejucteden. Seine Hleber= tragung gejobiebt am häufigiten durch die artmungsluft in bicht bejeb= ten, wenig bentilierten Stälfen, boch auth in Freien; als 3mifłben= träger trirfen Streu, Jutter, benutete Stallungen, Menjdben, Sunde uip.

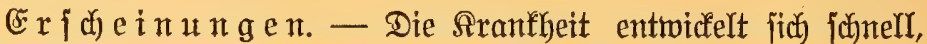
meift im $\mathfrak{B e r l a u f e ~ b o n ~ z w o ̈ l f ~ S t u n d e n , ~ o h n e ~ d a ß ~ \Re r a n f h e i t s z e i c h e n ~}$ boraufgehen. Der Sörper fühlt fich bremtend heip an, die (s)lied=

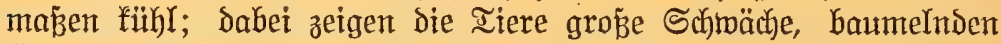
şang mit Anacfen in Den Sselenten. Şierzu fommen bie entzïndeten

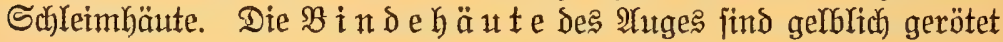
und gefdrwollen, Dabei zeigen fie Richtjucheu, meijt audich Iränen. Die Ra fenjaleimbaut ijt gerötet, gejumollen, anfangs ohne,

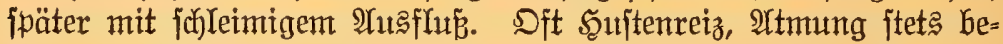

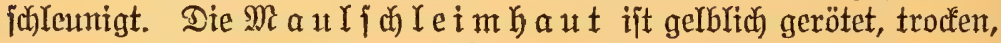
heip; Die 3unge jabwärzlich belegt. Frepluit fehlt, Durjt jtärfer,

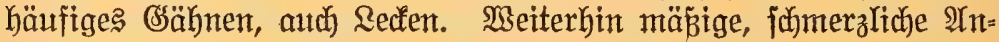

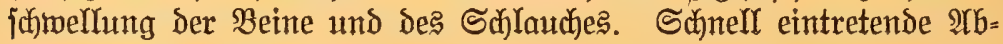
magerung.

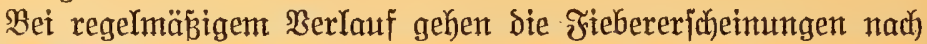
brei bis fünf Tagen zuriut und verjotwinden nach tweiteren zwei Iagen ganz und Damit audh bie meijten übrigen Ericheinungen. Einen un= regelmäbigen Berlauf, Der häufig mit Iod endet, beobachtet man bei

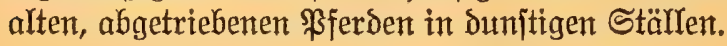

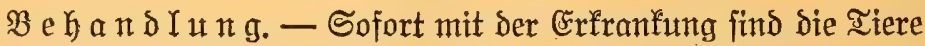
auber $\mathfrak{A}$ rbeit zu itellen und in einem füblen, trodnen Stall mit reiner 2uft und reich)licher Streu oder bei gutem $\mathfrak{B}$ etter im Freien unter= ubringen. 
כ̃n Sen meiften Fällen ift bas Cingeben bon $2 \mathfrak{T r}_{\mathfrak{r} z \text { neien }}$ unnötig;

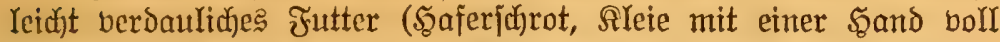

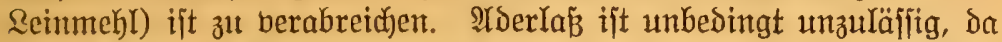

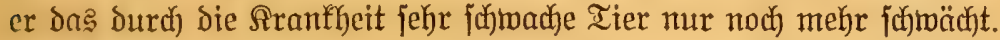

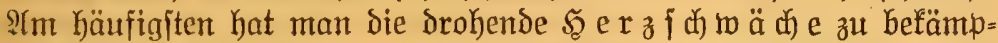

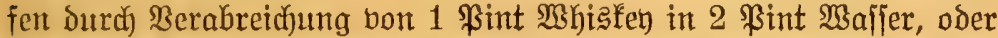

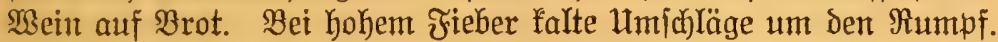

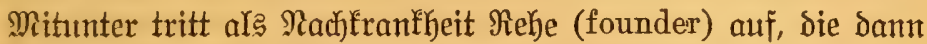
nad) Der gegebenen Boridjrift (S. 205) befandelt werden múp.

\section{Druje (distemper, strangles).}

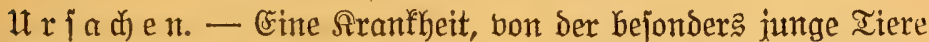
heimgejud)t werden; Dod) exfranfen audj äItere \$Ferde Daran, Dod)

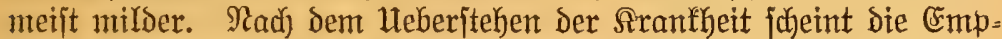

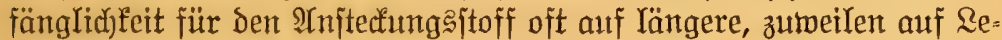

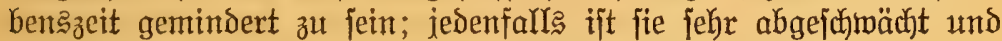
tritt bie Drufe bei einem Tiere zum ztweiten Male mildse auf.

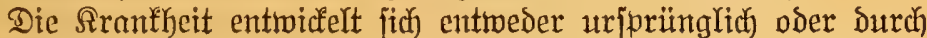

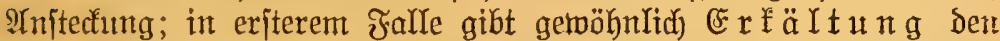

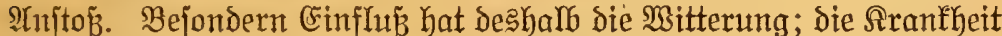
tritt Deshalb am häufigften int Den Frïhfingsmonaten auf. Der $\mathfrak{A} \mathfrak{H}=$

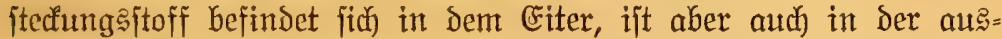
geatmeten \&uft be马 franfent Iieres borhanden. Die $\mathfrak{A}$ nitectung voll=

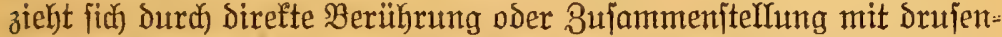

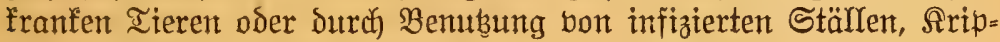

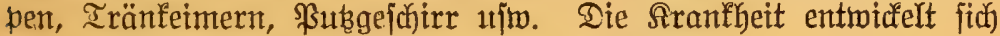
nadi) Der İnitecưng innerhalb vier bis neun Iage.

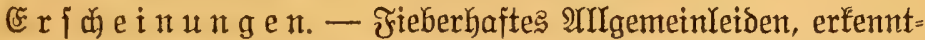

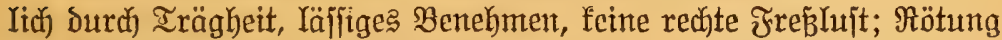

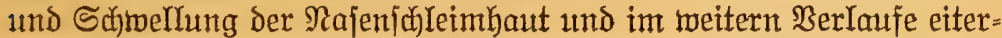

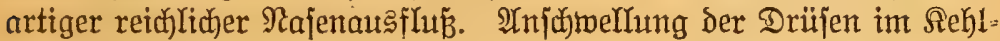

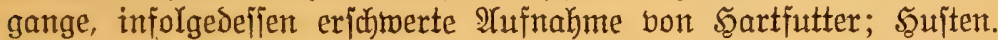
(E⿱ zehn Tagen hat biejes jeine Reife erlangt und briabt auf Doer muß geöffnet merben tund entreert einent rahmartigen (Fiter, der nad)

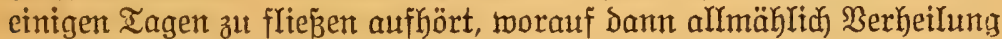
erfolgt. $\mathfrak{B}$ ölige Bsenejung im BerIaufe innerbalb ztwei bis brei, föchjtens vier $\mathfrak{3 0}$ ocjen.

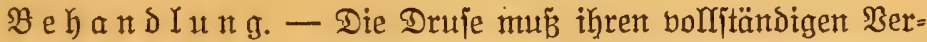

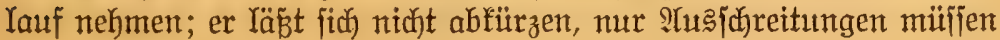




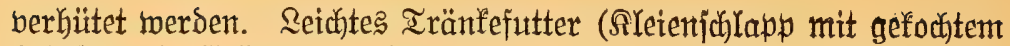

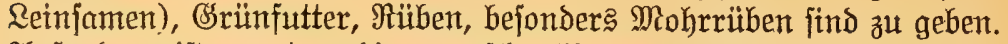

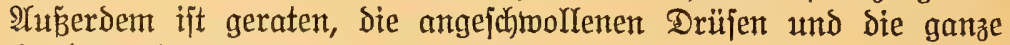
Sieble täglich mit warmem S(b) meinejamalz einzureiben, audh) mit wollenen Lappen twarm einzuhüllen. Das Deffnen des తsejhyürs ïberläbt man am bejten der Natur oder nimmt fie nidht früher bor,

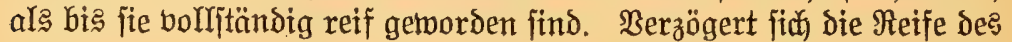

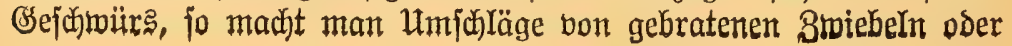

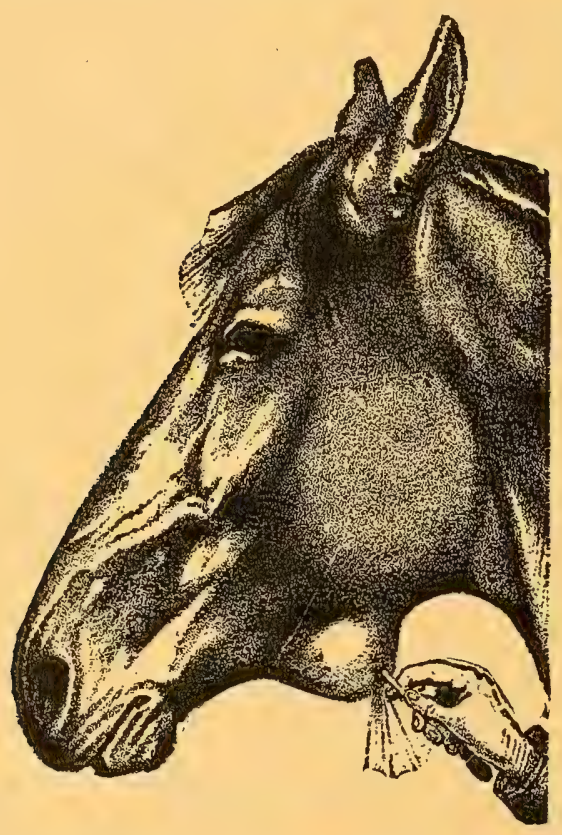

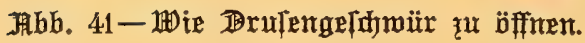

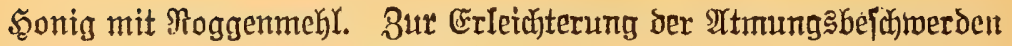
tragen Einatmungen bon Dämpfen bei: man füllt in einen đsetreide= jact ein \$ect Sleie, eine Şand voll Sopfen, gießst ein \$int Terpentin Ind eine IInze Teeröl darauf und hängt mitteljt eines Bandes dent

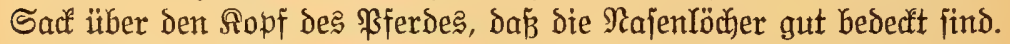
Sberhalb der Stoffe im Sact wird in diejen ein Lod gejohnitten and Durch Dasjelbe langjam heifßes Wiaffer auf bie Aleie und andern Stofie gegofien. Die aufiteigenden Dämpfe atmet bas ß̧ferd ein. Borfitit 


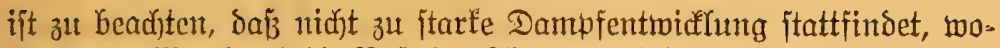

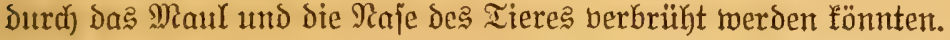

\section{Rotzfrnuffeit, 5̧autwurm (glanders, farcy).}

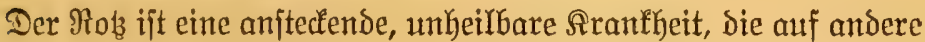
Tiere und aud auf Menjoben übertragbar ift. Beranlät wird bie

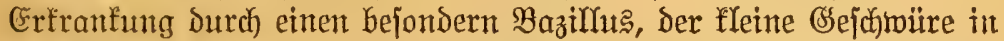

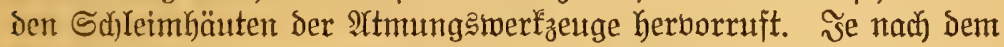

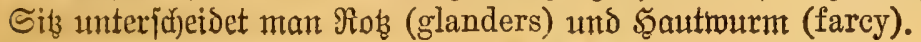

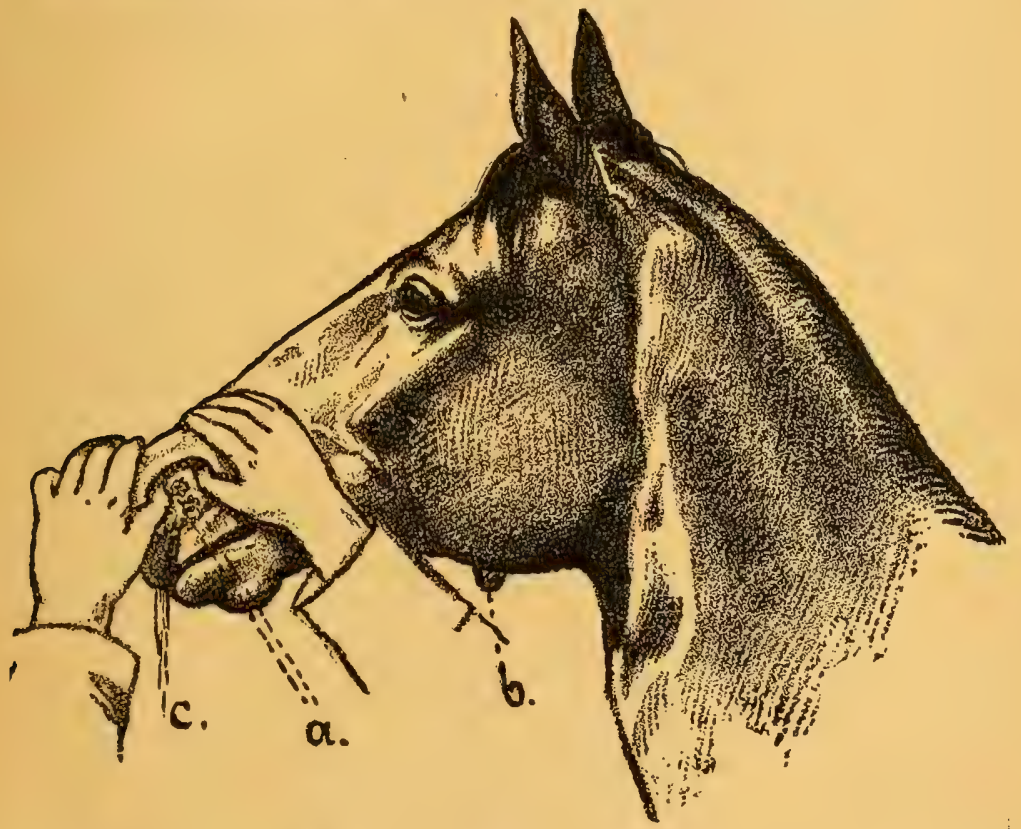

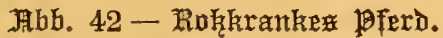

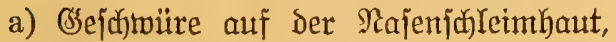

b) Sseidtwïr an ber Rehle,

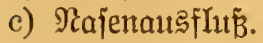

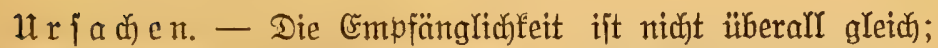
bcjonders find Fjel und Maulejel geneigt, die Rranfheit zu entwidfeln.

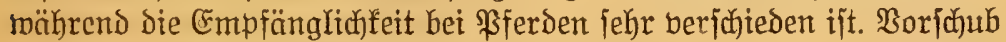
Ieijten mangelfafte Ernährung, Heberanitrengung und jobleichende Srantheiten. 


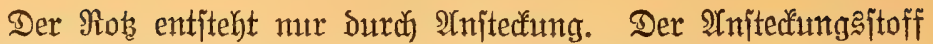

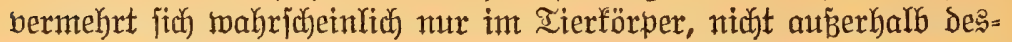
jelbent; er findet fich in dem Eiter Der Bsejublüre, in Dem Najenaus=

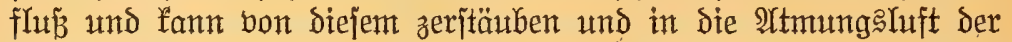

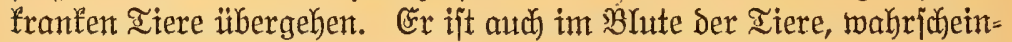

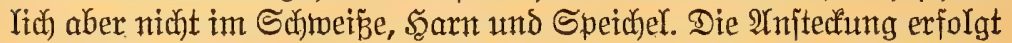

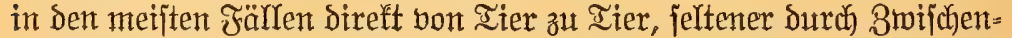

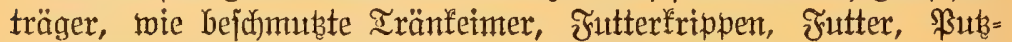

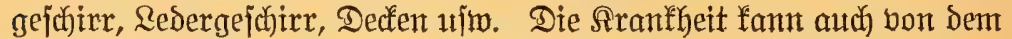
Muttertier auf das ingeborene Fohlen übergebent.

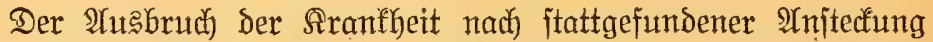

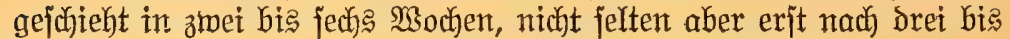

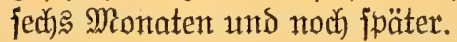

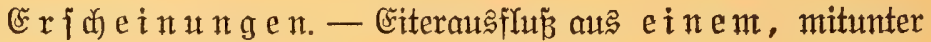

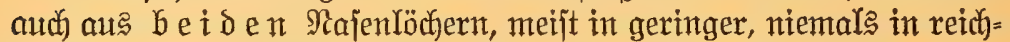

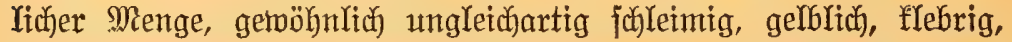

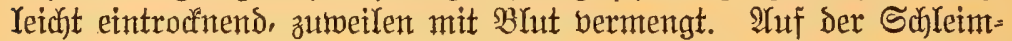

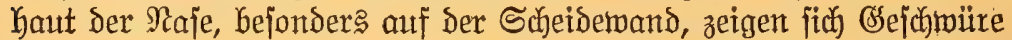

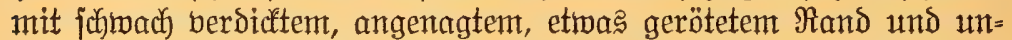
ebenem, blaffem, fahectigem Grumb, melche mentg êtter abjondern und

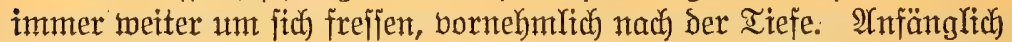

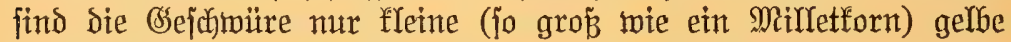
ßntötchen, Die in Der Mitte eimfallen, Damn fich ausbreiten und burch

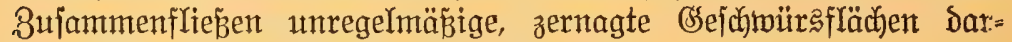
ftellen. Sie bedectent fich felten mit Sthorfe.

Bei Yängerem Beftehen Der Sranfheit tritt Ifbmagerung und alfgemeine Schbäche, Dumpjer Şuftent und Sutrzatmigfeit eit. Die

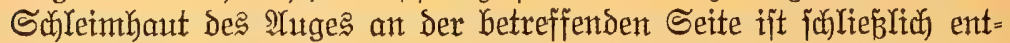

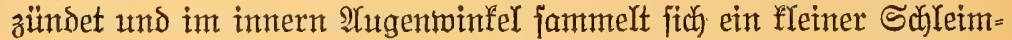

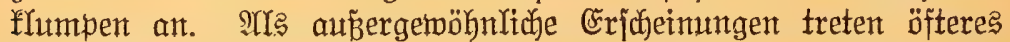

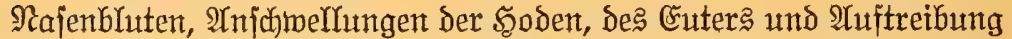
ber Rieferböhle an der franfen Seite auff.

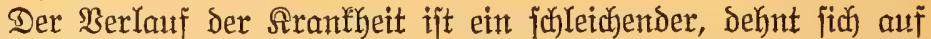

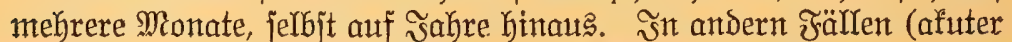

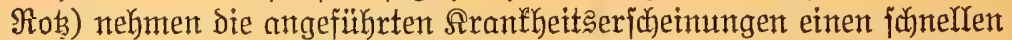

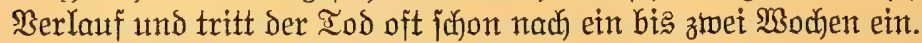

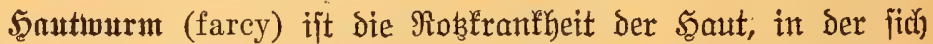

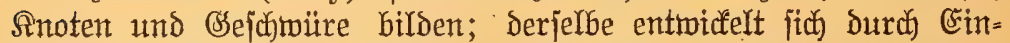

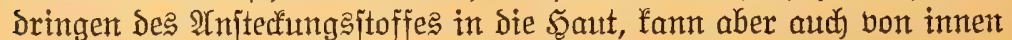

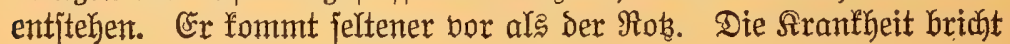




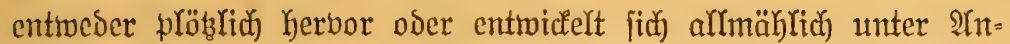

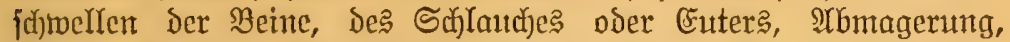

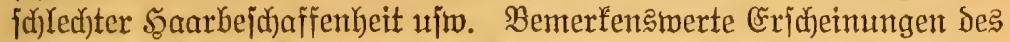
Sauttourms find: Ât einer oder der andern Rörperitelle, meiftens an

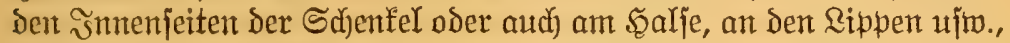

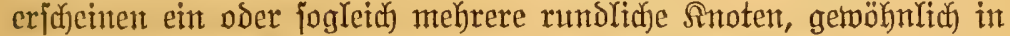

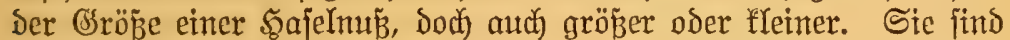

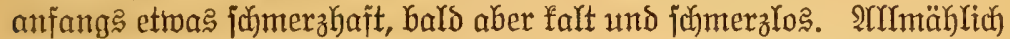
ertweidjen fie und bredjen auf, gewöhnlidy in acht ober vierzehn Iagen,

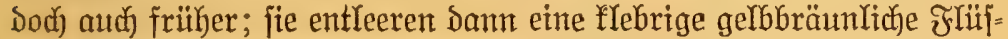

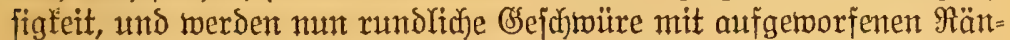

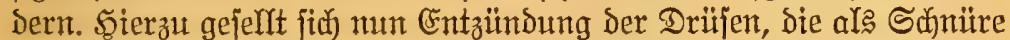

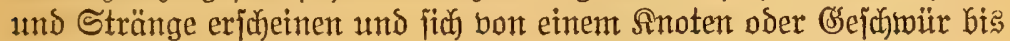
zum andern eritrecken. Die Tiere fönnen babei ganz munter exicheinert.

כ̌m meiteren Berlanfe treten neute Beulen auf, Sie fich nadh Ser

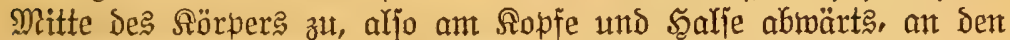

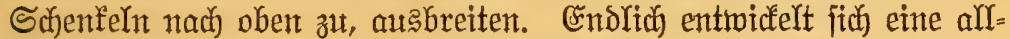

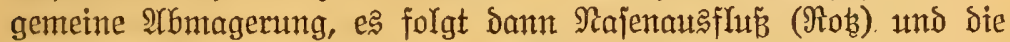
Tiere verfalfen dem Tobe. In ber Regel ift ser BerIanf Iangjant,

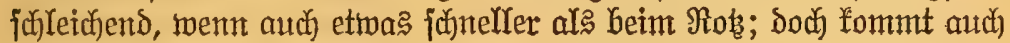
bismeilen ein fodneller $\mathfrak{B e r Y a u f}$ bor.

$\mathfrak{B}$ e ha $\mathfrak{n} \delta \mathfrak{Y} \mathfrak{i} \mathfrak{n} \mathfrak{g}$. -

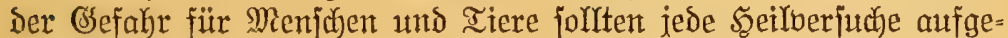

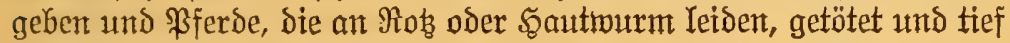
vergraben twerden.

\section{Sinudjentueidfe (osteoporosis, big head).}

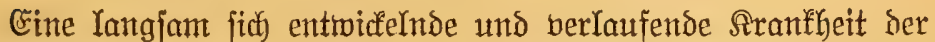

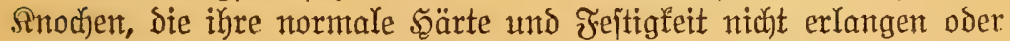
wieder verlieren. Sie tritt hattptiäd)lid an Den Snodhen bes Sopfes

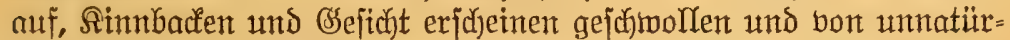

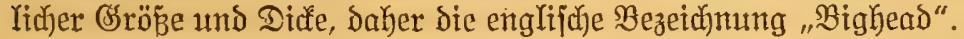

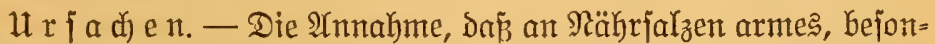

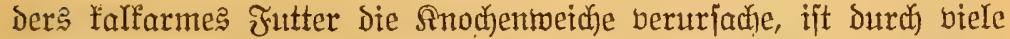
Unterjudjungen aIs unridjtig erwiejen; berartiges đintter fant jedod)

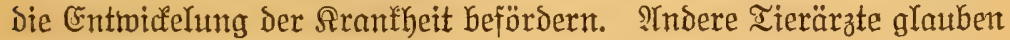

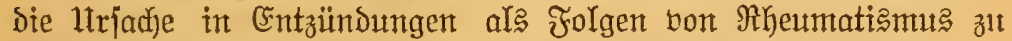
crfenten; wieder andere nehmen eine bejondere Beranlagung an.

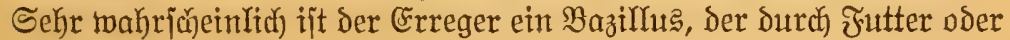




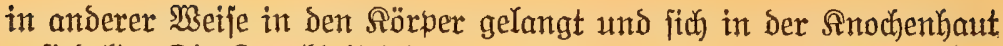
anfiedelt. Dic Rranflyeit tritt gewöbnlid bereinzelt auf, Doch weroen aud) häufig mehrere \$Fferde int einem Stalle dabon befallen, und i it in Den Nentenglanditaaten, an den UfFern Des Delatware und in den Rie=

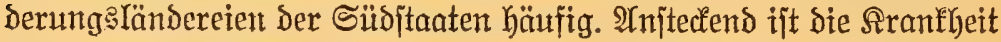
nidht; man hat Durch šmpfung gejumber mit dem B̧ht erfrantter

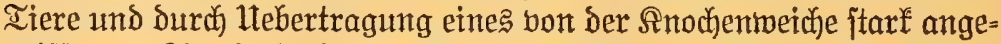
griffenen Simbadentnodjens auf ein gejundes \$ferd, dem bor= her ber betreffende Inochenteil herautggenommen twax, Die Rrant: Geit nicht erzeugt.

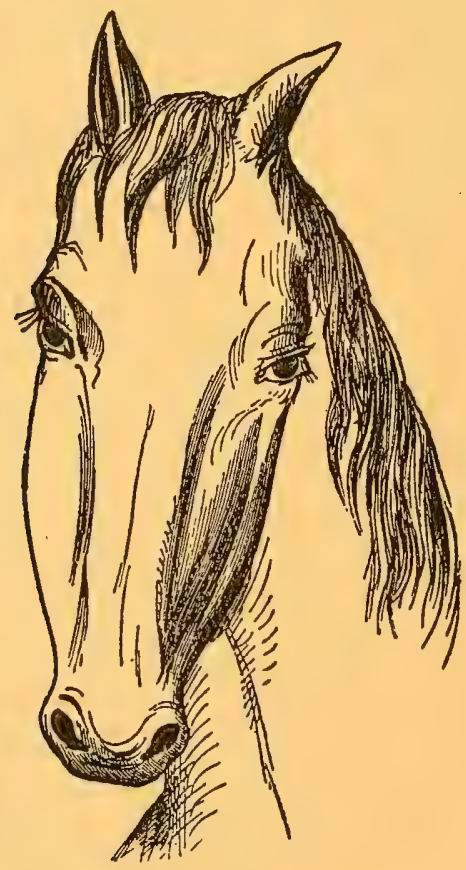

Mbb. 43- Finoryenmeidie am Finpfe (Bighead).

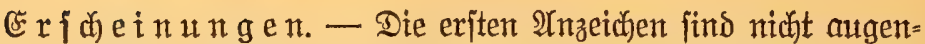
fällig und werden be引halb gemöhnlid überjehen. Meijtens zeigt fich

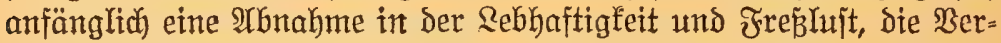
baunng ift gejtört und häufig ftolpern die Tiere beim Sehen auf ebner Erde. Nicht jelten treten an andern Stellen des నörpers, ‡. B. ant

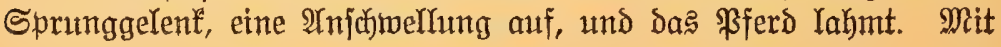


Der weitern Entwidelung zeigen fich bann. Die Înjüwellungen am

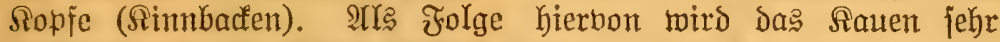
crid)mert und bie Bähne werben Ioder. Durch Befüblen mit dem

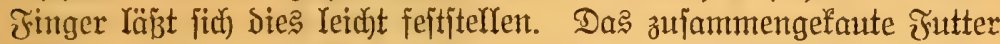

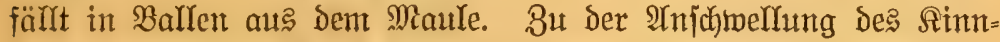

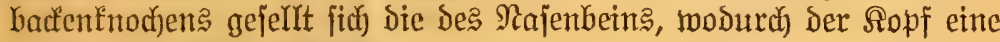

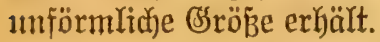

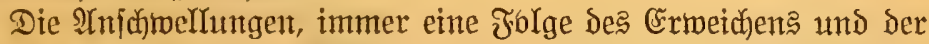

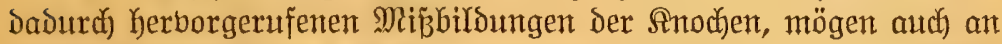

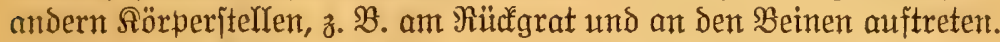

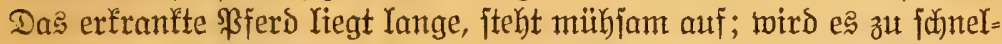
Iem Ssang angetrieben, fo mag plöblich ein Anochenbruch, bejonder马 an Den untern Teilen der $\mathfrak{B}$ eine auftreten.

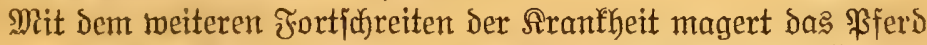
mehr und mehr ab, bas Fell wird hart und fejt (hidebound); ber Gang wird furz, ftelzenartig, die Beine find iteif wie bei Rehe. Das

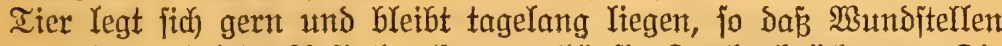

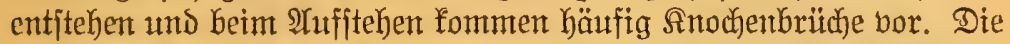
Sranfheit fann fich Derartig ourd) zmei bis drei Monate Ginziehen, hat

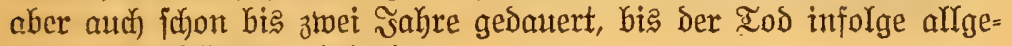
meiner Entfräftıng eintrat.

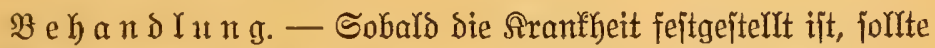

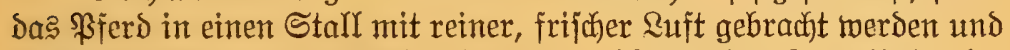

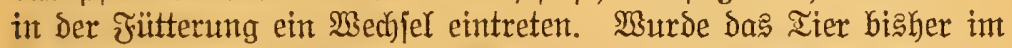
Stalle gehalten, fo jollte es auf die Weide gebracht werden, wenn die sahreszeit es erlaubt; ein ztwei= bis dreimonatiger \$seidegang mit

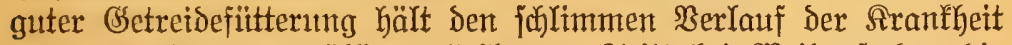
auf und führt zur bölYigen Seilung. Iritt bei Meidepferden dic Sinochentweiche auf, fo jollten fie auf Stallfüttentng gefterlt werden.

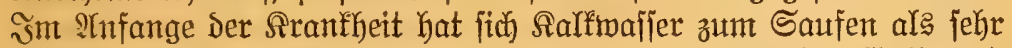

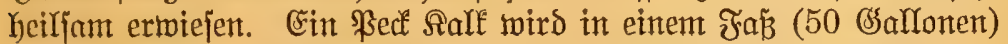

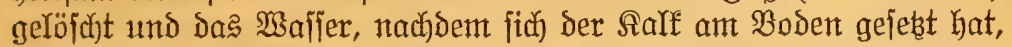
regelmäbig vermendet. Nebenher erhält das \$Fferd in jeber Jutter=

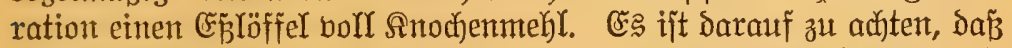

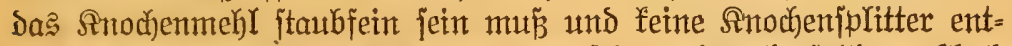
halten Darf. Irn Redfialz Darf es Dem Tiere niemals fehlen. IUth fam mit jedem Futter etwas \$Baummolljamenmehl - zwei bis brei EB̉löffel boll - gegeben werden; diejes Mehl befördert die Seilung in höherem Grabe als irgendeine andere Futterbeigabe. Fin an

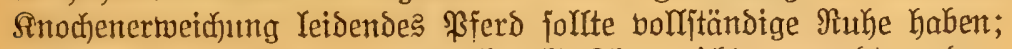
aud) 3ur 3udjt forten derartig erfranfte Tiere nidyt verwandt werden. 


\section{Anḩang.}

\section{Itnarten bes $\mathfrak{B f e r b e s .}$}

Das \$Ferd hat, wie jein Meijter und Seerr, ber Menjud, augge= zeidnete Eigenjafaften jomohl als Fehler; Dent obmohl es eines Der edeliten Tiere iitt, fo findet man bow aud biele $\mathfrak{l}$ tnarten an ifm. Die meiften derjerbent gehörent der ganzen \$ferderajfe an, während einige mur bei einzelnen Âtrten zut finden find. Mandfyal Iaffen fith diefe

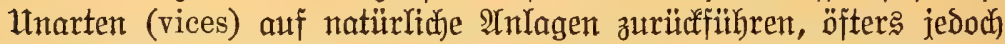

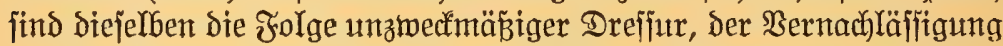

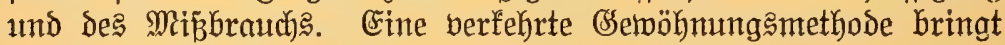
beim \$Ferde wie beim

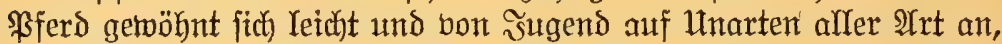
mesharb man e马 frühzeitig zähment, fontrollierent und meiftern follte; denn je mehr Utnarten ein \$Ferd äupert, beito mehr berliert e马 am MSert, und der untwiffende Säufer twird oft betrogen, weil er diafelbent

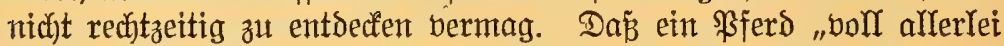

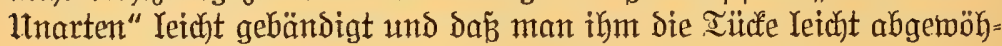

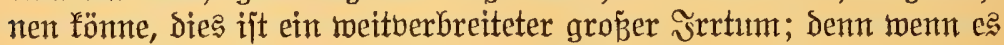

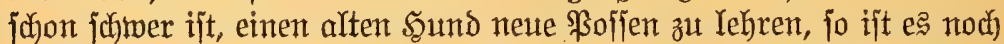
wiel jofwerer, ein altes \$ferd bon Tüften abzulbringen; ja, bies ift in

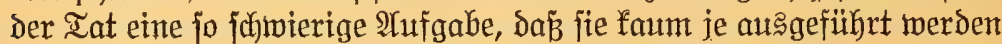

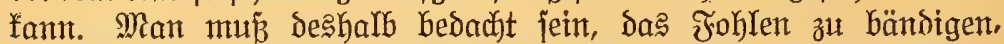

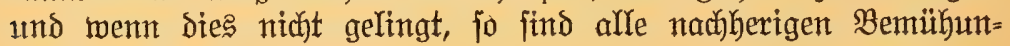
gen erfolglos.

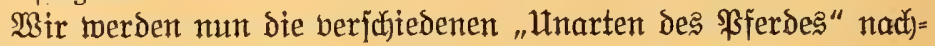
einander betraditten.

\section{1. शYษ}

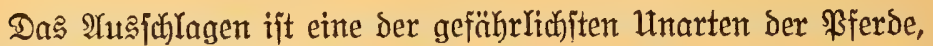

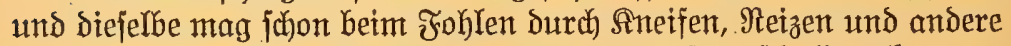
Plackereien, Deren fich Snaben und Snedbte oft zulduldon fommen

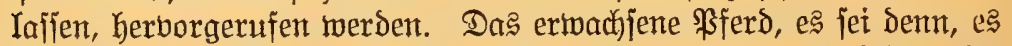
habe Sieje übłe Ssemohnheit fajon frühe angenommen, wird wahr=

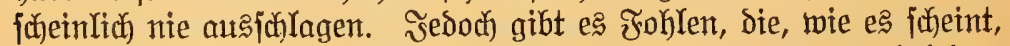

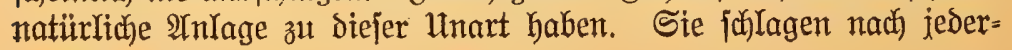


mann uns nady jesem in ihrer Rähe befindlidyen đsegenjtand. Die groß̌e Mehrzahl jedod) getwöhnt fich bieje Untugend an, indem fie durch unwifiende, unadjtiame, gleidgülttige Reute Dazu gereizt twerden. Dieje

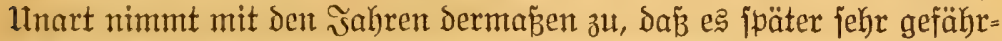

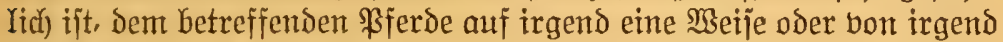
ciner Seite fich) zut nähern, atnd alle erinnern fich ber oft gehörten

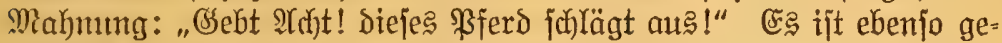

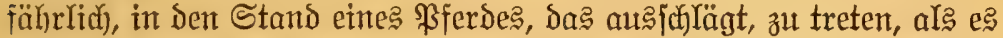
ift, Dasfelbe anzujufirren ober zu puben, oder es aud nur, wenn ange=

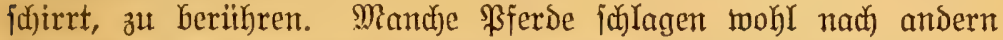
BFerden, aber nidjt nach Menjuen; mandje nach Den Retten, die in ihrer Hmgebung rafieln, aber nicht nach andern Ieilen des (sejuirrs. Mandje berhalten fid) ganz ruhig, wenn mur eine \$erjon auffibt, loolfen aber ztwei auf Dem Tiere reiten, jo jod)lägt es hinten und born

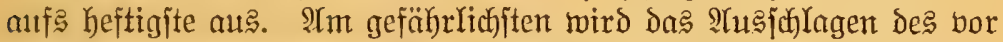

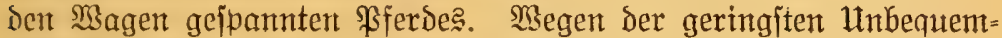
Iidffeit am Reibe oder Den Şinterteilen fohlagen mandje \$fFerde ganz wiitent aus und zerjamettern nicht nur ben $\mathfrak{M a g e n , ~ j o n b e r n ~ b r i n g e n ~}$

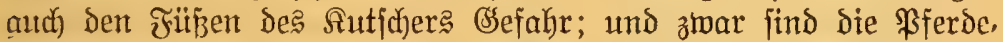
welde im Stall raftlos find, in biejer Sainjicht die heftigiten und

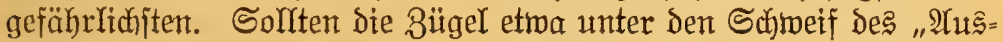

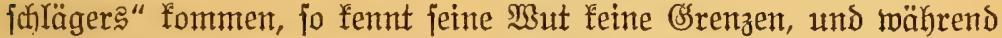
er Den Schmeif jo feit und heftig abrörts drüclt, daß es faum möglich ijt, bie Bügel borztbringen, fad)lägt bas Tier hinten und borne auts, bis es Gejefirr und Magen zertrïmmert hat.

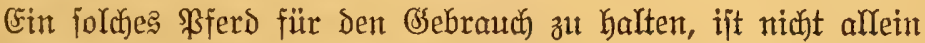
höchit anborfichtig, jondern aud verbrecherifac).

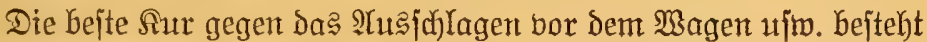
sarin, daj man ein feites dinnes Seil an das Shincifhaar bindet, Dasjelbe unter der Deidjel Durdziteht, am Unterleib hinlaufen läb̆t, unt es, jchr jtraff angezogen, am 3aumgebí befeftigt. W3irl mun bas Bferd ausjulagen, jo twird das fejt angezogene Seil jo jehr an jeinent

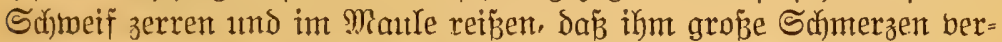

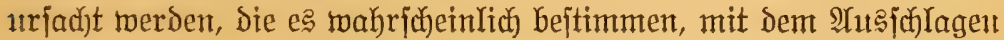
nack)zula

(Segen das ?lusjul)lagen im Stalle hat fidy die Methode bemährt, baß man Das ßferd in einem Stande mit Seitentwänden (Rajten= ftand) gut anbindet und Ginter sem $\mathfrak{P F e r \delta}$ an einem Strid einen mit

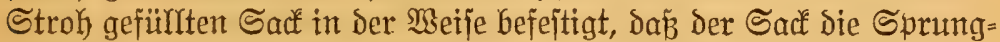

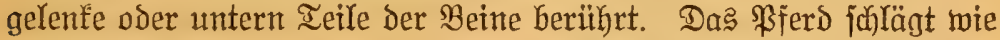

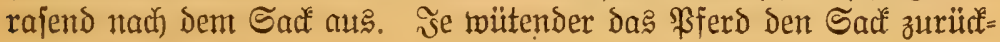




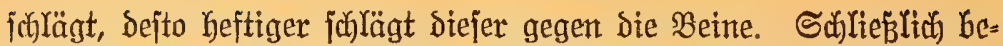
fommt das \$ferd vor dem unheimlicjen Sace Furditt umb bleibt zit=

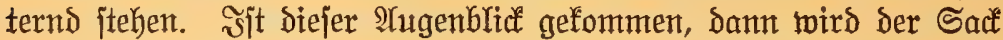

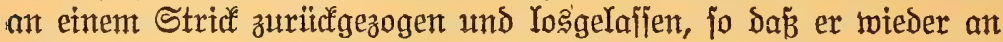

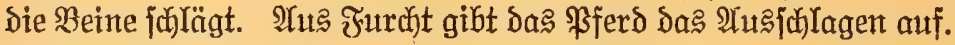

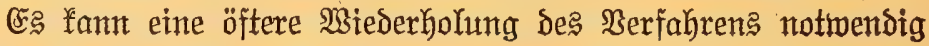
werden, um Dem \$ferde die lintugend gant abzugehöhnen.

\section{Beipen.}

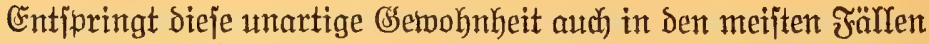

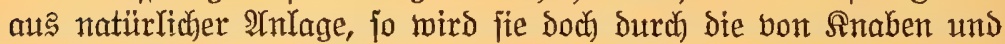

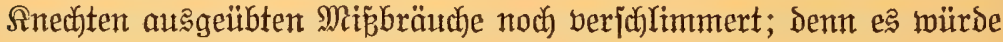

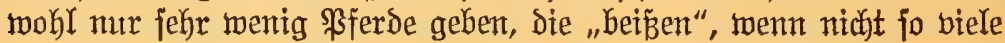
junge Tiere aflen möglichen \$lactereien ausgejest wären. \$Pferঠe,

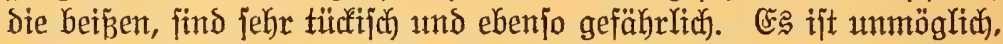
mit Sicherbeit in ihren Stand zu gehen oder fie zu ftriegelnt, zu jatteln

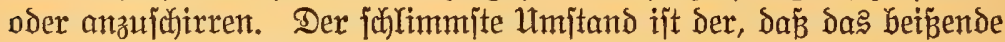

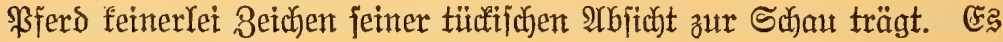
ift anjuheinend völlig zahm und fromm; jobald aber eine nidhtsahnende

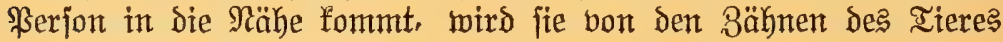
gepact' umb oft erkeblich bejäjösigt.

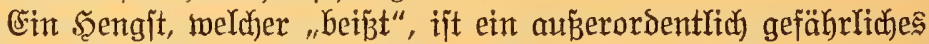

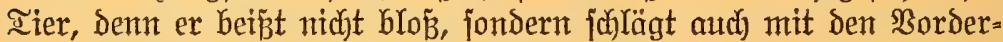

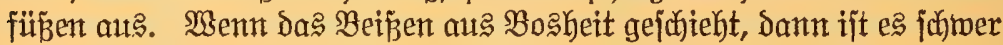

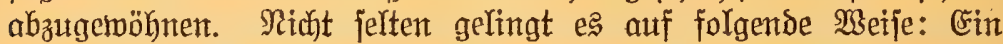

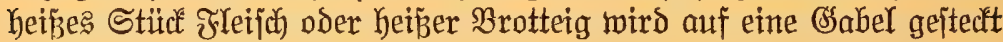

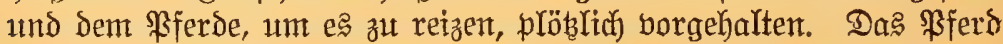

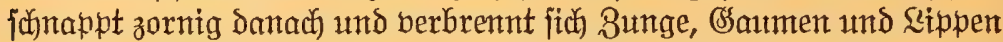

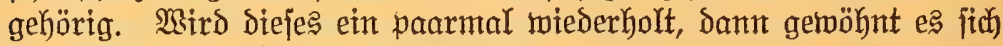

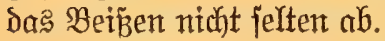

Seifft das Mittel nidut, Dann lege man dem BFerd einen Maulforb an, Der mur während des F̛̉itterns abgenommen wird.

\section{Bäนกนก (rearing).}

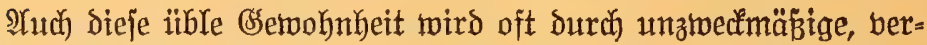

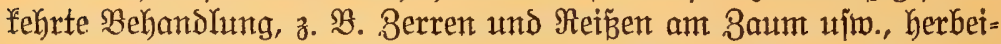
gefiührt. $\mathfrak{B a}_{a}$ aber auth immerbin die veranIaffende $\mathfrak{H} r$ jache jein mag, fo ift es immer ein beläftigenter, gefährlicher Febjer, ourd weld hen Sie meiften Reiter abgetworfent werden, was befanntlich jothon oft mit

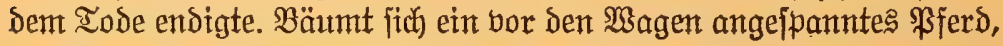




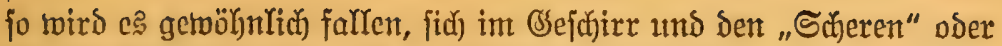

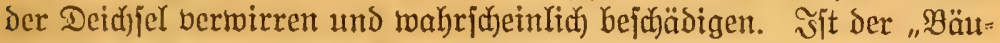
mer" neben cin anderes \$fFerd gejpant, fo wird biejes, went nidyt beföäsigt, jo doch furchtjam und jufjett werben.

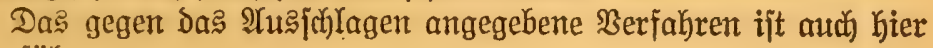

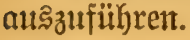

\section{Sdyentucroen.}

Dies ift ein jehr gemöhnlidjer Fehler. Mandje \$ferde juheuten beinake bor jedem (Segnjtans, ober werden fogar furdtjam, aud) wenn

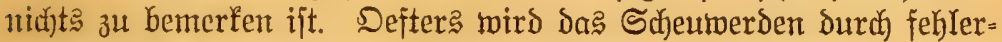

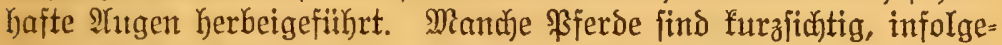
seffen fie bie đsegenjtände erjt fehen, wenn fie Denjerben fo nahe ge=

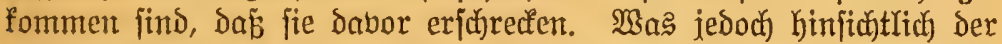

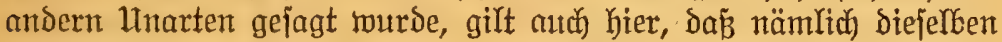
meiftens Durd) fuhledft geleitete Bähmung unt Bsemöhmung herhoi=

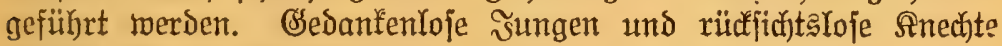
machen fid oft ein \$ergnügen Daraus, bie jungen Foblen zu er= fodrecken, fo oft fie denjelben nabe fommen, und hat fith bas junge Tier cinmal angewöhnt, jüeu zu werben, jo wirs ifm bieje Utntıgent immer anjängent. CEine Nabifalfur gibt es nidyt; jondern es gilt,

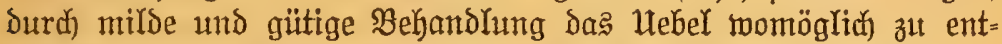

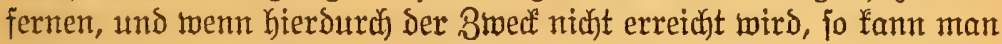
aud) mit andern Mitteln nidfots Kemirfen.

Mo bie unz̧wedtmäbigen Scheuflappen (blind-bridles) nidft mehr

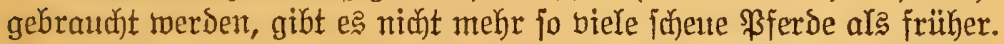

Da马 ßferb zeigt gemöhnlich Durch Seitenfprïnge, oder indem

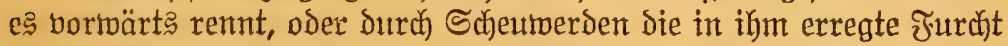
ar. Springt e马 zur Seite, oder vorwärts, fo ift am meiften \&sefahr vorfanden, dent biejes geht gewöhnlid bem Davonlaufent boraus,

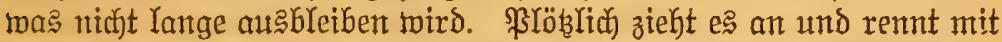

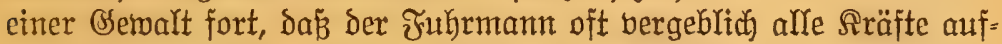

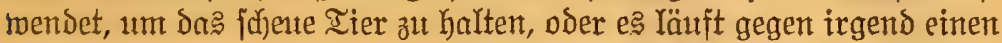

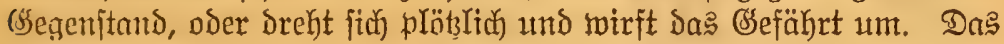

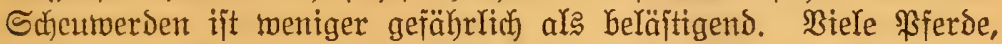

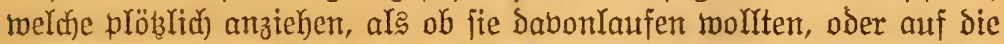
Seite jpringen und fajeu werden, gehen nie Durd), aber bon alfen fann bies nidjt gejagt werden.

\section{Durdjbrenten.}

Einem einmal sabongelaufenen \$ferd ift nidft mehr zu trauen;

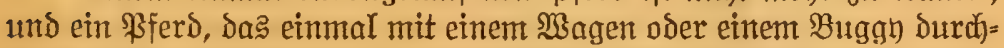

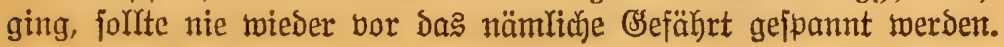


Roch wird es in den meiften Fällen ratjam fein, ein joldjes Iier -

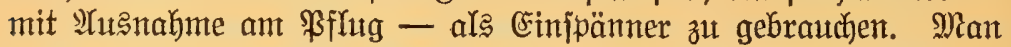
fann es zwar neben ein alte马, fromme? $\$$ fferd fpannen; weiter aber

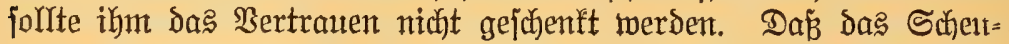
werden Das Davonlaufen exzeugt, hieran mur man fich bejtändig

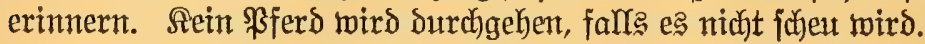

\section{Störrigfeit (balking).}

Dieje üble semohnheit ijt jo jolimm oder jollimmer als irgend welche andere Itnarten, und zwar marbt fie Die damit behafteten \$ferde

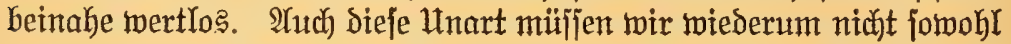

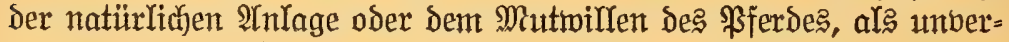

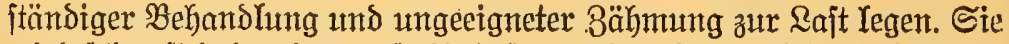
wird jehr oft dadur(f) verurjacht, das man dem jungen Tiere, ehe es on j(f)weres Biehen gewöhnt ijt, зu jujwere Rajten aufbürdet. Das über=

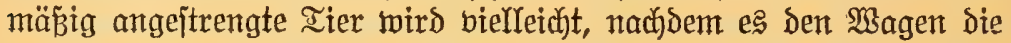

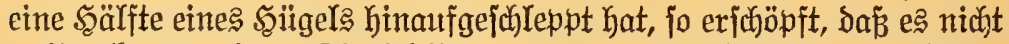
weiter tann und zu Dienjtleijtungen untauglich ift. Nun rollt ber

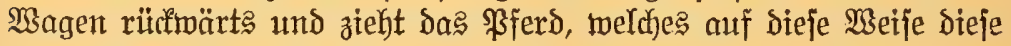
Unart zuterịt aus Not lernt, und fich diejelbe fpäter angetoöhnt, mit fict).

Ein nicht vor dem Dritten săbr angelerntes \$ferd wird eher in dieje Itntugend verfallen als eines, mit defjen Bähmung früber be= gonnen twurde.

Natürlich fann man fich auf ein folches ßferd nie berlajien; benn menn man jeiner Dienjte am meijten benötigt, Yeijtet es biejelben nicj)t.

Fine in allen. Jällen zuberläffige Sur für Störrigfeit gibt es

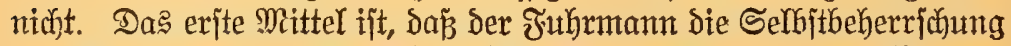
nicht berliert und das Tier nicht jallägt, fondern ifn ein paar Mimuten

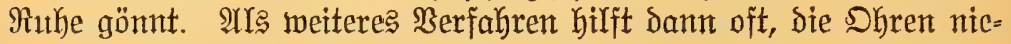

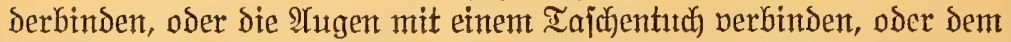

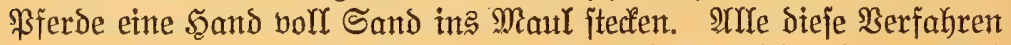
bezmedfen, sen Sinn des Iieres von ber Störrigfeit $a b=$ und auf andere Dinge zul renfen. Sobald bies gelingt, geht das \$Fferd vor= märt马. Durch Schlagen, rohe SBehandiung und হärmen wird hei folchen Iieren nidhts gebefiert, fondern bie Miderjpenjtigfeit ver= idflimmert.

\section{Benngen bes Rebers und anderex Bsegenitände.}

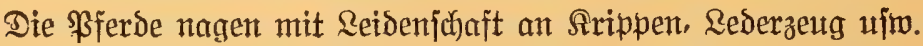
Man bejtreidyt hölzerne Gegenjtände mit Teer; Rederzeng twird nad́ Dem Einölen mit rotem şfeffer beitrent. 


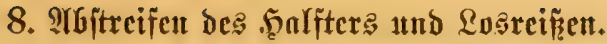

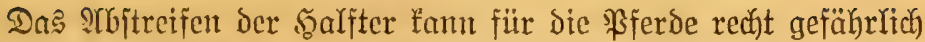
werden, ba bicjelben, wenn fie frei umbergeben fönnen, bäufig über

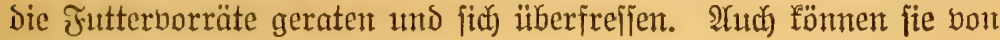
andern \$ferden geifjlagen werben.

Das fejte Bufammenziehen des Salsriemens am Salfter hilft in

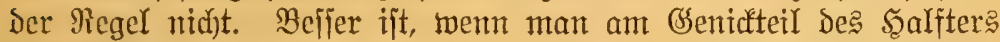
cinen Ring anbringt und einen Teil Der Mähne in Dem ßing fejłbindet.

Ein anderes Serfabren bejtebt barin, Dä man an Dent Gentid =

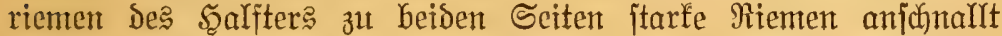
umb bieje Dam ftraff an einem (كurte, Der um den Reib gelegt wirs, befejtigt.

Mamde \$rerde haben die Itntugend, fobals fie int Stalle ange=

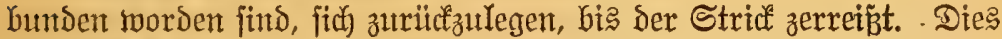

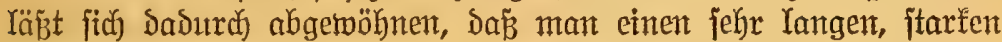

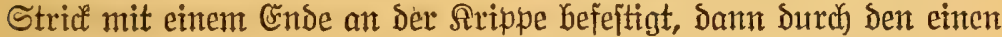

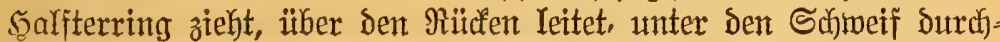

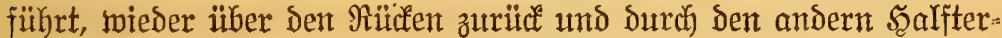
ring Yeitet und ebenfalls an ber Artppe bejejtigt. Beim plöblichen

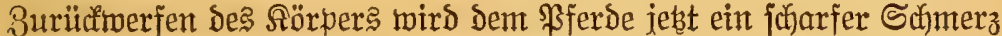
bercitet, fo dak es rajoj wieder vorwärts geht. Mehrere Errfahrungen

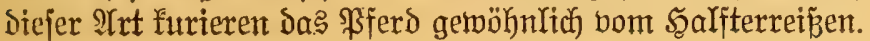

\section{Dås Sirippenjęzen แnd Sioppen (windsucking).}

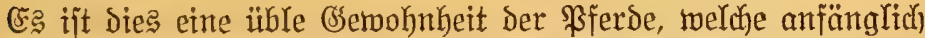
als Spielerei betrieben mirs, aber bald in eine bleibende, bei jeder (sclegentyeit ausgeilibte Utntugend ausartet und audi) bald bon andern
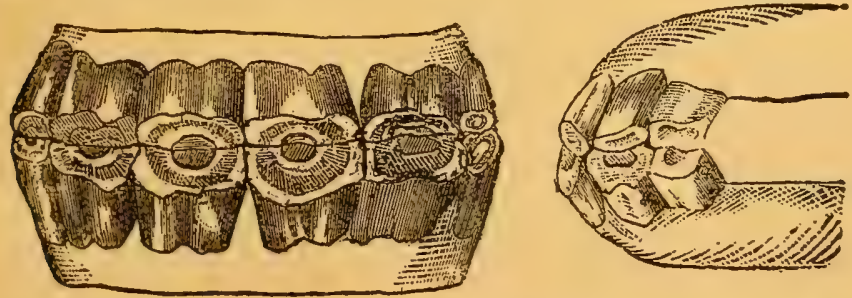

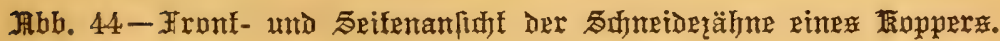

\$ferden im Stalle nadjgeahmt miro. Unter frampfhaftem Beugen

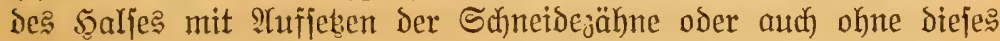

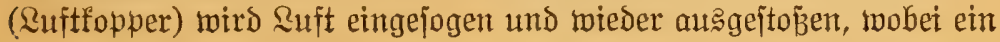


eigentümlicher hohler Ion entiteht. Bei alten auggebilseten Sopperut bringt Ruft aud in ben Saflund hinein und fo nad) Dem Magen.

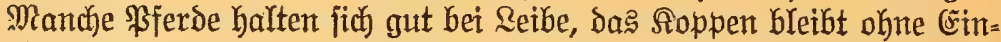
flü; bet andern beginnt die Berdaunng und Ernäbrung zu Yeiden; cs wird viel Futter berftreut und die Frefienszeit mebr zum Roppen alङ

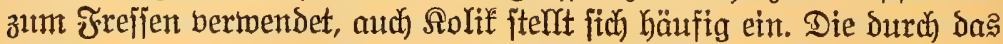

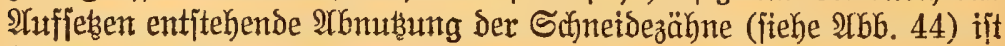
jelten nachteilig, aber fant als gutes Erfenmungszeichen eines Rop= pers bienten. Rangetweile, Yeerer Magen, Rachahmung, inzbejondere

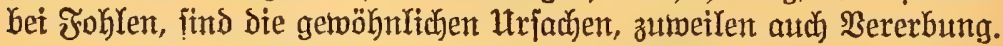

Irre Mittel dagegen find nur von borïbergebender Nirfung; nur in ber exjten Beit, wenn die Untugend noch nicft gehörig eingeübt ijt, läß̈t fie fich wieder abgemöhnent. Şierzu dienen: (Entfermung aller

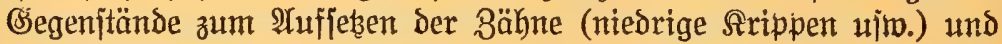

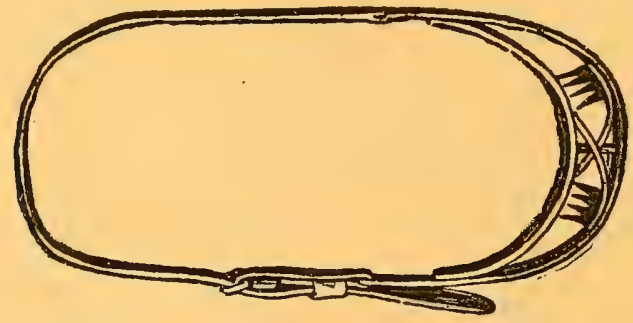

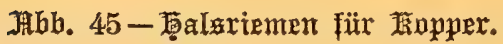

viele Bejüjätigung und $\mathfrak{A r b e i t . ~}$ Bon allen übrigen Mitteln hat fich

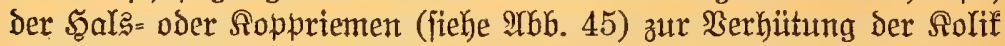

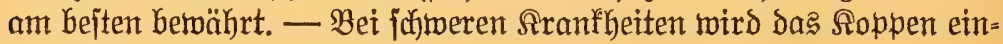
gejtelt; Der Wiederbeginn ift Daker ein Beichen Der Bejierung.

\section{Då Błngenf́trecfen.}

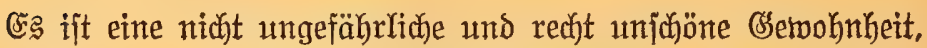

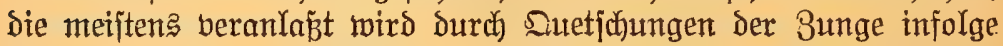

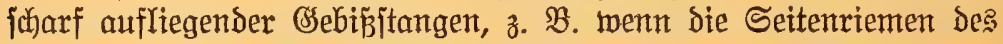
3aumes zu furz gejunallt find. Die ßjerde judjen bem Drud auझzu= weicjen und ftrecten bie 3unge heraus. Das 3ungenjtrecten wird da= Durch fïr bas \$ferd gefährlich, weil die zwijchen den Bähnen befind=

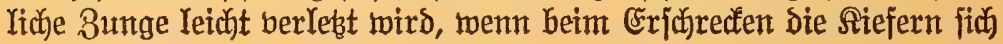




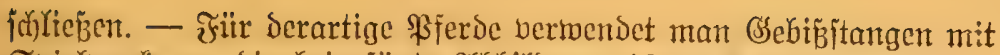
Spiclmerf an; Dic beigefügte Irbbildung 46 zeigt berartige Spiel= gebiffe; das Zaumgefd)irr muß Yodter und bequem fiben.
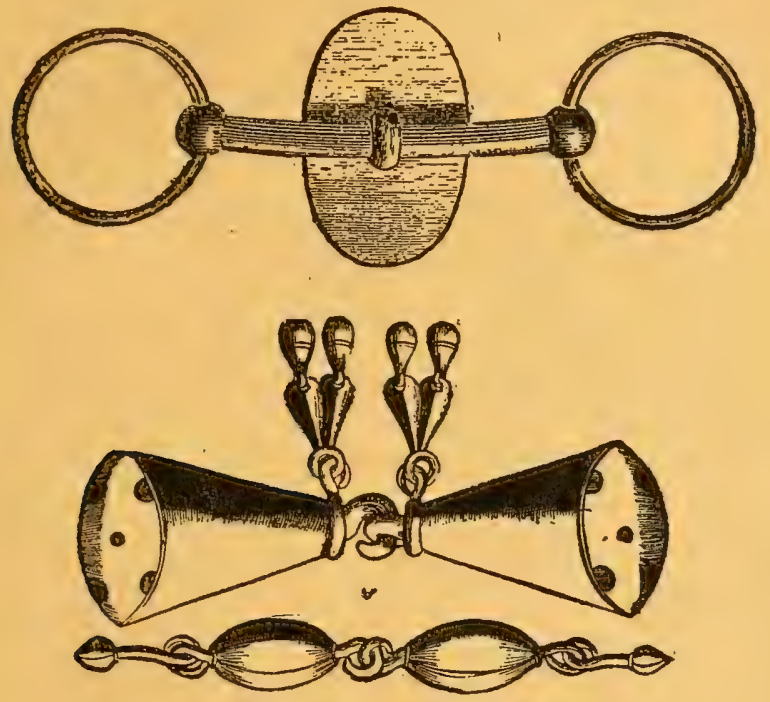

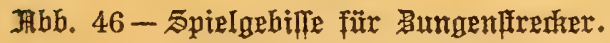

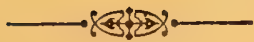





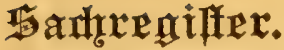

ホ.

Seite

Abortion .............. 139

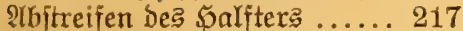

Inzeidien naber Seburt ...... 141

Irznei eingeben . ......... 52

भtmungsmerfzeuge ......... 34

ঐuficblagen der 5ufeifen .... 83

Yugapfelentzùnoung ....... 16:

Yugenflede, tweíze ......... 163

Y)

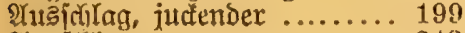

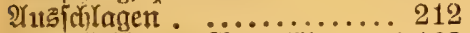

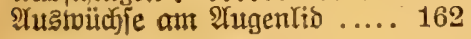

$\mathfrak{B}$.

Balking . .............. 216

Baudjpeidjeloruife . .......... 46

Räımen ................... 214

Behanilung ber Sufe....... 74

Bnhandhng trä̀dtiger Stuten 135

ßeiß̧en ................ 211

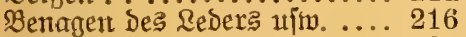

Bighead ............... 209

Blajenentzünute ......... 116

Blajeniteine ............... 113

Blind staggers ........... 147

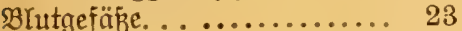

Bhutiger Itrit . ............ 112

Bots ................. 103

Brant auf iweiken 2 bzeidjen. 198

Bremie anlegen. . .......... 56

Bremienlaruen . ........... 103

Brennen ................. 57

Broken wind ................. 126

Bruitfelfentzünoung . ...... 125

c.

Contracted heels . ......... 194

Corns. . .................... 192

Curb .................... 185

D.

Dämbfigfeit . . ........... 126

Distemper . . .............. 205

Drufe .................... 205

Dummifolfex .................. 154

Ditrdibrennen . . ............. 215

Durdeffall. . ................. 102
(5.

Seite

Eingeben ber $\mathfrak{Y} r$ żneien. . .... 52

Eingetweidetwiurmex ........ 106

Einfauen ................ 187

Entzundung Der Maulighleim= haut .................. 96

Cntzünung Der Bunge ..... 96

Epilepsy .................. 148

Erfennen Der Яranfheiten.... 49

Erfennen des Bferbealters .. 60

Euter, franfes.....$\ldots \ldots .142$

ঋ.

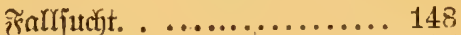

Farey ...................... 207

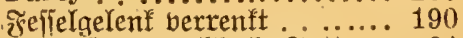

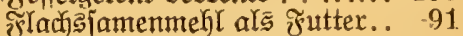

Fistula ................. 201

Founder .................. 195

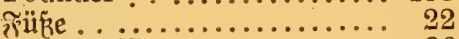

ซrutteritoffe .............. 86

(3).

Gsallenfieber . . .......... 108

bsesärme . ................ 43

Behirn ................. 29

(s)hirnentzünung ............. 144

Gselffuct. . .................. 103

(s)elenfentzübung ............. 181

Gsenictfittel .............. 203

Bseictwure in Der গaje....... 120

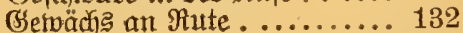

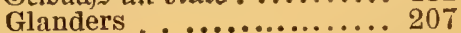

Gleet . ....................... 120

Ğliebmaken................ 7

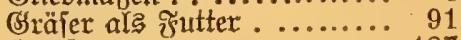

Greifen . .................. 187

$\mathfrak{5}$.

Srate ................ 21

Srarjeil ............... 54

5ahnentritt $\ldots \ldots \ldots \ldots \ldots \ldots \ldots \ldots .6148$

Sarn, weí und falfig ....... 143

5arnflutß, zu ftarfer......... 111

sarnfolie ................ 100

Sarnveritopiung. $6 \ldots \ldots \ldots \ldots . . .115$ 


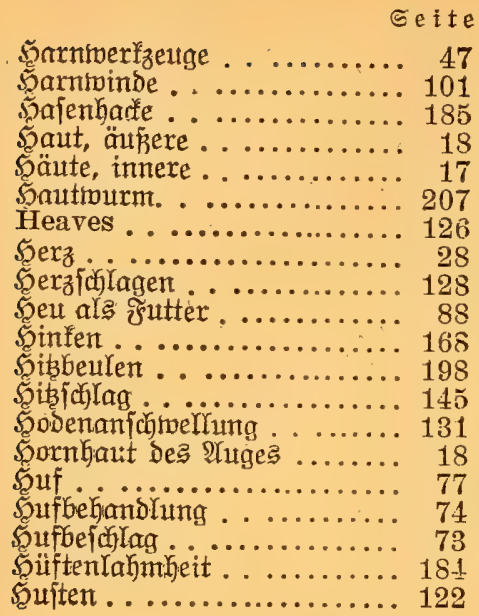

3.

Influenza . . ............. 204

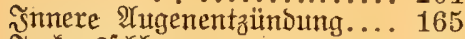

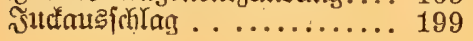

$\Omega$.

Saff, Berfüttern bon ....... 90

Sintoffeln alz ₹̧utter ....... 91

Staitrieren Der Sengite...... 132

Siehlfopf . . ............... 36

Siehlfopfentzinto.............. 122

গreuchen . ............... 123

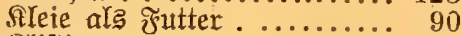

Silitier . . ................ 59

Intefofitamm . . ............. 187

Inochenbriadje ............ 177

Snochenerhobing unterhalb De? Antes . ............... 169

fnodhengeriujt ................. 7

Inochentweidbe .............. 209

fiolit ................... 98

froller . . ............... 15.

Stoppen . .................. 217

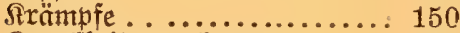

franffeiten erfennen . ...... 49

.rippenjesen . . . . . . . 217

Sirongełenf entzündet ........ 170

\&,

Sahmheit . . ............. 168

Lampers . . ............... 96

Ratwerge............. 53
Seite

Reber.................... 46

Reberbitt..................... 19

Reift ..................... 170

Lockjaw . . ................ 151

Rošreipen . .................. 217

\&unge ................... 34

\&ungenentzünotng ............... 123

$\mathfrak{M}$.

Magen ................. 38

Mais nIs ช̛uttex .............. 90

Mafienbafter Sarnflub ..... 111

Maufe . ................ 200

Mautlent zünoung . ............. 96

Maulfperre . .............. 151

$\mathfrak{M i l z}_{\mathrm{z}} \ldots \ldots \ldots \ldots \ldots \ldots \ldots \ldots \ldots, 47$

Mohrriben als ơstter ...... 91

Mondbinsheit . . .......... 163

Mugfeln .............. 13

\section{$\Re$.}

Rabelentzünoung bei รroblent. 159

Majenblutent ................ 121

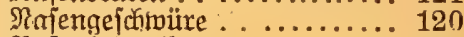

Majenfatarrh . . . ......... 120

Rervenfujtem ............. 29

Refielantsjultan . .......... 198

)iedertwerfen eines iperbes.. 58

Sierenentzüunout . ........ 10 ?

Niiitern, wumbe $. \ldots \ldots \ldots \ldots . . .120$

5.

Deffnen eines (ซ́efdyürs ....

Is.

Beriosifiche $\mathscr{A}$ tgenentzünoung. 163 isfeifendes $\mathscr{A}$ tmen . .......... 123 :Pferdefuk ................. 11

: Fferbettaupe . ............ 204

Pink eye ............... 201

Pleurisy. . ................ 125

Poll evil ................. 203

$\Re$.

Rabies, . ................. 157

Rehe..................... 195

Ringbone . .............. 170

Rippenfellentzünoung ........... 125

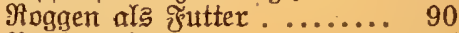

Rokftranfheit . ............... 207 


\author{
s.
}

Edjabhafte Bägne . .......... 95

Schale .................. 170

Schetmerben ............. 215

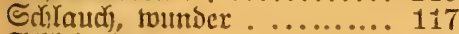

Ed) Icimharnen . ............. 112

Scratches ............... 200

Erfulterlabmiseit u. =idjumb 182

Edjumindel. . ............. 149

Eehnen ................. 10.

Sebnenflapp ............. 185

Seton .................. 54

Shoe boil . .............. 186

Sfelett................. 7

Eonnenbrand ............ 198

Sonnenjtich . . .............. 145

spasms ................ 150

Spat (spavin) ............ 172

Sneichels rüien . . .......... 37

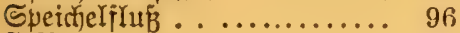

Splint. ................ 169

Epret als శ̣̌tter. ......... 90

Etactyeldrahtwumben .......2 201

Etrarrframpf . .............. 151

Steingahten ............. 192

Eterile Sengite und હtuten. 134

Stollbeule............... 186

Störrigfeit. . . ............. $216^{3}$

Etrahlfäule . . ............. 191

巨treidjen .................. 189

Etritje, tranfe ................ 142
Se ite

Stringhalt ............. 148

Stroh als fiutter........... 89

Sweeney .............. 182

T.

Thick wind ........... 123

Thumps ................. 128

Iolrnut . ................ 157

Irächtige Stuten........... 135

Irärtitigleitzzeichen .......... 134

Iränftwaffer ............. 85

Trush . . ............... 191

it.

Uturegermäbige ßähne . ..... 94

$\mathfrak{B}$.

Bergiftung Durch ₹̛utter oder Maffiex. ............... 147

ßerrentung Des テreflelgelentes 190

Beriäuterter Magen . ....... 97

Berjadlag . . ............. 195

Berwerfen. . ............ 139

2B.

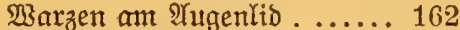

N3arzen an $\Re u t e . . . \ldots \ldots \ldots .132$

Warzen an Stricten ....... 143

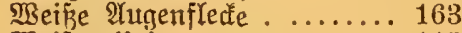

Meißer Urin . ............ 113

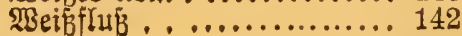





